\title{
$(4)$
}

UNIVERSIDAD PERUANA DE CIENCIAS APLICADAS

FACULTAD DE ARQUITECTURA

CARRERA DE ARQUITECTURA

\section{Polideportivo Inclusivo en Villa María del Triunfo}

Tesis para optar el título profesional de:

ARQUITECTO

AUTOR

Lertora Egoavil, Ghianella Francesca

(0000-0002-9922-4156)

ASESOR DE TESIS

Mazzarri Nava, Elsa

(0000-0002-6525-9238)

Lima, 23 de Agosto del 2018 
Dedico esta tesis a mi hermano Gian Carlo Lertora, porque de él nació la idea del tema de la tesis. Por ser mi motivación y mi guía durante todo el tiempo que la desarrollé y por ser mi mayor ejemplo de fortaleza, luz, felicidad, coraje y verdad. Te amo hermanito, un beso al cielo.

A mis padres, quienes me dieron todo lo que tenian para ayudarme, por las amanecidas, por creer en mi y por enseñarme a creer en mí. Por quererme tanto y tan bonito. Por ser mi soporte cuando los necesité durante el camino, por darme esos consejos cuando estaba a punto de tirar la toalla que me ayudaron a seguir adelante. Porque los amo mucho.

A mis hermanos, en especial a Julio y Neni. Por apoyarme, por estar ahi, por escucharme, por creer en mi manera idealista de ver la vida, los quiero muchísimo.

A mis sobrinos, en especial a Valentina, Rodrigo, Lucas y Rafaela. Por ser mi luz durante estos años, mi felicidad, y mi apoyo cuando los necesite.

A toda mi familia, muchísimas gracias por todo el cariño y apoyo. En especial a mi madrina Ana, a mi padrino Mario, y a mi tía Rosa.

A Indrit Murati, por ser la luz que necesitaba.

A mis amigos, por ayudarme tanto, por estar ahi durante todos estos años en los que crecimos juntos, sufrimos juntos, vivimos juntos y nos volvimos hermanos. Especialmente a Pía Felipa, Sebastian Ramos, Andrea Espejo, Allison Alayo, Vania Guedes, Sandra Guedes, Antonella Pantoja, Kiara Cribillero, Rafael Vergara, Deborah Torres, Mariana Osores, Lobelia Severino, Khendra Alvarez y Renzo Rivera. Los quiero muchísimo.

A mis maestros, en especial a Nicolás Moser, por ser un arquitecto admirable, que me enseñó una manera de ver la arquitectura diferente, a divertirme con ella y a ver hasta dónde podia llegar a producir. A Rodrigo Apolaya, mi profesor de taller I, porque su manera sensible y poética de ver la arquitectura, y su amor hacia ella, me contagia hasta hoy.

A mi asesora, Elsa Mazzarri Nava, quién mi acompaño desde lineamientos me guio, creyó en mí, me lleno de conocimientos y tuvo la paciencia para enfrentar el proyecto juntas. Muchisimas gracias Elsa.

A mi perro Joy Alberto, por nunca abandonarme en ninguna amanecida, por darme esa compañia cuando la necesitaba y por quererme tanto como lo quiero yo. Siempre tan leal hijito mío. 


\section{RESUMEN}

El proyecto es un Polideportivo Inclusivo en el distrito de Villa María del Triunfo en la ciudad de Lima, Perú. En Lima existe un déficit de espacios públicos recreativos deportivos. La estadística es peor aún si se habla de espacios deportivos accesibles. El problema principal es la falta de instalaciones donde toda persona, en el estado físico en el que se encuentre, pueda practicar todo tipo de deporte de acuerdo con sus necesidades. Las instalaciones deportivas actuales son inaccesibles en todo sentido. La mayoría no se encuentran en vías principales y la manera de llegar a ellos no es posible para todos por la falta de redes inclusivas de transporte público. No son accesibles tampoco funcionalmente, están diseñados solo para un grupo de la población porque el 11\% (personas con algún tipo de discapacidad) se encuentra actualmente ignorado. Se elije Lima Sur porque tiene los distritos con mayor índice de discapacitados y porque noté que existe una directa relación entre discapacidad y pobreza. Se plantea diseñar un Polideportivo verdaderamente inclusivo que sea accesible y funcional, basado en las necesidades analizadas y concluidas a través de esta investigación; así como la cultura, geografía, usuarios, problemas sociales y topografía en Villa María del Triunfo para lograr tener un espacio que se sienta propio de la comunidad.

Palabras clave: Polideportivo, Inclusivo, Diseño Universal, Villa María del Triunfo, Lima.

\section{ABSTRACT}

The Project is an Inclusive Sports Center in the district of Villa María del Triunfo in Lima, Perú. Lima has a deficit of recreational and sports public spaces, the statistic is even worse if we talk about inclusive public spaces. The main problem is the lack of infrastructure where all people, in every physical state, can practice sports according to their abilities. The sport infrastructure of the present is not accessible, most of them are not even on main streets, making the way to get to them even more difficult. They are not accessible in a functional way either, they are designed only for a group of the population, because the $11 \%$ (percentage of people with a disability) is currently completely ignored. I've chosen the south of Lima because it has the districts with higher percentage of people with a disability and I noticed that there's a direct relation between disability and poverty. The thesis objective is to design a Sport Center truly inclusive, accessible and functional, based on the analyzed and concluded needs through this investigation, as the culture, the geography, the user, social problems, topography of the district. To be able to create a space that feels of the community.

Keywords: Sports Center, Inclusive, Universal Design, Villa María del Triunfo, Lima. 


\section{TABLA DE CONTENIDOS}

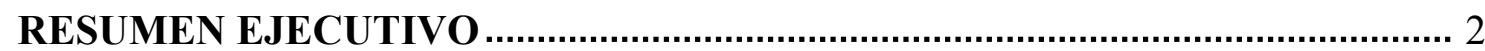

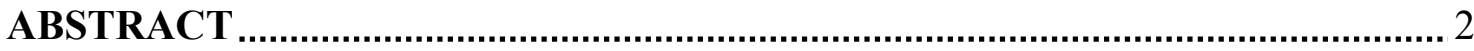

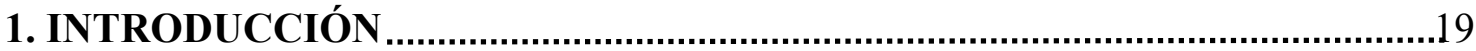

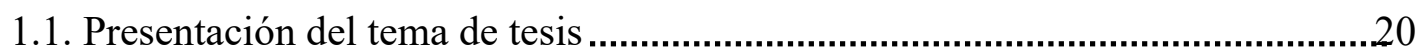

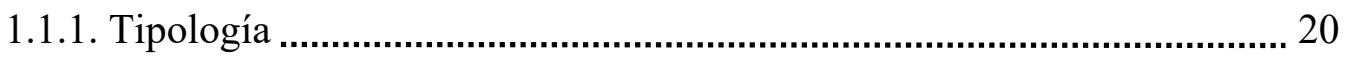

1.1.2. Énfasis / Concepto ............................................................................ 21

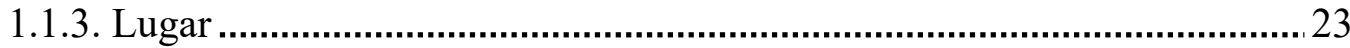

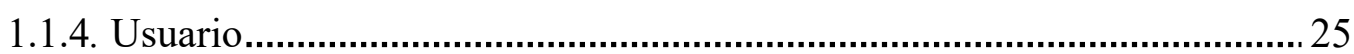

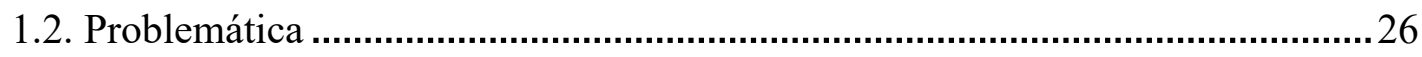

1.2.1. Problema Principal........................................................................... 26

1.2.2. Problemas Específicos ........................................................................... 26

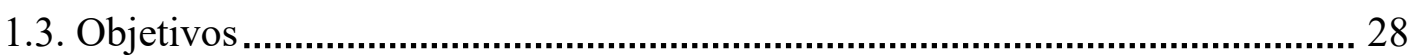

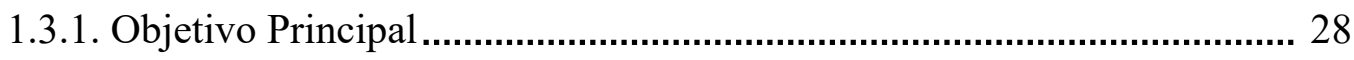

1.3.2. Objetivos Específicos...................................................................... 28

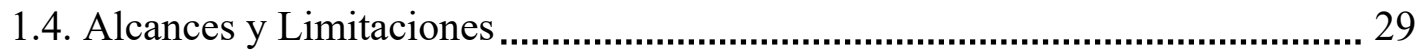

1.5. Metodología ................................................................................................ 30

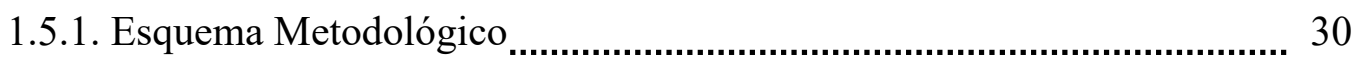

1.5.2. Plan de acciones a realizar ............................................................ 31

2. MARCO REFERENCIAL ,..................................................................... 33

2.1. Marco histórico ................................................................................... 34

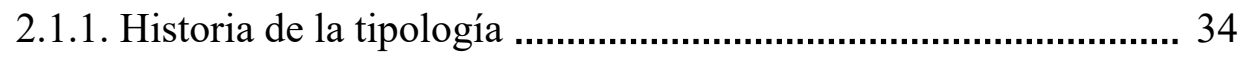

2.1.1.1. En el Mundo ................................................................... 34

2.1.1.2. En el Perú $\quad$.................................................................. 41

2.1.2. Historia del lugar $\quad$................................................................. 49

2.2. Marco Teórico-Conceptual................................................................... 62 
3.1. Análisis de los proyectos ........................................................... 73

3.2. Conclusiones comparativas de los proyectos ........................................ 114

4. ESTUDIO DEL LUGAR ........................................................................ 115

4.1. Localización ...................................................................................... 117

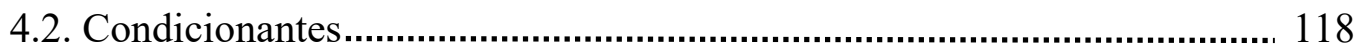

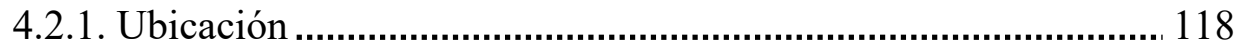

4.2.2. Físicas ........................................................................................ 119

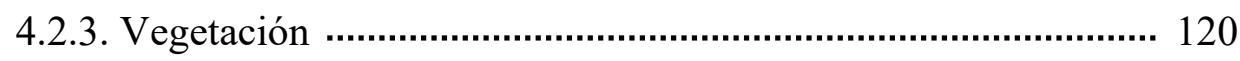

4.3. Criterios de selección del terreno …..................................................... 126

5. EXPEDIENTE URBANO ........................................................................ 135

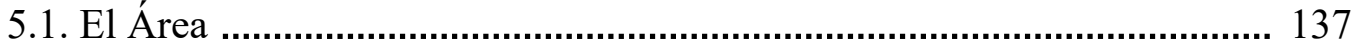

5.2. El Terreno y su entorno inmediato ...................................................... 141

6. EL USUARIO …............................................................................... 156

6.1. Definición de los usuarios …................................................................. 158

6.2. Aspectos cuantitativos ...................................................................... 159

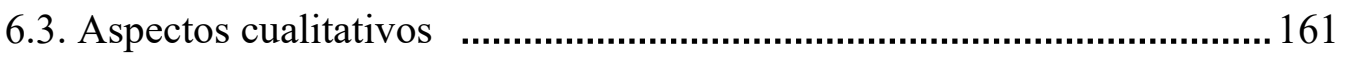

6.4. Resumen del tipo y número de usuarios ................................................. 170

7. PROGRAMACIÓN ARQUITECTÓNICA .................................................... 171

7.1. Organigrama institucional .................................................................. 172

7.2. Definición de paquetes funcionales ................................................. 172

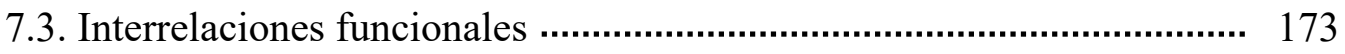

7.4. Análisis de la Normativa aplicable al proyecto (RNE y otras normas) ...175

7.5. Estudio de la antropometría y mobiliario general ................................... 194 
7.6. Análisis cuantitativo y cualitativo de los espacios funcionales

7.7. Áreas funcionales por ambiente

8. El Proyecto 229

8.1. Síntesis de necesidades y problemas a resolver 229

a) Enfoque del Proyecto 229

b) Definición de Conceptos 230

c) Definición de Criterios Arquitectónicos Urbanos .231

d) Determinación del Programa Arquitectónico .232

e) Paquetes Funcionales 232

f) Ubicación .233

g) Relación con el Contexto .234

h) Sistema Constructivo .235

i) Composición y Espacios Arquitectónicos. .236

j) Conclusiones. .237

9. CONCLUSIONES 240

10. BIBLIOGRAFÍA 247 


\section{Índice de Tablas}

Tabla $\mathrm{N}^{\mathrm{o}} 1 \quad$ Clasificación de personas con y sin algún tipo de discapacidad por edades

Tabla $\mathrm{N}^{\mathrm{o}} 2$ Clasificación de personas por tipo de discapacidad .12

Tabla $\mathrm{N}^{\mathrm{o}} 3$

Porcentajes de percepción de inseguridad por distrito.

Tabla No 4

Plan de acciones a realizar 18

Tabla $\mathrm{N}^{\mathrm{o}} 5$

Principios a considerar en la Arquitectura Eco-sostenible. ... .53

Tabla Nº

Resumen de tipo de deportistas.

Tabla $\mathrm{N}^{0} 7$

Resumen de tipo y número de usuarios en el polideportivo.....160

Tabla No 8

Cuadro Normativo y Cuadro de Áreas del proyecto. 164

Tabla N ${ }^{\circ} 9$

Espacios Funcionales: Cuadro de Guardería

Tabla No 10

Espacios Funcionales: Cuadro de Oficinas.

Tabla No 11

Espacios Funcionales: Cuadro de Espacio Polideportivo. .206

Tabla $\mathrm{N}^{\mathrm{o}} 12$

Espacios Funcionales: Cuadro de Bowling 208

Tabla $\mathrm{N}^{\mathrm{o}} 13$

Espacios Funcionales: Sala de Bailes .211

Tabla $\mathrm{N}^{\mathrm{o}} 14$

Espacios Funcionales: Cuadro de Piscina Olímpica. ...

Tabla $\mathrm{N}^{\mathrm{o}} 15$

Espacios Funcionales: Cuadro de Vestidores y SSHH

Tabla $\mathrm{N}^{\mathrm{o}} 16$

Cuadro de Áreas del Proyecto por Paquetes Funcionales

Tabla $\mathrm{N}^{\mathrm{o}} 17$

Cuadro de Áreas del Proyecto por Paquetes Funcionales .218

Tabla No 18

Cuadro de Áreas del Proyecto por Paquetes Funcionales .219 


\section{Índice de Figuras}

Figura $\mathrm{N}^{\mathrm{0}} 1 \quad$ Luminarium “A Sanctuary of the senses" Architects of Air........21

Figura $\mathrm{N}^{\circ} 2 \quad$ Mapas de Ubicación del Proyecto, Peru, Lima y zona sur..........23

Figura No3 Plano de ubicación de zona deportiva en Villa María.

Figura $\mathrm{N}^{\mathrm{o}} 4$

Mapa de accesibilidad del distrito de Villa María del Triunfo....24

Figura $\mathrm{N}^{0} 5$

Plano de Villa María del Triunfo y Villa el Salvador. .27

Figura $\mathrm{N}^{\mathrm{o}} 6$

Fotos de Puentes en zona de estudio .28

Figura $\mathrm{N}^{\mathrm{0}} 7$

Mapa de Lima y la red de Polideportivos Inclusivos propuestos.29

Figura $\mathrm{N}^{\mathrm{o}} 8$

Foto de zona accesible en Línea 1 del tren eléctrico. .30

Figura $\mathrm{N}^{\mathrm{0}} 9$

Esquema Metodológico del polideportivo inclusivo.... .30

Figura $\mathrm{N}^{\mathrm{o}} 10$

Vistas de Olympia of the Architectural Research. .35

Figura $\mathrm{N}^{\circ} 11$

The characteristics of Sports in various ages .36

Figura $\mathrm{N}^{\mathrm{o}} 12$

Foto del Coliseo Romano en Roma Italia - foto propia

Figura $\mathrm{N}^{\mathrm{o}} 13$

Bocetos de espacio deportivo interior del Royal Tennis

Figura $\mathrm{N}^{\mathrm{o}} 14$

Vista aérea de polideportivo londinense de la edad media. .38

Figura $\mathrm{N}^{\mathrm{o}} 15$

Fotos de instalaciones deportivas de los setentas .38

Figura $\mathrm{N}^{\mathrm{o}} 16$ Fotos de espacios acondicionados para deporte en interiores.....39

Figura $\mathrm{N}^{\mathrm{o}} 17$

Ilustración de chasqui

Figura $\mathrm{N}^{\circ} 19$

Vistas del antiguo estadio nacional en los cincuentas.

Figura $\mathrm{N}^{\circ} 20$

Vistas del antiguo estadio nacional en los cincuentas.

Figura $N^{0} 21$

Vistas del antiguo hipódromo de Santa Beatriz .44

Figura $\mathrm{N}^{\circ} 22$

Vistas del antiguo hipódromo de San Felipe .45 
Figura $\mathrm{N}^{\mathrm{o}} 23$

Figura $\mathrm{N}^{\circ} 24$

Figura $\mathrm{N}^{\mathrm{o}} 25$

Figura $\mathrm{N}^{\circ} 26$

Figura $\mathrm{N}^{\circ} 27$

Figura $\mathrm{N}^{\mathrm{o}} 28$

Figura No29

Figura $\mathrm{N}^{\circ} 30$

Figura $\mathrm{N}^{\circ} 31$

Figura $\mathrm{N}^{\circ} 32$

Figura $\mathrm{N}^{\circ} 33$

Figura $\mathrm{N}^{\circ} 34$

Figura No35

Figura $\mathrm{N}^{\mathrm{0}} 36$

Figura No37

Figura $\mathrm{N}^{\circ} 38$

Figura No39

Figura $\mathrm{N}^{\circ} 40$

Figura $\mathrm{N}^{\circ} 41$

Figura $\mathrm{N}^{\mathrm{o}} 42$

Figura $\mathrm{N}^{\mathrm{o}} 43$

Figura $\mathrm{N}^{\circ} 44$
Vistas del Hipódromo de Monterrico .45

Vistas del Hipódromo de Monterrico 45

Vistas del Hipódromo de Monterrico 45

Vistas del Coliseo Dibós .47

Vistas del Coliseo Dibós .48

Infografía Estadio Nacional....................................48

Infografía Estadio Nacional. .49

Infografía Historia del Lugar. 49

Infografía Historia del Lugar. .50

Infografía Historia del Lugar. ... 51

Infografía Historia del Lugar. .52

Infografía Historia del Lugar. .53

Infografía Historia del Lugar. .54

Infografía Historia del Lugar. .55

Infografía Historia del Lugar. .56

Infografía Historia del Lugar. .57

Infografía Historia del Lugar. .58

Infografía Historia del Lugar. .59

Infografía Historia del Lugar. .60

Infografía Historia del Lugar 61

Vista Sports and Fitness Center .63

Esquema Universal Design Equal Access City.... .64 
Figura $\mathrm{N}^{\circ} 45$

Figura $\mathrm{N}^{\circ} 46$

Figura $\mathrm{N}^{\circ} 47$

Figura $\mathrm{N}^{\mathrm{o}} 48$

Figura $\mathrm{N}^{\circ} 49$

Figura $\mathrm{N}^{\circ} 50$

Figura $\mathrm{N}^{\mathrm{0}} 51$

Figura $\mathrm{N}^{\mathrm{o}} 52$

Figura $\mathrm{N}^{\mathrm{0}} 53$

Figura $\mathrm{N}^{\circ} 54$

Figura No55

Figura $\mathrm{N}^{\circ} 56$

Figura $\mathrm{N}^{\circ} 57$

Figura $\mathrm{N}^{\mathrm{0}} 58$

Figura $\mathrm{N}^{\circ} 59$

Figura $\mathrm{N}^{\circ} 60$

Figura $\mathrm{N}^{\circ} 61$

Figura $N^{\mathrm{o}} 62$

Figura $\mathrm{N}^{\mathrm{o}} 63$

Figura $\mathrm{N}^{\mathrm{o}} 64$

Figura $\mathrm{N}^{\mathrm{o}} 65$

Figura $\mathrm{N}^{\circ} 66$
Brampton Soccer Center Vista Interior.

Brampton Soccer Center Vista Interior.

Ninisfil Recreation Complex Diagram. 70

Beijao Sports Center Sustainable Formal Concept Diagrams.....71

Beijao Sports Center Sustainable Formal Concept Diagrams.....72

Vistas del Sport and Fitness Center for the disabled People.......74

Vistas del Sport and Fitness Center for the disabled People........75

Vistas del Sport and Fitness Center for the disabled People........76

Vistas del Sport and Fitness Center for the disabled People........76

Vistas del Sport and Fitness Center for the disabled People........76

Mapas del Sport and Fitness Center for the disabled People.......77

Mapas del Sport and Fitness Center for the disabled People........78

Clima del Sport and Fitness Center for the disabled People........79

Clima del Sport and Fitness Center for the disabled People........79

Planimetria Sport and Fitness Center for the disabled People.....80

Esquema Sport and Fitness Center for the disabled People.........80

Vistas del Sport and Fitness Center for the disabled People.........81

Vistas del Sport and Fitness Center for the disabled People.........81

Vistas del Sport and Fitness Center for the disabled People.........81

Vistas del Sport and Fitness Center for the disabled People........82

Vistas del Sport and Fitness Center for the disabled People........82

Vistas del Sport and Fitness Center for the disabled People.........82 
Figura $\mathrm{N}^{\mathrm{o}} 67$

Figura $\mathrm{N}^{\mathrm{o}} 68$

Figura $\mathrm{N}^{\mathrm{0}} 69$

Figura $\mathrm{N}^{\circ} 70$

Figura $\mathrm{N}^{\circ} 71$

Figura $\mathrm{N}^{\circ} 72$

Figura $N^{\circ} 73$

Figura N ${ }^{\circ} 74$

Figura $N^{0} 75$

Figura $N^{\circ} 76$

Figura $N^{\circ} 77$

Figura $\mathrm{N}^{\circ} 78$

Figura $N^{0} 79$

Figura $\mathrm{N}^{\circ} 80$

Figura $\mathrm{N}^{0} 81$

Figura $\mathrm{N}^{\circ} 82$

Figura $\mathrm{N}^{\circ} 83$

Figura $\mathrm{N}^{\circ} 84$

Figura $\mathrm{N}^{\circ} 85$

Figura $\mathrm{N}^{\circ} 86$

Figura $N^{\circ} 87$

Figura $\mathrm{N}^{\circ} 88$
Vistas del Sport and Fitness Center for the disabled People

Vistas del Sport and Fitness Center for the disabled People.

Vista Interior de Escenarios deportivos en Medellín Colombia..83

Mapa de la ciudad de Medellín Colombia .84

Vista Exterior de Escenarios deportivos en Medellín Colombia.85

Vista Exterior de Escenarios deportivos en Medellín Colombia.85

Vista Aerea de Escenarios deportivos en Medellín Colombia....86

Planimetría de circulación vial y peatonal Medellín Colombia...87

Planimetría de circulación vial y peatonal Medellín Colombia...88

Vista Aerea de Escenarios deportivos en Medellín Colombia....88

Planimetría de Escenarios deportivos de Medellín Colombia.....89

Vistas de los alrededores de Escenarios deportivos de Medellin.89

Bosquejos conceptuales de Escenarios deportivos

91

Clima de Escenarios deportivos de Medellín... .91

Clima de Escenarios deportivos de Medellín. .92

Clima de Escenarios deportivos de Medellín. .92

Planimetría de Escenarios deportivos de Medellín Colombia.....92

Vistas estructuras Escenarios deportivos de Medellín Colombia94

Vistas estructuras Escenarios deportivos de Medellín Colombia94

Vistas del Arteixo Sports Center en España. . .96

Vistas del Arteixo Sports Center en España.............................96

Vistas del Arteixo Sports Center en España. .96 
Figura $\mathrm{N}^{\circ} 89$

Figura $\mathrm{N}^{\mathrm{o}} 90$

Figura $\mathrm{N}^{\circ} 91$

Figura $\mathrm{N}^{\circ} 92$

Figura $\mathrm{N}^{\circ} 93$

Figura $\mathrm{N}^{\circ} 94$

Figura $\mathrm{N}^{\circ} 95$

Figura $\mathrm{N}^{\circ} 96$

Figura $\mathrm{N}^{\circ} 97$

Figura No98

Figura $\mathrm{N}^{\circ} 99$

Figura $\mathrm{N}^{\mathrm{o}} 100$

Figura $\mathrm{N}^{\mathrm{o}} 101$

Figura $\mathrm{N}^{\mathrm{o}} 102$

Figura $\mathrm{N}^{\mathrm{o}} 103$

Figura $\mathrm{N}^{\mathrm{o}} 104$

Figura No 105

Figura $N^{\circ} 106$

Figura $\mathrm{N}^{\mathrm{o}} 107$

Figura $\mathrm{N}^{\mathrm{o}} 108$

Figura $N^{\circ} 109$

Figura $\mathrm{N}^{\mathrm{o}} 110$
Vistas del Arteixo Sports Center en España. 96

Vistas del Arteixo Sports Center en España..............................96

Vistas del Arteixo Sports Center en España..............................96

Vistas del Arteixo Sports Center en España.

Vistas del Arteixo Sports Center en España.

Vistas del Arteixo Sports Center en España .98

Vistas del Arteixo Sports Center en España. .98

Vistas del Arteixo Sports Center en España..... .98

Vistas del Arteixo Sports Center en España. .99

Vistas del Arteixo Sports Center en España.

Asoleamiento Arteixo Sports Center en España....

Planimetría del Arteixo Sports Center en España. .101

Esquema funcional del Arteixo Sports Center en España 102

Vistas del Arteixo Sports Center en España 103

Vistas del Arteixo Sports Center en España .103

Ubicación de la Videna de San Luis. .104

Ubicación de la Videna de San Luis. 104

Ubicación de la Videna de San Luis .104

Ubicación de la Videna de San Luis .104

Ubicación de la Videna de San Luis .104

Vistas de la Videna de San Luis. ... 104

Vistas de la Videna de San Luis. ... 104 
Figura $N^{0} 111$

Figura $\mathrm{N}^{\mathrm{o}} 112$

Figura $\mathrm{N}^{\mathrm{o}} 113$

Figura $\mathrm{N}^{\circ} 114$

Figura $\mathrm{N}^{\mathrm{o}} 115$

Figura $\mathrm{N}^{\mathrm{o}} 116$

Figura $\mathrm{N}^{\mathrm{o}} 117$

Figura $\mathrm{N}^{\mathrm{o}} 118$

Figura $\mathrm{N}^{\mathrm{o}} 119$

Figura $\mathrm{N}^{\mathrm{o}} 120$

Figura $\mathrm{N}^{\circ} 121$

Figura $\mathrm{N}^{\mathrm{o}} 122$

Figura $\mathrm{N}^{\mathrm{o}} 123$

Figura $\mathrm{N}^{\mathrm{o}} 124$

Figura $\mathrm{N}^{\mathrm{o}} 125$

Figura $\mathrm{N}^{\mathrm{o}} 126$

Figura $\mathrm{N}^{\mathrm{o}} 125$

Figura $\mathrm{N}^{\mathrm{o}} 126$

Figura $\mathrm{N}^{\mathrm{o}} 127$

Figura $\mathrm{N}^{\mathrm{o}} 128$

Figura $\mathrm{N}^{\mathrm{o}} 129$

Figura $\mathrm{N}^{\mathrm{o}} 130$
Flujo vial de la Videna de San Luis .105

Vistas de la Videna de San Luis.... 106

Vistas de la Videna de San Luis.

Vistas de la Videna de San Luis.

Vistas alrededores de la Videna de San Luis.

107

Flujo vial de la Videna de San Luis.

.108

Planta de la Videna de San Luis.

Asoleamiento de la Videna de San Luis.

109

Plantas de la Videna de San Luis

Planimetría de la Videna de San Luis.

Infografía de la Videna de San Luis 114

Mapa Lima Sur. 117

Mapa Lima Sur. 118

Vista del terreno 1

Vista de los terrenos

Vista de los terrenos 120

Vista de paisaje rural de VMT.

Vista de los terrenos .121

Vista de los terrenos 122

Vista de los terrenos .123

Vista de los terrenos

Vista de los terrenos 125 
Figura $\mathrm{N}^{\mathrm{o}} 131$

Figura $\mathrm{N}^{\mathrm{o}} 132$

Figura $\mathrm{N}^{\mathrm{o}} 133$

Figura $\mathrm{N}^{\mathrm{o}} 134$

Figura $\mathrm{N}^{\mathrm{o}} 135$

Figura $\mathrm{N}^{\mathrm{o}} 136$

Figura $\mathrm{N}^{\mathrm{o}} 137$

Figura $\mathrm{N}^{\mathrm{o}} 138$

Figura $\mathrm{N}^{\mathrm{o}} 139$

Figura $\mathrm{N}^{\mathrm{o}} 140$

Figura $\mathrm{N}^{\mathrm{o}} 141$

Figura $\mathrm{N}^{\mathrm{o}} 142$

Figura $\mathrm{N}^{\mathrm{o}} 143$

Figura $\mathrm{N}^{\mathrm{o}} 144$

Figura $\mathrm{N}^{\mathrm{o}} 145$

Figura $\mathrm{N}^{\mathrm{o}} 146$

Figura $\mathrm{N}^{\mathrm{o}} 147$

Figura $\mathrm{N}^{\mathrm{o}} 148$

Figura $\mathrm{N}^{\circ} 149$

Figura $\mathrm{N}^{\mathrm{o}} 150$

Figura $\mathrm{N}^{\mathrm{o}} 151$

Figura $\mathrm{N}^{\mathrm{o}} 152$
Vista de puente peatonal Oshbelt.

Cuadro comparativo terrenos

Cuadro comparativo terrenos. 128

Terreno 1 128

Vistas Terreno 1 129

Vistas Terreno 1 129

Vistas Terreno 1 130

Vistas Terreno 1 130

Terreno 2 131

Vistas Terreno 2.

Vistas Terreno 2

Vistas Terreno 2 .131

Vistas Terreno 2. .131

Terreno 3 132

Vistas Terreno 3 132

Vistas Terreno 3

Vistas Terreno 3

Vistas Terreno 3

Cuadro comparativo terrenos .133

Cuadro comparativo terrenos. .134

Planimetría + esquemas de terreno elegido 137

Planimetría + esquemas de terreno elegido 138 
Figura $\mathrm{N}^{\mathrm{0}} 153 \quad$ Planimetría + esquemas de terreno elegido.

Figura $\mathrm{N}^{\mathrm{o}} 154$ Planimetría + esquemas de terreno elegido 140

Figura $\mathrm{N}^{\mathrm{0}} 155$ Planimetría + esquemas de terreno elegido

Figura $N^{\circ} 156$

Planimetría + esquemas de terreno elegido

Figura $\mathrm{N}^{\mathrm{o}} 157$

Planimetría + esquemas de terreno elegido

Figura $\mathrm{N}^{\mathrm{o}} 158$

Planimetría + esquemas de terreno elegido 144

Figura $\mathrm{N}^{\mathrm{o}} 159$

Planimetría + esquemas de terreno elegido 145

Figura $\mathrm{N}^{\mathrm{o}} 160$

Planimetría + esquemas de terreno elegido 146

Figura $\mathrm{N}^{\mathrm{o}} 161$

Planimetría + esquemas de terreno elegido

Figura $\mathrm{N}^{\mathrm{o}} 162$

Planimetría + esquemas de terreno elegido

Figura $\mathrm{N}^{\circ} 163$

Planimetría + esquemas de terreno elegido

Figura $\mathrm{N}^{\mathrm{o}} 164$

Planimetría + esquemas de terreno elegido

Figura $\mathrm{N}^{\mathrm{o}} 165$

Zona de estudio

Figura $\mathrm{N}^{\mathrm{o}} 166$

Zona de estudio.

Figura $\mathrm{N}^{\mathrm{o}} 167$

Fotos Terreno elegido

Figura $\mathrm{N}^{\mathrm{o}} 168$

Fotos Terreno elegido

Figura $\mathrm{N}^{\mathrm{o}} 169$

Planimetría + esquemas de terreno elegido

Figura $\mathrm{N}^{\mathrm{o}} 170$

Fotos Terreno elegido .154

Figura $\mathrm{N}^{\circ} 171$

Fotos Terreno elegido .154

Figura $\mathrm{N}^{\mathrm{o}} 172$

Fotos Terreno elegido 155

Figura $N^{\circ} 173$

Fotos Terreno elegido .155

Figura $\mathrm{N}^{\mathrm{o}} 174$

Diagrama características del usuario. 158 
Figura $\mathrm{N}^{\mathrm{o}} 175$

Figura $\mathrm{N}^{\mathrm{o}} 176$

Figura $\mathrm{N}^{\mathrm{o}} 177$

Figura $\mathrm{N}^{\mathrm{o}} 178$

Figura $N^{\circ} 179$

Figura $\mathrm{N}^{\circ} 180$

Figura $\mathrm{N}^{\mathrm{o}} 181$

Figura $\mathrm{N}^{\mathrm{o}} 182$

Figura $\mathrm{N}^{\mathrm{o}} 183$

Figura $\mathrm{N}^{\mathrm{o}} 184$

Figura $\mathrm{N}^{\mathrm{o}} 185$

Figura $\mathrm{N}^{\mathrm{o}} 186$

Figura $\mathrm{N}^{\circ} 187$

Figura $\mathrm{N}^{\mathrm{o}} 188$

Figura $\mathrm{N}^{\mathrm{o}} 189$

Figura $\mathrm{N}^{\mathrm{o}} 190$

Figura No191

Figura No192

Figura $\mathrm{N}^{\circ} 193$

Figura $\mathrm{N}^{\mathrm{o}} 194$

Figura $N^{\circ} 195$

Figura $\mathrm{N}^{\mathrm{o}} 196$
Diagrama características del usuario

Diagrama características del usuario 160

Diagrama características del usuario

Diagrama características del usuario.

Diagrama características del usuario.

Diagrama características del usuario.

164

Diagrama características del usuario

165

Diagrama características del usuario. 166

Diagrama características del usuario.

Diagrama características del usuario. 168

Diagrama características del usuario.

Diagrama características del usuario 170

Organigrama funcional del proyecto.

Organigrama funcional del proyecto 172

Organigrama funcional del proyecto

Organigrama funcional del proyecto

Cuadro normativo y de áreas del proyecto

Planimetría + esquemas de terreno elegido. 176

Planimetría + esquemas de terreno elegido 176

RNE. 178

RNE. 180

RNE. 
RNE 
Figura No219

Figura No220

Figura Nº221

Figura No222

Figura $N^{\circ} 223$

Figura Nº224

Figura No225

Figura No226

Figura No227

Figura No228

Figura No229

Figura No230

Figura No231

Figura $\mathrm{N}^{\mathrm{o}} 232$

Figura No233

Figura Nº234

Figura No235

Figura No236

Figura No237

Figura No238

Figura No239

Figura No240
Planimetría de Oficinas .207

Planimetría de Polideportivo. .209

Planimetría de Polideportivo. .210

Planimetría de Polideportivo.

Planimetría de Polideportivo.

Planimetría de Polideportivo. .214

Planimetría de Polideportivo. .215

Planimetría de Polideportivo. 216

Planimetría de Polideportivo. .216

Planimetría de Bowling.

Planimetría de Bowling. .218

Planimetría de Bowling. .218

Planimetría de Sala de Baile. .219

Planimetría de Sala de Baile. .220

Planimetría de Piscina Olímpica. .221

Planimetría de Piscina Olímpica. .222

Planimetría de Vestuarios y SSHH. .223

Planimetría de Vestuarios y SSHH. .224

Planos de ubicación del Proyecto .229

Esquemas explicativos del proyecto.. .230

Esquemas explicativos del proyecto... .231 Planimetría del proyecto. .232 
Figura $\mathrm{N}^{\circ} 240$

Figura $\mathrm{N}^{\circ} 241$

Figura $\mathrm{N}^{\circ} 242$

Figura $\mathrm{N}^{\mathrm{o}} 243$

Figura $\mathrm{N}^{\mathrm{o}} 244$

Figura $\mathrm{N}^{\mathrm{o}} 245$

Figura $\mathrm{N}^{\mathrm{o}} 246$

Figura $N^{\circ} 247$

Figura $\mathrm{N}^{\circ} 248$

Figura $\mathrm{N}^{\mathrm{o}} 249$
Infografía del proyecto

.233

Boceto del proyecto 234

Planimetría estructural. .235

Vistas 3D del proyecto. .236

Vistas 3D del proyecto. .236

Boceto sostenibilidad del proyecto. .238

Vistas 3D del proyecto .239

Vistas 3D del proyecto. .239

Vistas 3D del proyecto. .239

Boceto sostenibilidad del proyecto. .246 
1. INTRODUCCION 


\section{La Introducción}

\subsection{Presentación de la Tesis}

\subsubsection{Tipología}

Polideportivo:

"Una arquitectura para dar cabida a las miles de formas que adoptan los valores deportivos, que, al fin y al cabo, han sido, son y serán un reflejo de los valores de la sociedad en cada período de la historia."

\section{CARLES BROTO}

Es un conjunto de espacios que se han diseñado para la práctica de distintos deportes. Está usualmente dividida en las siguientes partes: la zona principal (área de entrenamiento y competencia), las zonas que asisten a estas principales o auxiliares, (vestidores, zona de duchas, los cuartos de los dirigentes, cuarto de los equipos), las zonas administrativas, zonas de mantenimiento y control del edificio y las zonas para el espectador e intermedias (lobby, snack bar, SSHH).

Con la interminable multiplicidad de consideraciones que conllevan (capacidad de aforo, distribución de las localidades, espacios para concesiones, diversidad de accesos, prestaciones y servicios para los deportistas y la prensa) el diseño de instalaciones deportivas se sitúa con pleno derecho en una categoría aparte. Viendo las características de los usuarios, he visto la necesidad de incluir otras áreas dentro del programa como área de rehabilitación sensorial, una posta para que se atiendan eventualidades con los usuarios que puedan darse dentro de este establecimiento, zona donde puedan hacerle las pruebas de circuito que requieren las personas con discapacidad para definir su calificación como deportista, y también complementar al deportista con un plan alimenticio.

Además, la incorporación de una guardería sería un espacio óptimo para que los padres puedan dejar a sus niños cerca de ellos mientras se ejercitan. Esta guardería estaría equipada para recibir a niños discapacitados. 


\subsection{2. Énfasis/Concepto}

Arquitectura eco-sostenible:

Existen muchas definiciones de arquitectura sostenible. Según Jason F. Mclennan, el diseño sostenible es simplemente expandir la definición de diseño para incluir un rango más amplio de problemas a resolver que antes han sido ignorados o tomados muy a la ligera. El diseño sostenible ayuda a inculcar un sentido de responsabilidad y fundamentos de mayor categoría de vuelta al diseño.6 "El diseño sostenible busca dar soluciones que sean buenas para todas las especies para todos los tiempos."

Las ideas de Stefan Behnisch me parece que complementan y terminan de englobar el concepto de sostenibilidad y green buildings.

"Mi punto de vista es que, la sostenibilidad tiene que ser redefinida para cada proyecto en relación con su contexto cultural, social, geográfico, topográfico, climático, geopolítico, y la política de donde esta ubicado. No es posible hacer arquitectura sostenible si la cultura donde se posiciona es ignorada."

\section{Arquitectura sensorial:}

Este tipo de arquitectura se centra mas en cómo se siente el espacio y qué transmite a los sentidos, que en cómo se ve. A través del color, sonido, texturas y olores busca transmitir sensaciones a las personas para darle una cualidad más al espacio. En el caso de este Polideportivo, el factor inclusivo estaría intensificado por este tipo de arquitectura que haría que personas sordas, ciegas, con síndrome de Down, Asperger, Autismo, etc., puedan sentir a través de todas estas tácticas el espacio y disfrutarlo.

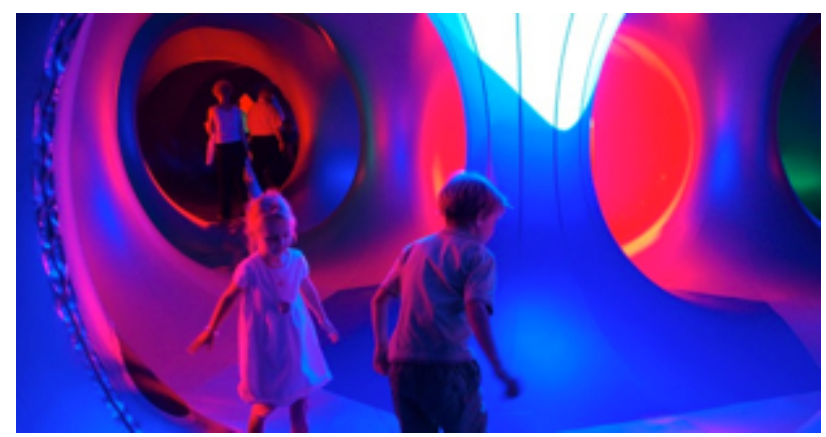

IMAGEN 2 - 10, Luminarium "A sanctuary of the senses" ARCHITECTS OF AIR 
Arquitectura Inclusiva: es un aspecto que todo edificio debería tener por defecto. La arquitectura es para las personas y debería tomar en cuenta a todos los tipos y condiciones físicas en las que se puedan encontrar. Actualmente, de acuerdo a estadísticas oficiales plasmadas en "La Convención sobre los Derechos de las Personas con Discapacidad", el Perú tiene 2 millones 400 mil ciudadanos discapacitados. Busco diseñar una solución verdaderamente inclusiva.

"En los últimos años, el concepto de Accesibilidad Universal ha ido calando en los ámbitos relacionados con la discapacidad. En un primer momento, la palabra accesibilidad estaba asociada a la eliminación de barreras físicas, a facilitar el acceso a los entornos urbanos, arquitectónicos. Sin embargo, hemos ido avanzando desde esa concepción parcial de la accesibilidad a englobarla en un concepto que considera a la persona y a su entorno como un todo: abarcando el medio físico, los transportes, la educación, el deporte, la cultura, el ocio o la sociedad de la información; en definitiva, hemos de plantear soluciones que no señalen de manera diferenciada a los ciudadanos según sus capacidades.

Se trata de poner en marcha alternativas que puedan ser utilizadas por todos, intentando así conseguir una sociedad en la que los ciudadanos, sin exclusión, puedan desenvolverse de una manera autónoma y en completa libertad." 12

"El mundo del diseño universal no tiene límites. Pensar en edificios diseñados y construidos para que todos los seres humanos puedan utilizarlos sin restricciones es una utopía de referencia, un anhelo; y como toda utopía, nace de la carencia, de una realidad imperfecta que hay que modificar. Habrá que facilitar el uso del entorno al ser humano común, al mayor número posible de individuos, en la conciencia de que siempre existirán personas a las que les resultará difícil utilizar, con plena autonomía, todo lo que está a nuestro alrededor." 
Lima Perú, distrito de

Villa el Salvador $y$ Villa

María del Triunfo

IMAGEN 4- MAPA DEL
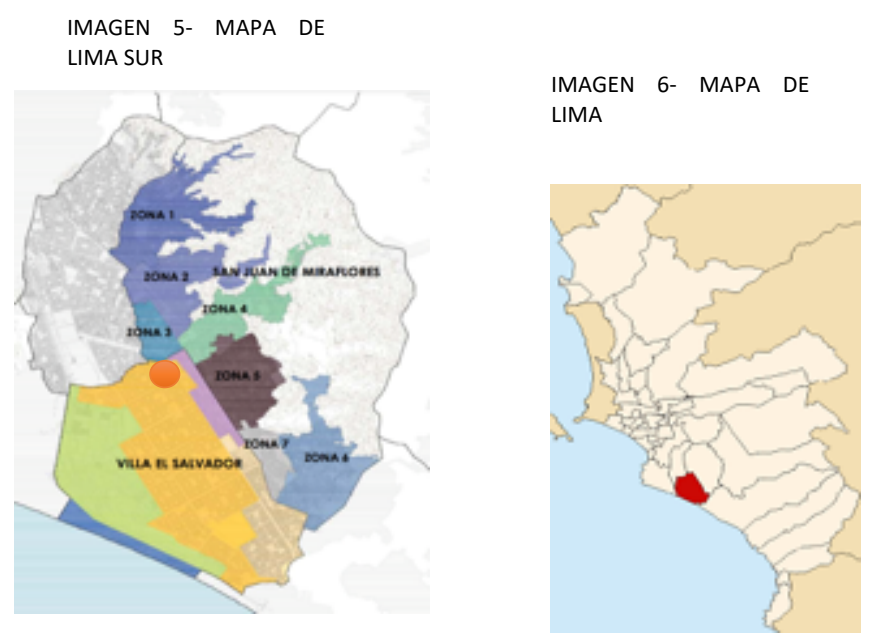

\subsubsection{Lugar}

Este Polideportivo se ubicaría en Lima Sur, en los limites del distrito de Villa el Salvador con Villa María del Triunfo ya que son distritos con muchas oportunidades. Actualmente son muy peligrosos y carecen de áreas públicas habilitadas. Cuentan con terrenos al lado de las líneas del tren eléctrico, accesibles por todos (discapacitados y no discapacitados) si estas personas se transportan en tren eléctrico. En el caso de los discapacitados sería la única manera de llegar en transporte público. El tren cubre dos aspectos: un aspecto positivo y otro negativo. Positivo porque con él el distrito se ha conectado con el resto de Lima. Negativo porque además de dividir el distrito en dos creando inseguridad, el tren eléctrico no esta habilitado para llevar más de una persona en silla de ruedas por vagón lo que limita a las personas discapacitadas.

Lima Sur se encuentra ahora conectada a través del tren y las líneas del metropolitano y los proyectos a futuro. La presencia del Parque Industrial crea un flujo alto hacia Villa el Salvador. 
En los límites de Villa el Salvador con Villa María del Triunfo se encuentra un eje deportivo informal, el cual visto como una oportunidad podría ser potenciado.
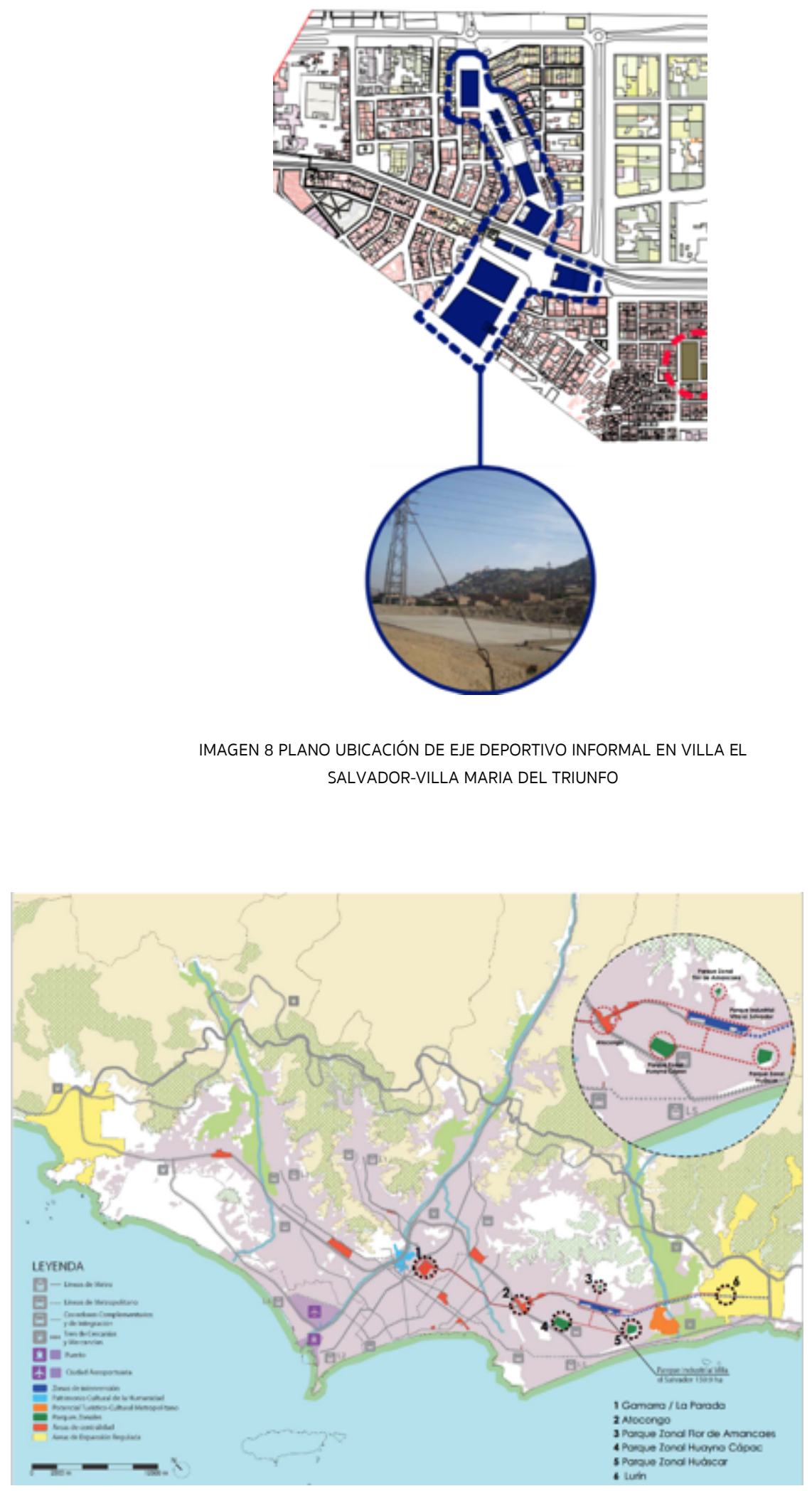

IMAGEN 7 - MAPA - ACCESIBILIDAD DEL DISTRITO Y PUNTOS DE CONCENTRACION 


\section{.2.4. Usuario}

Las personas que utilizarían este polideportivo, serían principalmente los que viven en Villa María del Triunfo y Villa el Salvador y los distritos circundantes (Chorrillos, Lurín, y San Juan de Miraflores). Y secundariamente, los deportistas que deseen utilizar el recinto, ya que estaría conectado con todos los distritos por los que pasa el tren eléctrico y el Metropolitano.

La población de Villa María del Triunfo y Villa el Salvador se caracteriza por una histórica capacidad de organización y cariño por su territorio, lo que a diferencia de otros le da una cualidad de barrio y entendimiento de quiénes son y qué necesitan.

Está dirigido a deportistas de toda edad y capacidad físico-motora, principalmente a los estratos C y D. El concepto principal para este Polideportivo es que sea verdaderamente un espacio diseñado para la convivencia de todos, discapacitados y no discapacitados. Es una manera de inculcar la visión global de la sociedad no sectorizada sin excluir ni dividir a la población por discriminaciones.

Podría subdividir a los usuarios por necesidades de espacios distintos, edad y estado físico.
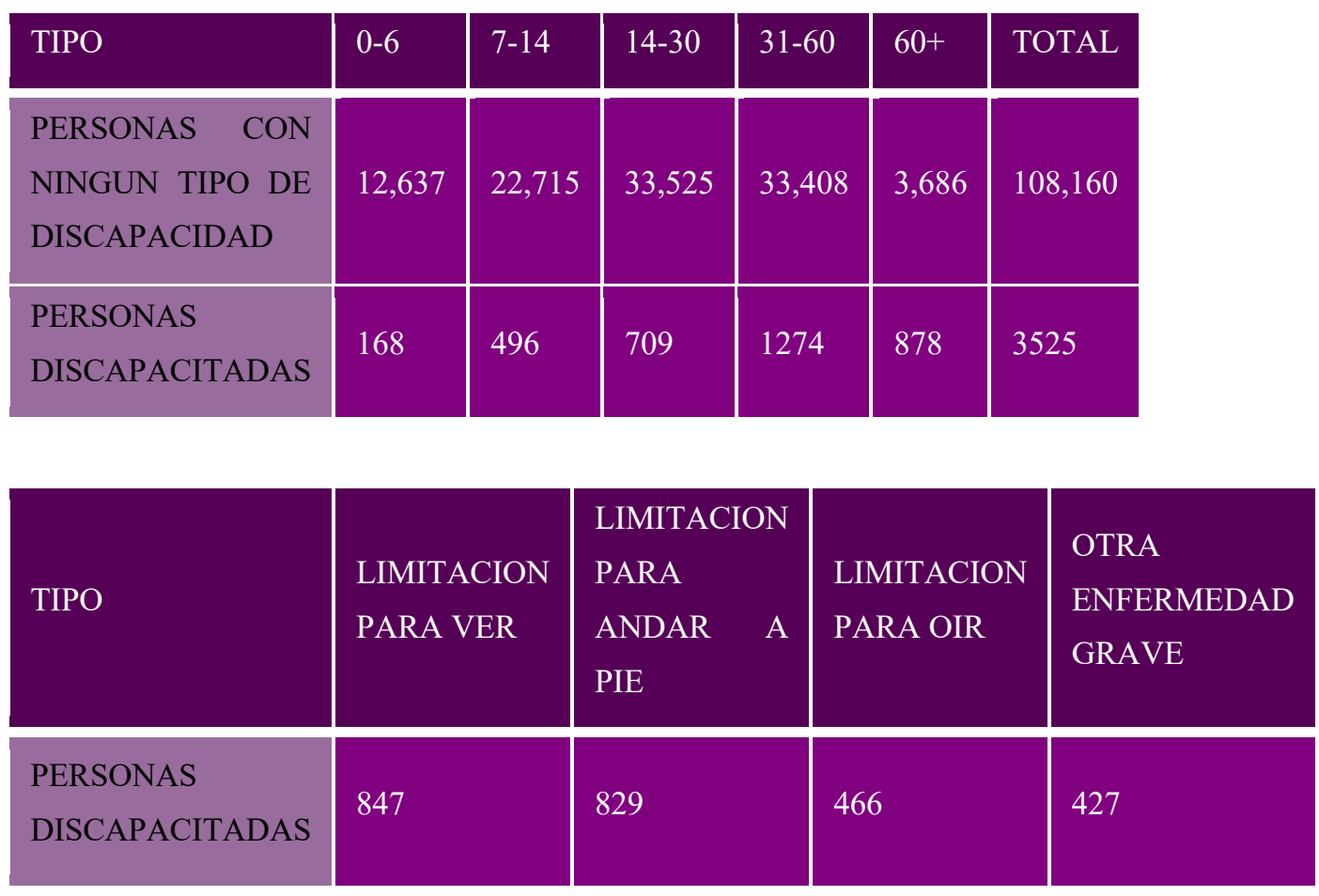

IMAGEN 9 - ELABORADO CON DATOS DEL PROPOLI DEL 2005 DE VILLA EL SALVADOR 


\subsection{Problemática}

\subsubsection{Problema Principal}

El problema principal es la falta de instalaciones donde toda persona en el estado físico en el que se encuentre pueda practicar todo tipo de deporte de acuerdo a sus necesidades. Las instalaciones deportivas actuales son inaccesibles en todo sentido. La mayoría no se encuentran en vías principales y la manera de llegar a ellas es difícil por la falta de redes inclusivas de transporte público. Tampoco son accesibles funcionalmente, ya que están diseñadas solo para un grupo de la población, el 11\% (personas con algún tipo de discapacidad) se encuentra actualmente ignorado.

\subsubsection{Problemas Específicos}

La necesidad del $70 \%$ de la población limeña de más y mejores espacios deportivos. Específicamente, la falta de espacios públicos de calidad inclusiva en Villa el Salvador y Villa María del Triunfo.

La inseguridad de los puentes peatonales que cruzan el tren eléctrico en Villa el Salvador.

El alto nivel de inseguridad actualmente en Villa el Salvador y Villa María del Triunfo.

\begin{tabular}{|l|c|l|c|}
\hline \multicolumn{2}{|c|}{$\begin{array}{l}\text { Distritos con menor } \\
\text { percepción de inseguridad }\end{array}$} & \multicolumn{2}{c|}{$\begin{array}{c}\text { Distritos con mayor percepción de } \\
\text { inseguridad }\end{array}$} \\
\hline San Isidro & $21.4 \%$ & Rímac & $84.8 \%$ \\
\hline San Borja & $32.8 \%$ & San Juan de Miraflores & $84.3 \%$ \\
\hline Miraflores & $34.0 \%$ & La Victoria & $82.5 \%$ \\
\hline La Molina & $34.6 \%$ & Comas & $80.6 \%$ \\
\hline Jesús María & $42.5 \%$ & Ate & $80.5 \%$ \\
\hline Surco & $43.5 \%$ & El Agustino & $80.0 \%$ \\
\hline Lurín & $49.0 \%$ & Villa El Salvador & $79.8 \%$ \\
\hline Magdalena & $52.3 \%$ & Villa María del Triunfo & $79.3 \%$ \\
\hline Puente Piedra & $54.3 \%$ & Independencia & $79.3 \%$ \\
\hline Los Olivos & $55.5 \%$ & San Juan de Lurigancho & $78.6 \%$ \\
\hline
\end{tabular}

Fuente: Ciudad Nuestra - Segunda Encuesta Metropolitana de Victimización 2012. 
- El desaprovechamiento de terrenos en Villa el Salvador y Villa María del Triunfo.

- La división distrital que produce el tren eléctrico en Villa el Salvador.

- La alta peligrosidad de los puentes peatonales que cruzan sobre el tren eléctrico.

- La falta de instalaciones deportivas verdaderamente inclusivos y que tomen en cuenta todas las necesidades de los deportistas.

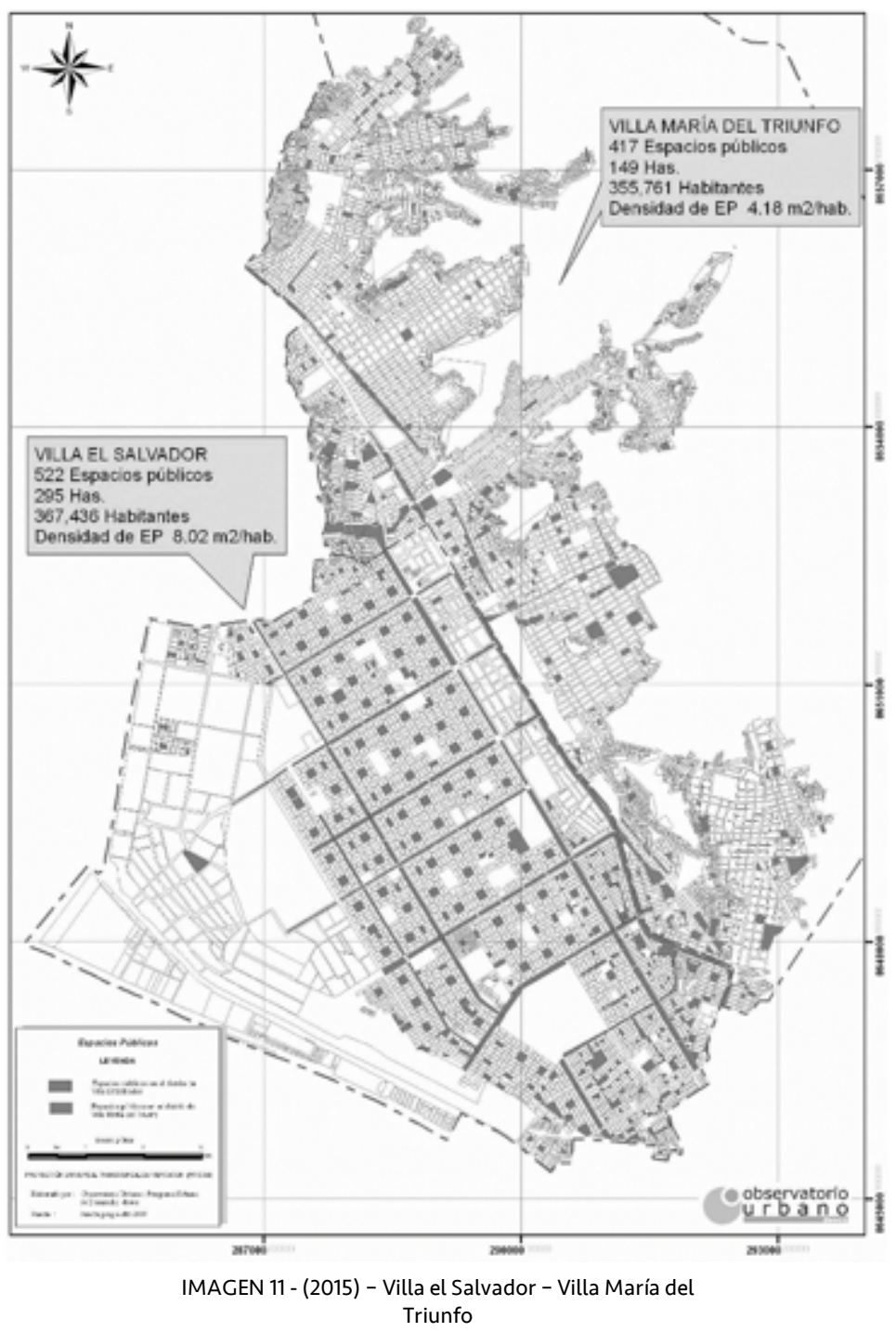




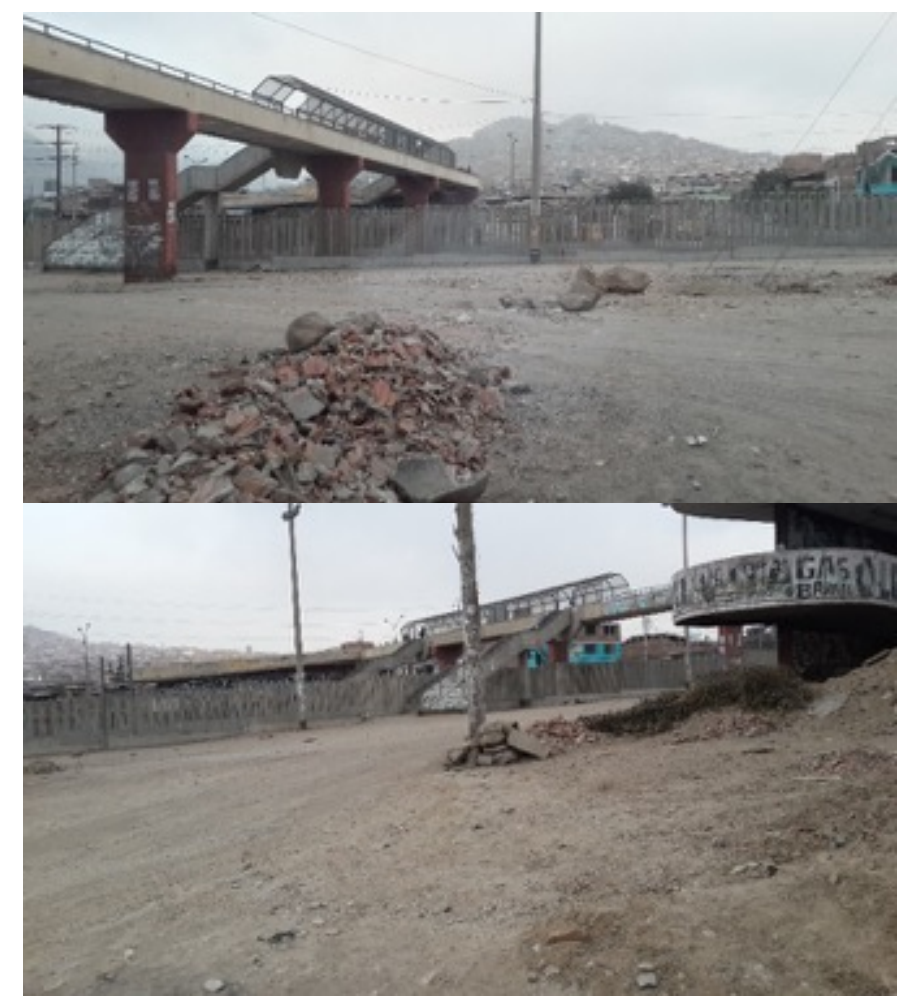

IMAGEN 12 - Fotografía Puente en Villa el Salvador - fotografía propia

\subsection{Objetivos}

\subsubsection{Objetivo Principal}

Diseñar un Polideportivo verdaderamente inclusivo eco-sostenible, que sea accesible y seguro, basado en las necesidades analizadas y concluidas a través de esta investigación. Además, tome en cuenta la cultura, geografía, usuarios, flora y fauna, problemas sociales y topografía en Villa María del Triunfo y Villa el Salvador para lograr tener un espacio que se sienta propio de las personas que lo usen, y que a su vez, logre reducir la inseguridad actual del distrito.

\subsubsection{Objetivos Específicos}

- Diseñar un polideportivo accesible para todos en Villa el Salvador.

- Diseñar nuevos puentes peatonales para distrito. Solucionando el problema de la división del distrito.

- Proponer una red nacional de polideportivos para lograr poco a poco, abastecer el alto porcentaje que necesita espacios públicos deportivos 
- Aprovechar los terrenos de Villa el Salvador y Villa María del Triunfo para proponer áreas publicas.

- Abarcar las disciplinas deportivas siguientes principalmente: fútbol, vóley, tenis, tenis de mesa, básquet, béisbol, squash, tiro, ajedrez, atletismo, bádminton, pool, box, ciclismo, fisicoculturismo, fitness, gimnasia, balonmano, karate, judo, kickboxing, kung fu, pesas, lucha, muay thai, nado, frontón, rugby, softball, tae kwon do, arquería.

\subsection{Alcances y Limitaciones}

\subsubsection{Alcances:}

El proyecto sería de carácter distrital, con la idea a futuro de que sea repetido en todo el sur y norte de la capital, ya que el resto de los distritos cuentan con instalaciones deportivas de algún tipo. En cuanto al planteamiento urbano que sería propuesto, el polideportivo sería parte de un proyecto más macro de todo el distrito, pero en esta tesis solo se desarrollaría a detalle el polideportivo y sus alrededores más cercanos.

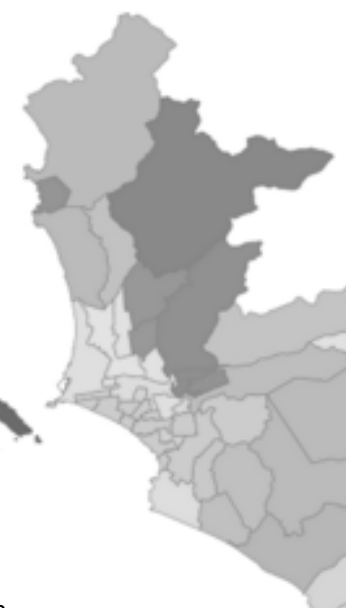
eco sostenibles 


\subsubsection{Limitaciones:}

La limitación principal que encuentro que está verdaderamente fuera de mi alcance, es el problema de la limitada accesibilidad actual en el tren eléctrico. Las personas discapacitadas, pueden utilizar el tren, pero de a una, ya que las instalaciones solo han habilitado un espacio por vagón, y además este espacio habilitado no les brinda seguridad de viaje, ya que no cuenta con seguros para la silla para evitar que se mueva durante el viaje. Esto limita a mi usuario ya que hace que personas que quieran viajar juntas o más seguras no lo puedan hacer.

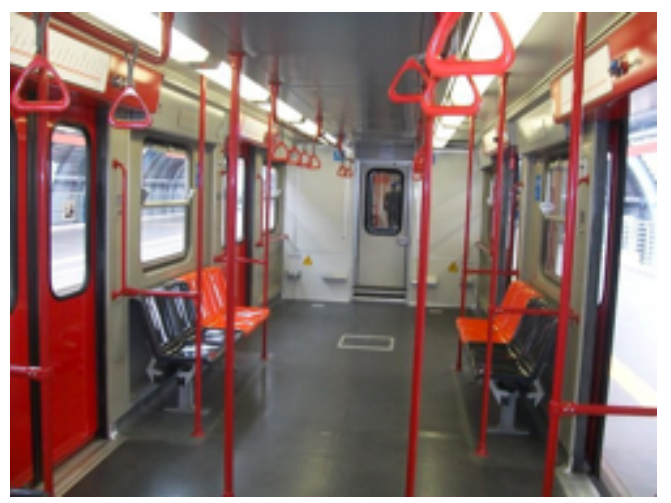

1.6 Metodología

IMAGEN 14 I2011) INSTALACIONES DEL TREN ELECTRICO DE LIMA

\subsubsection{Esquema Metodológico}

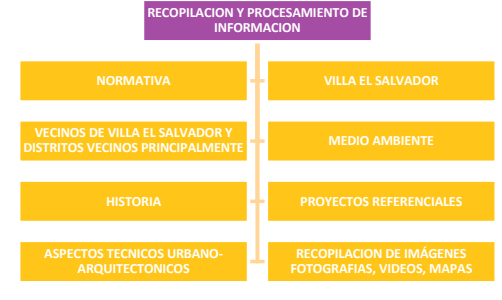

ETAPA DE ANALIISIS

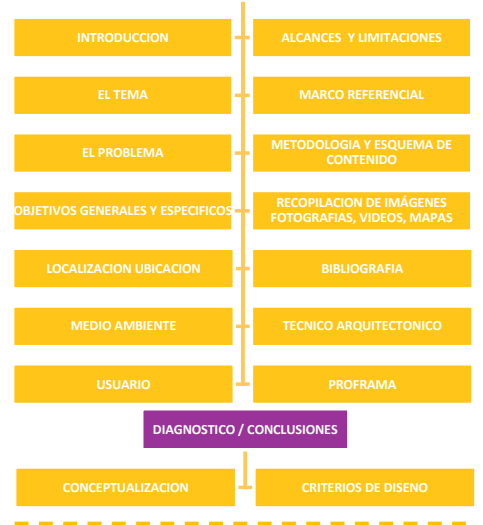

IMAGEN 15 - ESQUEMA METODOLOGICO
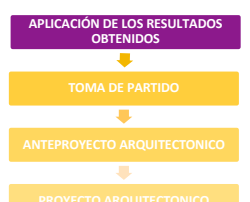


\subsubsection{Plan de acciones a realizar}

\begin{tabular}{|c|c|c|}
\hline PRINCIPALES ACTIVIDADES & \multicolumn{2}{|l|}{ ACTIVIDADES CONCRETAS } \\
\hline \multicolumn{3}{|c|}{ LINEAMIENTOS DEL POLIDEPORTIVOPROBLEMA } \\
\hline \multirow{2}{*}{$\begin{array}{l}\text { ECOSOSTENIBLE EN VILLA EL } \\
\text { SALVADOR }\end{array}$} & \multicolumn{2}{|l|}{ OBJETIVOS } \\
\hline & \multicolumn{2}{|c|}{ PLANTEMIENTO Y DEFINICIÓN DE ESTRATEGIAS } \\
\hline \multirow[t]{2}{*}{$\begin{array}{l}\text { PRIMER ACERCAMIENTO A CONTEXTO } \\
\text { GEOGRÁFICO, SOCIAL Y CULTURAL }\end{array}$} & \multirow[t]{2}{*}{$\begin{array}{l}\text { VISITA AL LUGAR } \\
\text { DOCUMENTACIÓN PRELIMINAR }\end{array}$} & $\begin{array}{l}\text { - INSPECCIÓN OCULAR } \\
\text { Olores, sensaciones, colores, qué veo, hasta donde se puede } \\
\text { ver, } \\
\text { Peligros, basura etc. }\end{array}$ \\
\hline & & $\begin{array}{l}\text { - LEVANTAMIENTO FOTOGRÁFICO DEL LUGAR } \\
\text { (Realizado } 2 \text { veces, Julio } 2014 \text { y } 15 \text { Agosto 2015) }\end{array}$ \\
\hline \multirow{3}{*}{ REGISTRO DE INFORMACIÓN } & \multirow[b]{2}{*}{ EN EL LUGAR } & $\begin{array}{l}\text { - LEVANTAMIENTO DE ASPECTOS DEL ENTORNO Y } \\
\text { POSIBLES TERRENOS: ESTADO ACTUAL, } \\
\text { MATERIALES, ETC. } \\
\text { Estado actual - desolado, sucio, vacío. } \\
\text { Visita a la Videna (5 setiembre 2015) } \\
\text { Visita polideportivo San Borja (5 setiembre 2015) }\end{array}$ \\
\hline & & $\begin{array}{l}\text { - INFORMACIÓN GRÁFICA Y TESTIMONIAL } \\
\text { VIDEOS, FOTOS, ENTREVISTAS, APUNTES } \\
\text { Setiembre 2015) } \\
\text { (entrevistas a usuarios, directores de rugby y vóley grabada } \\
\text { en video) } \\
\text { Entrevista a DF de rugby y de tenis sobre las necesidades } \\
\text { limitadas de los usuarios. } \\
\text { Visita a la VIDENA, Visita a Polideportivo del Callao, } \\
\text { Visita a Polideportivo de San Borja (13 de Julio 2015) }\end{array}$ \\
\hline & 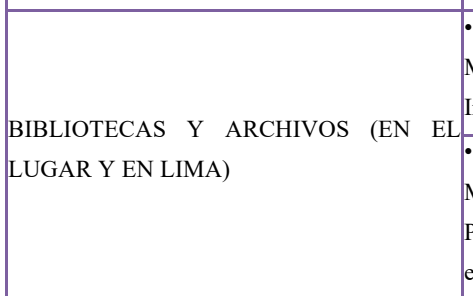 & $\begin{array}{l}\text { - INFORMACIÓN GRÁFICA: PLANOS } \\
\text { MUNICIPALIDAD } \\
\text { Informe de planificación urbana de la municipalidad } \\
\text { INFORMACIÓN DOCUMENTAL E HISTÓRICA: PDF } \\
\text { MUNICIPALIDAD, DATOS MUNICIPALES, INEI } \\
\text { Pdf dado por la municipalidad sobre planes urbanos de Villa } \\
\text { el Salvador y Villa María del Triunfo. }\end{array}$ \\
\hline \multirow{3}{*}{ ANALISIS DE DATOS } & \multicolumn{2}{|l|}{ ESTUDIO BIBLIOGRAFICO Y DOCUMENTAL } \\
\hline & \multicolumn{2}{|l|}{ ANALSIS DE LA INFORMACION } \\
\hline & \multicolumn{2}{|l|}{ CARACTERIZACIÓN DE LA PROPUESTA } \\
\hline \multirow{3}{*}{ DESARROLLO FINAL } & \multicolumn{2}{|l|}{ SINTESIS Y CONCLUSIONES } \\
\hline & \multicolumn{2}{|l|}{ DIAGNOSTICO Y PROGNOSTICO } \\
\hline & \multicolumn{2}{|l|}{ CRITERIOS DE DISEÑO } \\
\hline \multirow{2}{*}{ TALLER X } & \multicolumn{2}{|l|}{ • FORMULACIÓN DEL ANTEPROYECTO } \\
\hline & \multicolumn{2}{|c|}{ - DESARROLLO DE PROYECTO ARQUITECTÓNICO } \\
\hline
\end{tabular}


PREGUNTAS A USUARIOS

NOMBRE

EDAD

DEPORTES QUE REALIZAS

DONDE VIVE

ACOMPAÑADOS - CON O SIN SUS HIJOS

ENFERMEDAD O DISCAPACIDAD

¿Cuan accesibles son para ellos los centros deportivos?

¿Cómo llegan a estos centros deportivos?

¿Pueden usar con total libertad estos edificios?

¿La discapacidad los limita a practicar algún tipo de deporte?

¿Existe la necesidad de que una persona los asista a toda hora?

¿Cómo entrenan?

¿Qué equipos utilizan?

¿Se les dan estos equipos o ustedes tienen que llevarlos? ¿Cómo los llevan? 
2. MARCO REFERENCIAL 


\section{Marco Histórico}

\section{Marco Histórico}

\subsubsection{Historia de la tipología}

“En la actualidad, y con creciente profusión, las actividades deportivas están dando origen a multiplicidad de infraestructuras destinadas a su práctica y disfrute, muchas de ellas directamente relacionadas con la profesionalización del deporte y su difusión masiva gracias las nuevas tecnologías de comunicación. De forma paralela, la presencia cada vez más perceptible del deporte en la sociedad da lugar a una necesidad más "doméstica" de alojar, a pequeña escala, una serie de espacios deportivos capaces de absorber las diferentes necesidades lúdicas de ciudadanos de todas las edades y condiciones. Instalaciones ubicadas tanto en entornos aírales como urbanos, públicos o privados, al aire libre o cubiertos, y a escalas variables, desde los pequeños clubes y gimnasios escolares hasta polideportivos y grandes estadios. Añadido a las cualidades formales y expansivas que presentan, estos proyectos tienen en común la inquietud de sus arquitectos por explorar alternativas a las ineludibles exigencias de las reglamentaciones deportivas, alejándose de la sombra que la estandarización proyecta sobre este tipo de infraestructuras. En definitiva, una arquitectura para dar cabida a las miles de formas que adoptan los valores deportivos, que, al fin y al cabo, han sido, son y serán un reflejo de los valores de la sociedad en cada período de la historia. " 20

\subsubsection{En el mundo}

Antigua Grecia y Roma:

Estas civilizaciones tenían fuertes e identificables culturas físicas. Es interesante como entre ellas eran tan diferentes y como se relacionaban con los espacios creados para estos eventos deportivos. En Grecia, el deporte y los juegos estaban mezclados con sus rituales y festividades que a su vez congregaban a varias ciudades independientes.

La religión y la espiritualidad de los juegos siempre tenía relación con este tipo de eventos. Los ideales de fuerza y belleza estaban presentes, era para los dioses. Siendo los juegos tan asociados a lo divino, se emplazaba en zonas religiosas y de rituales. Estaban alejadas de cualquier ciudad en particular, ciudades como Delphi, Delos y Olympia, 
elegidos por proveer un paisaje neutro, amplio, y la negociación política era manejable. El deporte representaba un balance sociopolítico.
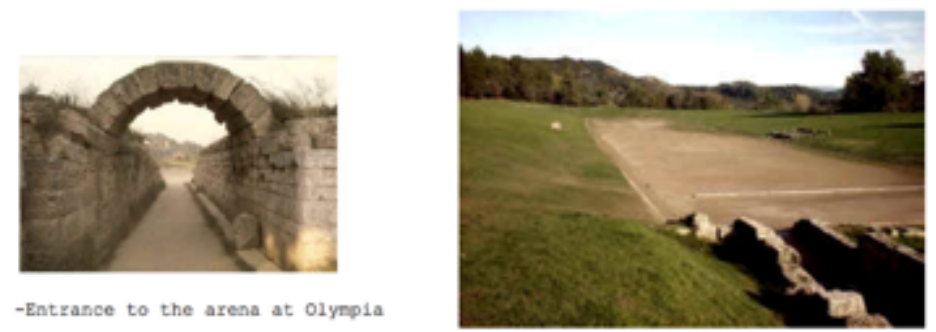

-Spectator berning at the olymis ruins

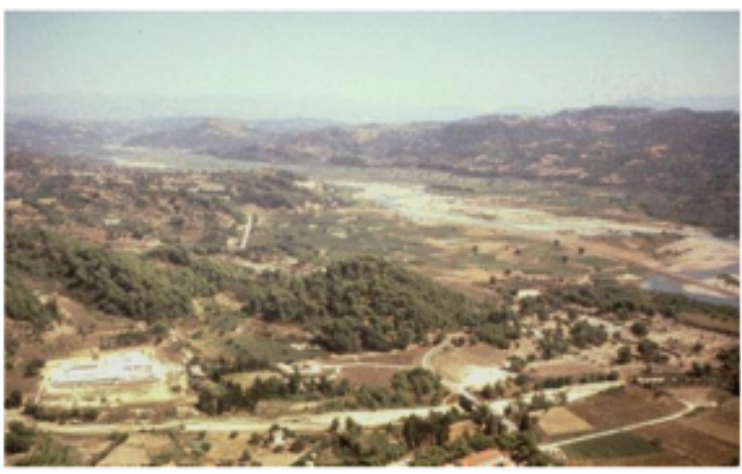

-The Olympian sacred site

IMAGEN 1. VISTAS DE OLYMPIA - 2006 ARCHITECTURAL RESEARCH ARCHITECTURE AND SPORT

El prestigio de los juegos griegos se limitaba a familias adineradas, generando mayores honores con las victorias. La presión de una aceptación de los dioses fue substituida eventualmente por un deseo de victoria. El deportista se convirtió en el nuevo foco central de atención, reemplazando el concepto religioso de los juegos. Pronto fue convertido en una industria de imagen, agentes y publicidad. Esta situación hizo que los ciudadanos prefieran ver los juegos y permitieron a los extranjeros participar, lo que se evidencia en la evolución del papel protagónico que tiene la audiencia en la arquitectura deportiva.

El deporte Romano y la educación física, como mucho de su cultura, derivo de otras. Vinieron influencias etruscas, y griegas. La fascinación que encontraban los romanos en la muerte es atribuida a su lado etrusco, y famoso en sus juegos en la arena.

El atletismo griego y la intensidad de los atletas griegos no encajaba con la mentalidad romana. La audiencia romana prefería ejercicio más ligero, y uno más intenso en el entrenamiento de los soldados, como método de disciplina, coraje y trabajo en equipo. Los romanos utilizaban métodos brutales para entrenar el cuerpo. 
En la época de la república, los baños y termas eran considerados tan importantes aspectos de la salud como el deporte. Un área amplia y enorme, con un templo dedicado a Marte, el dios de la guerra era un campus donde los hombres eran educados en las distintas disciplinas, como correr, saltar, nadar, luchar, equitación, boxeo, arquería y obediencia. Es un ejemplo de tratamiento de nivelación de suelo, y creación de un espacio dedicado al deporte, que es consistente con cualidades actuales de las instalaciones deportivas.

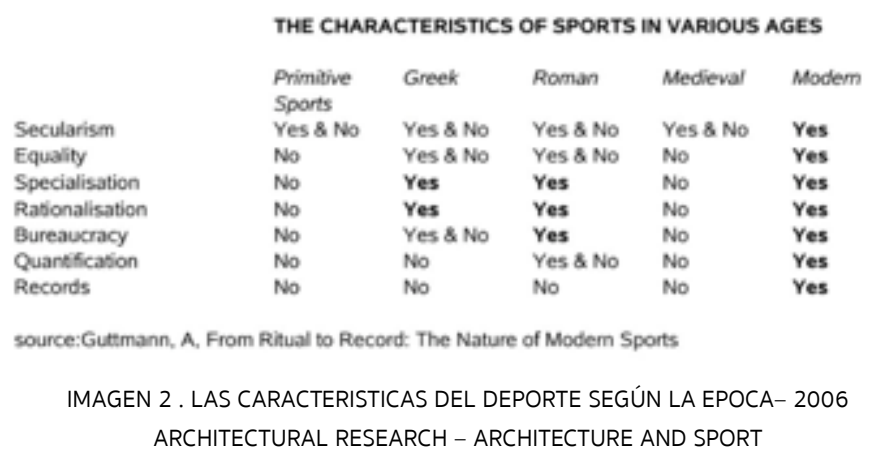

Mientras la república progresaba, la envergadura de estos eventos deportivos crecía. La política utilizaba el deporte como un método de controlar a las masas, para sacar a la población del aburrimiento. El Coliseo, fue creado para ser la casa de estos espectáculos imperiales. La forma ovalada le permitía abastecer a toda la ciudad, era de 4 pisos y tenía 8 entradas. El escalonamiento refuerza la estratificación de la sociedad, con diferentes secciones que ofrecen una mayor vista, se convierte en una instalación deportiva arquetipo de la época. Su tipología casi canónica, es evidenciada en la forma de los estadios actuales. 


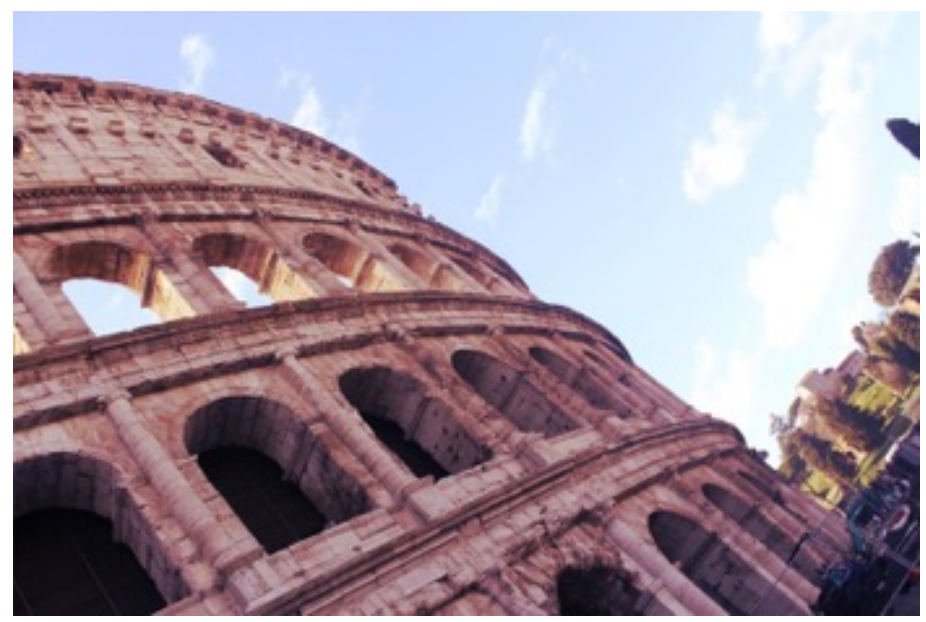

Imagen 3. (2015) Coliseo Romano, Roma, IT - foto por Ghianella Lertora

Esto indica que la actitud antigua hacia el deporte puede que este mas alineada a la idea moderna, que a las ideas primitivas y medievales. Conceptos modernistas de estandarización, producción en serie, se ve reflejado en la tradición antigua de controlar el evento de manera escalonada, y sectorizada.

La edad media cambia el uso del paisaje en contraste con la época anterior, y por lo tanto repercute en la cultura física. En esta época, la segmentación del tiempo y el espacio dio como resultado el deporte competitivo, en el que pueblos se vuelven competitivos y violentos. Se utilizaban edificios amplios y el equipo local, tenía ventaja porque jugaba bajo sus propias reglas. En el renacimiento el futbol, conocido en ese momento como Calcio, fue practicado en las calles y plazas. En este contexto social, el aspecto deportivo fue tomado en cuenta en el diseño de las ciudades. Poco a poco, el deporte fue encerrado dentro de arquitectura, y el edificio en sí se volvió parte del juego.

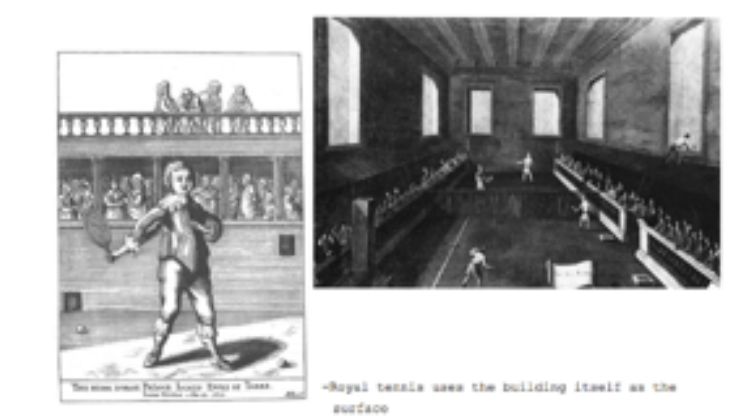

Imagen 4. BOCETOS DE ESPACIO DEPORTIVO EN INTERIORES - 2006 ARCHITECTURAL RESEARCH - ARCHITECTURE AND SPORT 
El auge de la industrialización en Europa tuvo un impacto en la evolución del deporte y los juegos. En paralelo a esto estaba la influencia del Romanticismo. La visión matemática, empírica, científica de ver el mundo que es el resultado del pensamiento iluminado y el cambio en la estructura social a una sociedad burguesa de clase media. Guttam ha clasificado las siguientes características: secularismo, igualdad en la opción de jugar, especialización, racionalismo, organización. Todas relacionadas al concepto de progreso, y de rapidez.

Se abren instalaciones deportivas específicas por tipos de disciplinas, edificios que concuerdan con la tipología de gimnasio en la actualidad. El concepto de espacio al aire libre, y conexión con la naturaleza está presente en la arquitectura.

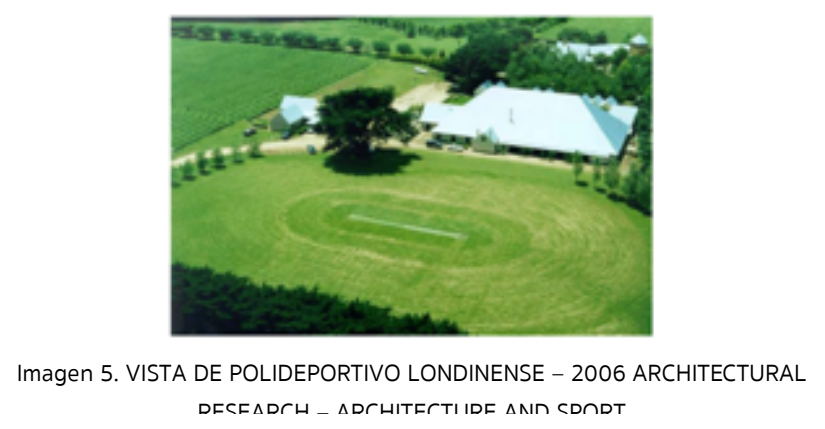

La urbanización de América se vuelve un proceso de dos factores cruciales. La formación de deporte organizado y la mayor influencia en la formación del crecimiento de deportes recreacionales. El deporte era una manera de promover la sinergia en la sociedad.
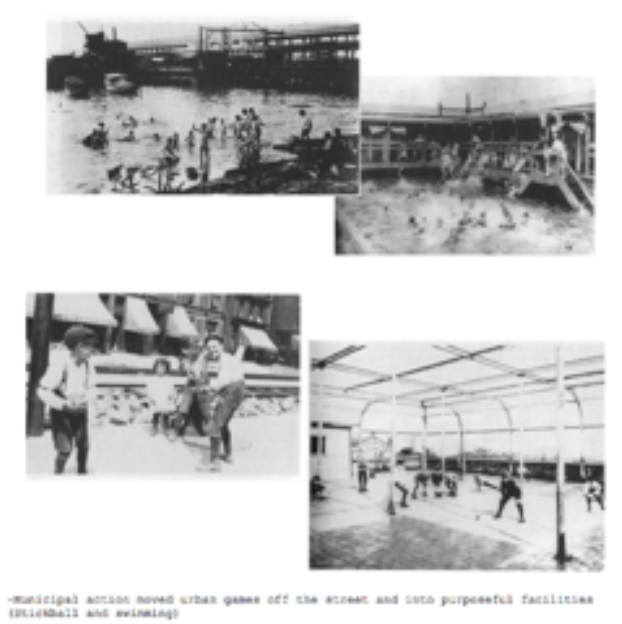

Imagen 6. FOTOS DE INSTALACIONES DEPORTIVAS- 2006 
Las ciudades de crecimiento radial tuvieron que adaptar espacios para deportes que se puedan realizar en recintos cerrados, como el billar o el bowling y colocaron actividades al aire libre en las afueras de la ciudad. El box y el básquetbol se convirtieron en deportes urbanos para municipalidades de baja inversión pública.

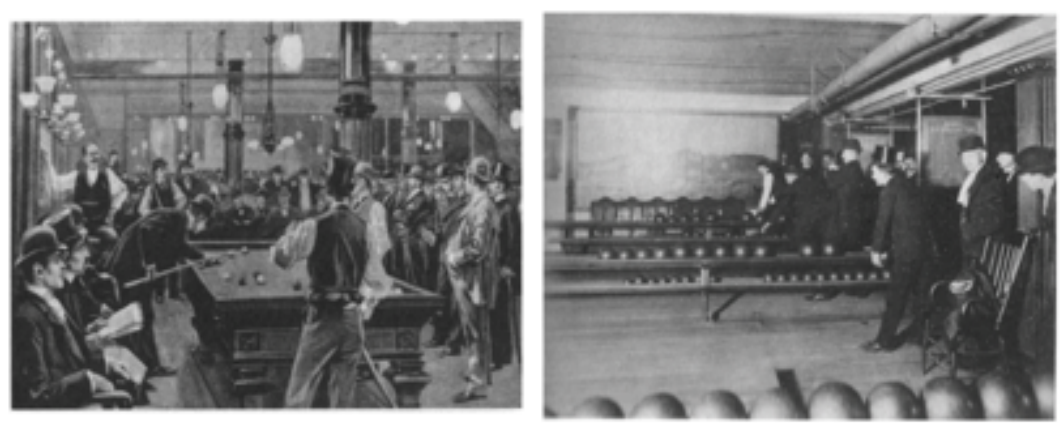

Imagen 7 FOTOS DE ESPACIOS ACONDICIONADOS PARA DEPORTE EN ESPACIOS CERRADOS- 2006 ARCHITECTURAL RESEARCH - ARCHITECTURE AND SPORT

Los grandes estadios y arenas fueron colocados en las periferias de la ciudad, limitando su usuario a personas adineradas, favoreciendo a las empresas de transporte. El avance de la tecnología favoreció al deporte como disciplina y a la manera de construir estos espacios.

Más tarde, en la época modernista, la idea de instalación deportiva se convierte en el concepto ortogonal de contenedor de deporte.

Posteriormente, suplantados por el concepto postmoderno de un deporte en familia, flexible, transformable y más familiar que de disciplina. Desde el punto de vista del diseño, o era un diseño completamente funcionalista $\mathrm{y}$ frio, o era un parque de diversiones.

\begin{tabular}{|c|c|}
\hline Modernism & Postmodernism \\
\hline $\begin{array}{l}\text { form } \\
\text { purpose } \\
\text { design } \\
\text { hierarchy } \\
\text { achievement } \\
\text { distance } \\
\text { totalisation } \\
\text { phallic } \\
\text { Fordist } \\
\text { homotopia } \\
\text { race } \\
\text { nurture }\end{array}$ & $\begin{array}{r}\text { antiform } \\
\text { play } \\
\text { chance } \\
\text { anarchy } \\
\text { happening } \\
\text { participation } \\
\text { deconstruction } \\
\text { androgynous } \\
\text { flexible } \\
\text { heterotopia } \\
\text { run } \\
\text { nature }\end{array}$ \\
\hline
\end{tabular}

Imagen 8 DIFERENCIAS DEL ESPACIO DEPORTIVO MODERNO Y POSTMODERNO- 2006 ARCHITECTURAL RESEARCH - ARCHITECTURE AND SPORT 


\begin{tabular}{|c|c|c|c|}
\hline & Traditional gawes & Madern sport & 'Postmoderniy' \\
\hline 1. Time & $\begin{array}{l}\text { Festivity } \\
\text { Rhythmic } \\
\text { repetition }\end{array}$ & $\begin{array}{l}\text { Leisure/work time } \\
\text { Futurist maximisation }\end{array}$ & $\begin{array}{l}\text { Sport of the unemployed } \\
\text { Experience of stress }\end{array}$ \\
\hline 2. Space & $\begin{array}{l}\text { Integration } \\
\text { Local identity }\end{array}$ & $\begin{array}{l}\text { Specialisation } \\
\text { Standardisation } \\
\text { Isolation }\end{array}$ & $\begin{array}{l}\text { Jogging space } \\
\text { 'Community sport' } \\
\text { Crisis of 'container } \\
\text { architecture' }\end{array}$ \\
\hline 3. Energy & $\begin{array}{l}\text { Laughter } \\
\text { Music } \\
\text { Ritual 'spirituality' }\end{array}$ & $\begin{array}{l}\text { Disappearance of } \\
\text { laughter } \\
\text { Disappearance of } \\
\text { music } \\
\text { Dynamic of speed }\end{array}$ & $\begin{array}{l}\text { New carnivalism } \\
\text { Re-musicalisation } \\
\text { New religious body } \\
\text { cultures }\end{array}$ \\
\hline $\begin{array}{l}\text { 4. Interpersonal } \\
\text { relations }\end{array}$ & $\begin{array}{l}\text { Patriarchy/ } \\
\text { matriarchy? } \\
\text { Togetherness of } \\
\text { ages } \\
\text { Locality/ } \\
\text { internationality }\end{array}$ & $\begin{array}{l}\text { Male dominance } \\
\text { Classes of gender } \\
\text { age, weight } \\
\text { National } \\
\text { identification/ } \\
\text { results }\end{array}$ & $\begin{array}{l}\text { 'Sport across the limits' } \\
\text { Family sport } \\
\text { Social sport } \\
\text { Multiplicity of cultural } \\
\text { identities }\end{array}$ \\
\hline 5. Objectives & $\begin{array}{l}\text { 'The strong man' } \\
\text { 'Glory' }\end{array}$ & $\begin{array}{l}\text { Production of results } \\
\text { Quantification of } \\
\text { records } \\
\text { Achievement }\end{array}$ & $\begin{array}{l}\text { Crisis of educational } \\
\text { quantification } \\
\text { Media circus }\end{array}$ \\
\hline $\begin{array}{l}\text { 6. Values and } \\
\text { ideas }\end{array}$ & $\begin{array}{l}\text { Christian/pagan? } \\
\text { Traditionalism }\end{array}$ & $\begin{array}{l}\text { Faster, higher, } \\
\text { stronger } \\
\text { c-g-s rationalisation } \\
\text { Olympic ideology }\end{array}$ & $\begin{array}{l}\text { Criticism of sport } \\
\text { New Age ideology of } \\
\text { sport } \\
\text { 'Health' sport }\end{array}$ \\
\hline 7. Institutions & $\begin{array}{l}\text { Local self- } \\
\text { determination } \\
\text { Age-groups? }\end{array}$ & $\begin{array}{l}\text { Hierarchical system } \\
\text { Bureaucratic control }\end{array}$ & $\begin{array}{l}\text { Non-organised sport } \\
\text { Commercial sport } \\
\text { Alternative body culture }\end{array}$ \\
\hline
\end{tabular}

Imagen 9 CARACTERISTICAS DE EL DEPORTE EN EL TIEMPO - 2006 ARCHITECTURAL RESEARCH - ARCHITECTURE AND SPORT

"El inicio de la Arquitectura Deportiva está ligado directamente al desarrollo del deporte como tal, y cuando éste logra llegar a un grado importante de arraigo, genera explícitamente la necesidad de un desarrollo arquitectónico que dé una respuesta mediante instalaciones concretas para las diferentes disciplinas. El deporte surge como una necesidad superior de manifestación capital del hombre. Desde los arcaicos juegos funerarios en los que se quería honrar a través de la competición lúdica al entrañable recuerdo dejado por el muerto entre parientes y amigos, a las confrontaciones rituarias ulteriores donde la competición es base de la liturgia, aunque se venera al dios patrón de santuario. En esta sucesiva manifestación de deporte-religión o culto-deporte, el lugar o escenario del desarrollo agónico es siempre el mismo en el que el culto, veneración o devoción, da lugar a la confrontación deportiva.” 21

\section{Recientes tipologías internacionales de instalaciones deportivas}

El diseño de instalaciones deportivas cubre una inmensa cantidad de variaciones. Distintos programas, presupuestos, usuarios, culturas y más aspectos que producen 
diferentes respuestas de la misma tipología. Sin embargo, y tras haber explicado la evolución social histórica de la misma, algunas tipologías actuales pueden proveer algo de información acerca de estrategias de diseño. Las 4 estrategias prominentes son:

1. Infraestructura

2. Contenedores decorados

3. Experiencia directa, movimiento

4. Inmersión en el paisaje

\subsubsection{En el Perú}

El deporte ha estado presente en la historia del Perú desde las épocas prehispánicas en donde se realizaban deportes como el juego de pelota en canchas o en terrenos nivelados. El entrenamiento del chasqui también puede ser considerado como una tipología de deporte, ya que la persona tenía que pasar por una serie de pruebas para poder realizar este trabajo. Realizaban pruebas y un entrenamiento muy duro y disciplinario. 22

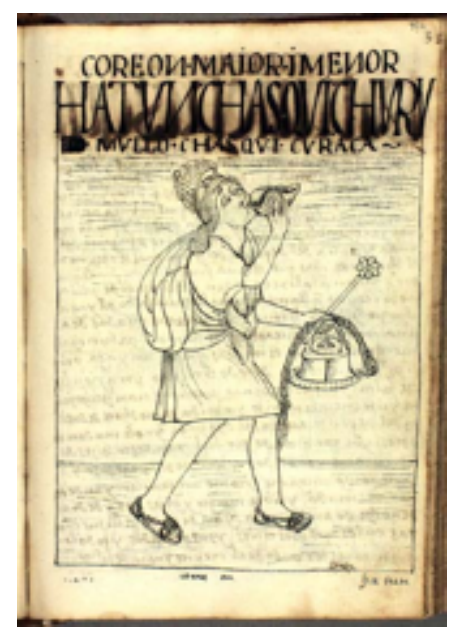

IMAGEN 10 - ILUSTRACION DE CHASQUI - (2012) DEPORTES QUE PRACTICABAN LOS INCAS - LIMA PERU

Posteriormente, empezó la construcción de instalaciones deportivas y la habilitación de zonas para el deporte en Lima. La primera construcción deportiva fue el Antiguo Estadio Nacional en 1897, al que se le conoce como el Estadio Nacional. Existió desde el 18 de julio de 1897 hasta 1951, cuando se hizo la primera remodelación.

A finales del siglo XIX, cuando se iniciaba la práctica del fútbol, existían en Lima solo dos terrenos habilitados. Uno en Lima, propiedad de Lima Cricket y otro en el Callao 
ubicado en la costa sur. El terreno hoy pertenece al Distrito de Lima. Así, este terreno se convirtió en el primer y principal escenario deportivo para la práctica exclusiva del fútbol que se creó en el país. En este escenario se jugaron los primeros campeonatos peruanos y se convirtió en el centro deportivo de Lima. Para 1921, la ciudad de Lima experimentó un proceso de embellecimiento impulsado principalmente por el presidente Augusto B. Leguía. El planteamiento inicial contemplaba la construcción de un gran complejo deportivo y por ello su construcción demoró varios años. El Nacional contaba con una tribuna preferencial de madera y algunos palcos laterales a nivel del piso. Contaba además con una cancha auxiliar sin tribunas. El complejo deportivo contaba con una piscina olímpica donada por la colonia japonesa en 1935. 23

En 1951, el presidente de la Sociedad de Beneficencia de Lima, Miguel Dasso alentó a la reconstrucción de un nuevo estadio que reemplace al pequeño "Nacional". El Perú gozaba de una "fiebre" de construcciones monumentales impulsada por el presidente de la República, General Manuel A. Odria. En los años 50 se construyeron, en el Perú, grandes hospitales, grandes colegios, grandes edificios públicos y grandes complejos de vivienda. Odría decidió apoyar la iniciativa decidiendo que las viejas tribunas de madera sean utilizadas en el estadio "Lolo Fernández" del Club Universitario de Deportes que fue su principal beneficiario y que se utilizaron hasta el año 2000.

Se proyectó que el nuevo estadio tuviera una capacidad de 55.000 espectadores y sería íntegramente de cemento. Las dos tribunas populares (norte y sur) albergaban un aproximado de 16.000 espectadores cada una y las tribunas preferenciales (oriente y occidente) contaban con tres niveles (alta, baja e intermedia).
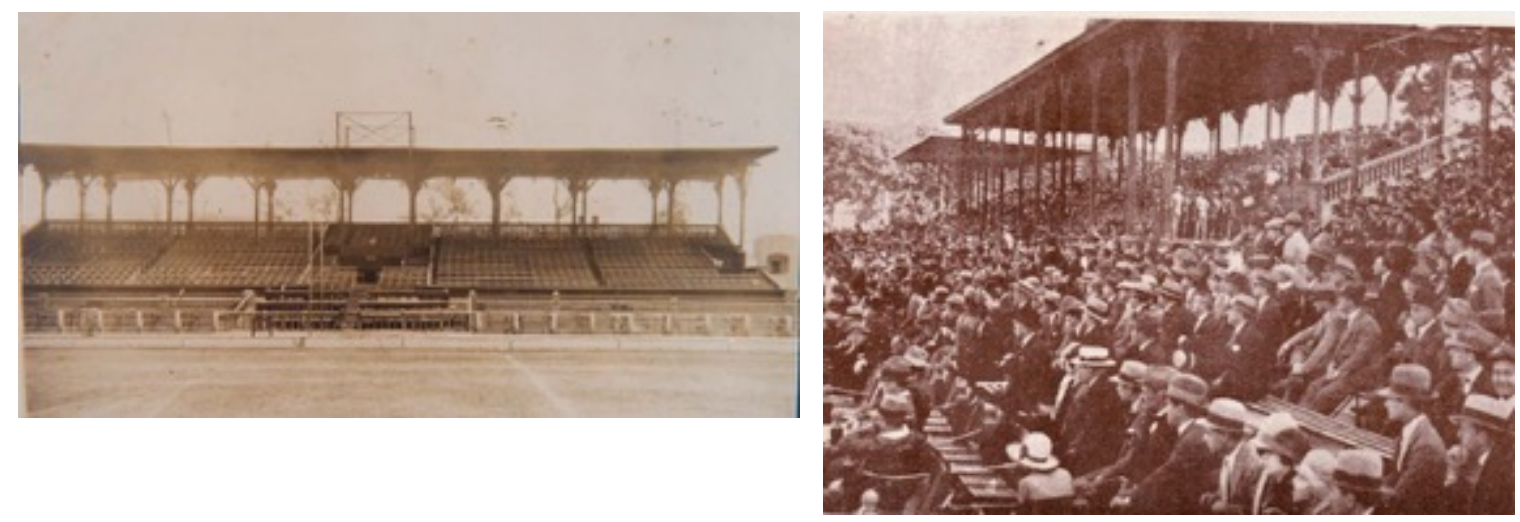

IMAGEN 11. VISTAS DE EL ANTIGUO ESTADIO NACIONAL EN LOS 50`S (2008) DESARROLLO PERUANO BLOG - “Lima postulara para ser sede de Panamericanos del 2015" - Lima, Perú 
La estructura principal del estadio se mantuvo hasta hace pocos años prácticamente inalterada y tuvo como elemento distintivo una torre en tribuna norte que albergaba los palcos oficiales. La Torre del Estadio Nacional quedó inoperativa hasta el año 2004 cuando fue remozada para la Copa América. Asimismo, considerando el tamaño del estadio se construyeron además facilidades para la práctica de otros deportes como el Boxeo, Natación y Atletismo a la par que oficinas administrativas para el Instituto Peruano del Deporte y las demás federaciones deportivas.
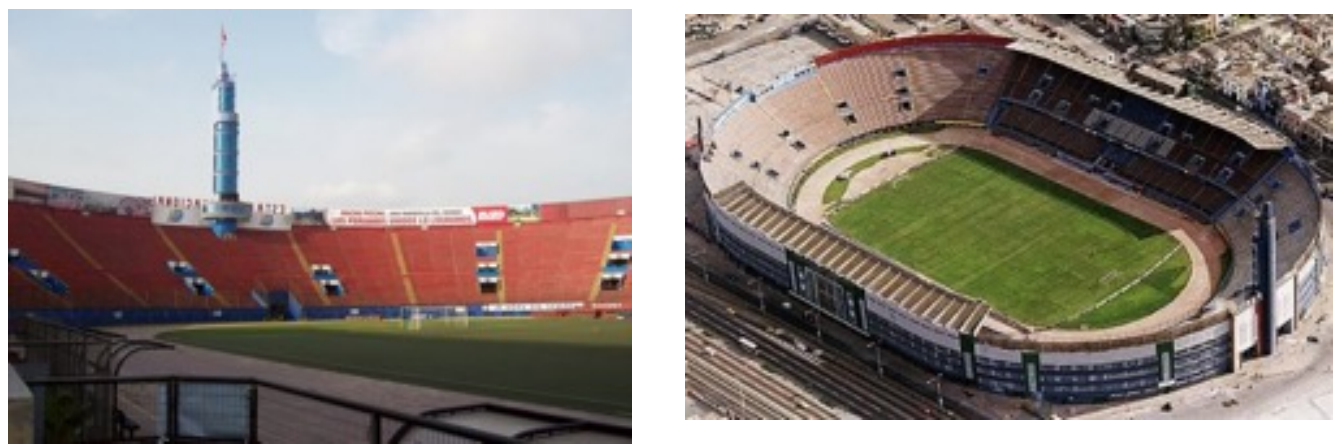

IMAGEN 12. VISTAS DE EL ANTIGUO ESTADIO NACIONAL EN LOS 905 (2008) DESARROLLO PERUANO BLOG - " Lima postulara para ser sede de Panamericanos del 2015" - Lima, Perú 
Hipódromo de Santa Beatriz (1903)

El Hipódromo de Santa Beatriz fue una instalación deportiva ubicada en el barrio de Santa Beatriz, en la ciudad de Lima, capital del Perú. De propiedad del Estado Peruano y administrado por el Jockey Club del Perú, se ubicaba donde actualmente está el Campo de Marte. Acogió la actividad hípica desde 1903 hasta 1938 cuando se inauguró el Hipódromo de San Felipe. 25

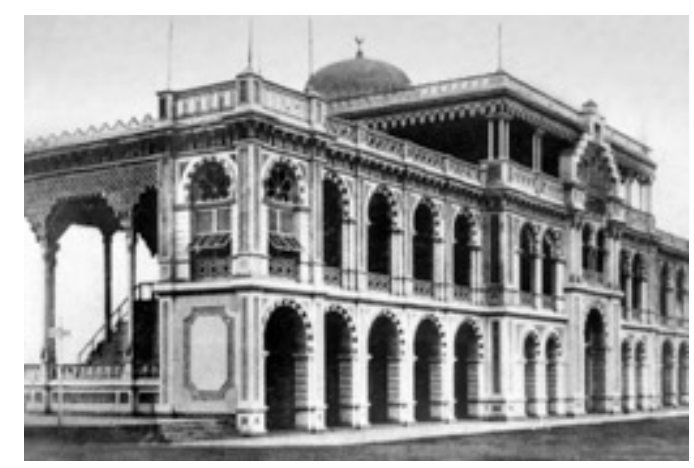

IMAGEN 13 - Fotografía de Santa Beatriz - (2011) Lima la

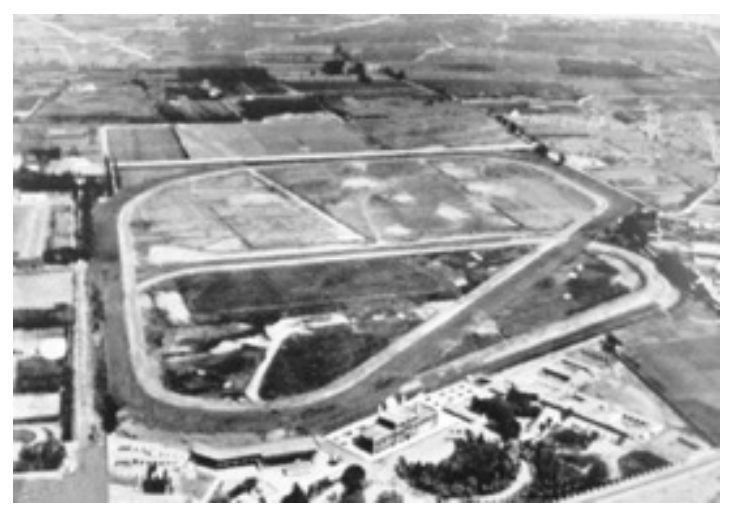

IMAGEN 14 - Fotografía de Hipódromo de San Felipe - (2013) ECURED -

Hipódromo de San Felipe (1938)

Fue una instalación deportiva ubicada en el distrito de Jesús María, en la ciudad de Lima, Perú. Es propiedad del estado peruano y administrada por el Jockey Club. Se ubicaba por las cercanías de la Avenida Salaverry. 26. La construcción de este recinto se inicia en 1955 y culmina en 1960. Ese año es el último que se utiliza el hipódromo de San Felipe, el 18 de diciembre de 1960 se iniciaron las actividades en Monterrico, quedando el hipódromo de San Felipe en total desuso. 
En años posteriores es demolido este hipódromo y se otorgaron los terrenos al Ejército Peruano, que construyó el Centro de Esparcimiento. También entre 1964 y 1966 se construye un Conjunto Residencial en San Felipe.

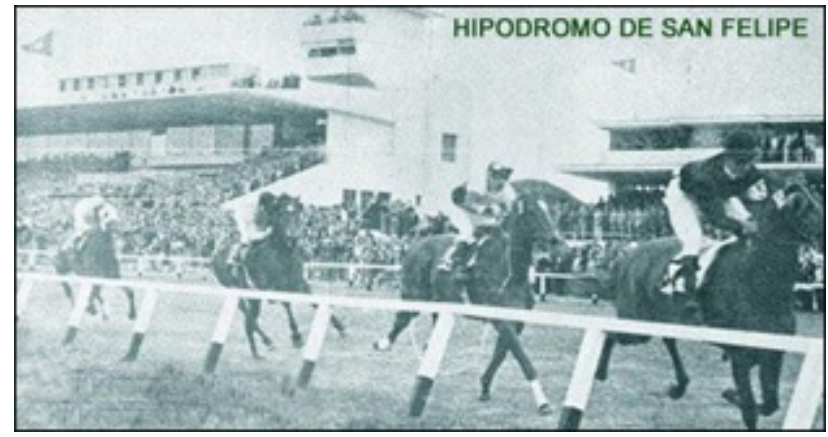

IMAGEN 15. Fotografía de Hipódromo de San Felipe - (2013) ECURED - Hipódromo de San Felipe - Lima, Perú

Hipódromo de Monterrico (1960)

La inauguración del Gran Hipódromo de Monterrico ( también llamado "El Coloso de Surco" ) fue posible por 4 socios que ejercieron la Presidencia del Jockey Club del Perú: Ernesto Ayulo Pardo (1952-53), quien adquirió el terreno; Oscar Berckemeyer Pazos (1954-55-58), que puso la primera piedra e inició la construcción; Gustavo Prado Heudebert (1956-57), quién mantuvo permanentemente el ritmo de la construcción y César A. del Río (1959-60) que consiguió un importante préstamo con aval del Gobierno que permitió dar término a la obra e inaugurar el gran Hipódromo. Hoy es uno de los mejores hipódromos de Sudamérica. 27

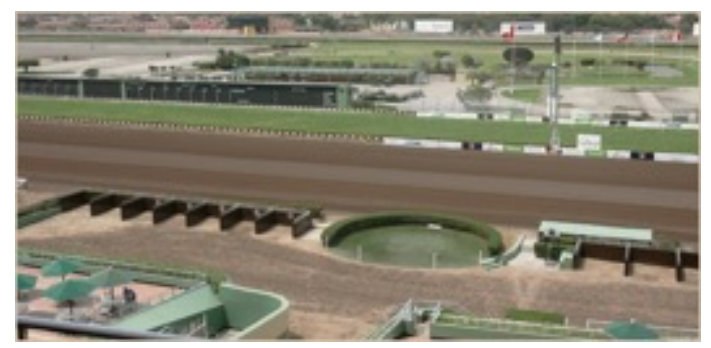

IMAGEN 16. Fotografía de Hipódromo de Monterrico - (2005) HIPODROMO DE MONTERRICO, Historia, Lima, Perú 

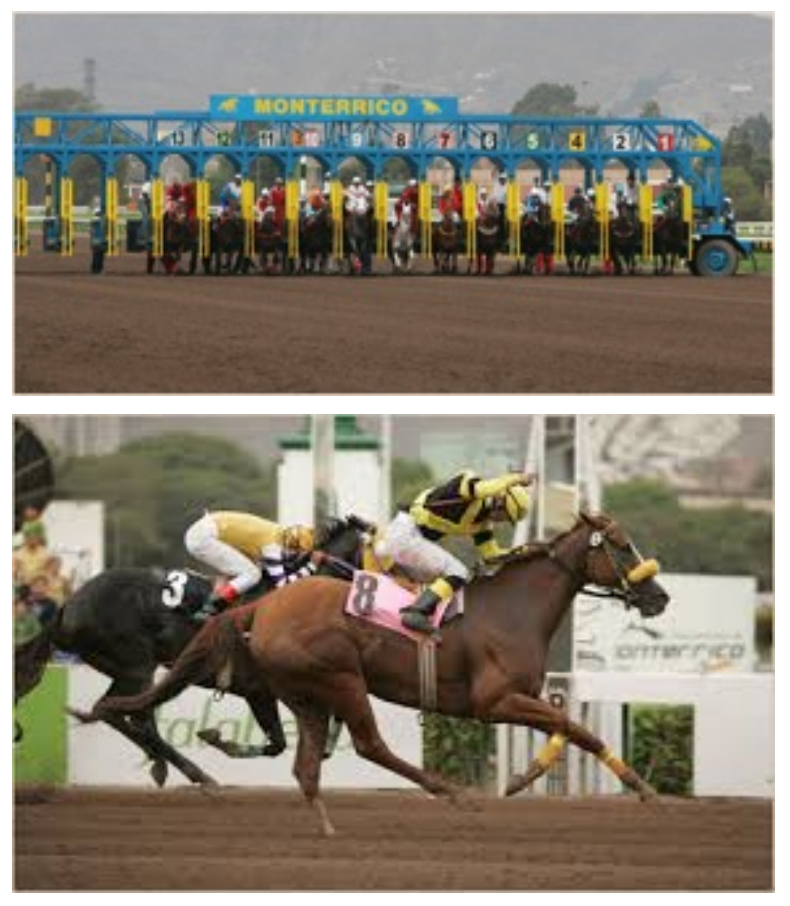

IMAGEN 17. Fotografías de Hipódromo de Monterrico - (2005)

IPD

La organización del Deporte Peruano data oficialmente del 28 de abril de 1920, cuando el entonces presidente de la República, don Augusto B. Leguía reconoció oficialmente a la Federación Atlética Deportiva del Perú, encargándole la realización y organización de los planes a don Alfredo Benavides Canseco, presidente de la primera institución oficial del deporte nacional. Poco después un 8 de setiembre de 1921, se dicta la Ley de "Estructuración del Deporte Nacional", donde se establecieron normas concordantes con los fines propuestos por la Federación Atlética Deportiva del Perú.

\section{VIDENA (1981)}

La Villa Deportiva Nacional es, junto con el Estadio Nacional, uno de los principales recintos deportivos de Perú. Se encuentra ubicada en el distrito de San Luis, en la ciudad de Lima. Es también llamado VIDENA, por las dos primeras letras de cada palabra que la conforma.

Dentro de este recinto, se encuentran las oficinas de las federaciones de fútbol, atletismo, ciclismo, gimnasia, softbol, béisbol y lucha. También se ubican las sedes de entrenamiento de las selecciones peruanas de fútbol, atletismo y béisbol. El Comité Olímpico Peruano tiene sus principales oficinas en este sitio. 
El 30 de octubre de 1969 el área ocupada se declara el parque zonal № 18 Túpac Amaru. El 11 de junio de 1981, se entrega al Instituto Nacional de Recreación, Educación Física y Deportes. En 1993, fue construida sobre un área total de 21,5 hectáreas. Entre los años 2009 - 2010, FPB (béisbol), FPS (softbol) y parte de la villa olímpica fue alquilada para la elaboración de los cimientos del tren eléctrico. Actualmente estas federaciones, practican en campos prestados, como el estadio municipal de San Luis, AELU, IPD Callao, entre otros.

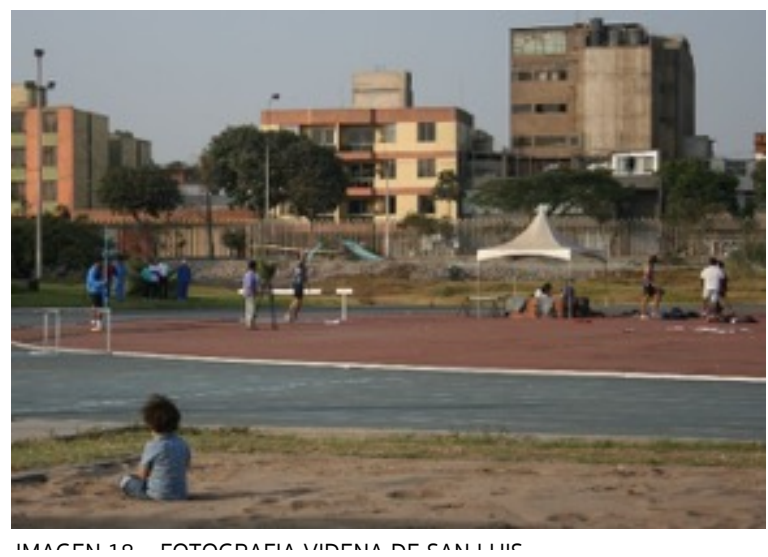

Coliseo Dibós (1989)

Es una instalación multiusos de Lima, ubicada en la Av. Aviación en el distrito de San Borja. Lleva el nombre de un ex-alcalde limeño recordado por su apoyo al deporte peruano, Eduardo Dibós Dammert. Fue fabricado por la empresa Técnicas Especiales S. A., bajo subcontratación de la empresa Constructora Monsa, en el primer gobierno del ex presidente del Perú Alan García.

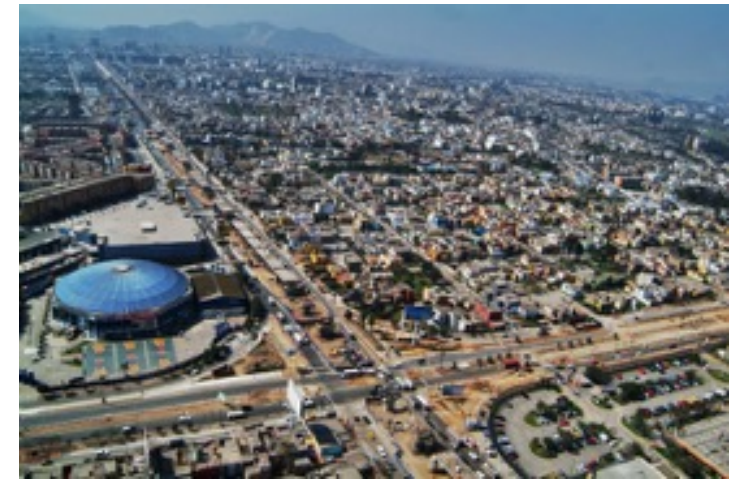

IMANCEM 1O IMAMrELA RE COI ICEO MIDOC

La capital, en cuanto a instalaciones deportivas se refiere, tiene una gran necesidad de más y mejores espacios de esta tipología. No cuenta con polideportivos distritales, y aquellos centros que existen no están en las condiciones optimas, o no son accesibles a todos. Otro factor es que no existe una variedad de disciplinas. Además, los espacios son 
ampliamente discriminantes en el aspecto de usuarios, no son inclusivos en un $95 \%$ de los casos.

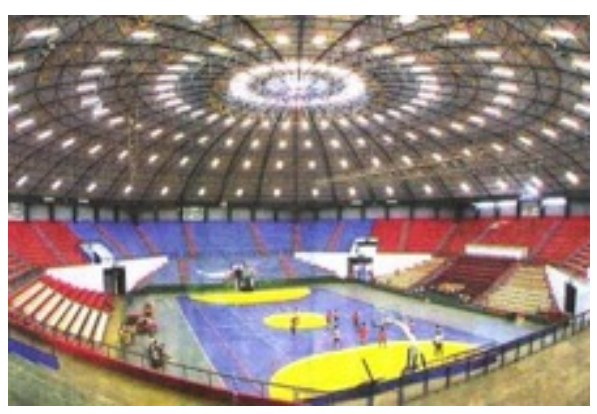

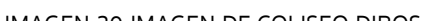

Nuevo estadio Nacional

(2009) Las remodelaciones del estadio empiezan tras el IPD y la UNI firmaran un acuerdo para remodelar y ampliar el estadio Nacional, renovar la pista atlética y remodelar las oficinas del estadio. La nueva estructura que luce el Estadio Nacional fue presentada por el presidente del Instituto Peruano del Deporte (IPD), Arturo Woodman, ante la Asamblea de la Organización de Deporte Panamericano (ODEPA). Este proyecto costó \$ 200.000 .000

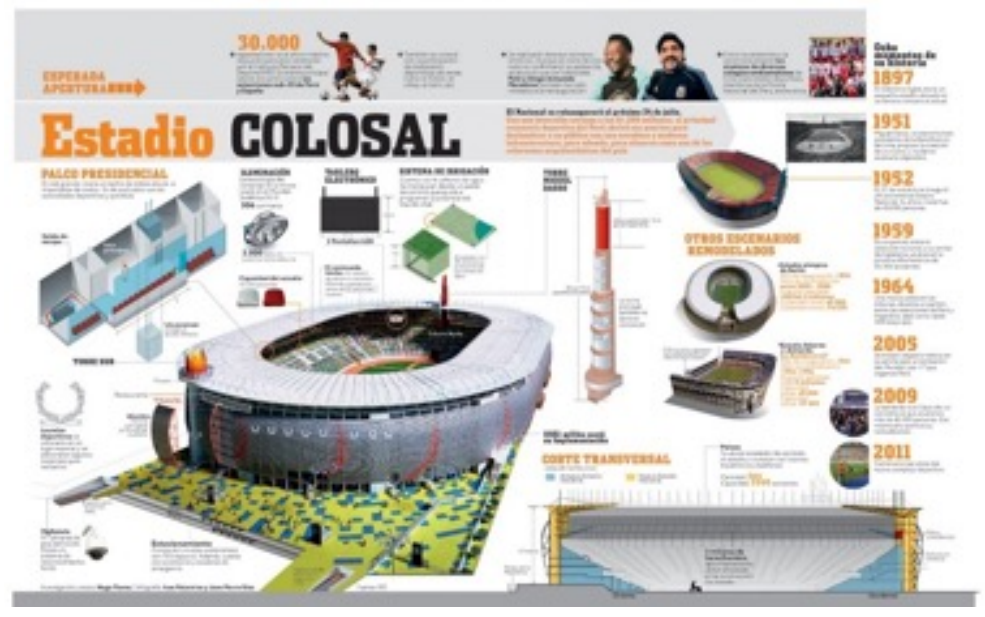

En 2009 se planeó la remodelación para los Juegos Panamericanos de 2015. En 2010 se anunció la construcción de un coliseo. En el 2014 se inició la construcción del Centro de Alto Rendimiento de Lima. Actualmente se encuentra en construcción un Centro de Alto Rendimiento para la práctica del voleibol. 


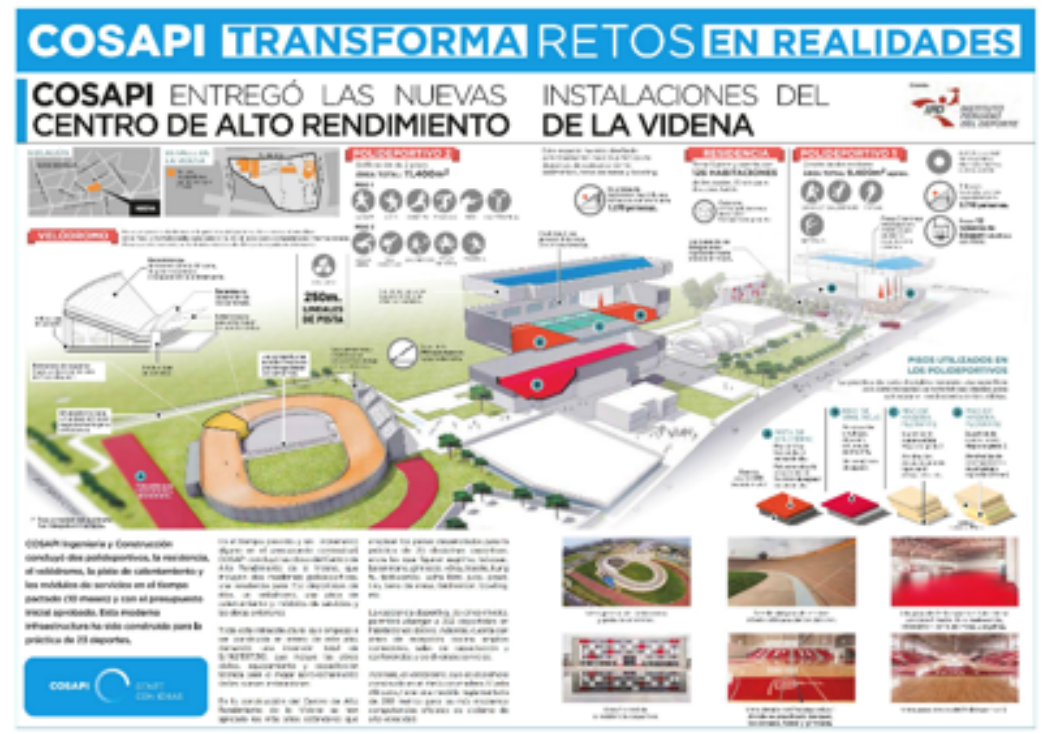

\subsubsection{Historia del lugar - VILLA EL SALVADOR - VILLA MARÍA DEL TRIUNFO}

DECADA DEL 70

- Personas de provincias migraban a Lima por el crecimiento en la industrialización; lograron establecerse en la ciudad y aumentar, así, su población.

- Aumento de flujo de zonas marginales a las consolidadas.

- En Lima, habitantes de Surquillo y Lima migraron a Pamplona,

donde invadieron $\mathrm{y}$ se establecieron en toda el área desértica. - Al crecer la ciudad, se necesitaron más vías para comunicarse, por lo que se construyó la Vía Expresa de Paseo de la republica.

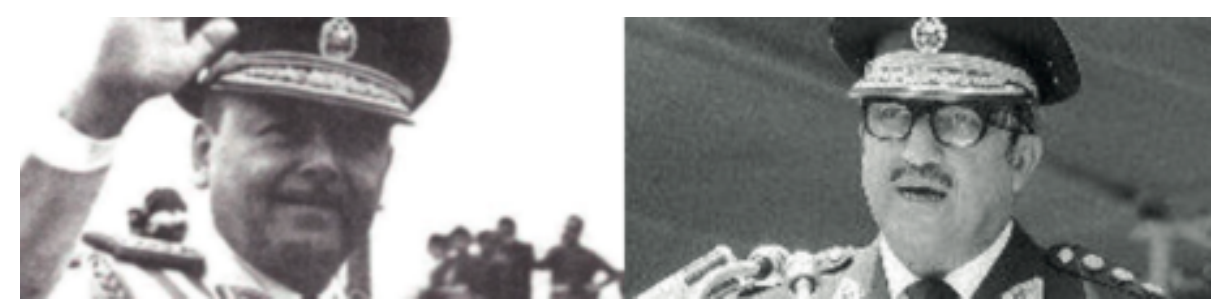




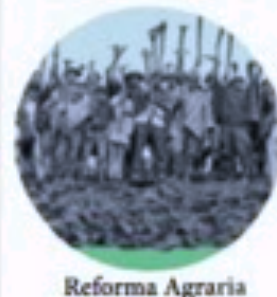

Reforma Agraria

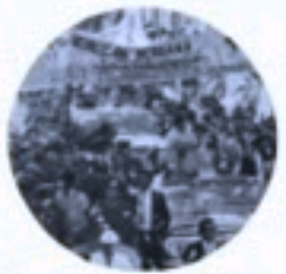

Nacionalización de recursos y servicios

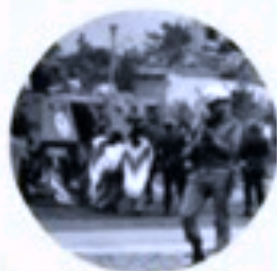

Pueblo sometido por goblerno

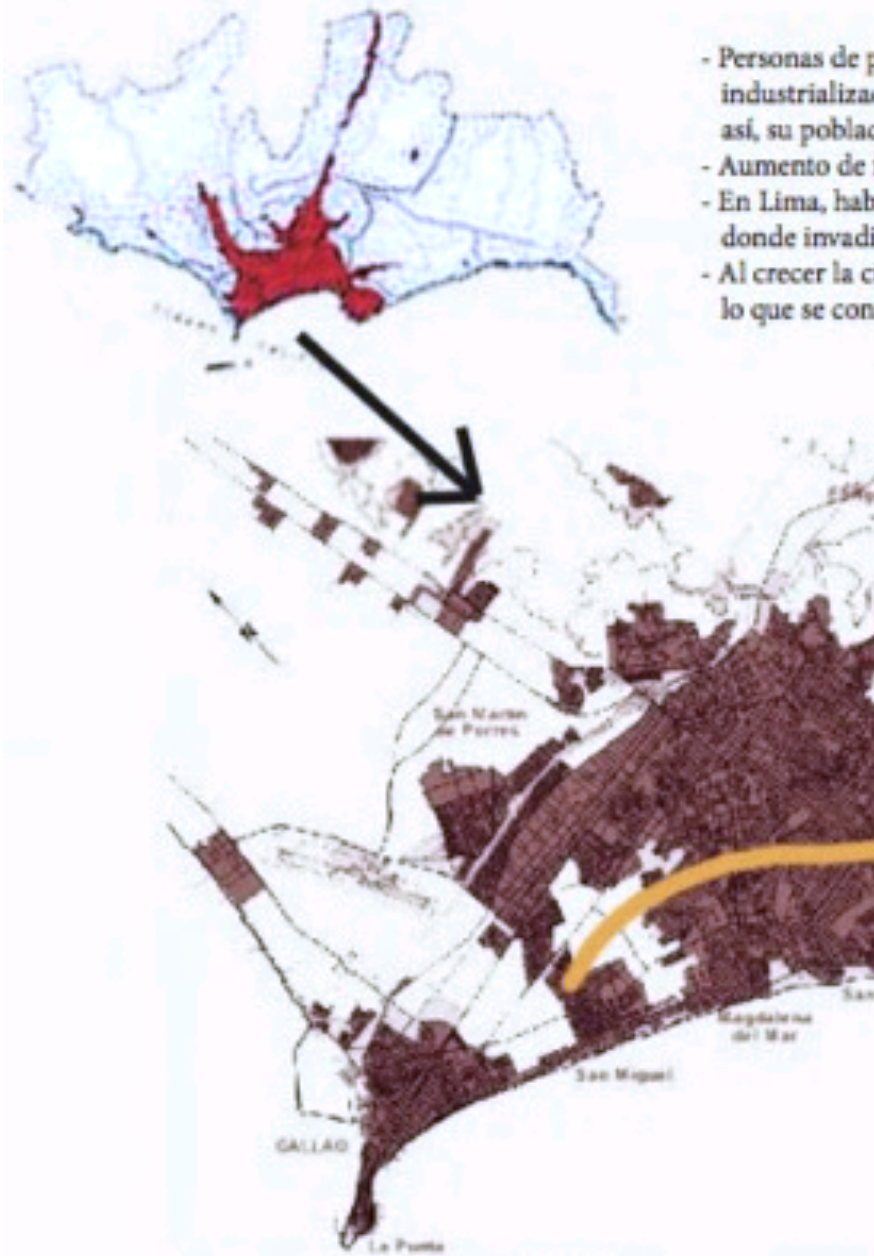

Lima y Surquillo invaden Pamplona

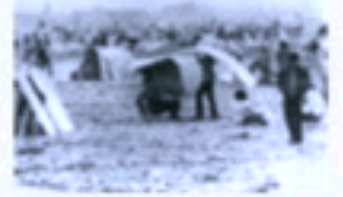

arovincias migraban a Lima por el crecimicnto en la asi., su población.

de flujo de zonas marginales a las consolidadas

Al crecer la ciudad, se necesitaron más vias para comunicarse, por lo que se construyó la Vla Expresa de Paseo de la república. 

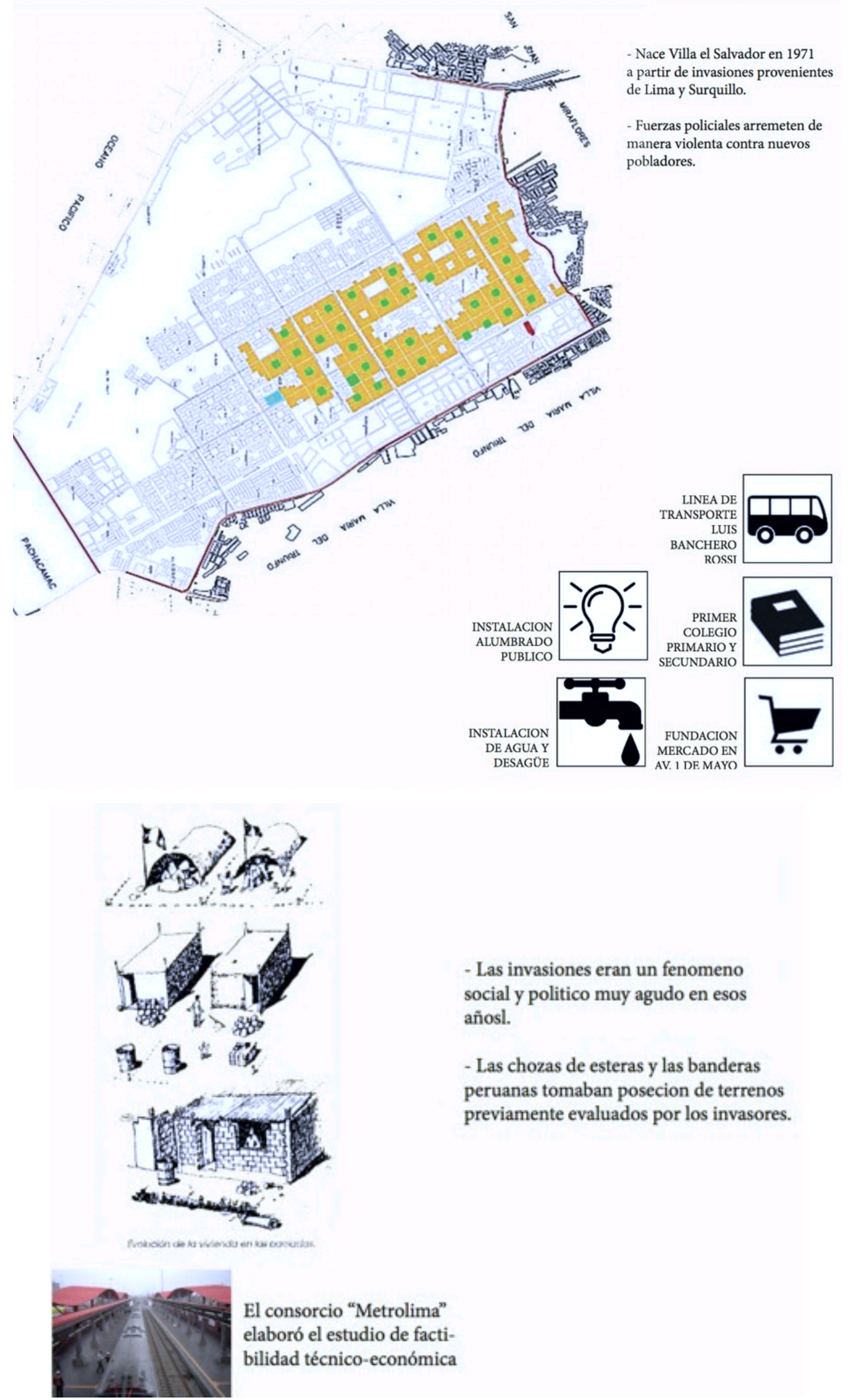

- Las invasiones eran un fenomeno social y politico muy agudo en esos añosl.

- Las chozas de esteras y las banderas peruanas tomaban posecion de terrenos previamente evaluados por los invasores. 


\section{DECADA DEL 80}

- Hubo una crisis industrial debido a la crisis del petróleo y el afán por cubrir la deuda externa.

Afectó al territorio y $\quad$ sus flujos.

- En los conos, los habitantes tuvieron que buscar una fuente de ingreso y puestos de trabajo. Por ello, hubo un cambio en la organización social y política. - Se crearon comunidades vecinales, llamadas "sobrevivientes", para

tomar decisiones de la población. Se dejó la planificación.

- La ciudad sufrió la violencia del conflicto armado, junto con atentados terroristas.

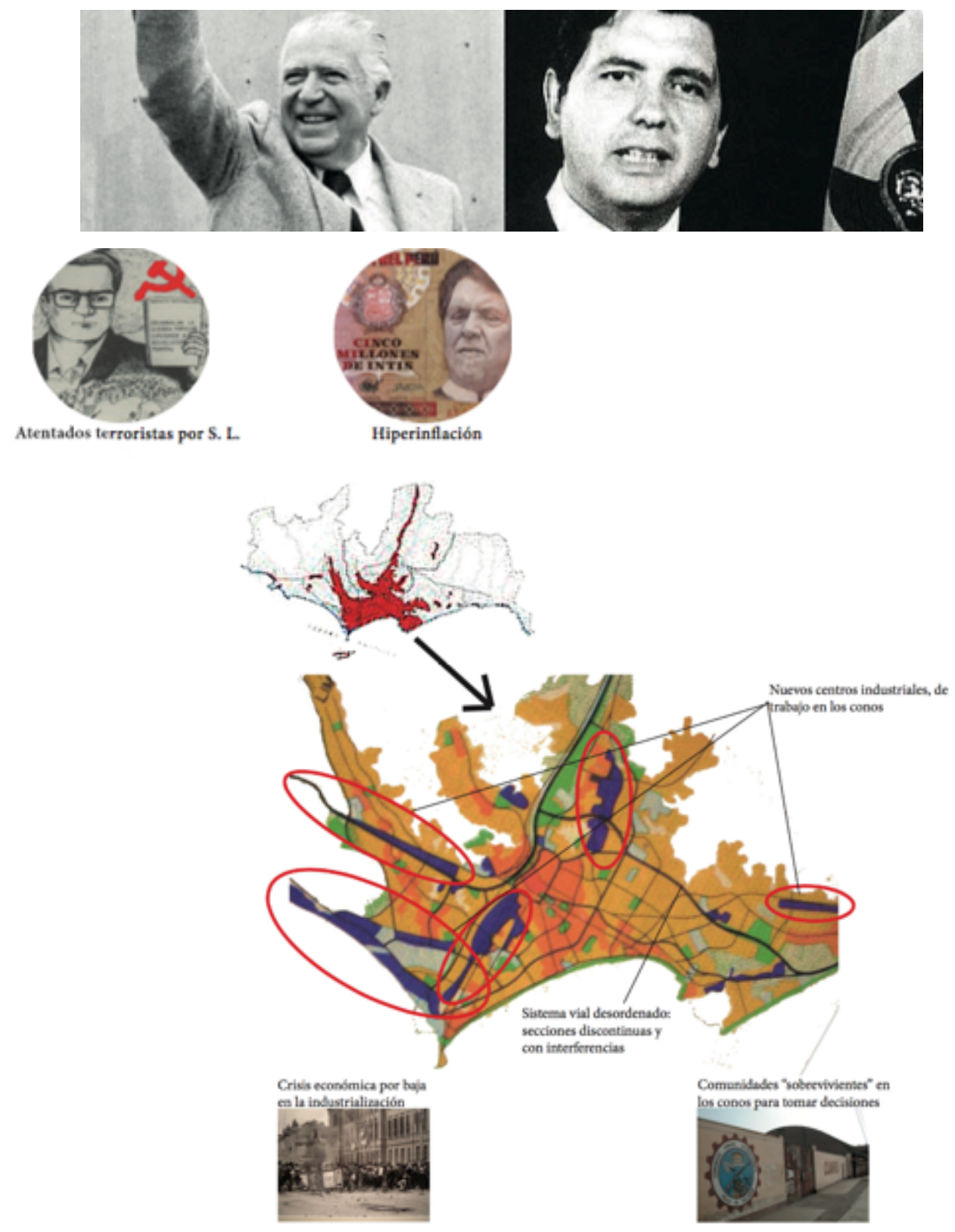



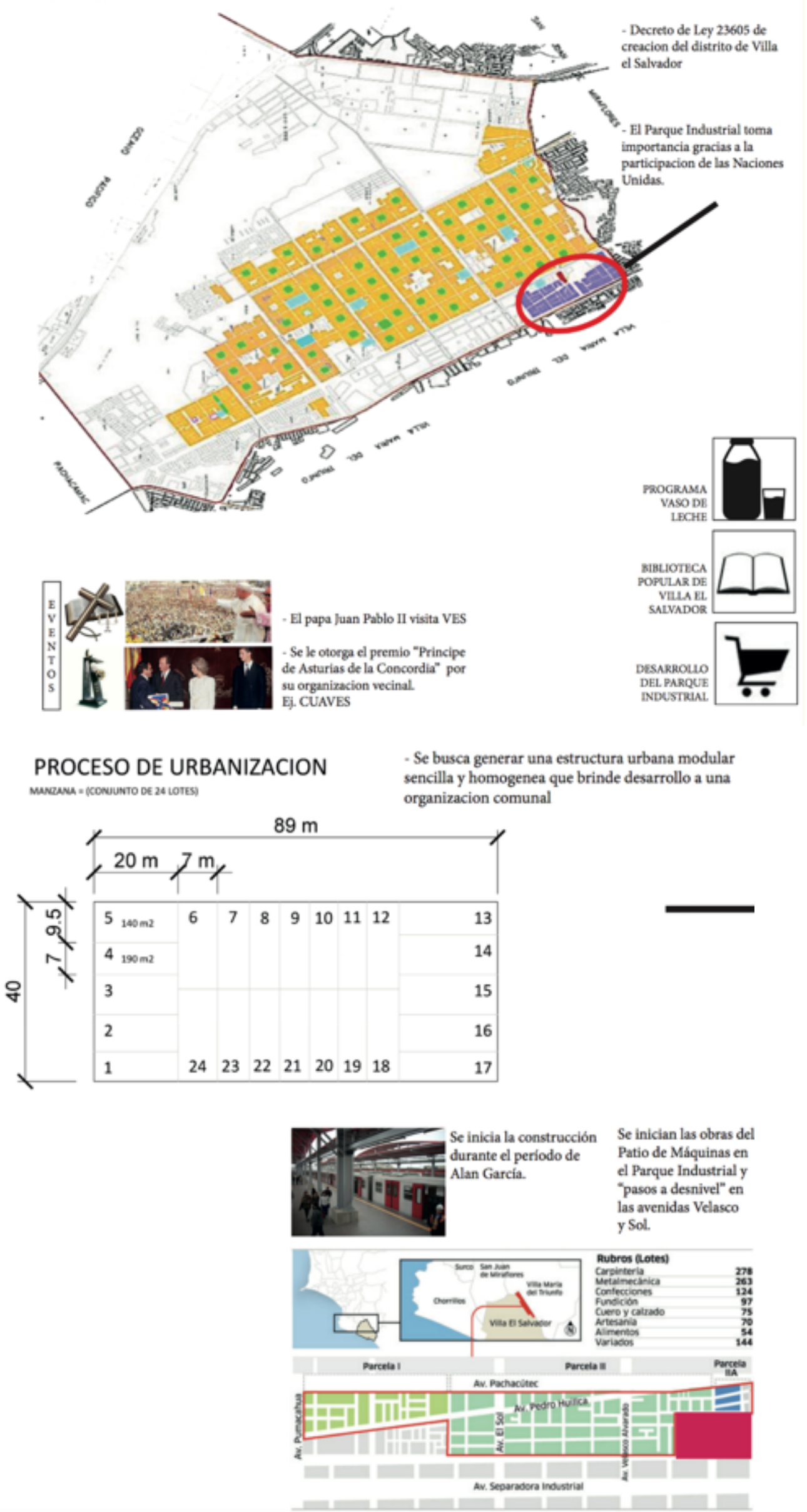


\section{DECADA DEL 90}

- Se inició el autoempleo informal y unipersonal, con personal capa- citado o autodidacta; quienes ofrecían sus servicios en toda la ciudad.

- Se dejó de lado la industrialización y la producción, por lo que la economía de la ciudad se centró en el comercio y los servicios.

- Las PYMES tienen un rol importante. Por ello, la PEA de la ciudad se desarrolla en actividades terciarias, generando nuevos estilos y condiciones de vida en la población.
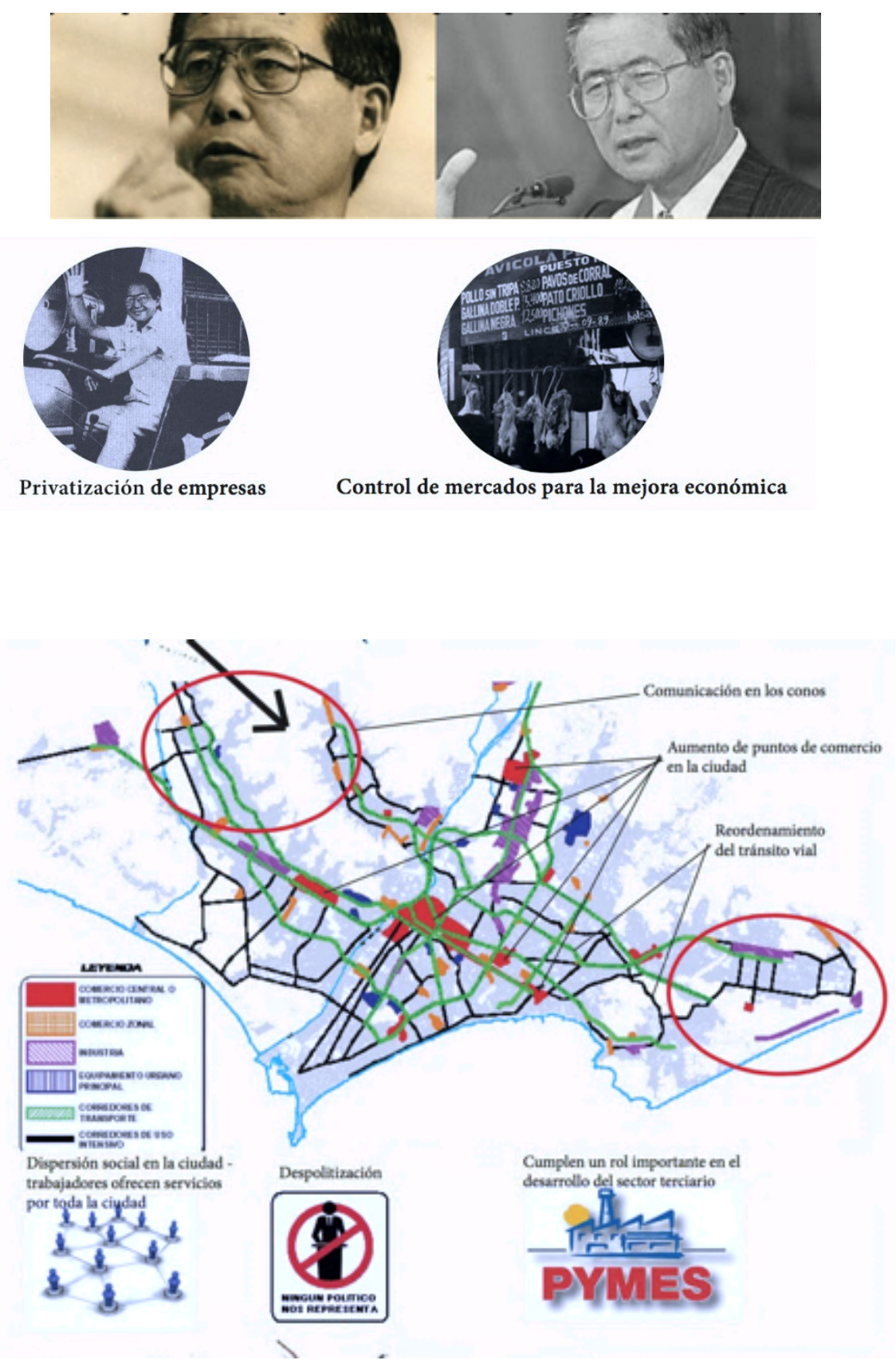

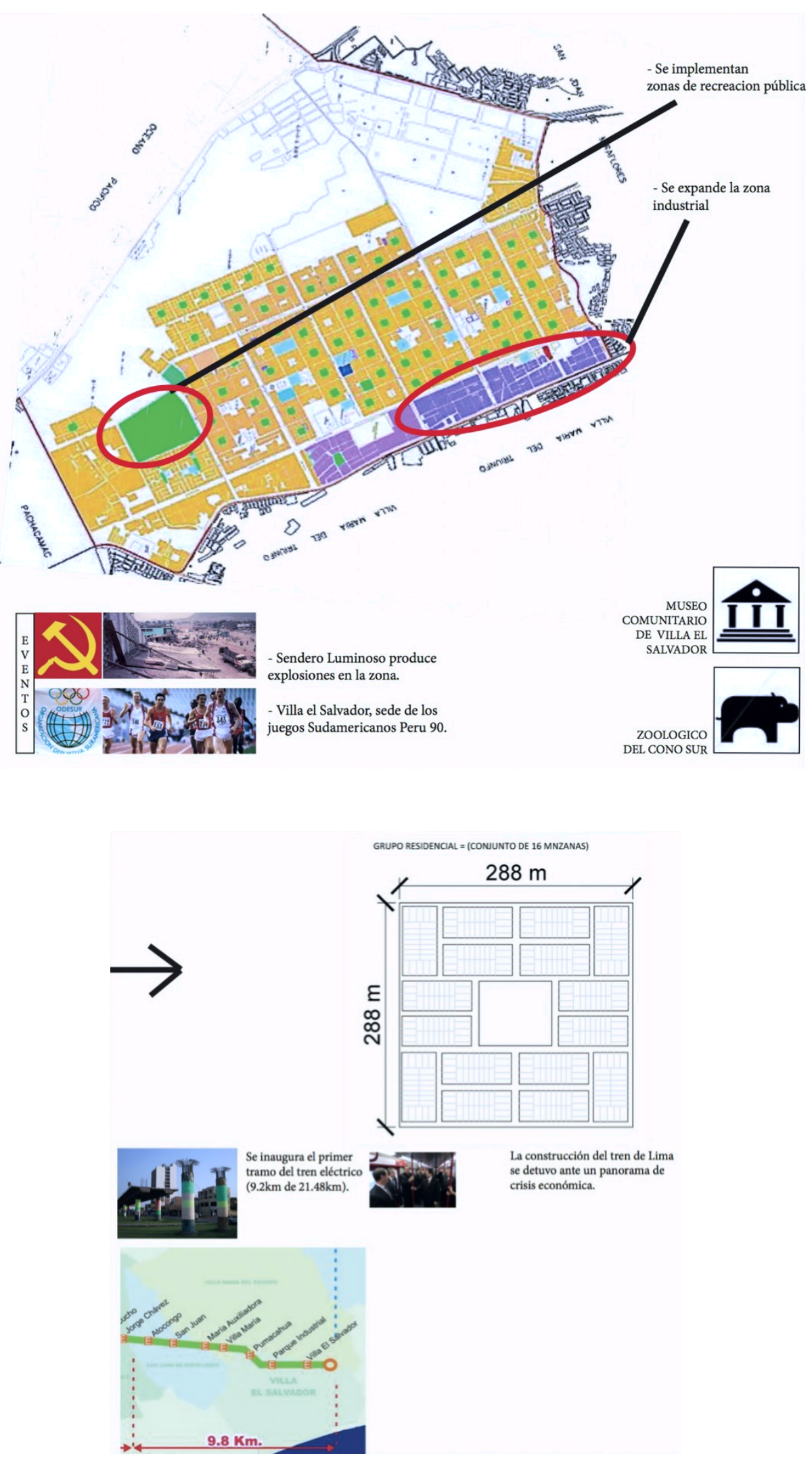
DECADA DEL 2000

Los nichos de mercados y lugares de inversión se dispersaron por la periferia de la ciudad, generando nuevos centros.

- Las organizaciones siguen siendo desarticuladas y se interesan sólo por los intereses sectoriales. Como consecuencia, se pensaron planes para unir a la sociedad y formar un solo grupo de ciudadanos.

- Se evitó el estancamiento en el desarrollo de la ciudad, a ser sólo local y se buscó formar una ciudad policéntrica pero articulada hacia adentro y conectada a todos sus territorios.
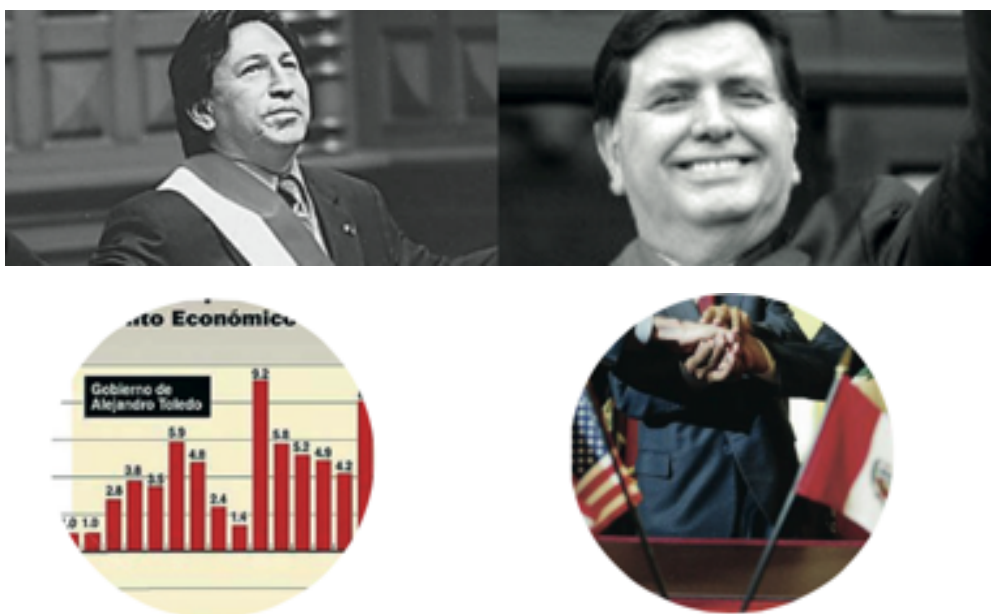

Crecimiento económico

TLC con EE.UU. y otros países (posterior)

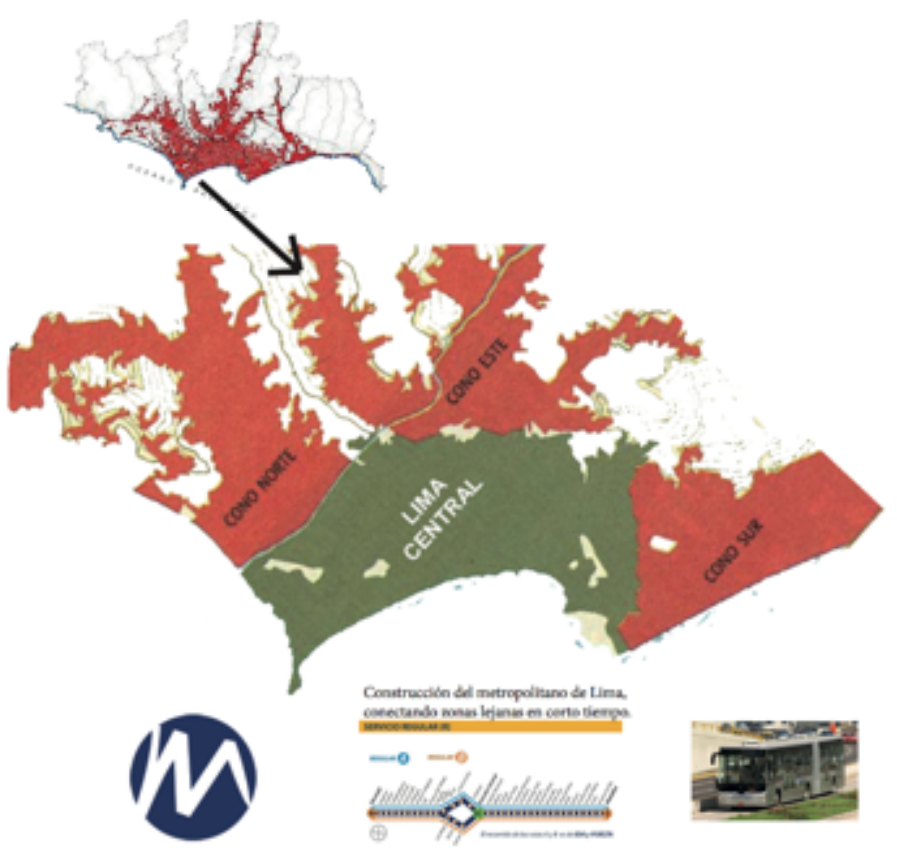




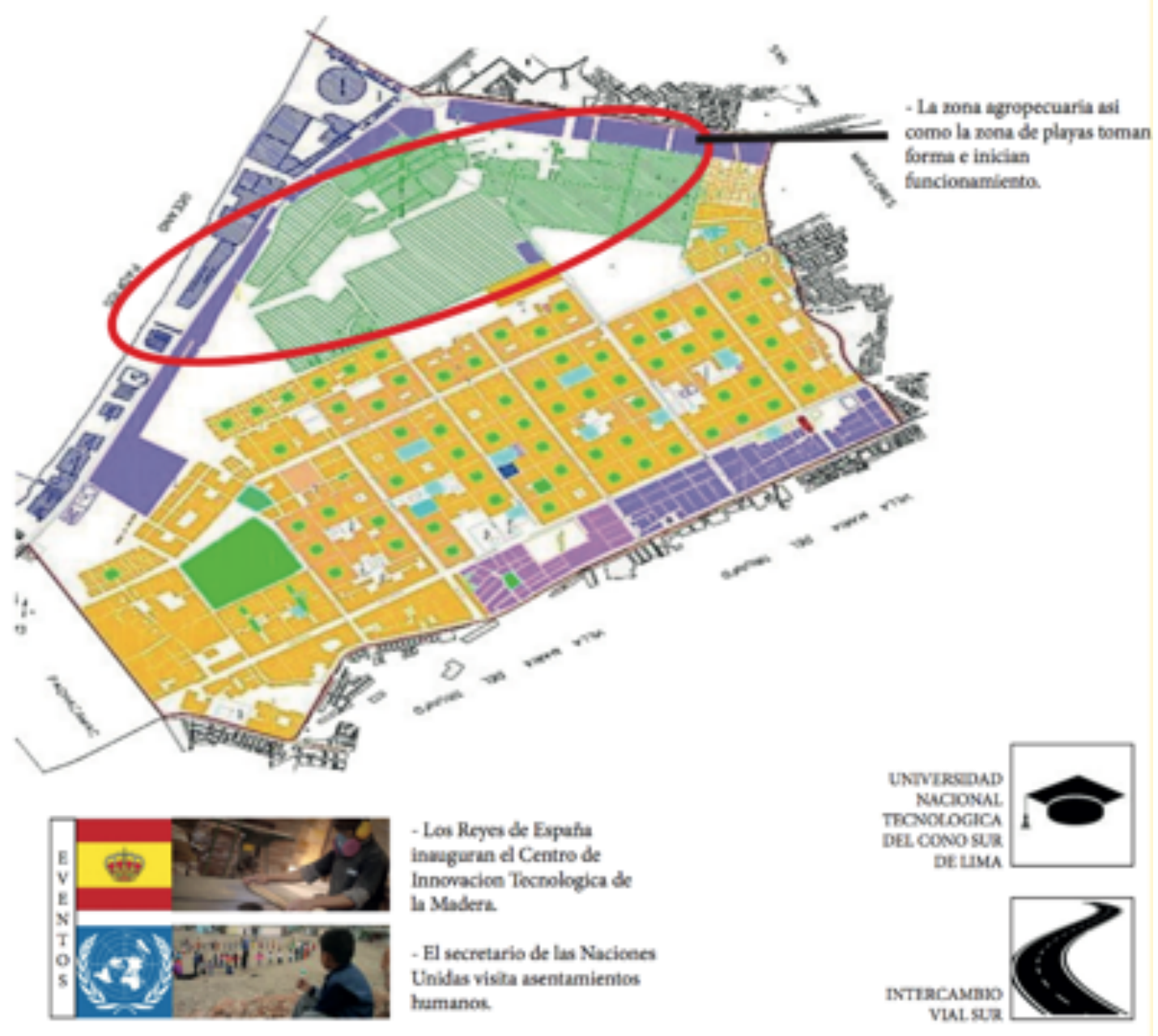

stctoa iconuumto of 24 Gaupos:

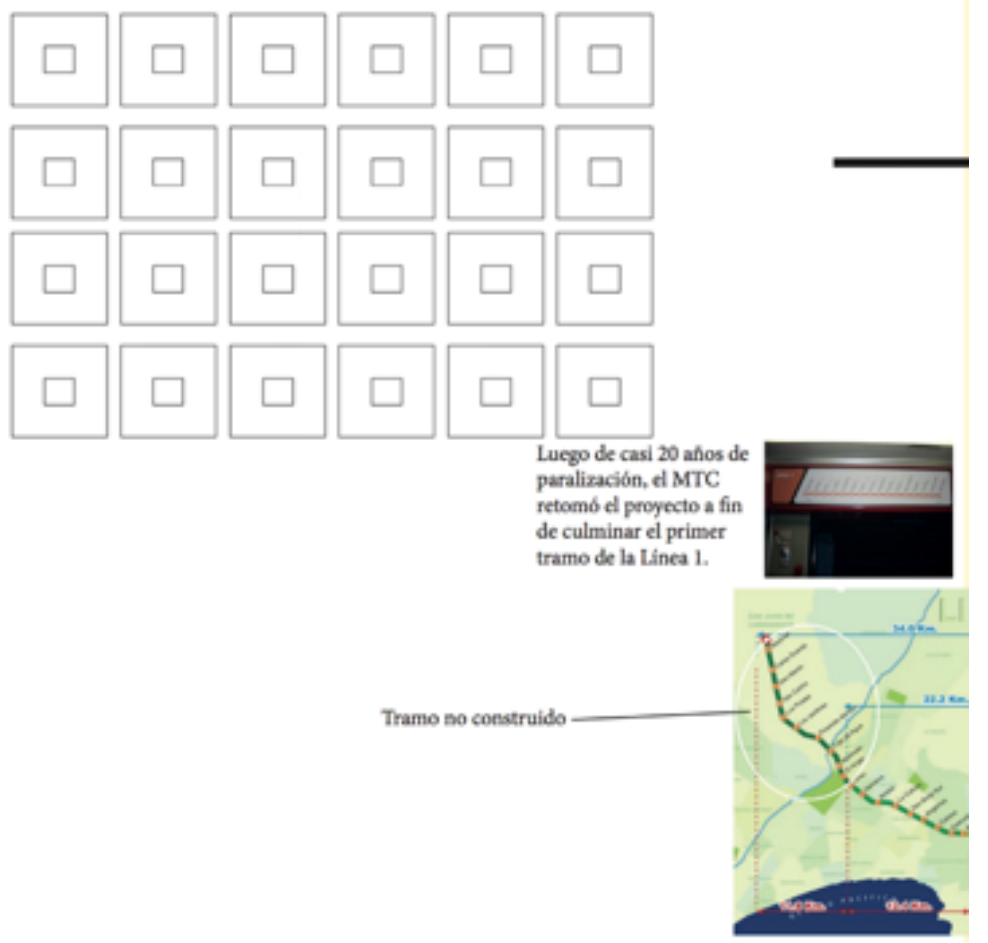


- Lima es ahora una ciudad policéntrica; es decir, cuenta con varios centros en diferentes puntos de la ciudad, que cumplen diferentes roles y funciones para el conjunto.

- Se ha reestructurado completamente la espacialidad de la ciudad, su organización social y política; con planes de desarrollo urbano a futuro, manteniendo la esencia de Lima y su nuevo formato.
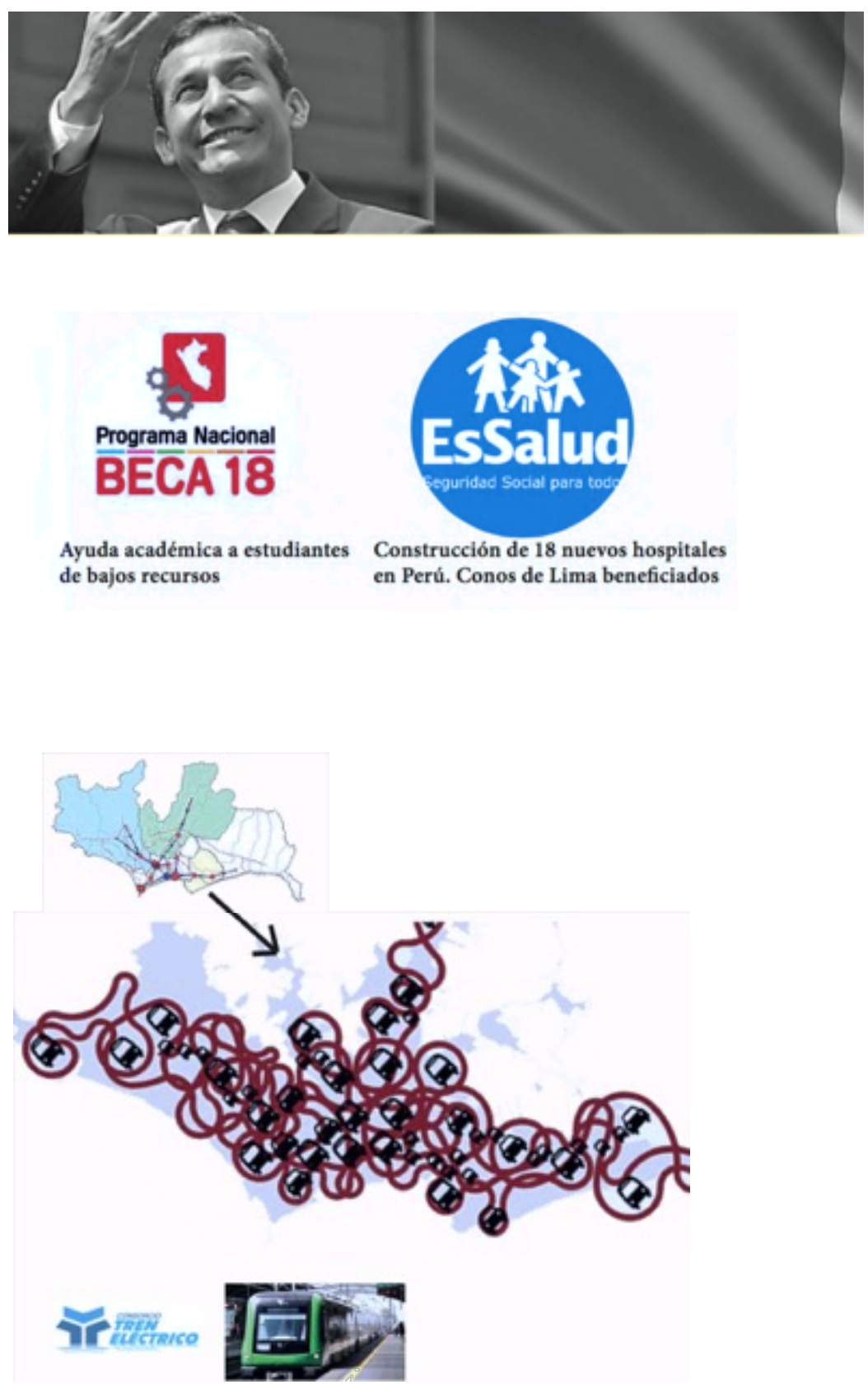


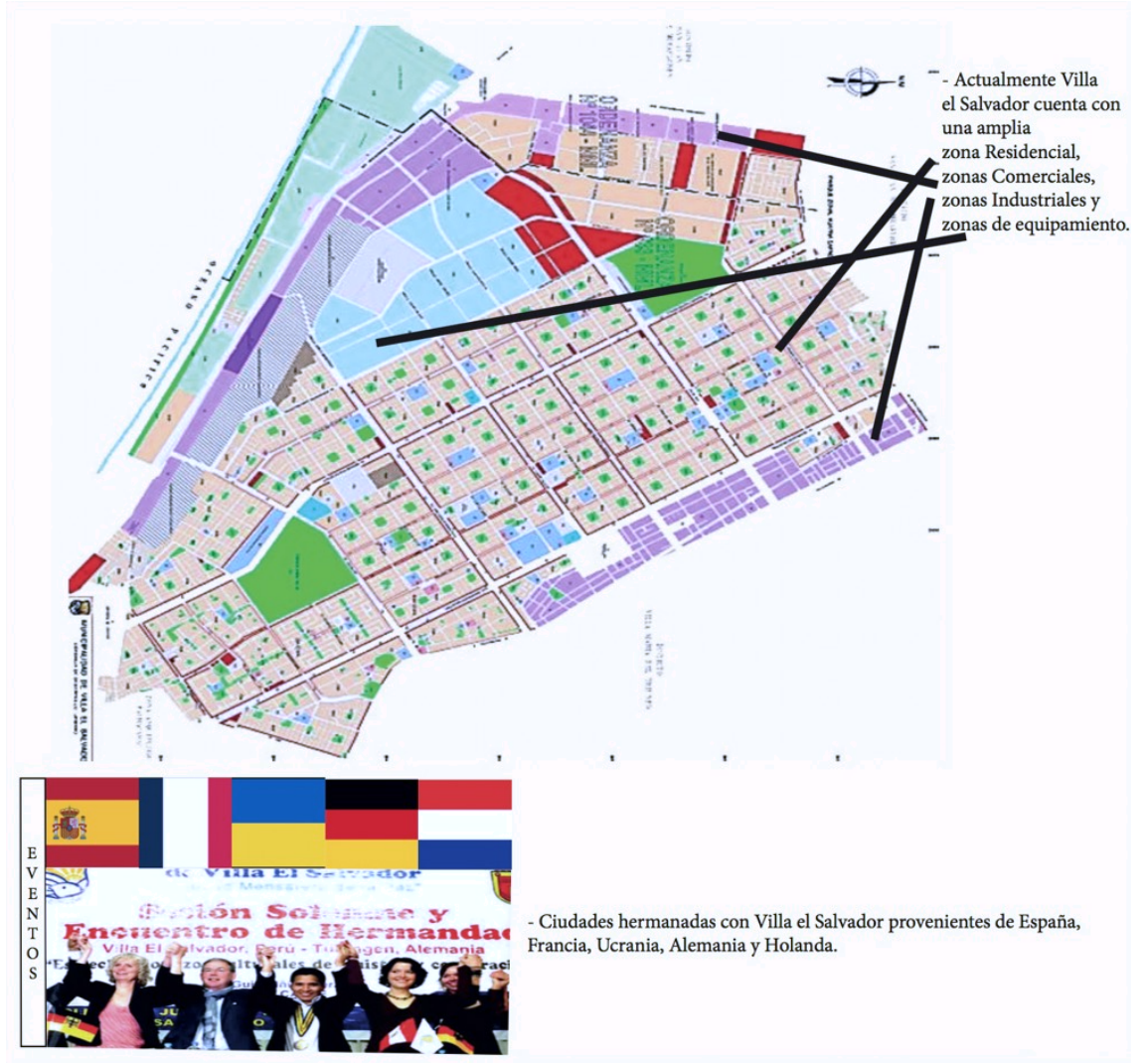

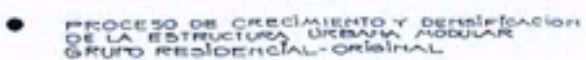

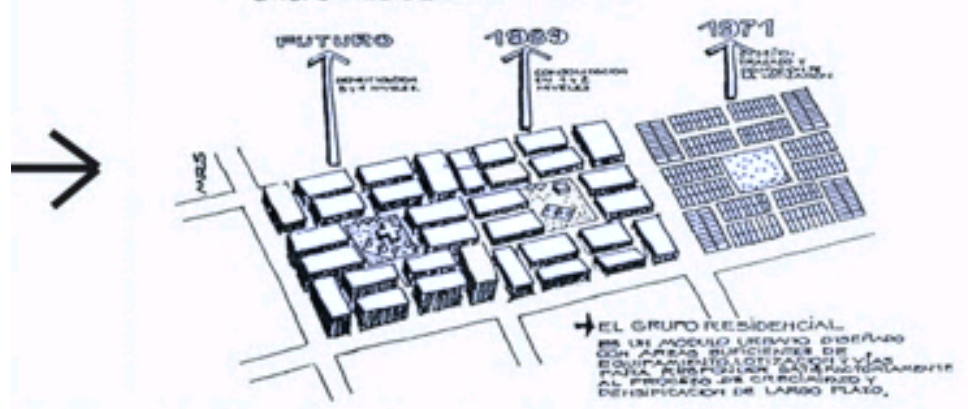

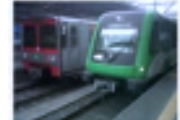

thauguracion: 11 de La plena operatividad se conduirse las obras del 2012, luego de algunos y completarse el pri- meses de pruebas en

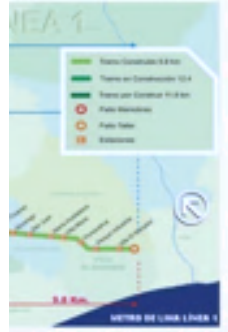

5128 de marno de 2014, el goblerno peruano concesloes la linea 2 .

RECORRIDO DEL TREN ELÉCTRICO

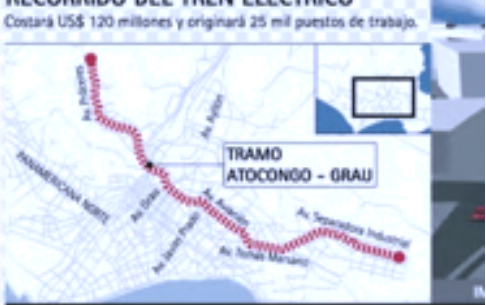




\title{
2.1.2. Historia del lugar - VILLA EL SALVADOR - VILLA MARÍA DEL TRIUNFO
}

\author{
FUTURO DE VILLA EL SALVADOR
}

- La movilidad urbana es la prioridad para proyectos futuros. Se desea contar con empresas de transporte formales, rutas organizadas y sistemas masivos de trasporte.

- El PLAM 2035 identificará los nuevos centros de desarrollo en el Norte, Sur y Este, para integrarlos con el Callao.

- Lima tendrá solo 16.500 vehículos de transporte publico de gran capacidad con buses de 12 y articulados de 18 metros, contará con una red de metro de 6 Líneas como red básica y una red de buses (corredores complementarios) todo esto formará parte del SIT (sistema integrado de transporte publico de Lima y Callao) además de trenes de cercanías.

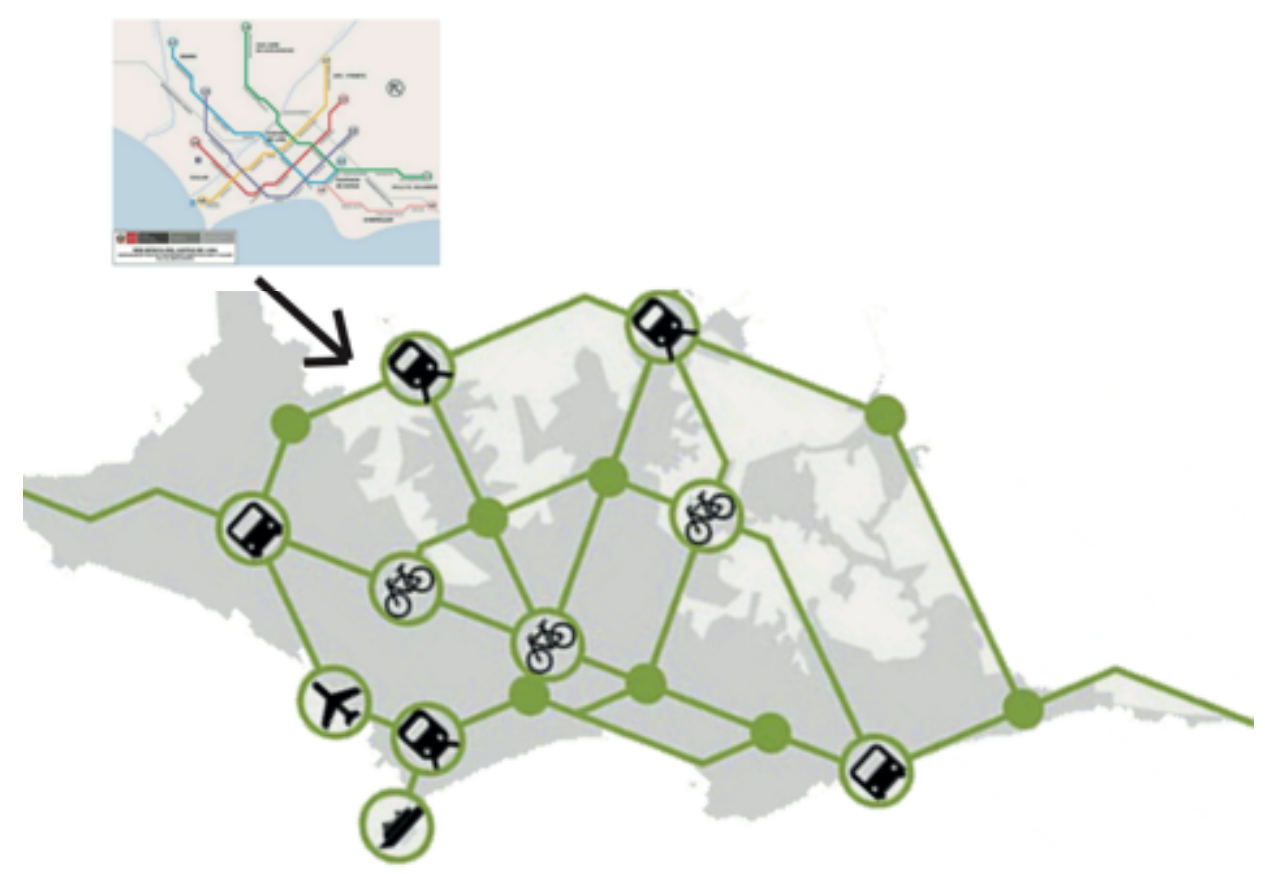

Plan de desarrollo urbano de Lima al 2035

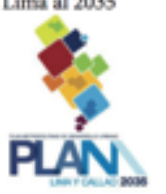

Bus patrón corredores complementarios al 2035

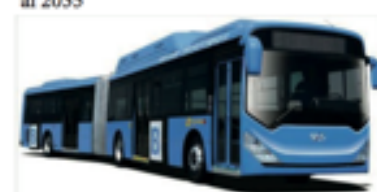

Incorporación de tren de cercanias para integrar Norte, Sar y Fste

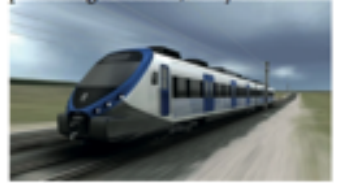




\section{FUTURO DE VILLA EL SALVADOR}

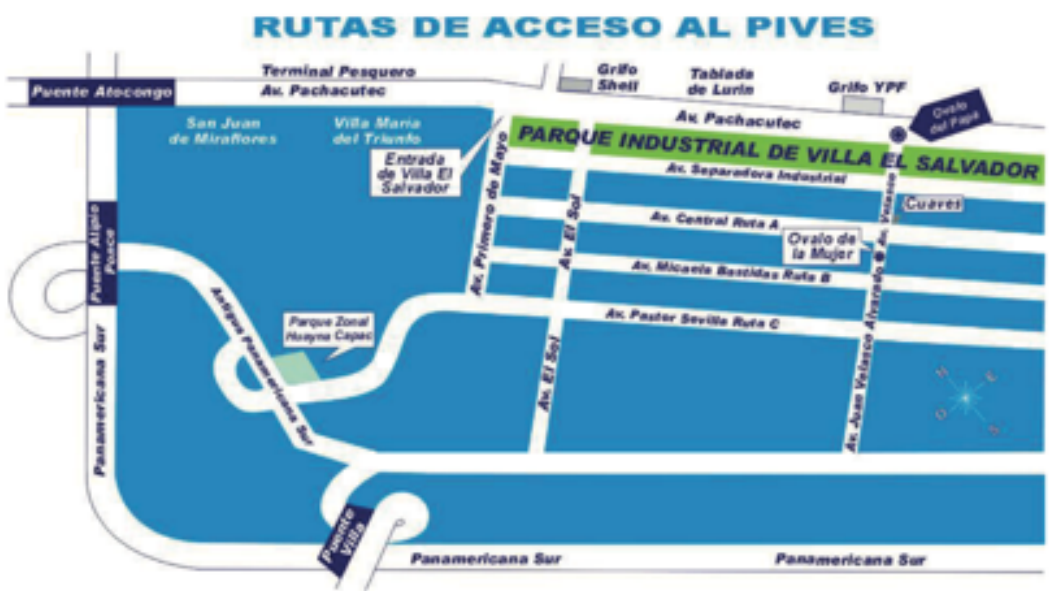

Ubicacion Geografica

RUTAS DE ACCESOS AL. PAROUE NOUSTRIAL DE VLLA EL SALVADOR

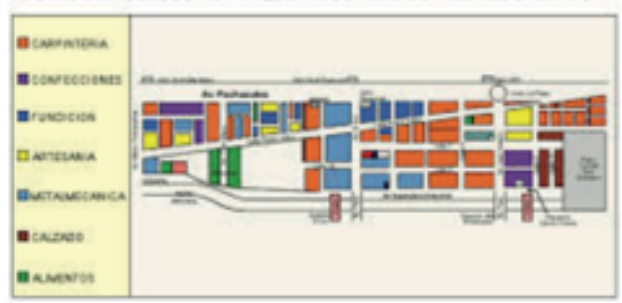

- PROYECTOS para autorregular la emergencia econoenica del Parque Industrial :

1) Politica economica que dote de valor agregado los productos

2) Estrategias urbanas de cambios de uso, dotacion de infraestructuras y de equipamientos complementarios.

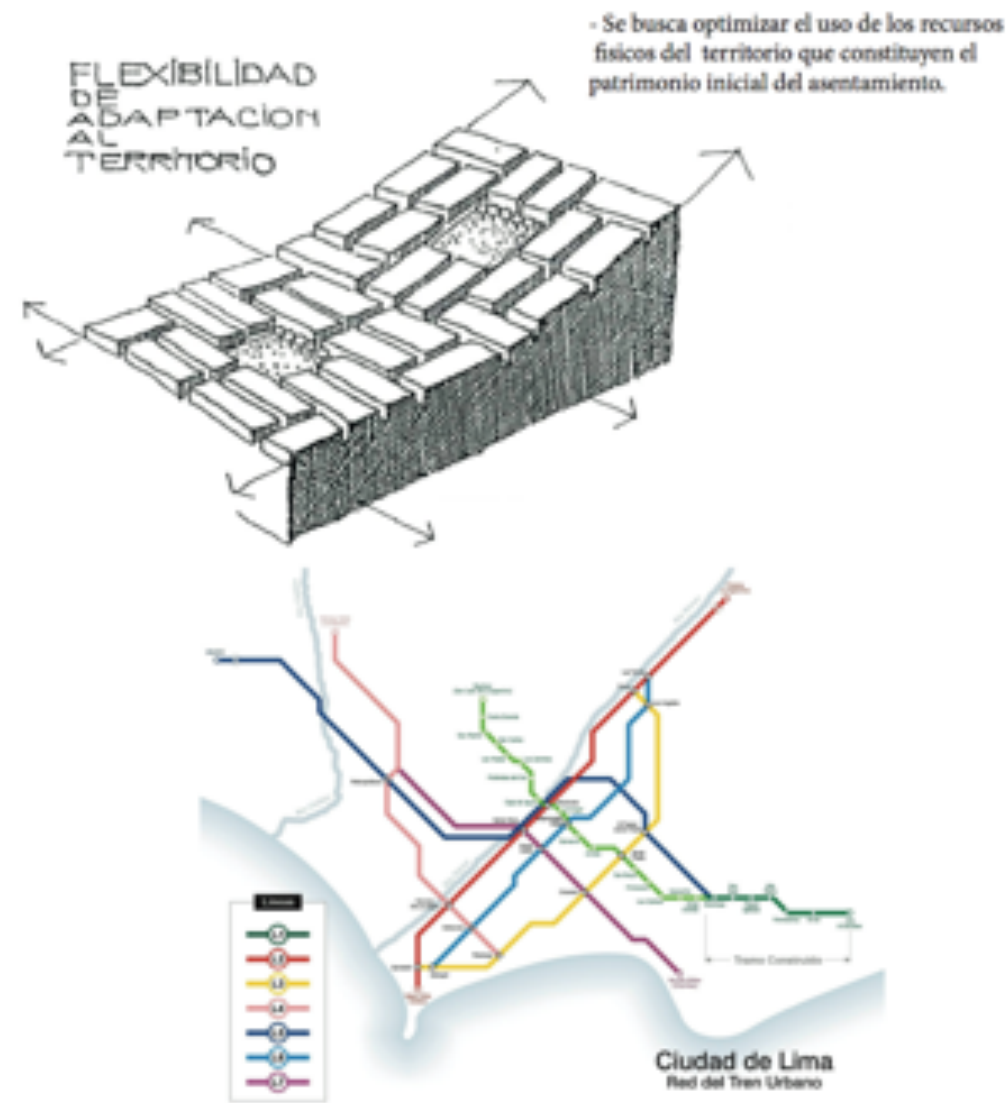




\subsubsection{Marco Teórico-Conceptual}

Arquitectura Inclusiva y accesibilidad:

Las personas con discapacidad constituyen, en el Perú y en los países en desarrollo, una de las poblaciones más vulnerables por su situación de exclusión, aislamiento y falta de acceso a oportunidades para su desarrollo y para su integración socioeconómica en condiciones de equidad.

Es difícil precisar el número de personas con discapacidad en el mundo debido a problemas de registro y de concepto, pues persisten definiciones diversas sobre quienes son personas con discapacidad. Según cifras proporcionadas por la Organización Mundial de la Salud (OMS), 650 millones de personas viven con algún tipo de discapacidad física, sensorial, intelectual o mental, lo cual representa el 10\% de la población mundial. En los países con una esperanza de vida superior a los 70 años, todas las personas pasan, en promedio, por lo menos 8 años de su vida con alguna discapacidad.

El Programa de las Naciones Unidas para el Desarrollo (PNUD) señala que el $80 \%$ de las personas con discapacidad vive en países en desarrollo y el $82 \%$ se encuentra en condiciones de extrema pobreza. Según el Banco Mundial (BM), el 20\% de las personas más pobres del mundo tiene alguna discapacidad. Estas personas, pobres y con discapacidades, constituye el grupo de población en situación de mayor des- ventaja y vulnerabilidad, por ello se les considera como "los más pobres entre los pobres". Existe pues una relación directa entre pobreza y discapacidad.

Las personas con discapacidad, en mayor medida si pertenecen a los grupos poblacionales en situación de pobreza o extrema pobreza, viven aisladas y limitadas debido a la indiferencia y a la discriminación que predomina en la sociedad. Es la discriminación la principal causa de la existencia de barreras físicas (arquitectónicas y tecnológicas), sociales (falta de acceso a información, servicios y oportunidades) y culturales (concepto de minusvalía), que colocan a estas personas en una situación de especial vulnerabilidad.

Esta situación afecta no solo a las personas con discapacidad, sino a sus familias, a sus comunidades, a las sociedades y a los Estados. El no reconocimiento de sus derechos y de su condición como parte de las diversidades que componen el mundo hace que estén excluidas y vistas desde su discapacidad y no desde sus múltiples potencialidades, lo que hace que no se aprovechen éstas para el desarrollo social y económico de las comunidades y sociedades. 35 
"Los derechos humanos de las personas que viven con alguna discapacidad son violentados cotidianamente, la sociedad ha sido educada

en estereotipos, que son trasmitimos cada día a estas personas en actitudes discriminatorias, que se imprimen en múltiples actos cotidianos.

Es necesario transformar estas actitudes e impulsar y apoyar políticas públicas que respeten el derecho humano de las personas con discapacidades a vivir con dignidad."

Organización de las Naciones Unidas

\subsubsection{Marco Teórico-Conceptual}

\section{Arquitectura Inclusiva y accesibilidad:}

Entender la accesibilidad como una premisa más del diseño y no como un añadido a posterior puede ofrecer interesantes posibilidades expresivas. No siempre el acceso en horizontal o la inclusión de los elementos de accesibilidad de forma que pasen desapercibidos o se mimeticen dentro del conjunto serán las soluciones más adecuadas o deseables. Por ejemplo, en determinadas ocasiones un elemento tan contundente como es la rampa puede utilizarse para definir o resaltar las características compositivas de un determinado edificio o espacio. 36

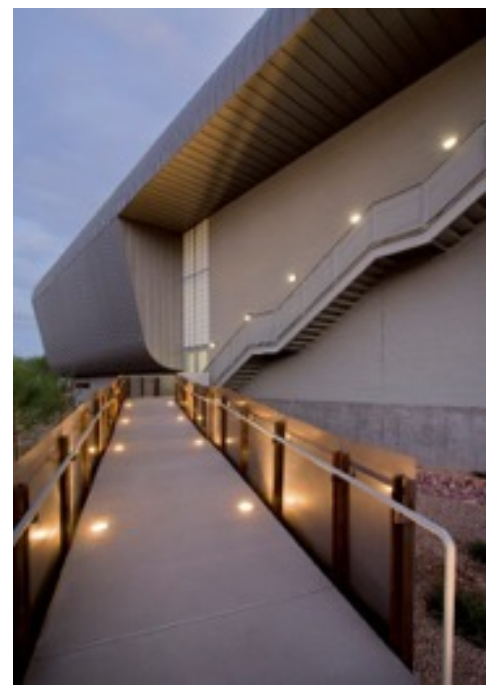

IMAGEN 36- 2012 Sport and Fitness Center for the disabled - Baldinger Architectural Studio - Foto de Raúl García 
1 Making it

available for use (Accessibility)

1

$x \times$

$\underline{-}$
2 Making it

easier to use

(Usability)

$\because$

$\because \ddot{*}$
Expanding the range of users (User diversity)

1

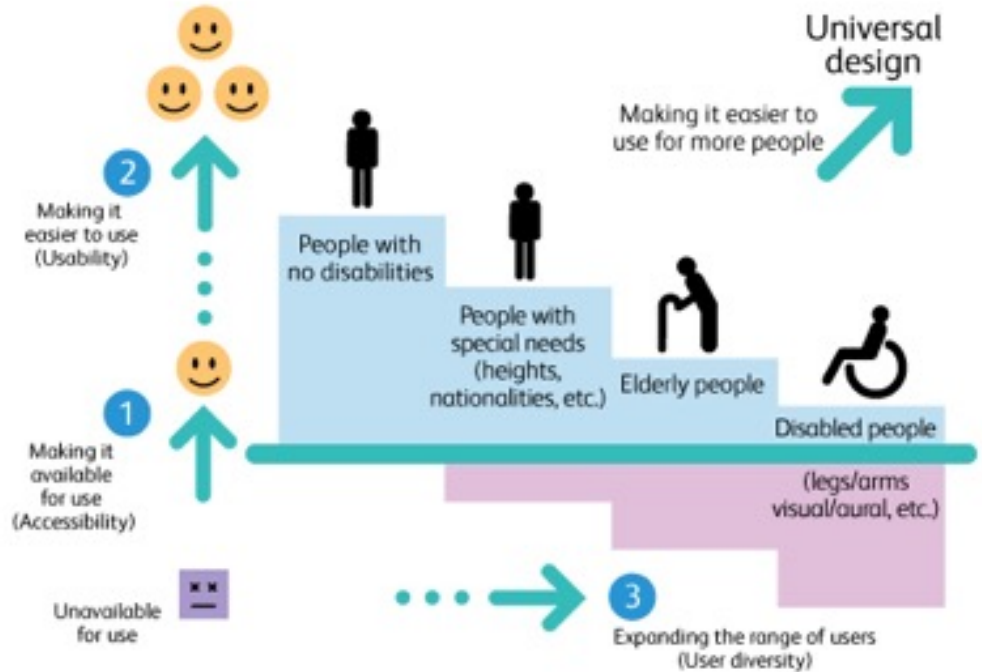

IMAGEN 37 - (2015) MORSEY, Universal Design: The Next Step in the

Equal-Access City - Jackson College of Urban Planning and Public
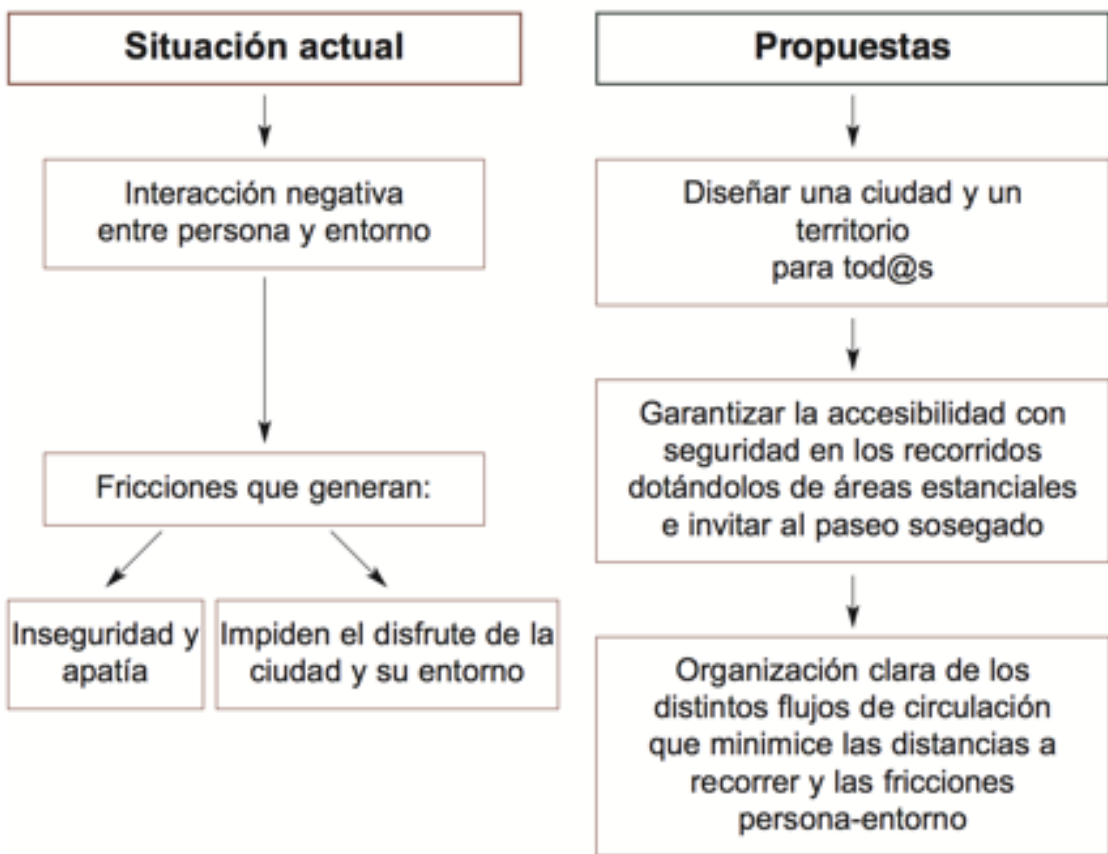

IMAGEN 38, (2008) MURILLO, Rosario - La inclusión de las personas

con discapacidad, PROPOLI, Lima, Perú 


\section{7 principios del Diseño Universal}

1. Uso equitativo: El diseño debe ser funcional y amable para personas con diversas habilidades.

2. Flexibilidad: El diseño se acomodaría a un rango amplio de necesidades individuales.

3. Uso simple e intuitivo: Uso de un diseño fácil de entender para toda persona, con dificultades del lenguaje, o problemas de concentración.

4. Información Perceptual: El diseño comunica la información necesaria de manera efectiva al usuario, sin importar las condiciones del ambiente o las habilidades sensoriales del usuario.

5. Tolerancia al error: El diseño minimiza situaciones adversas consecuencia de algún accidente.

6. Bajo esfuerzo físico: El diseño puede ser usado eficiente y confortablemente y con una fatiga mínima.

7. Tamaño y Espacio para Usos: Dimensionamiento apropiado de espacios, acondicionados para la accesibilidad de las acciones dentro de estos.

Arquitectura eco-sostenible:

La arquitectura eco-sostenible puede considerarse como aquel desarrollo y dirección responsable de un ambiente edificado saludable basado en principios ecológicos y de uso eficiente de los recursos. Los edificios proyectados con principios de sustentabilidad tienen como objetivo disminuir al máximo su impacto negativo en nuestro ambiente a través del uso eficiente de energía y demás recursos.

Así, el uso racional de recursos naturales y el manejo apropiado de la infraestructura e instalaciones del edificio contribuirán a la conservación de energía y a mejorar la calidad medioambiental. El edificio sustentable involucra tomar en cuenta el ciclo de vida entero de los edificios, teniendo en cuenta su calidad medioambiental, su calidad funcional y su valor de uso futuro. En el pasado, se ha enfocado la atención principalmente en el valor económico como bien raíz.

Podemos identificar identifica cinco objetivos para los edificios sostenibles, de la manera siguiente:

1. Uso eficiente de los recursos

2. Uso eficiente de energía (incluyendo la reducción de emisiones de gases invernadero) 
3. Prevención de contaminación (incluyendo mejorar la calidad del aire interior y disminuir el ruido)

4. Armonía con el ambiente (incluyendo la valoración medioambiental)

5. Enfoques Integrados y sistémicos (incluyendo un programa de manejo medioambiental)

Principios a considerar en la Arquitectura eco-sostenible:

1. Un ambiente interior saludable

2. Eficiencia energética

3. Materiales ecológicamente benigna

4. Forma medioambiental

5. Una solución coherente

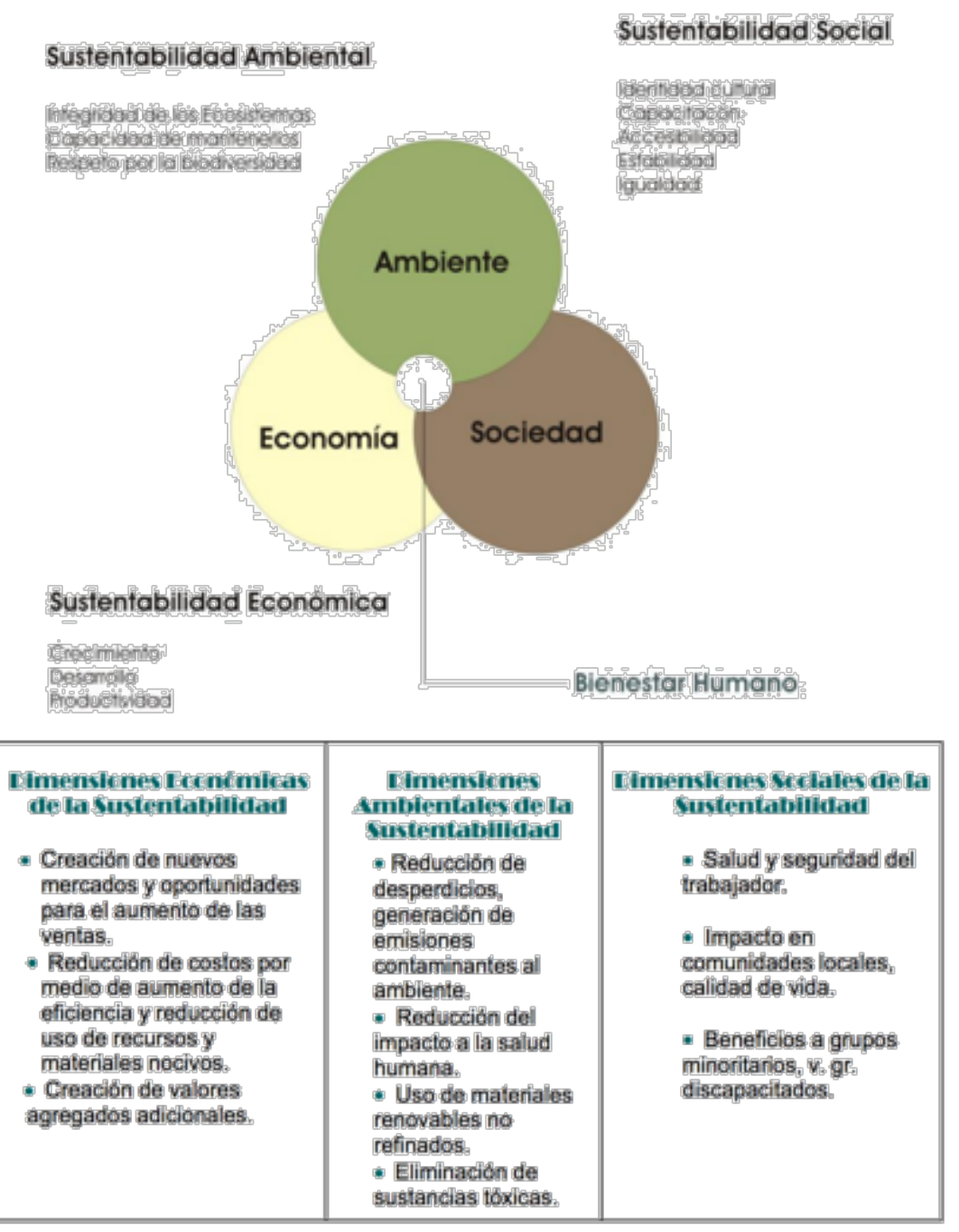




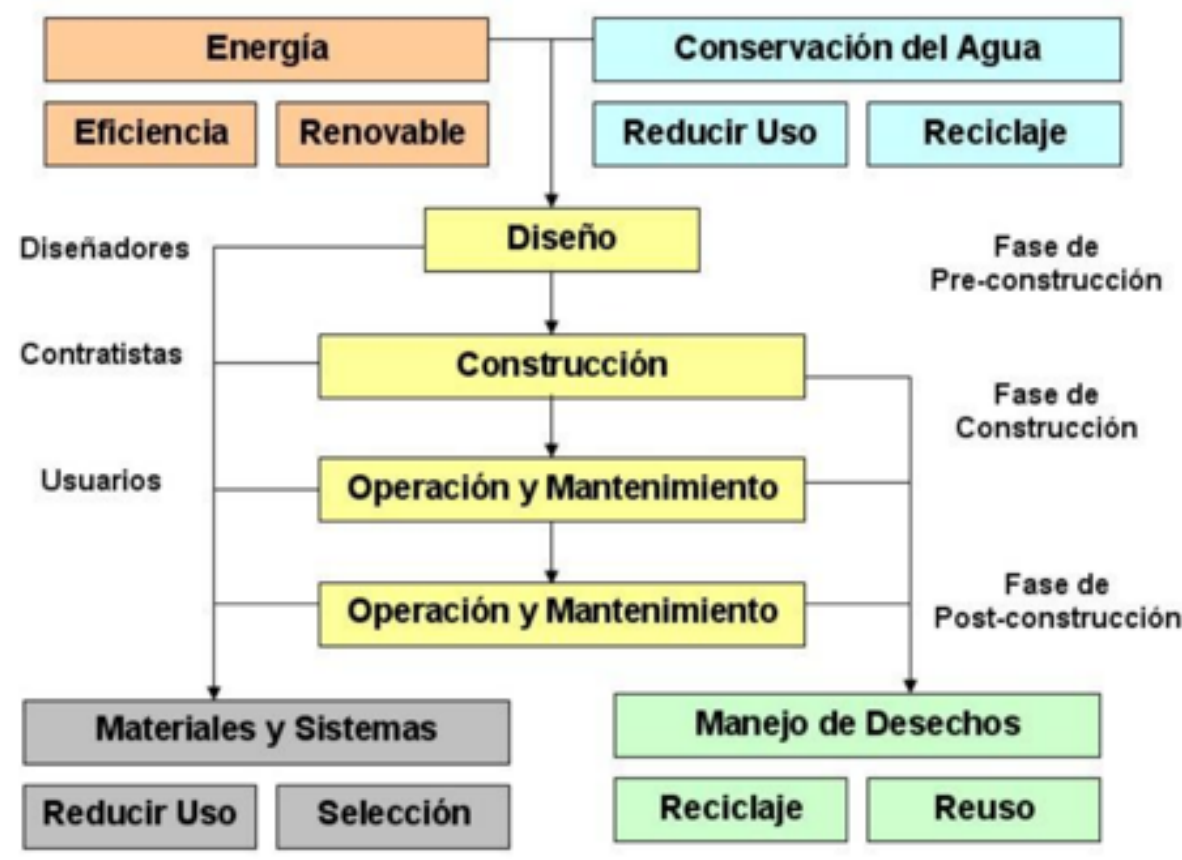

IMAGEN 40 - ESTRATEGIAS DE DISEÑO - MATERIALES, DESECHOS, AGUA Y ENERGIA

\section{SUSTAINABLE PUBLIC RECREATIONAL SPACES}

Arenas , piscinas , gimnasios , y grandes espacios de montaje se enfrentan a importantes retos de diseño del medio ambiente: las altas cargas de refrigeración para arenas de hielo ; cargas de calefacción altas y la humedad para piscinas ; altas cargas de iluminación para el funcionamiento durante todo el año ; los requisitos de calidad del aire en interiores únicos para los diversos espacios [ pista vs. piscina vs. gimnasio vs. habitaciones comunitarios ]; y las preocupaciones de conservación del agua .

Teniendo en cuenta este impacto sustancial en la oferta cada vez menor de los recursos, se convierte en imperativo un diseño en el que el impacto ambiental de este tipo de instalaciones se reduzca al mínimo, y que sean lo más autosuficientes posible.

Hay muchas estrategias que se pueden aplicar a las instalaciones de recreación para abordar aspectos concretos de diseño para aumentar la energía y la eficiencia del agua, mejorar la calidad del aire interior y reducir la huella ambiental general, sin embargo, es en el nivel del programa de construcción que el mayor impacto posible hacerse. 73 
Los centros recreativos más exitosos han sido los que se combinan múltiples programas en un solo complejo consolidado. No sólo el edificio de recreación híbrida proporciona una experiencia más rica para los usuarios, sino también desde la perspectiva de las operaciones, su capacidad para aprovechar las relaciones funcionales ha llevado constantemente para mejorar el rendimiento del ciclo de vida, facilita el intercambio de recursos y minimiza la redundancia operativa. Sinergias de diseño múltiples pueden producir ahorros significativos. 73

Ejemplos exitosos de este enfoque incluyen el Complejo Innisfil Recreación en Ontario, que organiza un complejo multi-arena operado por la ciudad de Innisfil, y el YMCA local que ofrece servicios de bienestar, en un nuevo organismo colectivo. El plan de construcción fue racionalizado con una simetría orgánica que refleja dos culturas operativas distintas y complementarias. Para ahorrar energía y la eficiencia operativa del programa se organizó en un lado "caliente" y un lado "frío".73

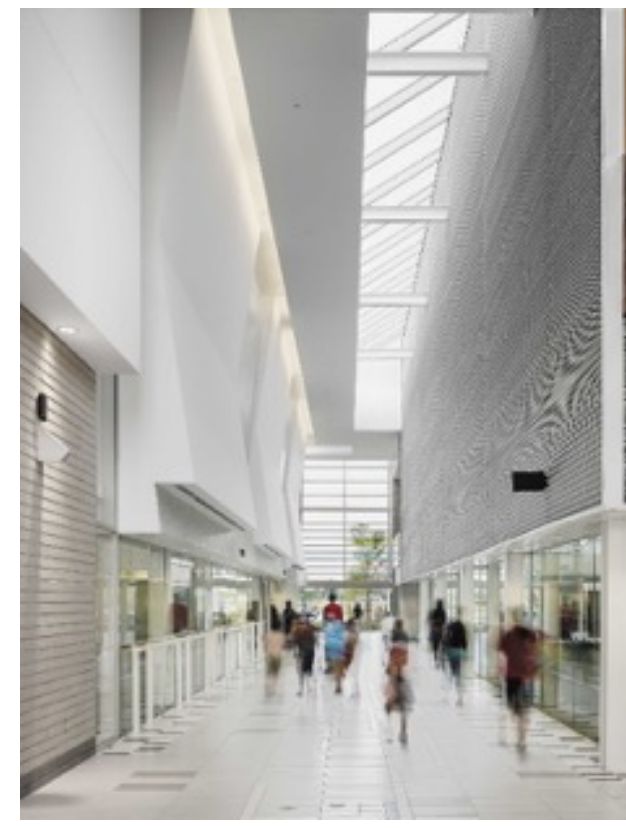

IMAGEN 41 BRAMPTON SOCCER CENTER - IMAGEN 1

Los usos complementarios permiten que el complejo de emplear la estrategia de ahorro de energía de reutilizar o reciclar la energía residual de un componente de construcción para calentar el espacio de otro. El calor residual exceso del sistema de refrigeración de arena se aplica a diversas fuentes de calor de baja calidad durante el resto del edificio, tales como en la planta de calefacción radiante, la fusión de la nieve y la repavimentación de hielo, duchas, agua de la piscina, la recarga deshumidificadora, y precalentamiento de el aire y el agua para uso doméstico. 73 
Del mismo modo, en el Centro de Salud y Bienestar Port Colborne, el calor residual del sistema de refrigeración de hielo se utiliza para proporcionar calefacción en el suelo en todo el edificio. La demanda de energía en las arenas se puede reducir mediante el uso de controles de velocidad variable de la bomba, techos de baja emisividad, agua desmineralizada, el espesor del hielo minimizado, y controles de temperatura del hielo para diferentes actividades como el hockey o patinaje recreativo.

Vellore Village Community Centre y St. Jean de Brebeuf Catholic High School es un ejemplo de cómo recreativo y programas no recreativo se pueden combinar para lograr la eficiencia en función del uso del espacio. 73

El complejo fue diseñado para permitir a los programas basados en los patrones de uso generados por la escuela y la comunidad se superponen. Grandes espacios como los gimnasios y la cafetería se encuentran en el centro y se puede acceder a ninguno de los grupos, maximizando el uso de tiempo que permite el funcionamiento autónomo de cada socio. Los estudiantes que solían ser llevados en autobús a las clases de natación ahora caminar a la piscina, y los usuarios de centros de la comunidad tengan acceso a las artes escolares y salas especializadas después del horario escolar. 73

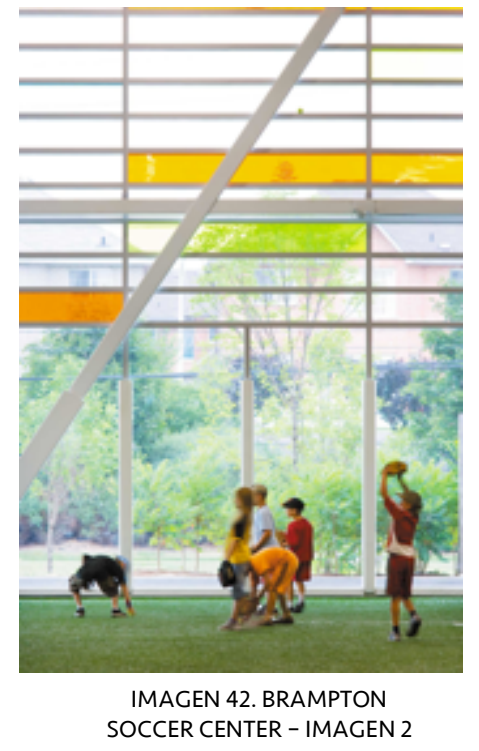




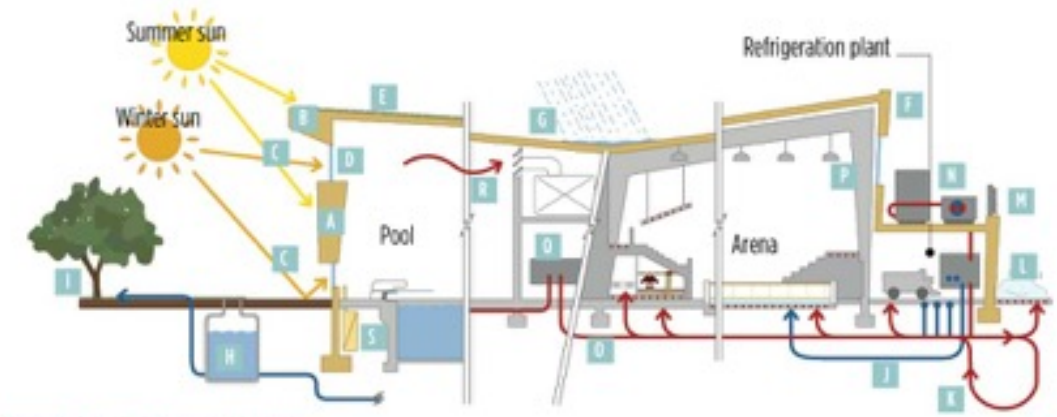

PASSIVE AMD ACTIVE SYSTEMS DLAGOAY

Passive systems

A Solar wall

B Light shelf [blocks summer sun]

C Natural light

D High-performance glazing [High R-value]

E Green roof

F High-performance building envelope

G Rainwater collection

H Rainwater harvesting

I Landscape buffer

\section{Active systems}

J Refrigeration

K Geothermal loops

I Snow melt

M Shielded mechanical

N Heat recovery

- Domestic energy supply via stored heat

P Zoned/staged lighting

Q Filtration

R Return to high-level mechanical

S Perimeter duct/displacement ventilation

IIMAGEN 43. NNISFIL RECREATION COMPLEX -

IMAGEN 1

Un modelo de diseño verde recreativo debe crear un equilibrio de las mejores prácticas, incluyendo bajos y estrategias de alta tecnología y soluciones alcanzables, junto con todos los enfoques asociados.

Por ejemplo, el Innisfil Recreation Complex [IRC] es uno de los primeros complejos deportivos con certificación LEED en Canadá, y es representativa de las iniciales logros sostenibles que ahora son posibles en la arquitectura recreación. Logros de sostenibilidad para el IRC incluyen: reducción del 39\% en el consumo de energía, reducción del 32\% en costos de energía, el $89 \%$ de los residuos de la construcción desviada del vertedero, y el $40 \%$ menos de consumo de agua que un edificio convencional. 73

Otras estrategias sostenibles a tener en cuenta de que no son específicos de los edificios de recreación incluyen: control de ganancia de calor utilizando techos altos; maximización de la luz del día a través de ventanas y claraboyas; la instalación de alta eficiencia de la iluminación artificial con sensores de luz natural y de ocupación y control de la zona; especificando alta eficiencia equipo mecánico con recuperación de calor completo para calefacción y filtración; y la garantía de que todos los sistemas están bien y frecuentemente monitoreados por personal cualificado. Mientras que un edificio de recreación es una tipología difícil, hay muchas oportunidades de diseño para hacer frente 
a las deficiencias ambientales, y que sólo le ayudará a aumentar su valor cívico a la comunidad. 73

\section{BEIJAO SPORTS CENTRE - SUSTAINABLE FORMAL CONCEPT}

Este proyecto se soluciona bajo el concepto de desniveles continuos que unen todo el proyecto y hacen que la forma fluya y envuelva todo el proyecto, articulando los espacios y el espacio público. Funciona alrededor de una plaza verde central que a la vez que ordena el programa, funciona como centro verde.

Como concepto es innovador y también formalmente, dándole al polideportivo una forma no-ortogonal, que es la primera respuesta por el tecnicismo de los deportes.

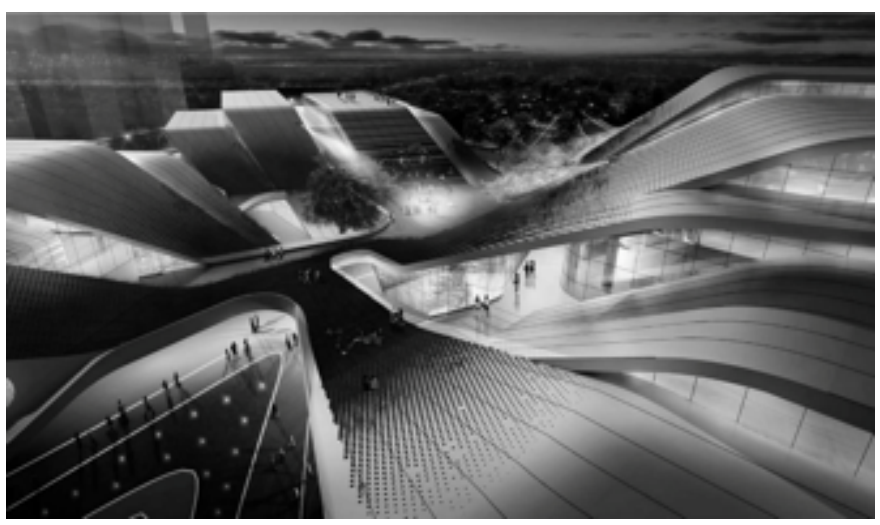

IMAGEN 44 - PLAZA BEIJAO

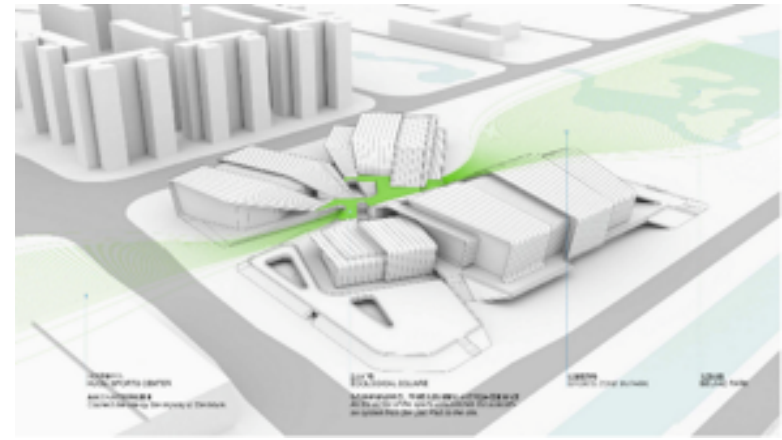

IMAGEN 45 - ESQUEMA BEIJAO

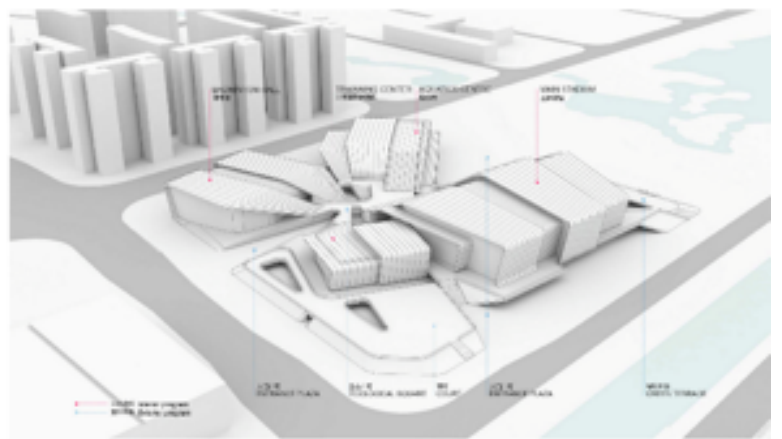

IMAGEN 46 - ESQUEMA BEIJAO 


\section{BEIJAO SPORTS CENTRE - SUSTAINABLE FORMAL CONCEPT}

En el primer nivel coloca comercio en todo el borde de la plaza central para mantenerlo activado, y es el ingreso a las losas deportivas. En el segundo piso es el ingreso a las tribunas.
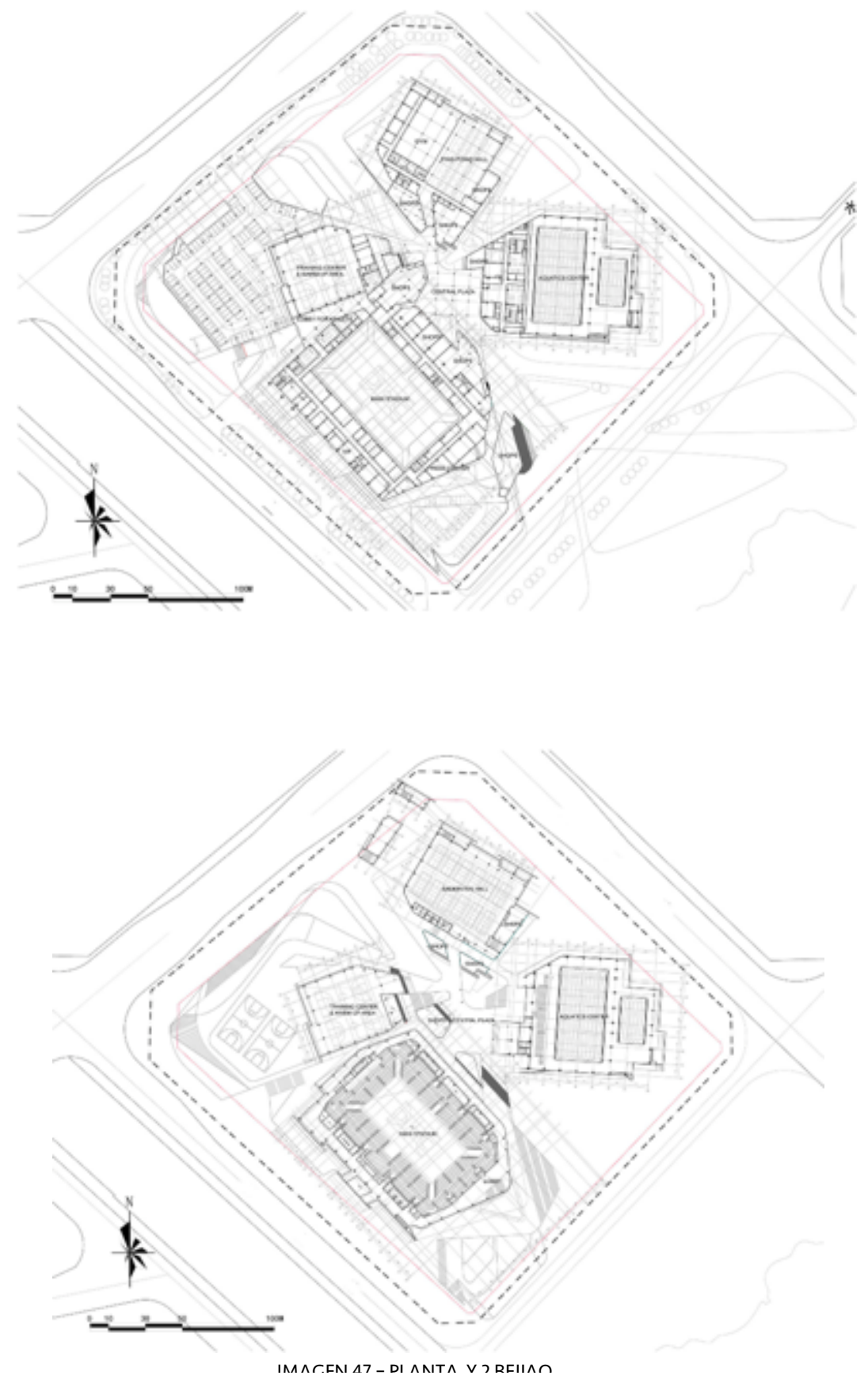
3.ANALISIS CRÍTICO DE PROYECTOS REFERENCIALES 


\section{SPORT AND FITNESS CENTER FOR DISABLED PEOPLE / BALDINGER}

\section{ARCHITECTURAL STUDIO}

\section{INFORMACIÓN GENERAL DEL PROYECTO:}

\section{Nombre:}

Sport and Fitness Center for Disabled People

Autor:

Baldinger Architectural Studio

Año de inauguración: 2012

Dirección:

Disability Empowerment Center Campus of Arizona

5025 E Washington St

Phoenix, Arizona 85034

United States

\section{Tipología:}

Polideportivo

Área de proyecto: $4180.6 \mathrm{~m} 2$

Área libre: $2600 \mathrm{~m} 2$

Área total: $7899 \mathrm{~m} 2$

Datos relevantes: RED Award for 'Best Public Building' for the Virginia G. Piper Sports

$\&$ Fitness Center for Persons with Disabilities from Arizona Real Estate Magazine

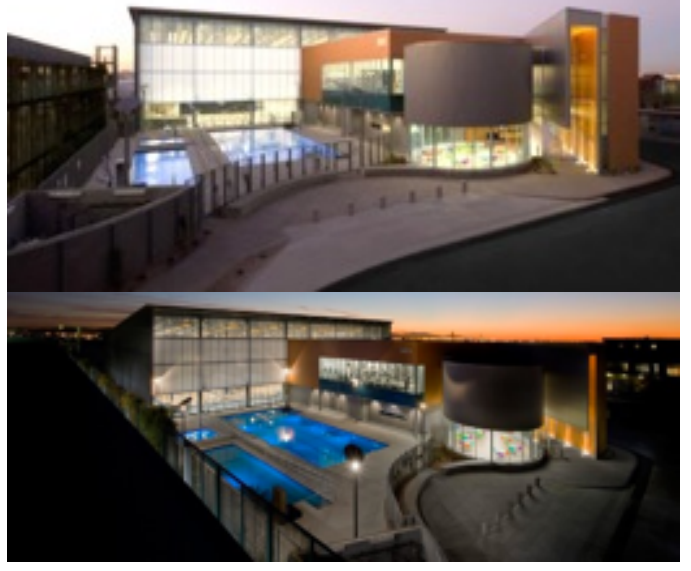

ARCHDAILY- 2015 -Sport and Fitness center (22 de setiembre del 2015)

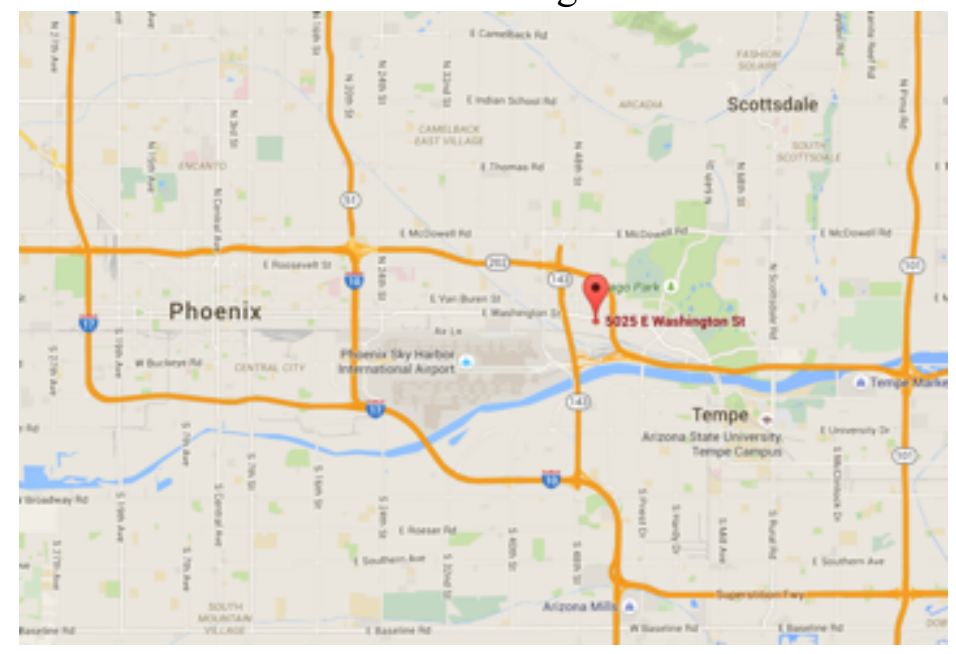

MAPA DE PHOENIX - AZ - GOOGLE MAPS
UBICACIÓN

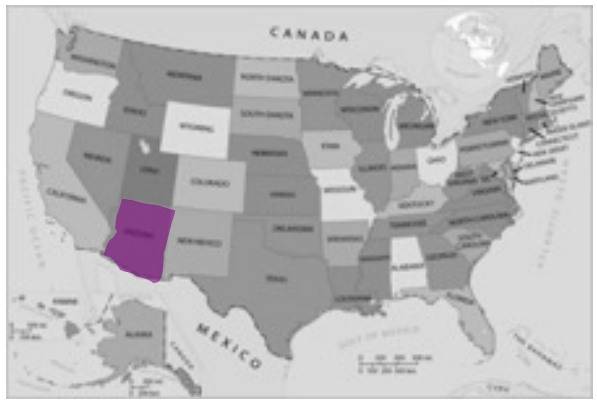

TERRENO

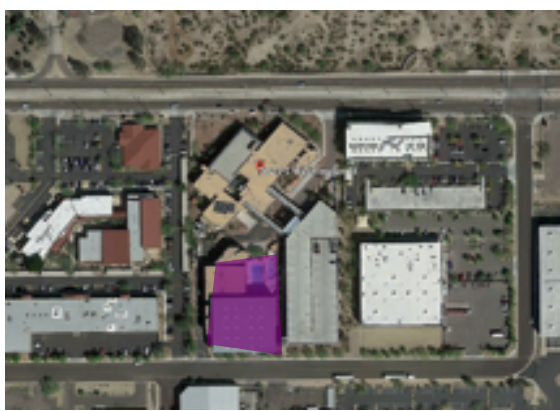


Es accesible ya que se encuentra en el centro de la ciudad de Phoenix. Esta cerca al aeropuerto y a las vías principales de la ciudad. Además, se encuentra al lado de las vías del tren.

\section{SPORT AND FITNESS CENTER FOR DISABLED PEOPLE / BALDINGER} ARCHITECTURAL STUDIO

\section{ANTECEDENTES HISTÓRICOS}

El polideportivo fue construido en el terreno de al lado de la sede del DEC (Disability Empowerment Center) es una organización de los Estados Unidos, necesitaba un espacio en el que la persona pueda ser independiente, y autodidacta y a la vez que se vuelva un modelo nacional de diseño universal e integrador. El polideportivo para personas discapacitadas de Arizona tuvo 2 faces, la primera también diseñada por Baldinger Studio, fue el DEC y la segunda, el polideportivo. Fué terminada en el 2012.

\section{IDENTIFICACION DE VALOR HISTORICO:}

El edificio no tiene valor histórico porque no se encuentra en una zona histórica ni de valor monumental, tampoco se encuentra cerca de edificios de carácter monumental ni histórico. Se encuentra cerca de la estación de tren y esta rodeado de edificios de carácter público.

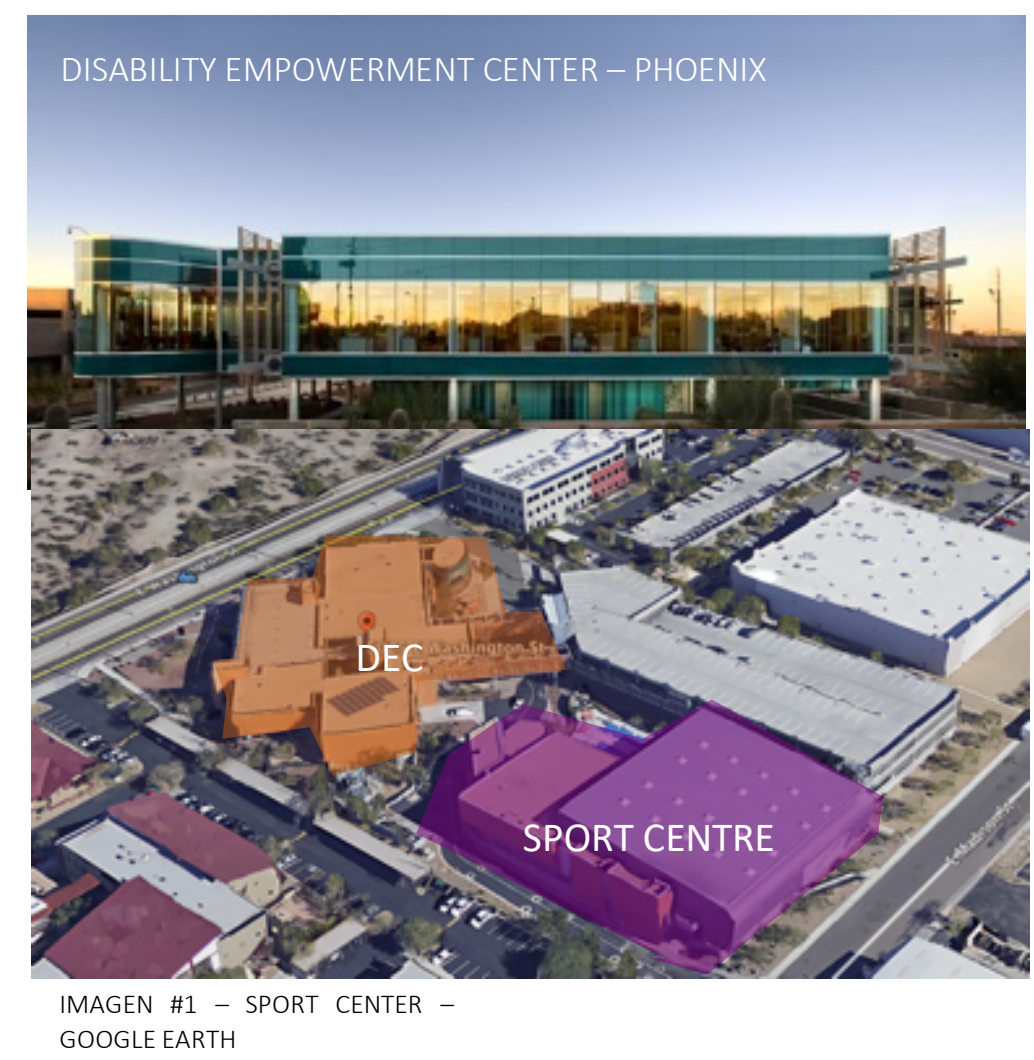


SPORT AND FITNESS CENTER FOR DISABLED PEOPLE / BALDINGER ARCHITECTURAL STUDIO

\section{CONCEPTUALIZACIÓN DE LA PROPUESTA:}

Con la experiencia ganada de la primera fase del proyecto (DEC) y con el mismo compromiso de remover todas las barreras, crear una fusión de la función, la preocupación por el medio ambiente y buscando crear un espacio estético de carácter universal. Generaron el concepto de una conexión continua a través de una rampa que conectaría los dos niveles del polideportivo.

\section{RELACIÓN CON EL EXTERIOR}

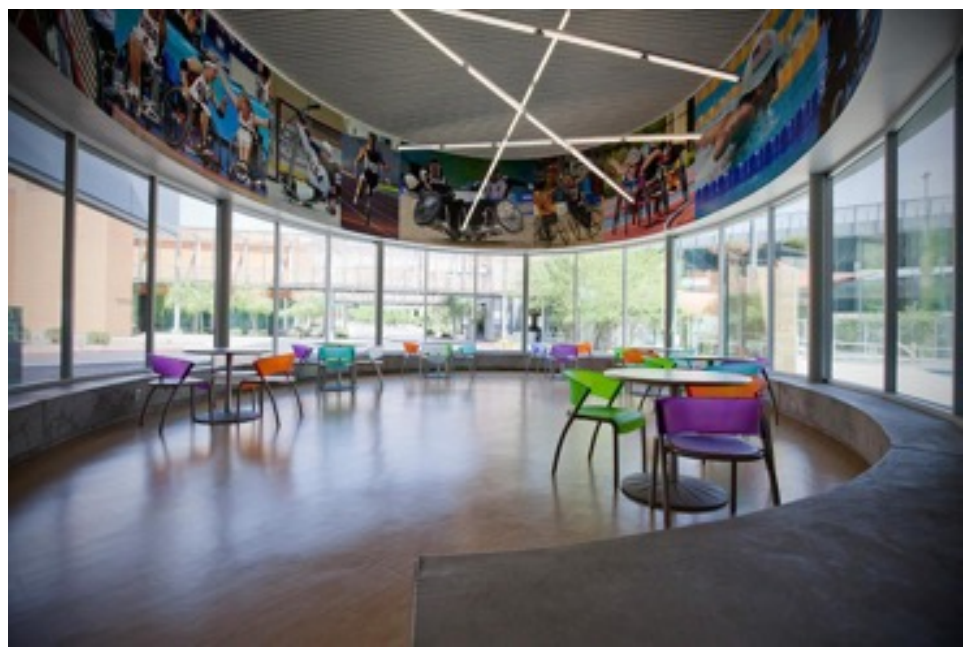

IMAGEN \#2 - SPORT CENTER
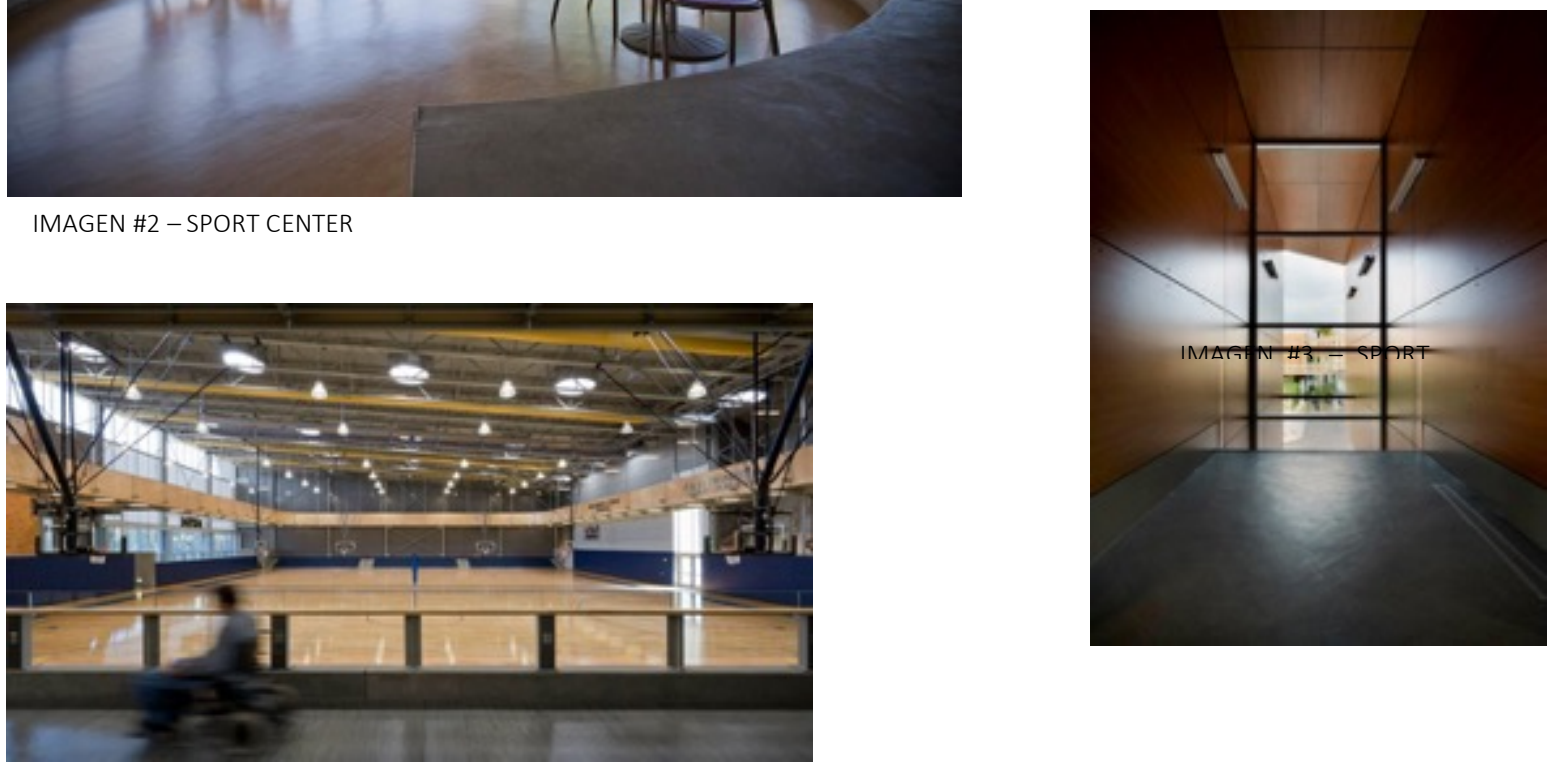

IMAGEN \#4 - SPORT

El espacio se caracteriza por ser un espacio integrado, se han mezclado funciones dentro del mismo espacio aportándole variadas percepciones de profundidades y alturas al espacio. 
SPORT AND FITNESS CENTER FOR DISABLED PEOPLE / BALDINGER ARCHITECTURAL STUDIO
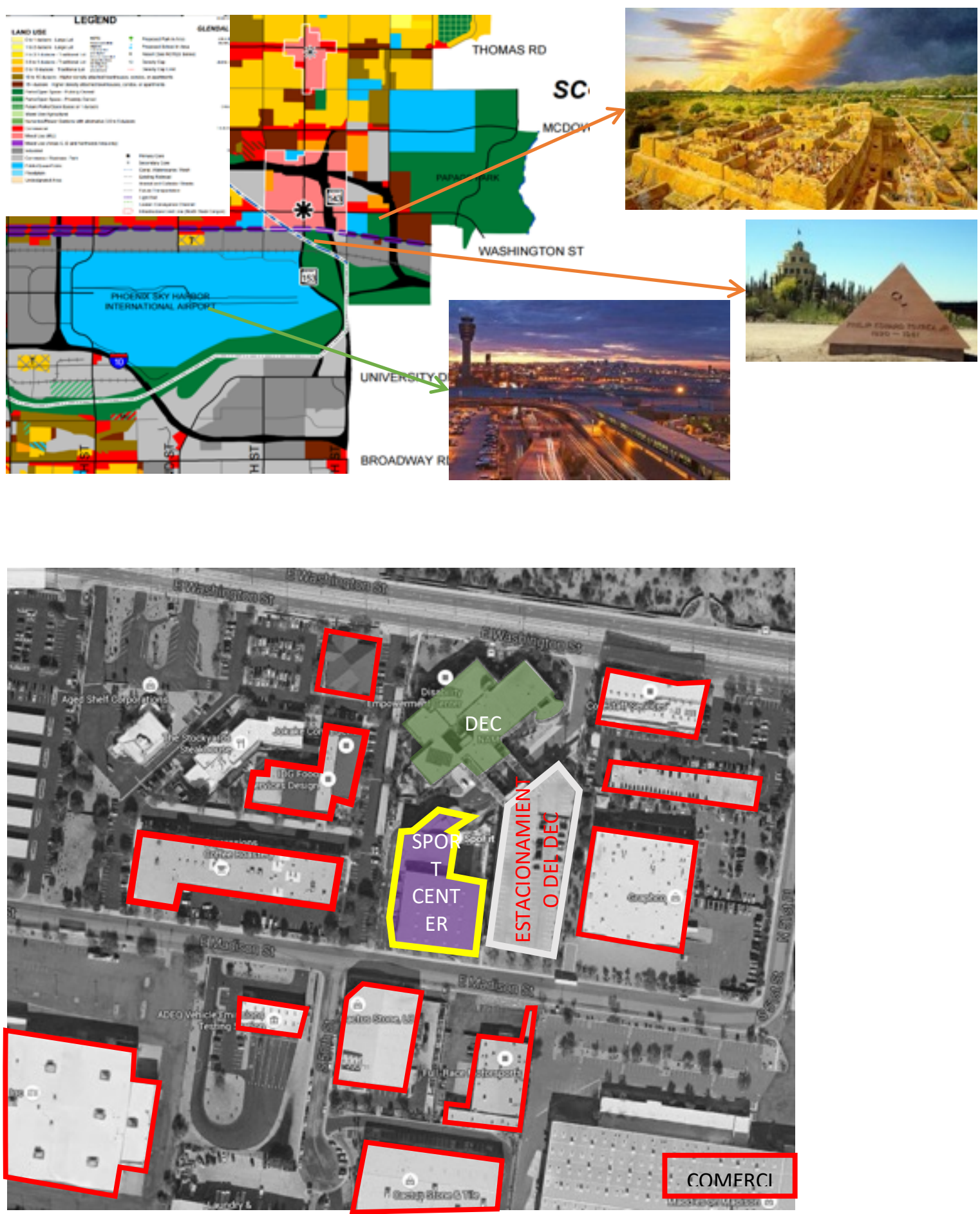


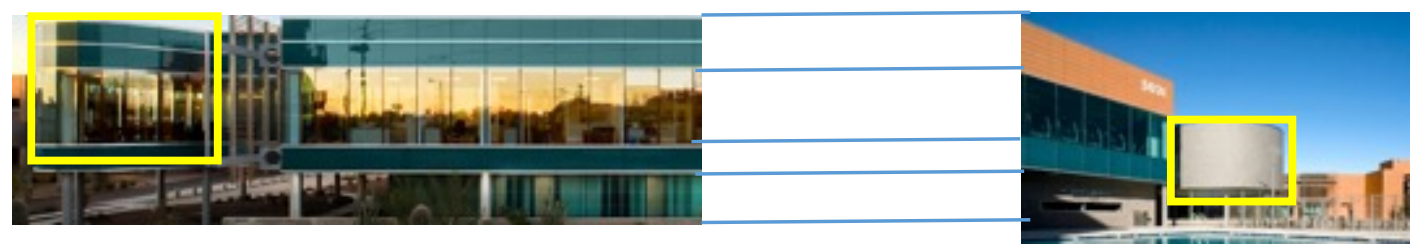

\section{UBICACIÓN COMPLETAMENTE ACCESIBLE}
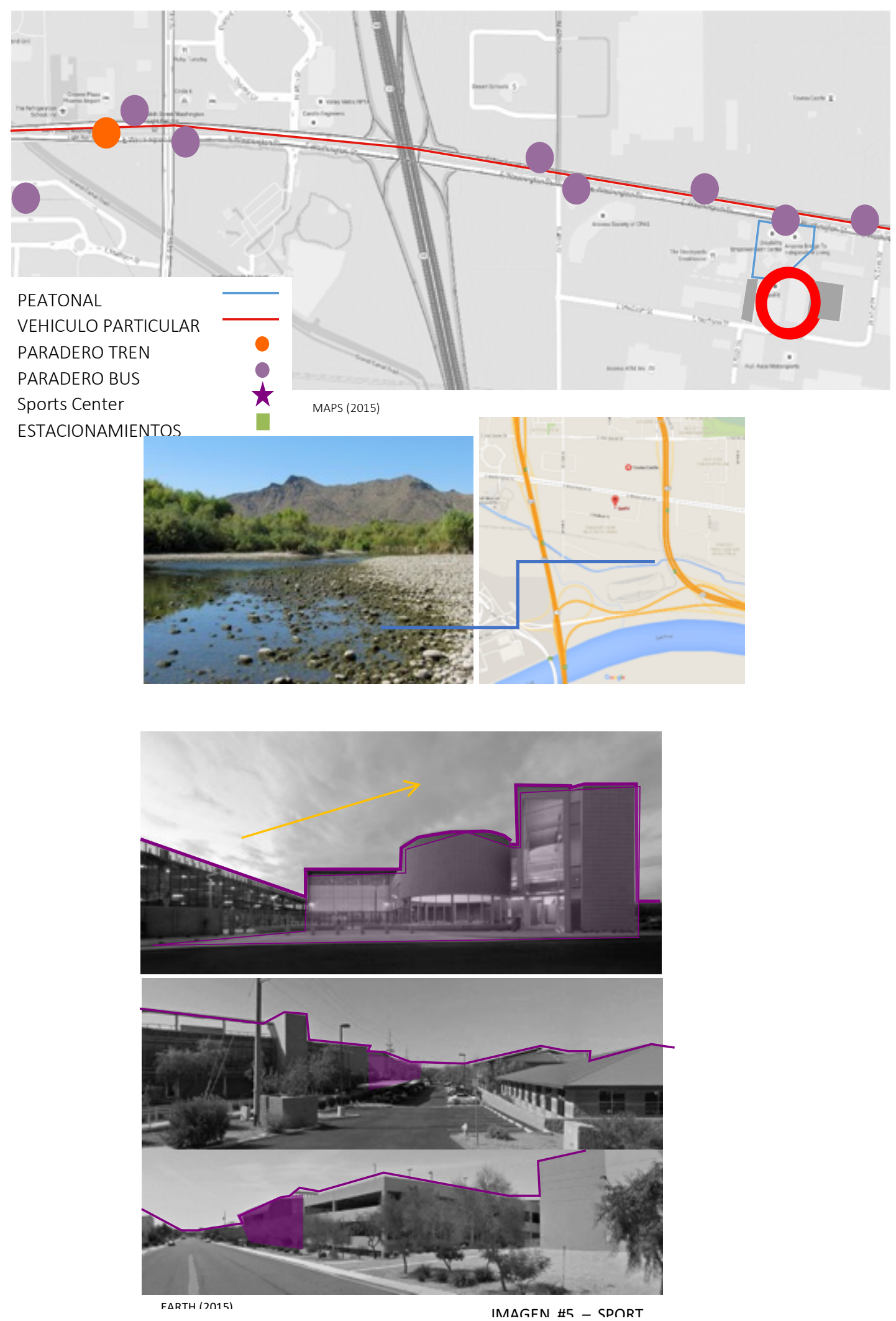
El edificio se encuentra en una zona de bajas alturas y de constantes escalonamientos. Además se encuentra frente a una zona verde, hacia la que dirige las vistas. Tiene un río seco a 10 cuadras.

\section{MEDIO AMBIENTE}

\section{ASOLAMIENTO}
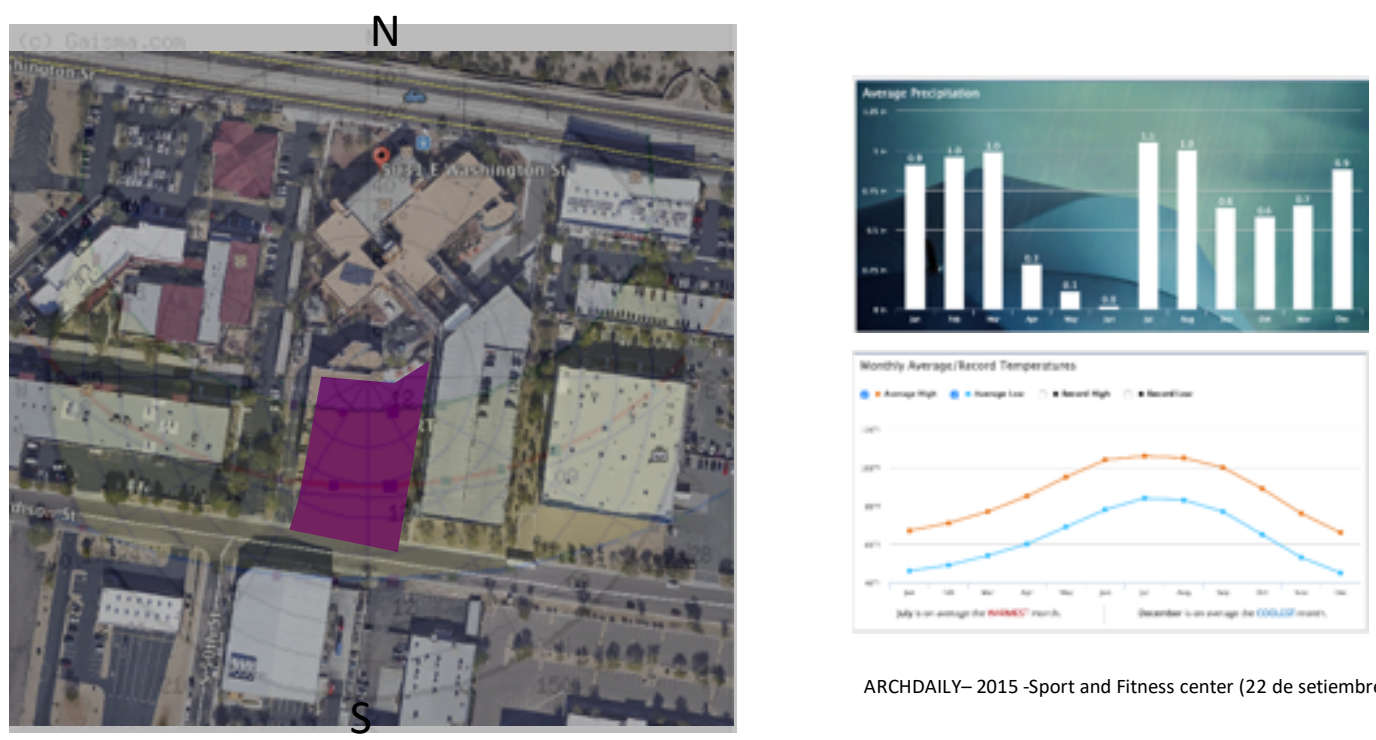

ARCHDAILY- 2015 -Sport and Fitness center (22 de setiembre del 2015)

El edificio esta girado en una posición del noreste al suroeste para reducir el impacto de los rayos solares.

\section{CLIMA}

\begin{tabular}{|l|r|c|c|c|c|c|c|c|c|c|c|c|}
\hline \multicolumn{1}{|c|}{ Variable } & I & II & III & IV & V & VI & VII & VIII & IX & X & XI & XII \\
\hline Insolation, $\mathbf{k W h} / \mathbf{m}^{2} /$ day & 2.98 & 3.78 & 5.06 & 6.53 & 7.37 & 7.54 & 6.99 & 6.21 & 5.46 & 4.30 & 3.30 & 2.74 \\
\hline Clearness, $\mathbf{0 - 1}$ & 0.56 & 0.57 & 0.60 & 0.65 & 0.67 & 0.66 & 0.62 & 0.60 & 0.61 & 0.59 & 0.58 & 0.56 \\
\hline Temperature, "C & 6.84 & 8.53 & 11.77 & 15.84 & 21.19 & 25.81 & 27.91 & 26.37 & 23.48 & 17.91 & 10.72 & 6.52 \\
\hline Wind speed, $\mathrm{m} / \mathrm{s}$ & 5.33 & 5.12 & 5.20 & 5.31 & 5.31 & 5.18 & 4.31 & 3.88 & 4.55 & 4.77 & 5.31 & 5.16 \\
\hline Precipitation, mm & 21 & 18 & 22 & 6 & 3 & 2 & 20 & 29 & 21 & 16 & 17 & 22 \\
\hline Wet days, d & 3.9 & 3.7 & 4.0 & 1.6 & 0.8 & 0.7 & 4.4 & 4.8 & 3.2 & 2.7 & 2.8 & 4.0 \\
\hline
\end{tabular}

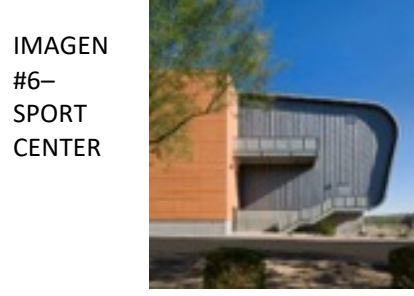

El clima es de fríos fuertes y de veranos intensos. Llueve con frecuencia y cuenta con temperaturas muy altas en Julio. En diciembre registra las temperaturas más bajas. El clima en general es árido. 


\section{ASPECTOS FUNCIONALES}

El mayor logro es el "medio ambiente total" ofreciendo una completa libertad de movimiento y actividad en un ambiente seguro y saludable. Este "medio ambiente total" contribuye al sentimiento de propiedad de una comunidad que durante mucho tiempo tuvo que adaptarse a soluciones parciales.

COMEDOR

ZONA ADMINISTRATIVA

ZONA DE DEPORTES/GYM

VESTIDORES/BAÑOS

CIRCULACIONES VERTICALES

PISCINA

SERVICIOS
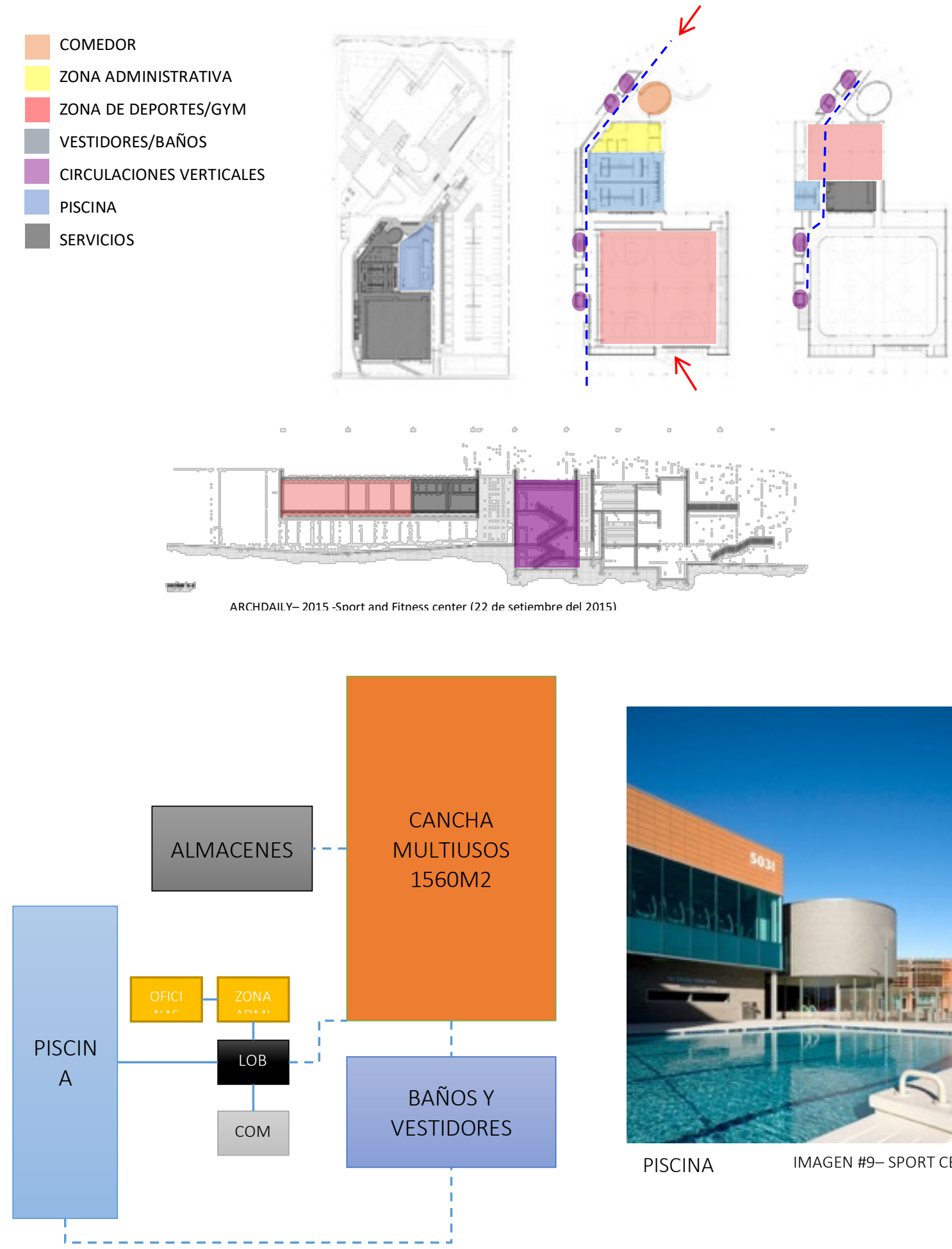

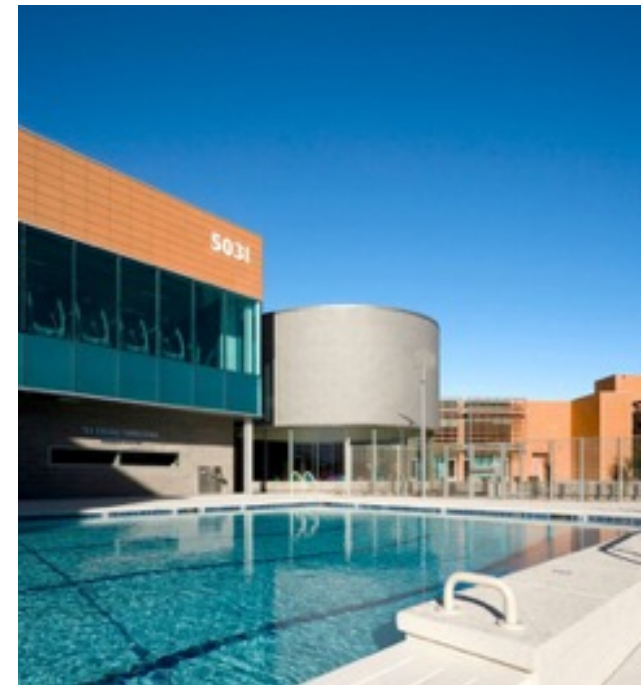

PISCINA

IMAGEN \#9-SPORT CENTER 


\section{ASPECTOS FUNCIONALES (PROGRAMA)}

El SpoFit cumple sus requisitos del programa previsto y metas, mientras que la promoción de la salud, el bienestar y la participación activa en las actividades deportivas y de acondicionamiento físico del grupo más amplio de usuarios habilitados; ya sea el usuario individual, el atleta olímpico, un club deportivo local o un equipo nacional.

Cuenta con 94 estacionamientos y 22 para discapacitados.

\section{PROGRAMACION}

\begin{tabular}{|c|c|c|}
\hline \multicolumn{3}{|c|}{ PROGRAMA } \\
\hline PISO 1 & $\begin{array}{c}\text { - Estacionamientos } \\
\text { - Piscina } \\
\text { - zona administrativa } \\
\text { - Oficinas } \\
\text { - Almacenes } \\
\text { - cancha multiusos } \\
\text { - baños y vestidores } \\
\text { - zona de comedor }\end{array}$ & $\begin{array}{l}\text {. } 4626 \mathrm{m2} \\
\text {. } 651 \mathrm{m2} \\
\text {. } 63 \mathrm{m2} \\
\text {. } 52 \mathrm{m2} \\
\text {. } 200 \mathrm{m2} \\
\text {. } 1560 \mathrm{~m} 2 \\
\text {. } 360 \mathrm{m2} \\
\text {. } 70 \mathrm{m2}\end{array}$ \\
\hline $\mathrm{PISO}_{2}$ & $\begin{array}{l}\text { - Almacenes } \\
\text { - Baños } \\
\text { - Gimnasio }\end{array}$ & $\begin{array}{r}\text {. } 100 \mathrm{~m} 2 \\
\text {. } 120 \mathrm{~m} 2 \\
\text {. } 763 \mathrm{~m} 2\end{array}$ \\
\hline
\end{tabular}
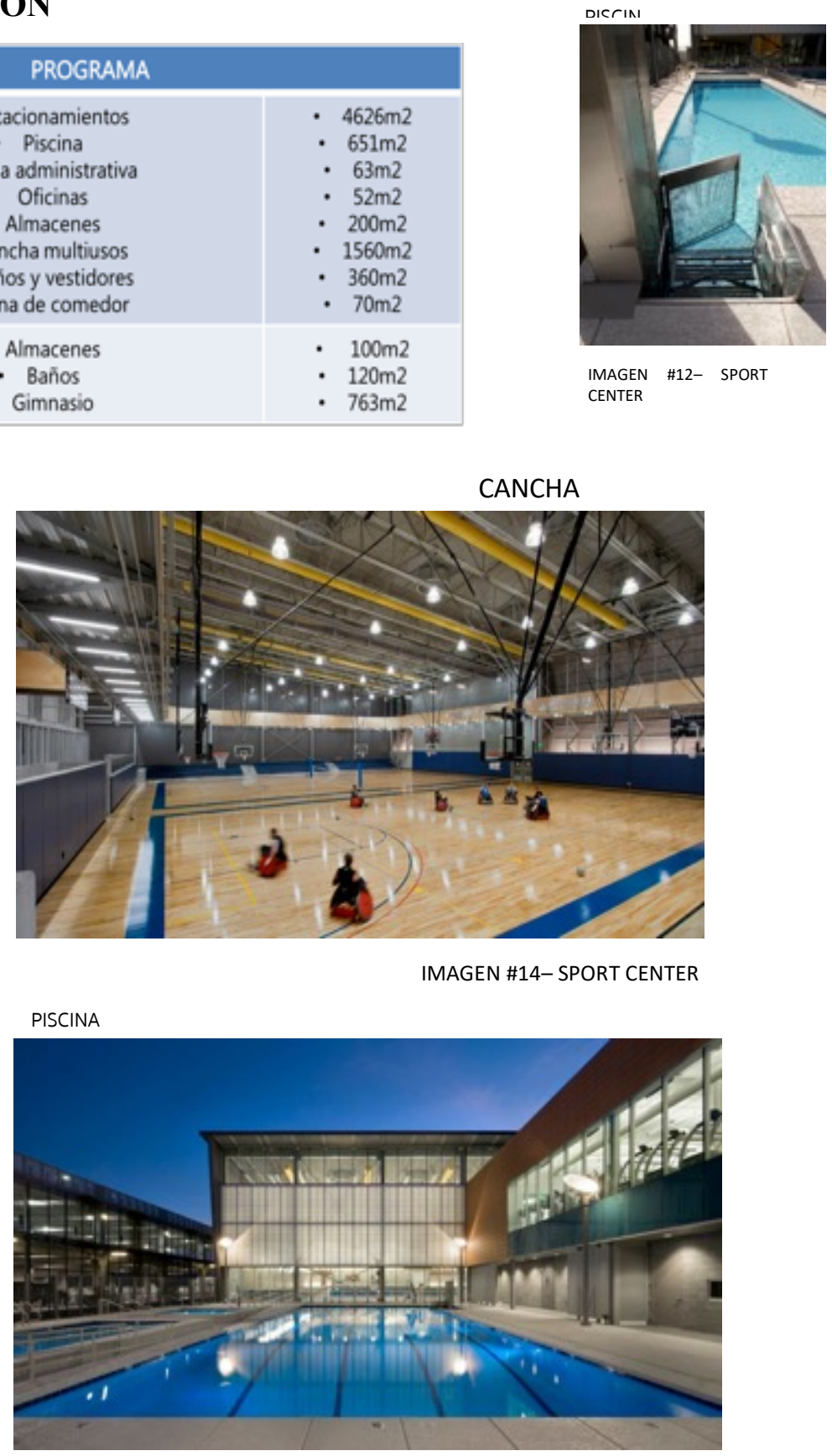

IMAGEN \#15-SPORT CENTER 


\section{ASPECTOS TECNOLOGICOS}

El edificio está construido en concreto y acero, con revestimientos en madera y acero. Utilizan distintos revestimientos de acero, como planchas perforadas, en el caso de diseñar espacios permeables o intermedios, y en el caso de cerramiento total, planchas lisas.

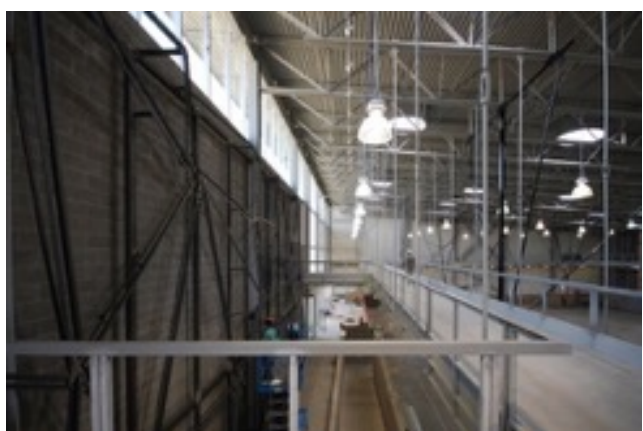

IMAGEN \#17- SPORT CENTER

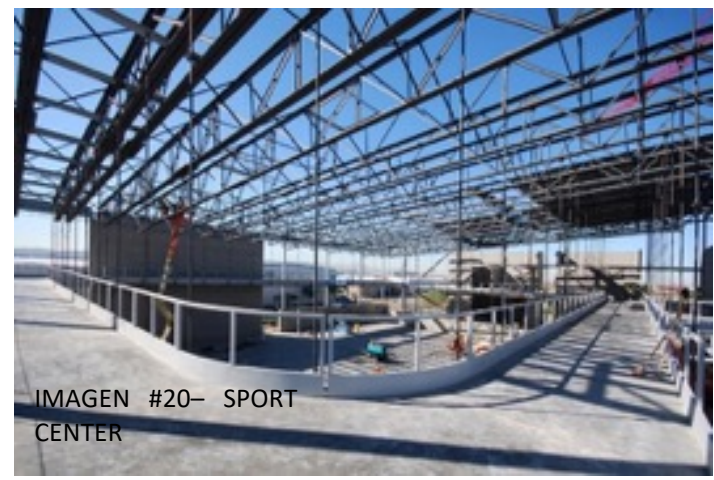

TIJERALES DE ACERO Y RAMPA DE

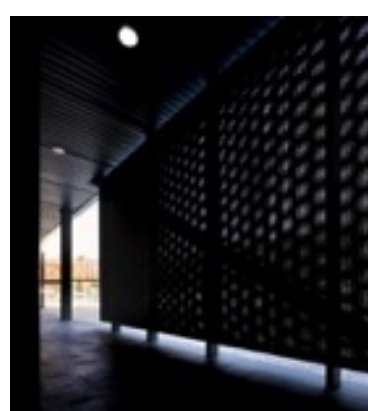

IMAGEN \#21- SPORT CENTER

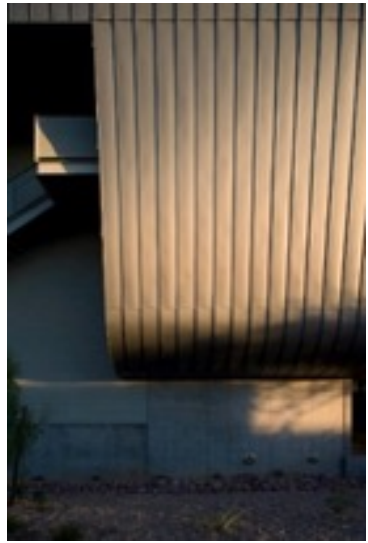

IMAGEN \#19- SPORT CENTER

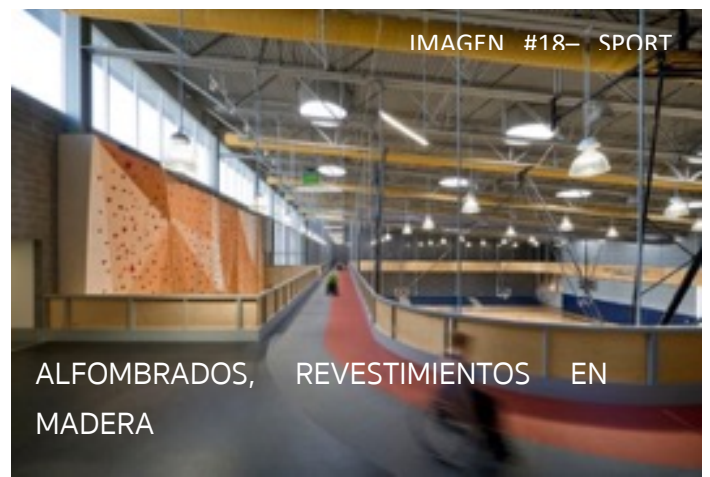

MUROS DE BLOCKS DE CONCRETO, REVESTIMIENTOS EN MADERA PARA APORTAR CALIDEZ 


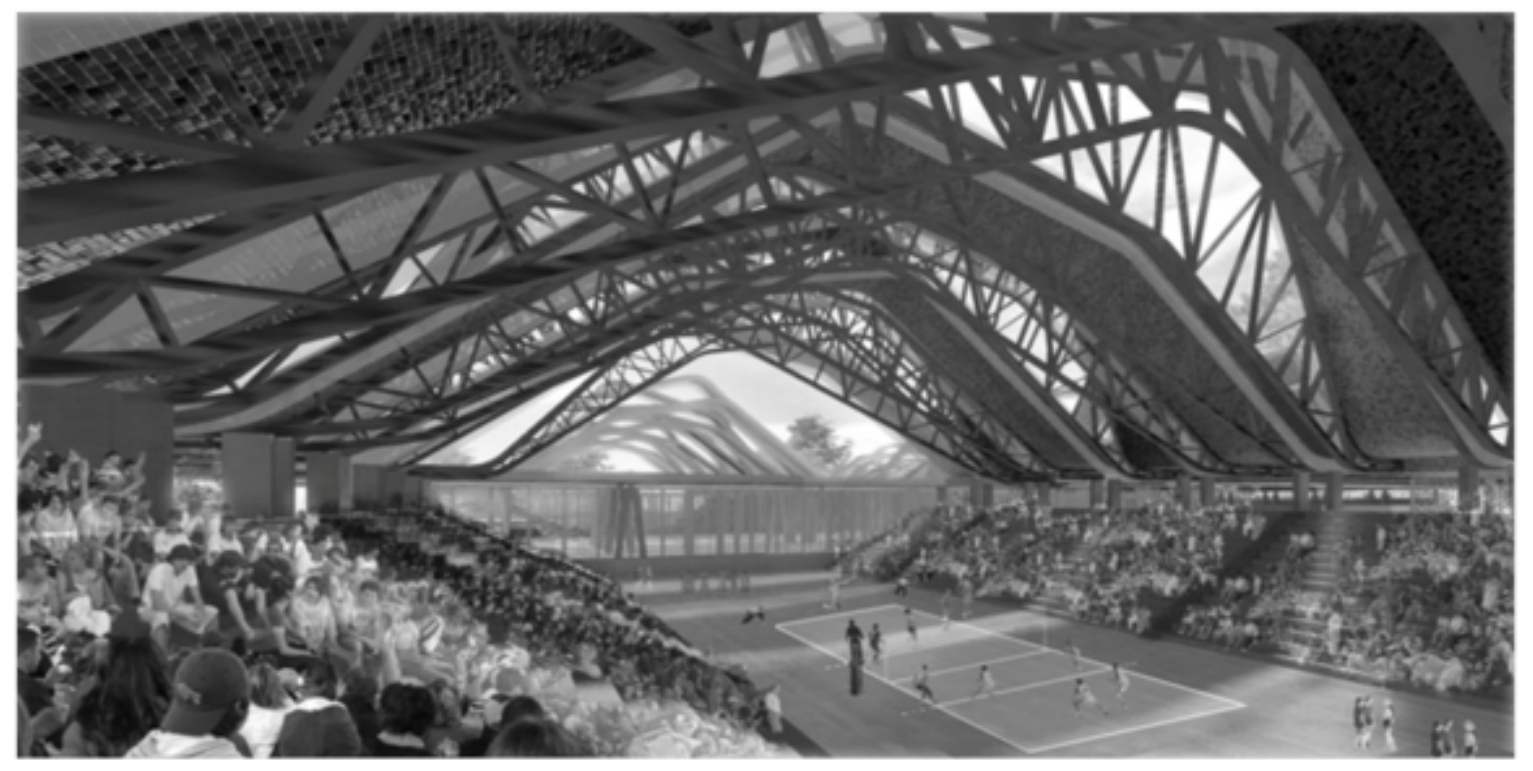

2. ESCENARIOS DEPORTIVOS - GIANCARLO MAZZANTI, PLAN B

MEDELLIN, ANTIOQUIA, COLOMBIA 


\section{ESCENARIOS DEPORTIVOS - GIANCARLO MAZZANTI + PLAN B}

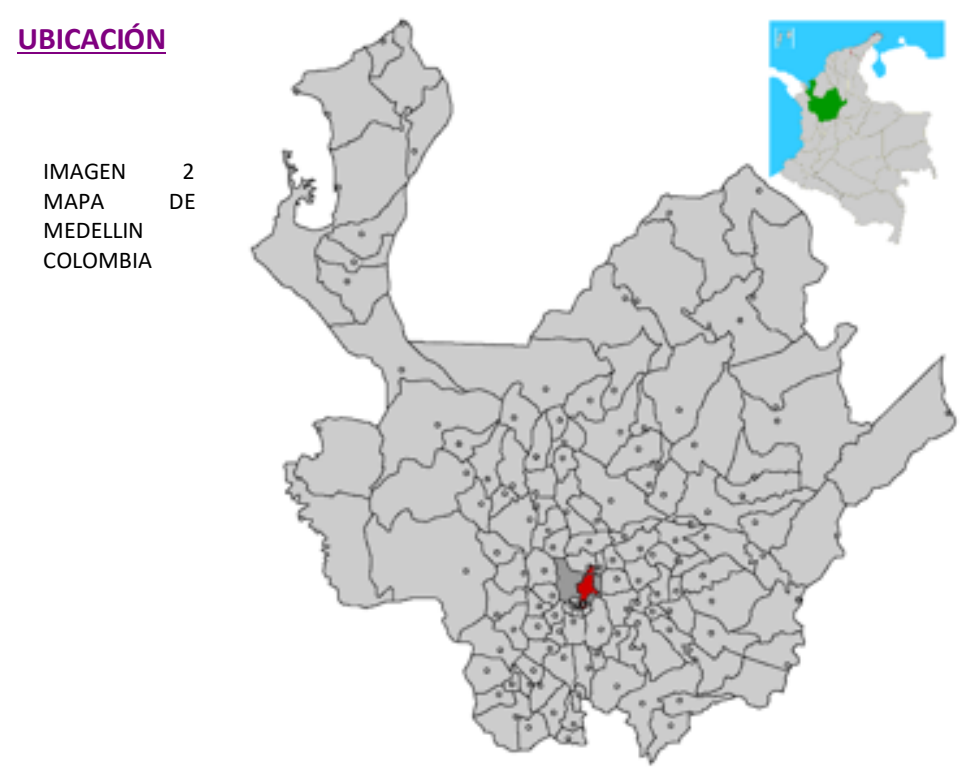

1. INFORMACIÓN GENERAL DEL PROYECTO:

Nombre:

ESCENARIOS DEPORTIVOS

Autor:

GIANCARLO MAZZANTI, PLAN B

Año de inauguración: 2009

Dirección:

Medellín, Antioquía, Colombia

Tipología:

Polideportivo

Área de proyecto: $30694 \mathrm{~m} 2$

Área libre: $7800 \mathrm{~m} 2$

Área total: $38,494 \mathrm{~m} 2$

Datos relevantes: Propuesta ganadora de un concurso público internacional para albergar los IX Juegos Sudamericanos 2010 en Medellín, Colombia.

Arquitectos Colaboradores Concurso: Andrés Sarmiento, Jairo Ovalle, Luz Rocío Lamprea, Fredy Pantoja, Carlos Bueno, Ana Prado, Carlos Acero, Jaime Borbón

Arquitectos Desarrolladores Proyecto: Luz Rocío Lamprea, Alberto Aranda, Carlos Bueno, Susana Somoza, Luisa Restrepo, María Alejandra Pérez, Esteban Monsalve, Andrés Cardona

Diseño de Iluminación: ISOLUX 
Constructor: Coninsa-Ramón H.

Practicantes: Julio Gallego, Yerickson Rodríguez, Andrea Retat, Verónica Betancur, Julio Moreno, Luisa Amaya, Sebastián Serna, Andrés Prado, María Camila Giraldo, Lucia Largo

Estudios de Topografía: Libardo Larrota - TOPOGRAFÍA Y AMBIENTES GRÁFICOS

Cliente: INDER

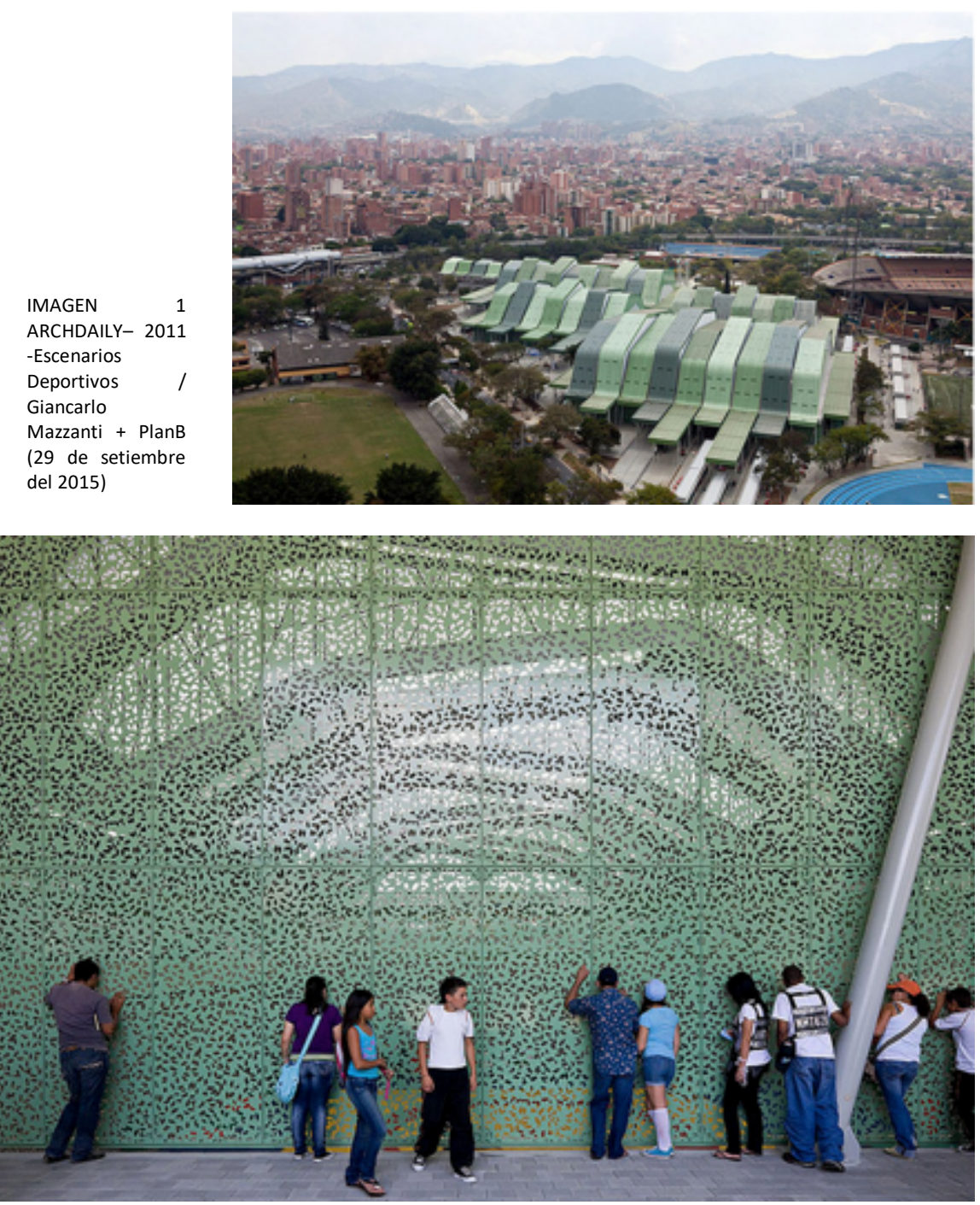

IMAGEN 3 - ARCHDAILY (2011) 


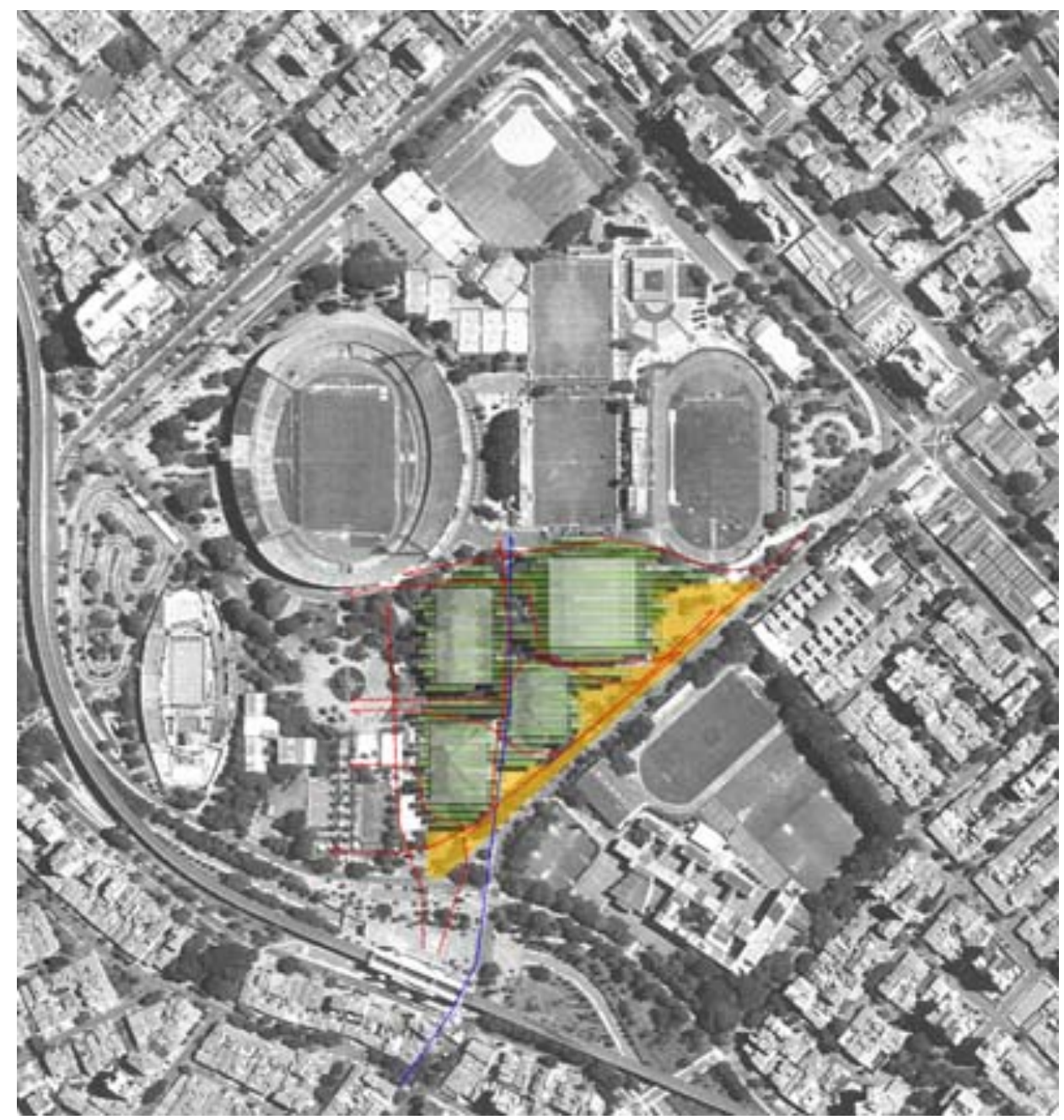

IMAGEN 4 - ARCHDAILY (2011)

Nuestro proyecto ha sido planteado como una nueva configuración geográfica al interior del alargado Valle de Aburrá, a medio camino entre el Cerro Nutibara y el Cerro El Volador. Es una topografía arquitectónica con cualidades específicas paisajísticas y espaciales: desde la lejanía o desde lo alto posee una imagen geográfica abstracta y festiva; a nivel urbano o desde su interior, el movimiento de la estructura de cubierta genera el acceso de una luz tenue y filtrada, adecuada para la realización de eventos deportivos.

El proyecto se suma al sentido urbano existente, con la ubicación de los tres nuevos escenarios deportivos en la misma posición que el coliseo Iván de Bedout, permitiendo las siguientes ventajas:

A. Continuidad e introducción visual y peatonal de la Carrera 70 al interior de la unidad deportiva Atanasio Girardot. (La pequeña desviación que sufre esta importante vía al llegar a la unidad deportiva, es continuada y enfatizada en el proyecto). 
B. La creación de cuatro nuevas plazas triangulares y conectadas, que enriquecen el espacio urbano del paseo de la Carrera 70, y que además permiten el intercambio social y deportivo.

C. Libre circulación peatonal alrededor de todos los edificios, cruces y paseos urbanos peatonales diversos.

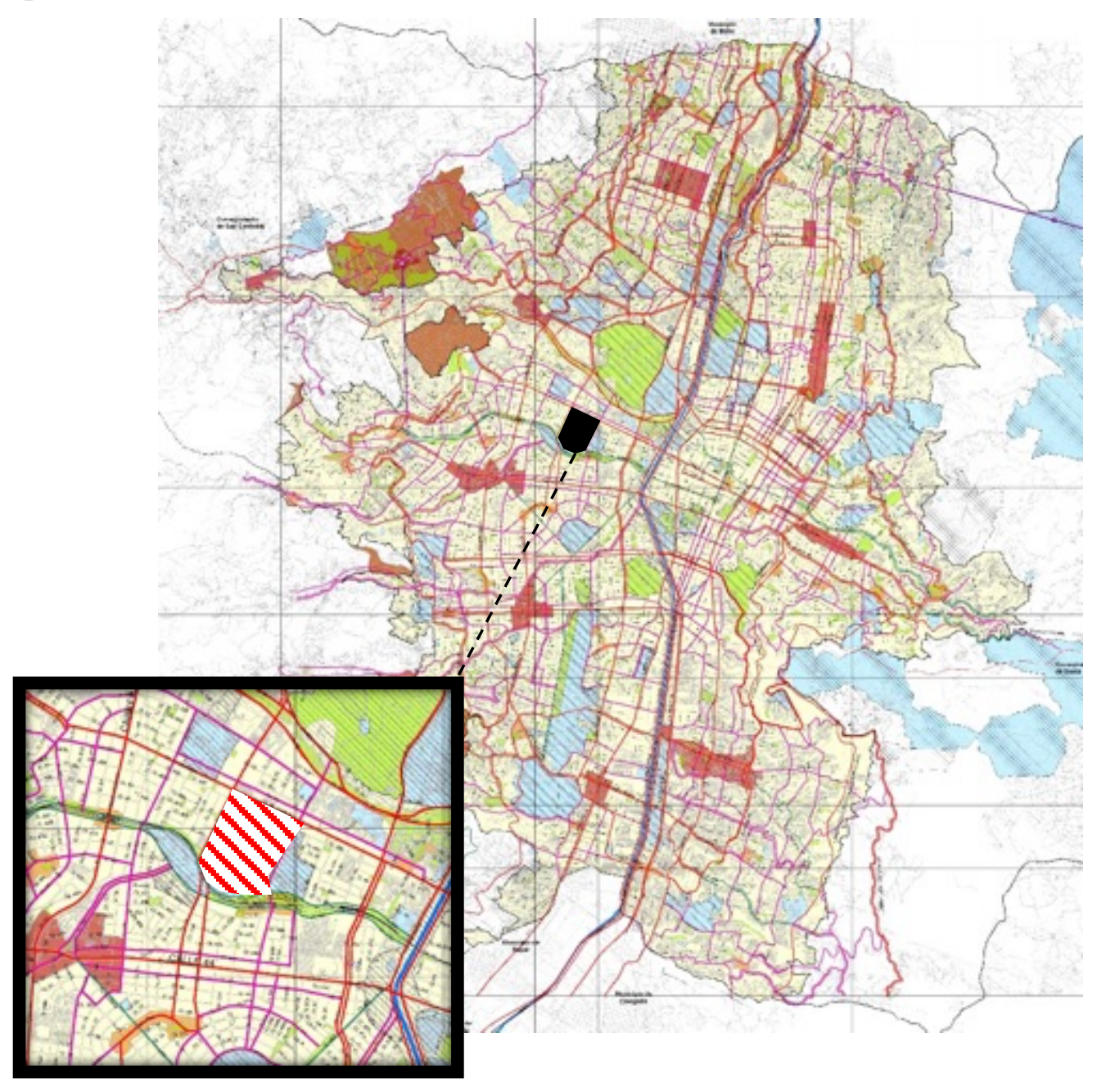



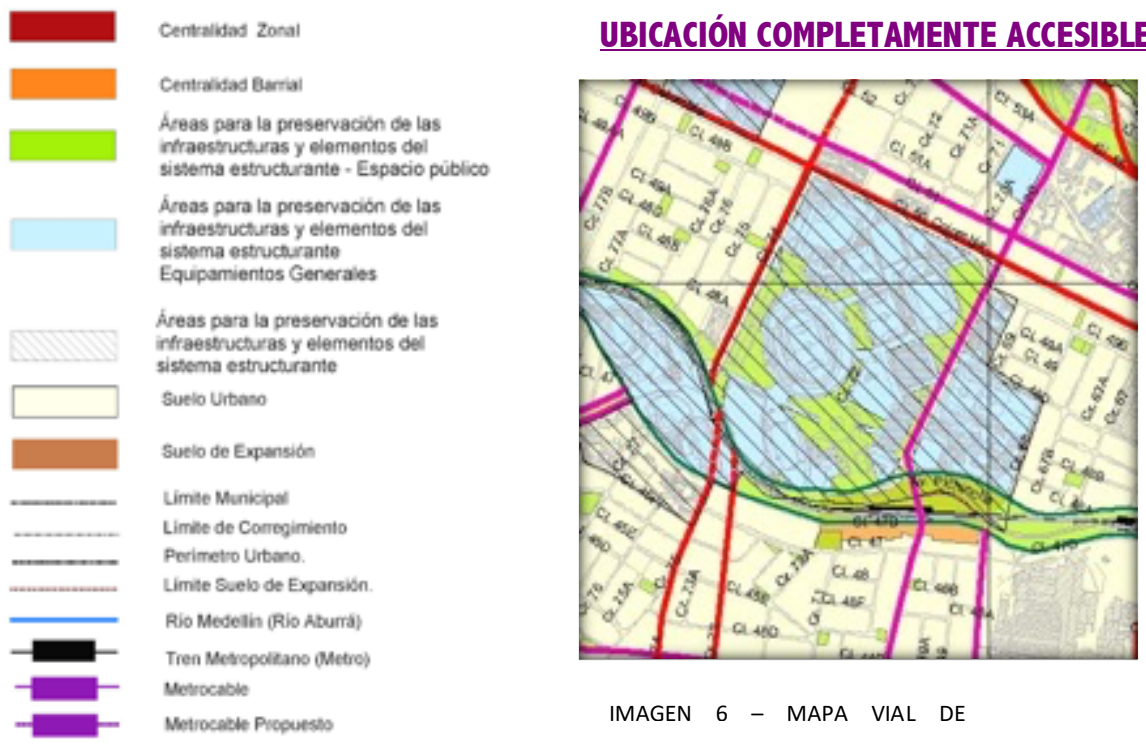

IMAGEN 6 - MAPA VIAL DE

Se encuentra en un área de preservación de elementos del sistema estructurante - espacio público y de equipamientos generales. Se encuentra cerca de la columna vertebral de Medellín el río Aburrá.

Es accesible porque se encuentra cerca de la estación del metro y tiene paradas de bus circundantes.

Parada de bus

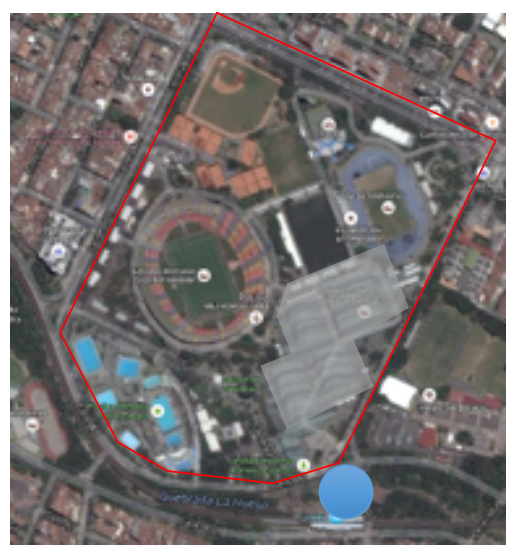

IMAGEN 7 - PLANO MAPS - ZONA DE CONJUNTO DEPORTIVO 


\section{RELACIÓN CON EL CONTEXTO}
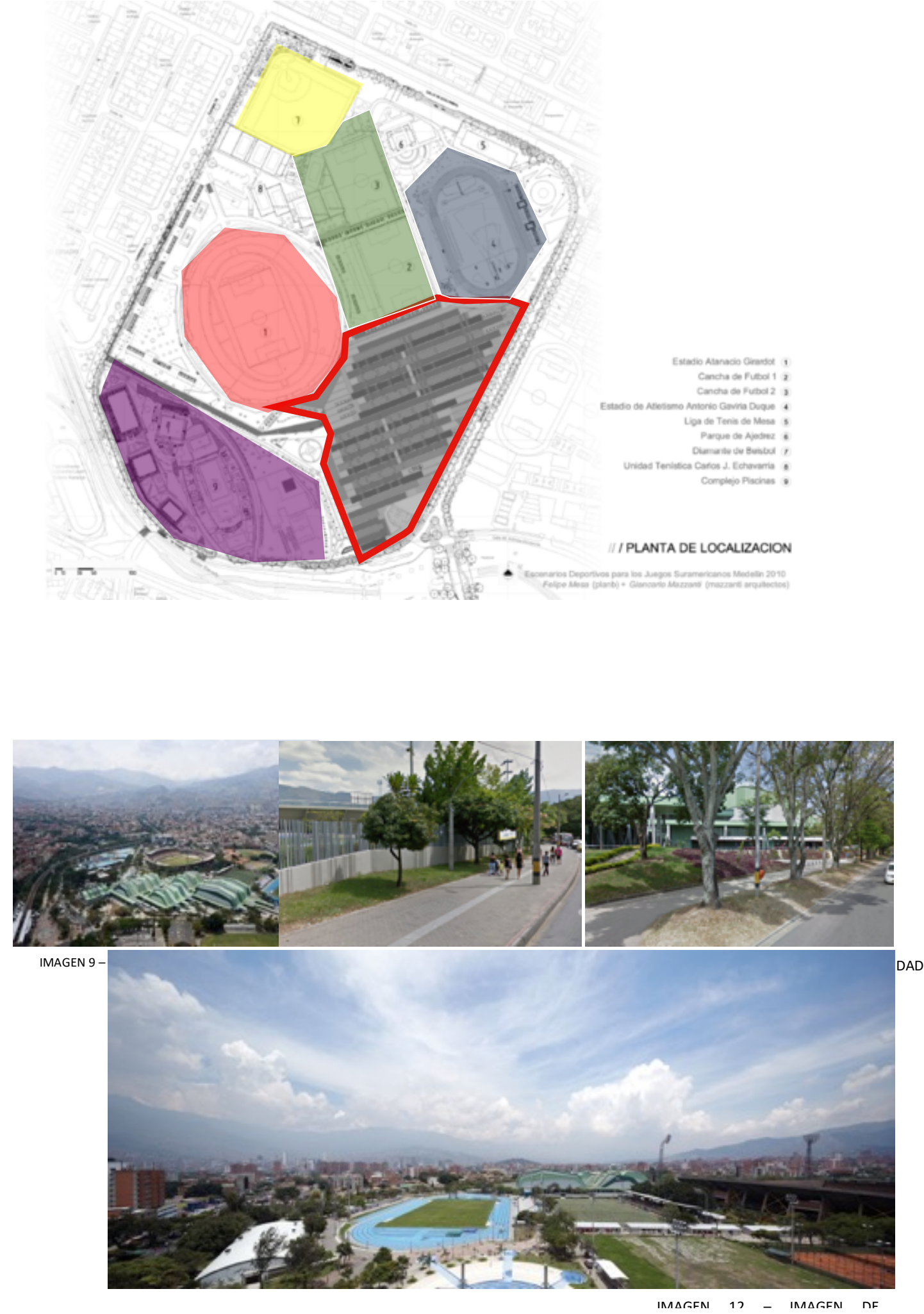
- La unidad Deportiva Atanasio Girardot, inscrita en un amplio perímetro de ciudad, sugiere una ley de posicionamiento de lo edificado: el sentido Norte - Sur (Con una leve inclinación al occidente), determinada por el mejor posicionamiento de las canchas deportivas descubiertas.

- El proyecto se encuentra al lado del estadio Giradot, 2 canchas de fútbol, el estadio de atletismo, Parque de Ajedrez, canchas de básquet, unidad técnica, y el complejo de piscinas. Frente al conjunto de polideportivos se encuentra el colegio San Ignacio, el parque de las banderas, el río quebrada de hueso y la pista de atletismo.

- El proyecto se posiciona en una zona de alturas variadas, el complejo quiere ser una topografía intermedia entre los dos cerros en los que se ubica.

- La relación de el edificio con la calle es permeable, las veredas son anchas, el muro perimetral deja ver que sucede dentro y tiene vegetación para darle escala al peatón $\}$

Sombra

Proponemos un espacio público definido por una amplia sombra generada por la prolongación de las franjas de cubierta como extensiones apergolladas.

Agrupamientos

Nuestro proyecto presenta tres posibles agrupamientos:

A. Cada uno de los cuatro coliseos puede entenderse como un edificio independiente, relacionado urbanamente con los demás.

B. Los tres nuevos coliseos pueden entenderse como un único gran edificio, independientes del coliseo Iván de Bedout.

C. Los cuatro coliseos pueden entenderse como un gran lugar que configura tanto las edificaciones como el espacio público.

Flexibilidad y transparencia

Nuestro proyecto plantea la posibilidad de que los nuevos edificios funcionen como unidades independientes durante los juegos, pero también la posibilidad de que en otros momentos puedan abrirse en sus caras norte y sur, de manera que puedan comportarse como un gran parque público cubierto y deportivo, con transparencias visuales $\mathrm{y}$ continuidades espaciales. En éste último caso, los programas que se encuentran bajo las tribunas, se controlarían de manera independiente. 
Construcciones de baja escala

En cada nuevo escenario deportivo los programas y zonas de competencia se hunden levemente con respecto al nivel urbano, y las cubiertas se elevan para obtener la altura adecuada de competencias, sin necesitar construir edificios de gran escala o impacto urbano.

\section{RELACIÓN ESPACIAL}

El espacio público exterior y los coliseos se plantean en una relación espacial continua, gracias a una gran cubierta construida a través de unas extensas franjas de relieve, perpendiculares al sentido principal del posicionamiento de los edificios. Los cuatro coliseos funcionan de manera independiente, pero desde el punto de vista urbano y espacial se comportan como un gran continente edificado con espacios públicos abiertos, espacios públicos semi-cubiertos, e interiores deportivos.

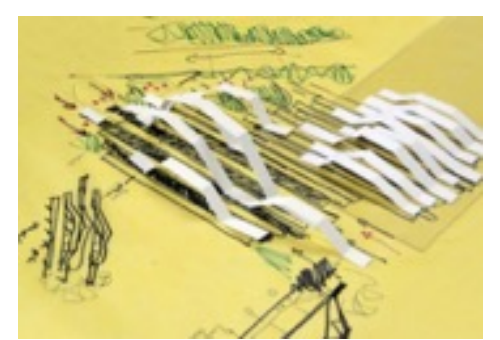

IMAGEN 13 - CONCEPTO 1

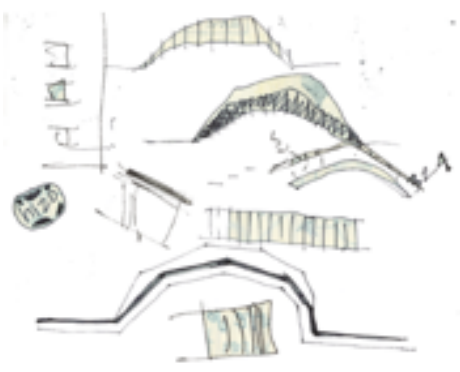

IMAGEN 15 - CONCEPTO 3

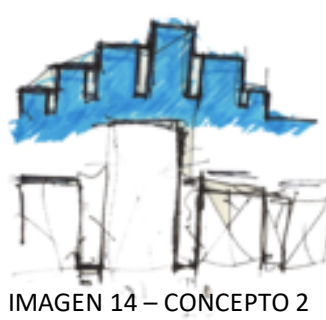

IMAGEN 14 - CONCEPTO 2

\section{MEDIO AMBIENTE}

ASOLAMIENTO

CLIMA
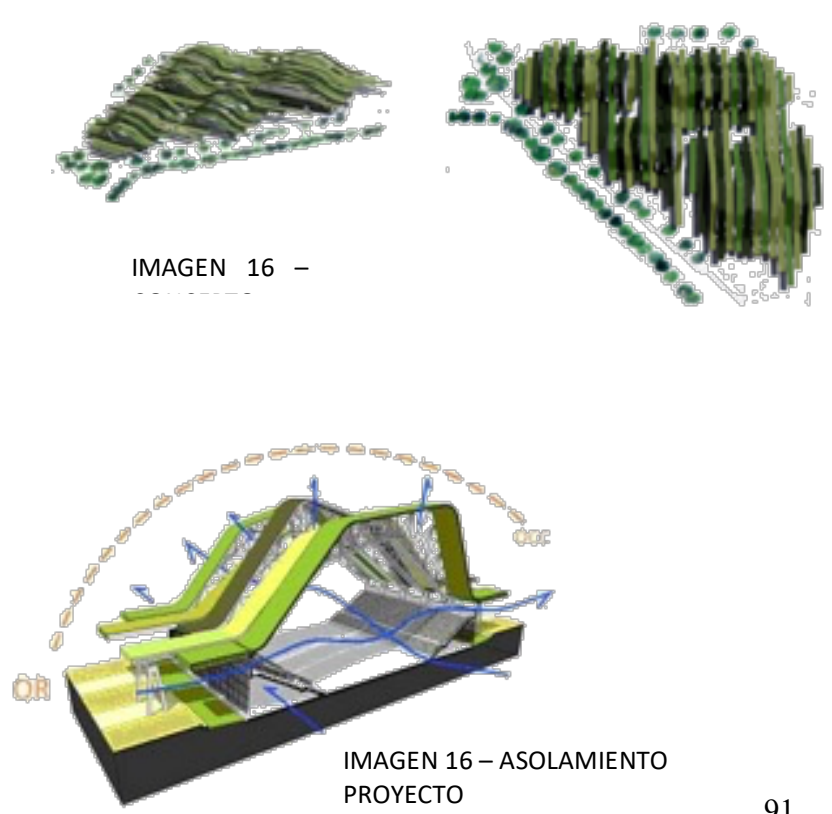


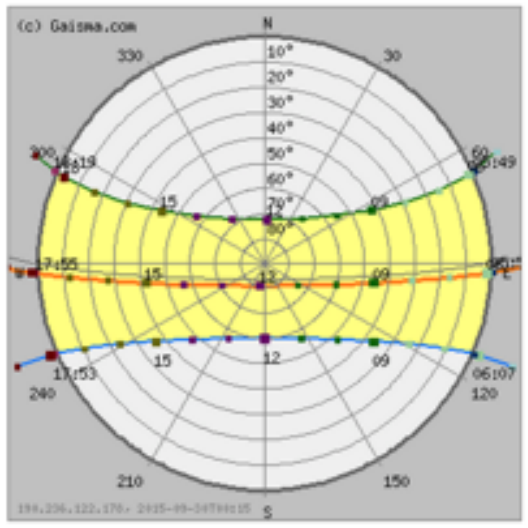

\begin{tabular}{|l|r|c|c|c|c|c|c|c|c|c|c|c|}
\hline \multicolumn{1}{|c|}{ Variable } & \multicolumn{1}{c|}{ I } & \multicolumn{1}{c|}{ II } & III & IV & V & VI & VII & VIII & IX & X & XI & XII \\
\hline Insolation, $\mathbf{~ k W h / m} / \mathbf{d a y}$ & 4.12 & 4.26 & 4.33 & 3.99 & 4.11 & 4.33 & 4.70 & 4.65 & 4.31 & 4.04 & 3.90 & 3.84 \\
\hline Clearness, $\mathbf{0 - 1}$ & 0.44 & 0.43 & 0.42 & 0.38 & 0.41 & 0.44 & 0.47 & 0.46 & 0.42 & 0.41 & 0.41 & 0.42 \\
\hline Temperature, ${ }^{\circ} \mathbf{C}$ & 21.37 & 22.09 & 21.92 & 21.89 & 21.87 & 21.85 & 21.89 & 22.12 & 21.48 & 20.92 & 20.77 & 21.09 \\
\hline Wind speed, m/s & 2.13 & 2.05 & 1.91 & 1.72 & 1.75 & 1.97 & 2.02 & 1.87 & 1.86 & 1.84 & 1.85 & 2.08 \\
\hline Precipitation, mm & 97 & 106 & 165 & 280 & 323 & 234 & 200 & 254 & 290 & 323 & 239 & 137 \\
\hline Wet days, d & 10.1 & 11.6 & 13.9 & 18.9 & 21.7 & 16.3 & 14.0 & 17.0 & 19.7 & 23.2 & 19.1 & 13.0 \\
\hline
\end{tabular}

These data were obtained from the NASA Langley Research Center Atmospberic Science Data Center; New et al. 2002

La unidad Deportiva Atanasio Girardot, inscrita en un amplio perímetro de ciudad, sugiere una ley de posicionamiento de lo edificado: el sentido Norte - Sur (Con una leve inclinación al occidente), determinada por el mejor posicionamiento de las canchas deportivas descubiertas.

El clima es de fríos fuertes y de veranos intensos. Llueve con frecuencia y cuenta con temperaturas muy altas en Julio. En diciembre registra las temperaturas más bajas. El clima en general es árido.

\section{ASPECTOS FUNCIONALES}

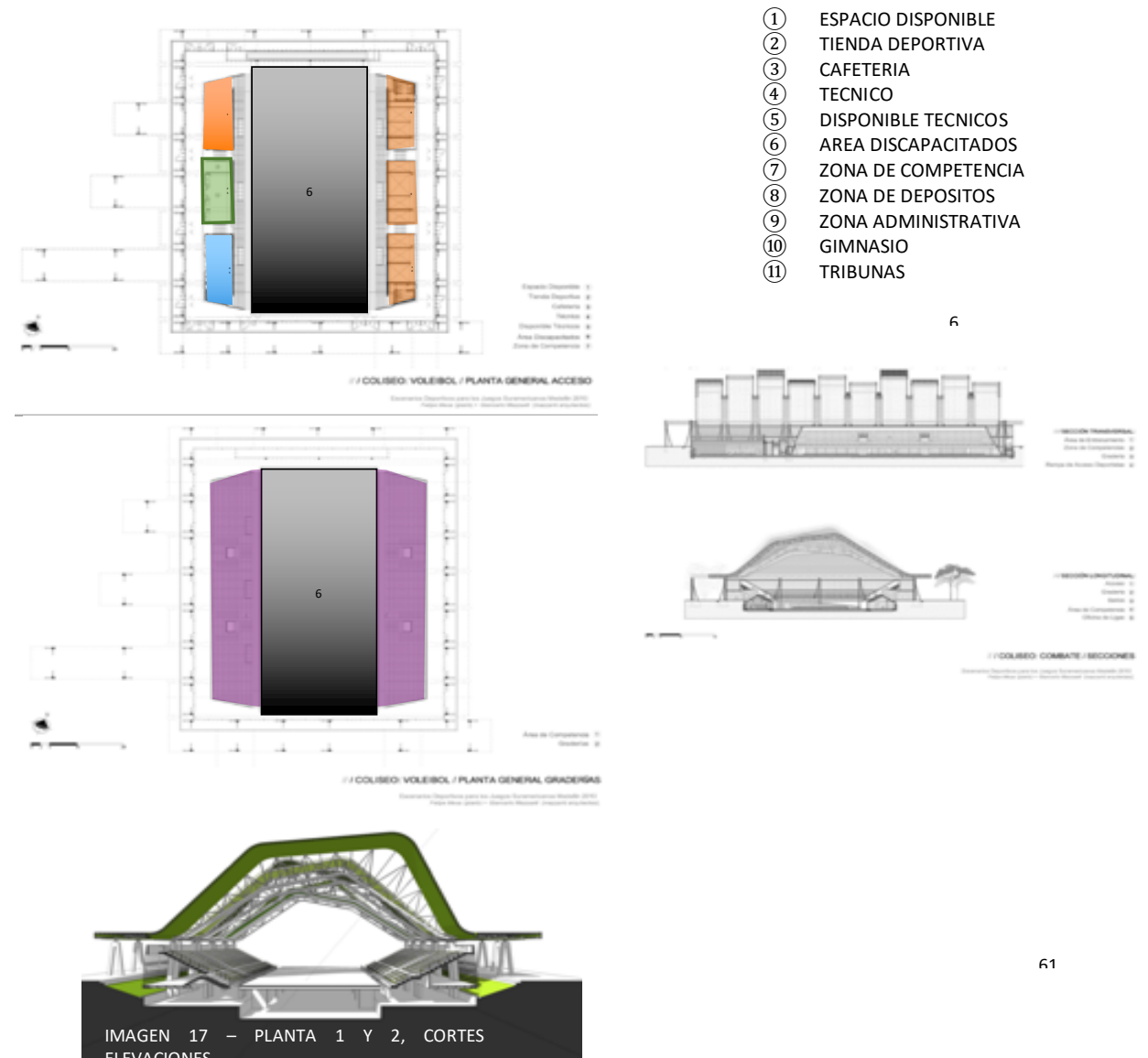


Existen 4 ingresos a las tribunas, el espacio bajo estas se utiliza para el resto de los paquetes funcionales, las canchas están iluminadas por la forma del techo por donde también ventila.

\section{PROGRAMACION (30,694 AREA TOTAL)}

\begin{tabular}{|c|c|c|}
\hline BALONCESTO & ESPACIOS & AREA $9240 M 2$ \\
\hline ZONA DE CANCHAS & CANCHAS & $4700 \mathrm{M} 2$ \\
\hline ZONA ADMINISTRATIVA & OFICINAS, BANNOS & $790 \mathrm{Ma}$ \\
\hline ZONA SERVICIO & DEPOSITOS, OFICINAS & $730 \mathrm{M} 2$ \\
\hline ZONA BANNOS Y VESTUARIOS & ZONA HUMEDA, SECA, VESTUARIOS & $1820 \mathrm{M} 2$ \\
\hline TRIBUNAS & TRIBUNAS, AREA DISCAPACTIADOS & $1200 \mathrm{M} 2$ \\
\hline COMBATE & ESPACIOS & AREA $7500 \mathrm{M} 2$ \\
\hline ZONA DE CANCHAS & CANCHAS & $3900 \mathrm{M} 2$ \\
\hline ZONA ADMINISTRATIVA & OFICINAS, BANNOS & $670 \mathrm{M} 2$ \\
\hline ZONA SERVICIO & DEPOSITOS, OFICINAS & $830 \mathrm{M} 2$ \\
\hline ZONA BANOSS Y VESTUARIOS & ZONA HUMEDA, SECA, VESTUARIOS & $1200 \mathrm{M} 2$ \\
\hline TRIBUNAS & TRIBUNAS, AREA DISCAPACTTADOS & $900 \mathrm{M} 2$ \\
\hline GIMNASIA & ESPACIOS & AREA $6860 \mathrm{M} 2$ \\
\hline ZONA DE CANCHAS & CANCHAS & $2960 \mathrm{M} 2$ \\
\hline ZONA ADMINISTRATIVA & OFICINAS, BANOOS & moм2 \\
\hline ZONA SERVICIO & DEPOSITOS, OFICINAS & $830 \mathrm{M} 2$ \\
\hline ZONA BANOOS Y VESTUARIOS & ZONA HUMEDA, SECA, VESTUARIOS & $1400 \mathrm{M} 2$ \\
\hline TRIBUNAS & TRIBUNAS, AREA DISCAPACTTADOS & $900 \mathrm{M} 2$ \\
\hline COMBATE & ESPACIOS & AREA $7494 \mathrm{M} 2$ \\
\hline ZONA DE CANCHAS & CANCHAS & $3900 \mathrm{M} 2$ \\
\hline ZONA ADMINISTRATIVA & OFICINAS, BANOOS & $670 \mathrm{ML}$ \\
\hline ZONA SERVICIO & DEPOSITOS, OFICINAS & $830 \mathrm{M} 2$ \\
\hline ZONA BANOSS Y VESTUARIOS & ZONA HUMEDA, SECA, VESTUARIOS & $1200 \mathrm{M} 2$ \\
\hline TRIBUNAS & TRIBUNAS, AREA DISCAPACTTADOS & $896 \mathrm{MZ}$ \\
\hline
\end{tabular}

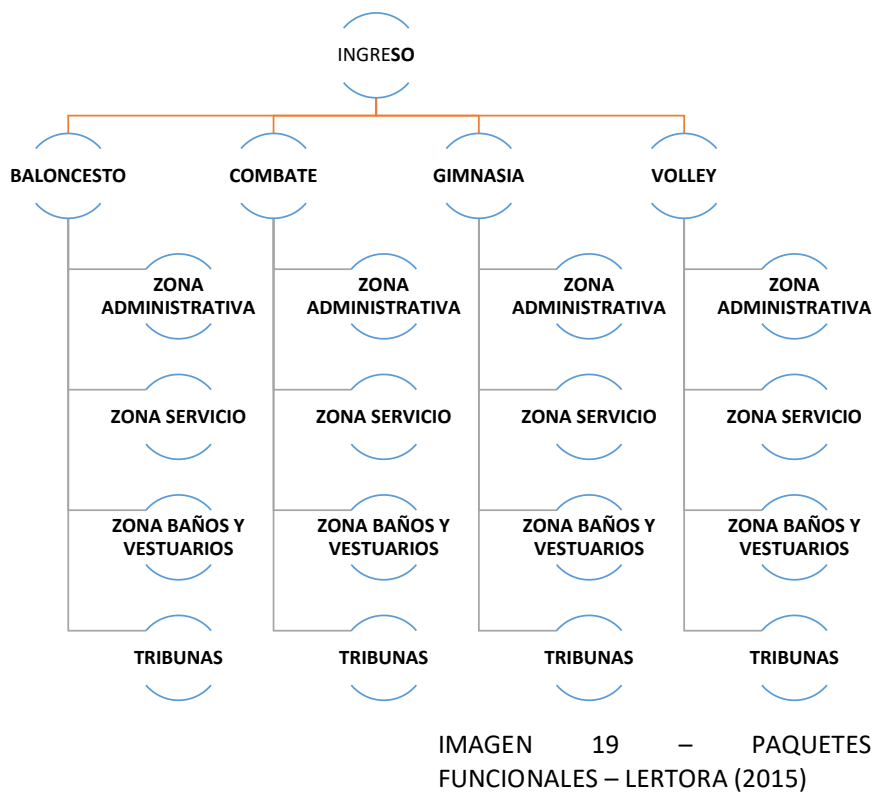




\section{ASPECTOS TECNOLOGICOS}

La forma de los edificios viene definida por la estructura misma, y para esto se opta por una estructura modular en acero que permite optimizar el proceso de fabricación y montaje.

La estructura de cubierta se plantea en cerchas metálicas en celosía (las más baratas del mercado) que se arman cada cinco metros. Estas vigas cajón, a manera de pórticos paralelos permiten vencer las luces de las canchas sin ninguna dificultad, y se apoyan en una serie de columnas dobles en concreto reforzado, localizadas en los extremos de las graderías y en las zonas exteriores. Lo anterior permite construir de manera independiente cada una de las vigas cajón, optimizando tiempos en la fabricación y el montaje. Entre viga y viga se proponen unas canoas que recogen el agua y dilatan las cubiertas permitiendo la entrada de luz filtrada a través de cerramientos laterales en policarbonato opalizado. Las vigas cajón vienen armadas de planta en módulos de 12 metros y se ensamblan en obra a través de grúas de obra simple: este sistema es el más sencillo y eficiente en el país para el montaje de elementos prefabricados en acero. Los elementos metálicos deben venir galvanizados de planta y sus uniones serán pernadas y atornilladas. Ya montada la estructura se deberá aplicar una pintura polimérica como segunda protección. La estructura metálica vendrá recubierta en la parte superior por un "sándwich" de superboard, tibek de Dupont, malla plástica con pega de látex (stone mix de Grossa) y como acabado final cristanac de varios tonos verdes.

La estructura de las graderías en hormigón reforzado y las graderías prefabricadas en el mismo material.

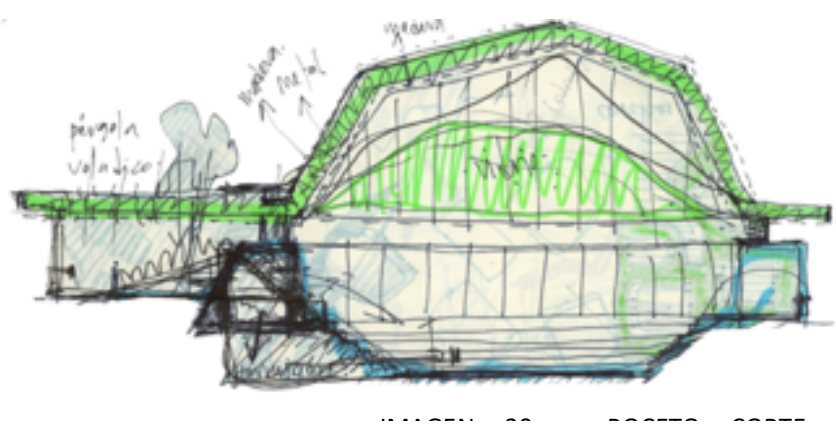

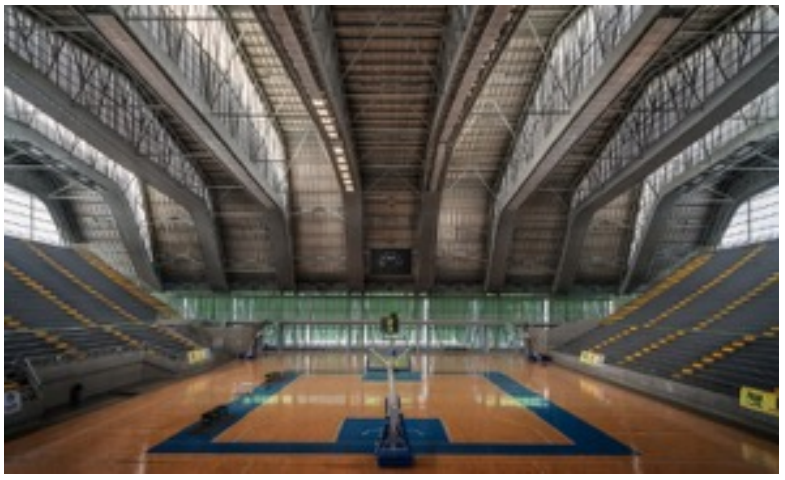

IMAGEN 21 - FOTOGRAFIA INTERIOR ESTRUCTURAS 


\section{Repetición, industrialización, modularidad y velocidad}

El proyecto plantea el encuentro de dos tipos de materiales:

\section{A. Franja 1}

Los suelos, la estructura de graderías, las graderías y columnas son en hormigón, con la opción de prefabricar las zonas de tribunas, y de trabajar con un único tipo de columna.

B. Franja 2

Las franjas de cubiertas se construyen a partir de cerchas metálicas livianas unidas de nuevo por cerchas metálicas más pequeñas, modulares, repetitivas, y fácilmente industrializables.

\section{Bioclimática}

Las franjas de cubierta planteadas se orientan paralelamente al sol, de manera que la luz solar nunca accedería al interior de los edificios de manera directa.

En sus caras norte y sur los edificios permiten el paso directo de las corrientes de aire y cada edificio posee amplias ventilaciones cruzadas.

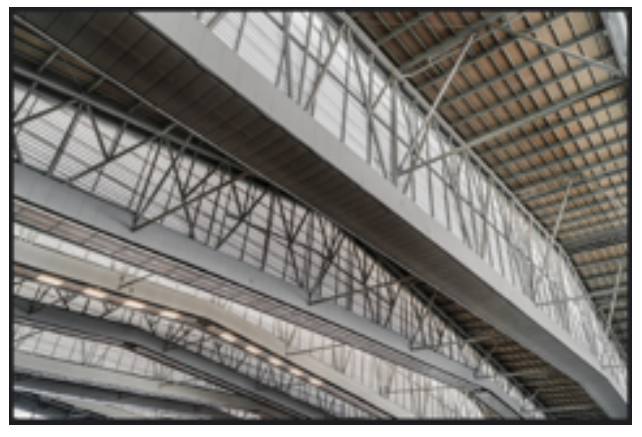

IMAGEN 22 - FOTOGRAFIA INTERIOR - ESTRUCTURAS

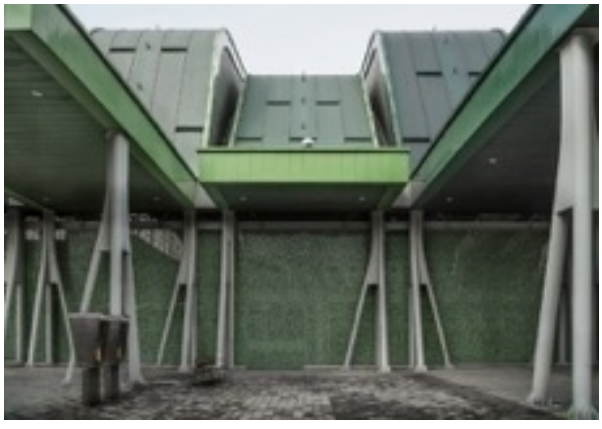

IMAGEN 23 - FOTOGRAFIA INTERIOR - ESTRUCTURAS 


\section{ARTEIXO SPORT CENTER / JOSE RAMON GARITAONAINDIA DE VERA INFORMACIÓN GENERAL DEL PROYECTO:}

\section{Nombre:}

Arteixo Sport Center

\section{Autor:}

José Ramón Garitaonaindia de Vera

Año de inauguración: 2011

\section{Dirección:}

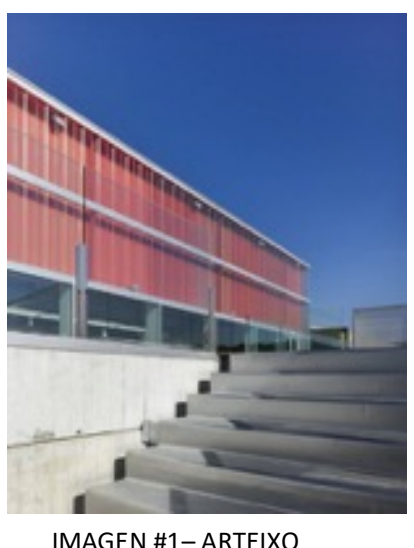

IMAGEN \#1-ARTEIXO

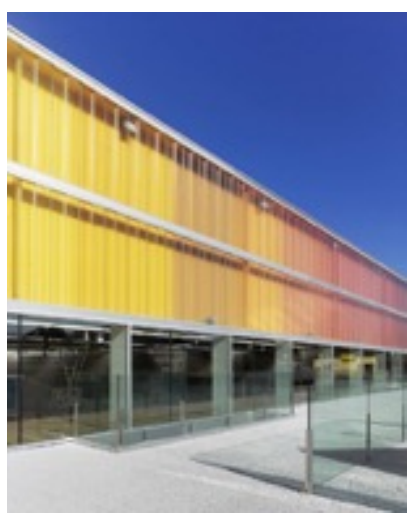

IMAGEN \#2-ARTEIXO

Avenida de Arsenio Iglesias, Arteixo,

A Coruña, España

Tipología:

Polideportivo

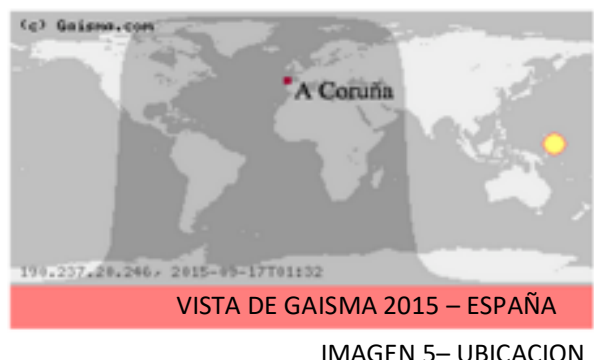

Área de proyecto: $4547 \mathrm{~m} 2$

Área libre: 1340m2

Área total: $5887 \mathrm{~m} 254$
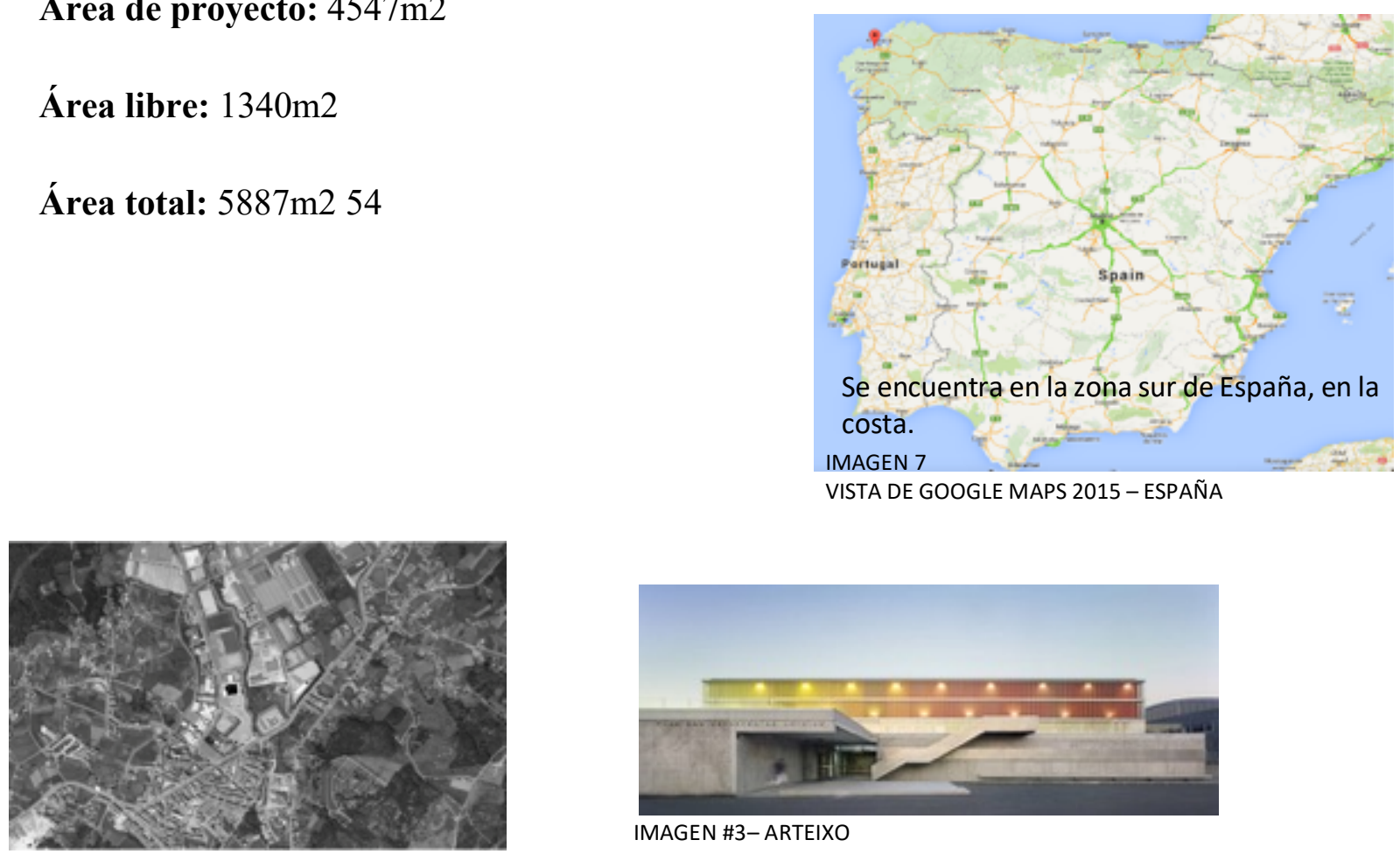

IMAGEN \#3-ARTEIXO 
"En una parcela con una forma regular y plana, con un río dentro de sus límites, se encuentra el Sport Center Arteixo. Al norte limita con la piscina municipal, al sur está delimitada con otra parcela propiedad de la misma Plan Parcial. En el oeste de la dirección se encuentra al camino conocido como " Travesía DOS colexios" y esto que proporciona acceso al centro deportivo. Finalmente, el río establece los límites al Este. 55

Una forma regular sin grandes estridencias para facilitar su funcionamiento." GARITAONAINDIA

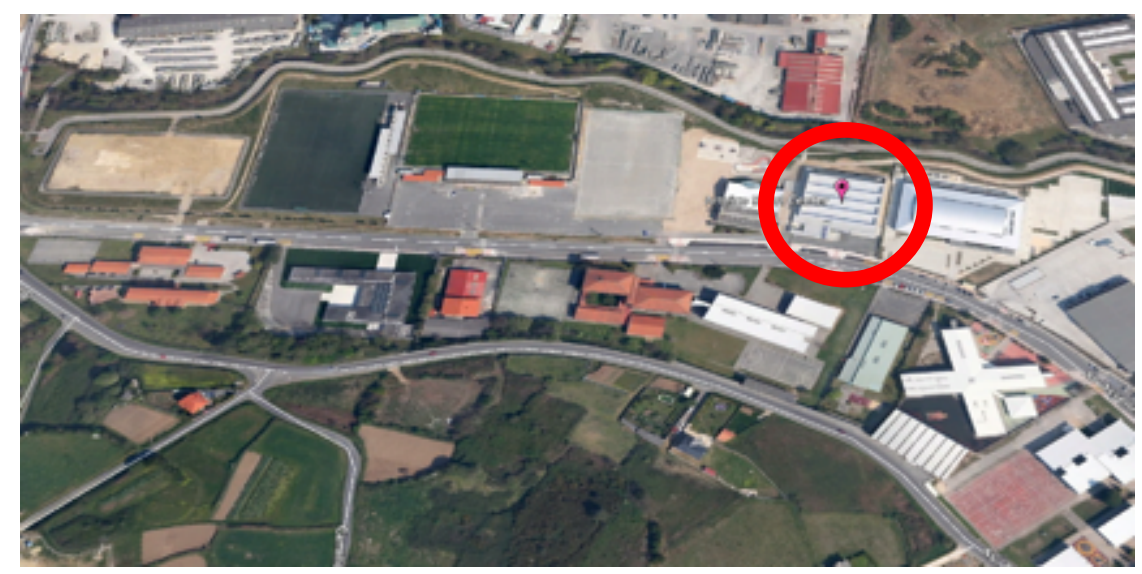

El terreno se encuentra en una zona de canchas al aire libre, zona industrial, institutos y cerca de un río.

\section{ARTEIXO SPORT CENTER / JOSE RAMON GARITAONAINDIA DE VERA}

El proyecto tiene el concepto de la conexión entre la calle y el interior esta reforzado a través de este concepto de espacio intermedio de calle que entra al edificio.

En otro orden de cosas, siguiendo el camino iniciado hace mucho tiempo, el Sport Center Arteixo surge como un arco iris, valga la metáfora para explicar el resultado final: el arcoíris que nos sorprende, que viene y nos deslumbra con su presencia y que no deja a nadie indiferente. 53

\section{RELACIÓN CON EL EXTERIOR}

El edificio enmarca vistas desde dentro del paisaje. Y se relaciona directamente con la calle ya que coloca una pasarela que invita al ingreso y a ver el desarrollo de las actividades. 55 


\section{CONCEPTUALIZACIÓN DE LA PROPUESTA:}

El proyecto tiene el concepto de la conexión entre la calle y el interior esta reforzado a través de este concepto de espacio intermedio de calle que entra al edificio.

En otro orden de cosas, siguiendo el camino iniciado hace mucho tiempo, el Sport Center Arteixo surge como un arco iris, valga la metáfora para explicar el resultado final: el arcoíris que nos sorprende, que viene y nos deslumbra con su presencia y que no deja a nadie indiferente. 53

\section{RELACIÓN CON EL EXTERIOR}

El edificio enmarca vistas desde dentro del paisaje. Y se relaciona directamente con la calle ya que coloca una pasarela que invita al ingreso y a ver el desarrollo de las actividades. 55
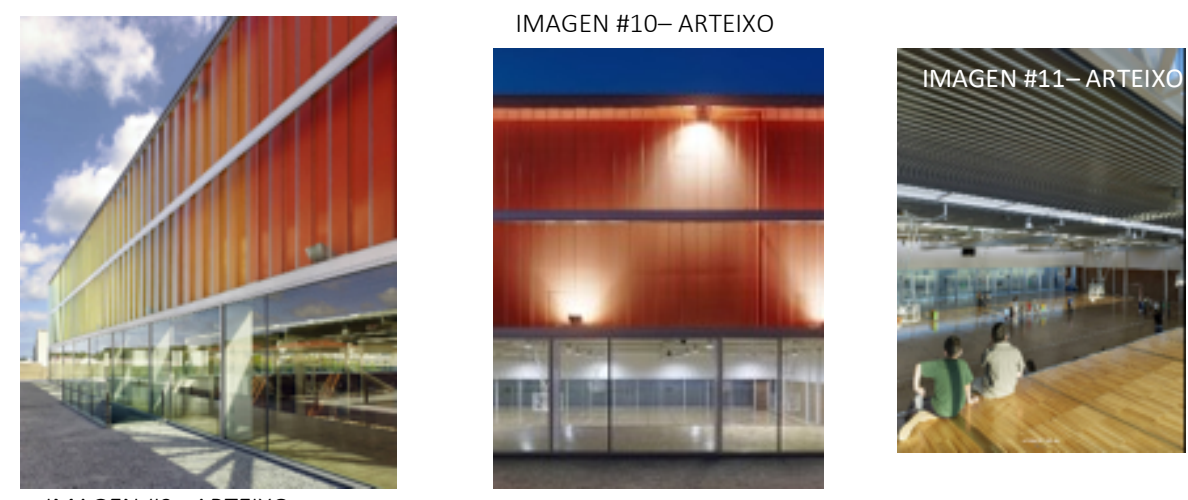

IMAGEN \#9-ARTEIXO

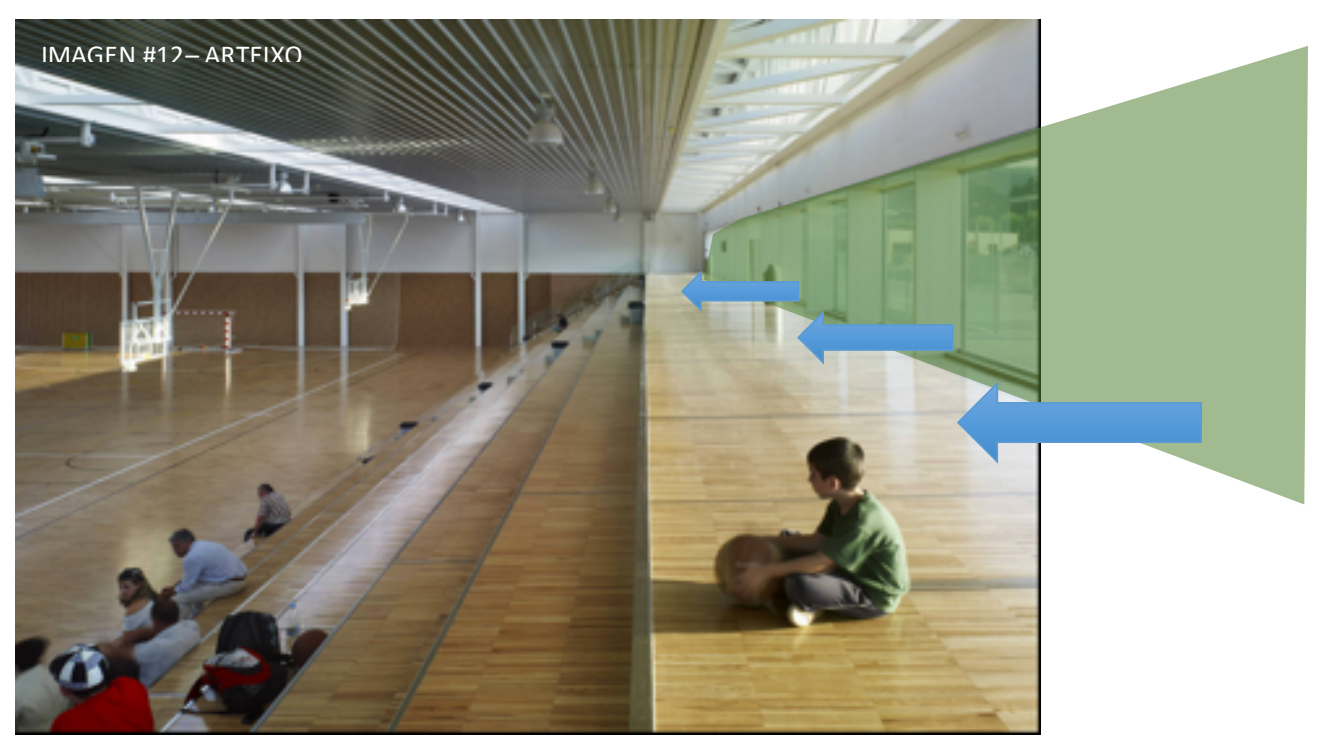

IMAGEN DE RELACION ENTRE CALLE Y ZONA DE CANCHAS 
El espacio principal se caracteriza por ser un espacio de triple altura con distintas texturas y opacidades. En el que la calle entra al edificio y se vuelve un espacio de contemplación hacia las canchas.

El espacio se caracteriza por ser cálido por los materiales y la iluminación tamizada que tiene.

El espacio es flexible para distintas disciplinas ya que tiene la posibilidad de funcionar como varias canchas o como una sola grande. 54

\section{UBICACIÓN POCO ACCESIBLE}

Se encuentra a $10 \mathrm{~km}$ de la estación de buses más cercana. Es su característica mas débil, ya que limita al usuario a llegar en carros particulares.

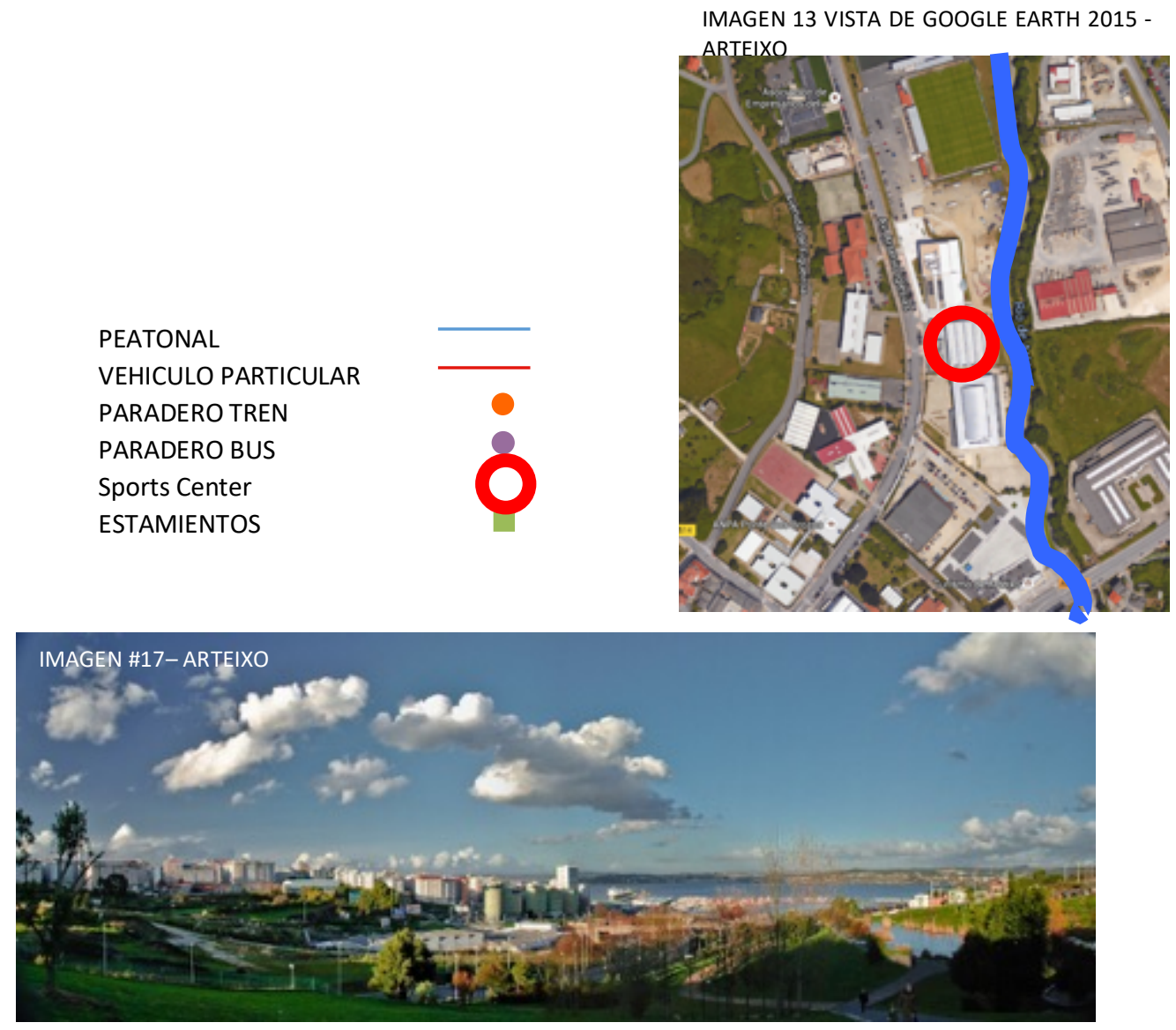

VISTA A CORUÑA ESPAÑA - PANORAMICA DE LA CIUDAD

Se encuentra en un contexto de alturas bajas y de polideportivos al aire libre.

Colinda con el Río de Arteixo. Se encuentra frente a una zona verde de 4 veces el tamaño de el terreno del polideportivo. 55 
El perfil urbano de la zona es de un máximo de 5 pisos, y un mínimo de 1. El polideportivo de 3 pisos se inserta dentro de la elevación de la zona sin tener un impacto negativo de escala.
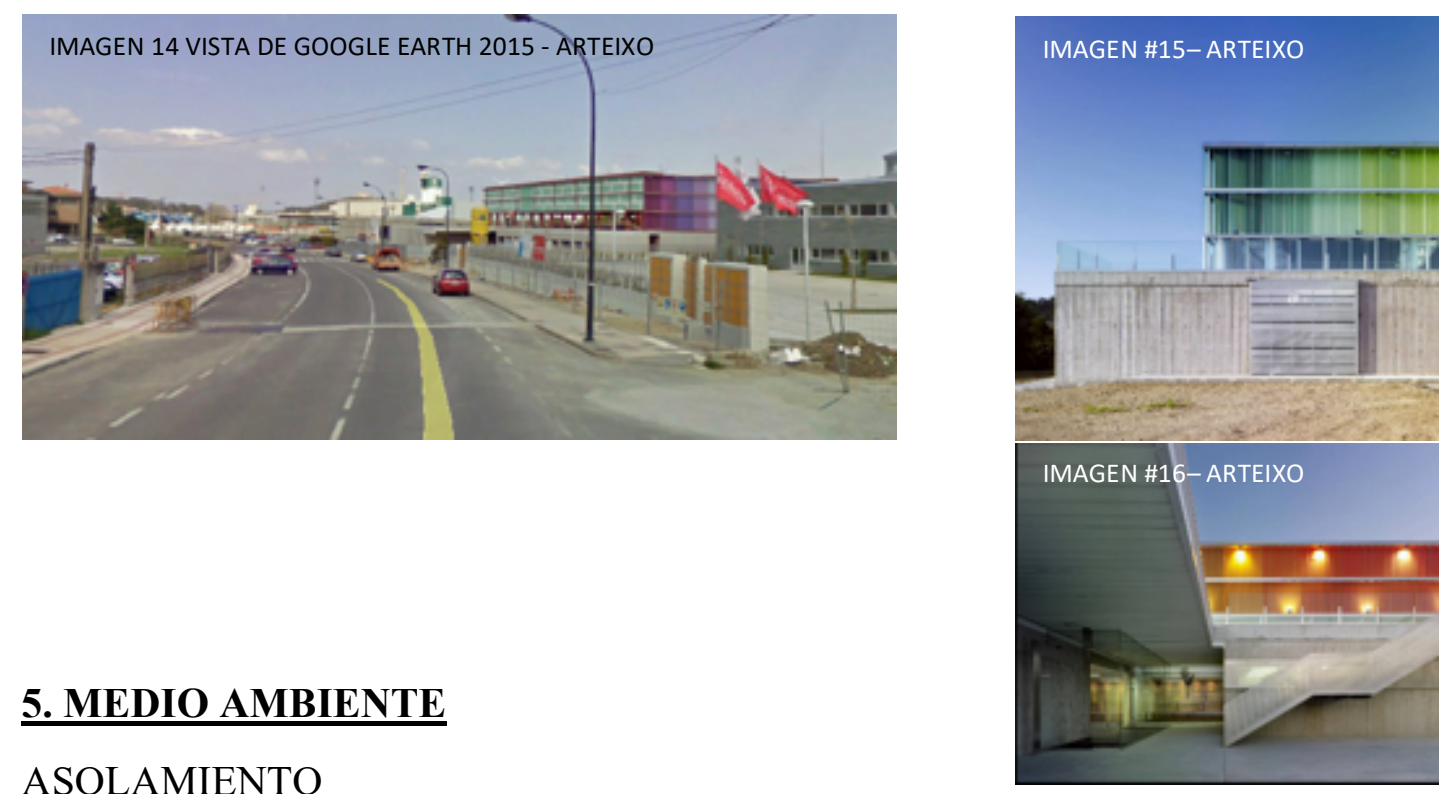

\section{ASOLAMIENTO}

El edificio esta girado en una posición del noreste al suroeste para reducir el impacto de los rayos solares. La elevación este y oeste del edificio son las más afectadas por el sol, por lo que se implemento este sistema de apersianado de vidrio colorado que tamiza la luz. 54

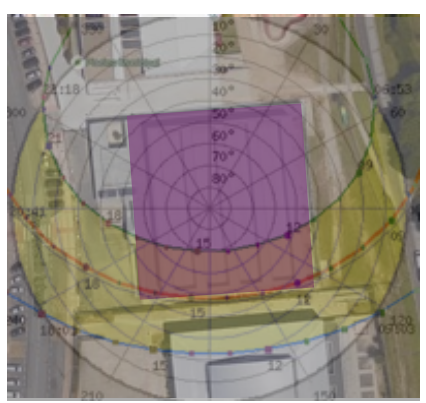

$S$

CLIMA

Los centros deportivos tienen una dimensión urbana relativamente agresiva debido a su escala. "Proponemos un área de soporte que envuelve a la pista principal para establecer la escala correcta en el medio ambiente. Además, estas instalaciones suelen ser oscuras, así que por eso, optamos por una estructura de caja, vigas en la dirección longitudinal de la pista, por lo que el norte recibe luz del Norte, ideal para juegos y la luz del Sur matizada a través de policarbonato transparente en que los cajones." GARITAONAINDIA DE VERA 53 


\begin{tabular}{|c|c|c|c|c|c|c|c|c|c|c|c|c|}
\hline Variable & I & II & III & IV & $\mathbf{v}$ & VI & VII & VIII & IX & $\mathbf{x}$ & XI & XII \\
\hline Insolation, $\mathrm{kWh} / \mathrm{m}^{2} / \mathrm{day}$ & 1.41 & 2.12 & 3.27 & 4.31 & 5.04 & 5.55 & 5.54 & 5.09 & 3.94 & 2.44 & 1.50 & 1.17 \\
\hline Clearness, 0 - 1 & 0.39 & 0.41 & 0.45 & 0.46 & 0.46 & 0.48 & 0.50 & 0.51 & 0.49 & 0.41 & 0.37 & 0.36 \\
\hline Temperature, ${ }^{\circ} \mathrm{C}$ & 8.98 & 9.14 & 10.40 & 10.98 & 13.42 & 16.40 & 18.45 & 19.02 & 17.80 & 14.98 & 12.01 & 10.17 \\
\hline Wind speed, $\mathrm{m} / \mathrm{s}$ & 8.62 & 8.43 & 7.89 & 7.65 & 6.42 & 5.78 & 6.00 & 5.54 & 6.06 & 7.28 & 7.98 & 8.27 \\
\hline Precipitation, mm & 178 & 158 & 120 & 105 & 100 & 59 & 29 & 35 & 82 & 134 & 146 & 172 \\
\hline Wet days, d & 20.8 & 19.2 & 18.3 & 17.2 & 16.1 & 11.7 & 8.4 & 9.4 & 12.6 & 17.1 & 19.7 & 20.5 \\
\hline
\end{tabular}

These data were obtained from the NASA Langley Research Center Atmospheric Science Data Center; New et al. 2002

\section{ASPECTOS FUNCIONALES}
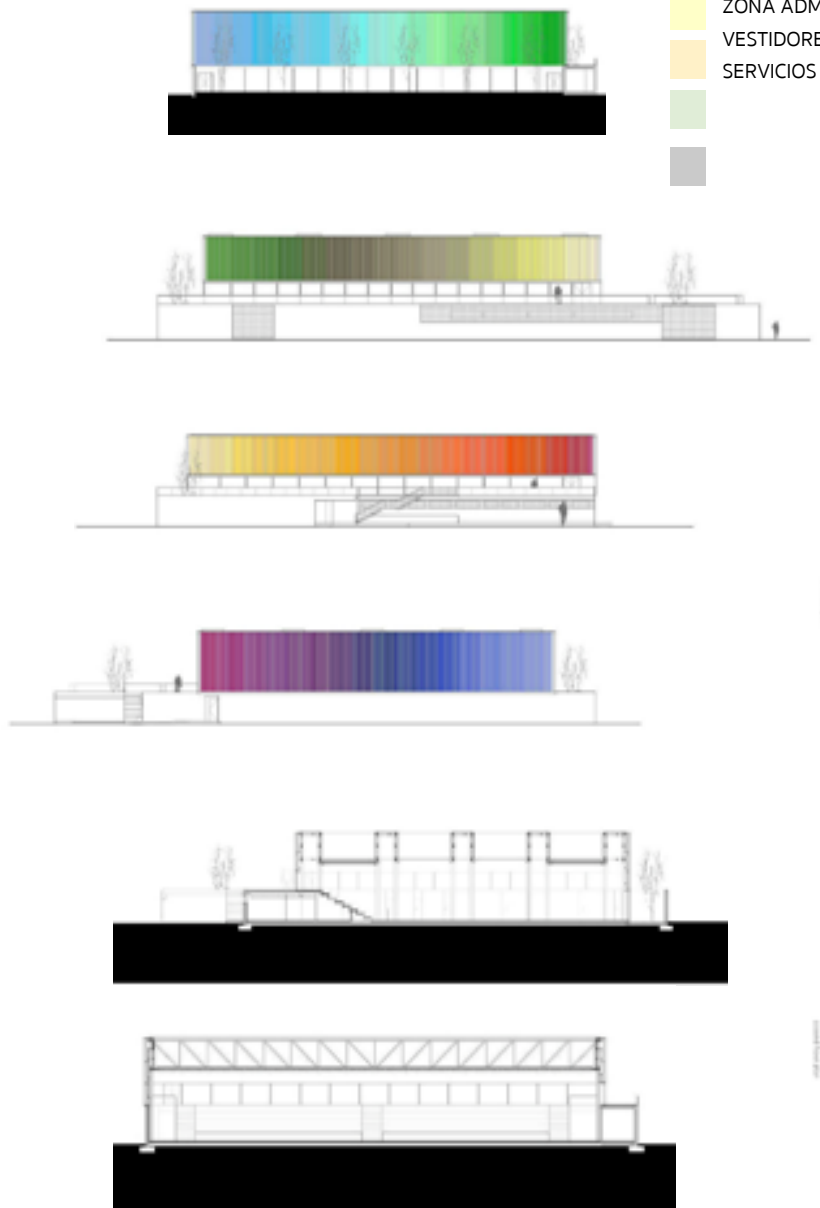

IMAGEN 18 ELEVACIONES, CORTES - ARTEIXO - ARCHDAILY
CANCHA MULTIUSOS

DEPOSITOS

TRIBUNA

ZONA ADM

VESTIDORES Y SSHH

SERVICIOS
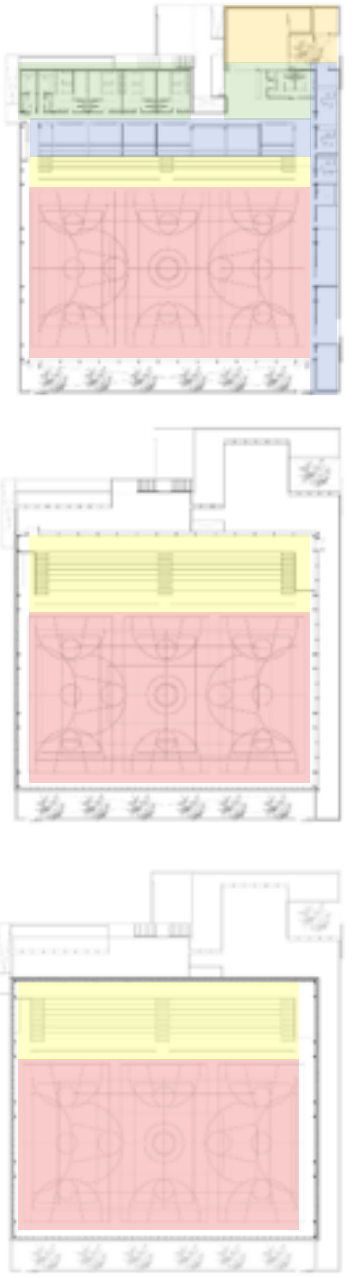

IMAGEN 19 PLANOS ARTEIXO - ARCHDAILY

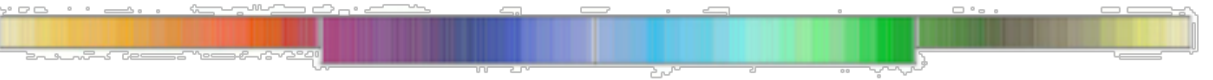




\section{ASPECTOS FUNCIONALES (PROGRAMA)}

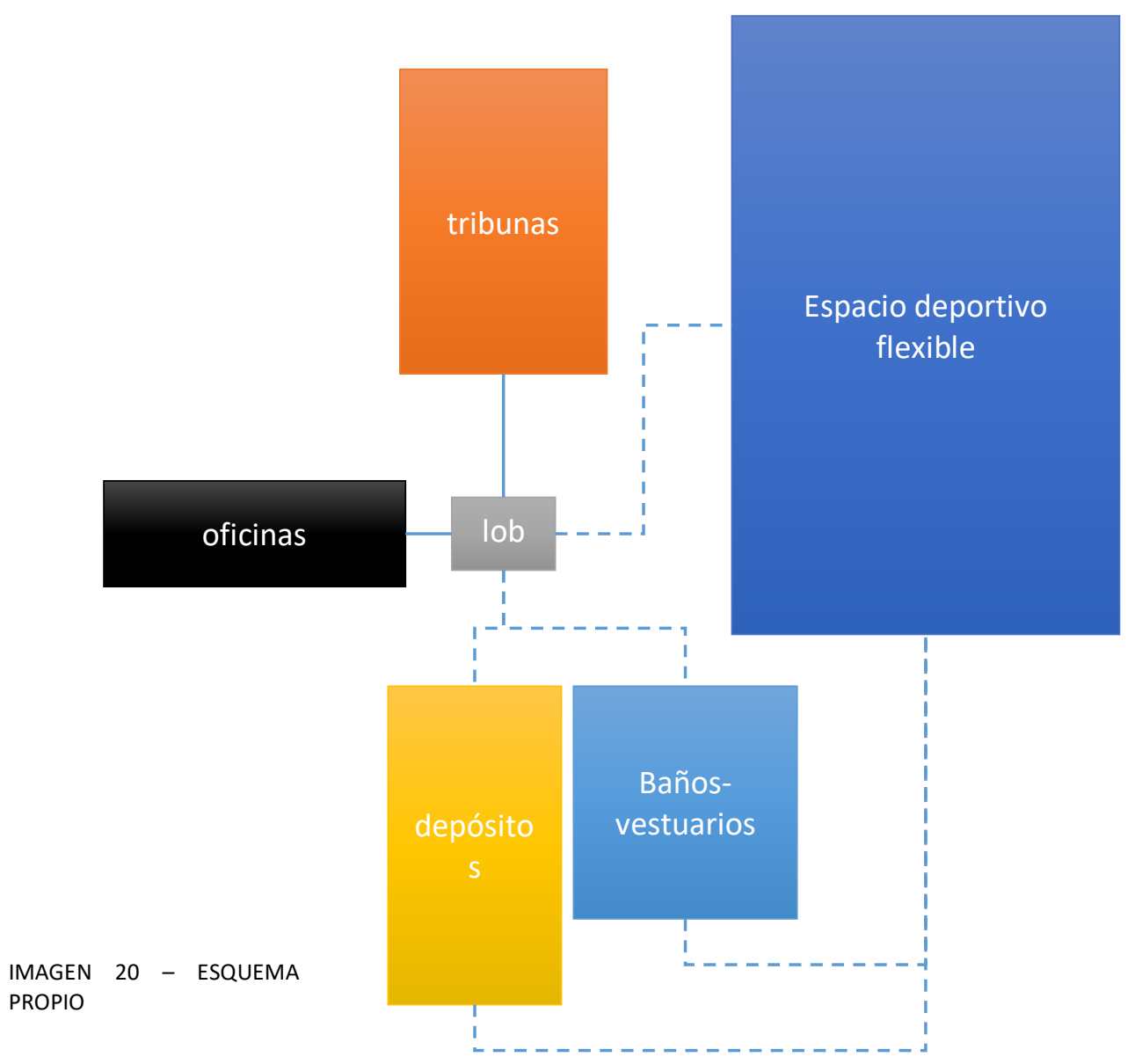

PROGRAMACION

La relación espacial esta diseñada para llegar indirectamente hacia el espacio principal (el espacio deportivo flexible). Las circulaciones son rectas y de circulación sencilla para evitar problemas a las personas discapacitadas.

\begin{tabular}{|l|l|l|}
\hline \multicolumn{2}{|c|}{ PROGRAMA } \\
\hline \multirow{2}{*}{ PISO 1 } & Zona administrativa & 150 \\
& depósitos & 400 \\
& baños y vestuarios & 343 \\
& cancha multiusos & 2874 \\
\hline \multirow{2}{*}{ PISO 2 } & Baños & 80 \\
\hline & zona de tribunas & 700 \\
\hline
\end{tabular}




\section{ASPECTOS TECNOLOGICOS}

"El edificio se levanta sobre una base de hormigón que mejora las fachadas ya ligeras; el color de cierre a través de la $U$ de vidrio que lo rodea permite que sea visible durante el día de una manera difusa y noches de algunos proyectores que indican al público cuando hay eventos importantes en el centro deportivo, estableciendo más allá de su propio uso directamente relación con el entorno urbano en el que se asienta.

Proponemos un patio en la dirección longitudinal con la intención de que la vegetación puede entrar en el edificio. Tome especial relevancia las terrazas que se puede acceder desde el exterior. Estos aumentos de la capacidad del centro deportivo, porque de ellos también se puede ver la zona de juegos, mientras que son un balcón exterior desde donde se ve Arteixo .

La estructura de la zona de servicio es de concreto, los pisos de losas y cercas prefabricadas, también un muro de hormigón con revestimiento de placas de yeso y aislamiento. La estructura se resolvió por cerchas paralelas sobre columnas de acero HEB - 300 . La estructura metálica revela aún más el carácter intrínseco de la obra en este caso con sujeción a un universo donde el color se ha llenado todo el espacio.

Por lo tanto el material utilizado para la fachada es la sobrecarga vidrio en paneles de madera pintados colores. Arquitecturas siempre diseñados para el usuario, el único camino posible para la formalización, el uso público más doméstico y por qué no , ilusiones siempre intrínsecas al camino trazado por algún tiempo, hacen que la tiña de trabajo de todos los colores." 53

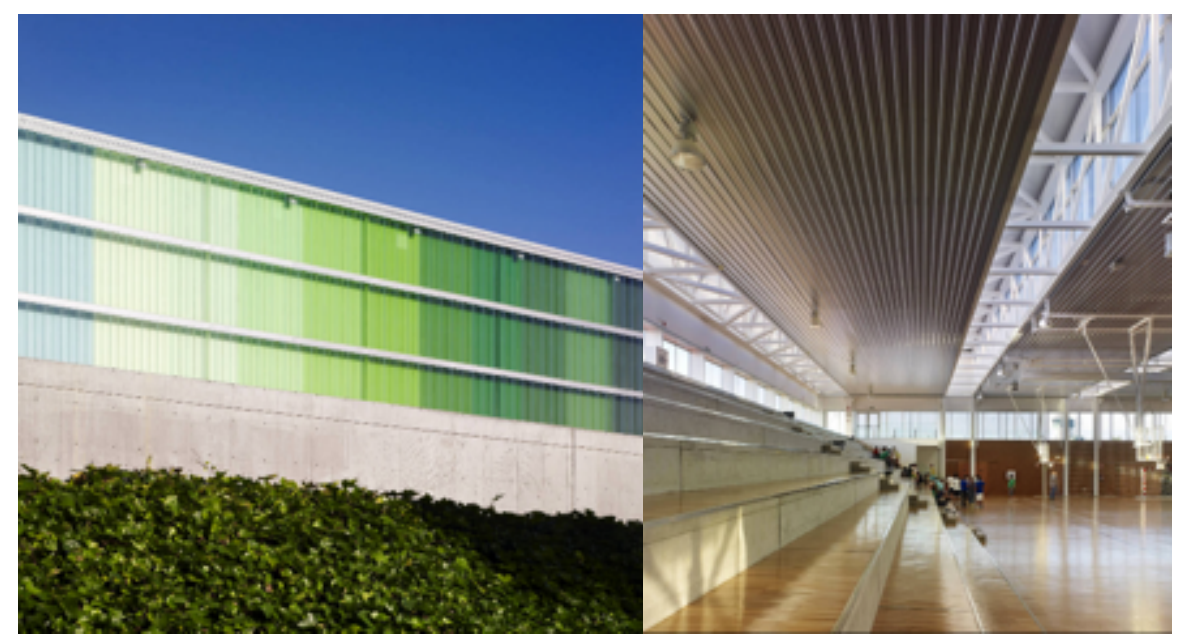

IMAGEN 22-25 - ARTEIXO STUDIO 


\section{VIDENA (Villa Deportiva Nacional)}

\section{INFORMACIÓN GENERAL DEL PROYECTO:}

\section{Nombre:}

Villa Deportiva Nacional (VIDENA)

\section{Autor:}

José Bentín Arquitectos S.R.L.

Año de inauguración: 1993

\section{Dirección:}

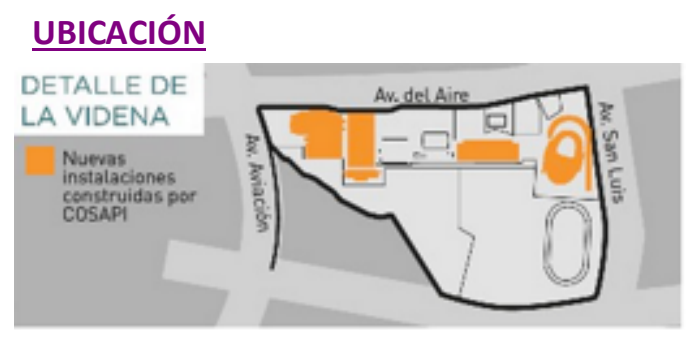

IMAGEN 3 -COINSA 1

Av. Del Aire s/n en el Distrito de San Luis, Provincia y Departamento de Lima.

\section{Tipología:}

Polideportivo

Área de proyecto:

Polideportivo 1: 9400m2

Polideportivo 2: 11,400m2

Área libre: $2600 \mathrm{~m} 2$

Área total: $7899 \mathrm{~m} 2$

Datos relevantes:

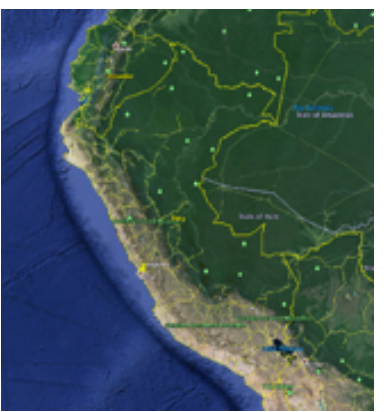

IMAGEN 1 - GOOGLE MAPS -
TERRENO

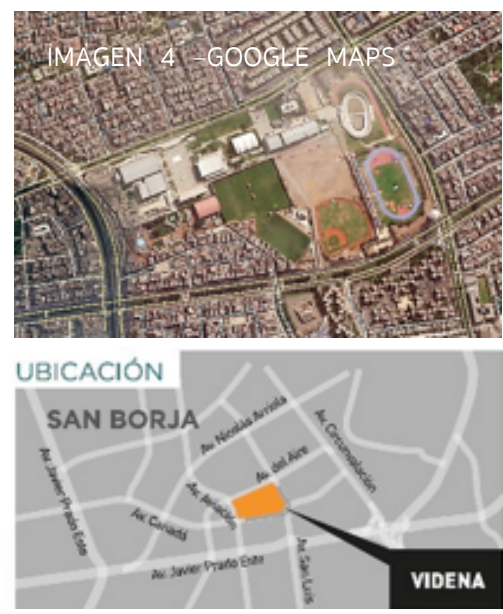

IMAGEN 2 - COINSA 2

2013 Juegos Bolivarianos

2014 construcción de Centro de Alto rendimiento

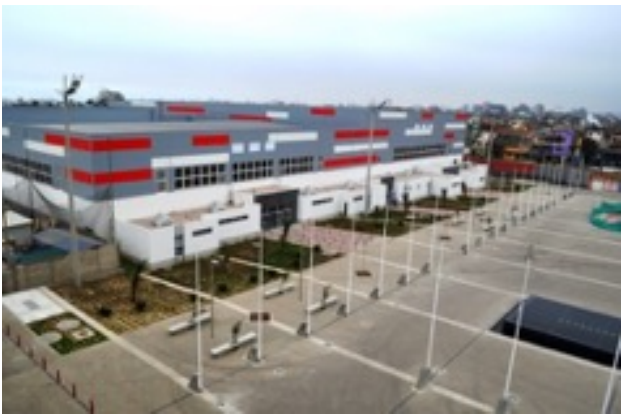

IMAGEN 6 - BENTIN

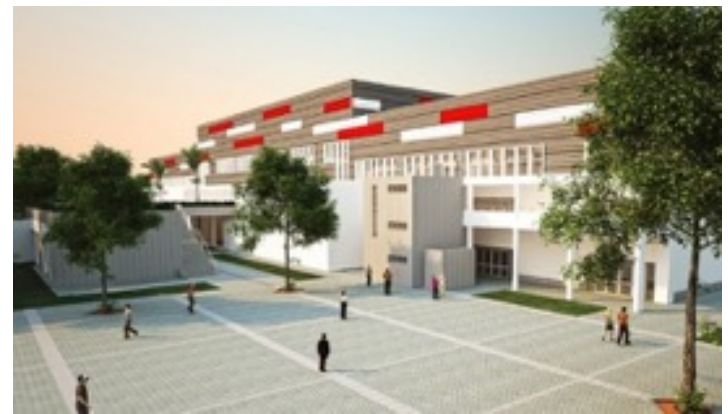

IMAGEN 7 - BENTIN 
Se encuentra cercano a la estación del Metropolitano, y cuenta con paraderos cercanos. Es medianamente accesible. Se encuentra en La Avenida Canadá que es de alto flujo de vehículos.

\section{SISTEMA VIAL CON RELACION A LA CIUDAD}

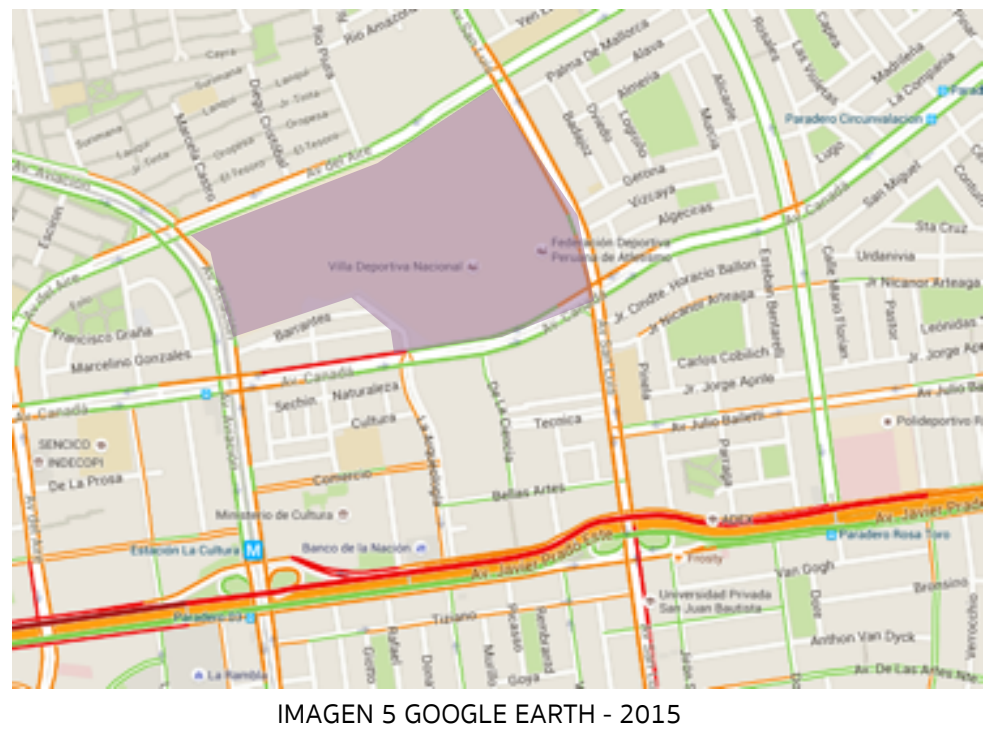

\section{ANTECEDENTES HISTÓRICOS}

Sobre el terreno antes descrito se han desarrollado diferentes áreas para el uso de diferentes Federaciones, como la Federación Peruana de Futbol, la Federación Peruana de Softbol y Beisbol, la Federación de Atletismo así como se han entregado en uso áreas para el Comité Olímpico (COI), un área reservada para el futuro edificio para el Instituto peruano del Deporte (IPD) y un área intangible donde se encuentra una huaca.

Asimismo se encuentra un área alquilada a la Constructora Oderbretch, y un área que no se interviene en el presente proyecto donde se encuentra el CEAR de Vóley y el CAR de Vóley.

\section{Terreno:}

En el área disponible se mantienen solo 2 edificios, el CEAR del Vóley y el CAR de Vóley, ambos construidos recientemente, estos 2 edificios se enmarcan en un área que no está incluida en el proyecto, así como las áreas softball, pista de atletismo, COP, federación peruana de Futbol, y demás indicadas en los planos.

Todas las demás infraestructuras serán demolidas incluyendo las veredas y pistas así como las edificaciones indicadas en planos, quedará también el cerco exterior del terreno 
que es de concreto prefabricado, salvo las zonas de intervención para las nuevas casetas de vigilancia. 66

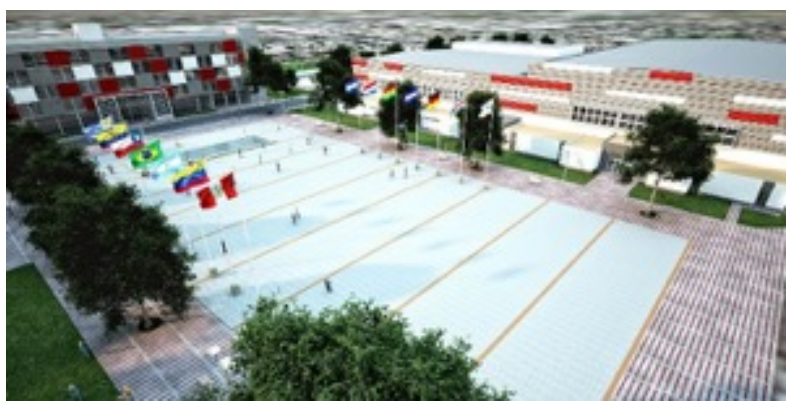

IMAGEN 8 - BENTIN

\section{CONCEPTUALIZACIÓN DE LA PROPUESTA:}

El planteamiento general elegido se basa en la discriminación de las circulaciones vehiculares y peatonales, para lo cual se plantea el ingreso peatonal principal a una Plaza Central, que servirá para las ceremonias protocolares y reuniones masivas, la cual está flanqueada al lado derecho por el Polideportivo 1 con la Gimnasia, por el fondo con la residencia de Deportistas y por la Izquierda por el CEAR de Vóley existente. En esta Plaza se cuenta con una pileta, astas de banderas, mobiliario fijo exterior como bancas y bebederos, dos tipo de arboles considerando dos alturas diferentes para manejar dos escalas en dicho espacio. 66

\section{RELACIÓN CON EL EXTERIOR}

La relación esta hecha como conjunto, es identificable como un solo proyecto.

El acceso vehicular es por 3 zonas: Dos ingresos por la avenida del Aire (Ingreso vehicular 1, 2- nuevos) y un ingreso por la Avenida Aviación (existente). El ingreso existente y el ingreso vehicular 1 nos llevan un bolsón de estacionamientos proyectado, el cual a futuro será conectado por el IPD. 66

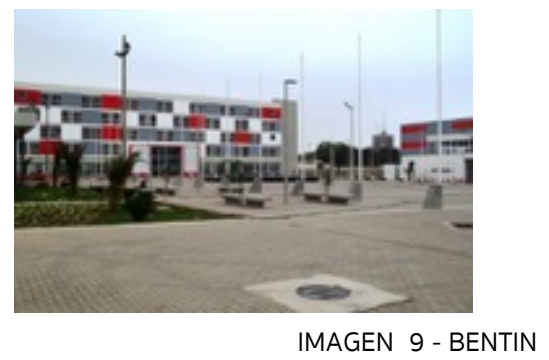




\section{RELACIÓN ESPACIAL}

Los polideportivos del conjunto, cuentan con espacios transformables. Puede ser usado como un solo gran espacio o como varios ya que es subdividible.

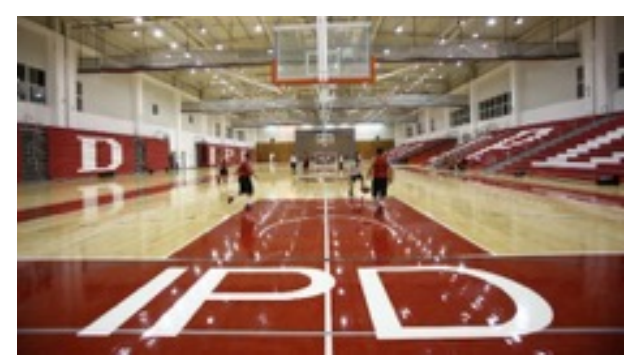

IMAGEN 10 - BENTIN

\section{RELACIÓN CON EL CONTEXTO}

El edificio en un terreno enorme, frente a conjuntos residenciales de 9 pisos, clínica, comercios y ferias. Existen distintas tipologías a su alrededor, así como distintas alturas.

Veredas poco amigables y contexto peligroso para los peatones.

\section{UBICACIÓN :}

Se ubica cerca de la estación del metropolitano, así también cuenta con varios paraderos de transporte público en sus alrededores, sin embargo la falta de transporte público inclusivo limita su publico discriminando a las personas discapacitadas.

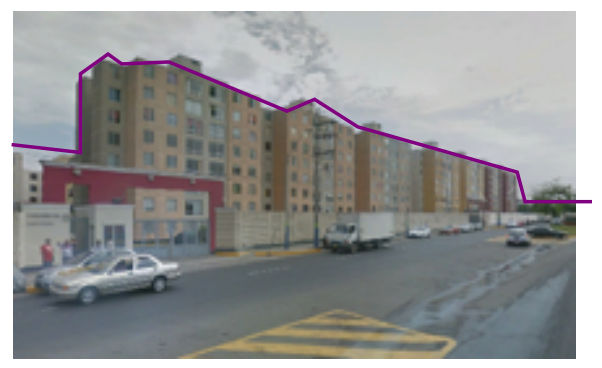

IMAGEN 11 VISTAS EARTH 2015
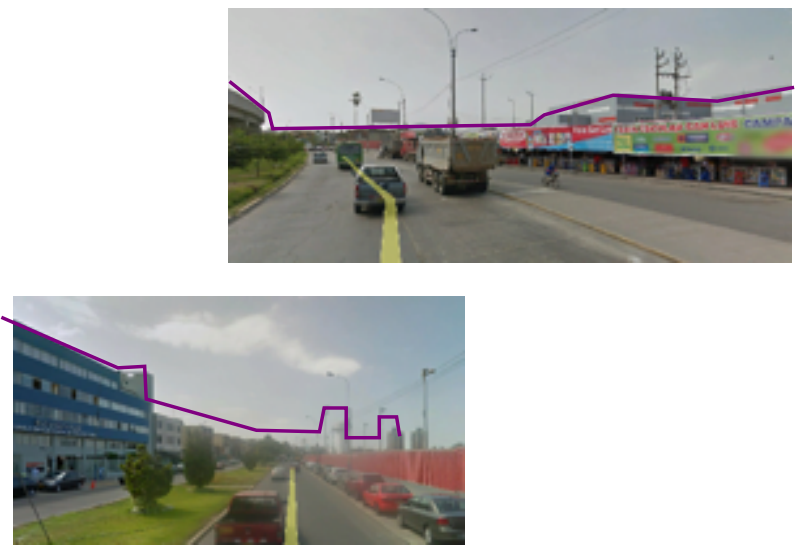


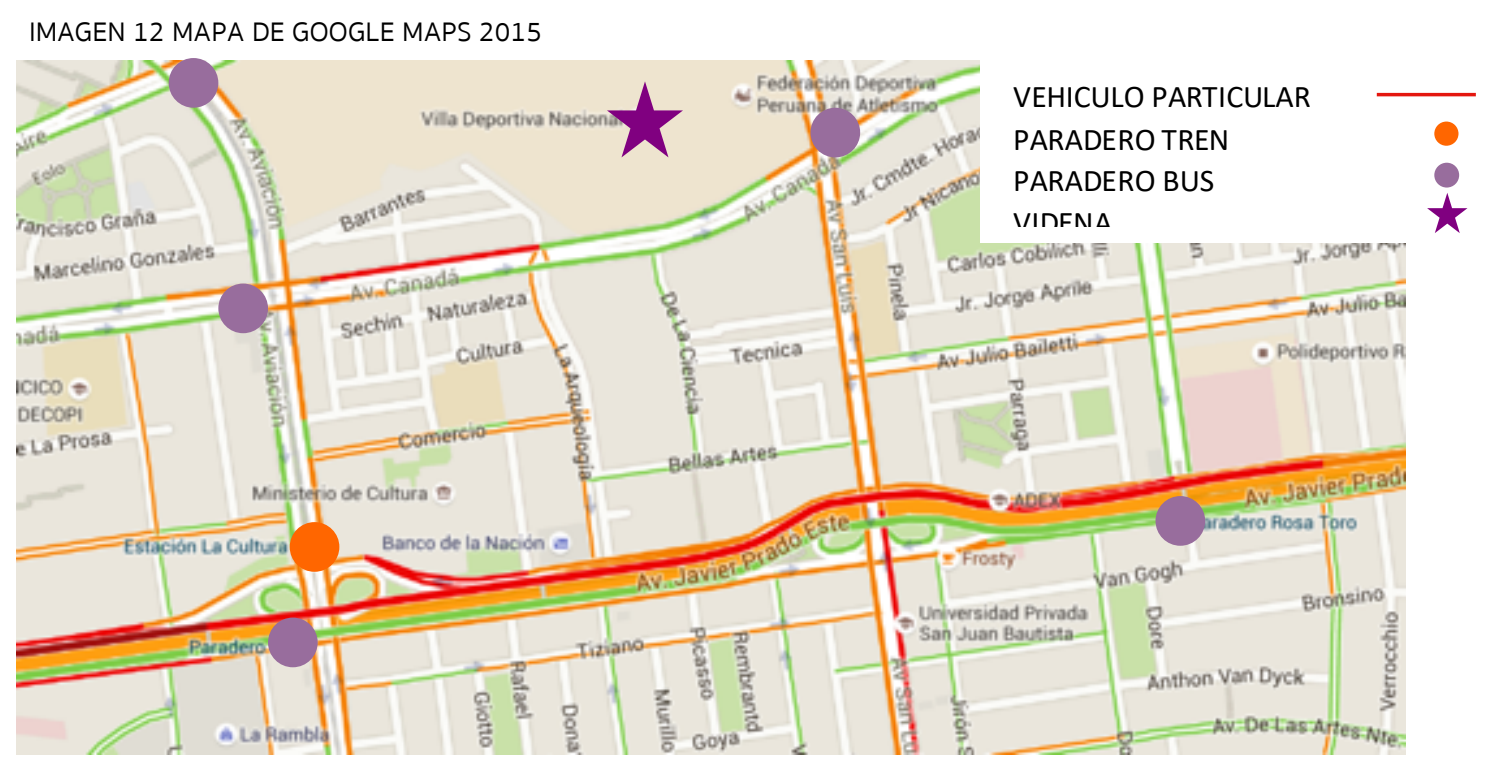

La llamada "Villa Deportiva Nacional, la Videna" promete ser, como su nombre lo indica una villa deportiva de alto rendimiento, pero aun está lejos de ello. En este complejo, ubicado entre las avenidas San Luis, Canadá, Aviación y Del Aire. Residen las federaciones de Gimnasia, Futbol, Softball, Beisbol, Lucha amateur, Atletismo y Ciclismo; dato increíble, todas se encuentran desvinculadas del conjunto con ingresos independientes.

La nula interconexión entre las federaciones genera aumento de costo (en cuanto a vigilancia y equipamiento extra por ejemplo) e imposibilita el trabajo en conjunto administrativo y deportivo de las instituciones. De no ser así, la integración del conjunto resultaría en mejoras académicas, sociales, anímicas y por ende de rendimiento deportivo. Se requiere una indispensable mejora en el ámbito administrativo.

Otro factor que es imposible resaltar con respecto a la carencia del funcionamiento en conjunto es la imposibilidad de uso de los "servicios comunes" como el gimnasio, vestuarios y otros. Esto influye en el entrenamiento y el desenvolvimiento del atleta y resulta ser totalmente frustrante y des animante para el cuerpo técnico y los atletas.

Alrededor del complejo se ubican 12 diferentes ingresos tanto peatonales como vehiculares los cuales rematan directamente con los campos deportivos sin (obviamente) mantener una conexión interior.

Por otro lado, la infraestructura de la Videna merece ser catalogada como inapropiada y en estado catastrófico con lo que respecta a normativa, higiene y actualización en materiales y equipamiento. A lo largo del recinto deportivo se pueden ver desmontes de 
basura o escombros que además de ensuciar y causar una mala imagen, obstruyen el paso en algunas circulaciones.

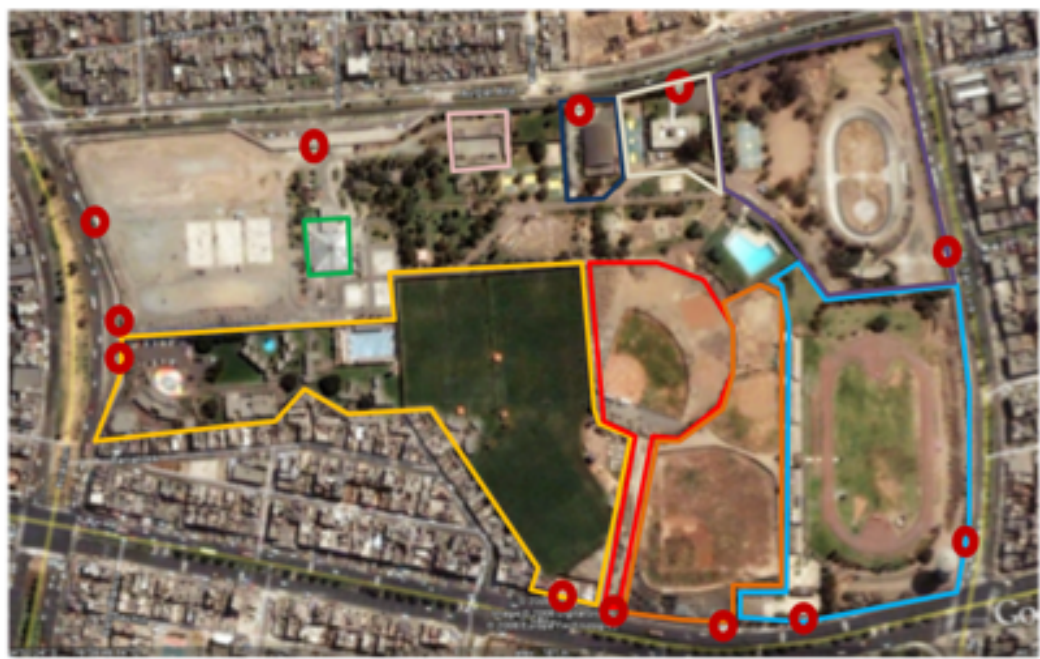

Plano del conjunto - Google Earth

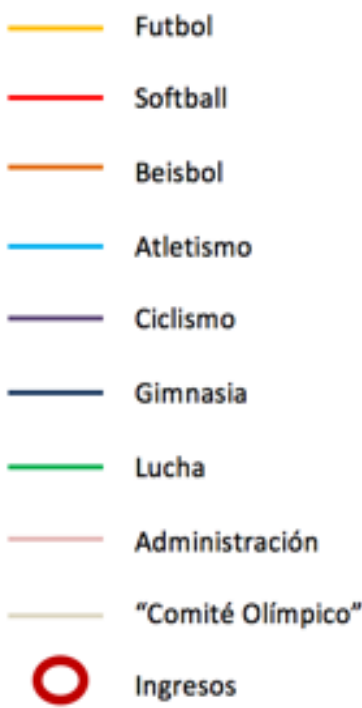

El ingreso de luz a los polideportivos es indirecto ya que los edificios están orientados del suroeste al noreste.

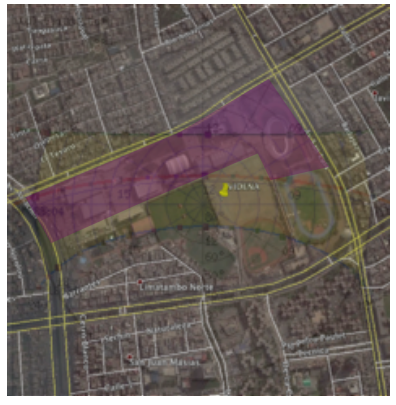

IMAGEN 14 -

GAISMA

(2015)

\begin{tabular}{|c|c|c|c|c|c|c|c|c|c|c|c|c|}
\hline Variable & I & II & III & IV & $\mathbf{v}$ & VI & VII & VIII & IX & $\mathrm{x}$ & XI & XII \\
\hline Insolation, $\mathbf{k W h} / \mathbf{r}$ & 5.25 & 5.31 & 5.52 & 5.14 & 4.57 & 3.97 & 4.28 & 4.78 & 5.24 & 5.63 & 5.91 & \\
\hline earı & 0.48 & 0.49 & 0.53 & 0.55 & 0.54 & 0.51 & 0.53 & 0.54 & 0.53 & 0.53 & 0.54 & 0.52 \\
\hline Temperature, ${ }^{\circ} \mathrm{C}$ & 13.85 & 13.99 & 14.15 & 13.83 & 12.84 & 11.45 & 11.171 & 12.09 & 13.281 & 14.281 & 14.39 & 14.27 \\
\hline Wind speed, $\mathrm{m} / \mathrm{s}$ & 3.52 & 3.36 & 3.30 & 3.49 & 4.04 & 4.84 & 4.88 & 4.68 & 4.48 & 3.93 & 3.78 & 3.71 \\
\hline Precipita & 1 & 0 & 0 & 0 & 1 & 2 & 3 & 3 & 2 & 1 & 1 & 2 \\
\hline et days, $d$ & 1.3 & 1.0 & 0.7 & 0.7 & 1.2 & 1.0 & 1.1 & 1.9 & 1.3 & 0.8 & 0.7 & $0.7 \mathrm{Y}$ \\
\hline
\end{tabular}

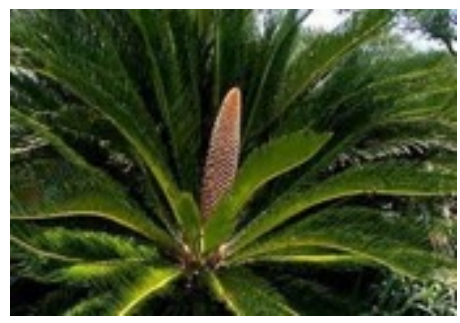

IMAGEN 16- PHOENIX

IMAGEN 15 - WASHINGTONIA 
El proyecto paisajista para la Videna está compuesto por la integración de nuevas especies con la vegetación ya existente ya sea árboles o palmeras que se van a mantener, logrando así un medio ambiente amigable para el usuario.

La propuesta se basa en la organización de elementos básicos por zonas: Estacionamiento, Plaza principal, Alameda, Plaza 1y2, Velódromo y Exteriores. Las especies seleccionadas y dispuestas en estas zonas consisten en árboles, palmeras y cycas, arbustos, enredaderas, gramíneas, herbáceas y cubre suelos; que son tolerantes a la sequedad, permitiendo así reducir el consumo de agua.

El trazo de las circulaciones peatonales ha tenido en consideración mantener algunos árboles existentes (indicados en planos) e incorporarlos a la propuesta arquitectónica. 66

\section{ASPECTOS FUNCIONALES}

Sectorización de áreas de estacionamiento para uso de los residentes y de los visitantes, que por el carácter del CAR.

Los edificios que componen el conjunto son los siguientes:

- $\quad$ Polideportivo 1,

- $\quad$ Polideportivo 2,

- Velódromo y pista de calentamiento

- $\quad$ Residencia de Deportistas

- $\quad$ Módulos de Servicios (2)

- Depósito de Materiales deportivos

- $\quad$ Casetas de vigilancia.

La circulación peatonal se ha distribuido desde el espacio central y a lo largo del CAR, mediante una Alameda que estructura el Conjunto, esta une la plaza principal, el Polideportivo 2 y las áreas de Velódromo y pista de Calentamiento. Esta circulación peatonal se encuentra diferenciada de la vehicular y diseñada para proteger la zona exclusiva de residentes, el área central y los diversos ambientes de entrenamiento. 66 


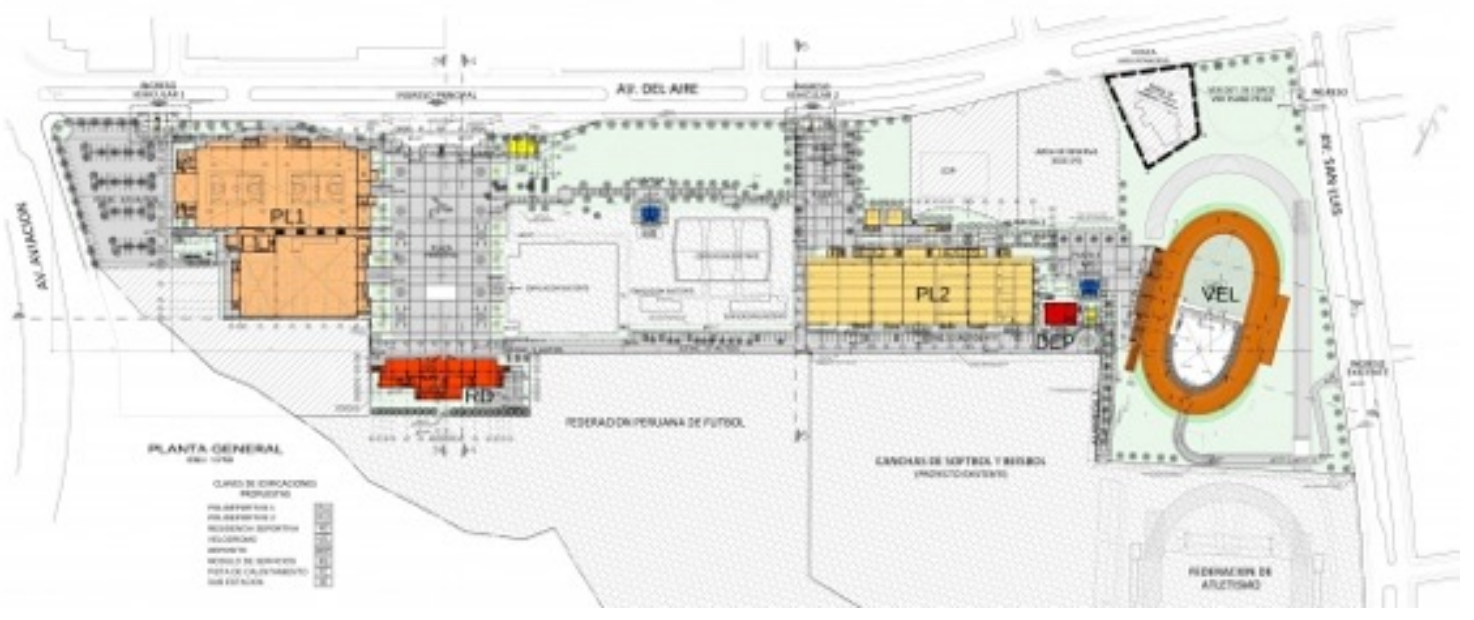

El proyecto se ha desarrollado respetando la programación planteada en el Estudio de Factibilidad del proyecto, aprobado por el MINEDU.

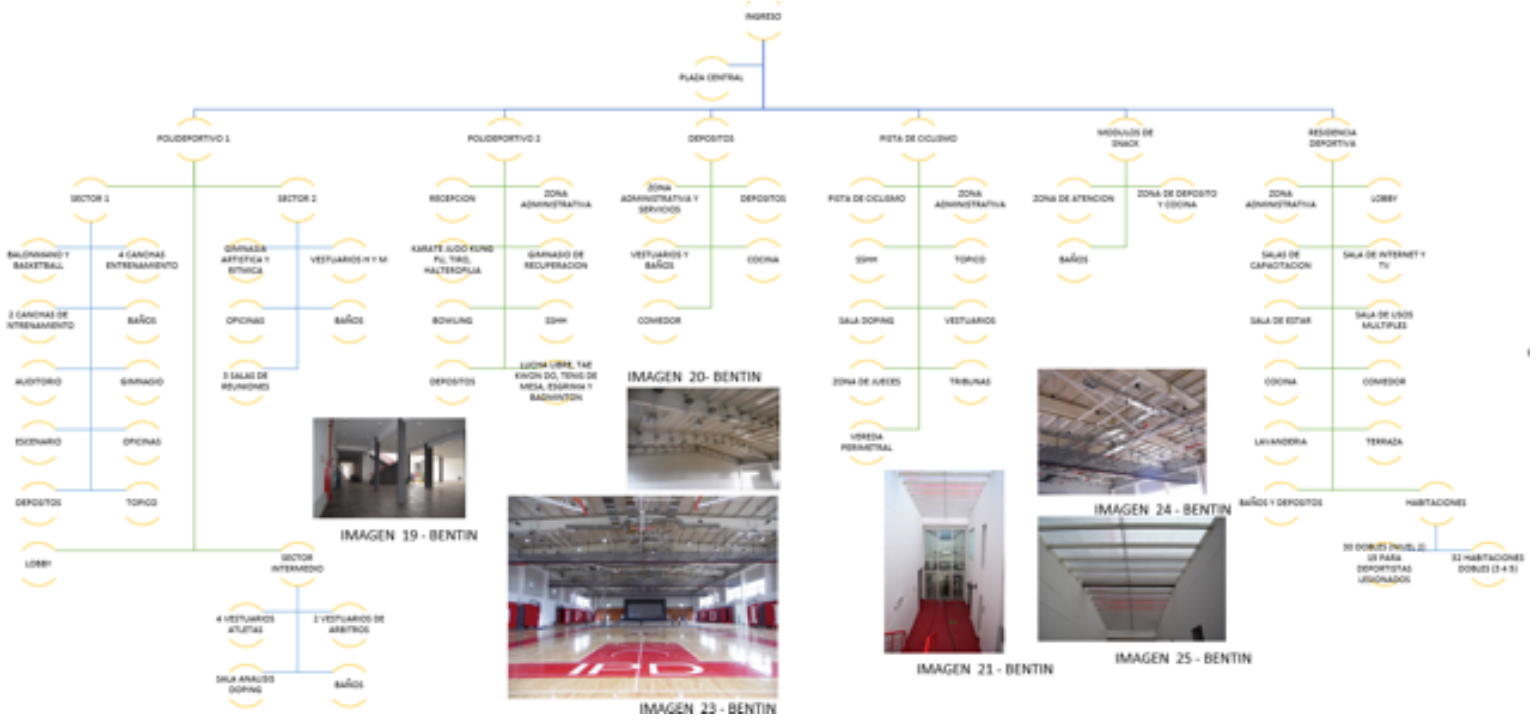

\begin{tabular}{|c|c|}
\hline \multicolumn{2}{|r|}{ PROGRAMA POLIDEPORTIVO 1} \\
\hline SECTOR 1 & 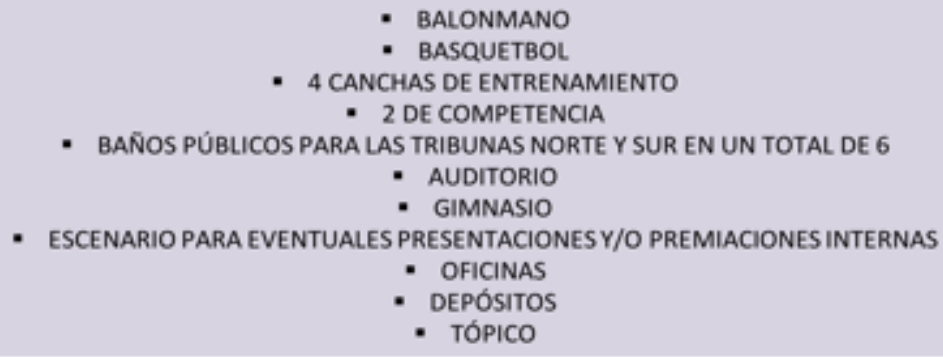 \\
\hline SECTOR 2 & $\begin{array}{c}\text { - GIMNASIA TANTO RITMICA COMO ARTISTICA } \\
\text { VESTUARIOS DE HOMBRES Y MUJERES } \\
\text { OFICINAS Y BAÑOS PARA TÉCNICOS } \\
\text { - DEPÓSITOSY UN ÁREA DE USO } \\
\text { - EN EL SEGUNDO PISO SE ENCUENTRAN OFICINAS ADMINISTRATIVAS } \\
* 3 \text { SALAS DE REUNIONES }\end{array}$ \\
\hline $\begin{array}{l}\text { ESPACIO ENTRE } \\
\text { SECTORES }\end{array}$ & $\begin{array}{l}\text { - } 4 \text { vestuarios de atletas } \\
\text { - } 2 \text { vestuarios de árbitros } \\
\text { - sala de análisis de Doping con baño }\end{array}$ \\
\hline
\end{tabular}




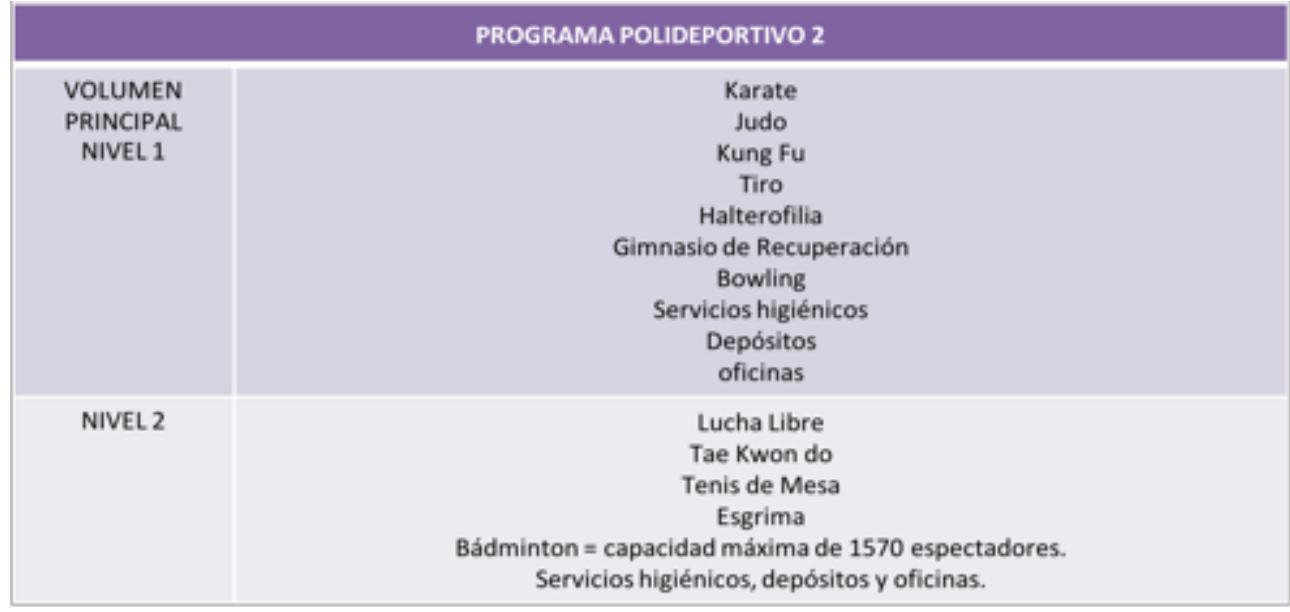

\section{PROGRAMA RESIDENCIA DEPORTISTAS}

\begin{tabular}{|c|c|}
\hline NIVEL 1 & $\begin{array}{c}\text { Zona administrativa y de servicios. } \\
\text { Lobby, } \\
\text { salas de capacitación, } \\
\text { sala de internet, } \\
\text { sala de estar y TV, } \\
\text { sala de usos múltiples, } \\
\text { cocina, } \\
\text { comedor, } \\
\text { lavandería, } \\
\text { terraza, } \\
\text { baños y depósitos. }\end{array}$ \\
\hline NIVEL 2 & $\begin{array}{l}30 \text { habitaciones dobles, } \\
\begin{array}{l}15 \text { de las cuales son dormitorios acondicionados para deportistas lesionados y que se } \\
\text { encuentren en terapia. }\end{array}\end{array}$ \\
\hline NIVEL 3,4 Y 5 & $\begin{array}{c}\text { En los pisos } 3,4 \text { y } 5 \text { se han distribuido } 32 \text { habitaciones dobles por piso, con un total de } 237 \\
\text { personas. }\end{array}$ \\
\hline
\end{tabular}

\begin{tabular}{|c|c|}
\hline & DEPósıTo \\
\hline NIVEL 1 & $\begin{array}{c}\text { Zona administrativa y de servicios. } \\
\text { materiales deportivos para todas las disciplinas. } \\
\text { Vestuarios y baños. }\end{array}$ \\
\hline NIVEL 2 & $\begin{array}{c}\text { Comedor y cocina. } \\
\text { Depósitos de materiales deportivos para todas las disciplinas. } \\
\text { Vestuarios y baños. }\end{array}$ \\
\hline
\end{tabular}

\begin{tabular}{|c|c|}
\hline & MÓdULOS DE SERVICIOS (2) \\
\hline AREA A & Área de atención tipo snack \\
\hline AREA B & Área de cocina y baños. \\
\hline
\end{tabular}

\section{VELÓDROMO Y PISTA DE CALENTAMIENTO}

\begin{tabular}{|c|c|}
\hline Pista de & Pista de competencia \\
\hline competenciay & oficinas \\
Pelouse & Baños \\
& tópico \\
& sala de doping \\
Vestuarios & zonas de jueces \\
Tribunas & vereda perimetral \\
\hline
\end{tabular}

IMAGEN 27 - TABLAS DE PROGRAMA AREAS - LERTORA (2015) 


\section{ASPECTOS TECNOLOGICOS}

Se ha contemplado que los ambientes deportivos y el gimnasio tengan un sistema de renovación de aire (inyección y extracción) y que los ambientes de oficinas y Auditorio tengan un sistema de climatización (aire acondicionado). 66

\section{POLIDEPORTIVO 1}

El polideportivo 1 ha sido subdivido en volúmenes independientes, sector 1 y Sector 2, ambos conformados por columnas de concreto armado sobre las cuales se apoyan techos metálicos de alma llena.

Para casos eventuales de competencias se han contemplado (según alcance) tribunas retractiles, las cuales serán desplegadas según el deporte que se practique ya que cada tipo de disciplina (Básquet o balón mano) requiere distintas dimensiones en las áreas de seguridad. La capacidad máxima es de 3790 espectadores.

\section{POLIDEPORTIVO 2}

Se han considerado separaciones con tabiques de drywall y en algunos casos con cortinas levadizas para mayor flexibilidad de los ambientes.

El volumen principal conformado de pórticos de concreto armado. El primer nivel tiene como techo una losa maciza con vigas pos- tensadas.

Para la zona de Bowling una depresión en el piso acabado en cemento frotachado para la instalación de los equipos correspondientes. El segundo nivel está formado por un techo con vigas metálicas de alma llena en las zona deportivas y techos aligeradas en los vestuarios y servicios higiénicos.

\section{RESIDENCIA DE DEPORTISTAS}

Es un edificio de pórticos de concreto armado con losas aligeradas y macizas y costa de 5 niveles la cual ha sido considerada como residencia para los deportistas.

\section{DEPOSITO}

Es un edificio conformado por columnas de concreto armado sobre las cuales se apoyan techos metálicos de alma llena y cobertura termotecho. 


\section{PISTA DE COMPETENCIA Y PELOUSE}

La pista de competencia será de madera afzelia africana sobre una estructura de madera que descansara sobre una base de concreto. La pista posee una barrera exterior de madera y una interior de policarbonato. El acceso a la Pelouse, donde se sitúan los deportistas con sus equipos es a través de un túnel vehicular de concreto con la altura suficiente para permitir el paso de una ambulancia y a través de un corredor y/o túnel de acceso peatonal ubicado en la parte inferior de las tribunas y que lo conecta con la plaza 2. 66

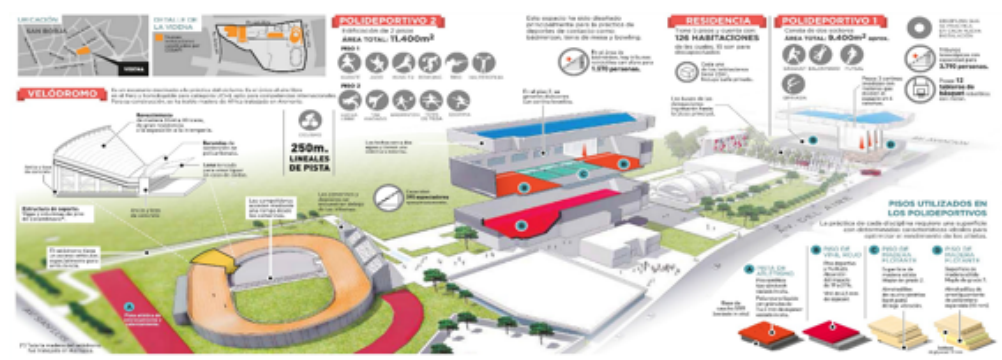

\subsection{CONCLUSIONES COMPARATIVAS}

\begin{tabular}{|c|c|c|c|c|}
\hline & 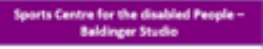 & Tuanumbat Deportives - & 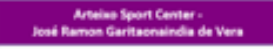 & 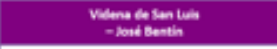 \\
\hline usciosion & 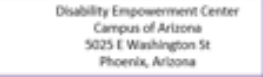 & 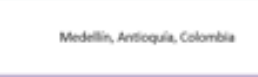 & 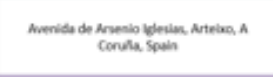 & 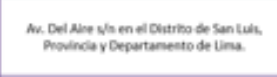 \\
\hline Emenos & 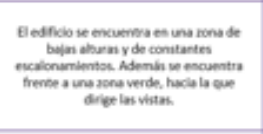 & 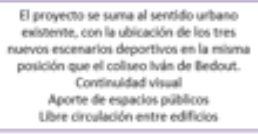 & 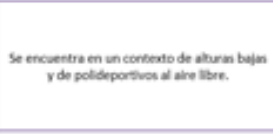 & 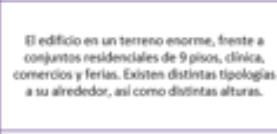 \\
\hline Antumber & 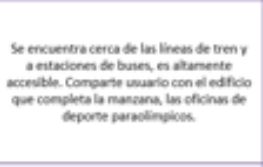 & 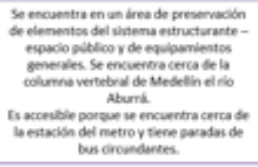 & 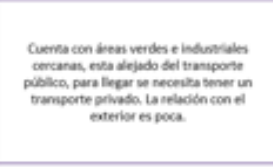 & 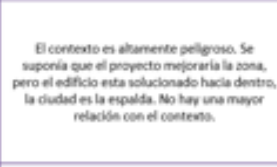 \\
\hline nosion & 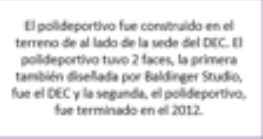 & 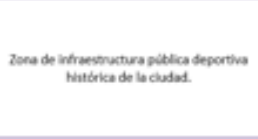 & 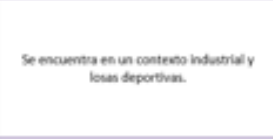 & 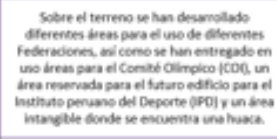 \\
\hline Fundonvilded & 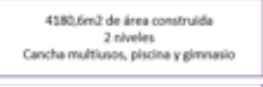 & 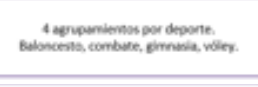 & 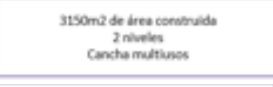 & 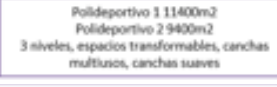 \\
\hline Treneteres & 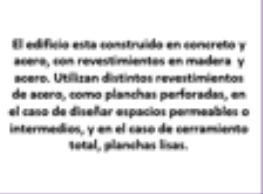 & 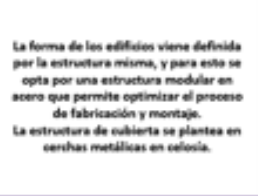 & 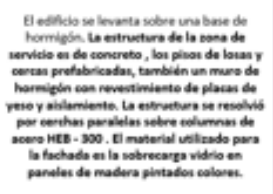 & 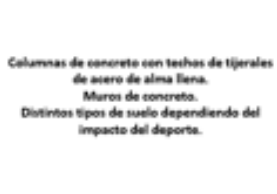 \\
\hline concestan: & 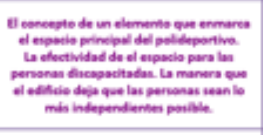 & 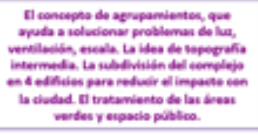 & 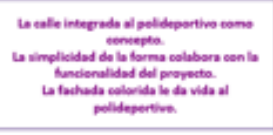 & 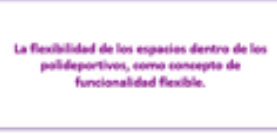 \\
\hline ankes & 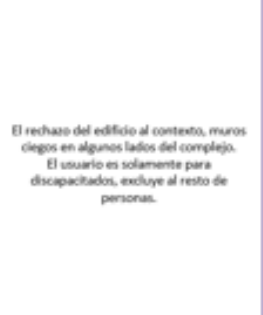 & 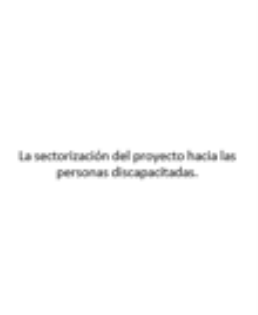 & 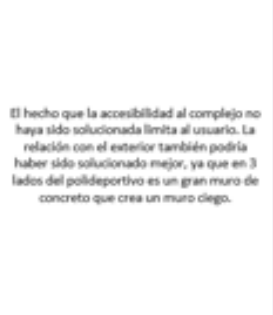 & 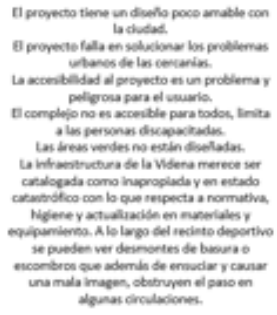 \\
\hline
\end{tabular}


4.ESTUDIO DEL LUGAR 


\section{ESTUDIO DEL LUGAR}

4.1. Localización

4.2. Condicionantes

4.2.1. De ubicación

\subsubsection{Físicas}

4.2.2.1. Topografía, Vegetación, Áreas Protegidas, Paisajes naturales

4.2.3. Estudio urbano

4.2.3.1. Zonificación y usos de suelo

4.2.3.2. Sistema Vial (conexión con la ciudad)

4.2.3.2.1. Vías expresas (regionales), semi-expresas, arteriales, colectoras, locales.

4.2.3.2.2. Transporte Público

4.2.3.3. Hitos

4.2.4. Factores climáticos

4.2.4.1. Clima

4.2.4.2. Humedad

4.2.4.3. Dirección del viento

4.2.4.4. Recorrido solar

4.3. Criterios de selección del terreno

4.4. Características de los terrenos

4.4.1. Datos generales

4.4.1.1. Ubicación

4.4.1.2. Disponibilidad

4.4.1.3. Situación y conexión con la ciudad

4.4.2. Parámetros Urbano-arquitectónicos

4.4.2.1. Zonificación y compatibilidad de uso, Altura de la Edificación, Retiros, Número de estacionamientos

\subsubsection{Análisis Espacial}

4.4.3.1. Recorridos por calles peatonales y vehiculares.

\subsubsection{Entorno urbano}

4.5. Cuadro de valoración de los terrenos según criterios y ventajas y desventajas 


\section{ESTUDIO DEL LUGAR}

\subsection{Localización}

Este Polideportivo se ubicaría en Lima Sur, en los límites del distrito de Villa el Salvador con Villa María del Triunfo ya que son distritos con muchas oportunidades. Actualmente son muy peligrosos y carecen de áreas públicas habilitadas. Cuentan con terrenos al lado de las líneas del tren eléctrico, accesibles por todos (discapacitados y no discapacitados) si estas personas se transportan en tren eléctrico. En el caso de los discapacitados sería la única manera de llegar en transporte público. El tren cubre dos aspectos: un aspecto positivo y otro negativo. Positivo porque con él el distrito se ha conectado con el resto de Lima. Negativo porque además de dividir el distrito en dos creando inseguridad, el tren eléctrico no esta habilitada para llevar más de una persona en silla de ruedas por vagón lo que limita a las personas discapacitadas.

Este proyecto apoyaría al gobierno en el plan que desde Junio de este año esta creando el IPD junto con la Municipalidad de Villa el Salvador, donde plantean la construcción de espacios deportivos y recreativos para poder ubicar por primera vez una infraestructura de carácter nacional en Villa el Salvador.

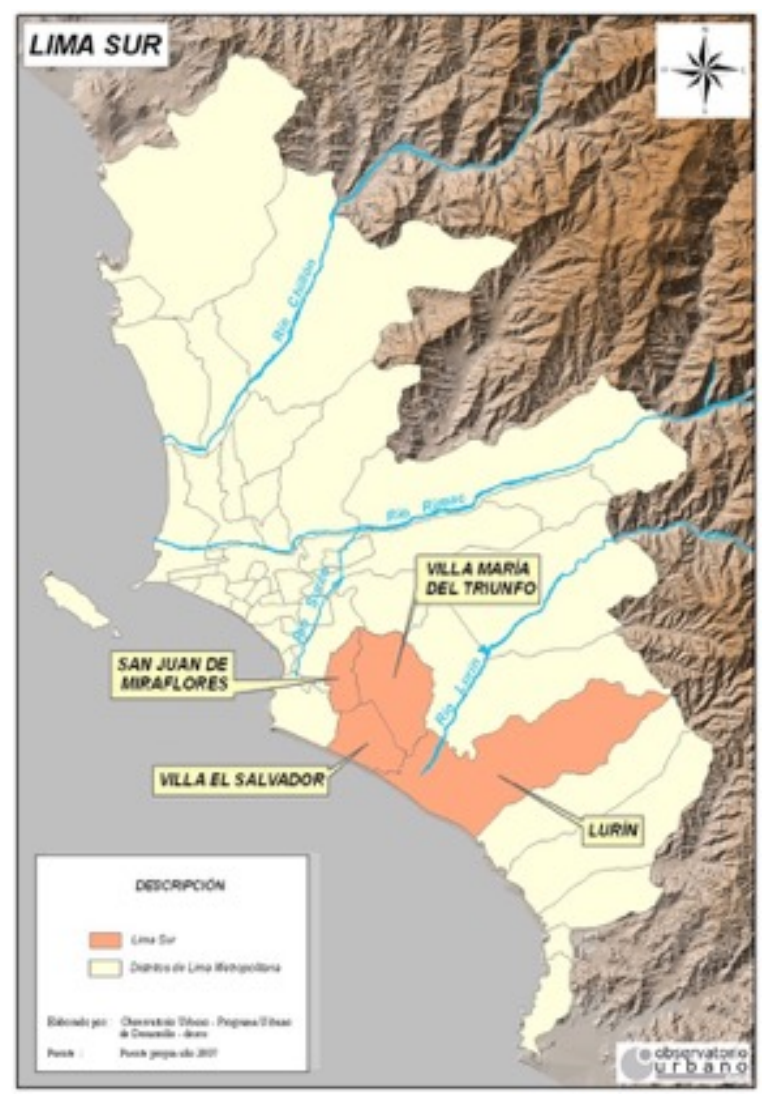

IMAGEN 1 - OBSERVATORIO URBANO (2011) - MAPA DE LIMA SUR 


\subsection{Condicionantes}

\subsubsection{De ubicación}

Considero importante que el terreno elegido se encuentre en una zona accesible y de alto flujo o de posible alto flujo. Con un área mínima de $6000 \mathrm{~m} 2$ en los que a pesar de que el proyecto no sea toda esta área, que exista la posibilidad de diseñar el entorno urbano y que se vuelva un proyecto detonante para la zona.

Una de las características principales de la ubicación es que se ubique en una zona que sea obvia la necesidad de este equipamiento.

Además, este proyecto tendrá un bosquejo de diseño del espacio urbano inmediato, porque busco aprovechar los terrenos vacíos y que son oportunidades para mejorar la zona.

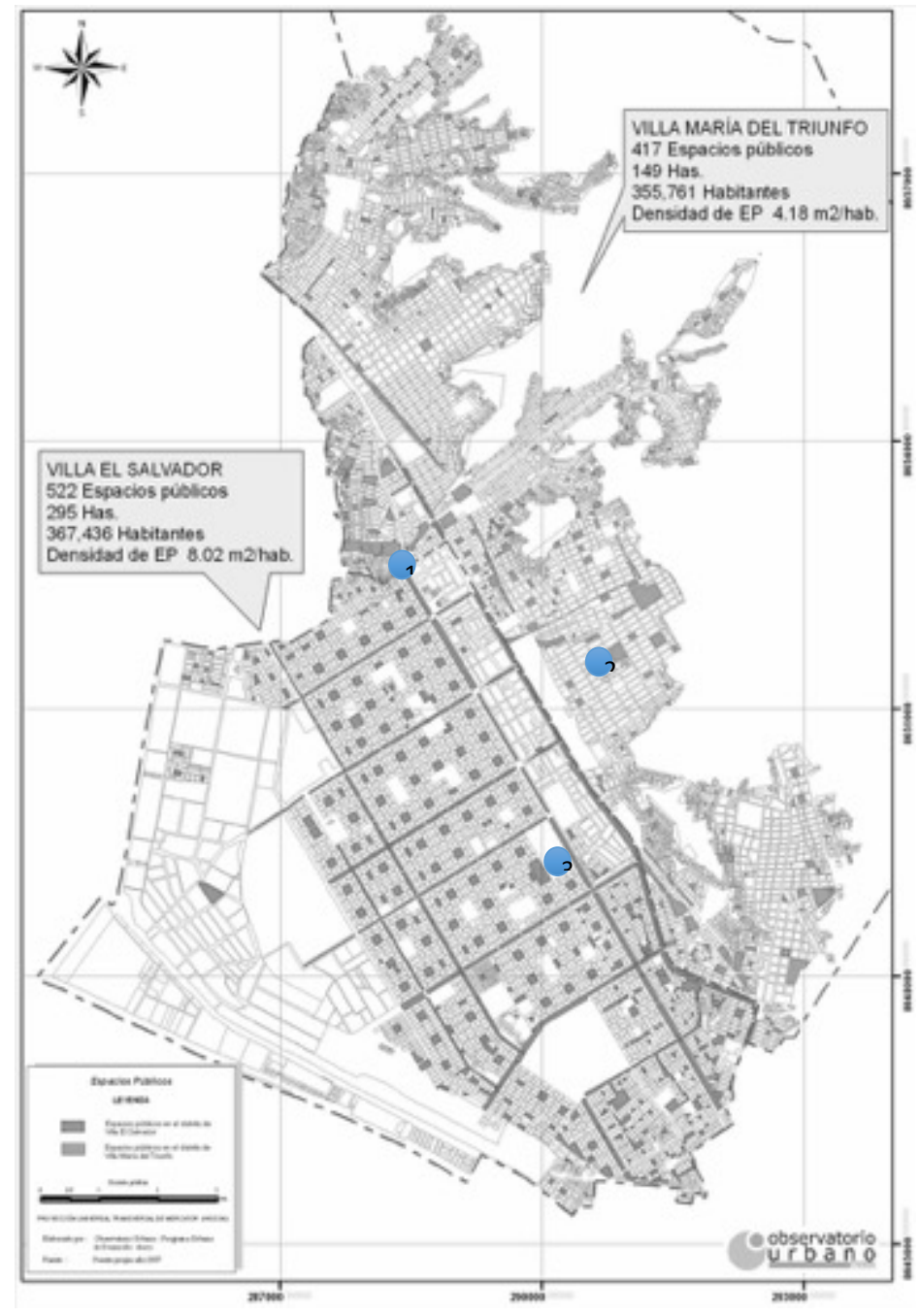

IMAGEN 2 - OBSERVATORIO URBANO (2011) - MAPA DE LIMA SUR 


\subsubsection{Físicas}

4.2.2.1. Topografía: La topografía de la zona es en la gran mayoría plana, con 3 puntos altos de los cuales 1 de ellos se encuentra cerca al terreno 1. Estos cerros influencian el diseño ya que en caso estar cerca de uno se tendría que decidir cómo el proyecto miraría a este hito.
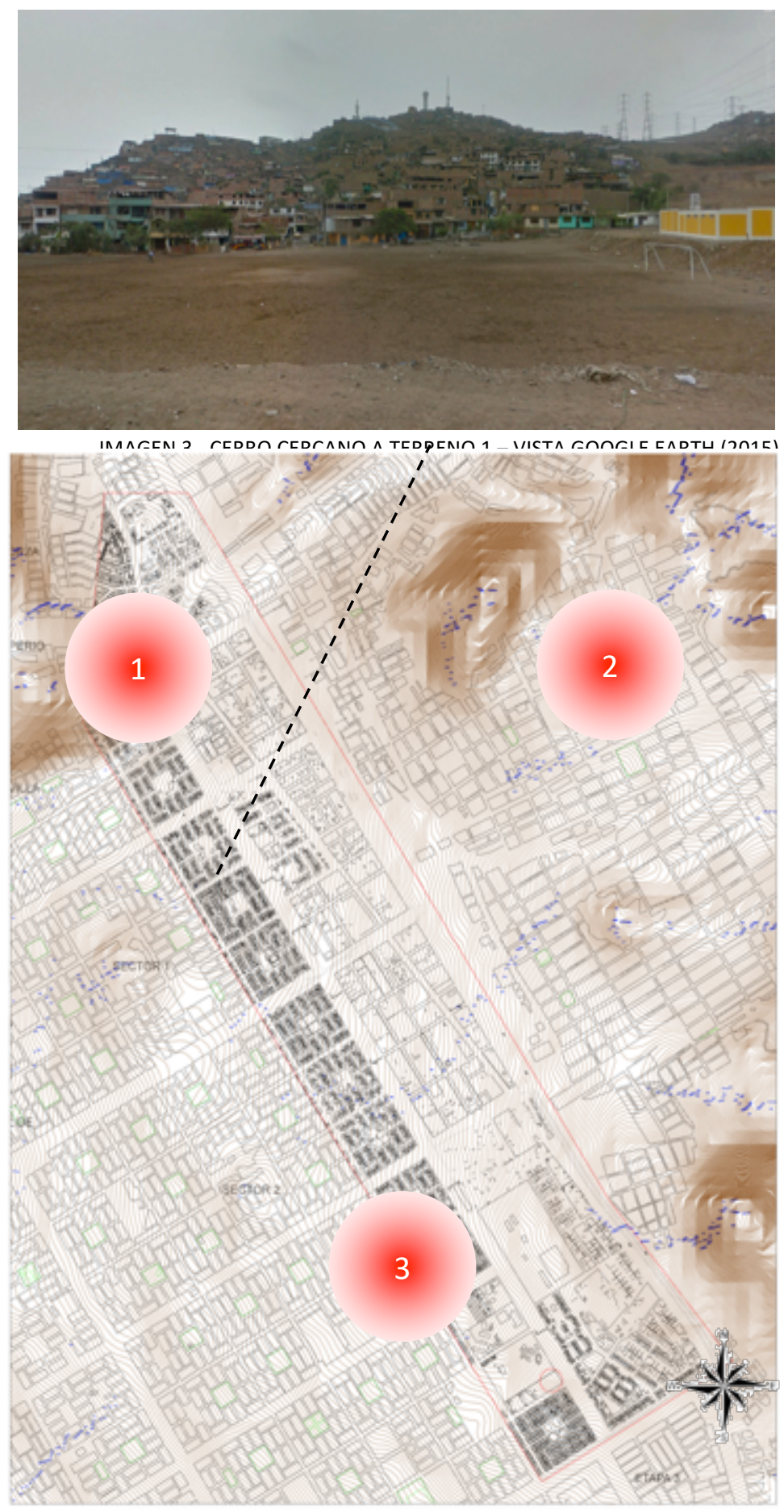

IMAGEN 4 -PLANO TOPOGRAFICO DE VILLA EL SALVADOR Y VILLA MARIA DEL TRIUNFO - LERTORA (2015) 


\subsubsection{Vegetación (situación real) y Zonas Protegidas}

La vegetación es mínima en los 2 distritos, a pesar de contar con parques zonales, y algunas intenciones de arborizar la zona falta área verde.

La causa principal de este fenómeno, es que son los mismos pobladores los que tienen que ir a recoger los árboles y plantarlos ellos mismos, lo que limita el crecimiento verde de los distritos.

La única zona protegida es la Zona arqueológica de la tablada de Lurín.

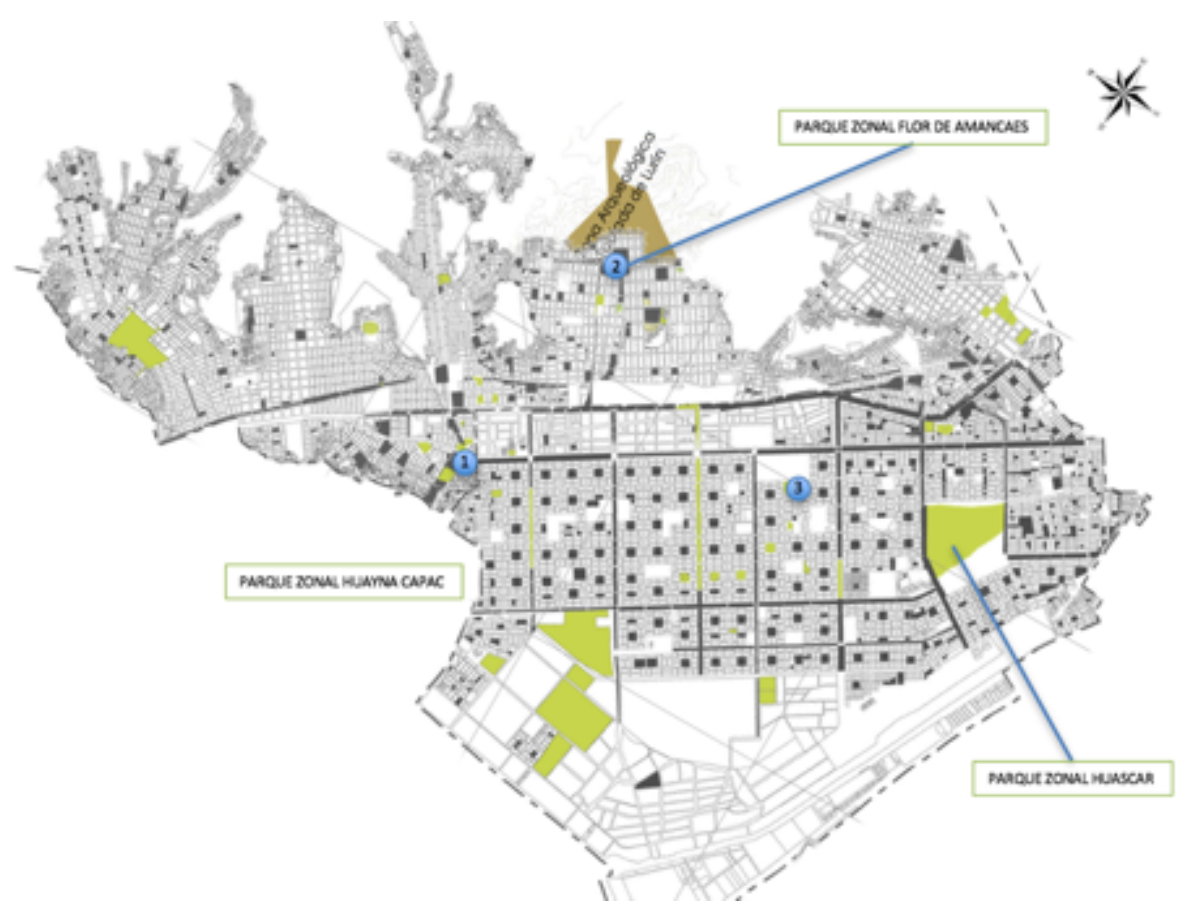

\subsubsection{Paisajes Naturales}

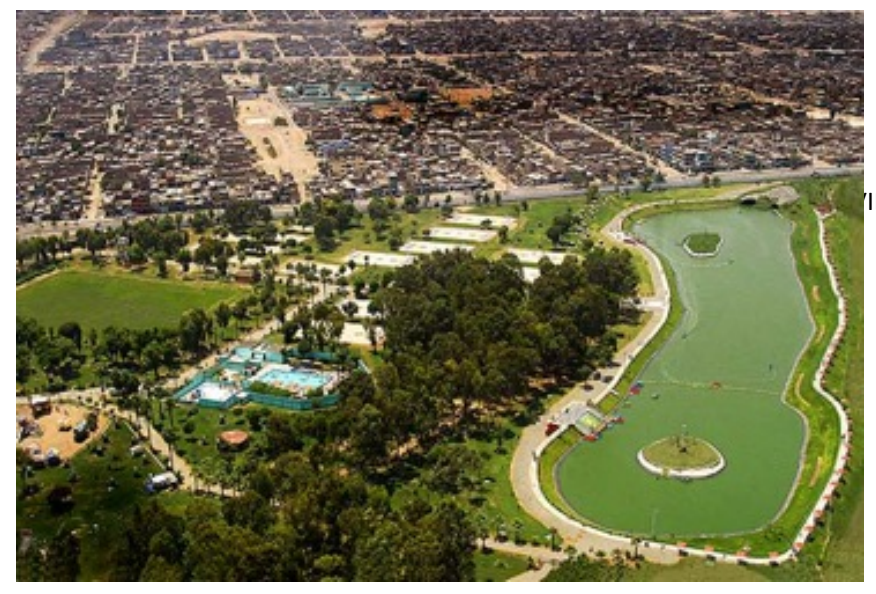

La zona es un $80 \%$ árida, tiene una zona agrícola y algunas zonas verdes ILLA MARIA DEL TRIUNFO - LERTORA (2015)

en los parques. Es un paisaje plano enmarcada por cerros que le dan el perfil a Villa el Salvador y Villa María del Triunfo.

En cuanto a su crecimiento urbano, es horizontal ocupando área, pero no densificando la zona. 


\subsubsection{ESTUDIO URBANO}

\subsubsection{Zonificación y usos de suelo}

La zonificación es en un mayor porcentaje de vivienda, la zonificación comercial que se da en el perímetro de las manzanas y en los bordes de las avenidas principales. La zonificación de áreas verdes es mínima y no están arborizadas

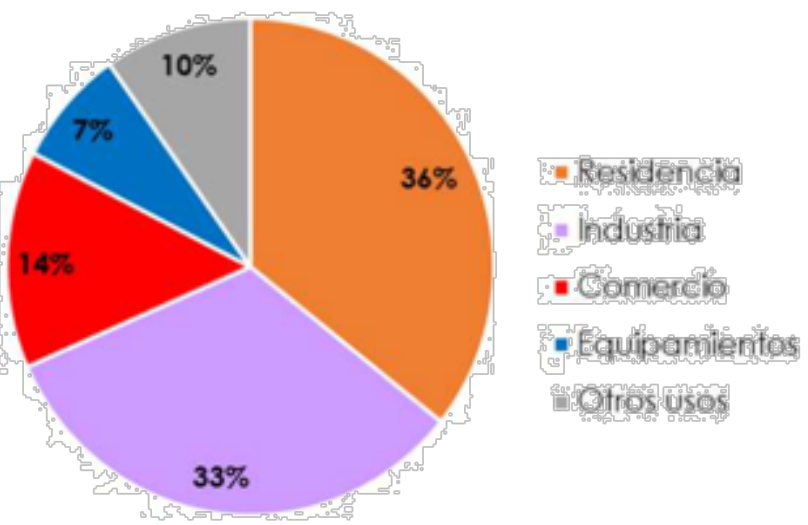

Fuente: Ordenanza Nº $620 \mathrm{MML} /$ Ordenanza Nº 933 MML(VES)/ Ordenanza No 1084 MML (VMT) Nota: Se ha considerado aprox. 300m alrededor del PIVES
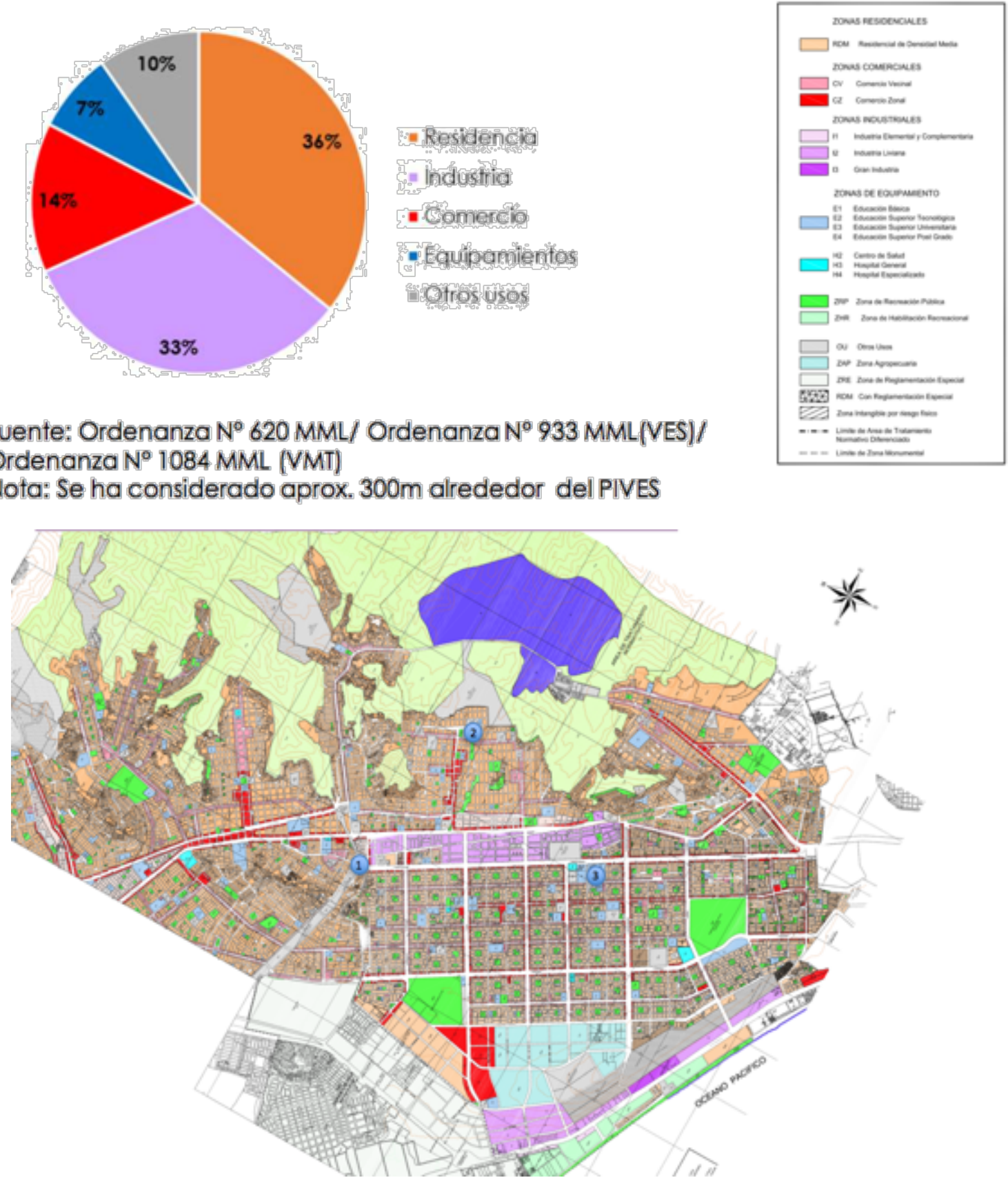

IMAGEN 7 -PLANO VILLA EL SALVADOR Y VILLA MARIA DEL TRIUNFO - MUNICIPALIDAD VILLA MARIA Y VILLA EL SALVADOR ZONIFICACION - MODIFICADO POR LERTORA (2015) 


\subsubsection{Sistema Vial (conexión con la ciudad)}

4.2.3.2.1.Vías expresas (regionales), semi-expresas, arteriales, colectoras, locales.

\subsection{Transporte Público}

La zona se encuentra conectada con la ciudad a través del tren eléctrico principalmente, además por el metropolitano que entra por la Av. El Sol en Villa El Salvador.

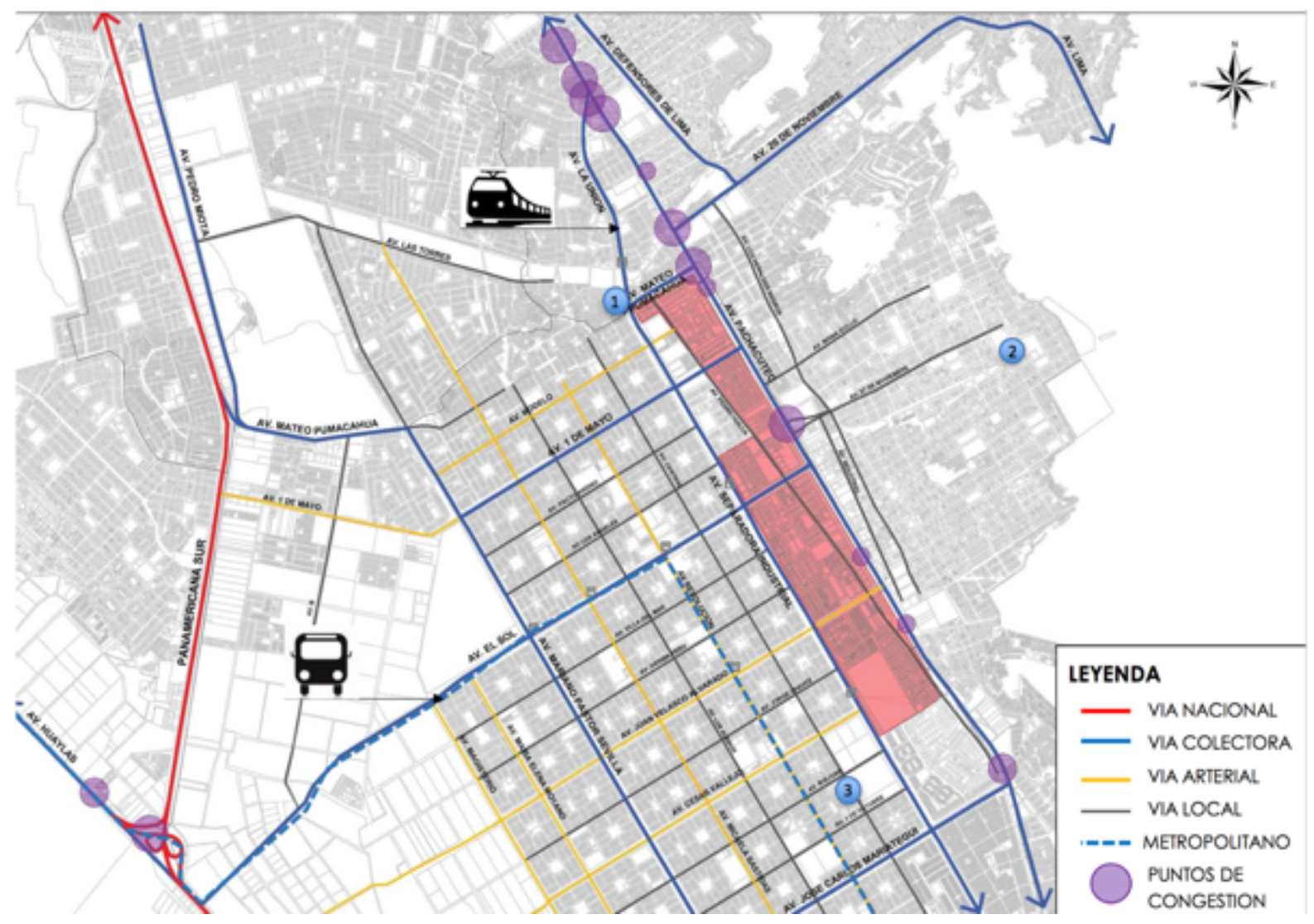




\subsubsection{Hitos}

Dentro de los hitos, el principal es el PIVES y los parques zonales.

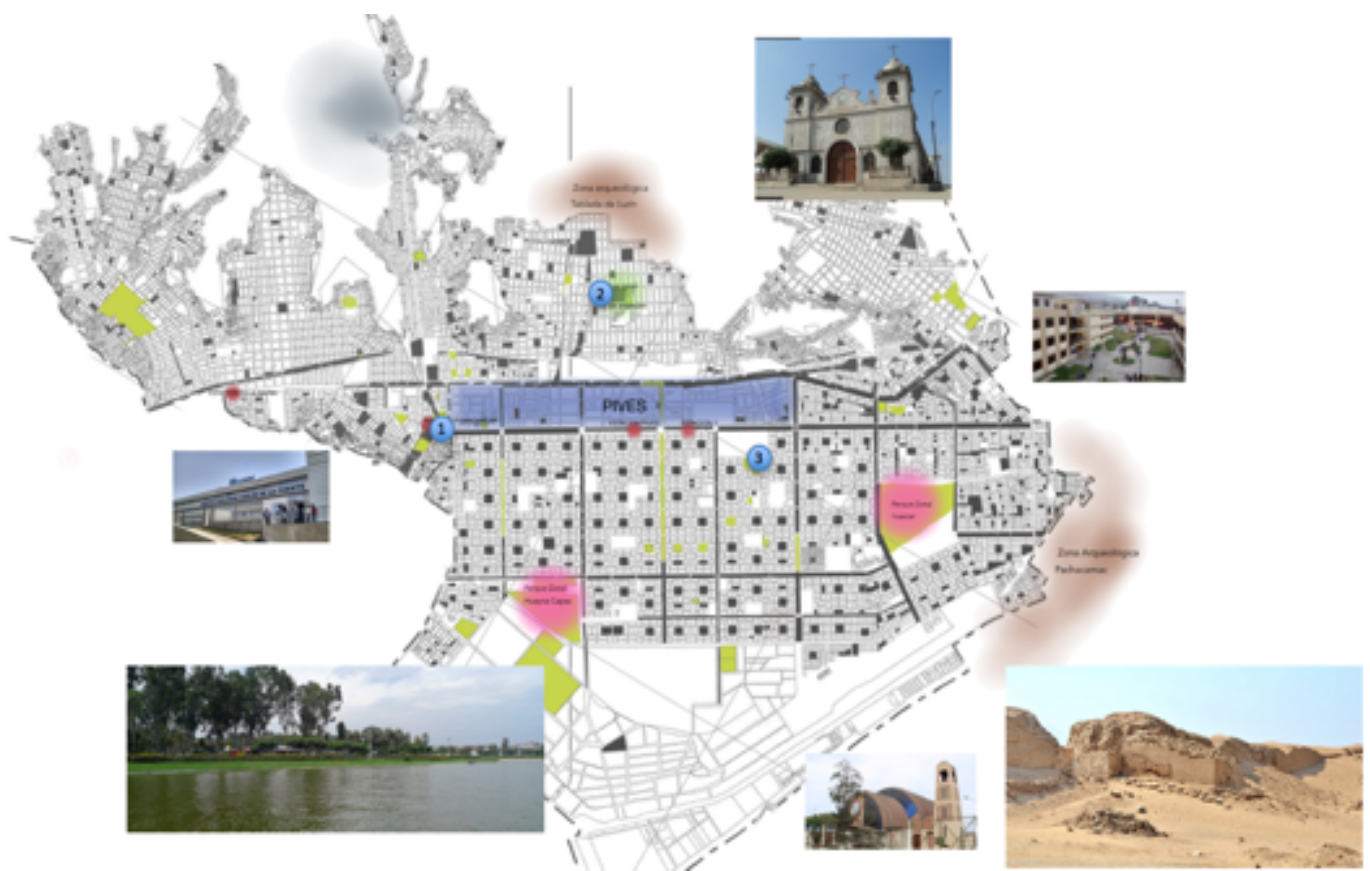

IMAGEN 9 -PLANO VILLA EL SALVADOR Y VILLA MARIA DEL TRIUNFO - LERTORA (2015)
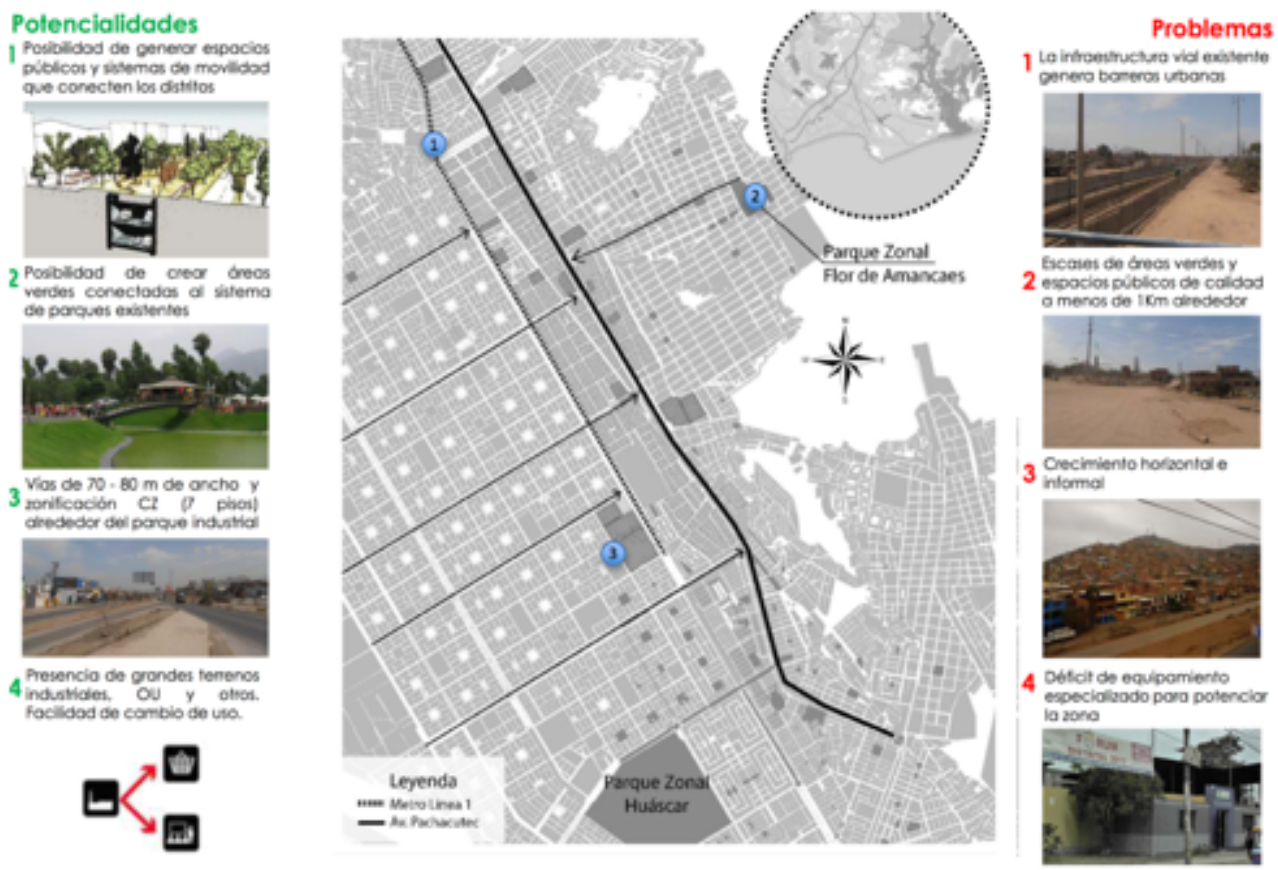


\subsubsection{Clima}

El clima combina una ausencia casi total de precipitaciones, con un alto nivel de humedad y persistente cobertura nubosa. La costa central peruana, muestra una serie de microclimas atípicos debido a la influyente y fría corriente de Humboldt que se deriva de la Antártida, la cercanía de la cordillera y su ubicación geográfica, dándole a Lima un clima subtropical, fresco, desértico y húmedo a la vez.

Se puede decir, que tiene un clima tibio sin excesivo calor tropical ni fríos extremos que requieran tener calefacción en casa, a excepción de muy pocos inviernos. La temperatura promedio anual es de 18,5 a $19{ }^{\circ} \mathrm{C}$, con un máximo estival anual de unos $29{ }^{\circ} \mathrm{C}$. Los veranos, de diciembre a abril, tienen temperaturas que oscilan entre los 29 a $30^{\circ} \mathrm{C}$ durante el día y 21 a $22{ }^{\circ} \mathrm{C}$ en las noches. Solamente cuando ocurre el Fenómeno del Niño, la temperatura en la estación de verano puede superar $\operatorname{los} 31^{\circ} \mathrm{C}$. Los inviernos van de junio a mediados de septiembre, con temperaturas que oscilan entre los 19 y $12^{\circ} \mathrm{C}$, siendo 8,8 ${ }^{\circ} \mathrm{C}$ la temperatura más baja comprobada históricamente.57 Los meses de primavera y otoño (septiembre, octubre y mayo), tienen temperaturas templadas que oscilan entre los 23 y $17^{\circ} \mathrm{C} .104$

\subsubsection{Humedad}

La humedad relativa es sumamente alta (hasta el 100\%), produciendo neblina persistente de junio a diciembre hasta la entrada del verano cuando las nubes son menores. Es soleado, húmedo y caliente en los veranos (diciembre-abril), nuboso y templado en los inviernos (junio a septiembre). La lluvia es casi nula.58 El promedio anual es de $7 \mathrm{~mm}$ reportado en el Aeropuerto Internacional Jorge Chávez, siendo la menor cantidad en un área metropolitana en el mundo. Una lluvia en Lima puede ser vista como un fenómeno extraño por la mayor parte de la población. 105

\begin{tabular}{|c|c|c|c|c|c|c|c|c|c|c|c|c|c|}
\hline \multicolumn{13}{|c|}{ Parámetros climáticos promedio de Aeropuerto Internacional Jorge Chávez (13 msnm), Lima } & [ocultar] \\
\hline Mes & Ene & Feb & Mar & Abr & May & Jun & Jul & Ago & Sep & Oet & Nov & Dic & Anual \\
\hline Temperatura máxima absoluta $\left({ }^{\circ} \mathrm{C}\right)$ & 31 & 32 & 32 & 31 & 30 & 2 & 30 & 26 & 26 & 26 & 27 & 31 & 32 \\
\hline Temperatura maxima media $\left({ }^{\circ} \mathrm{C}\right)$ & 26 & 26 & 26 & 24 & 22 & 20 & 19 & 18 & 19 & 20 & 22 & 24 & $n$ \\
\hline Temperatura minima media $\left({ }^{\circ} \mathrm{C}\right)$ & 20 & 20 & 20 & 18 & 17 & 16 & 15 & 15 & 15 & 16 & 17 & 18 & 17 \\
\hline Temperatura minima absoluta $\left({ }^{\circ} \mathrm{C}\right)$ & 16 & 17 & 16 & 13 & 12 & 11 & 10 & 10 & 10 & 10 & 8 & 10 & s \\
\hline Lluvias (mm) & 10 & 10 & 10 & 10 & 0 & 10 & 70 & 20 & 60 & 20 & 0 & 0 & 80 \\
\hline Horas de sol & 179.1 & 169.0 & 139.2 & 184.0 & 116.4 & 50.6 & 20.6 & 323 & 37.3 & 65.3 & 89.0 & 139.2 & 1284 \\
\hline Humedad relativa (\%) & 79.5 & 60 & 60.5 & 62 & 89.5 & 825 & 625 & 63.5 & 69 & 81.5 & 70.5 & 79 & 81.5 \\
\hline \multicolumn{14}{|c|}{ Fuente $n^{*} 1$ : Whatherbase, (Temperatura, precipiacion $y$ humedad relativa), ${ }^{68}$} \\
\hline \multicolumn{14}{|c|}{ Fuente ne2: Unviversidad Complutense de Madhid. (Horas de so/) ${ }^{67}$} \\
\hline
\end{tabular}

IMAGEN 11 - CLIMA DE LIMA PERÚ (2012) 


\subsubsection{Dirección del viento}

\subsubsection{Recorrido solar}

Los vientos diurnos son más cálidos y vienen del oeste y van hacia el norte. En la noche los vientos son entre temperados y fríos, van de Suroeste a Norte.

El recorrido solar es de Este a Oeste.

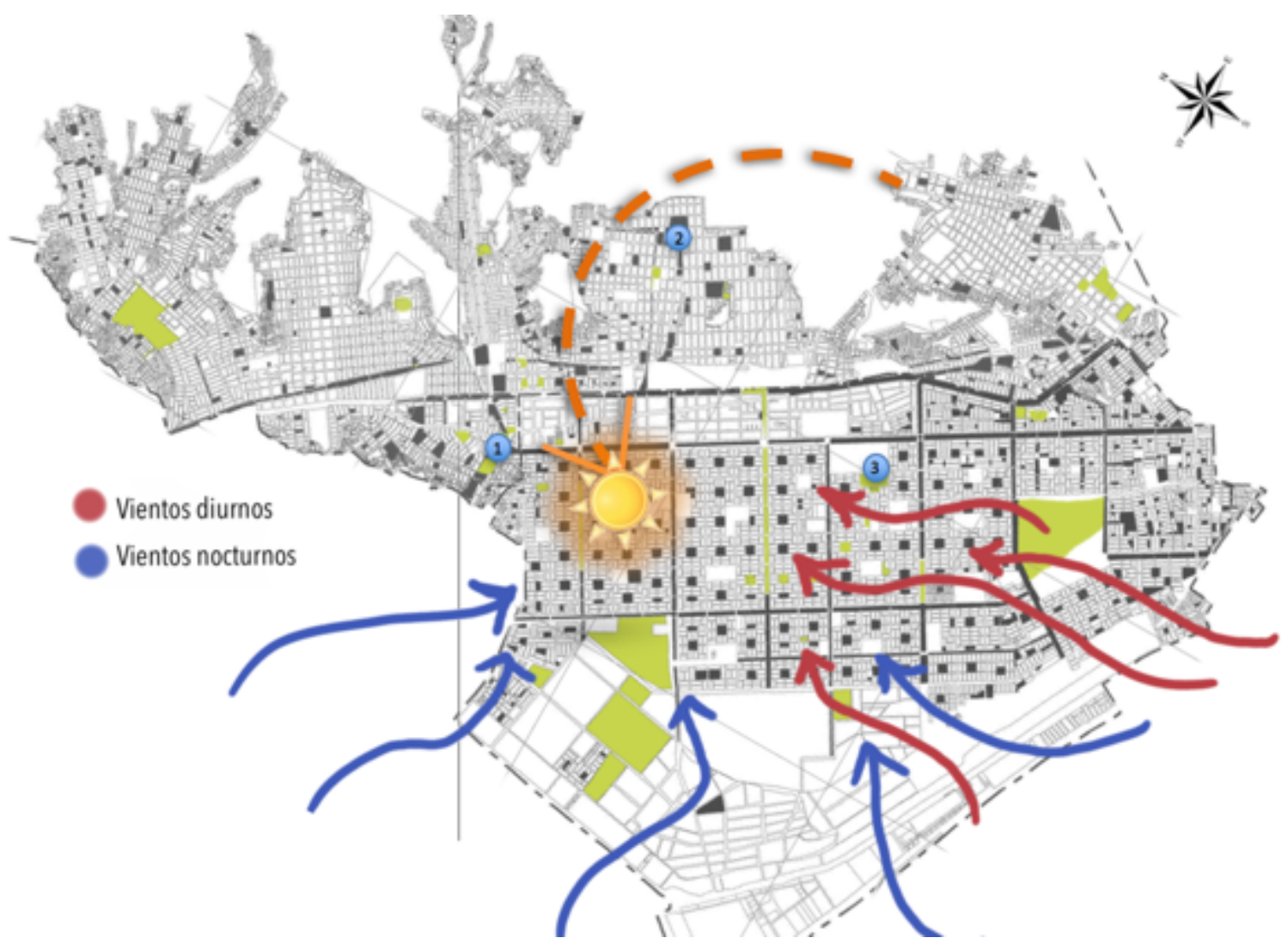




\subsection{Criterios De Selección Del Terreno}

Considero importante que el terreno elegido se encuentre en una zona accesible y de alto flujo o de posible alto flujo.

Con un área mínima de $6000 \mathrm{~m} 2$ en los que a pesar de que el proyecto no sea toda esta área, que exista la posibilidad de diseñar el entorno urbano y que se vuelva un proyecto detonante para la zona. Además, este proyecto tendrá un bosquejo de diseño del espacio urbano inmediato, porque busco aprovechar los terrenos vacíos y que son oportunidades para mejorar la zona.

Una de las características principales de la ubicación es que se ubique en una zona que sea obvia la necesidad de este equipamiento.

La topografía que sea de preferencia de pendiente baja o de máximo de 2 pisos de diferencia de lado a lado.

La contaminación visual, sonora, y ambiental de esta zona es precaria por lo que busco mejorarlo con el proyecto más que buscar una zona con una mejor calidad ambiental.

Es necesario que sea un terreno compatible con un edificio polideportivo y que los parámetros permitan libertad en el diseño del polideportivo.

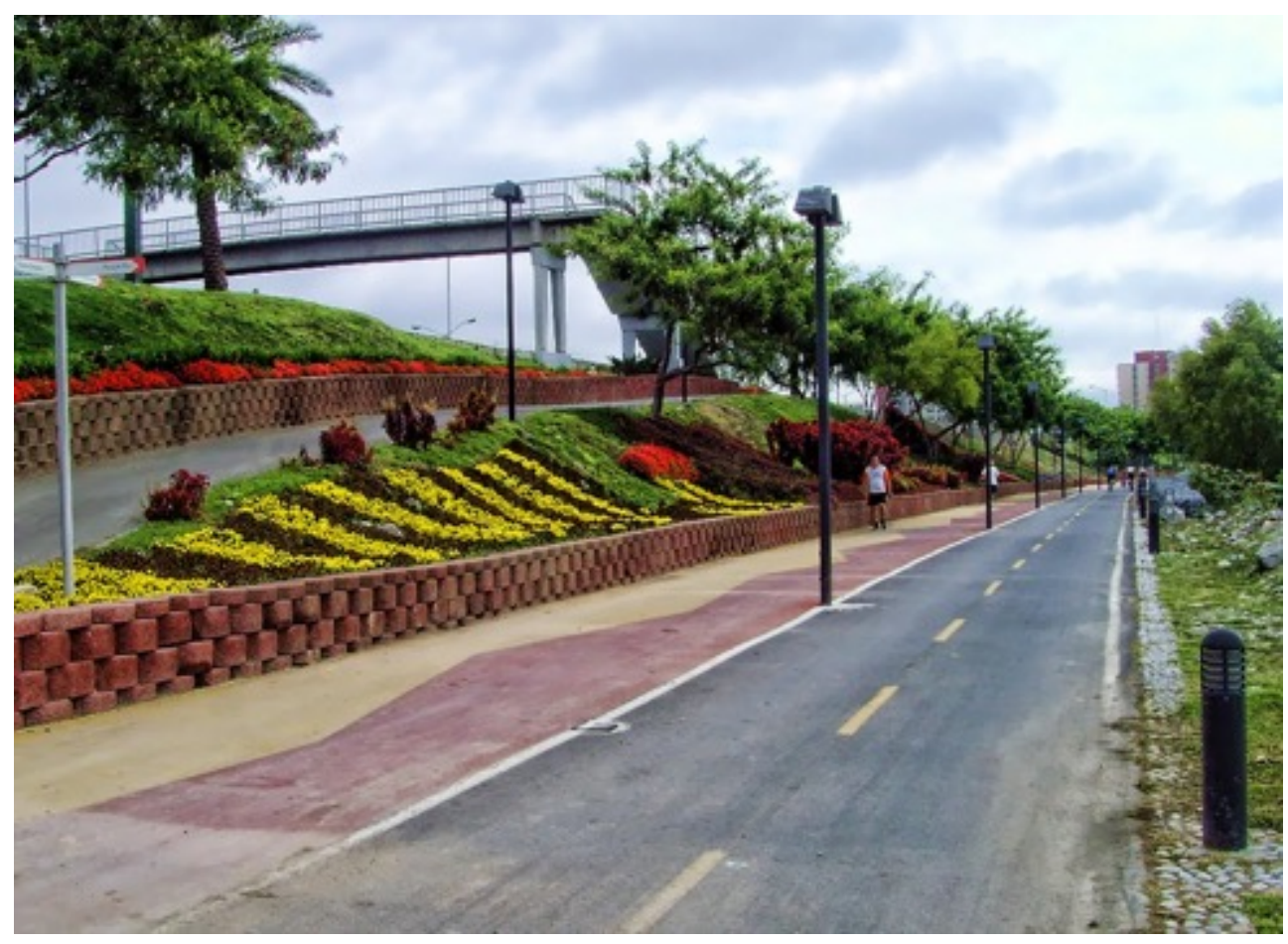

IMAGEN 13 - OSHBELT (2008) 


\subsection{Características De Los Terrenos}

\subsubsection{Datos generales}

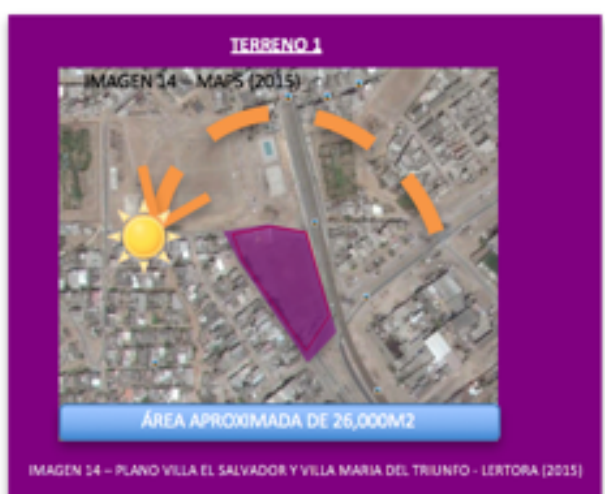

\section{UBICACIÓN}

El terreno se ubica en el distrito de Villa Maria del Triunfo. El proyecto sería el eslabón entre ambos. Se encuentra en la esquina de la Av. Pumacahua con la Av. Separadora Industrial.

\section{ACCESIBILIDAD}

Cuenta con la estación del tren eléctrico a un lado y se encuentra al lado de 2 avenidas colectoras importantes para Lima Sur. Además las lineas alimentadoras del metro pasaran por la Av. Pumacahua.

\section{CONDICIONES FISICAS}

Área aproximada de $26,000 \mathrm{~m} 2$

Se encuentra dentro de un eje de carácter deportivo. Que tiene un proyecto de rehabilitación actualmente.

Cuenta con 4 frentes a la calle.

\section{SITUACION}

El terreno es de la Municipalidad y tiene zonificación $\mathrm{OU}$.

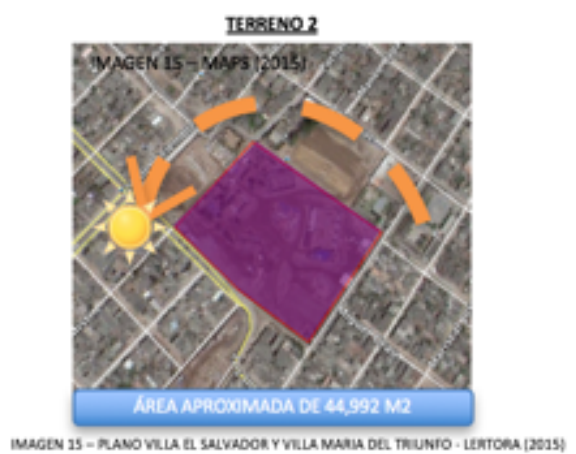

\section{UBICACIÓN}

El terreno se ubica en Villa María del Triunfo. Se encuentra en el nuevo parque zonal Flor de Amancaes.

\section{ACCESIBILIDAD}

Se encuentra insertado al lado de un parque $y$ frente a un terreno con zonificación OU (equipamiento) y 2 colegios. Se encuentra al lado de la Av. Los Incas que es una colectora que atraviesa gran parte del distrito.

\section{CONDICIONES FISICAS}

Área aproximada de 44,992 m2

Se encuentra dentro de un eje recreativo $\mathrm{y}$ tiene un proyecto de rehabilitación actualmente.

Cuenta con 4 frentes a la calle.

\section{SITUACION}

El terreno es de la Municipalidad y tiene zonificación OU (complejo deportivo).

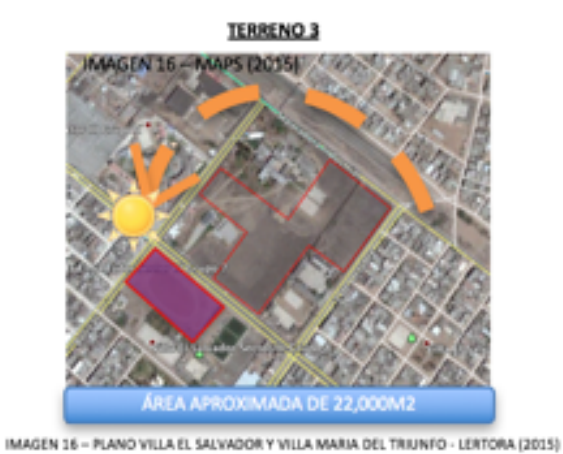

\section{UBICACIÓN}

El terreno se ubica en Villa el Salvador. En una manzana atípica dentro del tejido urbano del distrito.

\section{ACCESIBILIDAD}

Se encuentra cerca de la ultima estación del tren eléctrico. Al lado de la Av. Separadora Industrial. Se encuentra cerca de 2 paradas de el metropolitano y a 2 manzanas de la estación del tren eléctrico.

\section{CONDICIONES FISICAS}

Área aproximada de $22,000 \mathrm{~m} 2$

Se encuentra dentro de una zona de colegios e institutos.

Cuenta con 2 frentes a la calle.

\section{SITUACION}

El terreno es de la Municipalidad y tiene zonificación OU. 


\subsubsection{Parámetros Urbano-arquitectónicos}

4.4.2.1. Zonificación y compatibilidad de uso, Altura de la Edificación, Retiros, Número de estacionamientos
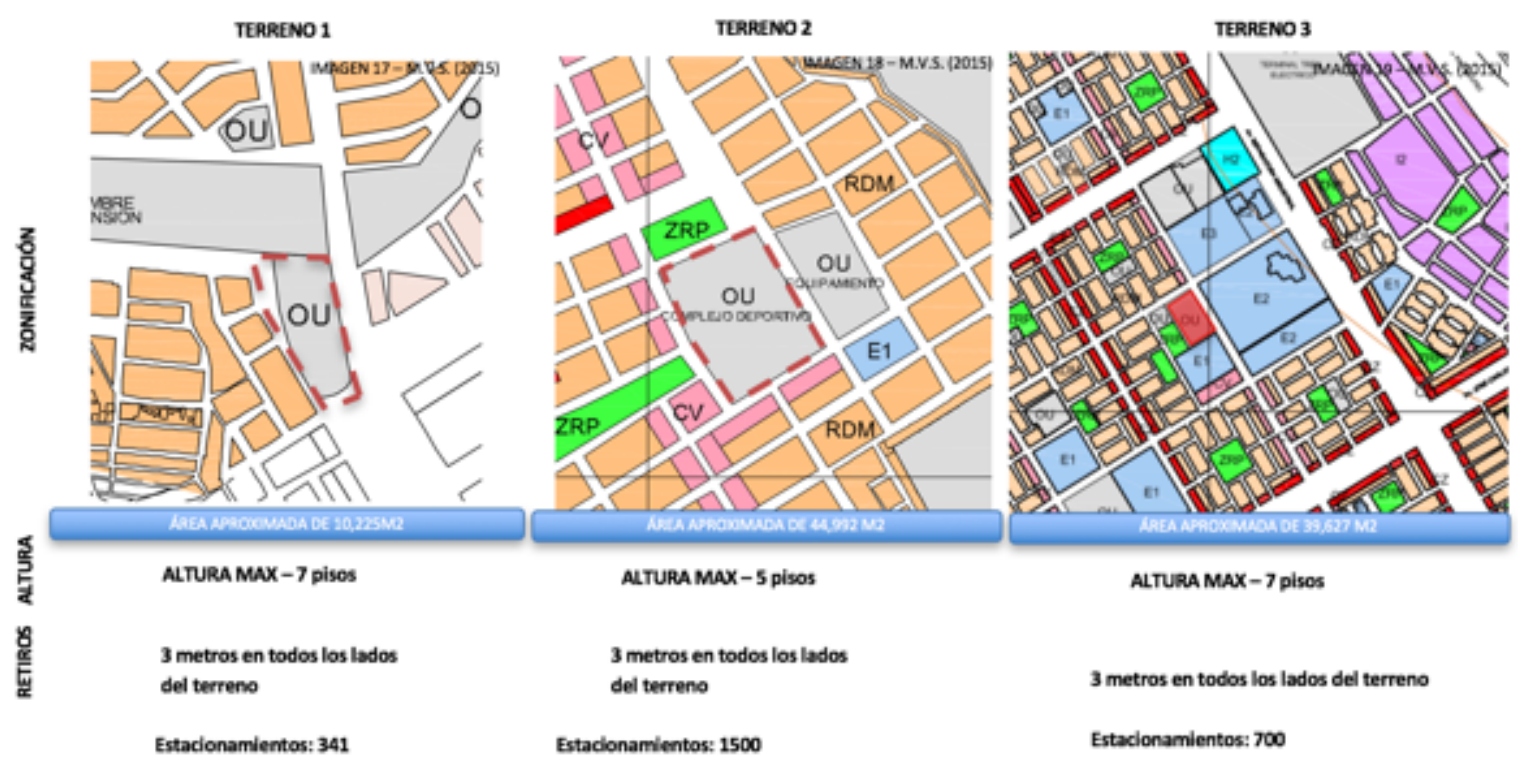

\subsubsection{Análisis Espacial}

4.4.3.1. Recorridos por calles peatonales y vehiculares. Descripción acompañada por fotografías, con sus respectivos comentarios.

4.4.4. Entorno urbano. Descripción acompañada por fotografías, con sus respectivos comentarios. ¿Qué problemas o condicionantes del entorno debe resolver el proyecto?

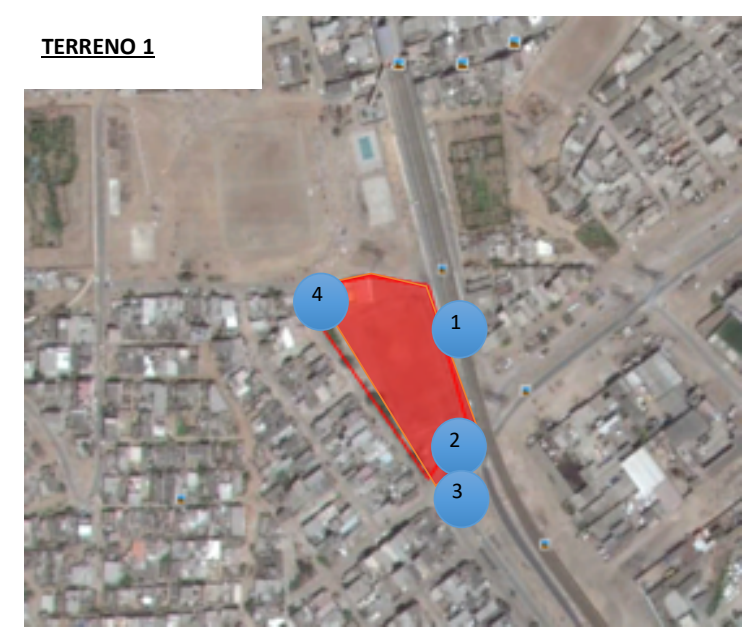

IMAGEN 20 - MAPS (2015) 
El terreno 1 se encuentra al lado de las líneas del tren el cual está en esta zona elevado, y sobre la Av. Separadora Industrial.

Esta avenida tiene un alto flujo, y se mantiene activa durante todo el día. La presencia de la estación crea un flujo en la zona Norte del terreno. Debería consolidarse con el proyecto.

Es en esta que se ve acumulación de desperdicios lo que el proyecto debería mejorar.

1. Vista desde las líneas del tren, el paisaje es importante, presenta un gran cerro en la parte posterior dándole carácter al terreno, lo veo como una oportunidad.

2. Vista desde la Ca. Pumacahua desde donde se aprecian los 3 principales condicionantes del terreno. Los cables de alta tensión, el cerro y el tren eléctrico.

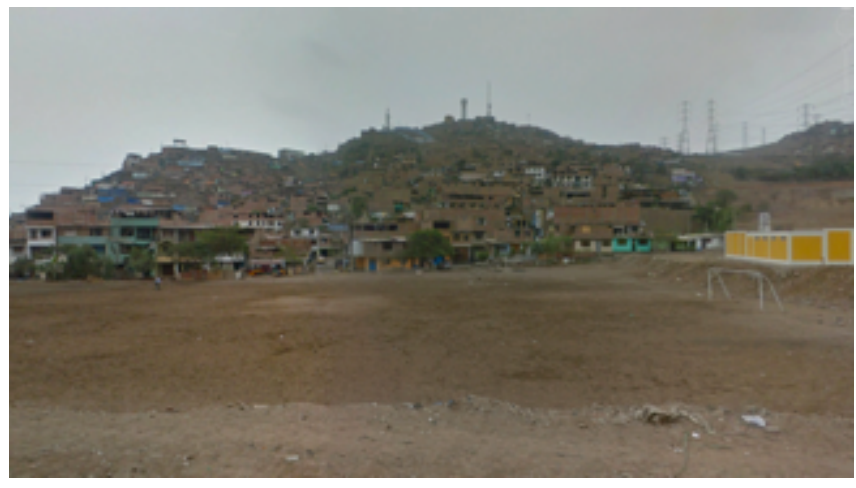

IMAGEN 22 - MAPS (2015)

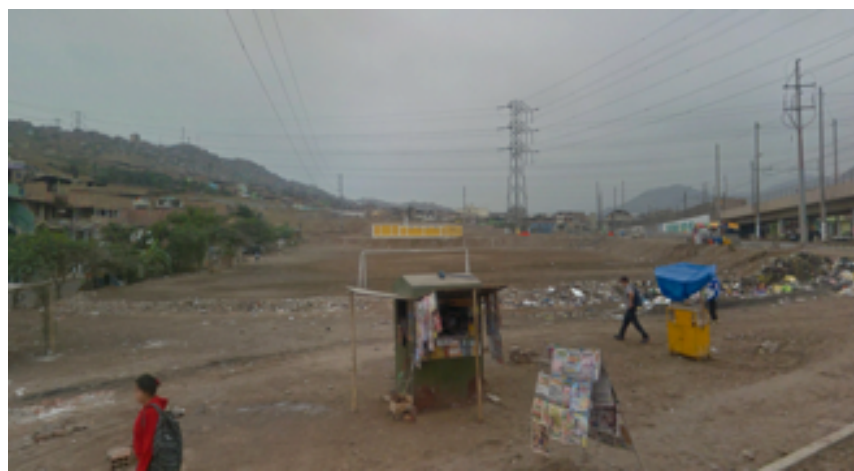

IMAGEN 21 - MAPS (2015) 
3. Vista desde la Ca. Santa Cruz de Flores donde se ve enmarcada por el contexto de solo 2 pisos la vista hacia el cerro.

4. Desde esta vista se puede ver todo el terreno, en el que actualmente hay una cancha informal donde se hacen algunas actividades recreacionales y se reúnen a juagar fútbol los fines de semana.

Se puede ver que el terreno tiene una ligera pendiente. Cuenta con huertas frente a la zona Oeste del terreno.

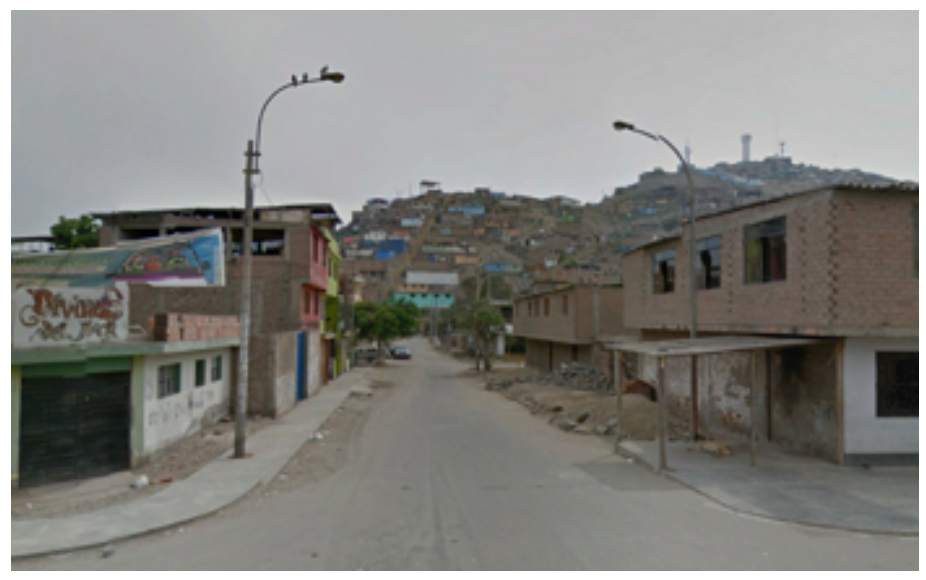

IMAGEN 23 - MAPS (2015)

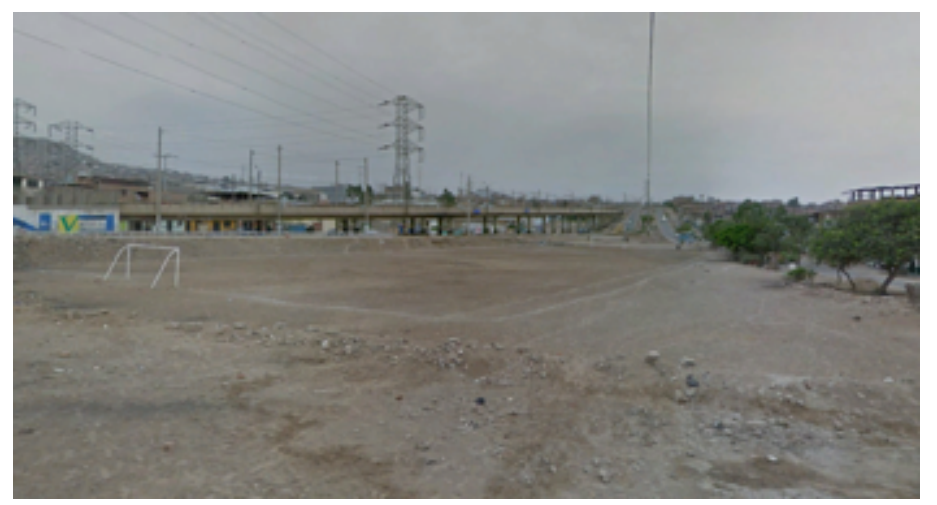

IMAGEN 24 - MAPS (2015) 


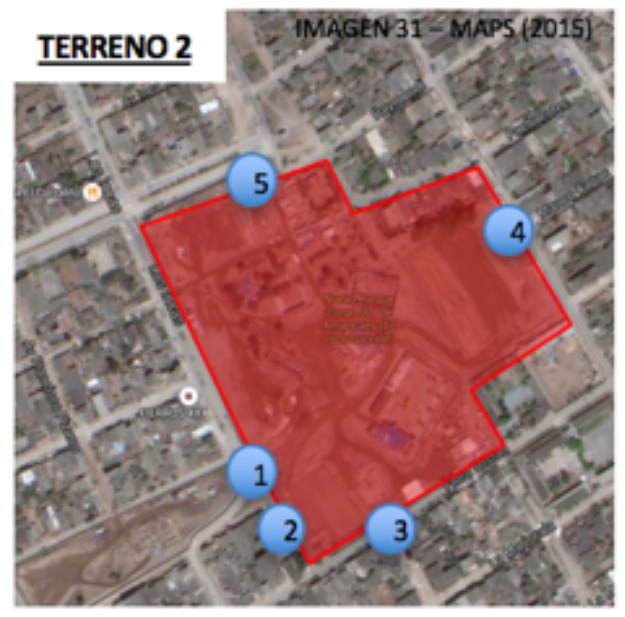

1 y 2. Vistas desde Av.Independencia. El terreno tiene acumulaciones de desperdicios en todo el perímetro.

3 Y 4. Vista desde la calle Flora Tristan y Calle Apurimac, donde se aprecia el contexto y la amplitud del terreno, tiene vista al cerro donde se encuentra la tablada de lurín. En esta zona hay una vereda y una intención de arbolizar pero aún sigue siendo una zona de pobre espacio público.

5. En esta vista se aprecia que inclusive donde se encuentra la señalización que esta prohibido botar basura es donde las personas botan los desperdicios.
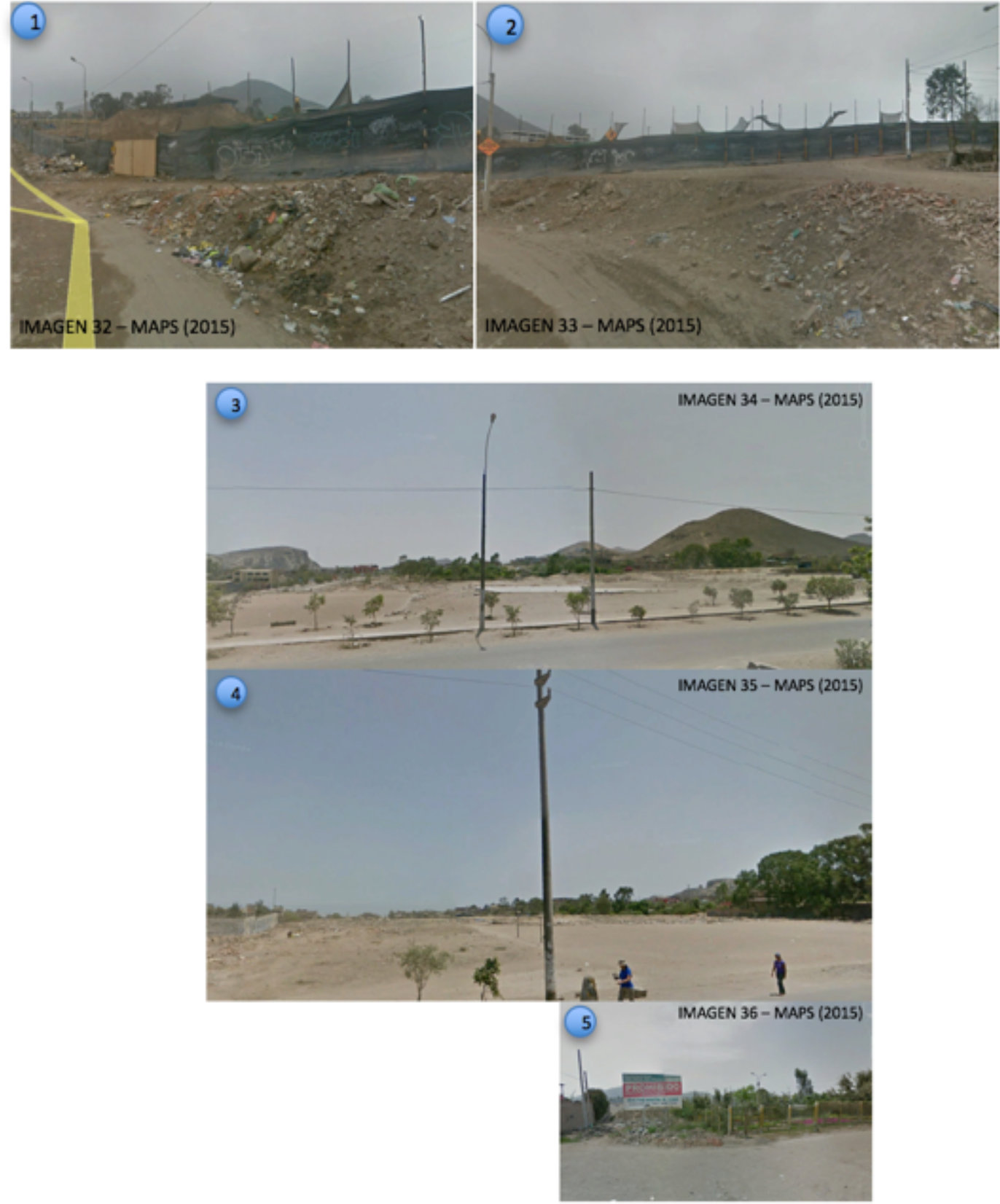

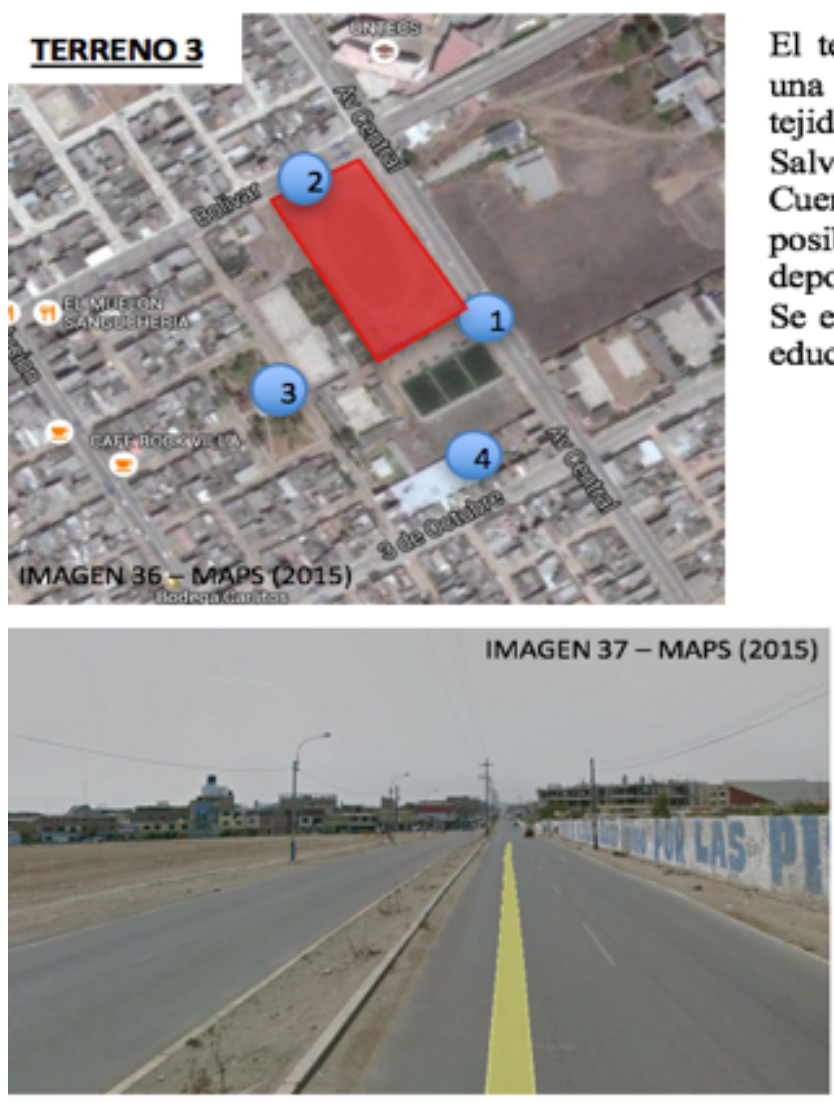

El terreno 3 se encuentra dentro de una manzana atípica dentro del tejido tradicional de Villa el Salvador.

Cuenta con 22,000 m2 lo que posibilitaria construir un complejo deportivo de gran escala.

Se encuentra en una zona de centros educativos y universidades.

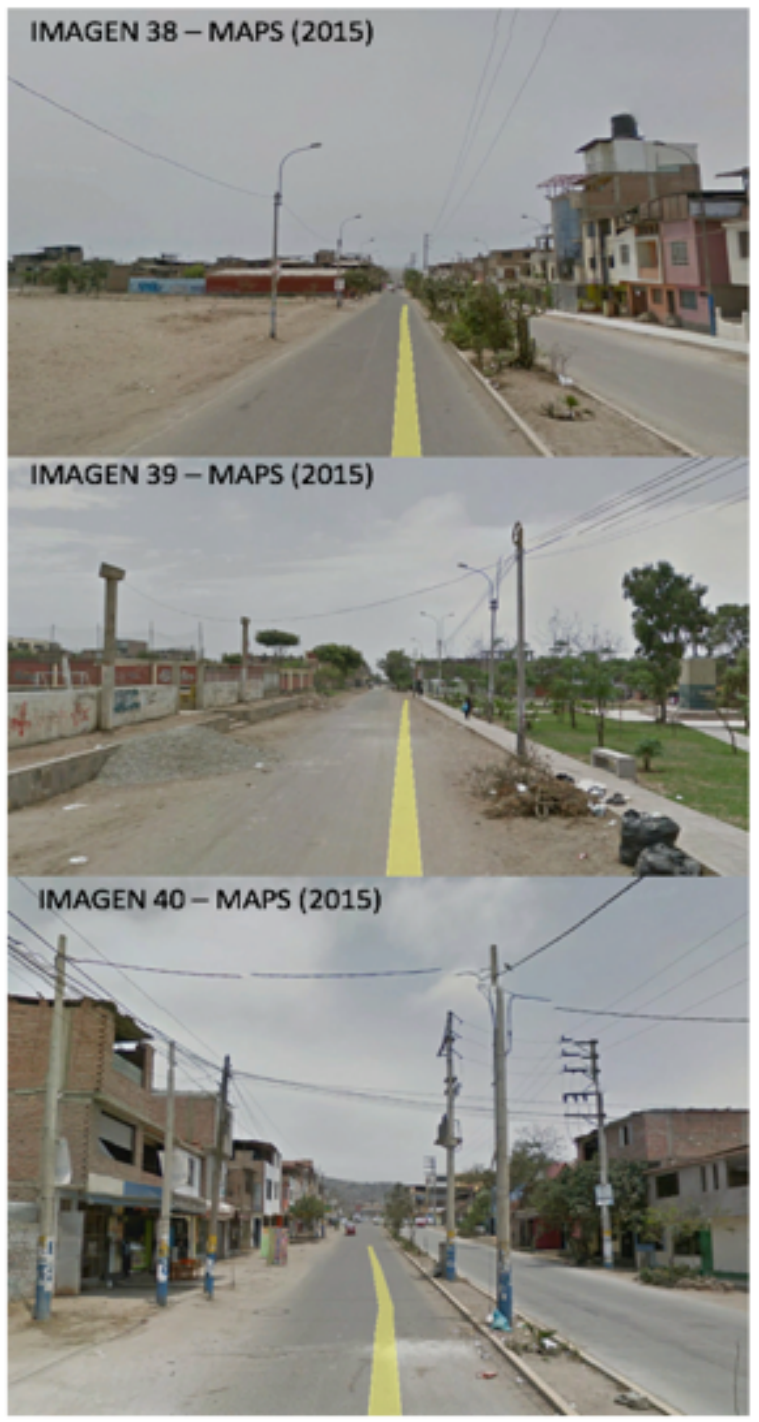

1. Vista desde Av. Central, la que atraviesa todo el distrito y tiene un ancho de via más amplio que otras y por donde se mantiene un alto flujo de vehiculos.

3. Vista desde la calle dentro de la manzana, que cuenta con un parque central a un lado $y$ canchas al aire libre al otro.

Existen restos de desmonte, de restos orgánicos del area verde y de basura.

4. Desde esta vista de la Av. 3 de octubre tiene un carácter comercial por ser una zona de universidades y de colegios. La zona es insalubre. 


\subsection{Cuadro De Valoración De Los Terrenos Según Criterios}

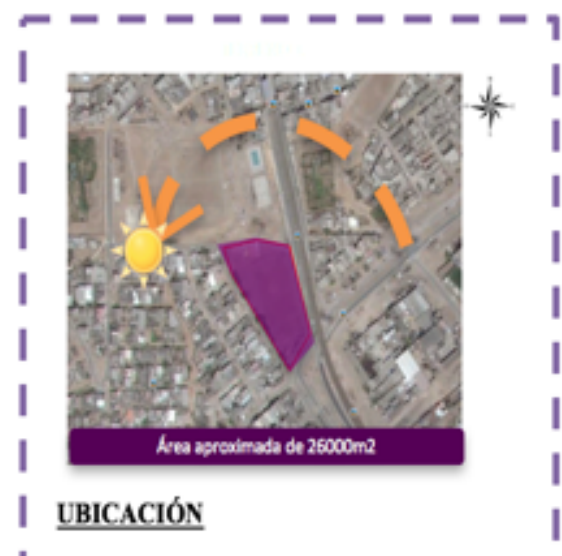

I El terreno se ubica entre los distritos de Villa I el Salvador y Villa María del Triunfo. El

I proyecto seria el eslabón entre ambos. Se

I encuentra en la esquina de la Av. Pumacahua

I con la Av. Separadora Industrial.

\section{ACCESIBILIDAD} I

| I

I I

CONDICIONES FISICAS

| Área aproximada de $26000 \mathrm{~m} 2$

I Se encuentra dentro de un eje de carácter

I deportivo. Que tiene un proyecto de

I rehabilitación actualmente.

I Cuenta con 4 frentes a la calle.

I SITUACION

El terreno es de la Municipalidad y tiene I

I

zonificación $\mathrm{OU}$
IERELNO2

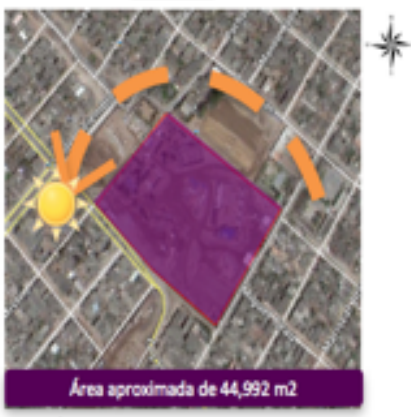

UBICACIÓN

El terreno se ubica en Villa Maria del Triunfo.

Se encuentra en el nuevo parque zonal Flor de

Amancaes.

\section{ACCESIBILIDAD}

I Se encuentra insertado al lado de un parque y I frente a un terreno con zonificación OU I (equipamiento) y 2 colegios. Se encuentra al lado de la Av. Los Incas que es una colectora I que atraviesa gran parte del distrito.

\section{CONDICIONES FISICAS}

I Área aproximada de 44,992 m2

I Se encuentra dentro de un eje recreativo y tiene I un proyecto de rehabilitación actualmente.

I Cuenta con 4 frentes a la calle.

\section{SITUACION}

I El terreno es de la Municipalidad y tiene zonificación OU (complejo deportivo).

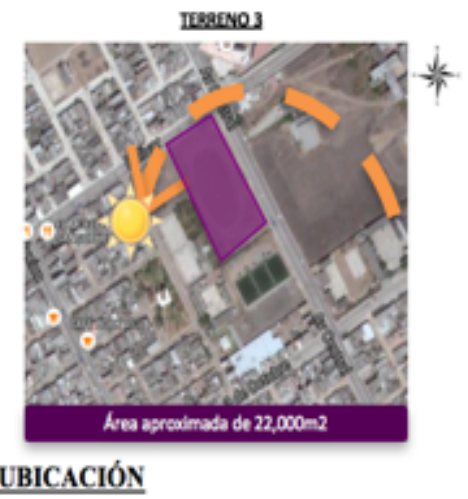

El terreno se ubica en Villa el Salvador. En una manzana atípica dentro del tejido urbano del distrito.

\section{ACCESIBILIDAD}

Se encuentra cerca de la ultima estación del tren eléetrico. Al una manzana de la Av. Separadora Industrial. En la Av. Central que conecta todo el distrito.

\section{CONDICIONES FISICAS}

Área aproximada de $22,000 \mathrm{~m} 2$

Se encuentra dentro de una zona de colegios e institutos.

Cuenta con 2 frentes a la calle.

\section{SITUACION}

El terreno es de la Municipalidad y tiene zonificación $\mathrm{OU}$. 


\subsection{Cuadro De Valoración De Los Terrenos Según Criterios Y Ventajas Y Desventajas}

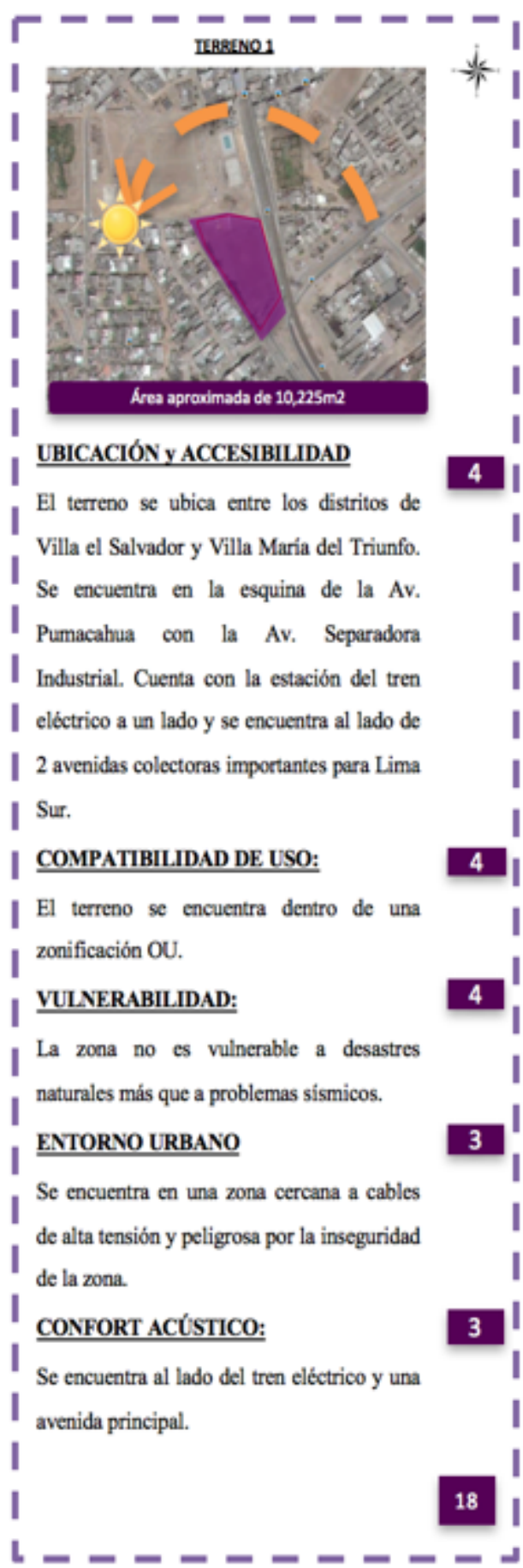

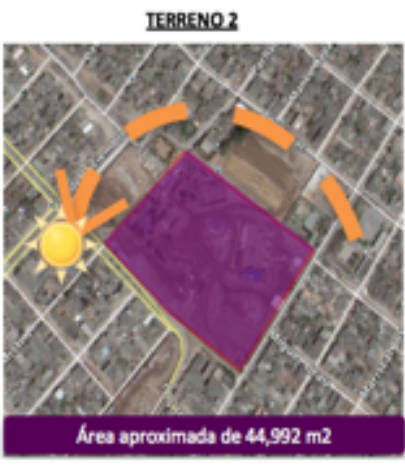

UBICACIÓN Y ACCESIBILIDAD

El terreno se ubica en Villa Maria del Triunfo. Se encuentra en el nuevo parque zonal Flor de Amancaes. Se encuentra al lado de la Av. Los Incas que es una colectora que atraviesa gran parte del distrito.

\section{COMPATIBILIDAD DE USO:}

I Se encuentra insertado al lado de un parque I y frente a un terreno con zonificación OU

La zona no es vulnerable a destres naturales más que a problemas sísmicos.

\section{ENTORNO URBANO}

Se encuentra en una poco consolidada.

\section{CONFORT ACÚSTICO:}

Se encuentra en una zona altamente contaminada por problemas de trafico.

3

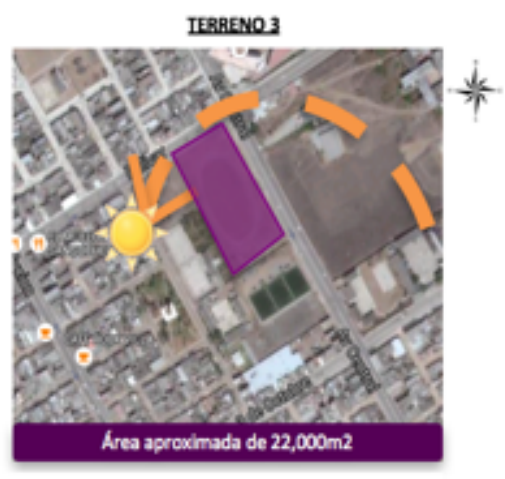

\section{UBICACIÓN y ACCESIBILIDAD}

El terreno se ubica en Villa el Salvador. En una manzana atipica dentro del tejido urbano del distrito. Se encuentra cerca de la ultima estación del tren eléctrico. Al una manzana de la Av. Separadora Industrial. En la Av. Central que conecta todo el distrito.

\section{COMPATIBILIDAD DE USO:}

Se encuentra insertado en una zona de

zonificación OU.

\section{VULNERABILIDAD:}

La zona no es vulnerable a desastres naturales más que a problemas sísmicos.

\section{ENTORNO URBANO}

2 Se encuentra en una poco consolidada. CONFORT ACÚSTICO: Se encuentra en una zona altamente contaminada por problemas de trafico.

IMAGEN 45 - CUNDRO DE VALORACION DE LOS TERRENOS SEGÚN CRITERIOS VENTANAS Y DESVENTAUAS (2015) LERTORA 
5.EXPEDIENTE URBANO 


\section{EXPEDIENTE URBANO}

\subsection{El Área}

5.1.1. El terreno y el área de influencia

5.1.2. Áreas verdes y zonas públicas

5.1.3. Zonas protegidas e intangibles, zonas arqueológicas y áreas de amortiguamiento, monumentos históricos, ambientes históricos

5.1.4. Hitos, nodos.

5.2. EI terreno y su entorno inmediato

5.2.1. Información del terreno

5.2.1.1. Ubicación (dirección), propiedad, situación

5.2.1.2. Área, linderos, orientación, topografía

\subsubsection{Parámetros urbanísticos}

5.2.2.1. Zonificación

5.2.2.2. Altura

5.2.2.3. Retiros

5.2.2.4. Estacionamientos

5.2.2.5. Compatibilidad de usos de suelo

5.2.2.6. Especificaciones normativas

5.2.3. Planos urbanos del terreno y entorno inmediato:

5.2.3.1. Zonificación y Usos de suelo (planos y comentarios)

5.2.3.2. Volumetría y tipología, edificaciones (planos y comentarios)

5.2.3.3. Llenos y vacíos (planta) (planos y comentarios)

5.2.3.4. Alturas de las edificaciones (planos y comentarios)

5.2.3.5. Vialidad (planos y comentarios)

5.2.3.5.1. Paraderos

5.2.3.5.2. Líneas de transporte público (metropolitano, tren eléctrico, buses etc.) y sus futuras ampliaciones

5.2.3.6. Secciones de vías y veredas (planos y comentarios)

5.2.3.7. Levantamiento de árboles, postes, $\mathrm{u}$ otros elementos relacionados al terreno, al interior $y$ al exterior, que sean condicionantes para el diseño

5.2.3.8. Circulaciones peatonales, alamedas, plazas, etc. (planos y comentarios)

5.2.3.9. Áreas de conflicto: contaminación sonora, alto tránsito vehicular, comercio ambulatorio etc.

5.2.3.10. ¿Qué problemas o condicionantes del entorno debe resolver el proyecto?

5.2.4. Aspectos históricos

5.2.4.1. Reseña histórica

5.2.4.2. Monumentos (planos y comentarios)

5.2.4.3. Ambientes urbanos monumentales (planos y comentarios)

5.2.5. Levantamiento fotográfico, mostrando el estado actual del terreno y de la zona, recorrido por todas las calles, con análisis espacial, y comentarios. 


\subsection{EL ÁREA}

\subsubsection{El terreno y el área de influencia}

El terreno se encuentra ubicado en los límites de Villa María del Triunfo, el proyecto sería el eslabón conector entre VMT. y VS. Se encuentra a 2 cuadras de la estación Pumacahua y cuenta con un paradero en el cruce de la Av. Separadora Industrial con la Av. Pumacahua.

Cuenta con un área de $8860 \mathrm{~m} 2$ en la cual se ubicaría el Polideportivo. Uno de los lados del terreno es paralelo a las líneas del tren eléctrico (zona en la que esta elevado). La condición del espacio público es deplorable, no existen veredas ni semáforos, no hay área verde ni Ciclovías, la zona es altamente insalubre, etc. Además, no hay una protección a las personas de los cables de alta tensión que pasan sobre la Av. Unión, lo que me preocupa. Inclusive existen canchas debajo de estos cables sin ninguna prevención.

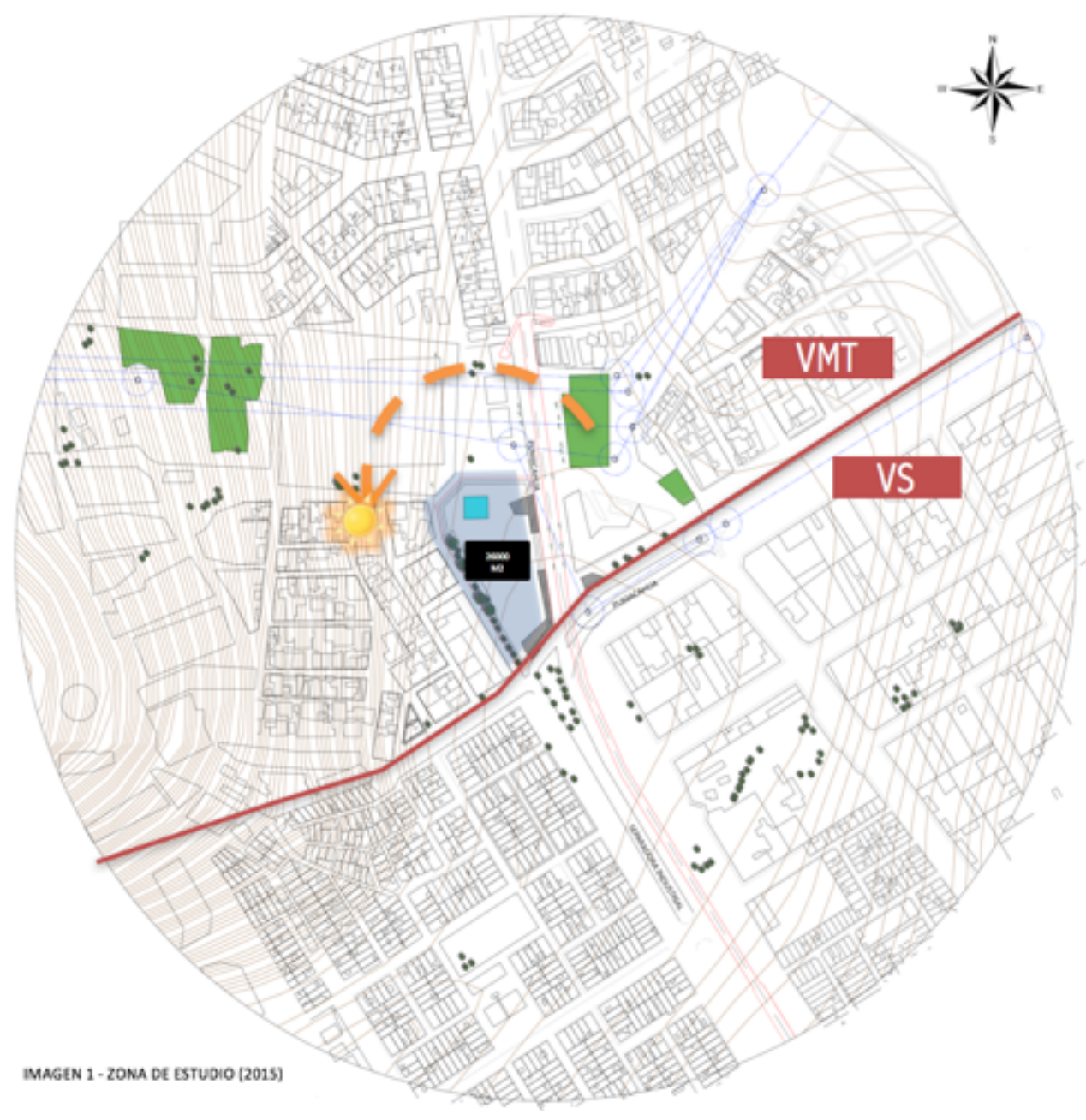




\subsection{2. Áreas verdes y zonas públicas}

La cantidad de áreas verdes es mínima en la zona a pesar de haber una oportunidad inmensa en 2 ejes clarísimos.

Mi proyecto buscará crear una estrategia en esta T vacía que conecta San Juan, Villa María y Villa el Salvador.

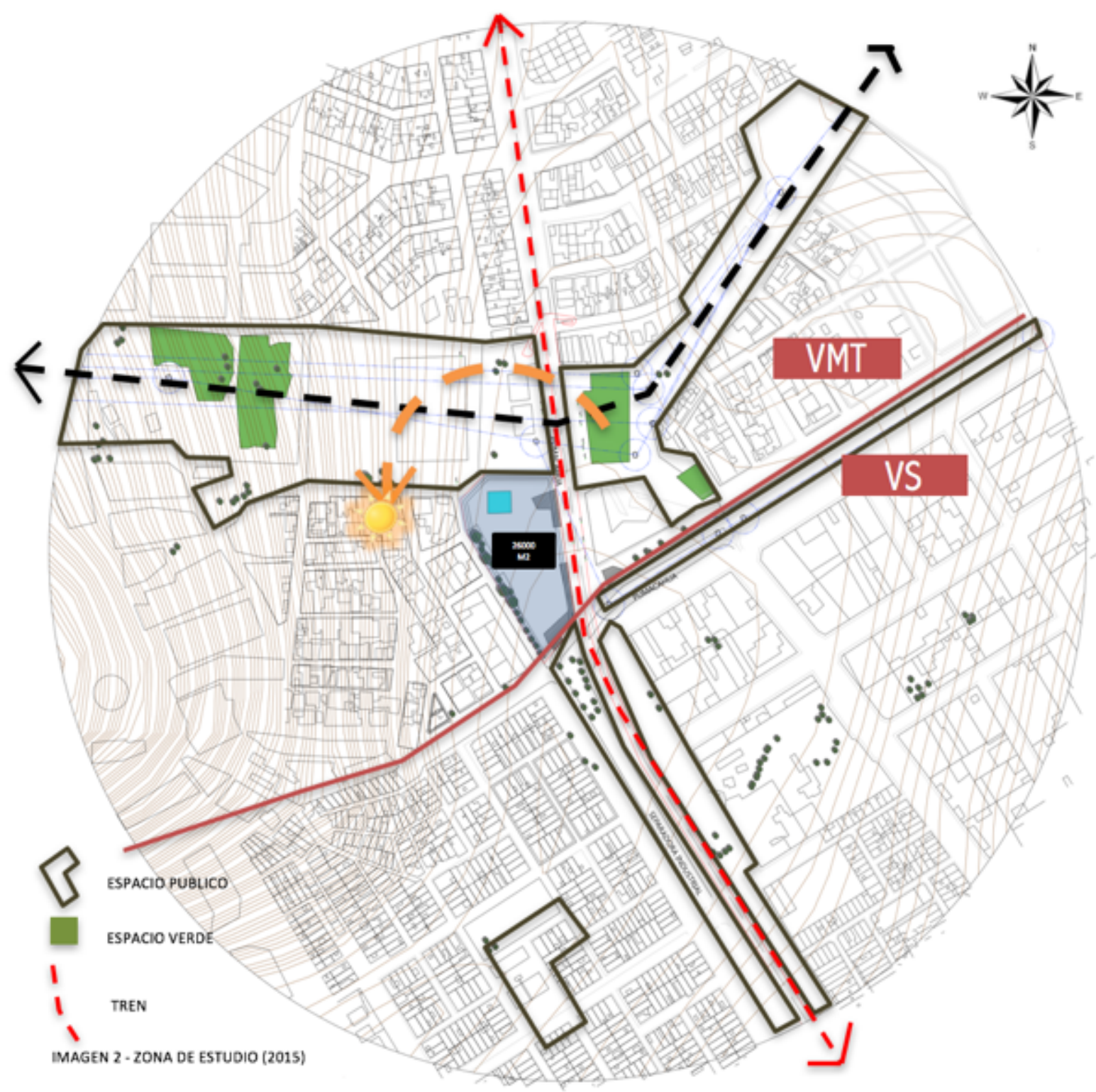


5.1.3. Zonas protegidas $\mathrm{e}$ intangibles, zonas arqueológicas $\mathrm{y}$ áreas de amortiguamiento, monumentos históricos, ambientes históricos

Esta zona dentro del proyecto, es una zona bajo la cual no se puede construir, pero sí es posible plantear un tratamiento paisajístico que aproveche esta área, la arborice y le dé un pulmón al Cono Sur de Lima.

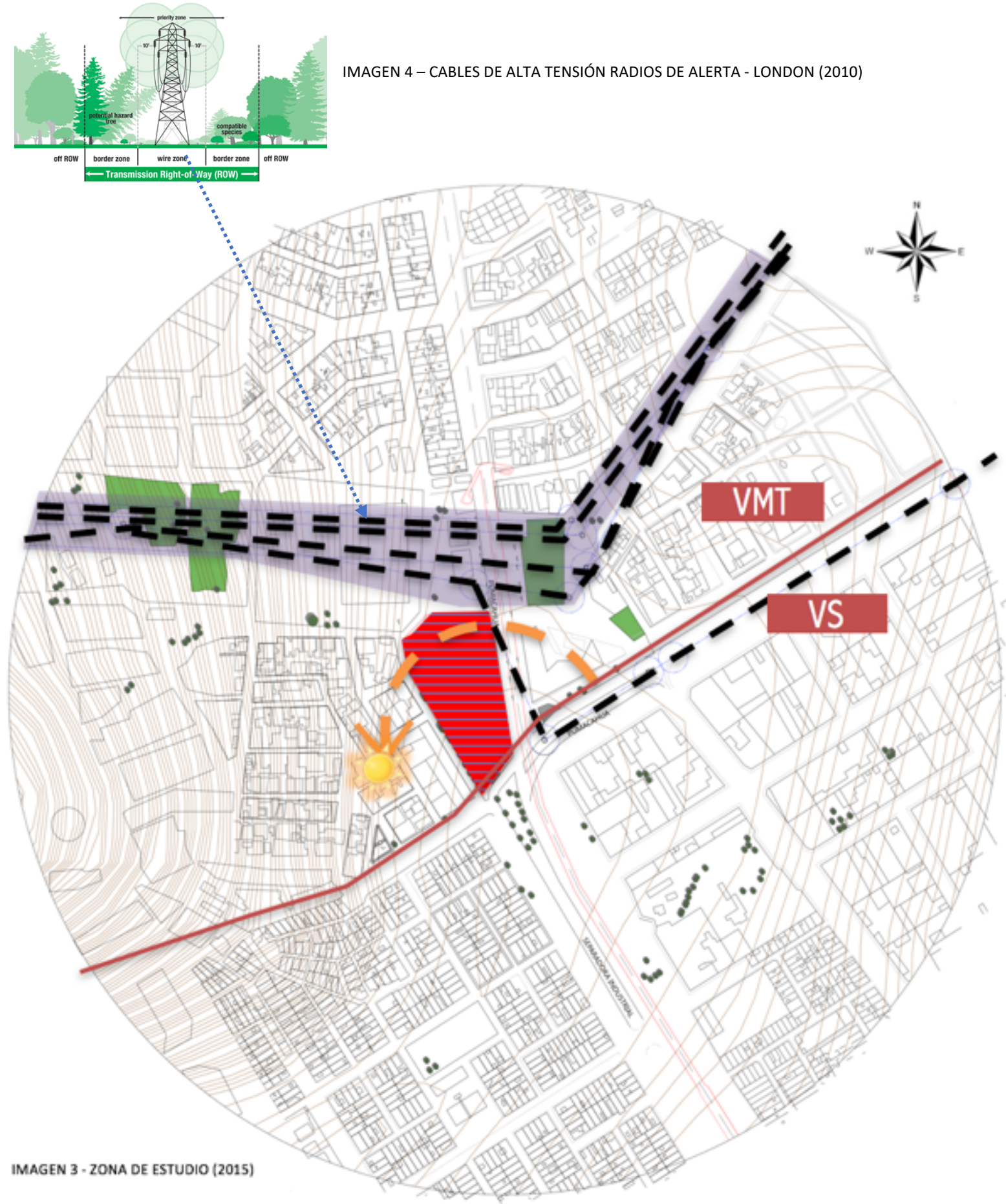




\subsubsection{Hitos, nodos}

Los hitos principales de la zona, son la Av. Separadora Industrial por su carácter atribuido por el tren eléctrico.

El cerro que por su altura y monumentalidad le da carácter a la zona.

La estación Pumacahua por su alto flujo de personas y su uso, es un elemento de guía dentro de esta zona.

Sedapal es otro hito de la zona por que las personas de la zona lo utilizan como punto de ubicación.

El puente peatonal que se encuentra un poco fuera de la zona de estudio es un hito de la zona porque es el elemento de conexión entre un lado y otro de Villa el Salvador.

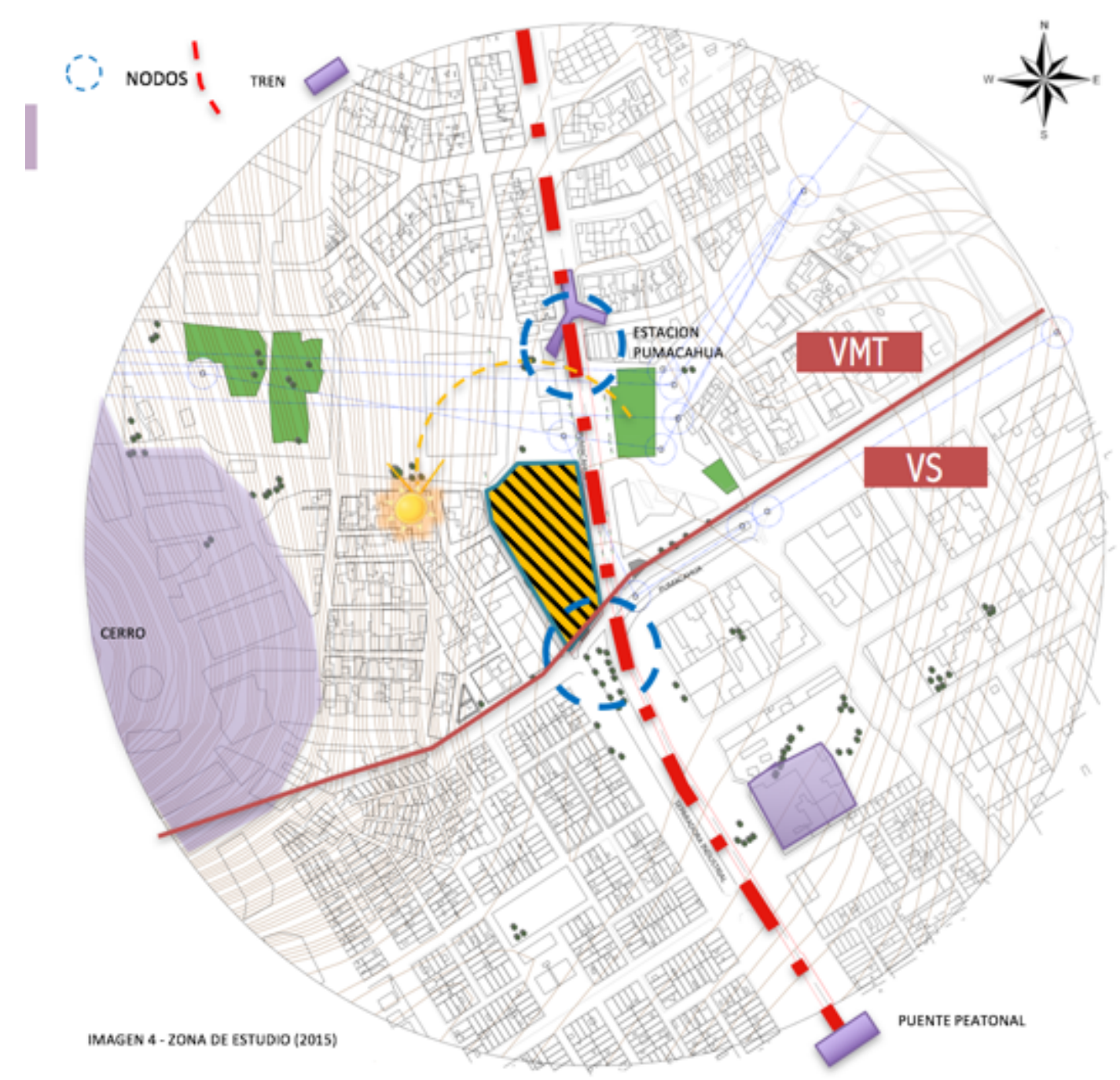




\subsection{EL TERRENO Y SU ENTORNO INMEDIATO}

\subsubsection{Información del terreno}

\subsubsection{Ubicación, propiedad, situación}

Se encuentra en la Av. Pumacahua 1482 Villa María del Triunfo, Lima, Perú.

La propiedad es de la Municipalidad de Villa el Triunfo se encuentra bajo el eje que está actualmente bajo la directiva de un proyecto urbanístico en el que se unió la Municipalidad de San Juan de Lurigancho con la Municipalidad de Villa María del Triunfo en el cual plantean regenerar la zona.

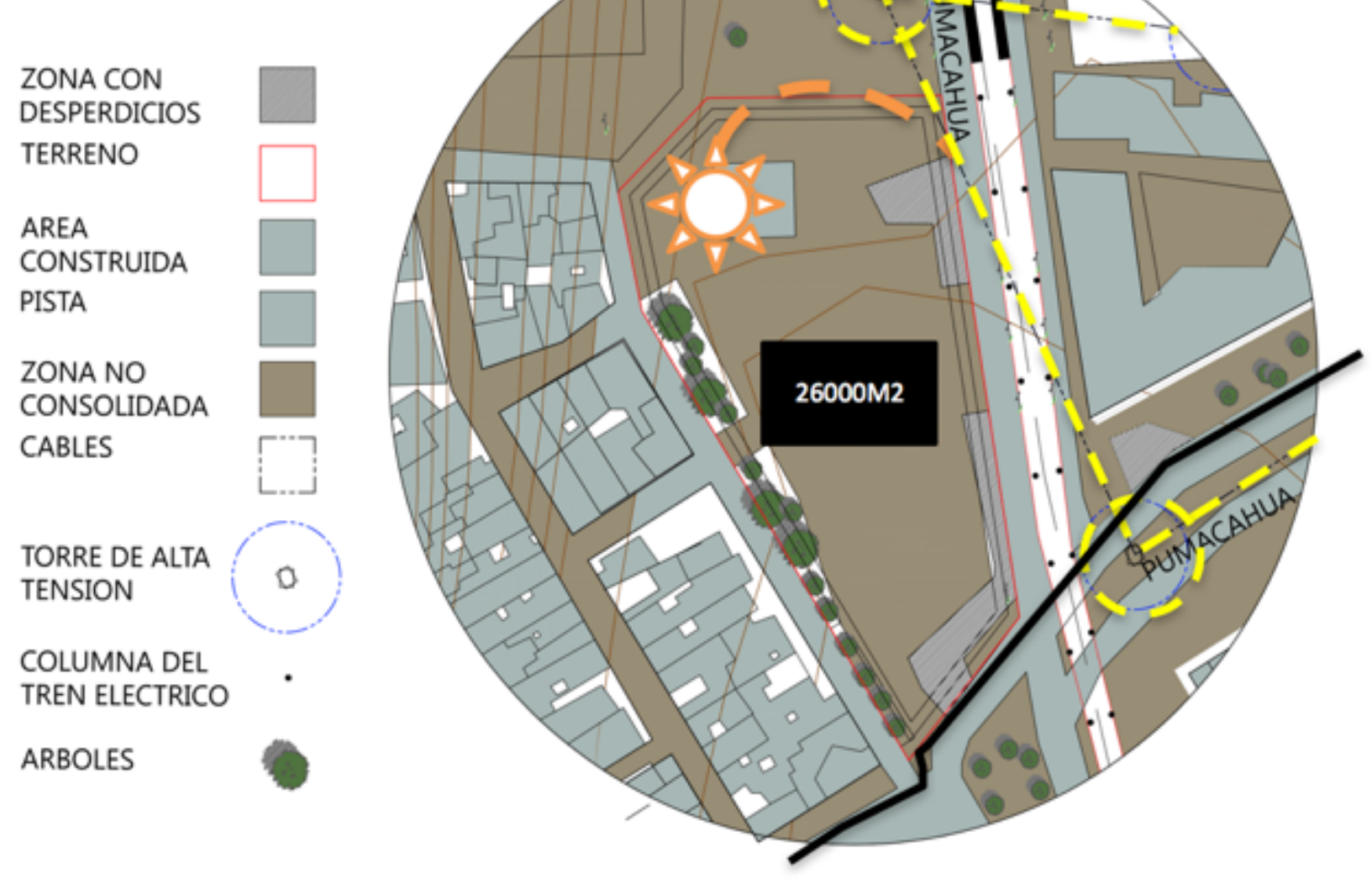

IMAGEN 5 - ZONA DE ESTUDIO (2015) 


\subsubsection{2. Área, linderos, orientación, topografía}

- Tiene un área de $26000 \mathrm{~m} 2$

- Tiene una orientación del Noroeste al Sureste.

- La topografía como se ve en el Gráfico, tiene una pendiente de $5 \mathrm{mts}$ de un lado al otro lo que permitiría enterrar parte del programa a un lado del terreno.

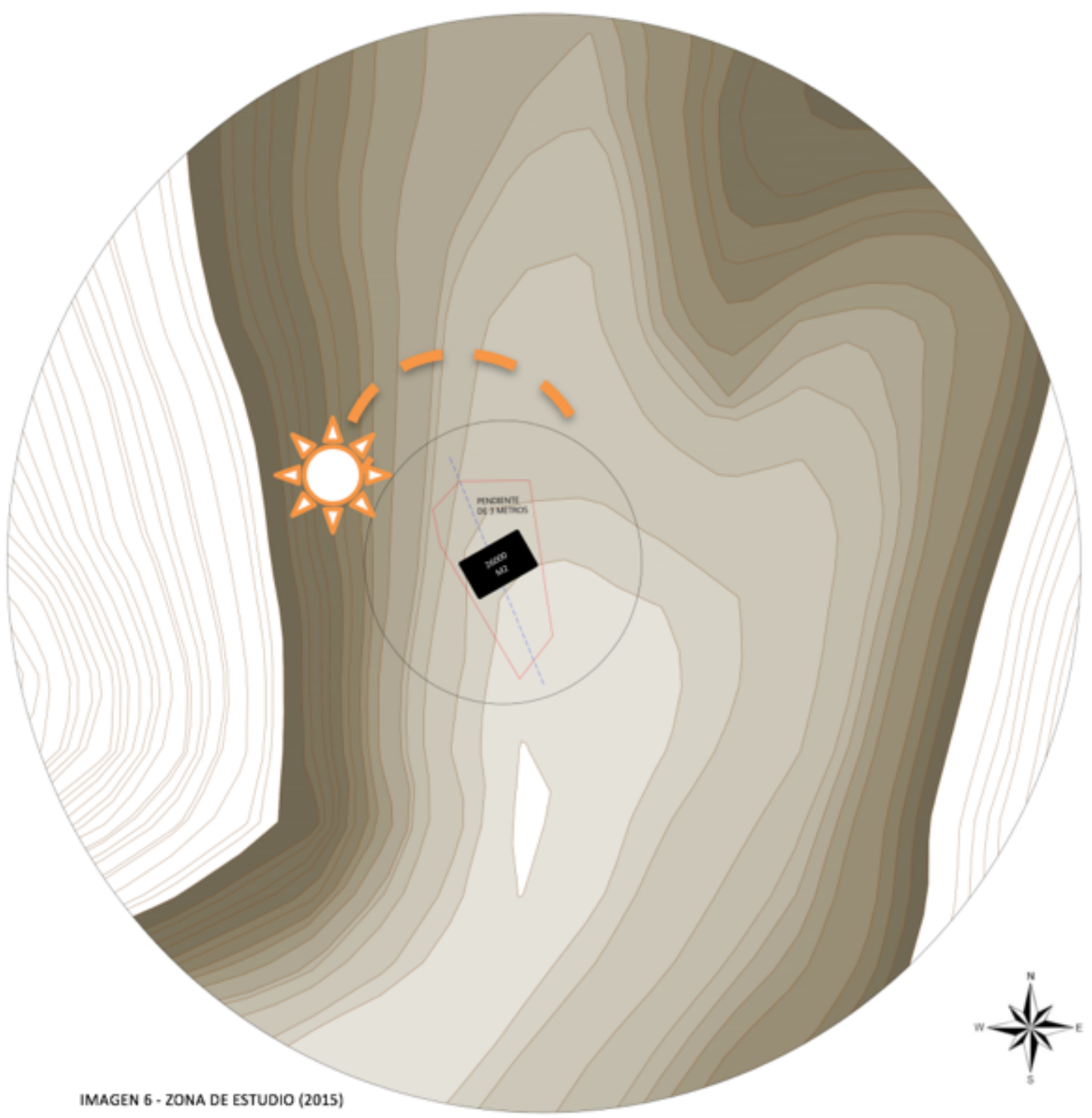




\subsubsection{Parámetros urbanísticos}

\subsubsection{Zonificación}

La zonificación del terreno es OU, la que permite colocar cualquier uso que sea compatible con la zonificación de la zona.

\subsubsection{Altura}

La altura máxima de la zona es de 7 pisos.

5.2.2.3. Retiros Según los parámetros el retiro mín. es $0 \mathrm{~m}$.

\subsubsection{Estacionamientos}

Para edificios de carácter deportivo indican 1 estacionamiento por cada 100 espectadores.

\subsubsection{Compatibilidad de usos de suelo}

Los usos de suelo en esta zona son primordialmente vivienda y comercio zonal lo que es compatible con un complejo deportivo.

\subsubsection{Especificaciones normativas}

La normativa indica que cada 100 espectador tendrá que haber 1 estacionamiento. 107

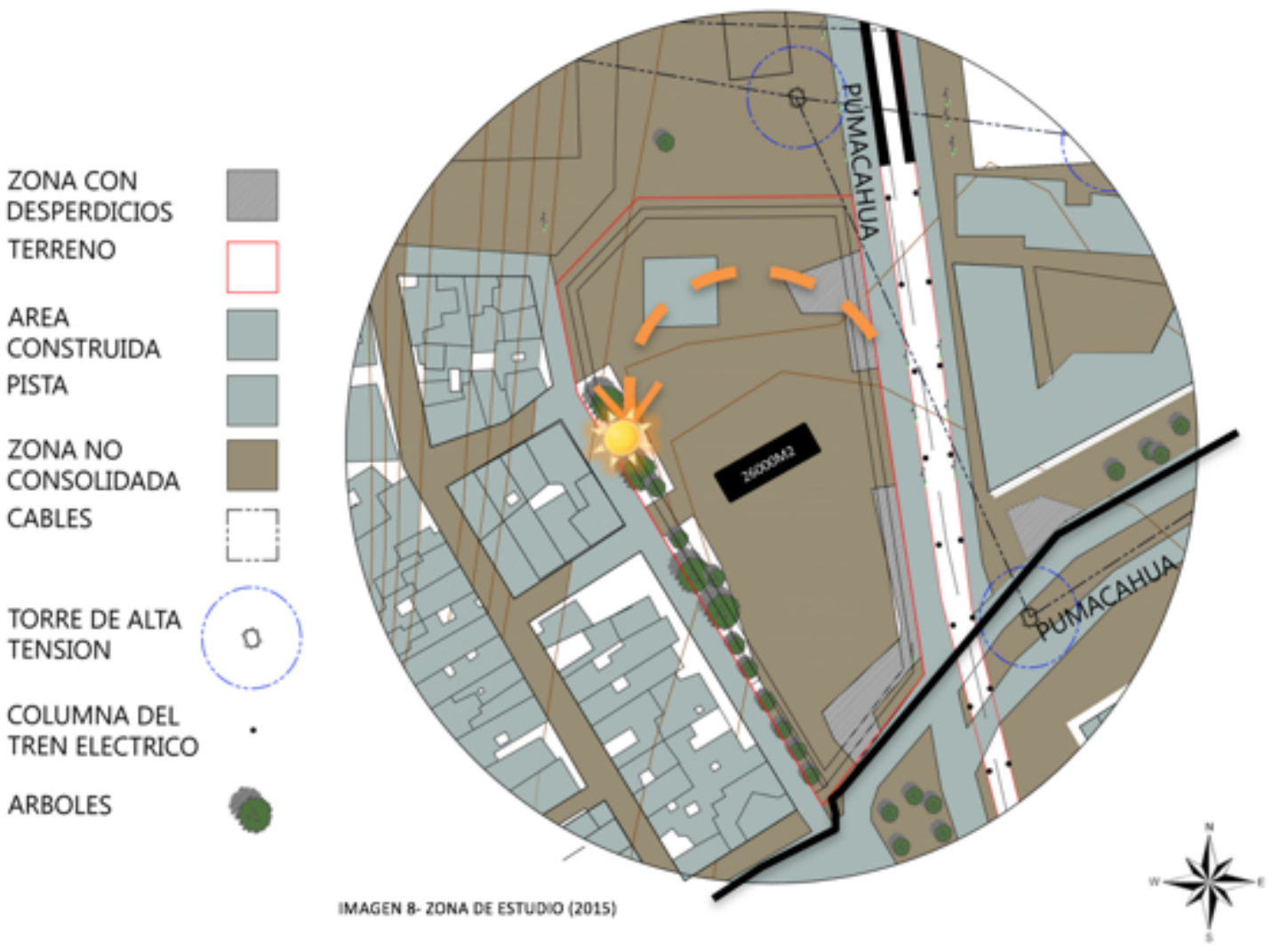




\subsubsection{Planos urbanos del terreno y entorno inmediato:}

\subsubsection{Zonificación y Usos de suelo (planos y comentarios)}

Los usos son distintos que los indicados en la zonificación de la municipalidad.

La zona de vivienda indicada por la municipalidad es donde se ubican también viviendas taller, comercios y colegios. En la zona industrial no solo hay fábricas, también existen talleres y viviendas taller.

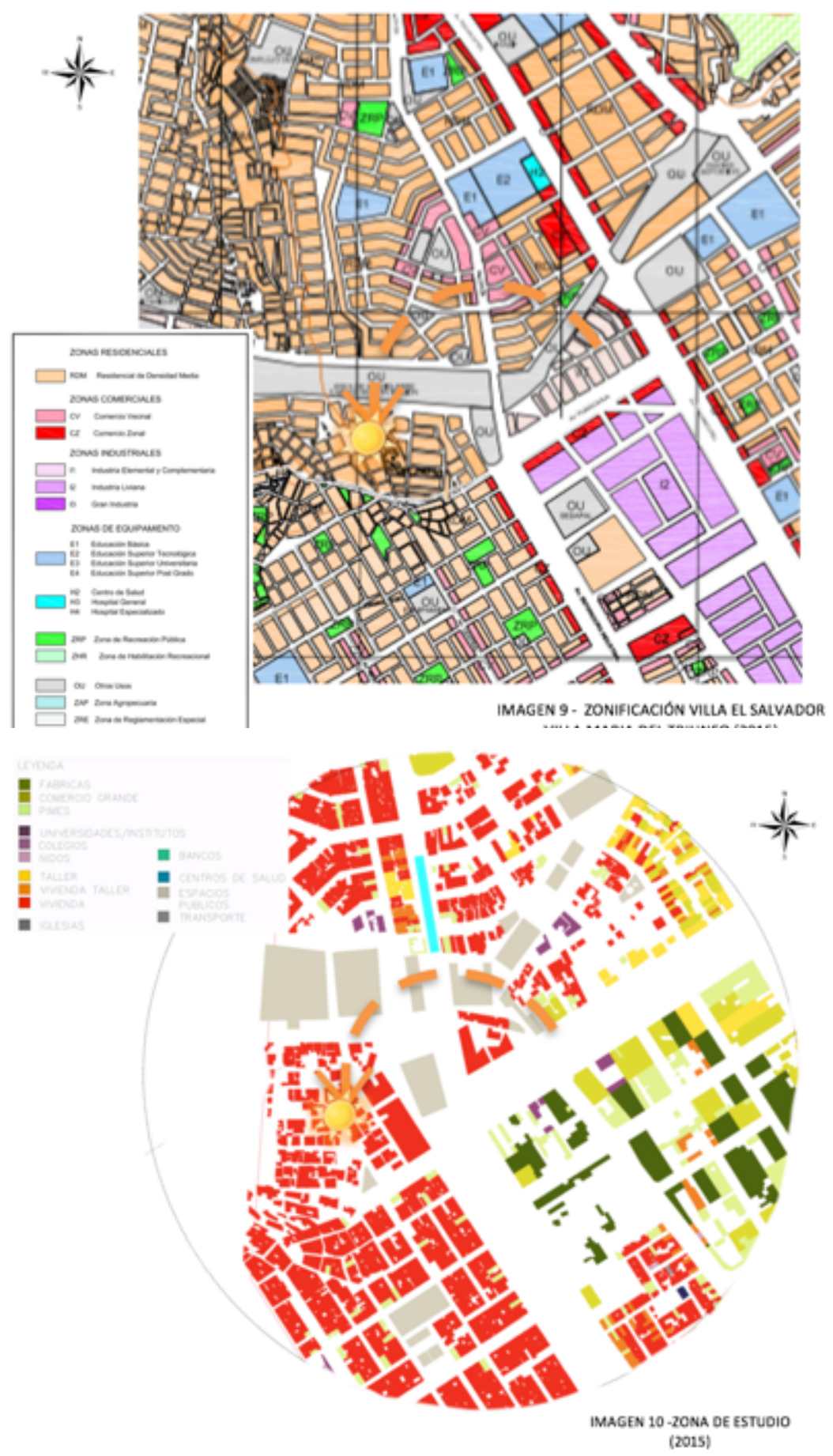




\subsubsection{Planos urbanos del terreno y entorno inmediato:}

\subsubsection{Volumetría y tipología, edificaciones (planos y comentarios)}

La tipología predominante es vivienda, en la cual es identificable una volumetría compacta con patios en algunos casos y en otros tienen 2 o 3 ductos.

Otra de las tipologías de la zona es la vivienda-taller o vivienda-comercio, la cual tiene la misma configuración, pero las áreas más públicas de la vivienda son usadas como taller, también utilizan el primer nivel para taller y los superiores para vivienda. Es importante recalcar que utilizan el espacio público para colocar su mercadería.

\subsubsection{Llenos y vacíos:}

Al analizar la zona en los llenos y vacíos es aún más claro, el gran vacío urbano en el que este terreno se ubica, los cuales son los terrenos más peligrosos porque no tienen ningún diseño del espacio público.

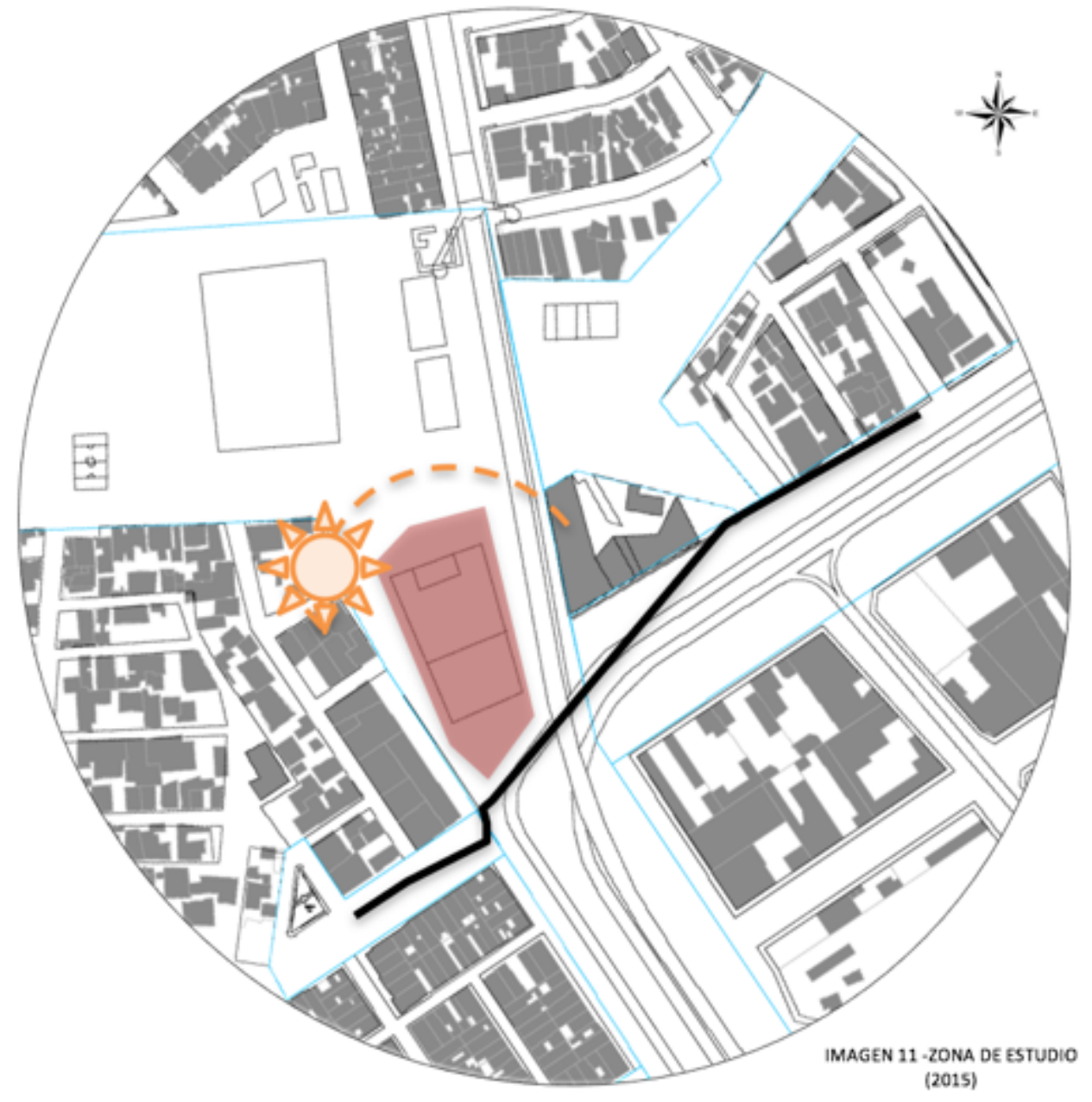




\subsubsection{Planos urbanos del terreno y entorno inmediato:}

\subsubsection{Alturas de las edificaciones (planos y comentarios)}

La altura máxima del entorno inmediato del terreno es de 12 metros y la mínima 3 metros.

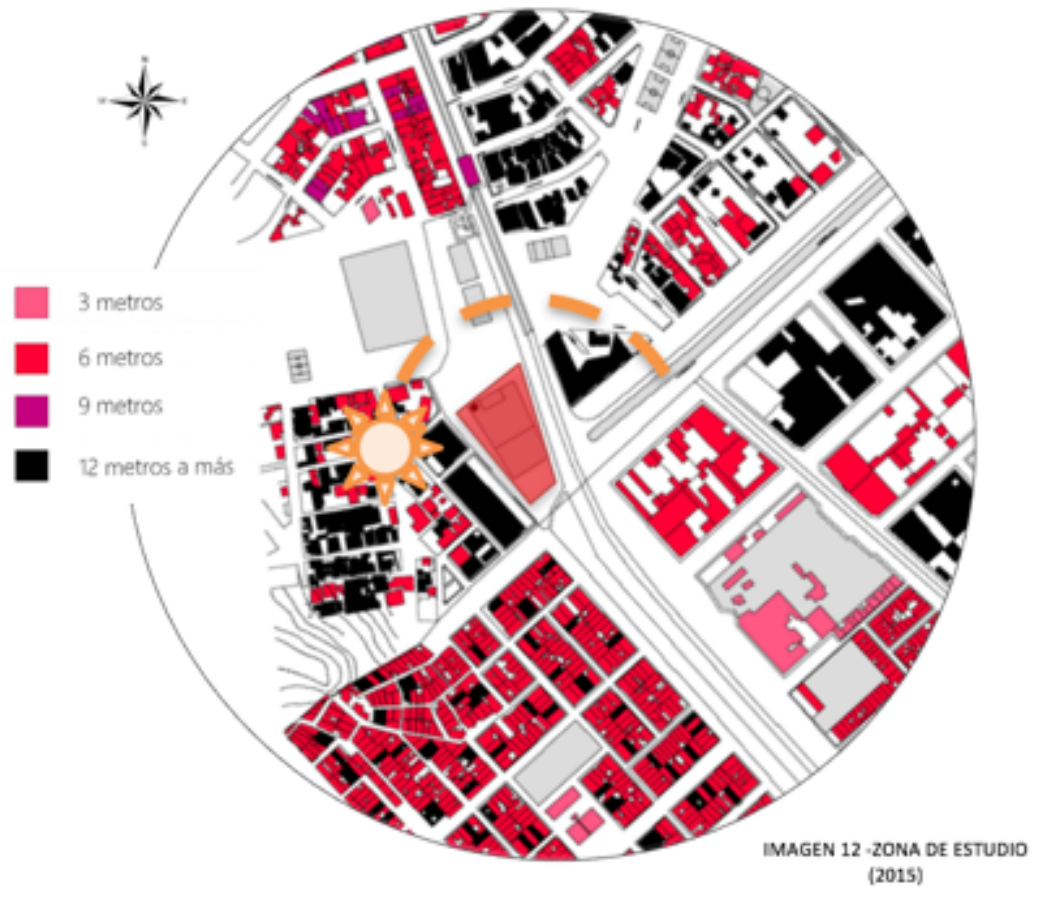

\subsubsection{Vialidad (planos y comentarios)}

\subsection{Paraderos}

\subsection{Líneas de} transporte público

La zona se caracteriza por estar al lado de la estación del tren eléctrico y por contar con paraderos en la Av. Pumacahua en la esquina del terreno.

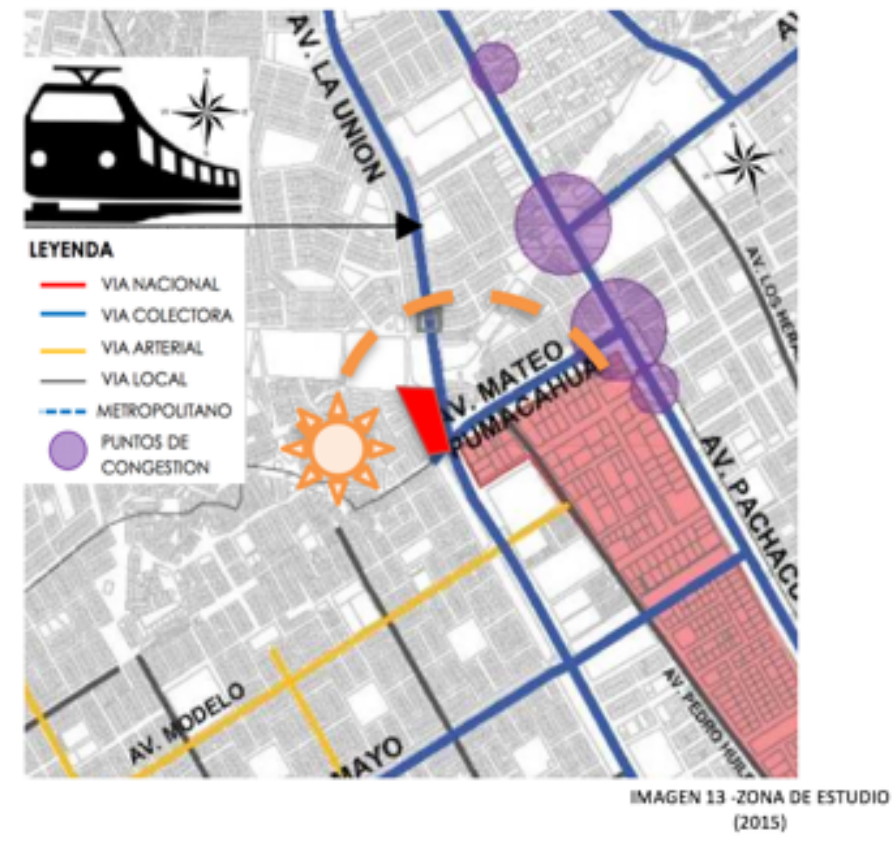




\subsubsection{Planos urbanos del terreno y entorno inmediato:}
5.2.3.6.
de
vías
$\mathbf{y}$
veredas

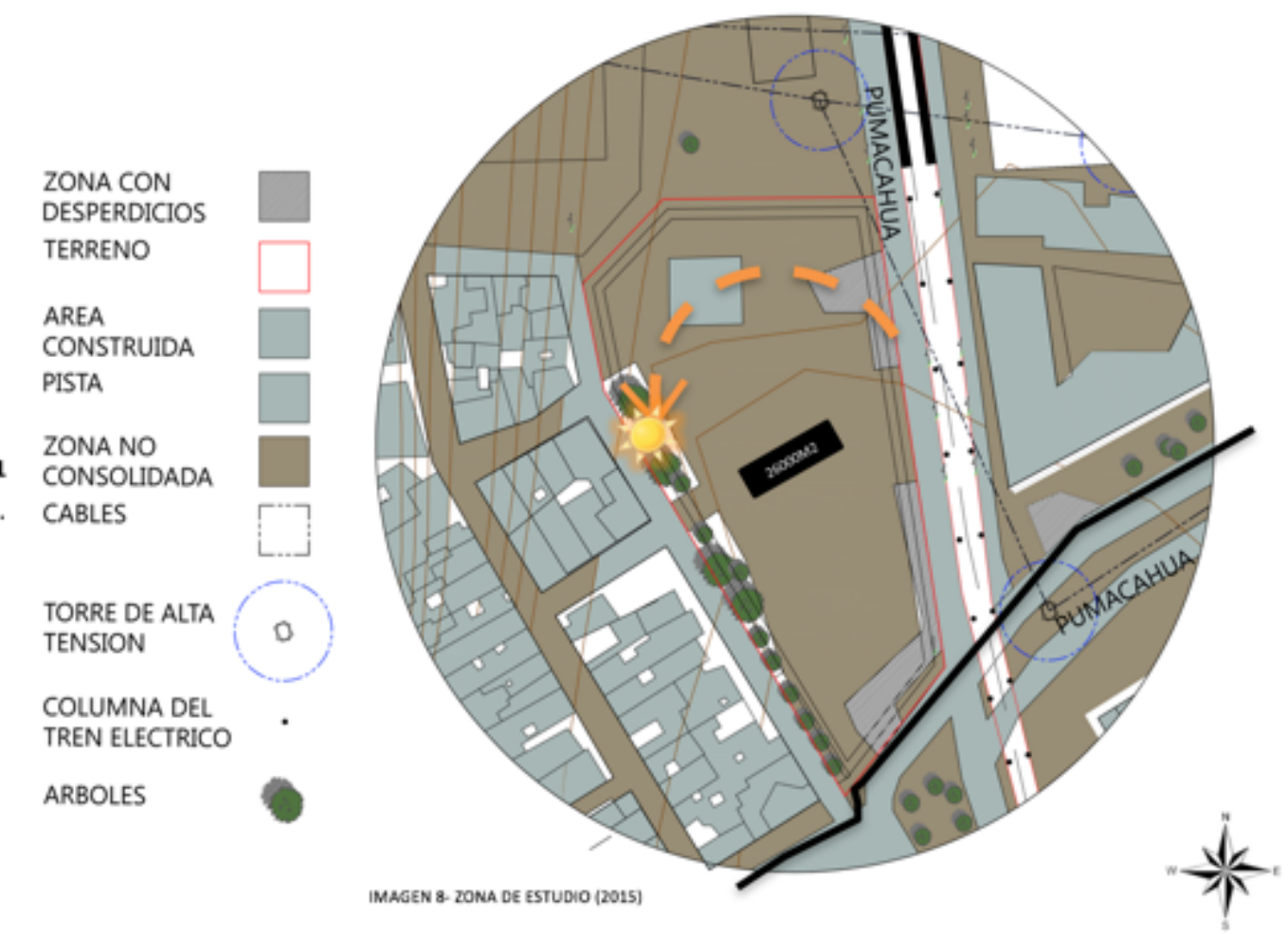

En la zona de Villa María plantean una vereda de $1.5 \mathrm{~m}$ a $3 \mathrm{~m}$ una berma y retiro de $0 \mathrm{~m}$. 108

Plantearía aprovechar los cultivos de los ciudadanos y potenciarlos con el proyecto, aumentaría el ancho de vereda a un mínimo de $3 \mathrm{~m}$ por el carácter público del edificio propuesto.
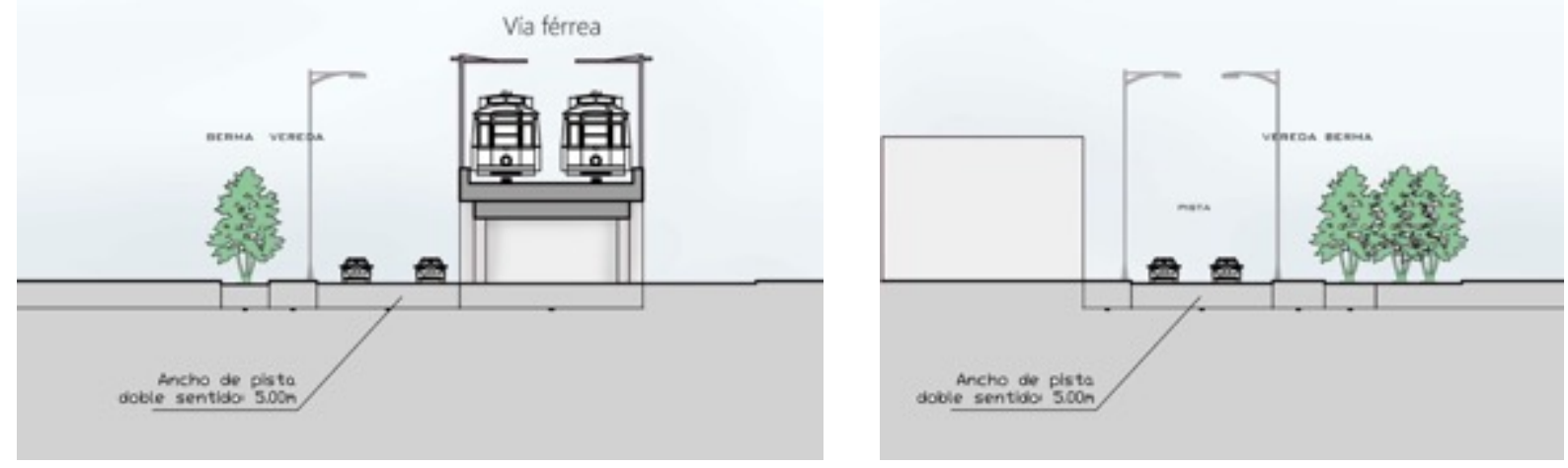

108. MUNICIPALIDAD VILLA MARÍA DEL TRIUNFO (2015) 


\subsubsection{Planos urbanos del terreno y entorno inmediato:}

5.2.3.7. Levantamiento de árboles, postes, $u$ otros elementos relacionados al terreno, al interior y al exterior, que sean condicionantes para el diseño.

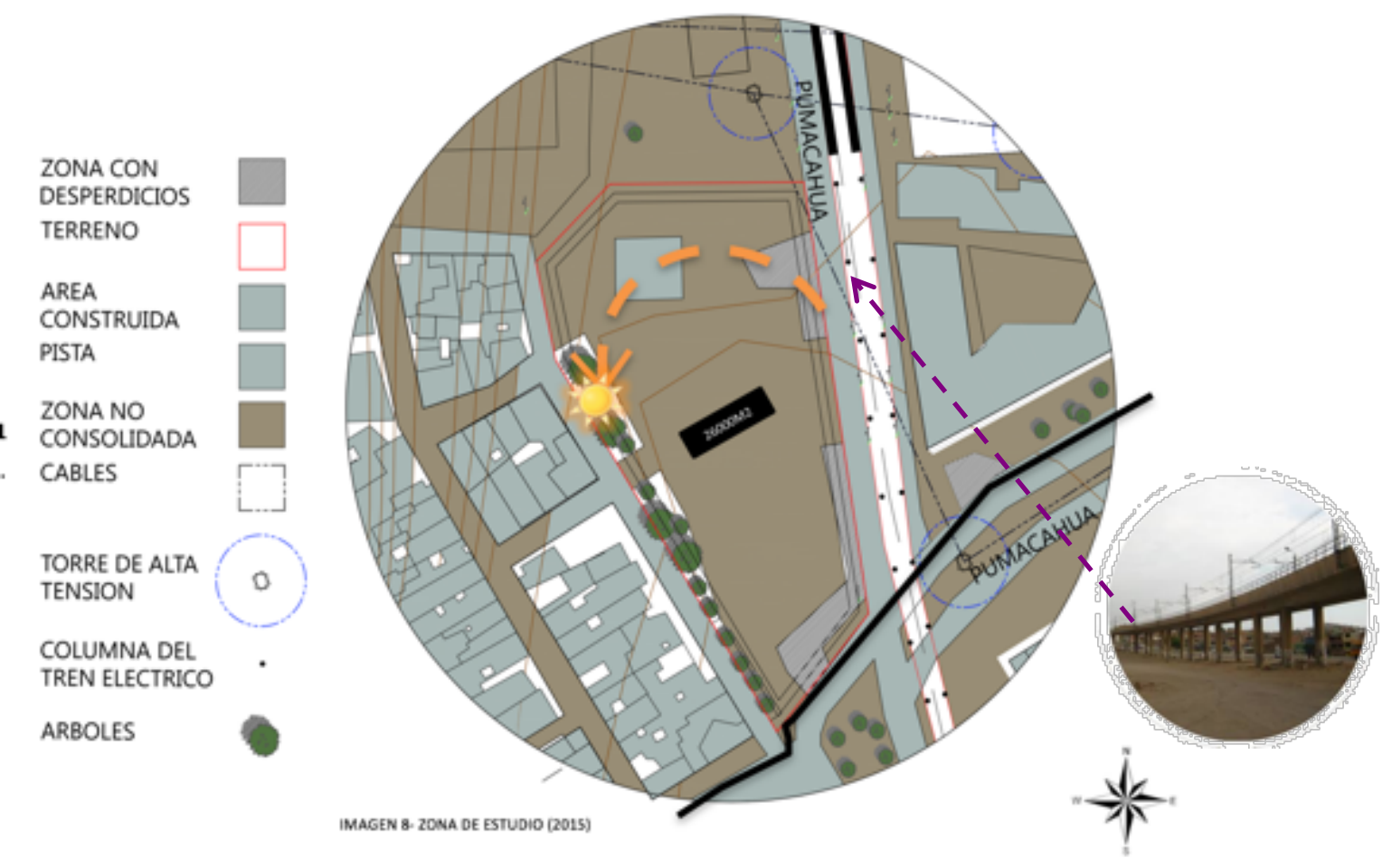

\subsubsection{Planos urbanos del terreno y entorno inmediato:}

- 5.2.3.7. Levantamiento de árboles, postes, u otros elementos relacionados al terreno, al interior $y$ al exterior, que sean condicionantes para el diseño.

- En tanto a los condicionantes de mi terreno:

- Postes: diseñaré tomando en cuenta la posición de los postes para evitar problemas de accesos y vistas.

- Cables y torres de alta tensión: me separaré más de los reglamentado, lo mínimo es 9 metros, me retiraré 15 y proyectaré lo más público lejos de este condicionante.

- Árboles, en este aspecto también respetaré la ubicación de ellos, y en el aspecto de las huertas también potenciaré la ubicación y el hecho que existan para que las costumbres y necesidades de las personas estén tomadas en cuenta.

- En el aspecto de la basura, se hará una limpieza de la zona para poder mejorar la zona.

- En tanto a las vías no consolidadas, propondré una regeneración urbana de esta zona. 


\subsubsection{Planos urbanos del terreno y entorno inmediato:}

\subsubsection{8.}

Bajo la estación al lado de las líneas del tren hay una alta concentración de gente. Al lado del terreno existe un flujo moderado peatonal.

El proyecto tendría que tomar en cuenta estos flujos existentes y crear espacios públicos adecuados para albergar la cantidad correcta de personas.

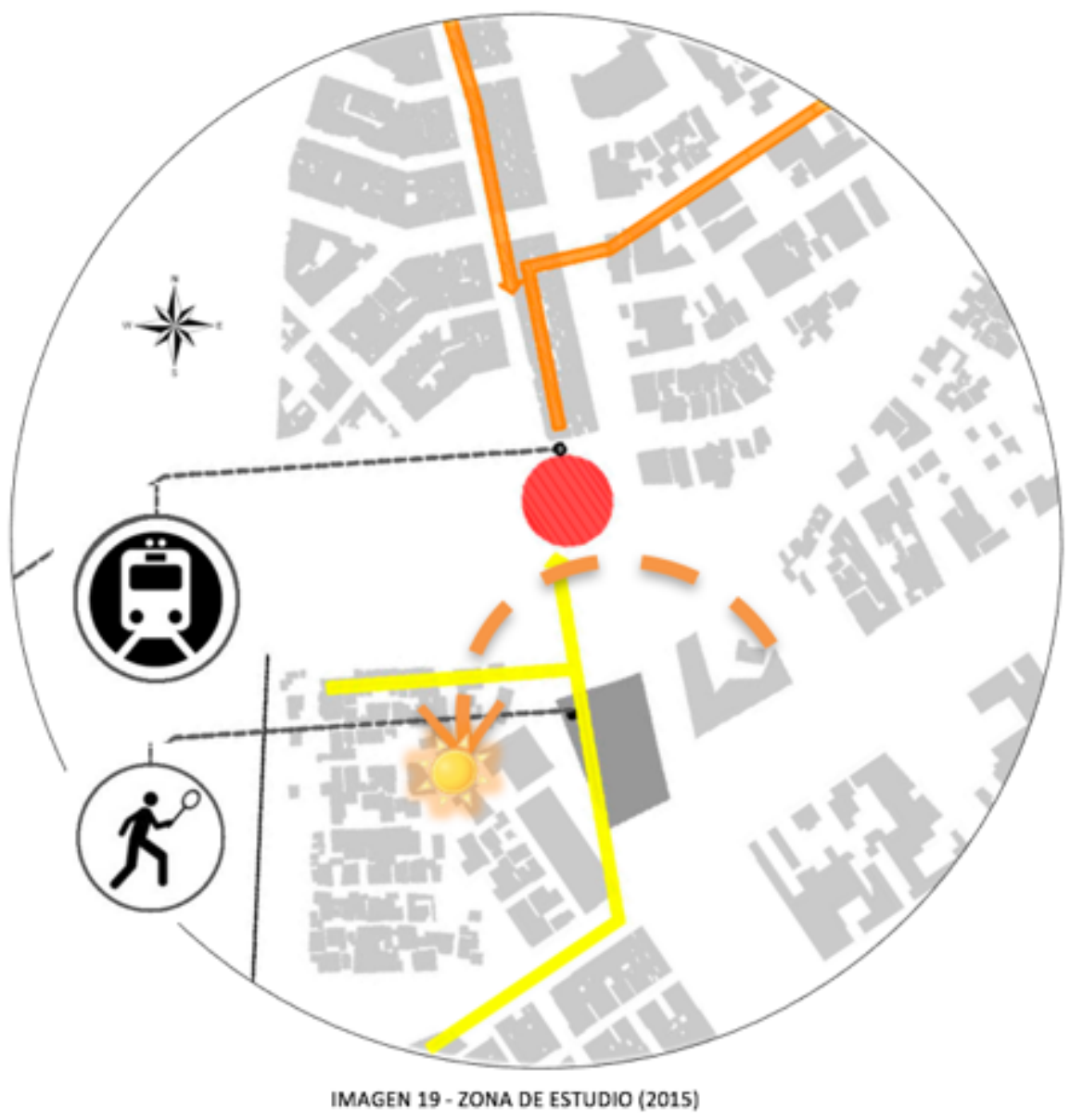

BAJO FLUJO PEATONAL

MODERADO FLUJO PEATONAL

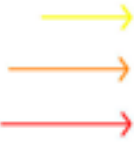

ALTA CONCENTRACIÓN DE FLUJO PEATONAL CONGREGACION DE GENTE 


\subsubsection{9. Áreas de conflicto:}

\subsubsection{0. ¿Qué problemas o condicionantes del entorno debe resolver el proyecto?}

- Cables y torres de alta tensión: me separaré más de lo reglamentado, lo mínimo es 9 metros, me retiraré 15 metros y proyectaré lo más público lejos de este condicionante.

- En el aspecto de la basura, se hará una limpieza para poder mejorar la zona.

- En tanto a las vías no consolidadas, propondré una regeneración urbana de esta zona.

- Existe comercio ambulatorio y me gustaría darle una plaza a estas personas para que puedan tener un espacio donde vender en un espacio público cómodo y propio.

- Existe una contaminación sonora leve a pesar de que la zona se ubica en una avenida y está al lado del tren, pero el flujo es leve, el tráfico es zonal, no llega a ser un tráfico distrital y es fluido. Buscaría de ordenar el programa de manera que lo que requiera más silencio lo pondría en la zona opuesta al tren.

- Suelo árido

- Barandas que limitan el ingreso de manera abrupta e inapropiada.

\subsubsection{Aspectos históricos}

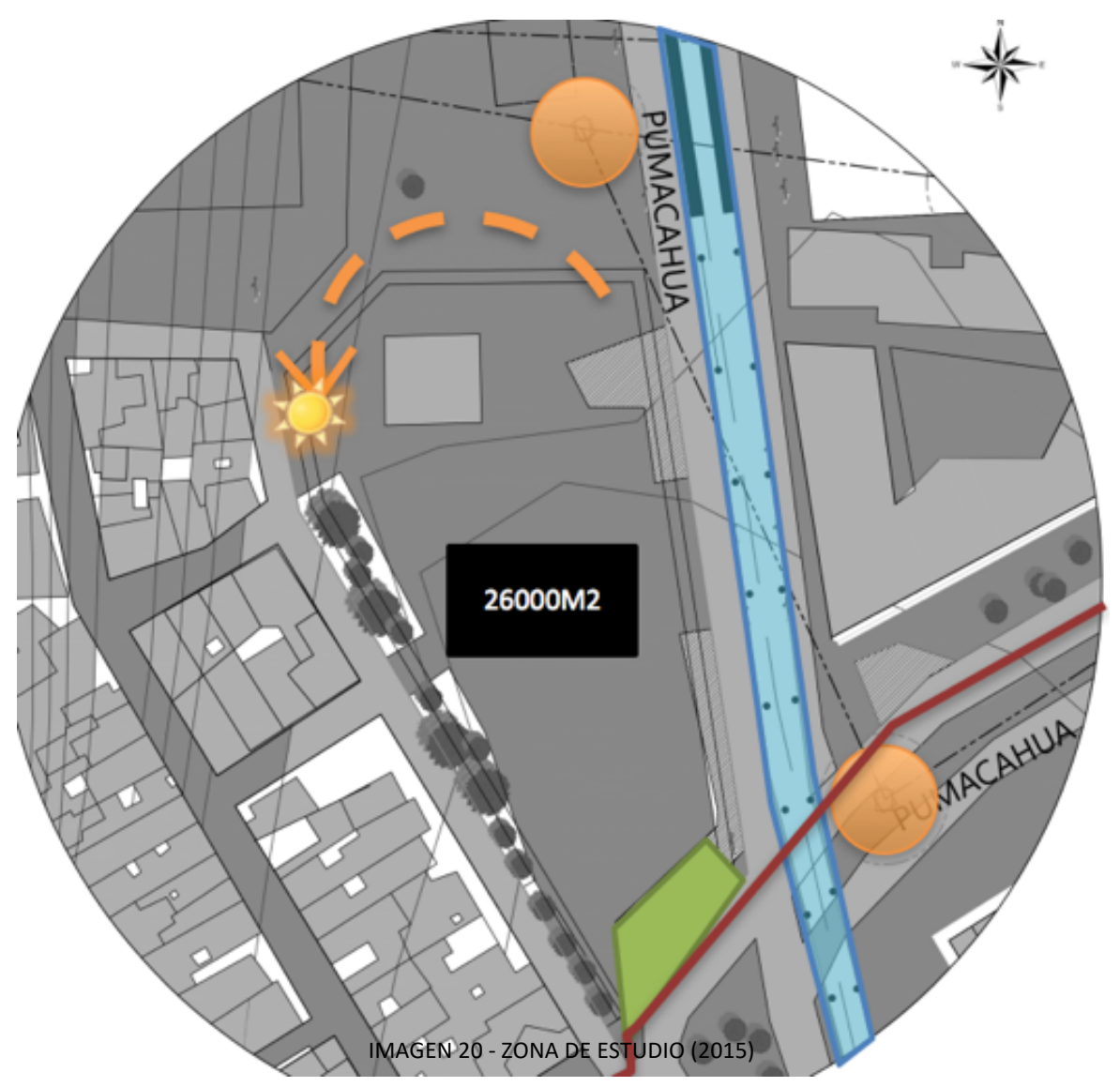




\subsubsection{Reseña histórica Villa María del Triunfo y Villa el Salvador}
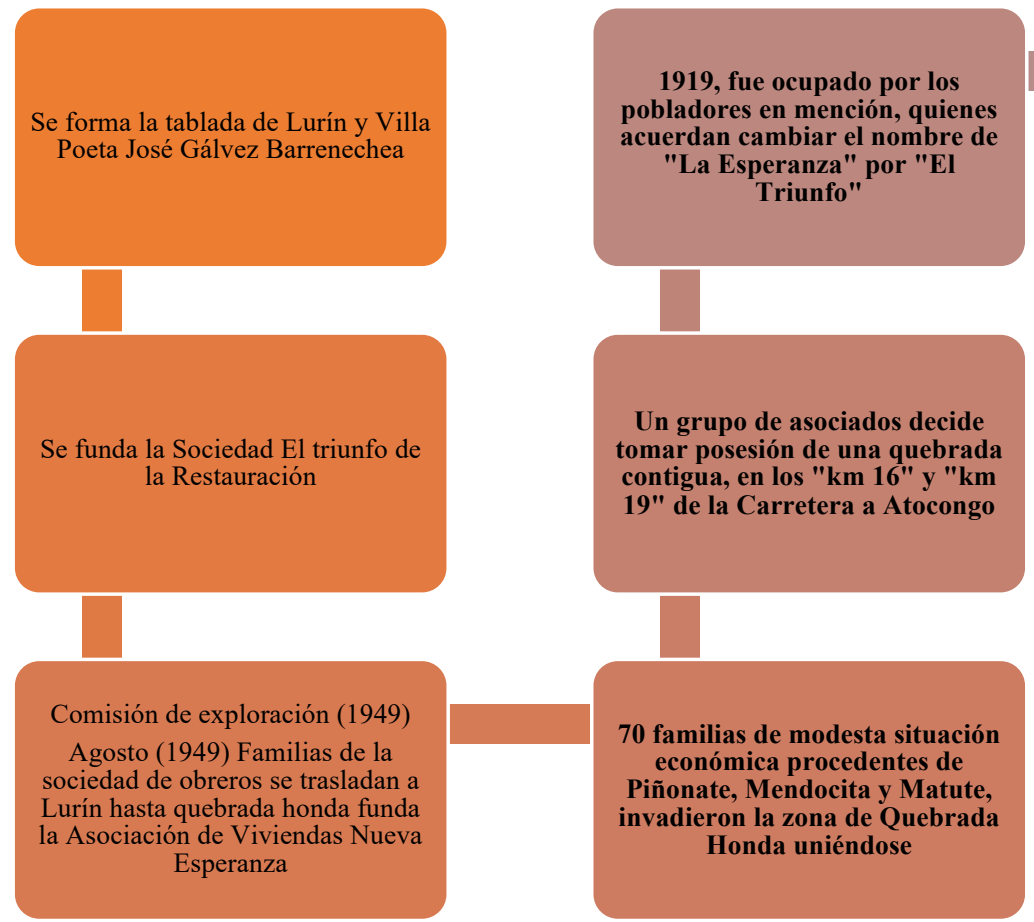

El 8 de agosto de 1960 un grupo de pobladores fue desalojado de la ribera del río Rímac para construir el puente Santa Rosa en la Av. Tacna.

Odría fueron reubicados en la antigua zona de tiro del ejército al pie del cerro Vigía y las lomas aledañas, a los que se unieron familias del barrio de Surquillo.

IMAGEN 21 - ZONA DE ESTUDIO (2015)

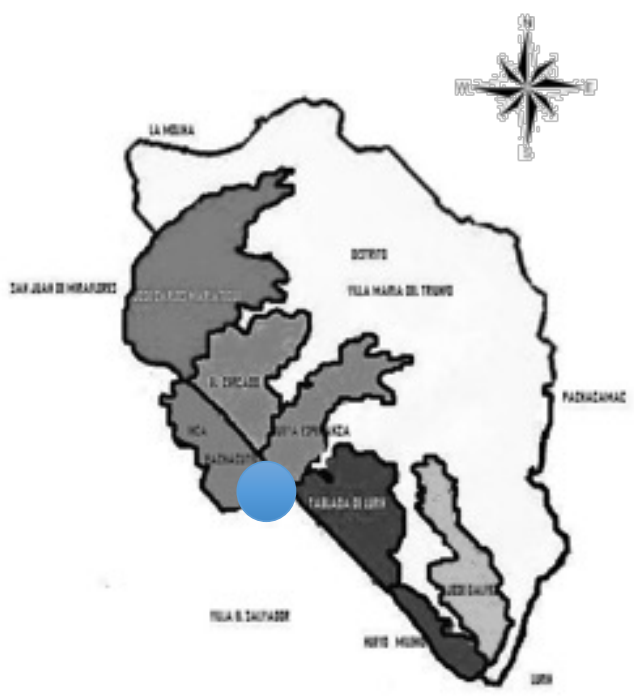




\subsubsection{Aspectos históricos}

\subsubsection{Reseña histórica}

Villa el Salvador nace como un Asentamiento Humano en mayo de 1971 cuando un grupo de pobladores invade unos terrenos eriazos ubicados en Pamplona. Luego de varios días de negociaciones con el gobierno militar de aquel entonces, presidido por el General Juan Velasco Alvarado, luego de un intento de desalojo que ocasionó la muerte de uno de los pobladores, gracias a la mediación de la iglesia, los pobladores son reubicados en unos arenales situados a 25 kilómetros al sur de Lima denominándose en ese entonces pueblo Joven Villa el Salvador.

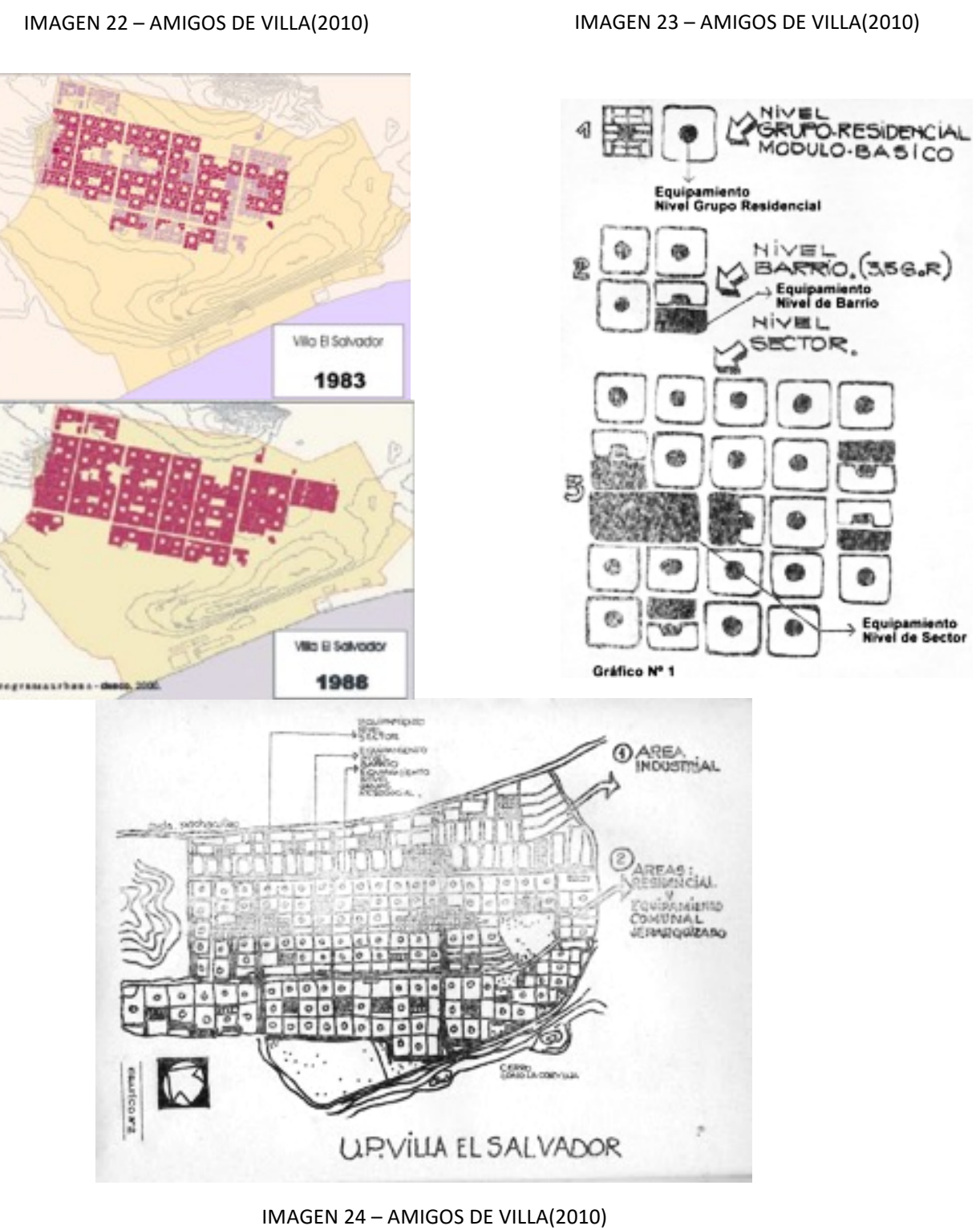




\subsubsection{Levantamiento fotográfico, mostrando el estado actual del terreno y de la}

zona, recorrido por todas las calles, con análisis espacial, y comentarios.

1.En esta vista se puede ver el terreno, el cual cuenta con una intención de tratar el espacio público, tiene una vereda que viene desde la estación, pero está incompleta y no rodea toda la calle.

Se puede observar el desnivel del terreno y la intención que hubo de enderezar el suelo para que pueda funcionar una cancha.

2.En esta otra vista se puede ver el desnivel más claramente y la vista importante del cerro con viviendas que tiene de un lado. Este es un hito de la zona y una vista importante para el proyecto que estaría frente a este, este cerro crea flujos de las personas que bajan en las mañanas para ir a trabajar, flujos que tomaré en cuenta en el diseño.

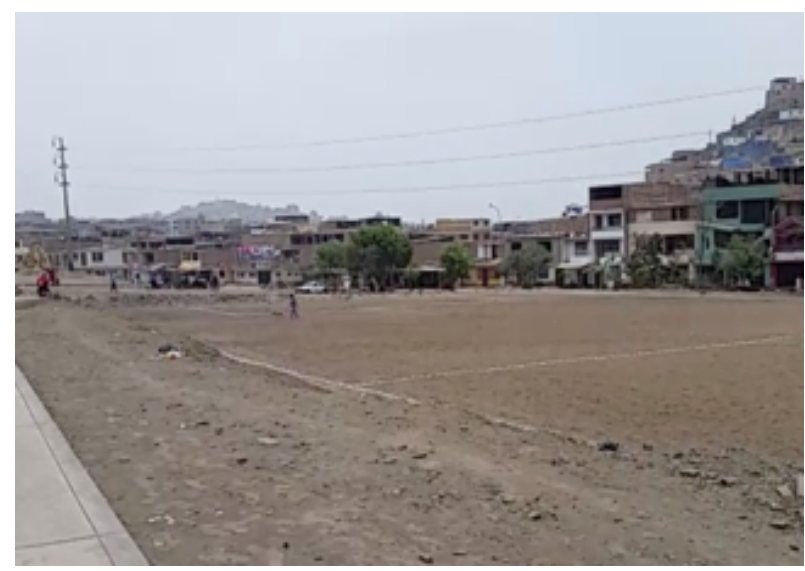

IMAGEN 26 - ZONA DE ESTUDIO- LERTORA (2015)

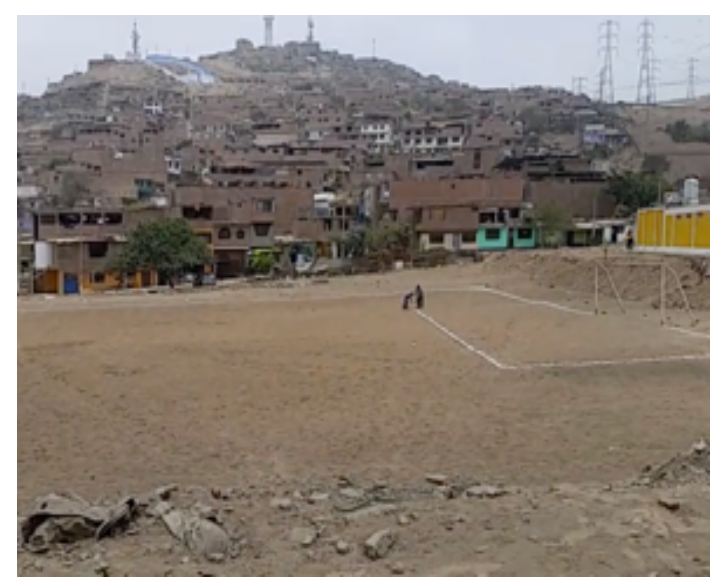

IMAGEN 27 - ZONA DE ESTUDIO- LERTORA (2015)

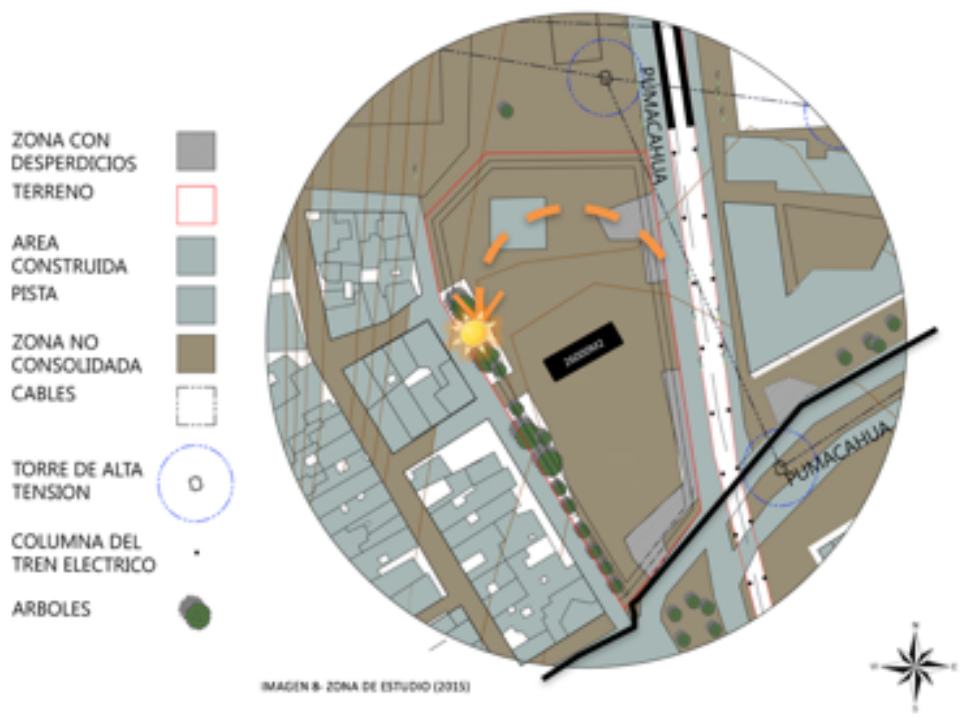


3.En esta vista vemos la vereda que llega hasta aquí desde la estación y el tren eléctrico elevado que crea una calle techada lo que falta hacer es indicar por donde pueden estar estos pases y qué no lo es.

4.En esta vista se puede ver la topografía posterior al terreno que ha sido escalonada y es a través de este eje de vacío urbano que se plantea hacer un parque lineal para aprovechar los terrenos y crear un impacto ambiental positivo.

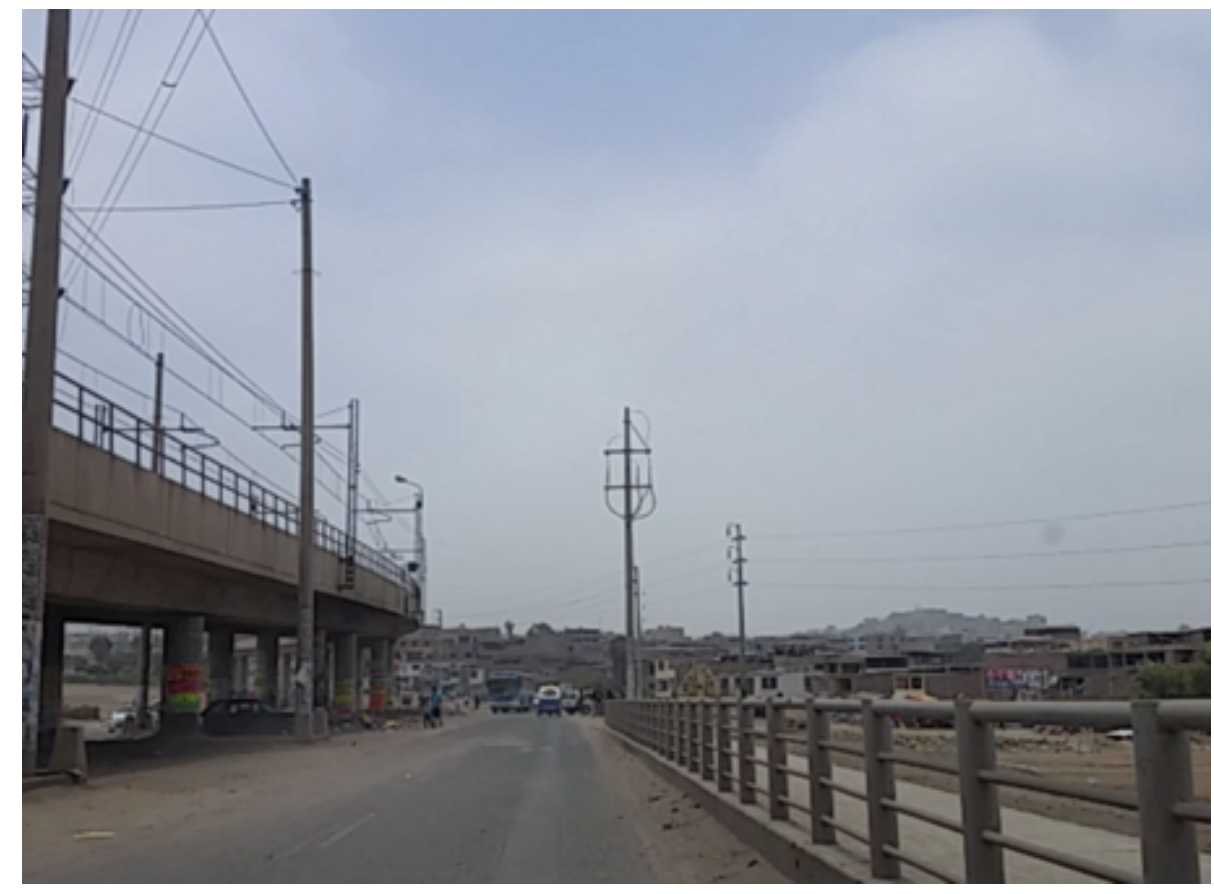

IMAGEN 29 - ZONA DE ESTUDIO- LERTORA (2015)

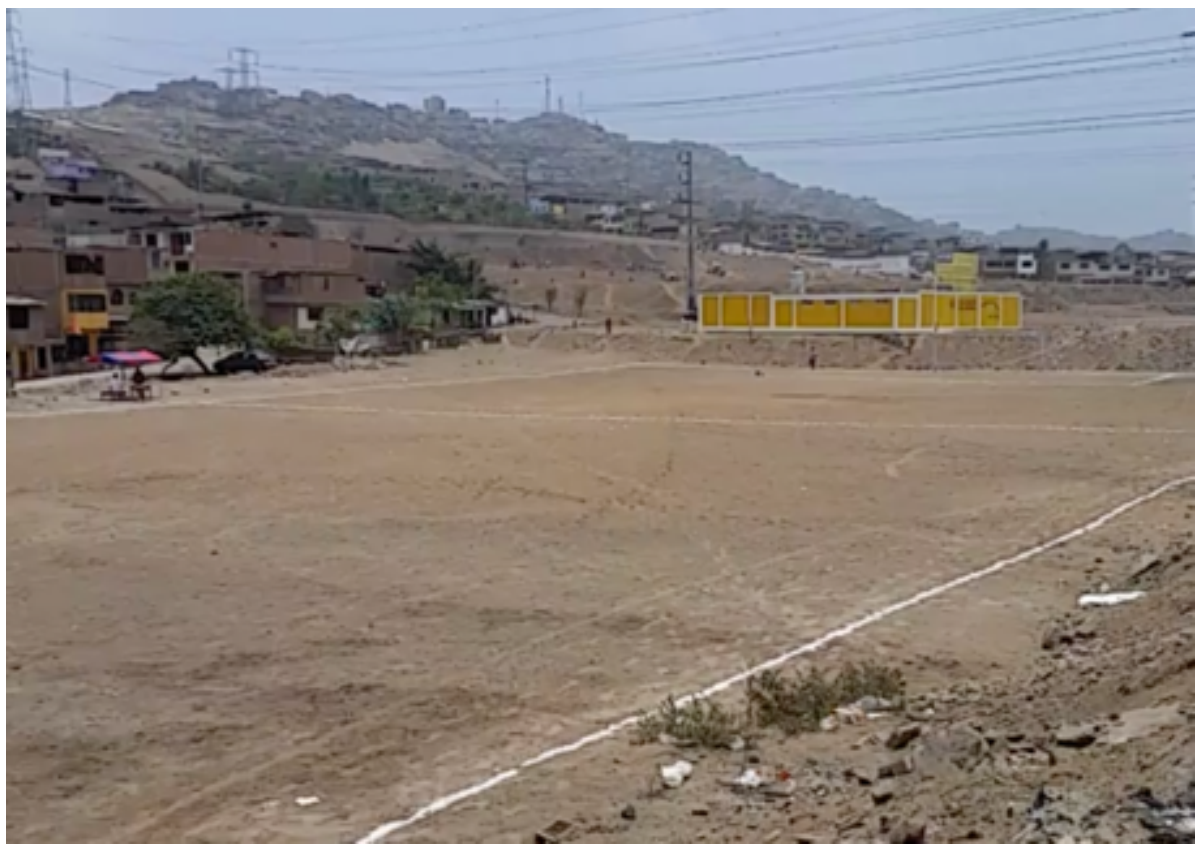

IMAGEN 30 - ZONA DE ESTUDIO- LERTORA (2015) 
5.Existe comercio ambulatorio en donde se ofrecen comidas y jugos para desayunar y almorzar al estar en camino a la estación las personas atienden con frecuencia.

6.Las personas del lado oeste del proyecto que tienen viviendas en este lado, utilizan el terreno como huerta y también plantan árboles o plantas para darle vida a su calle. Este factor como he mencionado anteriormente lo incluiría dentro del proyecto para que el impacto del proyecto sea positivo y bien recibido por las personas porque estaría pensando en sus costumbres y necesidades.

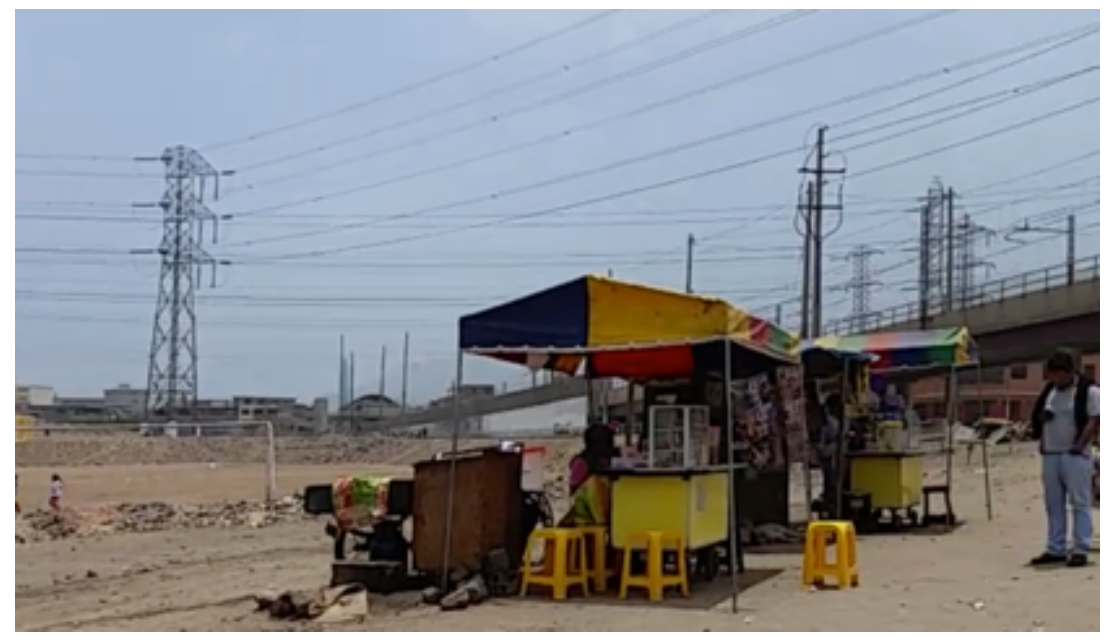

IMAGEN 32 - ZONA DE ESTUDIO- LERTORA (2015)

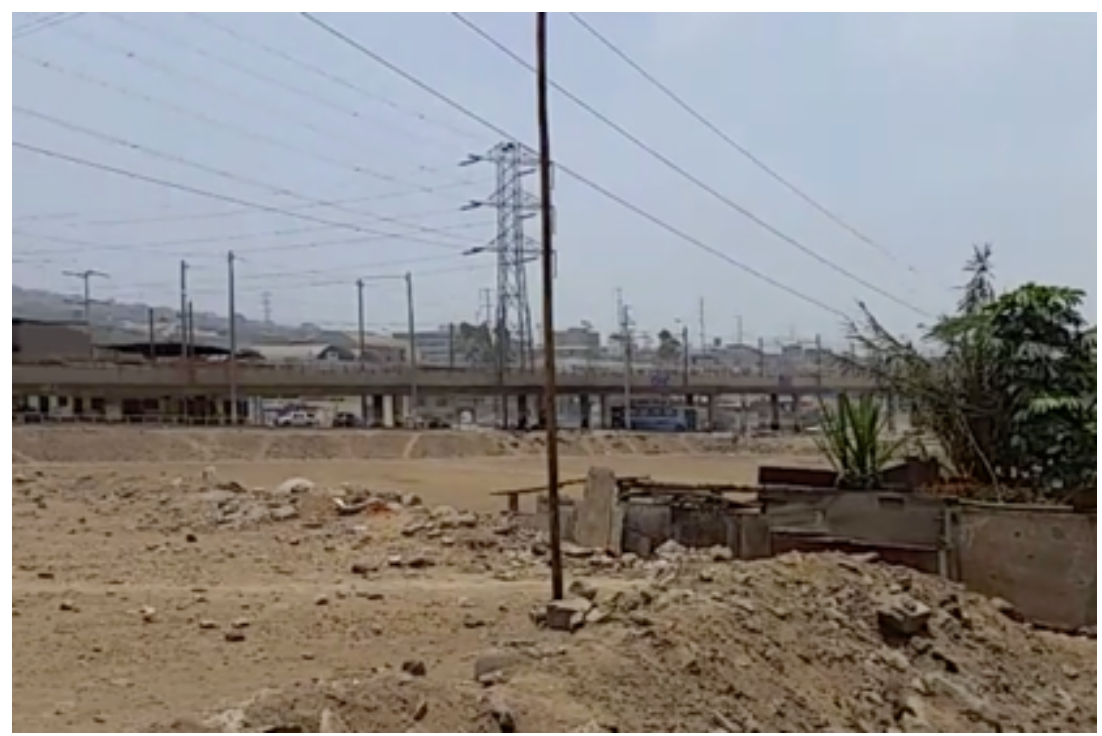

IMAGEN 33 - ZONA DE ESTUDIO- LERTORA (2015) 
6. ELUSUARIO 


\section{EL USUARIO}

6.1. Definición de los usuarios

6.1.1. Información Cuantitativa

6.1.1.1. Número y tipos de usuario. Proyección a futuro (10 años)

6.1.1.1.1. Edades. Horarios. Rotaciones (turnos).

6.1.1.1.2. Cuadro Resumen del número y tipo de usuarios

6.1.2. Información cualitativa

6.1.2.1. Flujos y necesidades de los usuarios

6.1.2.2. Funciones y espacios generados por las necesidades 


\subsection{EL USUARIO}

\subsection{DEFINICIÓN DE LOS USUARIOS}

Las personas que utilizarían este polideportivo, serían principalmente los que viven en Villa el Salvador y Villa María del Triunfo y los distritos de sus alredores (Chorrillos, Lurín, y San Juan de Miraflores). Y secundariamente, los deportistas que deseen utilizar el recinto, ya que estaría conectado con todos los distritos por los que pasa el tren eléctrico y el Metropolitano.

La población de Villa el Salvador y Villa María del Triunfo se caracterizan por tener histórica capacidad de organización y cariño por su territorio, los diferencia de otros y le da una cualidad de barrio y entendimiento de quiénes son y qué necesitan.

Deportistas de toda edad y capacidad físico-motora, principalmente de los estratos C y D. El concepto principal para este Polideportivo es que sea verdaderamente un espacio diseñado para la convivencia de todos, discapacitados y no discapacitados. Es una manera de inculcar la visión global de la sociedad no sectorizada ni excluyendo ni dividiendo a la población por discriminaciones.

En los distritos de Lima Sur, Lima Este y Lima Norte, se concentran las poblaciones con mayor pobreza.

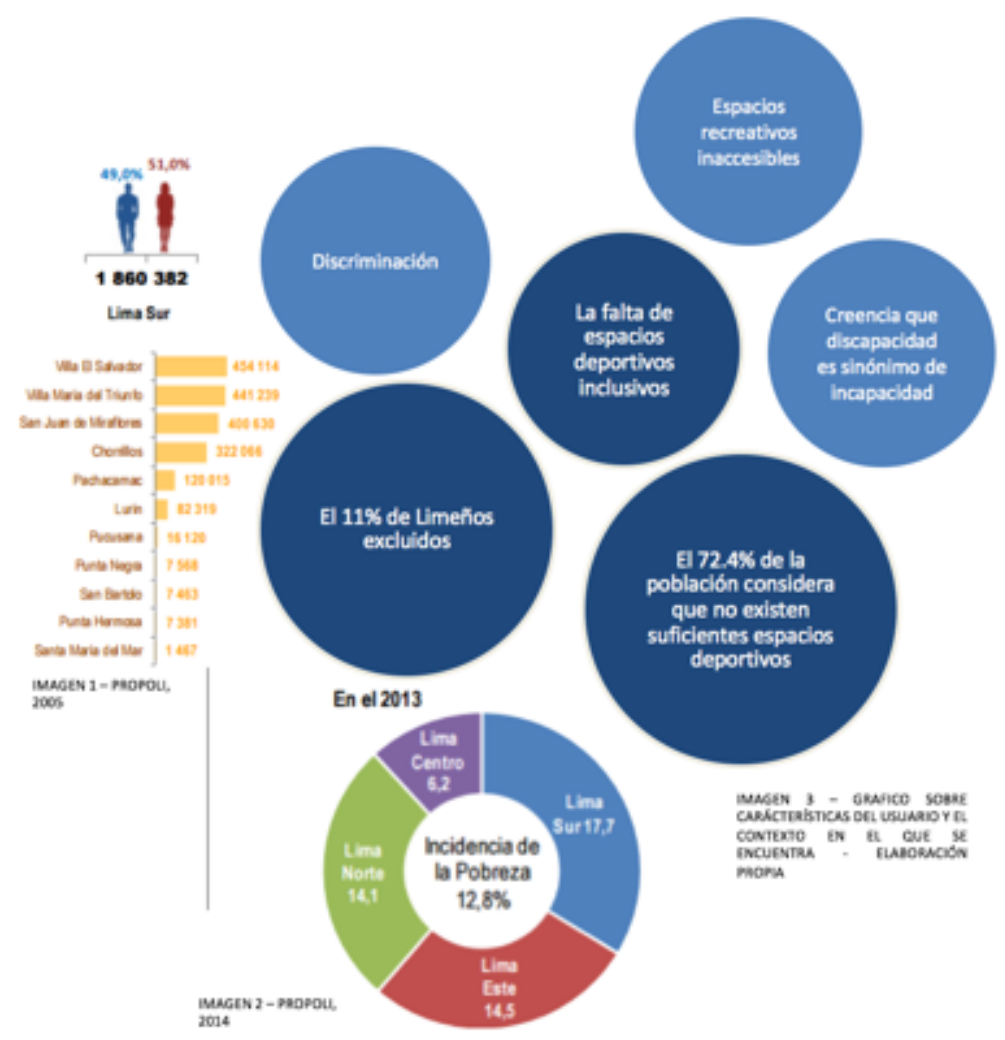




\subsection{ASPECTOS CUANTITATIVOS}

\section{TIPOS DE USUARIO}
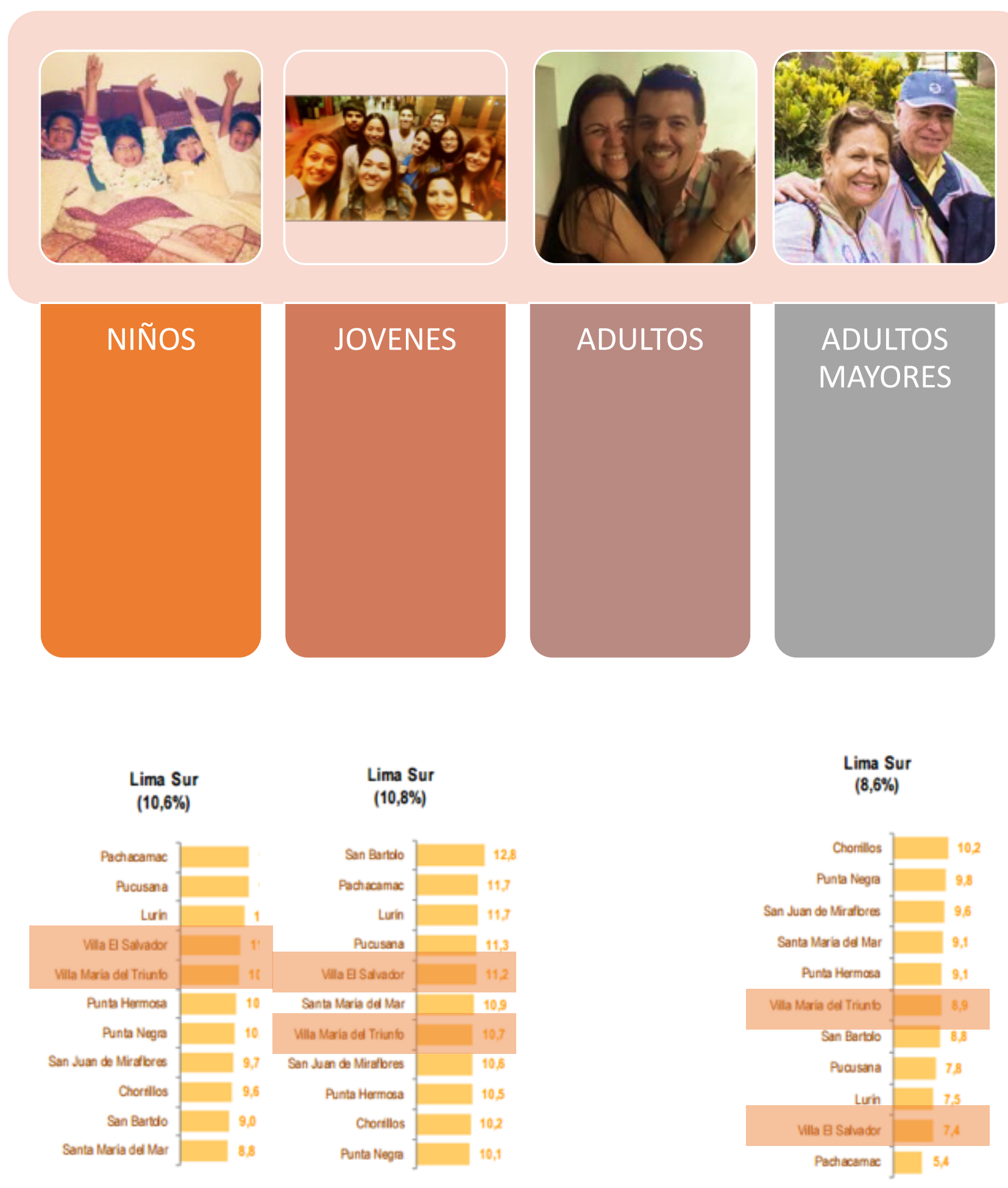

IMAGEN 4 - GRAFICO SOBRE CARÁCTERÍSTICAS DEL USUARIO ELABORACIÓN PROPIA + DATOS DEL PROPOLI 2014 
Cuadro $\mathrm{N}^{\circ}$ VIII.2

Villa El Salvador: Población que presenta alguna discapacidad, según grupos de edad y sexo, 2005

\begin{tabular}{l|c|c|c|c|c|c|}
\hline \multirow{2}{*}{ Grupos de Edad } & \multicolumn{2}{|c|}{ Total } & \multicolumn{2}{c|}{ Hombre } & \multicolumn{2}{c|}{ Mujer } \\
\cline { 2 - 7 } & $\begin{array}{c}\text { Cifras } \\
\text { absolutas }\end{array}$ & Porcentaje & $\begin{array}{c}\text { Cifras } \\
\text { absolutas }\end{array}$ & Porcentaje & $\begin{array}{c}\text { Cifras } \\
\text { absolutas }\end{array}$ & Porcentaje \\
\hline Total & 3525 & 100,0 & 1761 & 100,0 & 1764 & 100,0 \\
\hline menores de 6 años & 168 & 4,8 & 95 & 5,4 & 73 & 4,1 \\
De 6 a 14 años & 496 & 14,1 & 248 & 14,1 & 248 & 14,1 \\
De 15 a 17 años & 145 & 4,1 & 76 & 4,3 & 69 & 3,9 \\
De 18 a 29 años & 564 & 16,0 & 313 & 17,8 & 251 & 14,2 \\
De 30 a 59 años & 1274 & 36,1 & 629 & 35,7 & 645 & 36,6 \\
60 y más años & 878 & 24,9 & 400 & 22,7 & 478 & 27,1 \\
\hline
\end{tabular}

FUENTE: INEI-Registro y Caracterización de la Población en Riesgo-Programa de Lucha contra la Pobreza en Zonas Urbano Marginales de Lima Metropolitana (PROPOLI), 2005.

\section{Cuadro $\mathrm{N}^{\circ}$ VIII.3}

Villa El Salvador: Población que presenta alguna discapacidad, según tipo de limitación permanente que tiene, 2005

\begin{tabular}{|l|c|c|c|c|c|}
\hline & & \multicolumn{2}{|c|}{ Hombre } & \multicolumn{2}{|c|}{ Mujer } \\
\cline { 3 - 6 } & Total & $\begin{array}{c}\text { Cifras } \\
\text { Tipo de limitación permanente }\end{array}$ & Porcentaje & $\begin{array}{c}\text { Cifras } \\
\text { absolutas }\end{array}$ & Porcentaje \\
\hline Limitación permanente para oir & 466 & 249 & 53,4 & 217 & 46,6 \\
\hline Limitación permanente para ver & 847 & 391 & 46,2 & 456 & 53,8 \\
Limitación permanente para hablar & 284 & 143 & 50,4 & 141 & 49,6 \\
Limitación permanente para andar, estar de pie, subir & & & & & \\
escaleras o mover el cuerpo & 829 & 397 & 47,9 & 432 & 52,1 \\
Limitación permanente para agarrar o manipular objetos & 232 & 125 & 53,9 & 107 & 46,1 \\
Ha perdido algún miembro superior e inferior & 44 & 28 & 63,6 & 16 & 36,4 \\
Tiene retardo mental & 424 & 237 & 55,9 & 187 & 44,1 \\
Tiene enfermedad mental permanente & 254 & 148 & 58,3 & 106 & 41,7 \\
Tiene otra enfermedad fisica grave & 427 & 184 & 43,1 & 243 & 56,9 \\
Otra limitación permanente & 171 & 77 & 45, & 94 & 55, \\
\hline
\end{tabular}

FUENTE: INElFregistro y Caracterizacion de la Población en Riesgop Programa de Lucha contra la Pobreza en Zonas Urbano Marginales de Lima Metropoitana (PROPOLI), 2005.

IMAGEN 5 - DATOS CARÁCTERÍSTICAS DEL USUARIO DISCAPACITADO - DATOS DEL PROPOLI 2005 


\subsection{EL USUARIO}

\subsection{ASPECTOS CUALITATIVOS:}

El usuario de este polideportivo inclusivo son las personas de Villa el Salvador y Villa María del Triunfo. El total de personas discapacitadas en Villa el Salvador es de 40417 y el total de personas discapacitadas en Villa María del Triunfo es de 39133. De estas, el $18,9 \%$ son niños, el $20 \%$ jóvenes, el $36,1 \%$ adultos y el $25 \%$ adultos mayores. Haciendo un total de TOTAL DE 723,123 usuarios entre ambos distritos. Las personas discapacitadas son el $11 \%$ del total (79,550 personas). Las personas que practican deporte actualmente representan el $35 \%$ de la población sin ninguna discapacidad. El 20\% de los discapacitados practica deporte. El usuario total por lo tanto es de 225,277 personas sin ninguna discapacidad y 15,910 personas discapacitadas haciendo un total de 241,187 usuarios potenciales del polideportivo. (Basado en datos de Lima como vamos del 2014)

CONSIDERANDO QUE EL USUARIO FRECUENTE SEA SOLO EL 5\% DE LAS PERSONAS QUE PRACTICAN DEPORTE, EL USUARIO DEL POLIDEPORTIVO INCLUSIVO SOSTENIBLE DE LIMA SUR SERÍA 11260 PERSONAS AL AÑO, EN 10 AÑOS SERÍAN 14060 PERSONAS.

Clasifico a los usuarios por edades, discapacitados o no porque, si funciona para personas discapacitadas, funciona para todos. De esta manera no existe discriminación en el diseño y trato a ambos grupos de personas como un todo desde la definición del usuario.

Al mismo tiempo podría atender a 1056 personas (AFORO), las personas se quedan un promedio de 3 horas entrenando lo que permite 4 rotaciones de 1050 personas, lo que dejaría que atienda a 4200 personas diario, 29,400 semanalmente, 882,000 al mes.
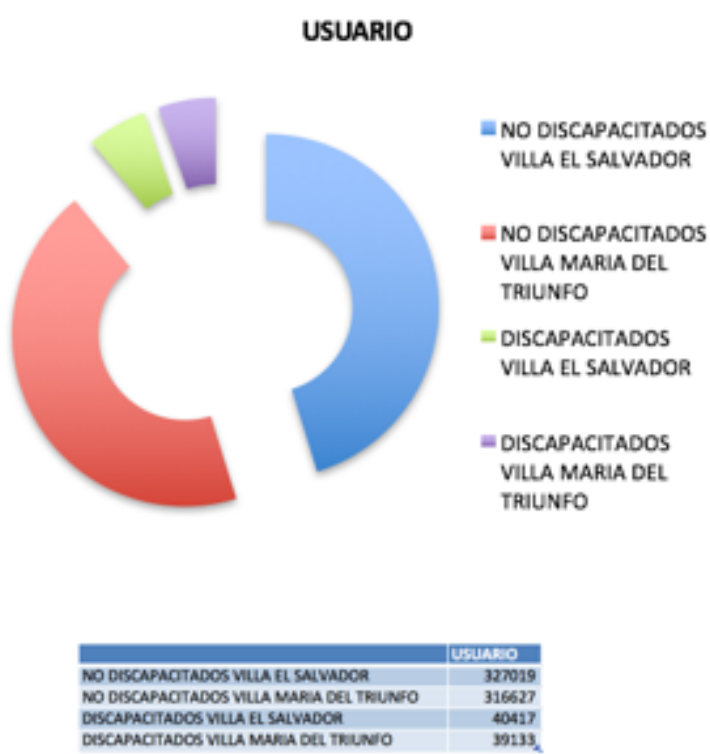

IMACEN 6 - CAARCO OUANTTATIVO DEL USLARO BASADO EN DATOS DE LUAA COMO VANOS DEL 2OLA-ELABORAOCN PACPEA

112. LIMA COMO VAMOS (2014) 


\subsection{ASPECTOS CUALITATIVOS}

\section{USUARIO DE LAS INSTALACIONES:}

Clasifico a los usuarios por edades, discapacitados o no porque, si funciona para personas discapacitadas, funciona para todos. De esta manera no existe discriminación en el diseño y trato a ambos grupos de personas como un todo desde la definición del usuario.

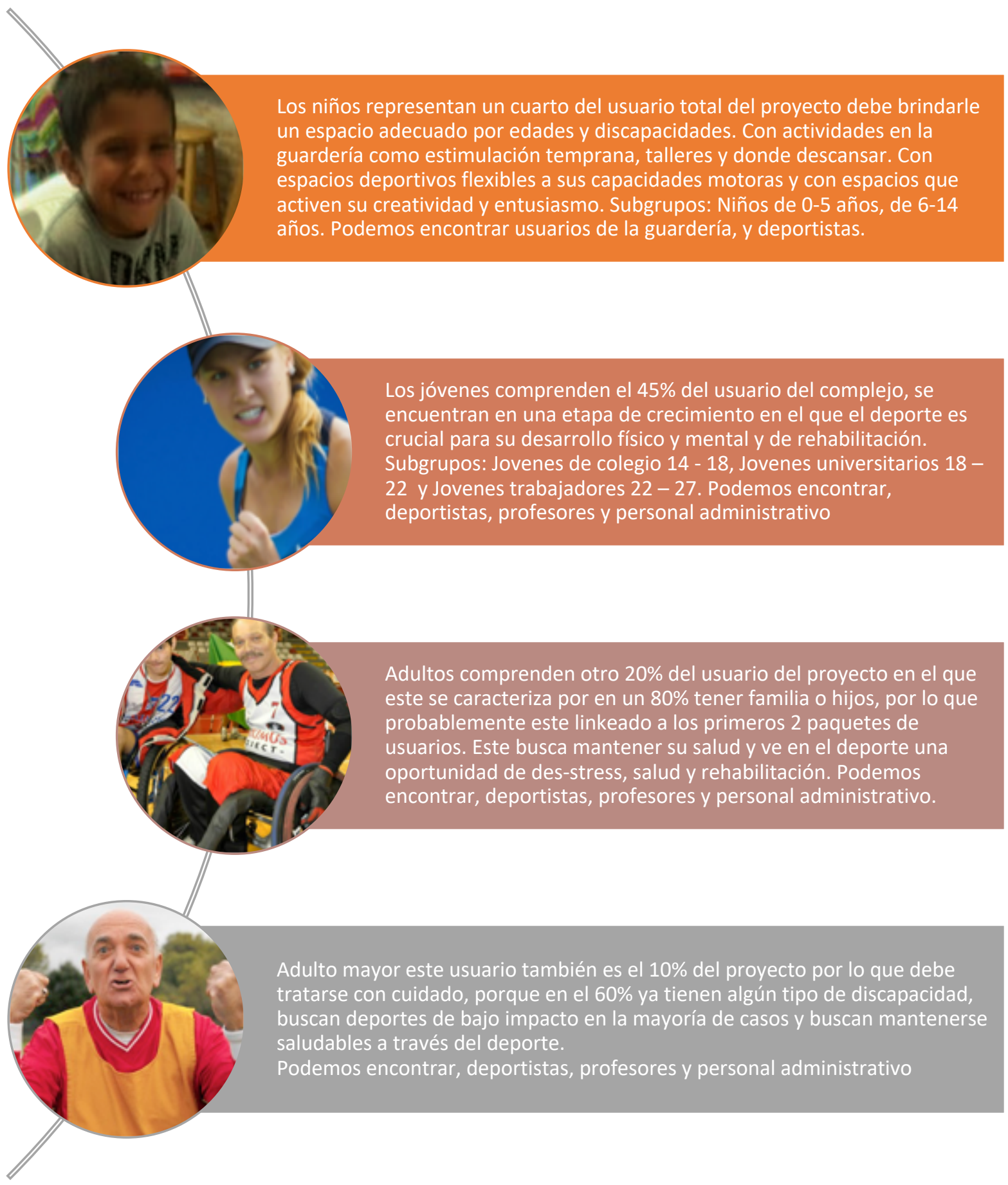

IMAGEN 7 - GRAFICO CUALITATIVO DE LOS TIPOS DE USUARIOS - ELABORACIÓN PROPIA 


\section{USUARIO DE LAS INSTALACIONES:}
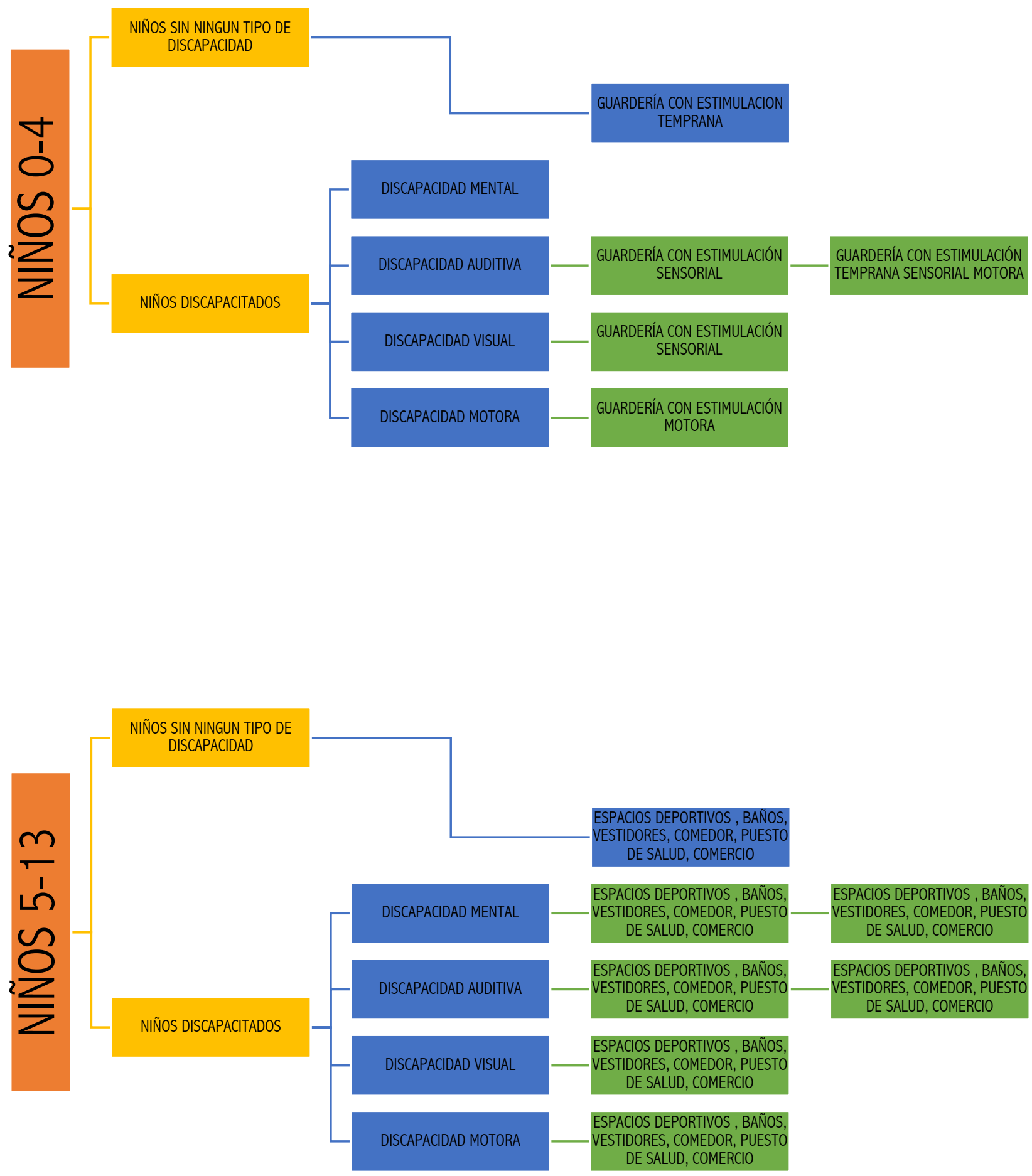

IMAGEN 8 - GRAFICO CUALITATIVO DE LOS TIPOS DE USUARIOS - ELABORACIÓN PROPIA 

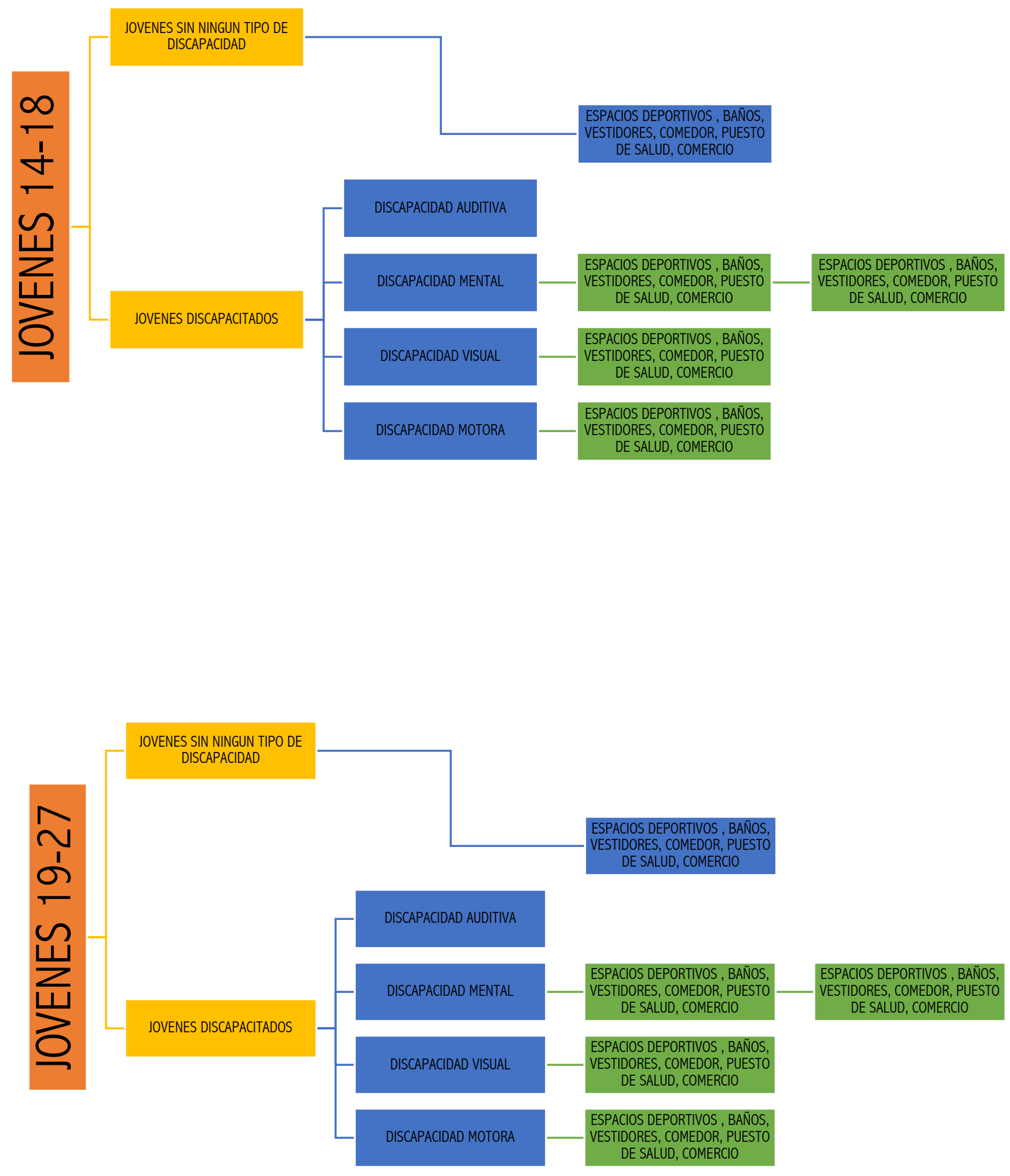

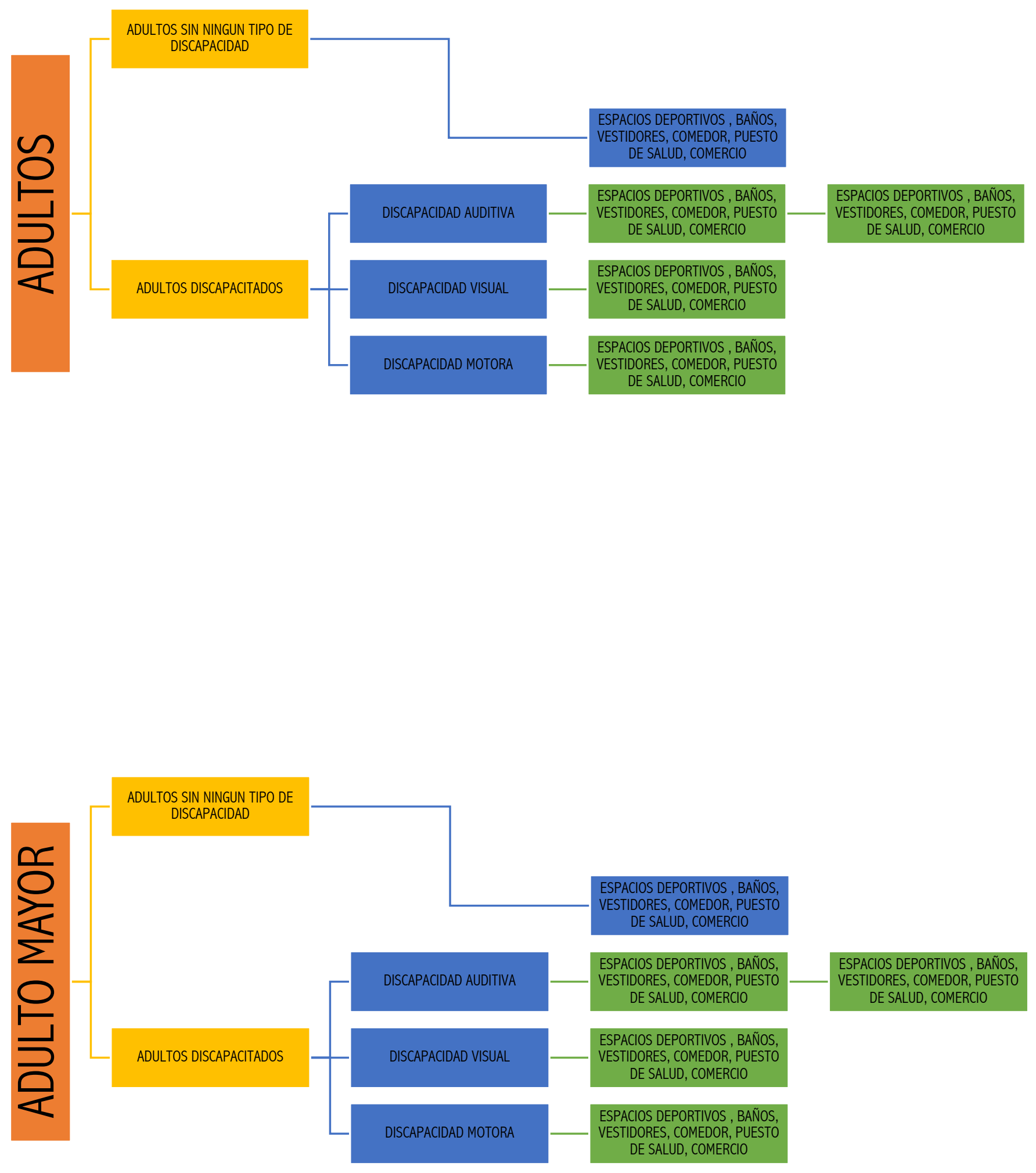

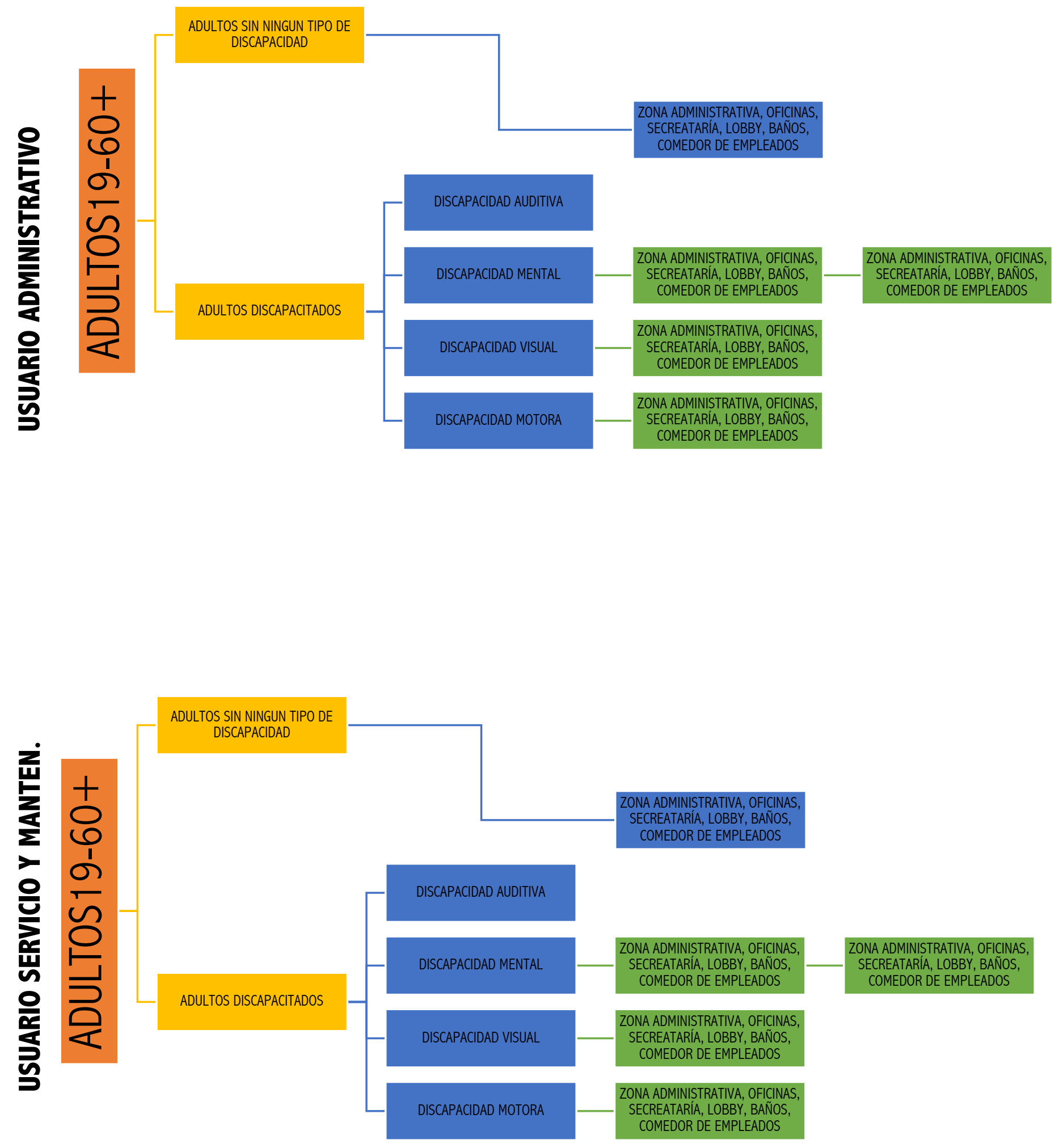

IMAGEN 11 - GRAFICO CUALITATIVO DE LOS TIPOS DE USUARIOS - ELABORACIÓN PROPIA 


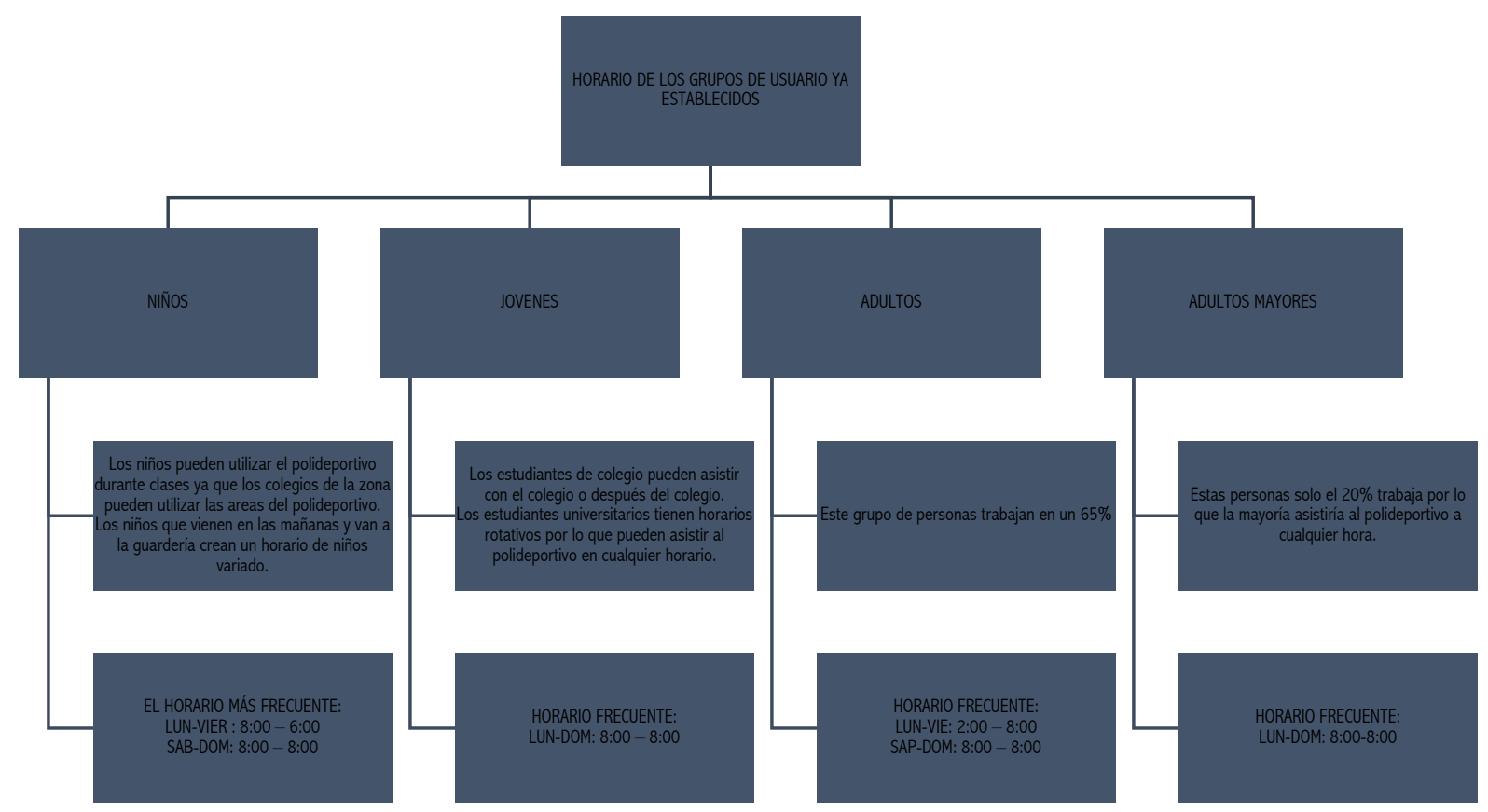

IMAGEN 12 - GRAFICO CUALITATIVO DE LOS TIPOS DE USUARIOS - ELABORACIÓN PROPIA

NECESIDADES DE LOS USUARIOS:

3 GRUPOS DE NECESIDADES DIFERENCIADOS

-Necesidades de los usuarios deportistas

- Necesidades del usuario administrativo

-Necesidades del usuario de servicio
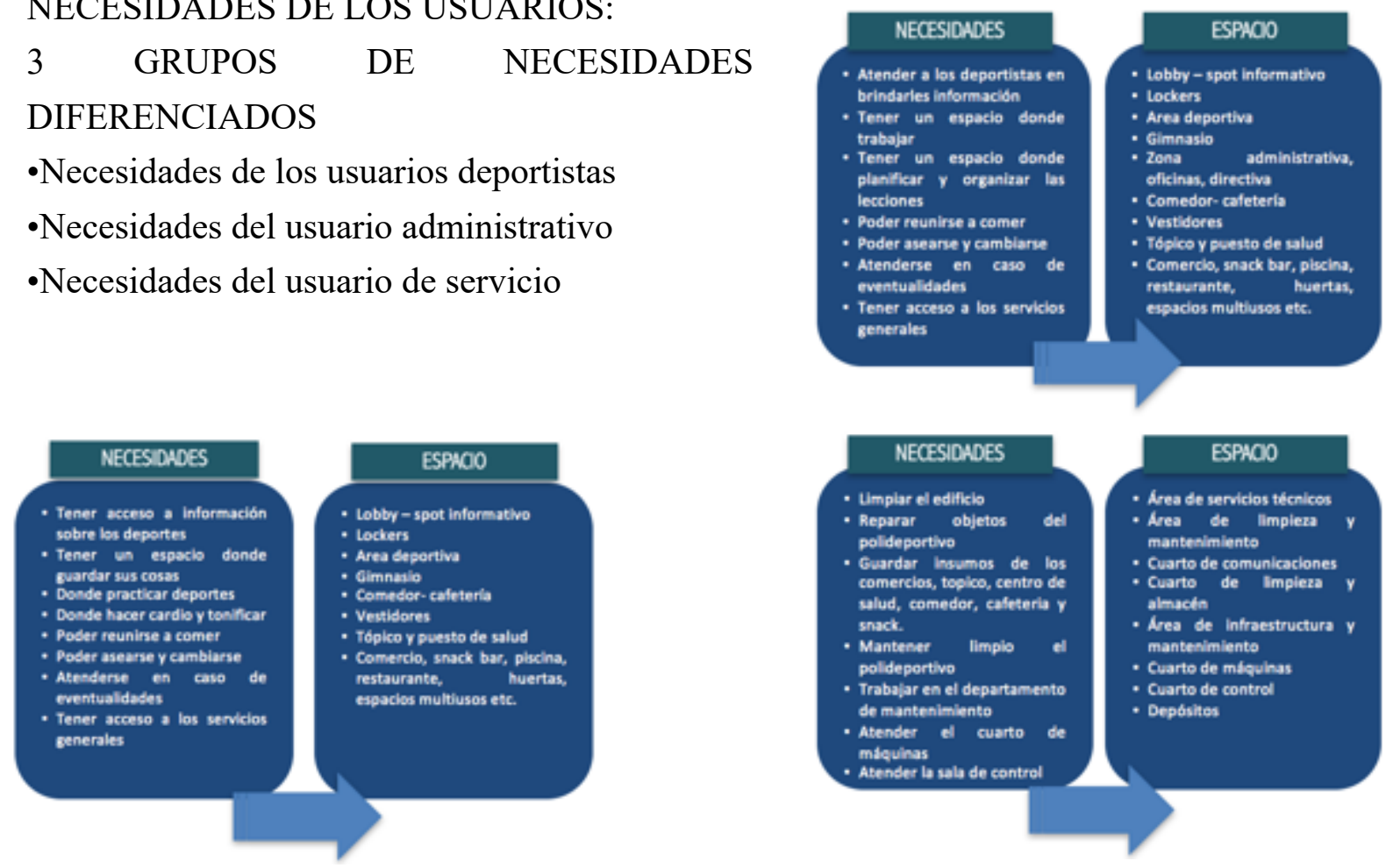


\subsection{ASPECTOS CUALITATIVOS FLUJO DE LOS USUARIOS:}

El flujo de los usuarios evidencia el buen funcionamiento del establecimiento. La circulación debe ser la mínima posible, clara y accesible. Al ser un polideportivo con énfasis en el diseño universal el acceso claro y los espacios y circulaciones accesibles son importantísimas para el éxito del edificio.

- La zona de niños debería tener un acceso casi directo, para que no perturbe las otras actividades del edificio.

- La circulación principal debe estar en el lobby principal del edificio desde el cual deberían verse los accesos a las actividades principales del polideportivo para que sirva de guía visual y de orientación.

- El flujo de personal de servicio y administrativo debe ser diferenciado. Así como el flujo de desechos e insumos.

\subsection{ASPECTOS CUALITATIVOS}

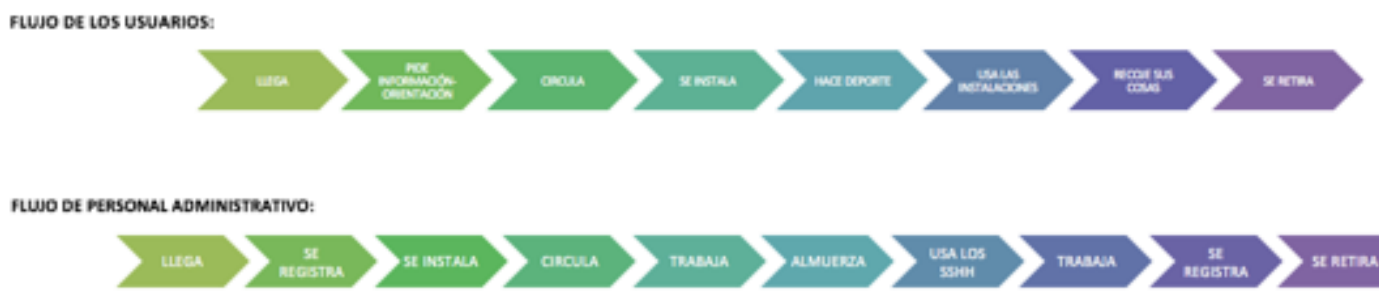

FLWO DE PAOFESORES DE OEPORTE:

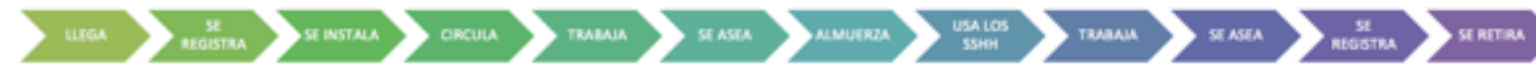

RUio de Espetradones:

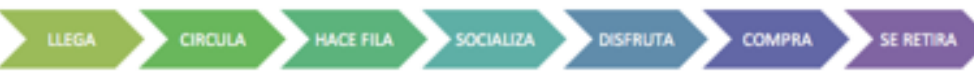

RUIO de personal of SERVicio:

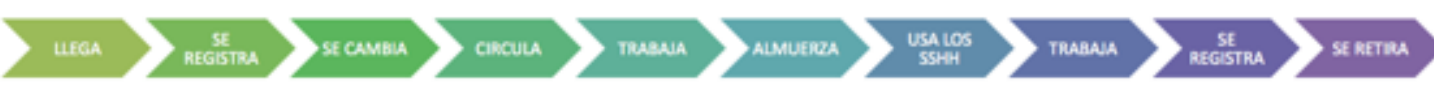

RUIO DE PLRSONAL StGUNIDAO:

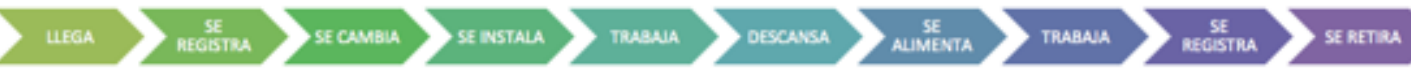

IMAGEN 15 - GRAFICOS CUALITATIVOS DE LOS TIPOS DE USUARIOS Y SUS FLUJOS - ELABORACIÓN PROPIA 


\begin{tabular}{|c|c|c|c|}
\hline DEPORTE & CANT DEPORTISTAS & CANTIDAD DE ESPACIOS & TOTAL \\
\hline BASQUET & 18 & 2 & 36 \\
\hline FUTBOL & 34 & 2 & 68 \\
\hline BAILE & 20 & 4 & 40 \\
\hline TENNIS & 6 & 4 & 24 \\
\hline VOLLEY & 20 & 4 & 80 \\
\hline ATLETISMO & 25 & 1 & 25 \\
\hline GIMNASIA & 30 & 1 & 30 \\
\hline CIRCUITO & 25 & 1 & 25 \\
\hline $\begin{array}{c}\text { SQUASH/ PING } \\
\text { PONG }\end{array}$ & 6 & 4 & 24 \\
\hline BOWLING & 6 & 6 & 36 \\
\hline FRONTON & 6 & 4 & 24 \\
\hline D. BATALLA & 6 & 4 & 24 \\
\hline NATACION & 18 & 1 & 18 \\
\hline \multicolumn{3}{|c|}{ TOTAL DE DEPORTISTAS POR TURNO } & 509 \\
\hline
\end{tabular}

IMAGEN 16 - CUADRO DE RESUMEN DE LOS USUARIOS DEPORTISTAS - ELABORACIÓN PROPIA

\begin{tabular}{|c|c|}
\hline USUARIO & CANTIDAD \\
\hline DEPORTISTAS & 509 \\
\hline P. ADMINISTRATIVO & 250 \\
\hline P. SERVICIOS & 110 \\
\hline PROFESORES & 40 \\
\hline P. CENTRO DE SALUD & 25 \\
\hline USUARIOS QUE ACOMPAÑAN AL \\
DEPORTISTA
\end{tabular}

IMAGEN 17 - CUADRO DE RESUMEN DE LOS USUARIOS - ELABORACIÓN PROPIA

\begin{tabular}{|c|c|}
\hline USUARIO EVENTUAL & CANTIDAD \\
\hline EXPECTADORES & 1500 \\
\hline TOTAL & 1500 \\
\hline
\end{tabular}

IMAGEN 18 - CUADRO DE USUARIO EVENTUALES- ELABORACIÓN PROPIA 


\subsection{RESUMEN DE TIPO Y NÚMERO DE USUARIO}

\begin{tabular}{|c|c|c|c|c|c|c|}
\hline \multirow{2}{*}{ NRO } & \multirow{2}{*}{$\begin{array}{l}\text { TIPO DE USUARIO SEGÚN SU } \\
\text { EDAD }\end{array}$} & \multirow{2}{*}{$\begin{array}{l}\text { NRO DE USUARIO } \\
\text { ANUAL }\end{array}$} & \multirow{2}{*}{$\begin{array}{l}\text { PROYECCIÓN A } \\
\text { FUTURO }\end{array}$} & \multirow{2}{*}{ DIAS DE ATENCIÓN } & \multicolumn{2}{|c|}{ HORAS DE ATENGOON } \\
\hline & & & & & LUNES-VIERNES & SABADO-DOMINGO \\
\hline 1 & NIÑOS DE 0-14 & 2815 & 3515 & LUNES A DOMINGO & $8: 00-6: 00$ & $8: 00-8: 00$ \\
\hline 2 & JOVENES $15-29$ & 5068 & 5768 & LUNES A DOMINGO & $8: 00-8: 00$ & $8: 00-8: 00$ \\
\hline 3 & ADULTOS 30-60 & 2252 & 2952 & LUNES A DOMINGO & $2: 00-8: 00$ & $8: 00-8: 00$ \\
\hline 4 & ADULTO MAYOR 60-+ & 1126 & 1826 & LUNES A DOMINGO & $8: 00-8: 00$ & $8: 00-8: 00$ \\
\hline 5 & $\begin{array}{c}\text { PERSONAL ADMINISTRATIVO, } \\
\text { PROFESORES Y } \\
\text { REAHIBILTADORES Y SERVICIO }\end{array}$ & 250 & 350 & LUNES A DOMINGO & $6: 00-8: 00$ & $6: 00-8: 00$ \\
\hline & TOTAL DE USUARIOS & 11260 & 14060 & & & \\
\hline
\end{tabular}

\section{CONCLUSIONES:}

El usuario base es de 11260 personas anualmente, en diez años serían 14060 personas.

Al mismo tiempo podría atender a 1056 personas (AFORO), las personas se quedan un promedio de 3 horas entrenando lo que permite 4 rotaciones de 1050 personas, lo que dejaría que atienda a 4200 personas diario, 29,400 semanalmente, 882,000 al mes.

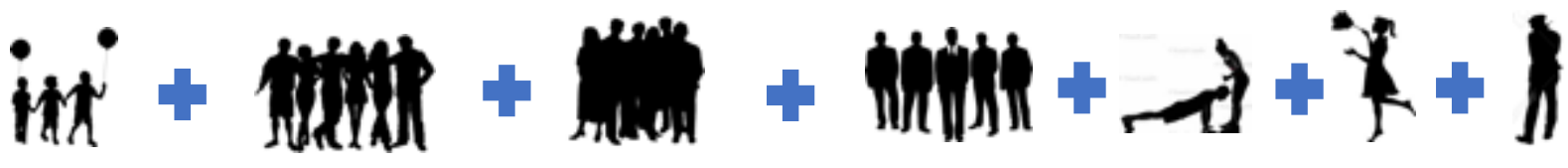


7.PROGRAMA 


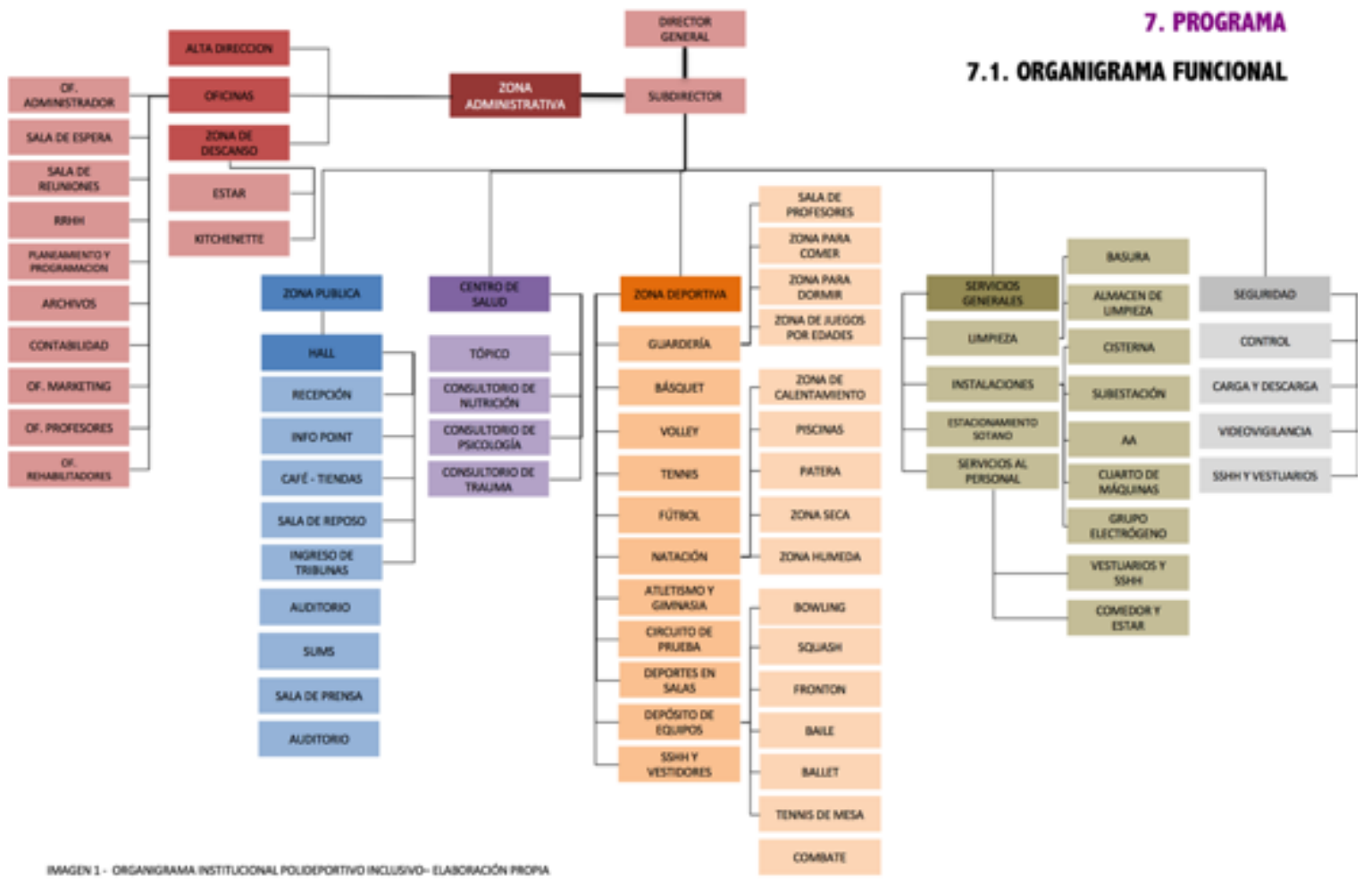

\subsection{DEFINICIÓN DE INTERRELACIONES ESPACIALES}

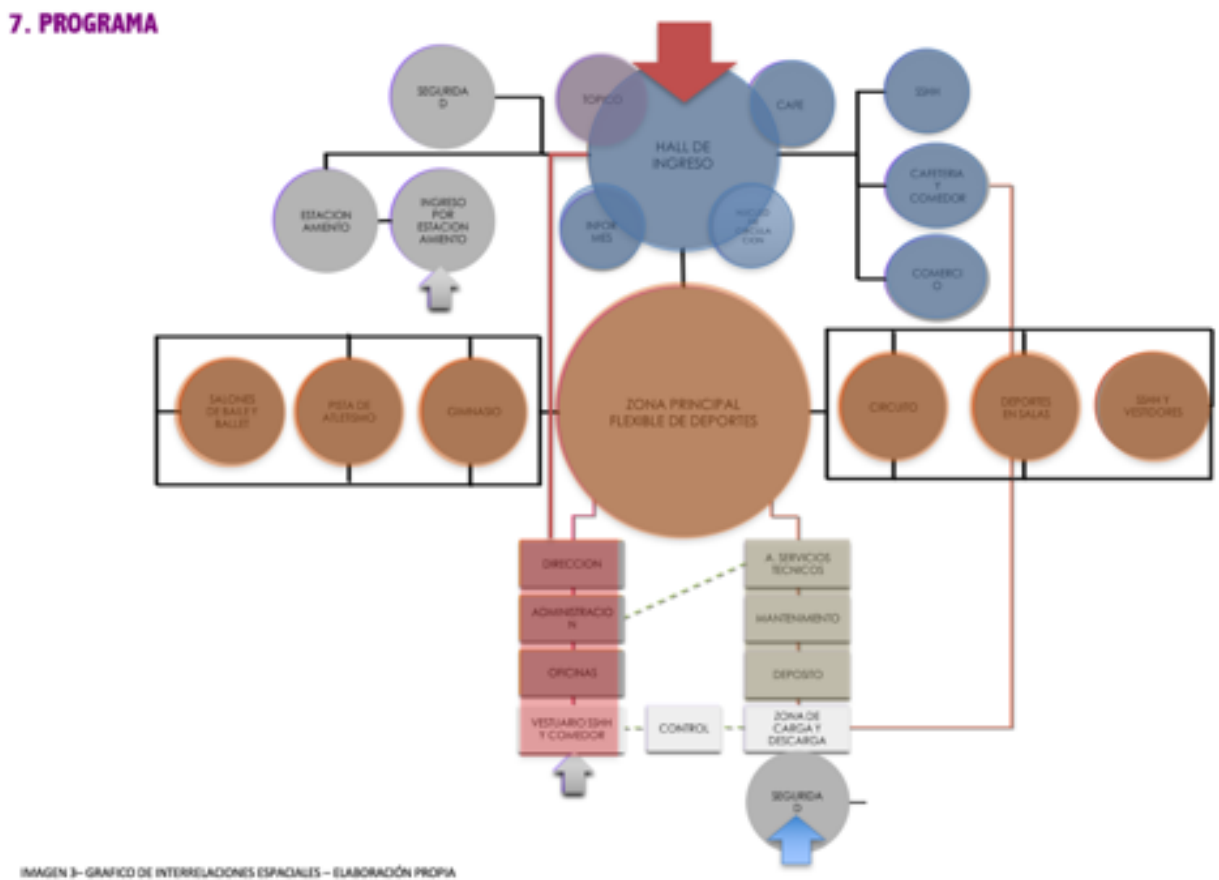




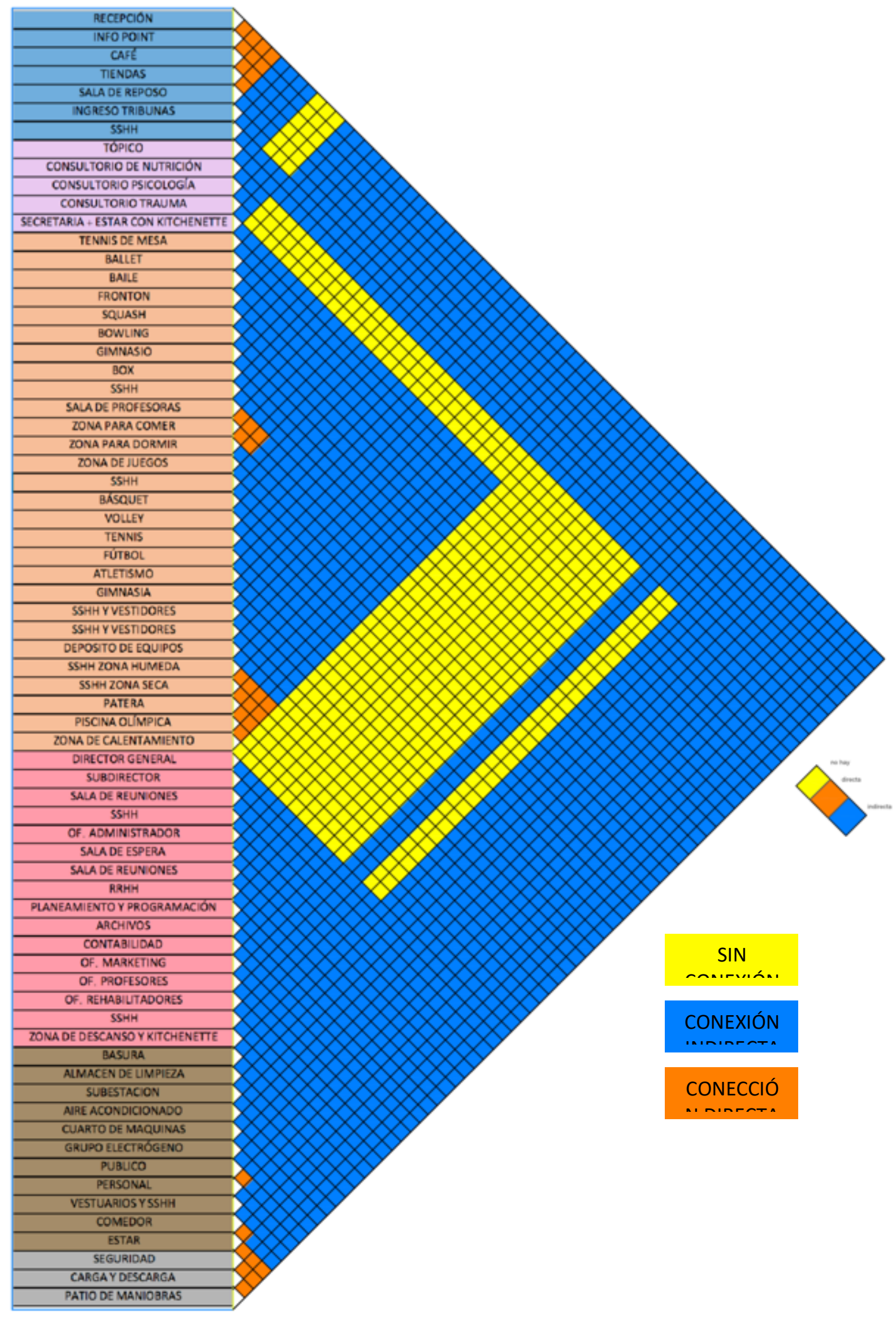

IMAGEN 4 - ORGANIGRAMA RELACIONES ESPACIALES- ELABORACIÓN PROPIA 


\section{PROGRAMA}

El área total del terreno es de $20000 \mathrm{~m} 2$.

Si se le resta el $72.3 \%$ de área libre quedan $13156 \mathrm{~m} 2$. El edificio tiene un sótano de $4500 \mathrm{~m} 2$, primer nivel de $6800 \mathrm{~m} 2$, segundo nivel de $4500 \mathrm{~m} 2$ y tercer nivel de $4400 \mathrm{~m} 2$. Resultando en un área total de $20240 \mathrm{~m} 2$. Restando el porcentaje de muros y circulación el proyecto tiene 13,157m2 de área ocupada. Sabiendo que mi usuario es de 1056 personas diarias base a este, me quedaría espacio para albergar al usuario eventual que acompaña al deportista o el usuario que asiste a los espectáculos deportivos.

\section{PROGRAMA BÁSICO}

\section{PROGRAMA}

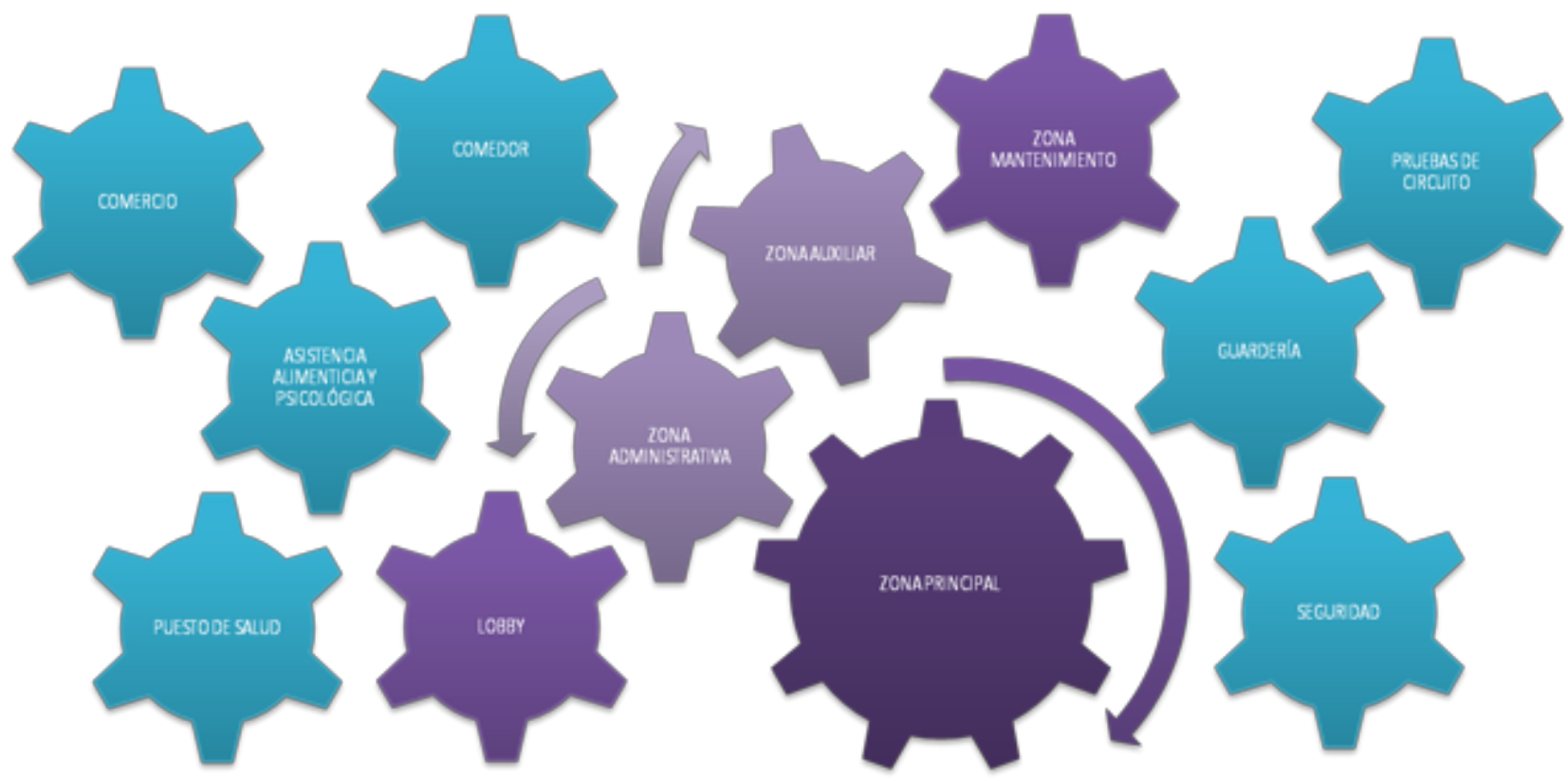

IMAGEN 2 - GRAFICO EN EL QUE SE VE EL PROGRAMA QUE SE HA AGREGADO AL BÁSICO DE UN POLIDEPORTIVO BASADO EN PROYECTOS REFERENCIALES EXITOSOS Y EN NECESIDADES DEL USUARIO - ELABORACIÓN PROPIA

\begin{tabular}{|c|c|c|c|c|c|c|}
\hline \multicolumn{4}{|c|}{ CUADRO NORMATIVO } & \multicolumn{3}{|c|}{ CUADRO DE ÁREAS (m2) } \\
\hline \multirow{2}{*}{\multicolumn{2}{|c|}{ 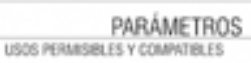 }} & RNE & PROYECTO & & PARCIAL & TOTAL \\
\hline & & OCD Y YEFORIES & Pouctportivo & sotions & $4500 \mathrm{me}$ & \multirow{4}{*}{$2020072 \mathrm{mo}$} \\
\hline \multicolumn{2}{|l|}{ Densoed NEM } & LOESTELECDO ROR EL FECLAESTO & mones.ma & ant-1 & $\operatorname{cosec2} 24 \pi^{2}$ & \\
\hline \multicolumn{2}{|c|}{ COEACENTE OE EDIRCUCOCH } & 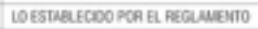 & 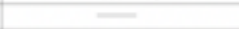 & PEMER NWEL & $\operatorname{sectan} 24 \mathrm{me}$ & \\
\hline \multicolumn{2}{|l|}{ hashunase } & 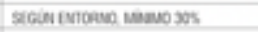 & 523 & SEOUNOO NEVL & $400024=0$ & \\
\hline \multicolumn{2}{|l|}{ ATURA Widenah } & 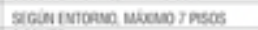 & Sotan + 3 REOS & AaLs ots municto. TLmeso & & 20 ase $3 \mathrm{sin}$ \\
\hline \multirow[t]{3}{*}{ RETRO Gean } & Fonte & $\begin{array}{l}\text { Dosuts } \\
\text { ampurs }\end{array}$ & Sons & IFEA LEAE & 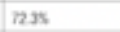 & $14802.43 \mathrm{me}$ \\
\hline & Prombil & $\begin{array}{l}\text { Douns } \\
\text { opours }\end{array}$ & $\frac{14 \mathrm{rts}}{26 \mathrm{st}}$ & \multirow{3}{*}{ assa coupada } & & \multirow{3}{*}{$131564.4=0$} \\
\hline & matrol & Dowers & 300 & & & \\
\hline \multicolumn{2}{|c|}{ Estackomaneasto } & LOESTRELECDO MOR E REQLAETTO & 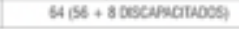 & & & \\
\hline
\end{tabular}




\subsection{ANÁLISIS DE LA NORMATIVA APLICABLE AL PROYECTO}

Al ser un polideportivo inclusivo, se tiene que analizar la normativa para centros recreativos y deportivos además la normativa para la circulación de personas discapacitadas. Adicionalmente, consultare normativa de salud por el centro de salud, normativa de accesibilidad, y comercio.

\section{NORMATIVA CAPITULO 1 - ASPECTOS GENERALES}

El artículo 3 de la Norma A.100 Recreación y Deportes del RNE indica que los proyectos de edificación para recreación y deportes, requieren la elaboración de estudios complementarios:

Estudio de Impacto Vial, para edificaciones que concentren más de 1000 ocupantes , se tendría que hacer un estudio de impacto vial porque mi número de ocupantes es 7250 .

Estudio de Impacto Ambiental para edificaciones que concentren más de $\mathbf{3 0 0 0}$ usuarios, en mi caso también tendría que hacerlo porque tengo 7250 usuarios.

El Artículo 4 dice que tienen que tener facilidad de acceso y evacuación para las personas que vienen de circulaciones diferenciadas hacia espacios abiertos.

En el proyecto crearé plazas a donde estas personas se puedan dirigir en caso de haber una necesidad de evacuar las instalaciones.

También indica que debe haber una factibilidad de servicios de agua y energía. Al analizar la zona vi que exista una red de agua que abastesca esta zona y de la misma manera eléctrica.

En cuanto al emplazamiento indica que el edificio debe considerar el terreno y el asolamiento. El cual planteo resolver de tal manera que se adapte a la topografía y controlando el ingreso de sol. En el planteamiento haré que se organizen las áreas con caras de mayor dimension en los lados norte y sur para que el recorrido solar se de en los otros lados del edificio, de manera que los otros lado del edificio les puedo dar un ttratamiento con brise soleils por ejemplo para controlar el ingreso de la luz solar. 


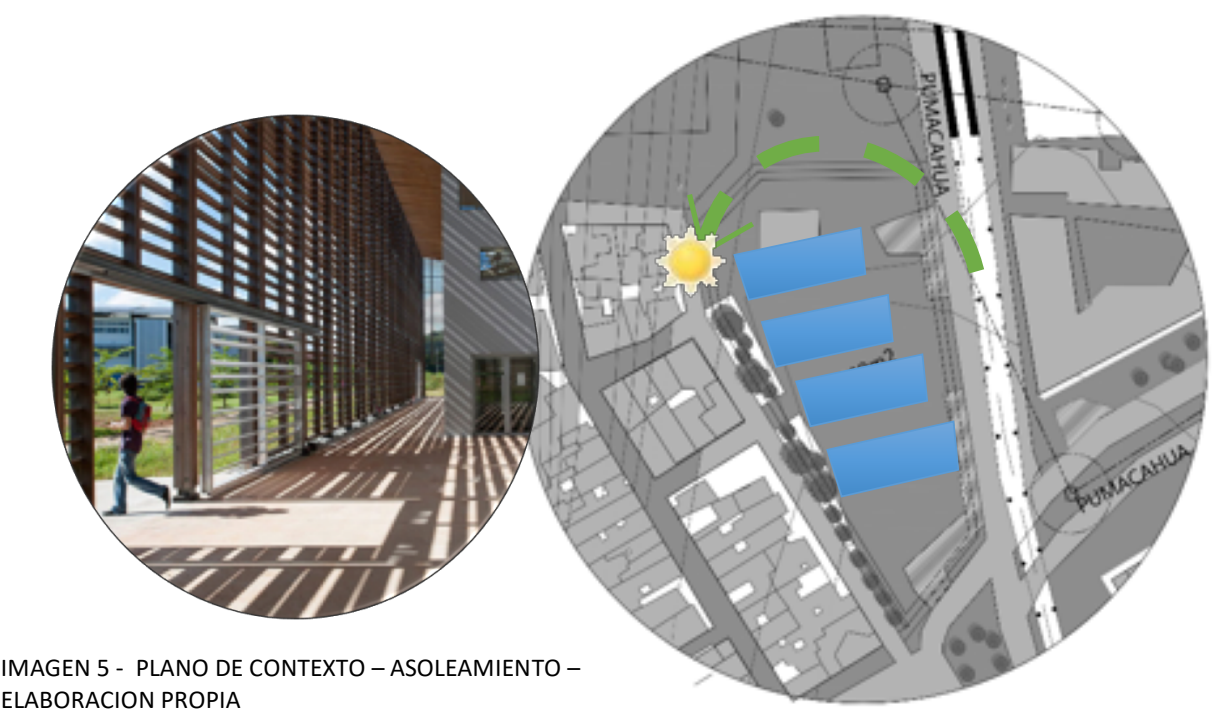

\section{NORMATIVA CAPITULO 1 - ASPECTOS GENERALES}

\section{FACILIDAD DE ACCESO A LOS MEDIOS DE TRANSPORTE:}

En este aspecto, el terreno se encuentra a 60 metros de la estación pumacahua, y esta en la Av. Pumacahua que es donde se encuentra el tren eléctrico.

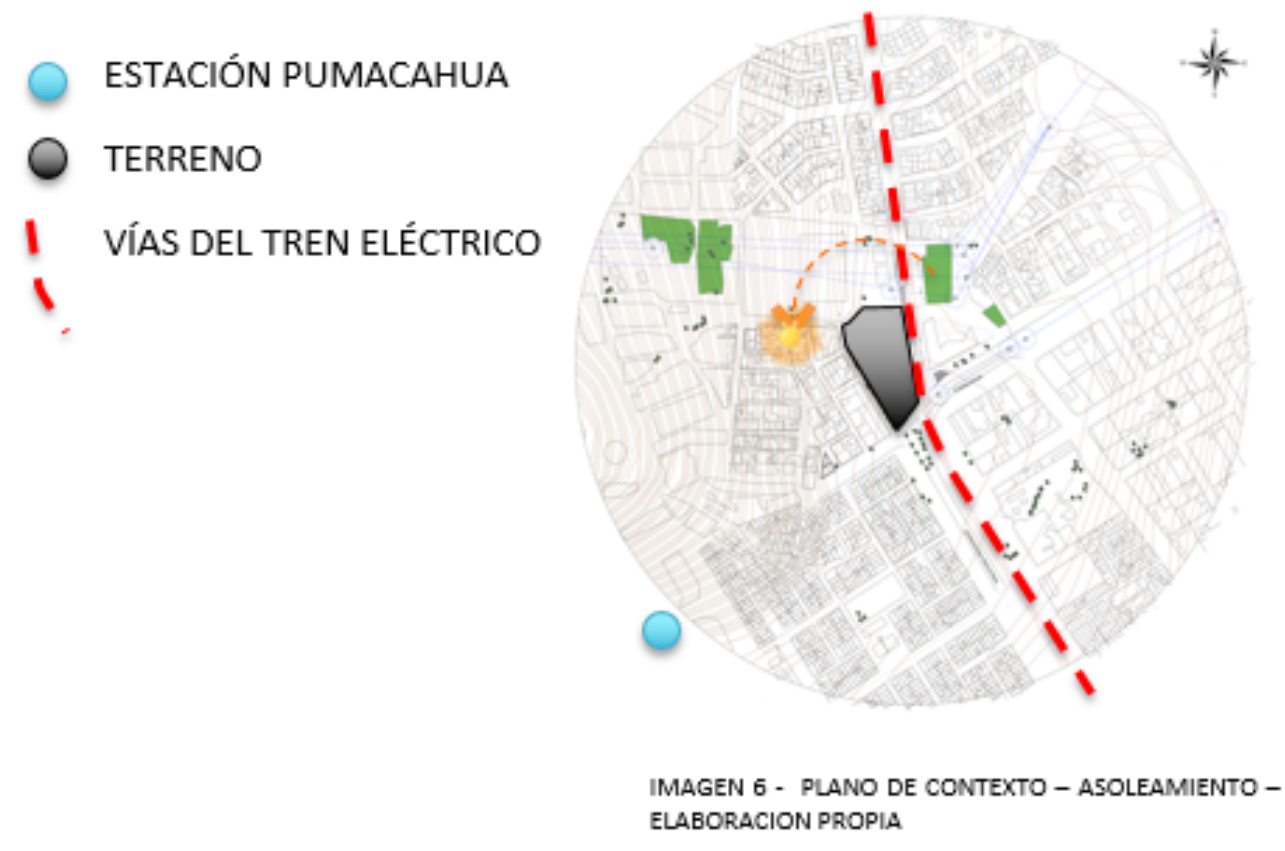




\section{NORMATIVA CAPITULO 2 - CONDICIONES DE HABITABILIDAD}

ARTICULO 5: Accesos diferenciados y circulaciones de acuerdo a uso y capacidad.

Existirán ingresos diferenciados para el público, personal administrativo, personal de mantenimiento, deportistas, jueces y periodístas. Bajo el criterio de número de ocupantes de cada zona del polideportivo.

ARTICULO 7: Numero de ocupantes se determinará de acuerdo a la siguiente tabla: Bajo el cual tengo un número de ocupantes de 7250 personas.

\section{Zona de público}

Discotecas y salas de baile

Casinos

Ambientes administrativos

Vestuarios, camerinos

Depósitos y almacenamiento

Piscinas techadas

Piscinas

\section{número de asientos o espacios para espectadores}

$1.0 \mathrm{~m} 2$ por persona

$2.0 \mathrm{~m} 2$ por persona

$10.0 \mathrm{~m} 2$ por persona

$3.0 \mathrm{~m} 2$ por persona

$40.0 \mathrm{~m} 2$ por persona

$3.0 \mathrm{~m} 2$ por persona

$4.5 \mathrm{~m} 2$ por persona

(*) El calculo del numero de ocupantes se pude sustentar con el conteo exacto en su nivel de máxima ocupación.

\section{NORMATIVA CAPITULO 2 - CONDICIONES DE HABITABILIDAD}

ARTICULO 8: Los locales ubicados a uno o más pisos por encima o por debajo del nivel de acceso al exterior deberán contar con una salida de emergencia, independiente de la escalera de uso general y que constituya una ruta de escape alterna, conectada a una escalera de emergencia a prueba de humos con acceso directo al exterior.

El nivel del polideportivo que estará bajo el nivel 0 tendrá una escalera diferenciada que se conecte con una escalera de emergencia a prueba de humos con acceso directo al exterior.

ARTICULO 9: Las edificaciones de espectáculos deportivos deberán contar con un ambiente para atenciones médicas de emergencia de acuerdo con el número de espectadores a razón de 1 espacio de atención cada 5000 espectadores, desde el que pueda ser evacuada una persona en ambulancia. 
En este aspecto he incluido dentro del programa un tópico y un centro de salud el cual estaría cerca de el hall de ingreso y a la vez tenga una salida al estacionamiento de la ambulancia.

\section{ARTICULO 10: Las edificaciones de espectáculos deportivos deberán contar con un sistema de sonido para comunicación a los espectadores, así como un sistema de alarma de incendio, audibles en todos los ambientes de la edificación.}

En el programa existe la sala de control desde donde una persona podría utilizar el sistema de sonido para dar indicaciones al público.

\section{ACCESOS Y PASAJES DE CIRCULACIÓN}

\section{Articulo 25 PASAJES}

Los pasajes para el trainsito de personas deberán cumplir con las siguientes caracteristicas:

A) Tendrán un ancho liore minimo calculado en función del nûmero de ocupantes a los que sirven.

B) Los pasajes que formen parte de una via de evacuación carecerán de obstáculos en el ancho requerido, salvo que se trate de elementos de seguridad o cajas de paso de instalaciones ubicadas en las paredes, siempre que no reduzcan en mas de $0,15 \mathrm{~m}$ el ancho requerido. El calculo de los medios de evacuación se establecen en la normaA-130.

C) La distancia horizontal desde cualquier punto, en el interior de una edificacion, al vestibulo de acceso de la edificacion o a una circulacion vertical que conduzca directamente al exterior, será como mabimo de $45 \mathrm{~m} \sin$ rociadores $\circ 60 \mathrm{~m}$ con rociadores.
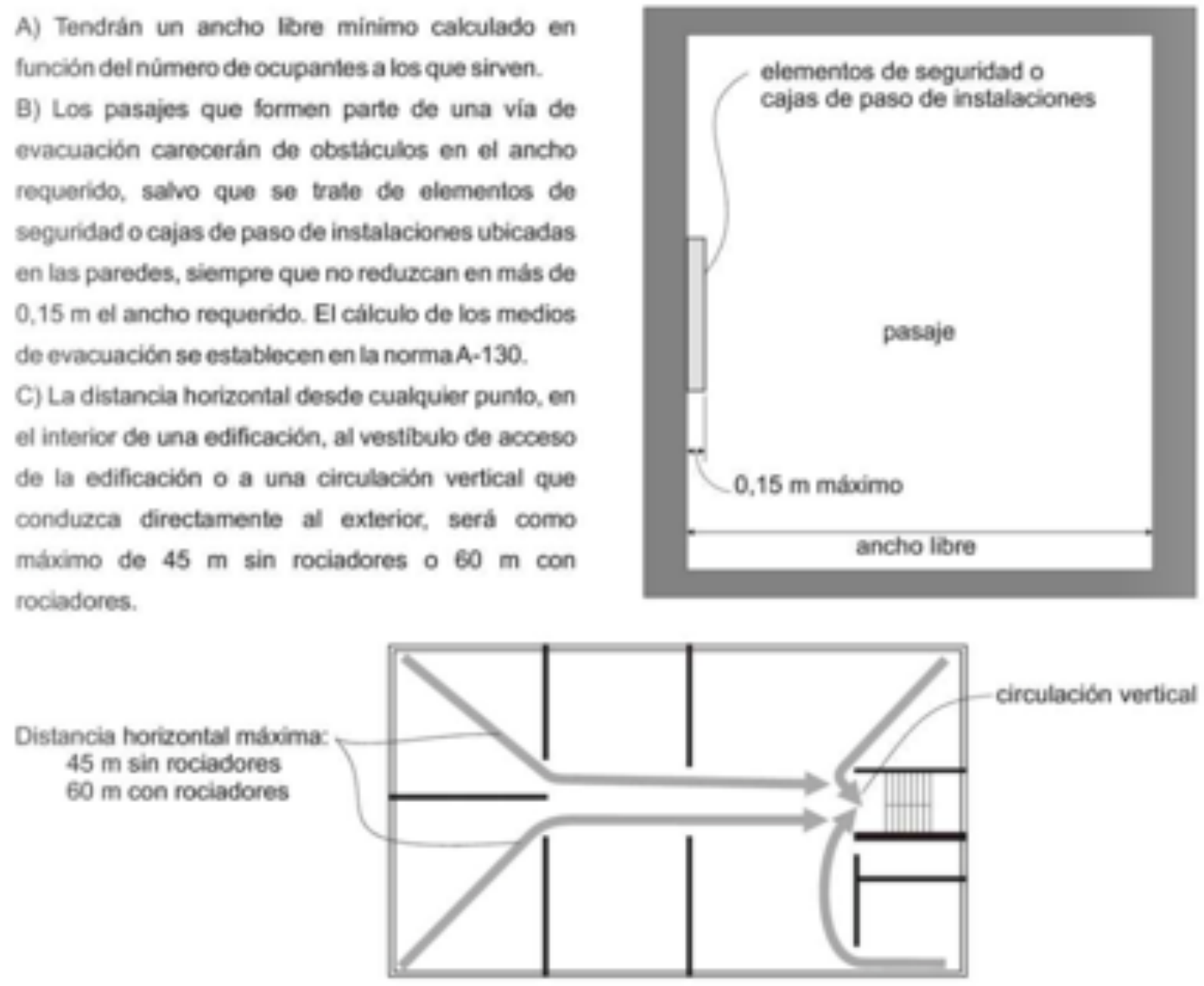

D) En edificaciones de uso residencial se podrá agregar $11 \mathrm{~m}$ adicionales, medidos desde la puerta del departamento hasta la puerta de ingreso a la ruta de evacuación. 
Articulo 13.- Los accesos a las edificaciones para espectáculos deportivos serán distribuidos e identificables en forma clara, habiendo cuando menos uno por cada sector de tribuna.

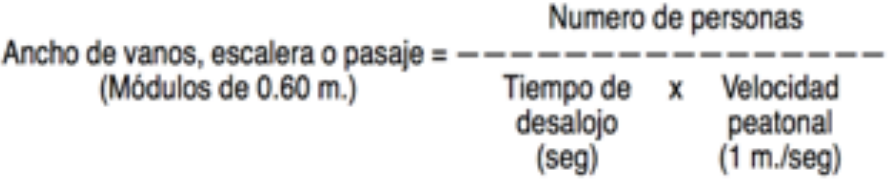

\title{
NORMATIVA CAPITULO 2 - CONDICIONES DE HABITABILIDAD
}

\author{
Articulo 14.- Circulación en las tribunas y bocas de \\ salida. \\ a) Los accesos a las tribunas llegarán a un pasaje de \\ circulación transversal, del que se conectan los pasajes \\ que servirán para acceder a cada asiento. El número \\ máximo de asientos entre pasajes de acceso será de 16. \\ b) El ancho mínimo de un pasaje de circulación trans- \\ versal o de acceso a los asientos será de $1.20 \mathrm{~m}$. \\ c) Los pasajes transversales deberán ubicarse como \\ máximo cada 20 filas de asientos. \\ d) El ancho de los pasajes, vanos de acceso y salida y \\ escaleras, será como mínimo el que resulte necesario para \\ la evacuación de manera segura, según la fórmula del \\ cálculo para su dimensionamiento de acuerdo con el nú- \\ mero de ocupantes, para casos de emergencia.

\begin{tabular}{cccc} 
Ancho de vanos, escalera o pasaje $=$ & \multicolumn{3}{c}{ Numero de personas } \\
(Módulos de $0.60 \mathrm{~m}$.) & Tiempo de & $\mathrm{x}$ & Velocidad \\
& desalojo & & peatonal \\
(seg) & & $(1 \mathrm{~m} / \mathrm{seg})$
\end{tabular} \\ e) El ancho de los pasajes y de las bocas de salida \\ serán múltiplos de $0.60 \mathrm{~m}$; \\ f) Las bocas de salida servirán a un máximo a 20 filas \\ de asientos;
}

En este aspecto las tribunas tendrán que regirse a estos requerimientos para la máxima seguridad de los usuarios, ampliare el ancho mínimo de 1,20 para la circulación a 3 metros para resolver temas de accesibilidad por mi usuario.

Articulo 15.- Las escaleras para público deberán tener un paso mínimo de $0.30 \mathrm{~m}$ de ancho.

Si el ancho de la escalera es mayor que $4 \mathrm{~m}$, llevará un pasamano central.

Las escaleras de el lobby principal tendrán un ancho considerable de un mínimo de 4 metros por lo que incluiré un pasamanos de 3 niveles para que sea más seguro para mi usuario y que de esta manera los niños no tengan problemas tampoco. 
Artículo 16.- Las salidas de emergencia tendrán las siguientes características:

a) Serán adicionales a los accesos de uso general y son exigibles a partir de ambientes cuya capacidad sea superior a 100 personas.

b) Las salidas de emergencia constituyen rutas alternas de evacuación, por lo que su ubicación debe ser tal que permita acceder a ella en caso la salida de uso general se encuentre bloqueada.

c) El número y dimensiones de las puertas de escape depende del número de ocupantes y de la necesidad de evacuar la sala en un máximo de de tres minutos

En este caso tendré salidas de emergencia en los ambientes principales y en por paquetes como en la zona administrativa, y en la zona de personal de mantenimiento, también en la zona de comedores.

Artículo 17.- Deberá proveerse un sistema de iluminación de emergencia en puertas, pasajes de circulación y escaleras, accionado por un sistema alterno al de la red pública.

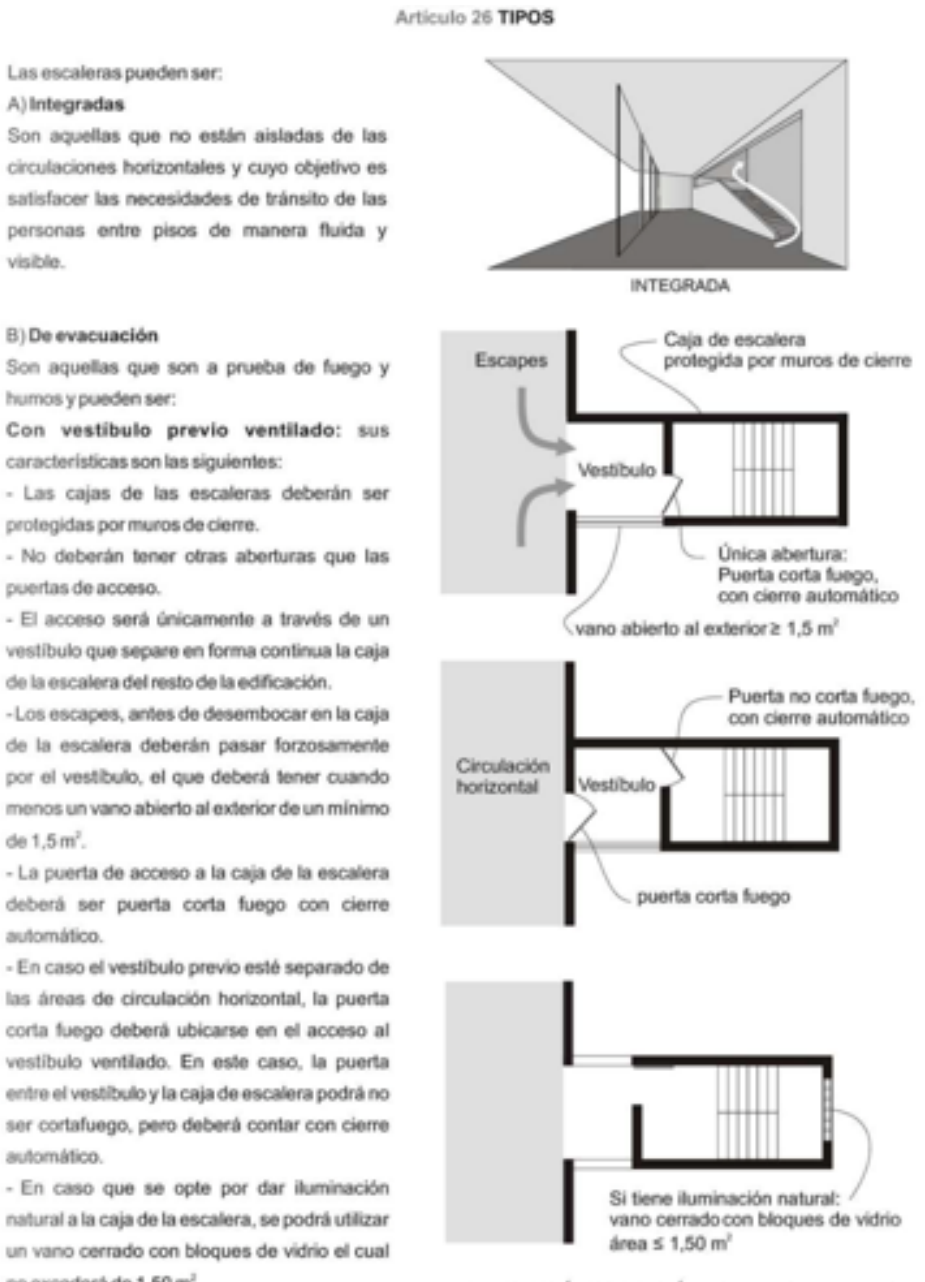

DE EVACUACICN CON VESTIBULO PREVIO VENTLADO 
Presurizadas: sus caracteristicas son las siguientes:

- Contarán con un sistema mecánico que inyecte aire a presión dentro de la caja de la escalera siguiendo los parámetros técnicos requeridos para estos sistemas.

- Deben estar cerradas al exterior.

- Este tipo de escaleras no está permitido en edificaciones residenciales.

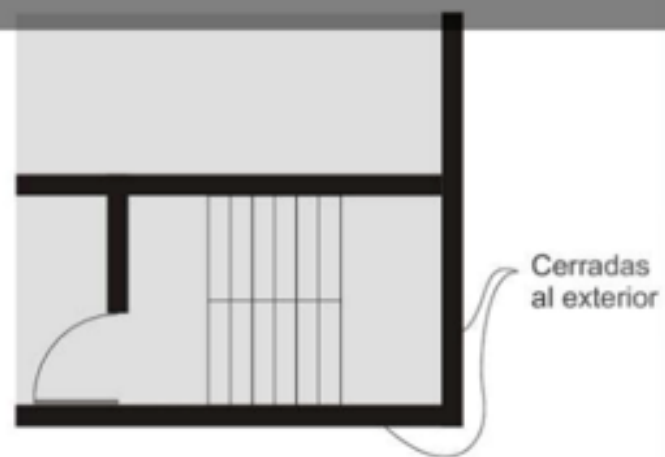

DE EVACUACIÓN PRESURIZADA

Abiertas: sus características son las siguientes:

-Están abiertas al exterior en uno de sus lados con una superficie de al menos $1 \mathrm{~m}^{2}$ en cada piso.

- El vano abierto al exterior estará a una distancia de 3 mo más de un vano de la edificación a la que sirve.

-Esta separación deberá tener una resistencia al fuego no menor de 1 hora.

- La separación de 3 m deberá ser medida horizontal y perpendicular al vano.

- Esta escalera es sólo aceptada para edificaciones residenciales no mayores de 5 niveles medidos sobre el nivel de la calle.

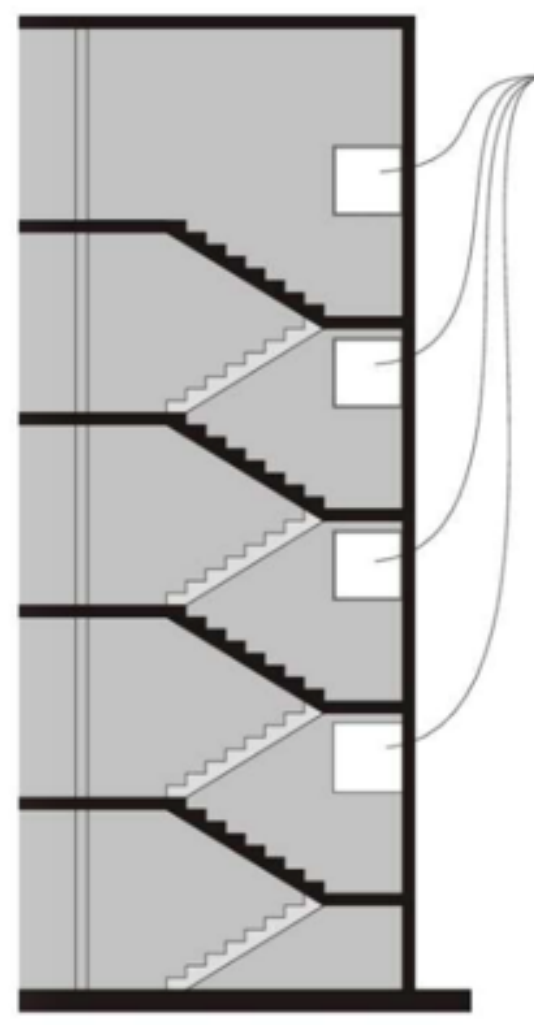

Aberturas al exterior en cada piso con superficie $\geq 1 \mathrm{~m}^{2}$

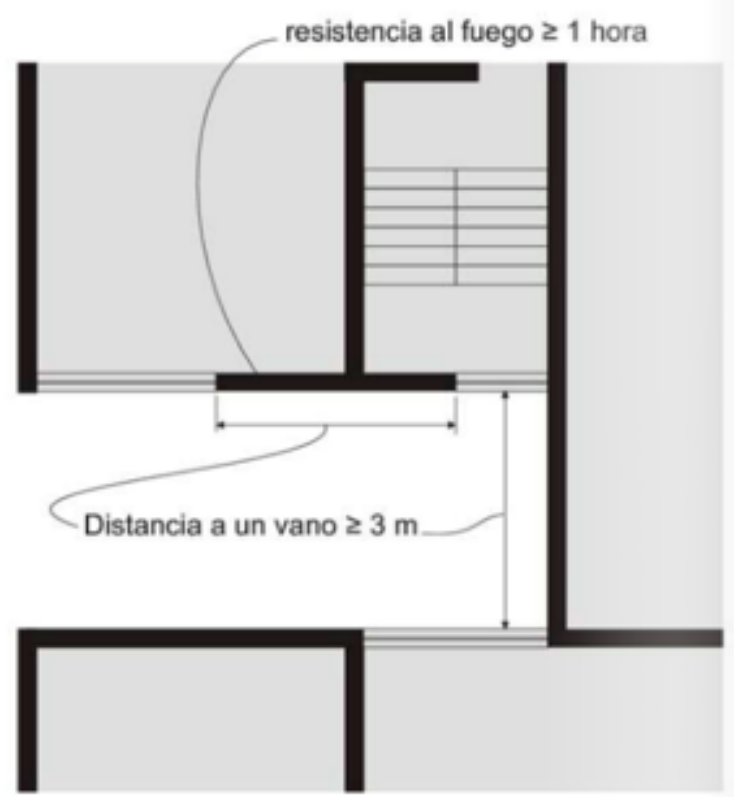

Sólo para edificaciones residenciales no mayores de 5 niveles medidos sobre el nivel de la calle.

DE EVACUACIÓN ABIERTA 
Cerradas: Sus caracteristicas son las siguientes:

- Cuando todos sus lados cuentan con un cerramiento corta fuego con una resistencia no menor a 1 hora, incluyendo la puerta.

- Serán aceptadas únicamente en edificaciones no mayor de 4 niveles y protegidas $100 \%$ por un sistema de rociadores según estándar NFPA 13.

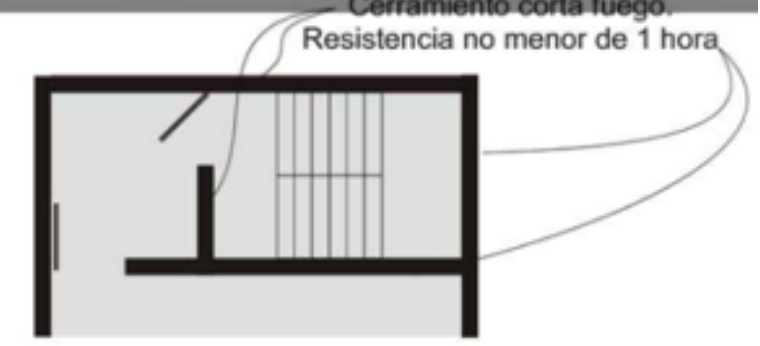

DE EVACUACIÓN CERRADA

El tipo de escalera que se provea depende del uso y de la altura de la edificación, de acuerdo con la siguiente tabla:

$\begin{array}{lll}\text { Vivienda } & \begin{array}{l}\text { Integrada } \\ \text { hasta } 5 \text { niveles }\end{array} & \begin{array}{l}\text { De evacuación } \\ \text { más de } 5 \text { niveles }\end{array} \\ \text { Hospedaje } & \text { hasta } 3 \text { niveles } & \text { más de } 3 \text { niveles } \\ \text { Educación } & \text { hasta } 4 \text { niveles } & \text { más de } 4 \text { niveles } \\ \text { Salud } & \text { hasta } 3 \text { niveles } & \text { más de } 3 \text { niveles } \\ \text { Comercio } & \text { hasta } 3 \text { niveles } & \text { más de } 3 \text { niveles } \\ \text { Oficinas } & \text { hasta } 4 \text { niveles } & \text { más de } 4 \text { niveles } \\ \text { Servicios comunales } & \text { hasta } 3 \text { niveles } & \text { más de } 3 \text { niveles } \\ \text { Recreación y deportes } & \text { hasta } 3 \text { niveles } & \text { más de } 3 \text { niveles } \\ \text { Transportes y comunicaciones } & \text { hasta } 3 \text { niveles } & \text { más de } 3 \text { niveles }\end{array}$

La ventilación al exterior puede ser a un pozo de luz, cuya dimensión medida perpendicularmente a la superficie abierta no debe ser menor que un quinto de la altura total del paramento más bajo del pozo, medido a partir del alféizar del vano más bajo de la escalera.

Las dimensiones del pozo no deberán ser menores que $2,20 \mathrm{~m}$ por lado
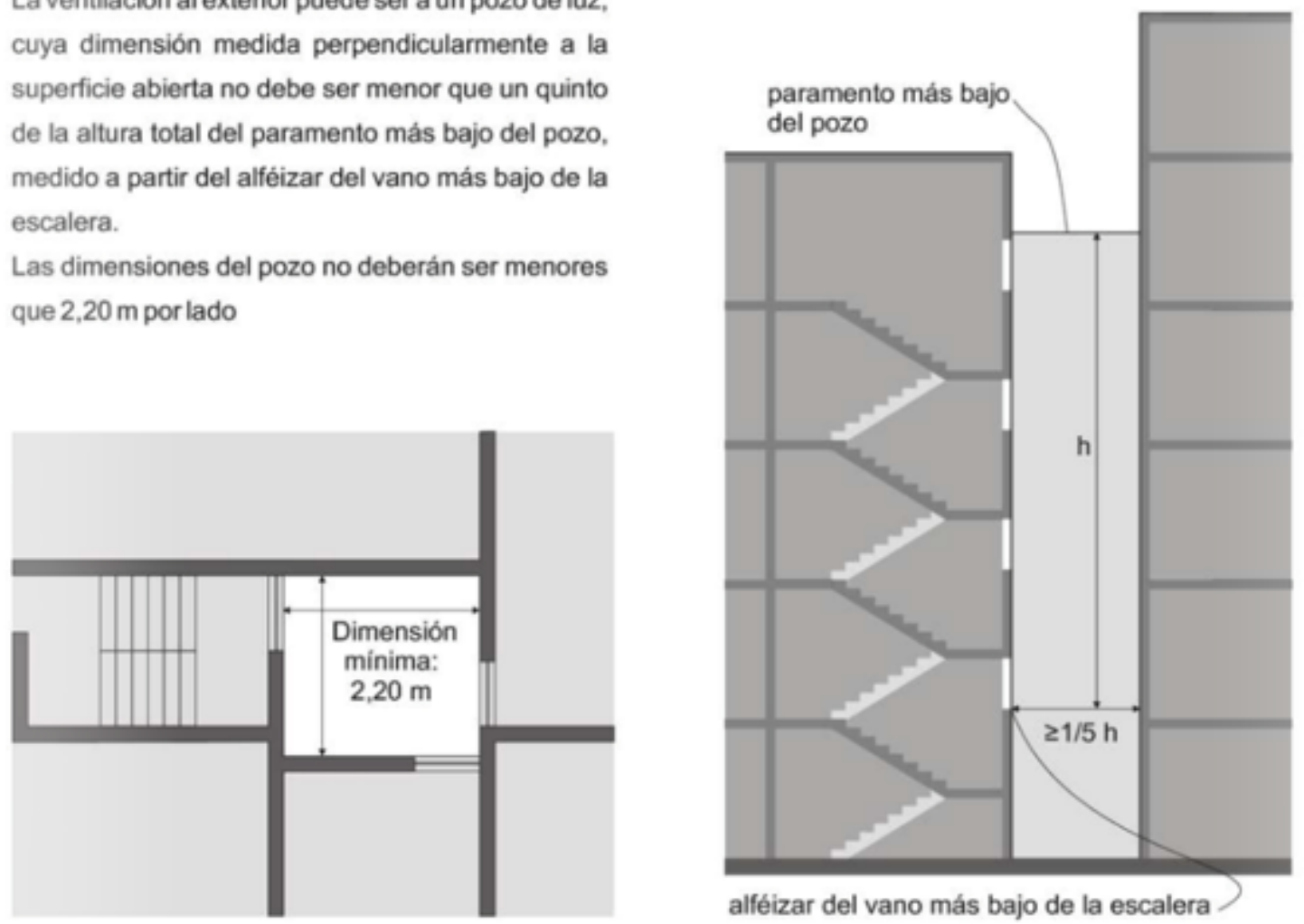
Las escaleras de evacuación deberán cumplir los siguientes requisitos:

a) Ser continuas del primer al último piso, entregando directamente hacia la vía pública o a un pasadizo compartimentado cortafuego que conduzca hacia la via pública.

b) Tener un ancho libre mínimo entre cerramientos de $1,20 \mathrm{~m}$.

c) Tener pasamanos a ambos lados separados de la pared un máximo de $5 \mathrm{~cm}$. El ancho del pasamanos no será mayor de $5 \mathrm{~cm}$. Pasamanos de anchos mayores requieren aumentar el ancho de la escalera.

d) Deberán ser construidas de material incombustible.

e) En el interior de la caja de la escalera no deberá existir materiales combustibles, ductos o aperturas.

f) Los pases desde el interior de la caja hacia el exterior deberán contar con protección cortafuego (sellador) no menor que la resistencia contra fuego de la caja.

g) Únicamente son permitidas instalaciones de los sistemas de protección contra incendios.

h) Tener cerramientos de la caja de la escalera con una resistencia al fuego de 1 hora en caso que tenga 5 niveles, de 2 horas en caso que tengan 6 hasta 24 niveles y de 3 horas en caso que tengan 25 niveles o más.

i) Contar con puertas corta fuego con una resistencia no menor del $75 \%$ de la resistencia de la caja de escalera a la que sirven.
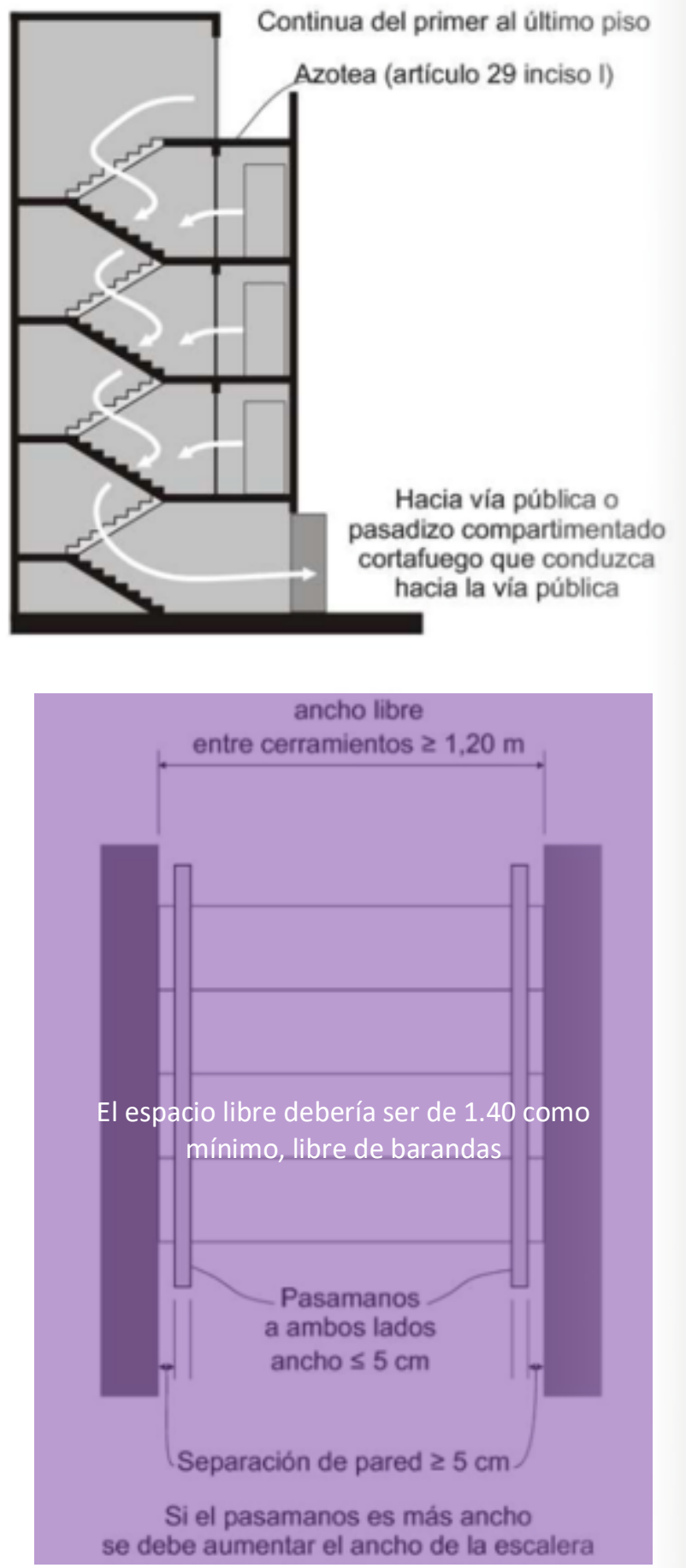

\section{Cerramientos}

Resistencia al fuego:

5 niveles 1 hora

6 a 24 niveles 2 horas

25 niveles o más 3 horas

puerta corta fuego

resistencia $\geq 75 \%$ de la resistencia de la caja de escalera 

primer piso, que imposibilite a las personas que evacuan el edificio continuar bajando accidentalmente al sótano.

k) El espacio bajo las escaleras no podrá ser empleado para uso alguno.

l) Deberán contar con un hall previo para la instalación de un gabinete de manguera contra incendios, con excepción del uso residencial.

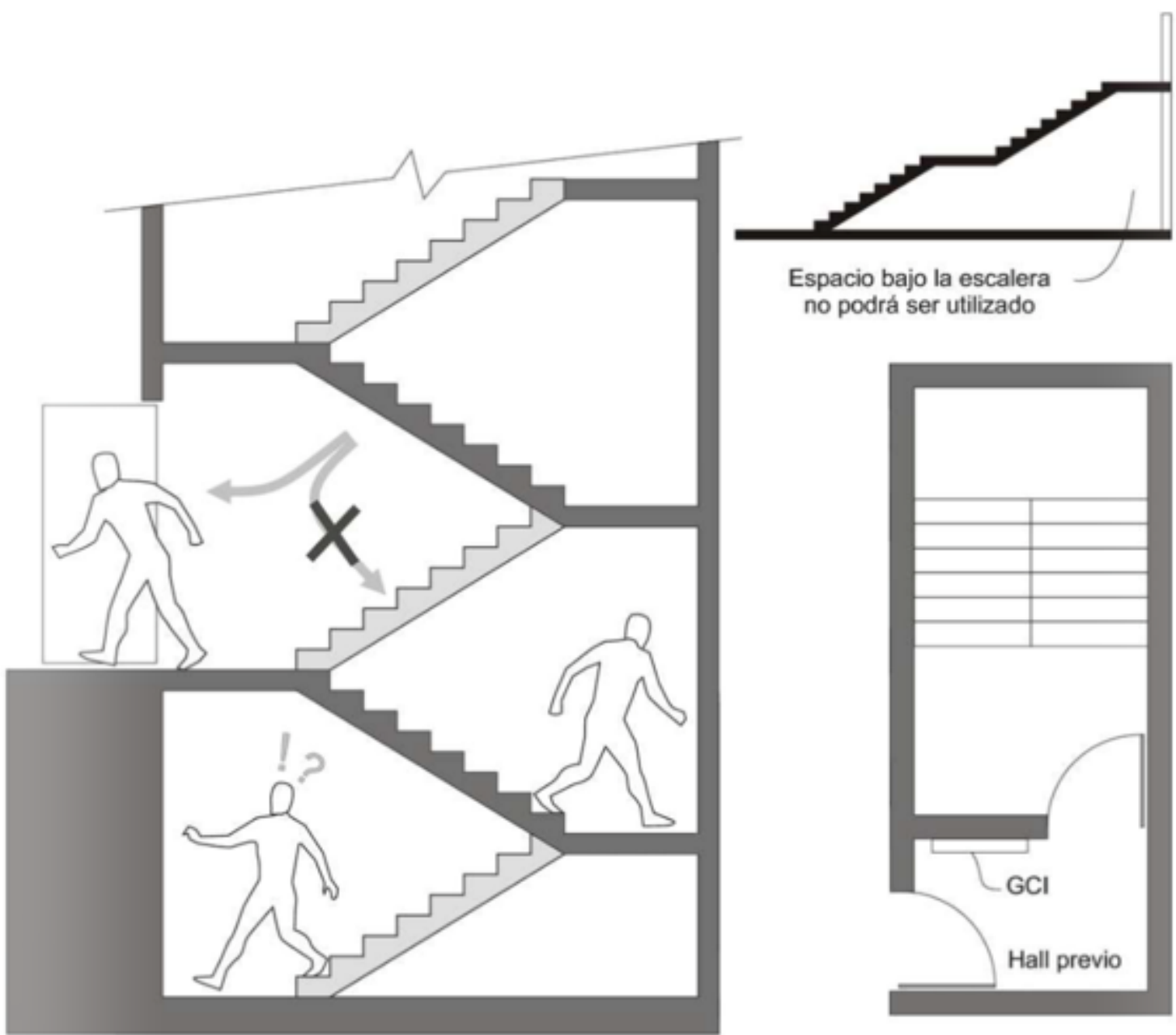

Articulo 28 NÚMERO Y ANCHO DE ESCALERAS

El número y ancho de las escaleras se define según la distancia del ambiente más alejado de la escalera y el número de ocupantes de la edificación a partir del segundo piso, según la siguiente tabla:

\section{Uso residencial}

De 1 a 300 ocupantes

De 301 a 800 ocupantes

De 801 a 1200 ocupantes

Más de 1201 ocupantes

\section{ancho total requerido}

1,20 m en escalera

2,40 men 2 escaleras

3,60 m en 3 escaleras

un módulo de $0,60 \mathrm{~m}$ por cada 360 ocupantes 
k) Las puertas de acceso-a las - cajas de escalera deberán abrir en la dirección del flujo de evacuación de las personas y su radio de apertura no deberá invadir el área formada por círculo que tiene como radio el ancho de la escalera.

I) Deberán comunicar todos los niveles incluyendo el acceso a la azotea.

m) Cuando se requieran dos o más escaleras, éstas deberán ubicarse en rutas opuestas.

n) Las escaleras deben entregar en el nivel de la calle, directamente hacia el exterior o a un espacio interior directamente conectado con el exterior, mediante pasajes protegidos corta fuego, con una resistencia no menor al de la escalera a la que sirven y de un ancho no menor al ancho de la escalera.

o) Las puertas que abren al exterior tendrán un ancho mínimo de $1 \mathrm{~m}$.

p) Para el cumplimiento de lo establecido en los incisos m, n y o se aceptarán las alternativas establecidas en el Código NFPA 101 para estos casos.

q) Las escaleras mecánicas no deberán ser consideradas como rutas de evacuación.
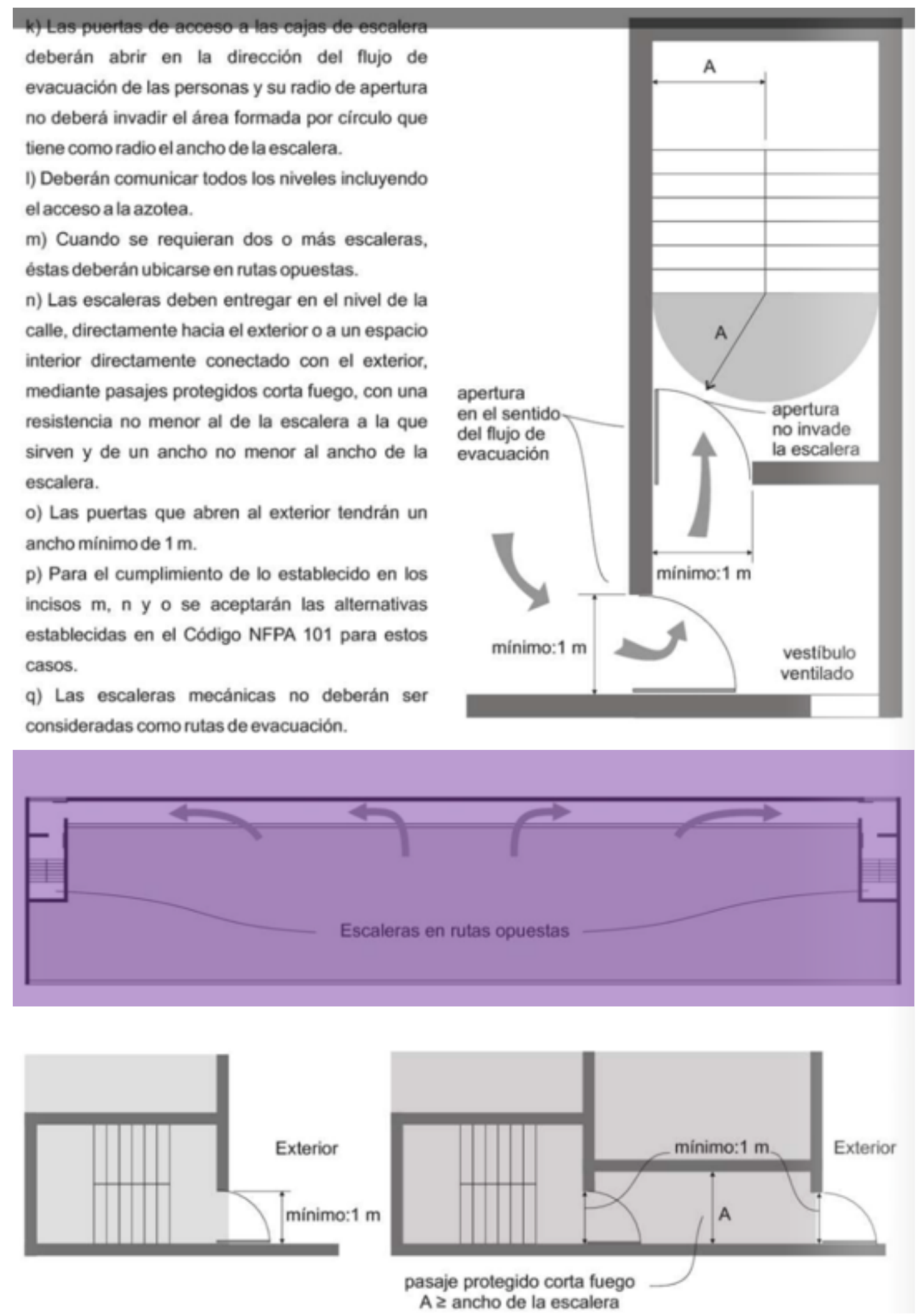
Los ascensores en las edificaciones deberán cumplir con las siguientes condiciones:

a) Son obligatorios a partir de un nivel de ingreso común superior a $11 \mathrm{~m}$ sobre el nivel del ingreso a la edificación desde la vereda.

b) Los ascensores deberán entregar en los vestibulos de distribución de los pisos a los que sirve. No se permiten paradas en descansos intermedios entre pisos. En caso de proponerse ascensores con apertura directa a las unidades residenciales en edificios multifamiliares, éstos deberán contar con un vestibulo previo cerrado.

c) En edificaciones residenciales, no es obligatoria la llegada del ascensor al sótano de estacionamiento.

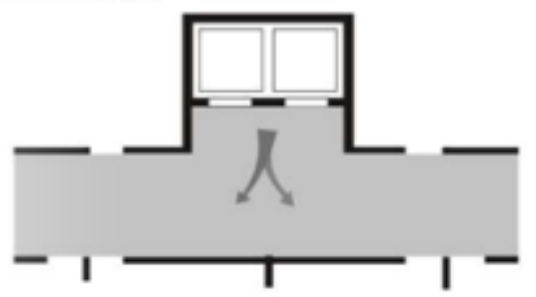

ENTREGA A VESTÍBULO DE DISTRIBUCIÓN

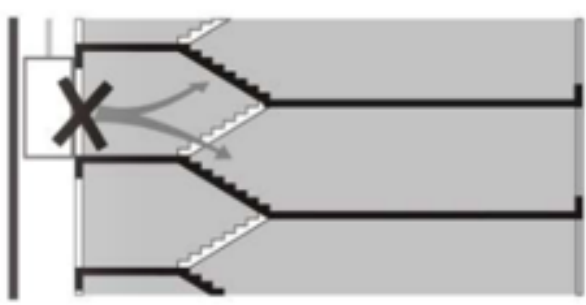

NO SE PERMITEN PARADAS EN DESCANSOS ENTRE PISOS

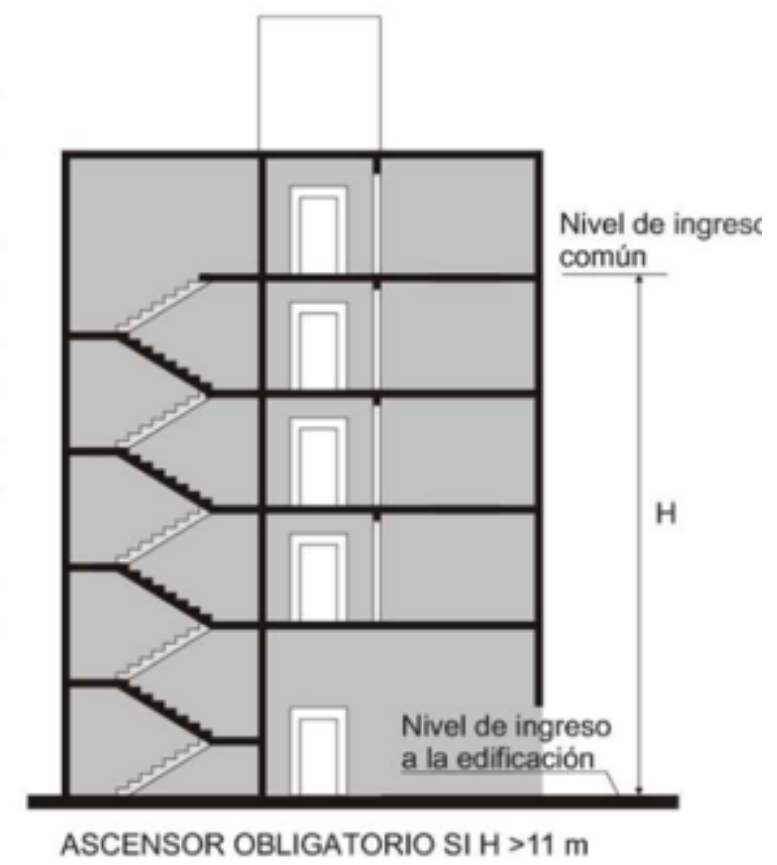

Articulo 31 NÚMERO DE ASCENSORES

Para el cálculo del número de ascensores, capacidad de las cabinas y velocidad se deberá considerar lo siguiente:

a) Destino del edificio.

b) Número de pisos, altura de piso a piso y altura total.

c) Área útil de cada piso.

d) Número de ocupantes por piso.

e) Número de personas visitantes.

f) Tecnologia empleada.

El cálculo del número de ascensores es responsabilidad del profesional responsable y del fabricante de los equipos. Este cálculo forma parte de los documentos del proyecto. 
Las rampas para personas deberdin tener las siguientes caracteristicas:

a) Tendrán un ancho minimo de $0,90 \mathrm{~m}$ entre los paramentos que la Imitan. En ausencia de paramento, se considera la seccion.

b) La pendiente máxima será de $12 \%$ y estará determinada por la longitud de la rampa.

c) Deberàn tener barandas según el ancho, siguiendo los mismos criterios que para una escalera.

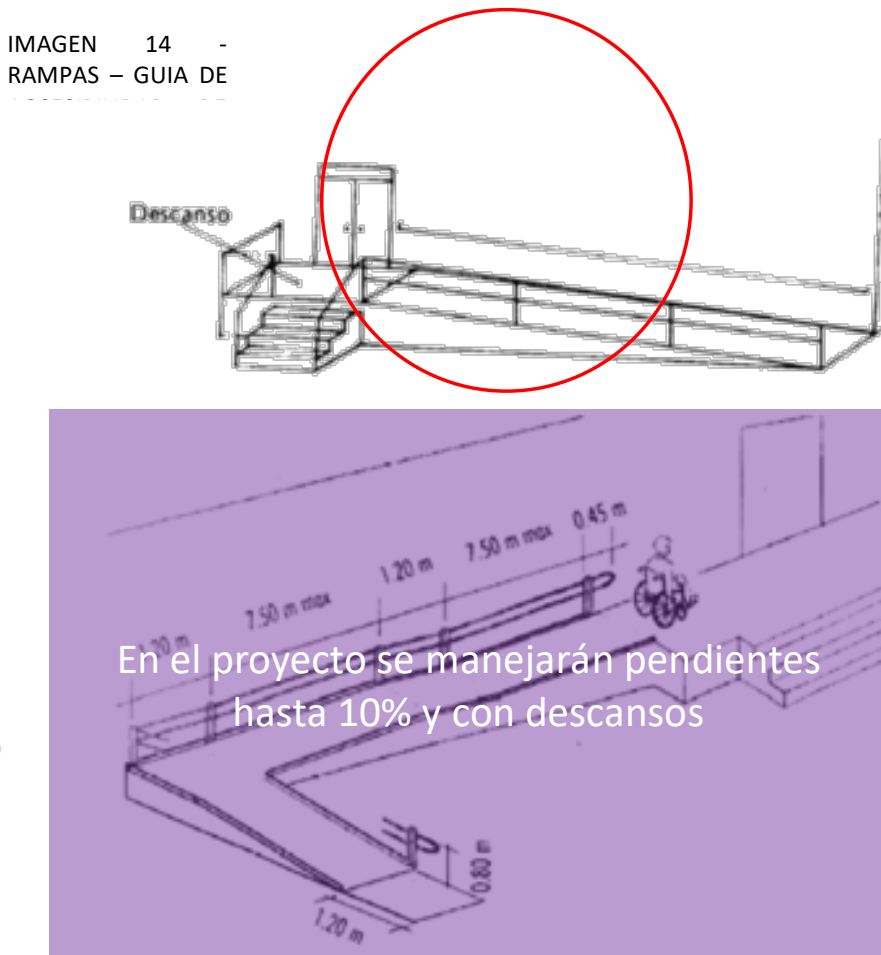

EN CUANTO A LA ACCESIBILIDAD PARA LAS PERSONAS CON ALGUNA DISCAPACIDAD:

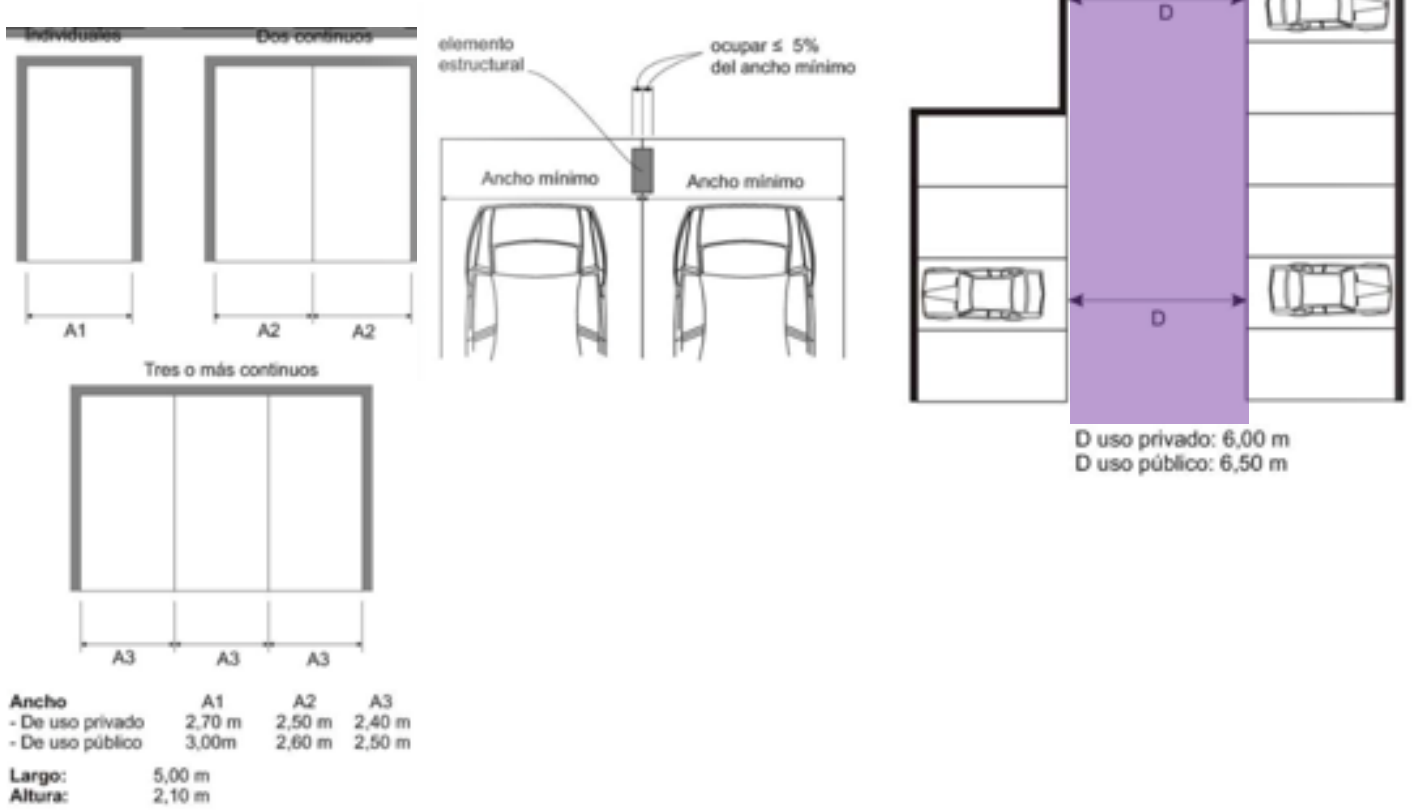




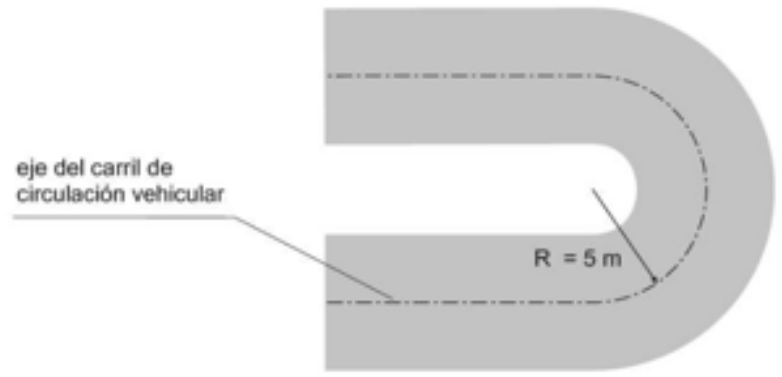

e) Las rampas deterbin iniciane a una distancia minims de $3.00 \mathrm{~m}$ del Iimte de propiedad. En esta distancia ef piso ceberd ser horiscontal al nivel de la vereda.

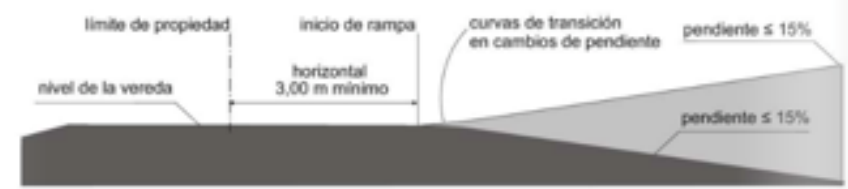

IMAGEN 15 ESTACIONAMIENTOS RNE (2013)

Artículo 18.- Las edificaciones para recreación y deportes deberán cumplir con los siguientes requisitos adicionales:

a) En las salas con asientos fijos al piso se deberá disponer de espacios para personas en sillas de ruedas, a razón de 1 por los primeros 50 asientos, y el $1 \%$ del número total, a partir de 51. Las fracciones ser redondean al entero mas cercano.

b) El espacio mínimo para un espectador en silla de ruedas será de $0.90 \mathrm{~m}$ de ancho y de $1.20 \mathrm{mts}$ de profundidad. Los espacios para sillas de ruedas deberán ser accesibles.

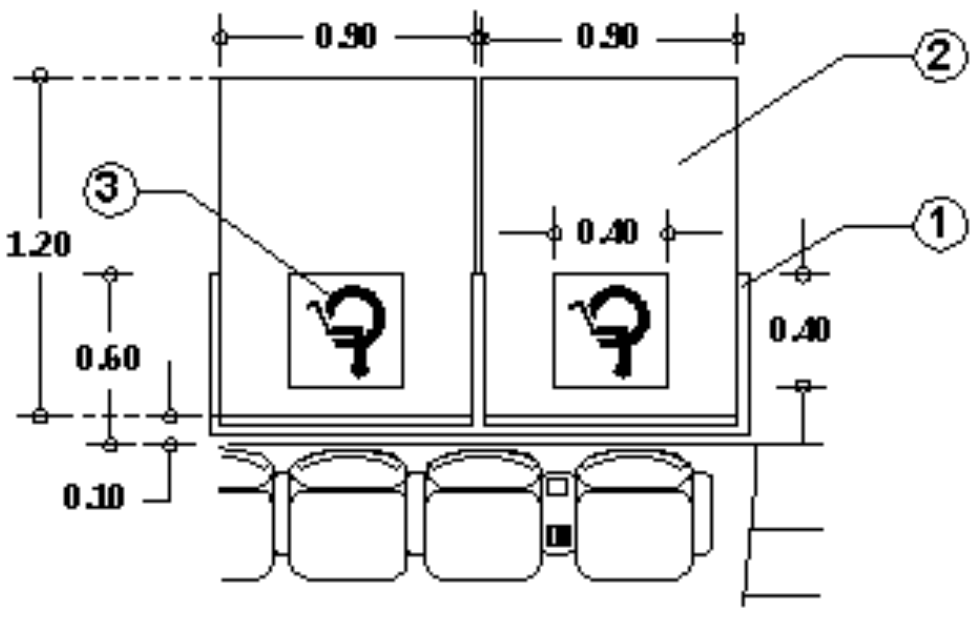

IMAGEN 16 - ACCESIBILIDAD- RNE (2013) 


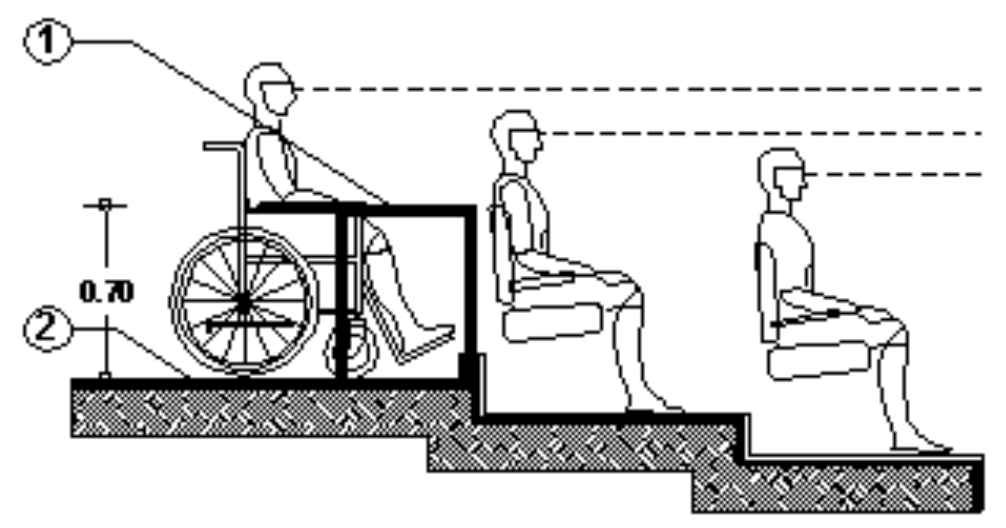

DISTRIBUCIÓN DE BAÑO PÚBLICO BÁSICO:
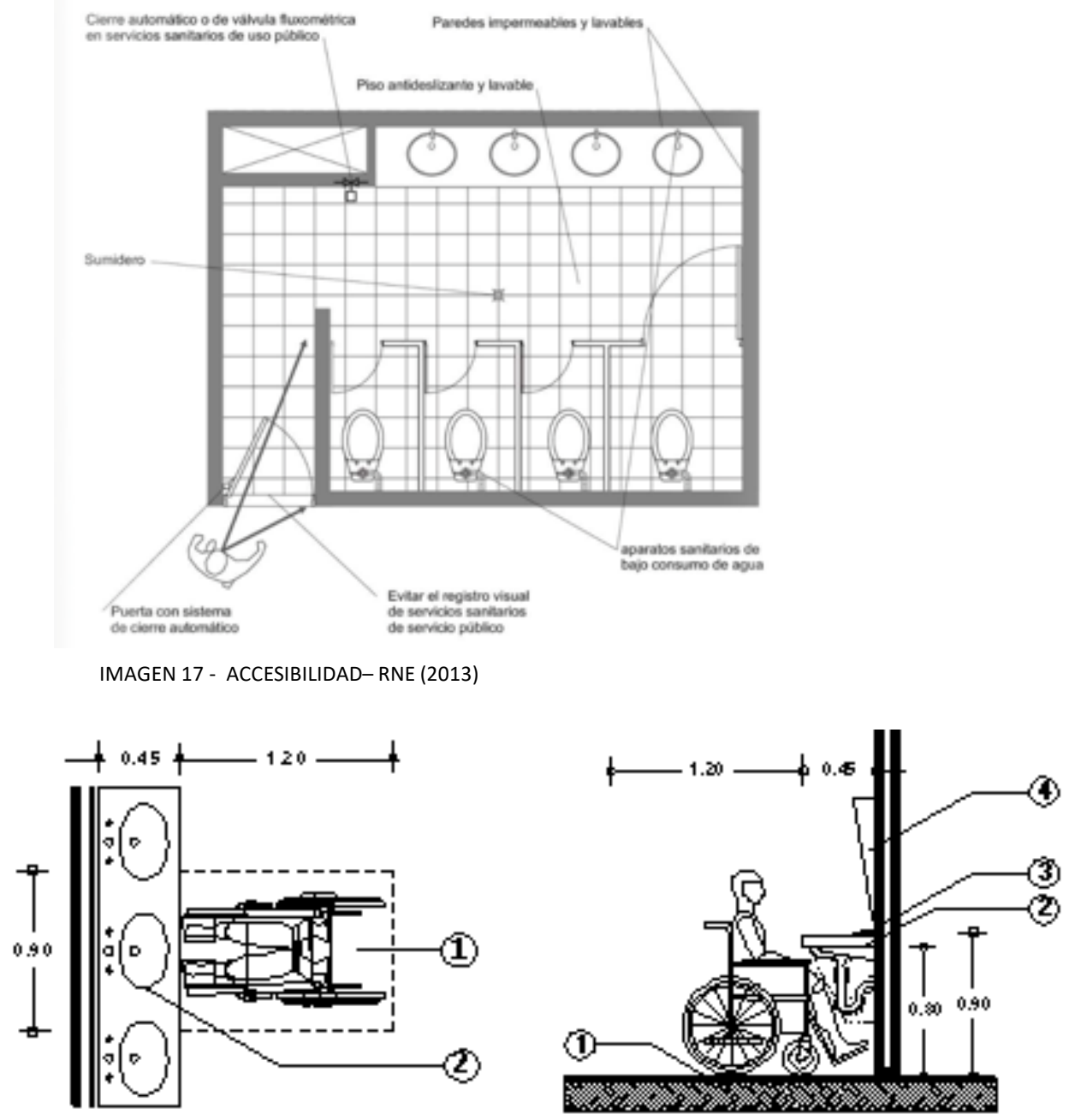

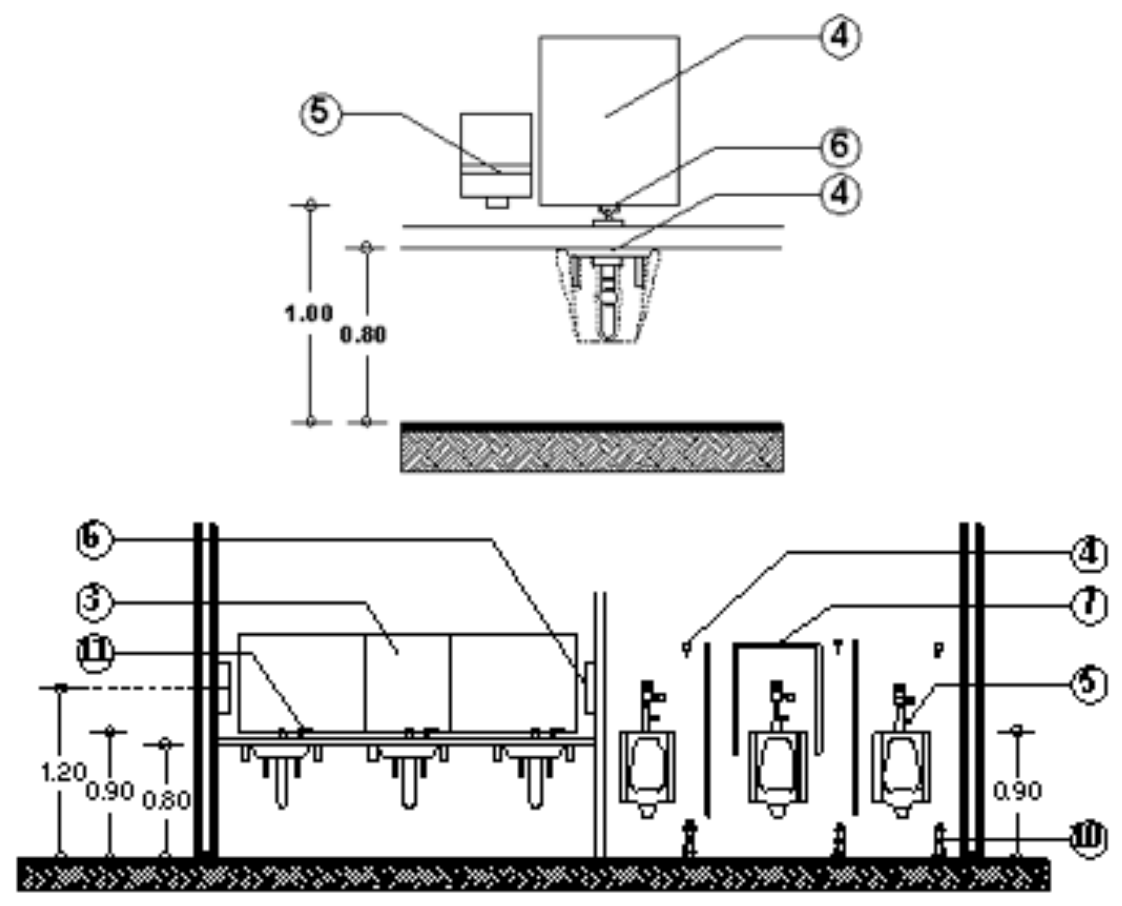

IMAGEN 18 - ACCESIBILIDAD- RNE (2013)

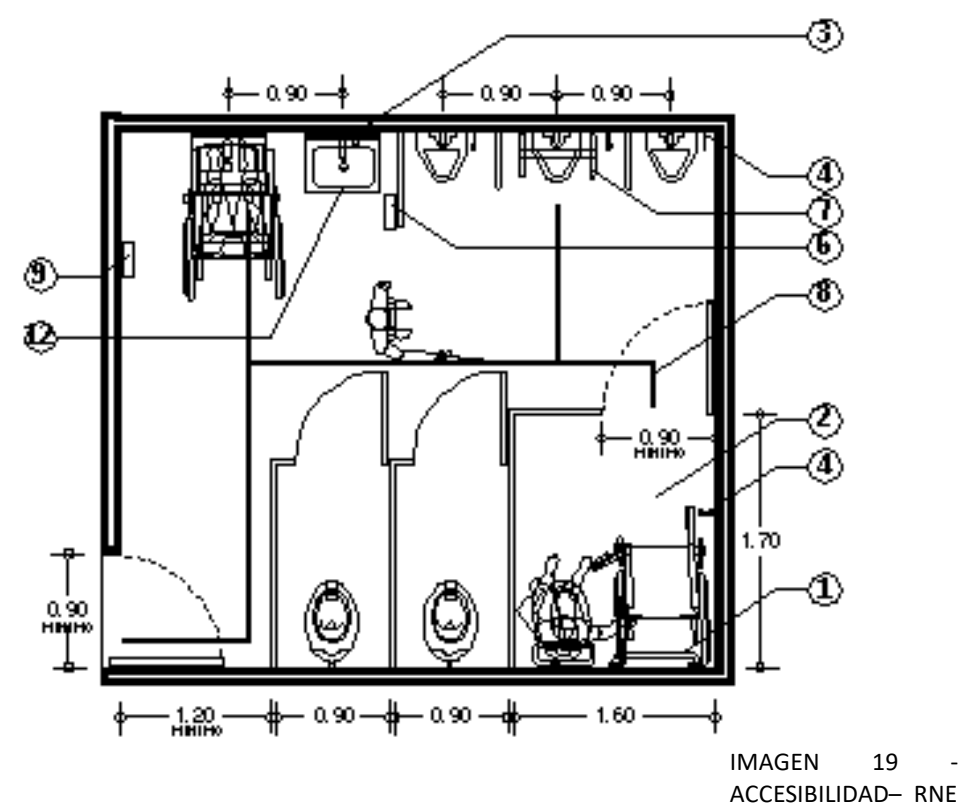

1. Barra de apoyo de acero inoxidable o de aluminio de $38^{\prime} \mathrm{m}^{\mathrm{m} m}$ ' $\left(1 /{ }^{\prime \prime}\right)$ de diámetro, Cal. 16.

2. Compartimento para personas con discapacidad en silla de ruedas.

3. Espejo inclinado a $10^{\circ}$, centrado sobre el lavabo.

4. Gancho o ménsula para colgar muletas.

5. Palanca manual para activar el fluido de agua del mingitorio. Debe haber palanca en vez de pedal en el mingitorio para personas en silla de ruedas. 6. Jabonera eléctrica o manual colocada a una altura máxima de $1.20 \mathrm{~m}$. a centro.

7. Tubo de acero inoxidable o de aluminio de $38 \mathrm{~mm}(11 / 2 ")$ de diámetro, Cal. 16. 
Tomaré de referente también la guía de accesibilidad de Ecuador y de Barcelona.

"Es un hecho que las personas con discapacidad deben tener igualdad de oportunidades, no discriminación y merecen accesi- bilidad universal. Por ello, se plantea algunos requerimientos para brindar accesibilidad.

Para trabajar en beneficio de las personas con discapacidad que usan silla de ruedas, es necesario considerar las medidas estándares de las mismas, de modo que puertas, pasillos, corre- dores, altura de ventanas, mostradores, etc. se adecúen a estas dimensiones. *

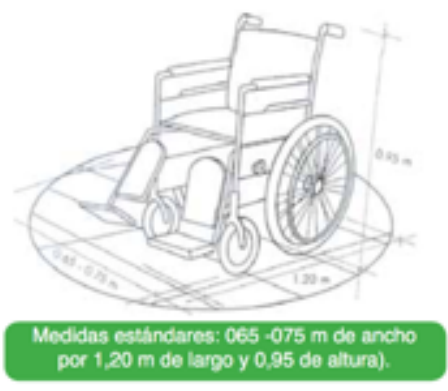

IMAGEN 20 - DIMENCIONES SILLA DE RUEDAS - GUÍA DE ACCESIBILIDAD DE BARCELONA (2005)

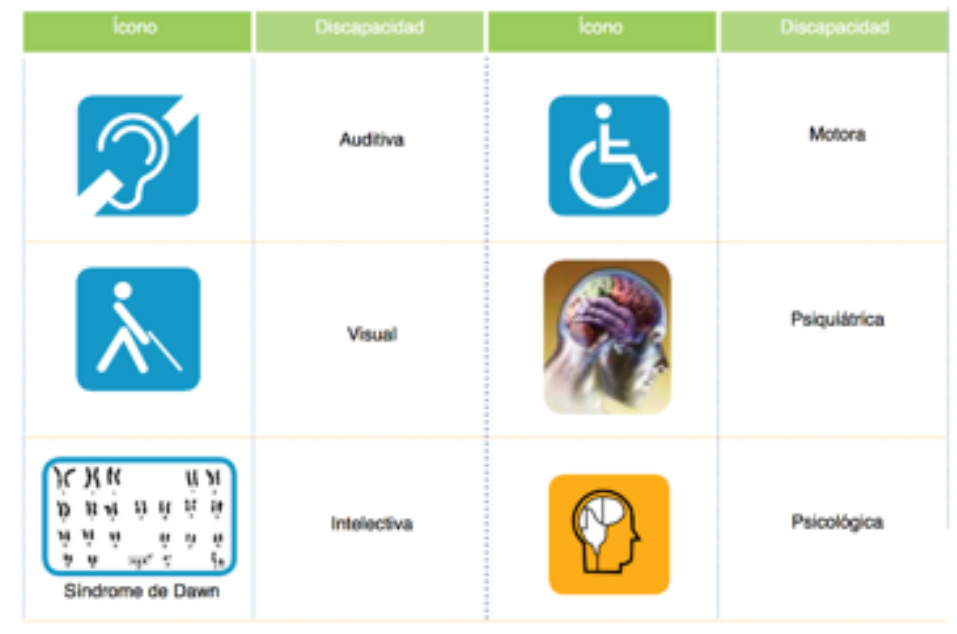

IMAGEN 21 - TIPOS DE DISCAPACIDAD - GUÍA DE ACCESIBILIDAD DE BARCELONA (2005) 


\section{ELEMENTOS DE ACCESIBILIDAD DEL ENTORNO URBANO}

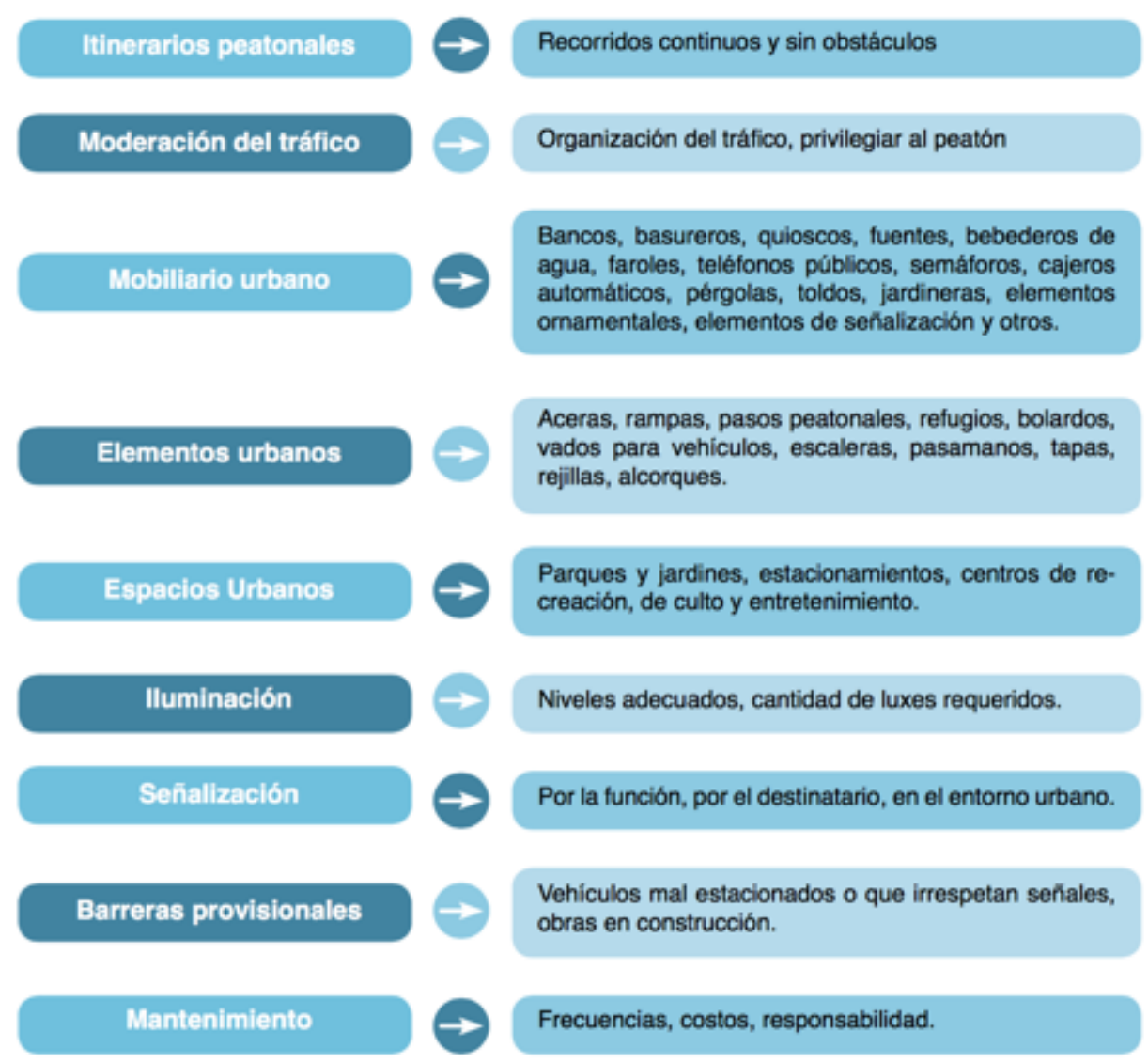

IMAGEN 22 - ELEMENTOS DE ACCESIBILIDAD DEL ENTORNO URBANO - GUÍA DE ACCESIBILIDAD DE BARCELONA (2005)

Se debe considerar en los edificios de atención al público, el diseño de un mostrador con medidas que permitan a las personas con discapacidad, específicamente que usan silla de ruedas, ser atendidas de manera cómoda y eficaz, libre de obstáculos.

El mostrador debe tener un espacio de $40 \mathrm{~cm}$ de profunda- dad para la colocación de sus piernas, una altura de $80 \mathrm{~cm}$ y una altura libre interior de $75 \mathrm{~cm}$, con un ancho de $80 \mathrm{~cm}$.

Se debe considerar el acceso de perros guía, sillas de ruedas, bastones y demás elementos o ayudas, para la movilidad y libre desplaza- miento de las personas con discapacidad. 115 

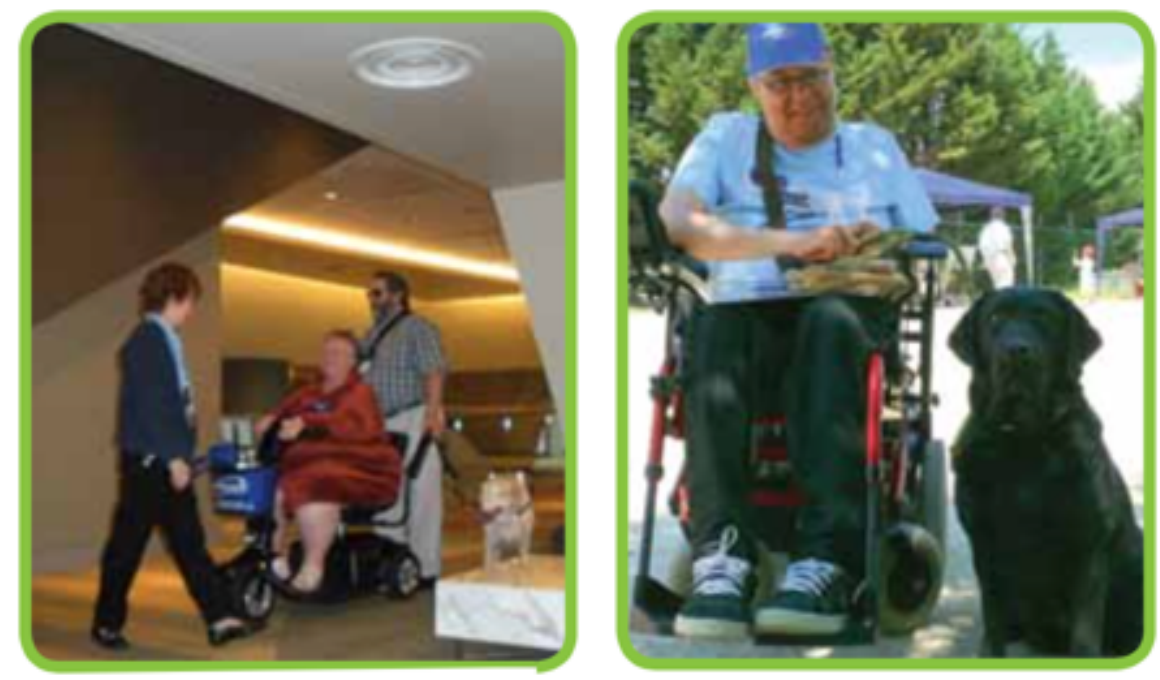

IMAGEN 23 - PERSONAS CON ALGUNA DISCAPACIDAD- GUÍA DE ACCESIBILIDAD DE BARCELONA (2005)

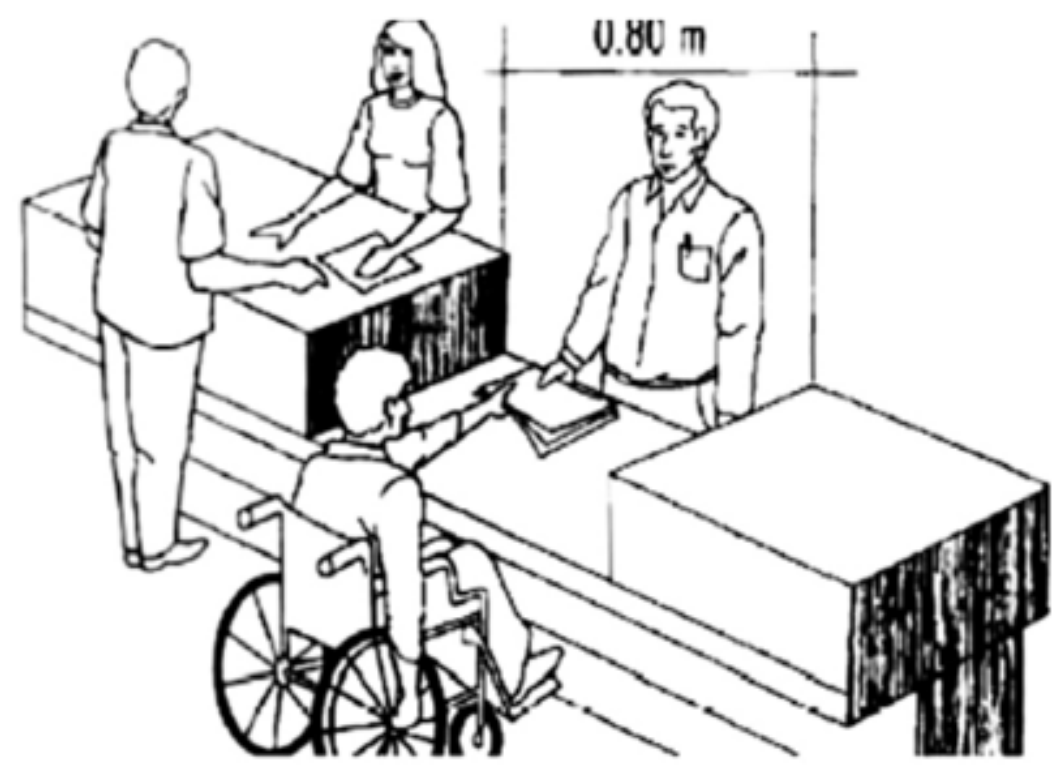

IMAGEN 24 - MUEBLE DE ATENCIÓN INCLUSIVO - GUÍA DE ACCESIBILIDAD DE BARCELONA (2005) 
7.4. ESTUDIO DE LA ANTROPOMETRÍA Y MOBILIARIO GENERAL ANTROPOMETRÍA PERSONAS SIN NINGUNA DISCAPACIDAD
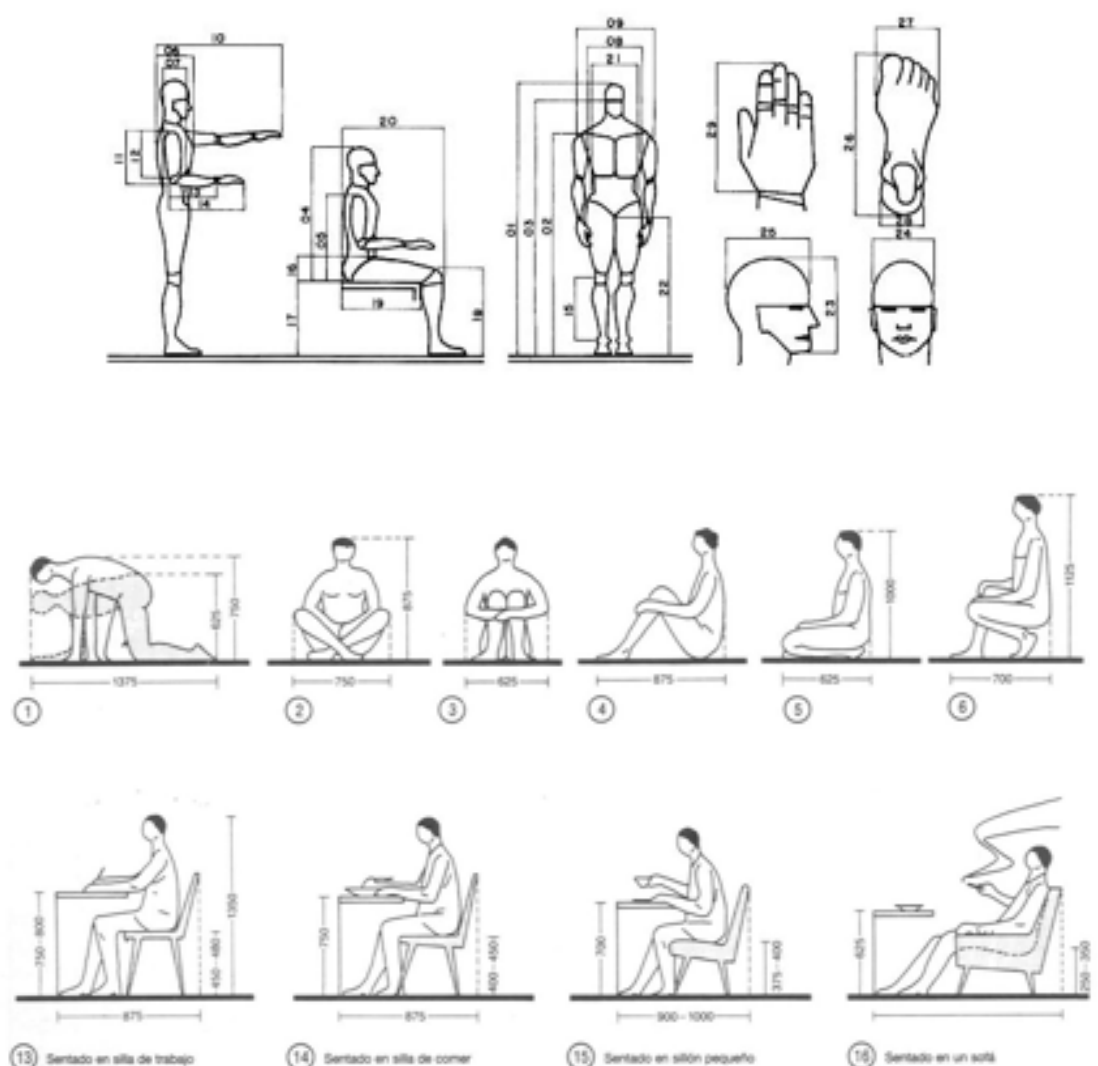

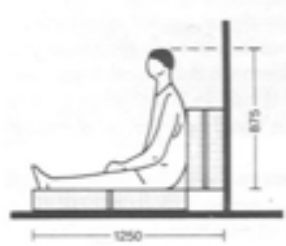

(21)

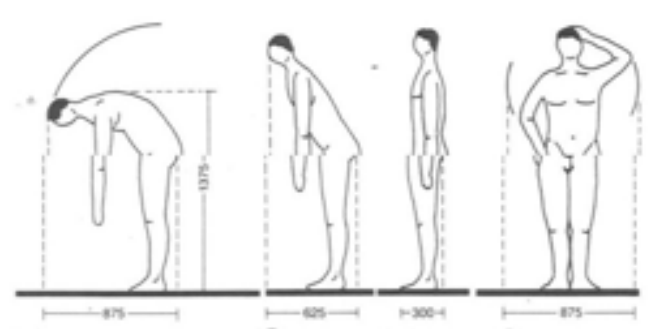

(7)
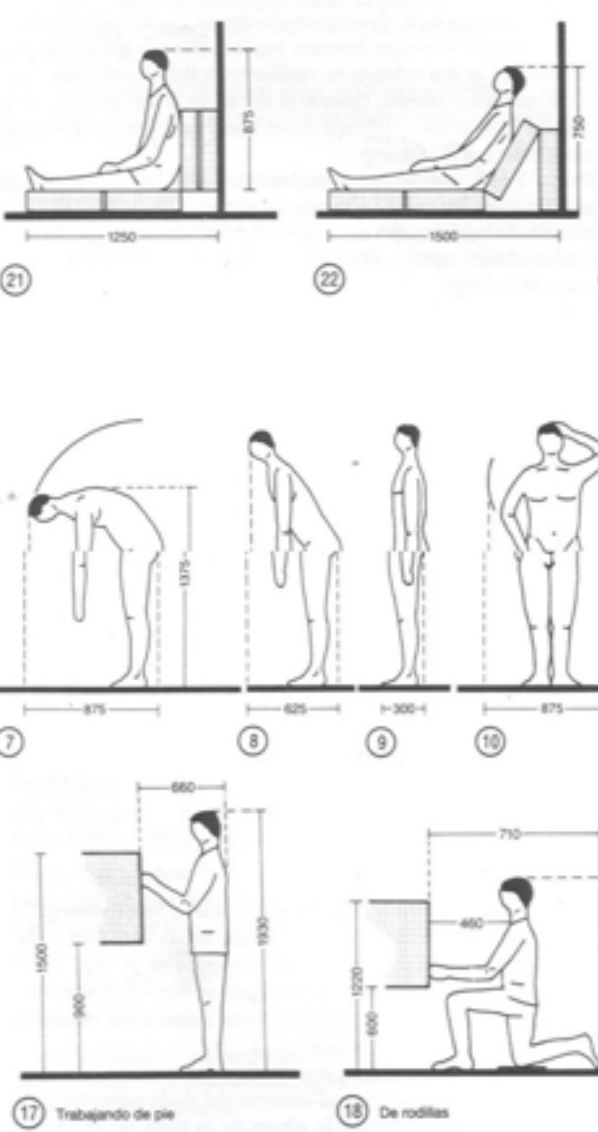

(22)

(20)

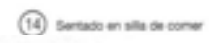
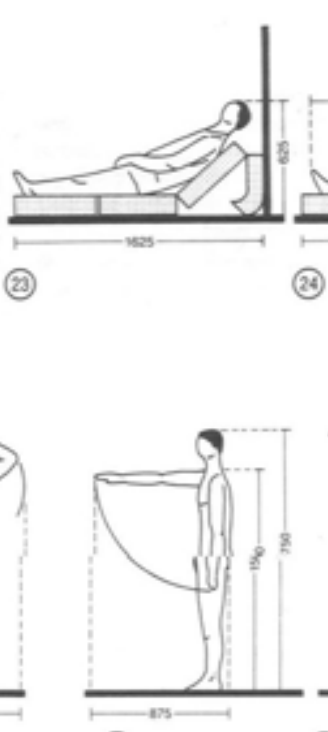

(11)

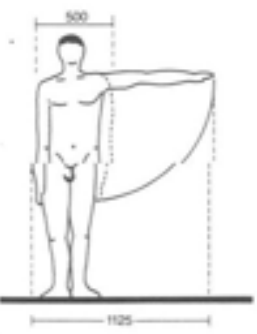

(12)

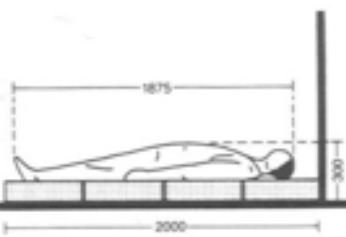

(24)
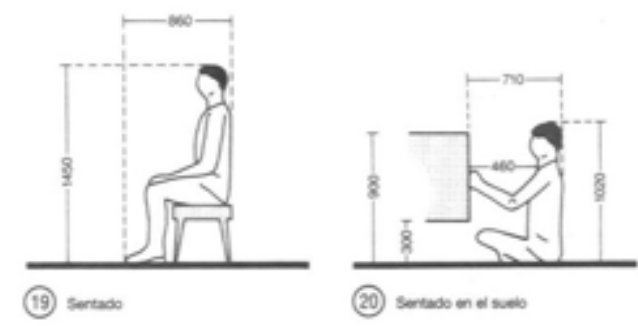


\section{ANTROPOMETRÍA PERSONAS SIN NINGUNA DISCAPACIDAD}

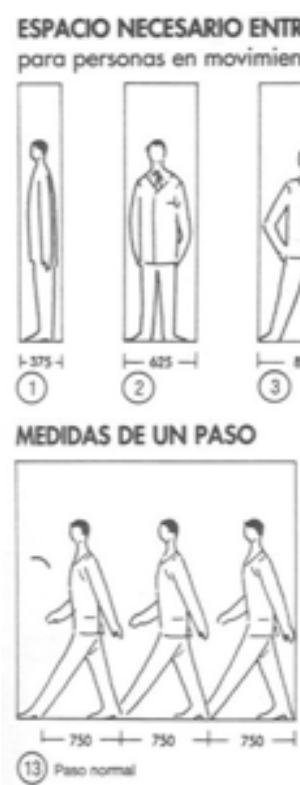

ESPACIO NECESARIO CON EQUIPAJE DE MANO
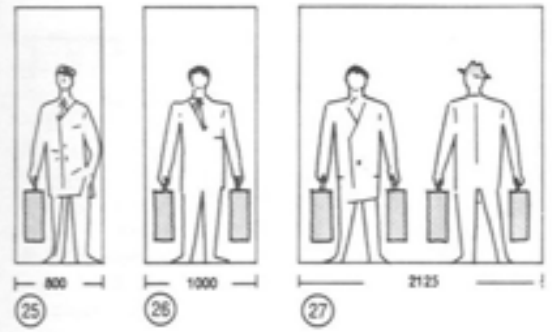
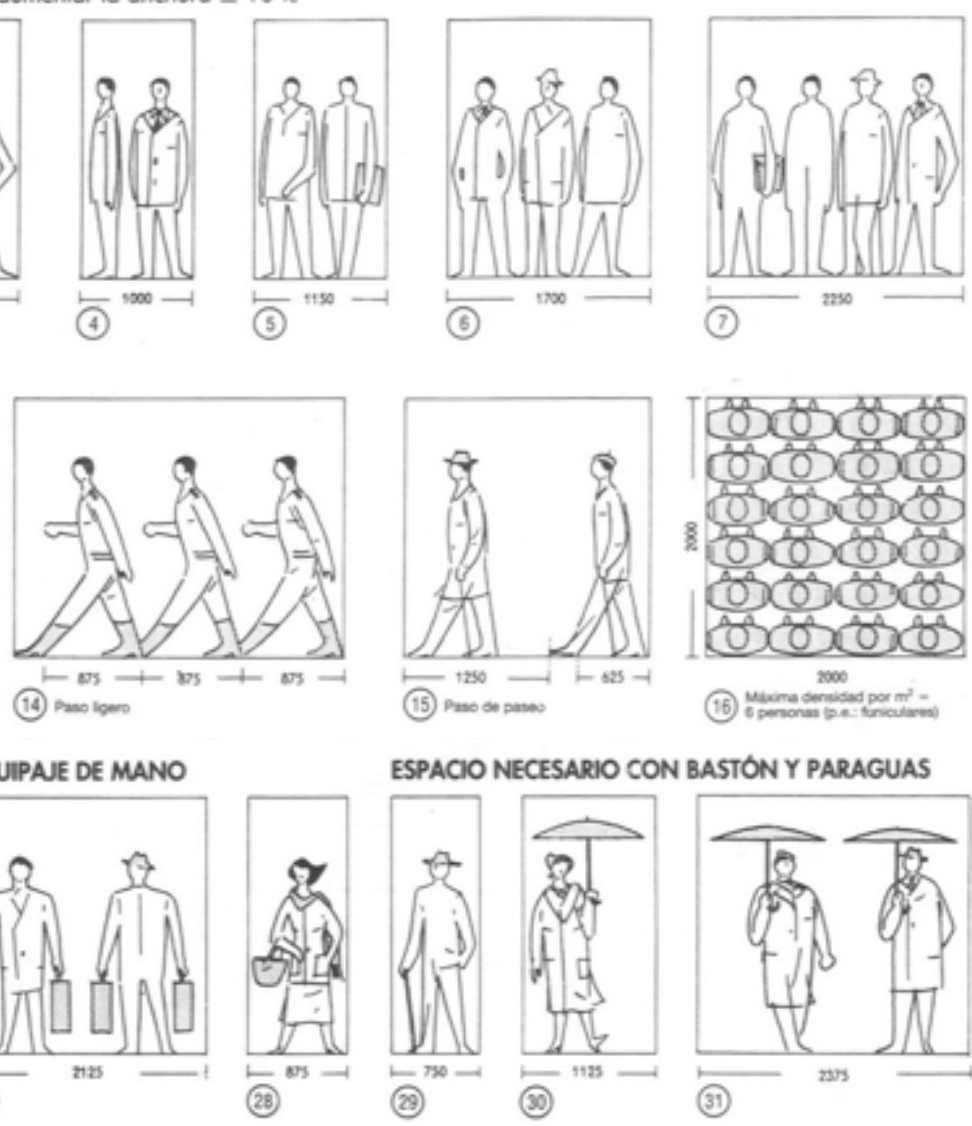

ESPACIO NECESARIO CON BASTON Y PARAGUAS
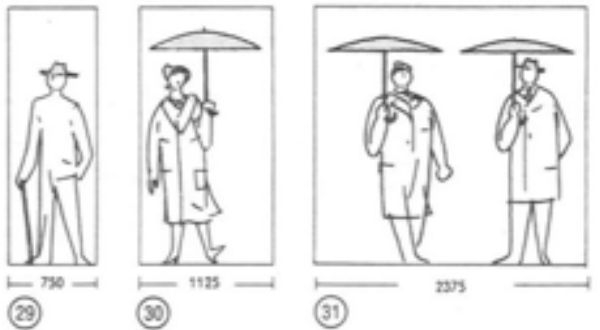

ESPACIO NECESARIO PARA GRUPOS
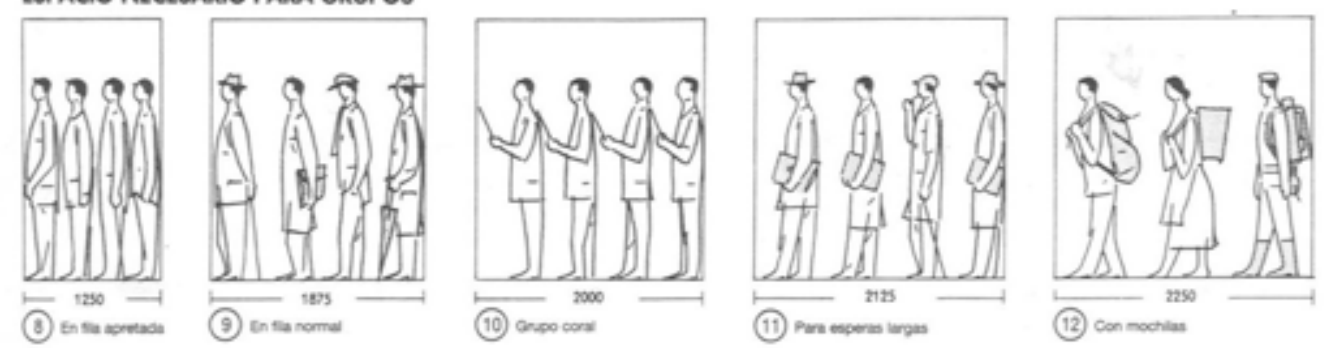

ESPACIO NECESARIO SEGÚN LA POSICIÓN DEL CUERPO
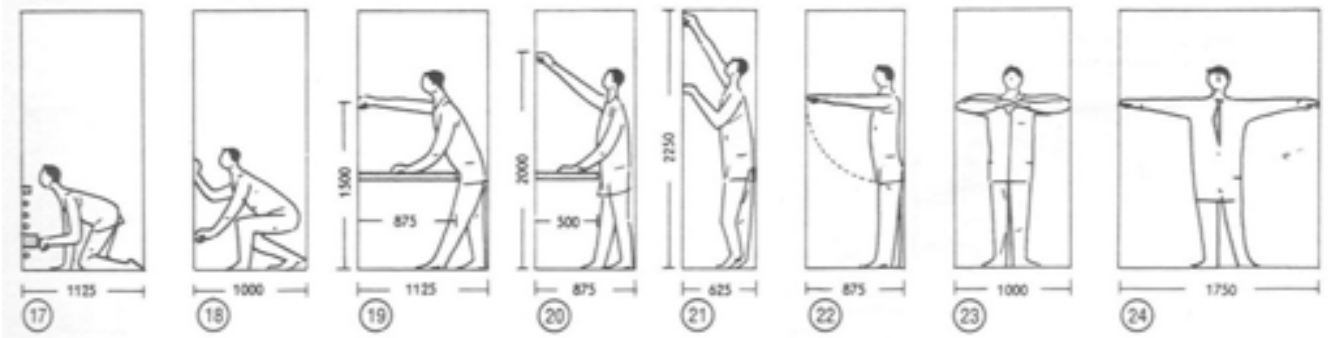

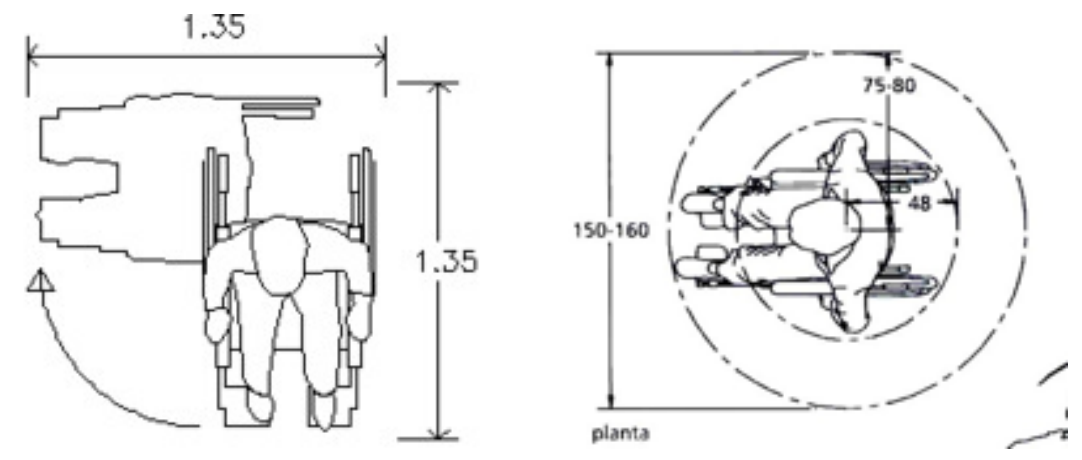

Planta
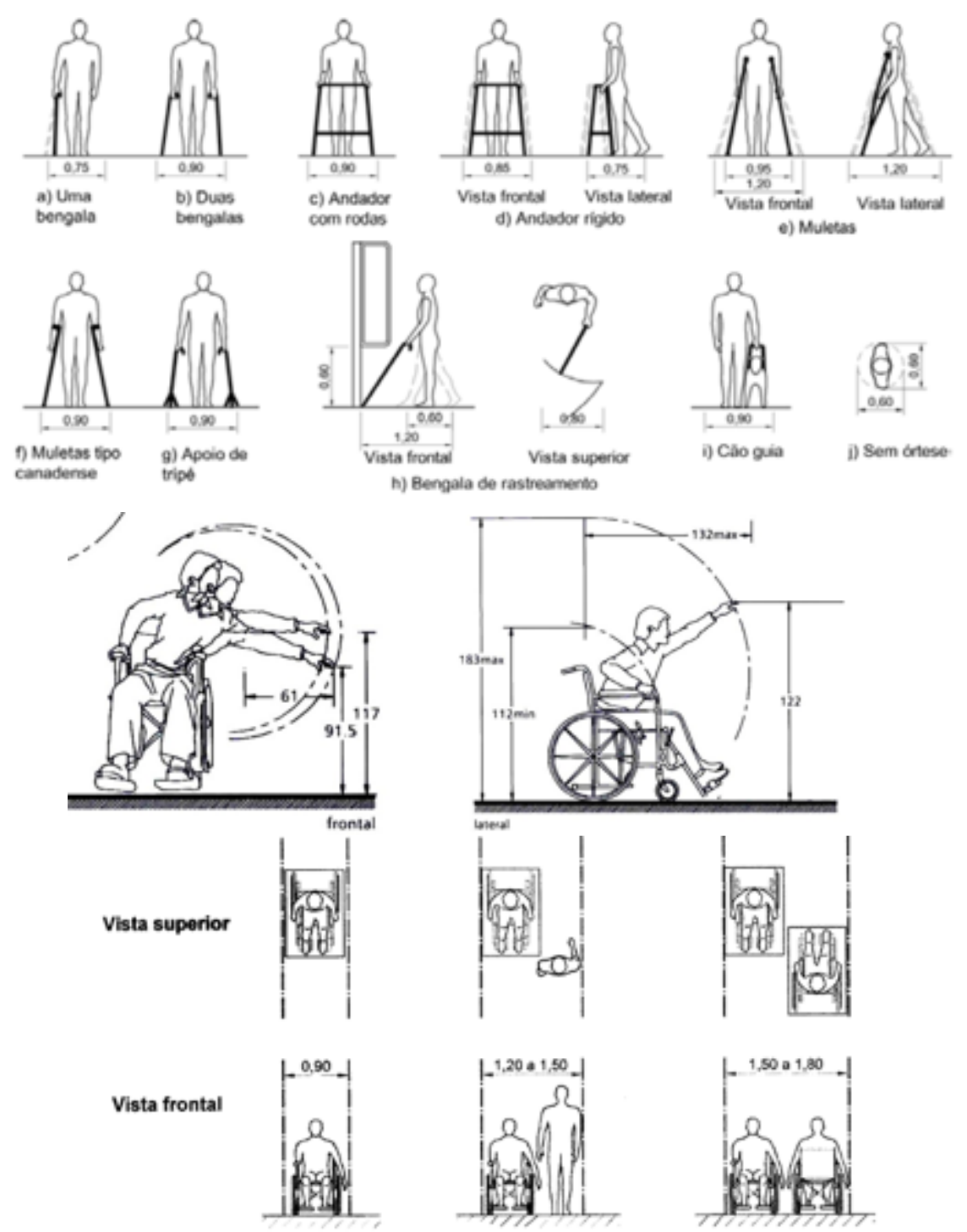


\section{- ELEMENTOS SOBRESALIENTES}

Todos los elementos sobresalientes scbre las circulaciones, deberán permitir un paso libre de cuando mencs $2.10 \mathrm{~m}$ de altura.

El mobliario y sefalizacion que sobresalgan de los paramentos, deberan contar con elementos de alerta y deteccion en los pavimentos, como cambios de textura.
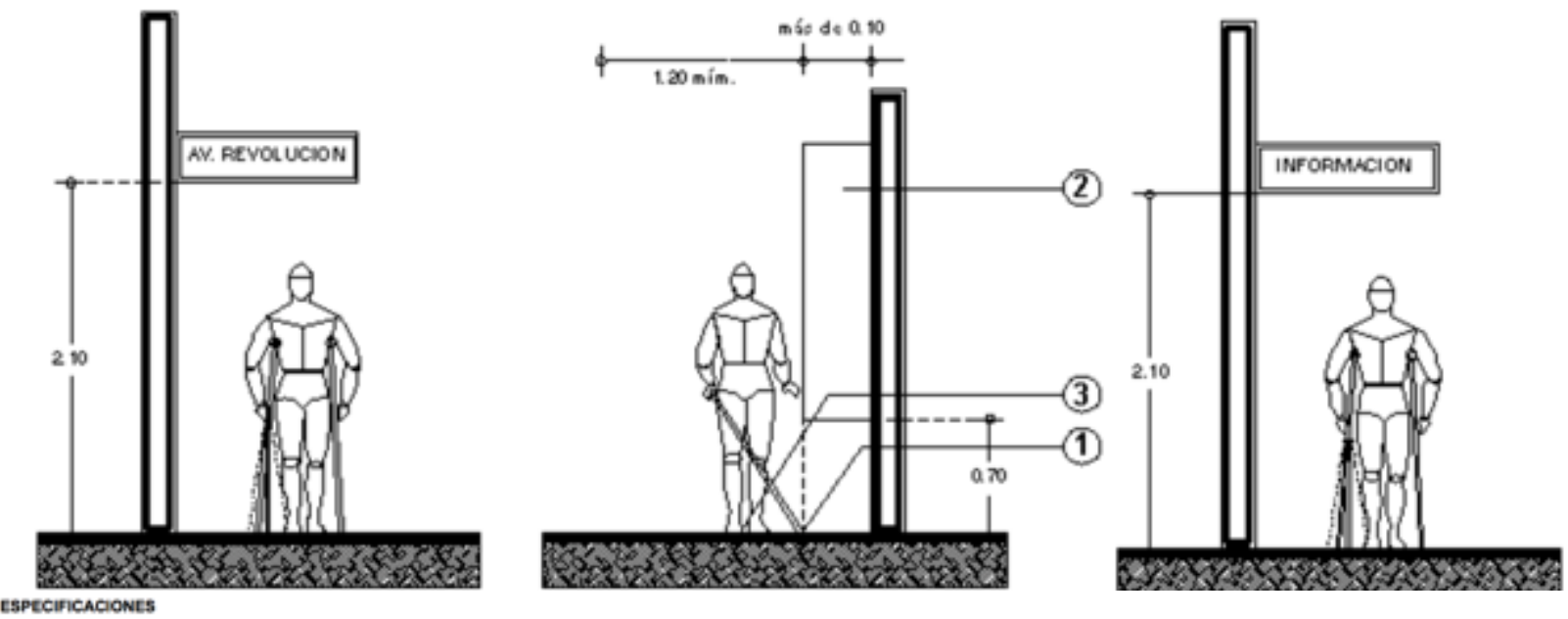

1. Cuando notro
otivitoulo.

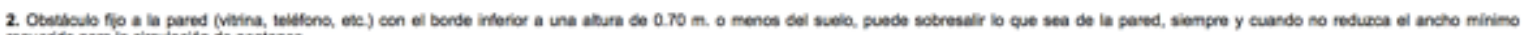
Centones.

3. Cambio de textura.

\section{ANTROPOMETRÍA DE DISCAPACITADOS EN LOS SSHH}
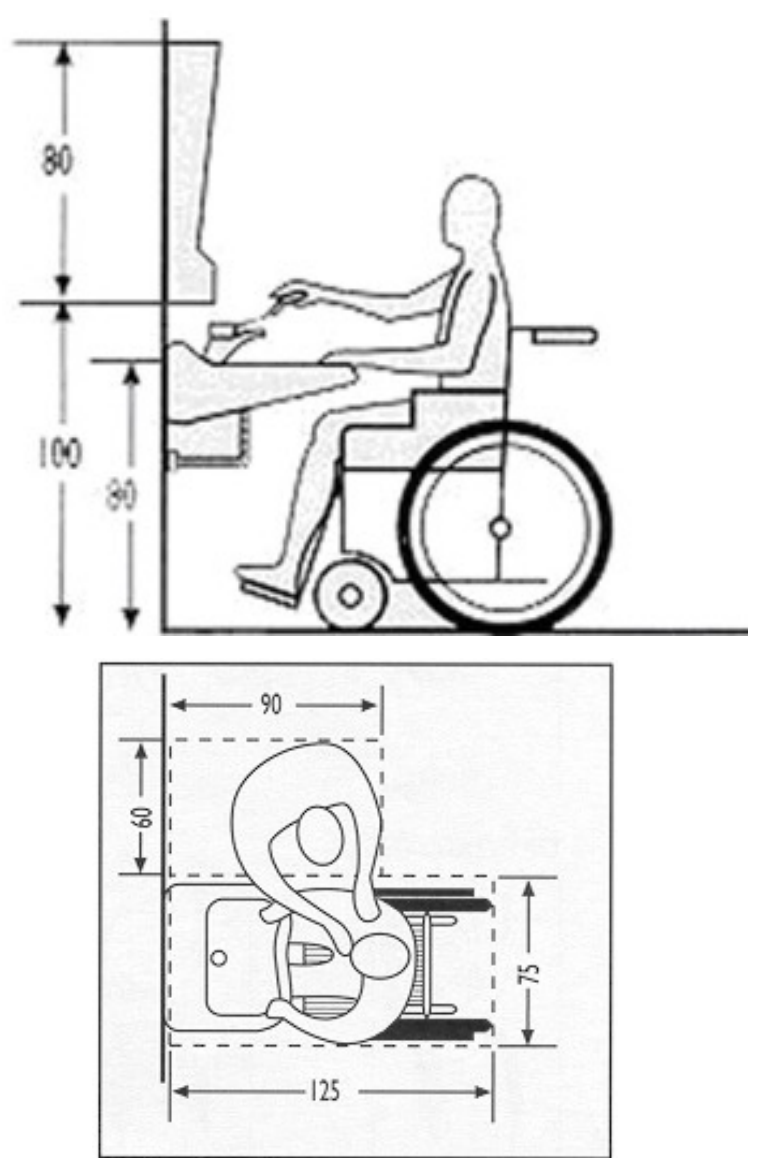

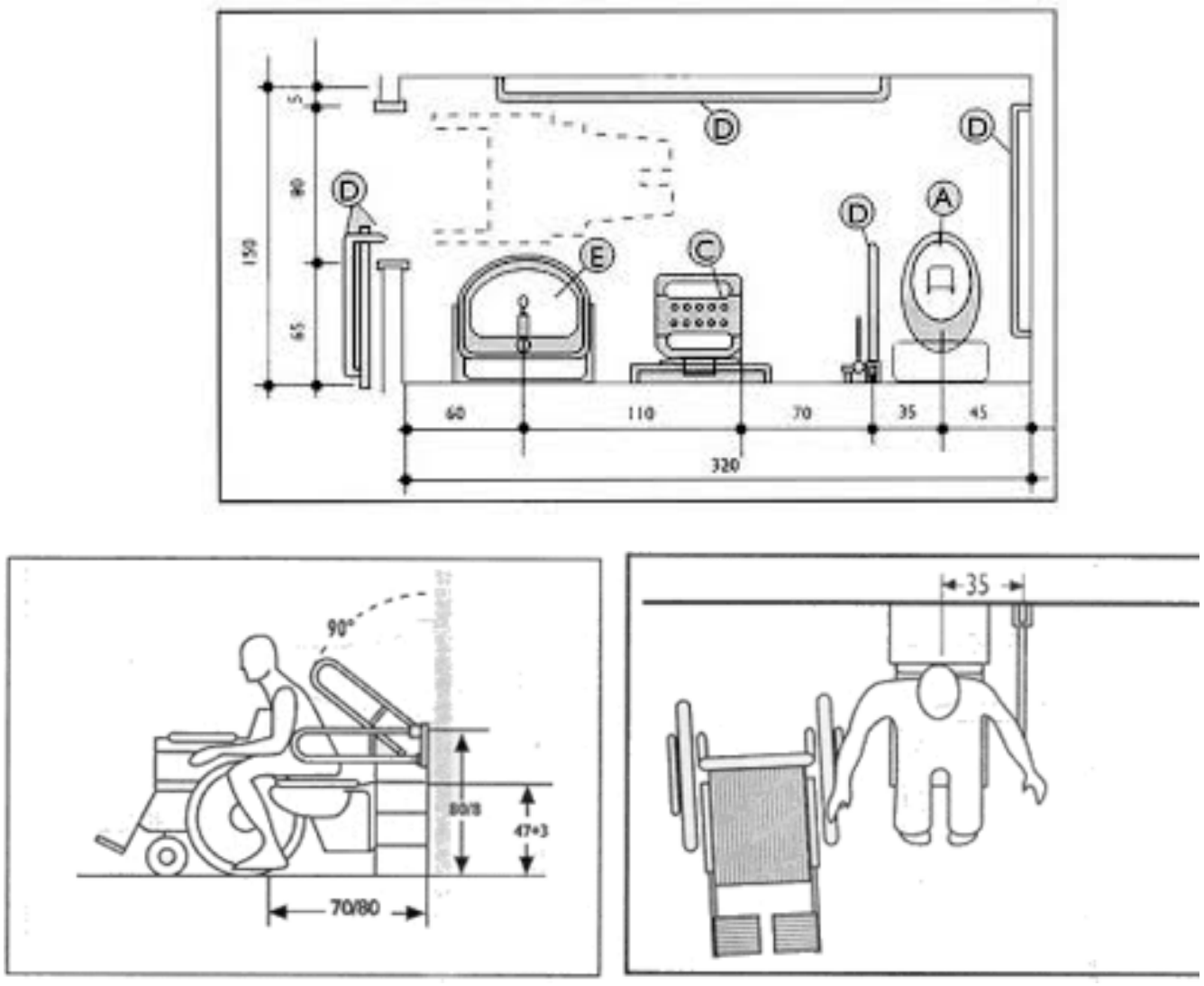

\section{ANTROPOMETRÍA DE MOBILIARIO - DISCAPACITADOS}
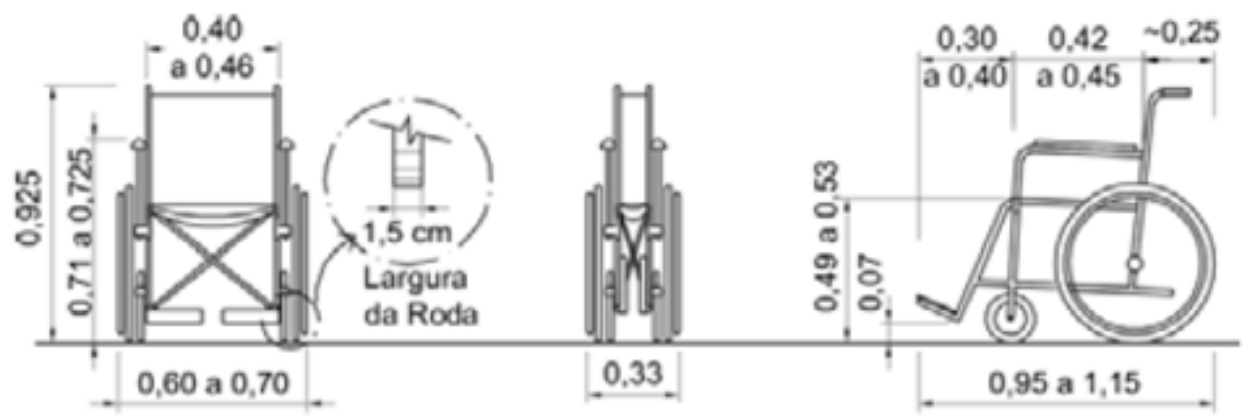

a) Vista frontal aberta

b) Vista frontal fechada

c) Vista lateral

IMAGEN 31 - ATROPOMETRÍA ACCESIBLE-CLIFFORD (2008)
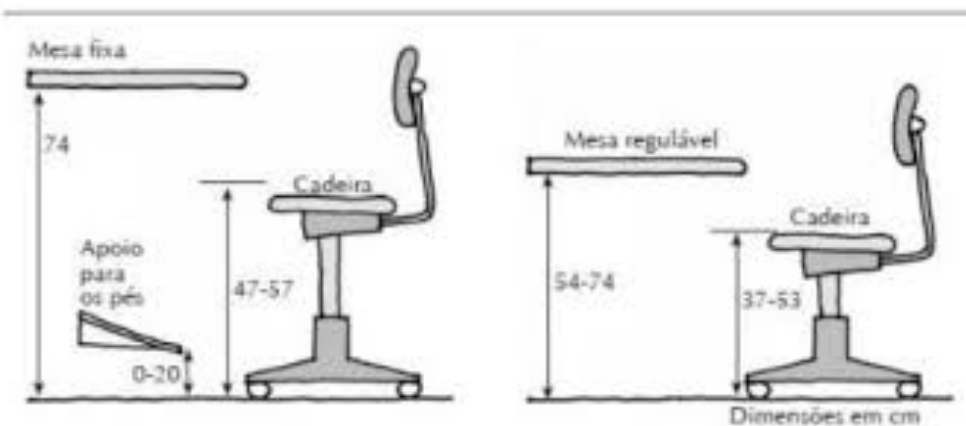

IMAGEN 32 - ATROPOMETRÍA ACCESIBLE- OFFICE ATROMOPHORMY (2008) 

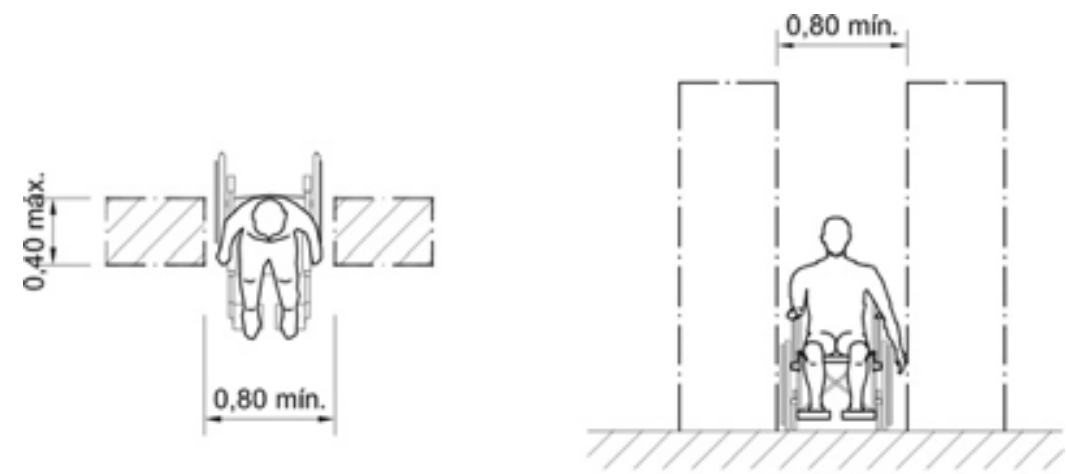

IMAGEN 33 - ATROPOMETRÍA ACCESIBLE- CLIFFORD (2008)
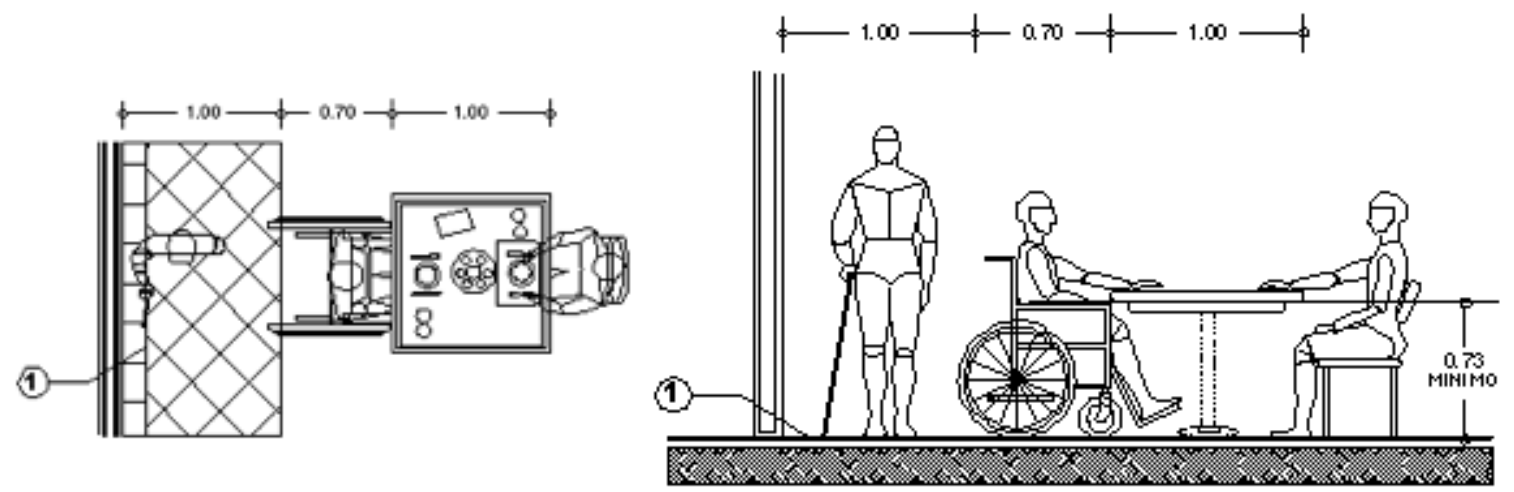

IMAGEN 34 - ATROPOMETRÍA ACCESIBLE- CLIFFORD (2008)

\section{ANTROPOMETRÍA DE NIÑOS}

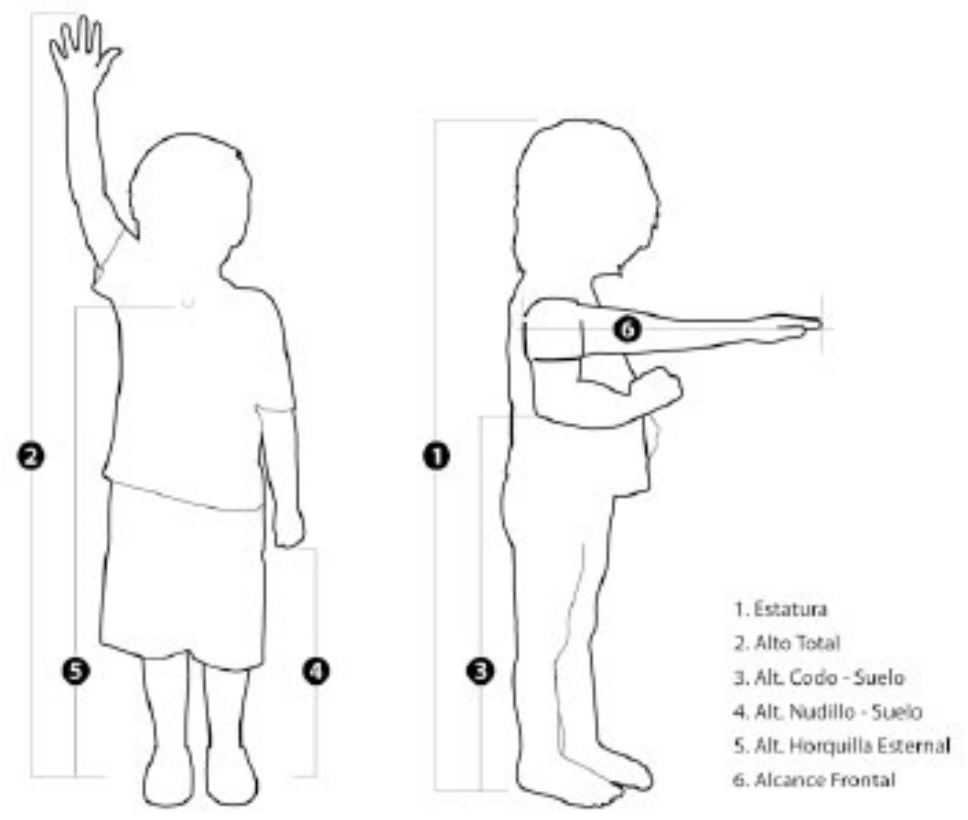

IMAGEN 35 - ATROPOMETRÍA NIÑOS-SCIELO (2010) 

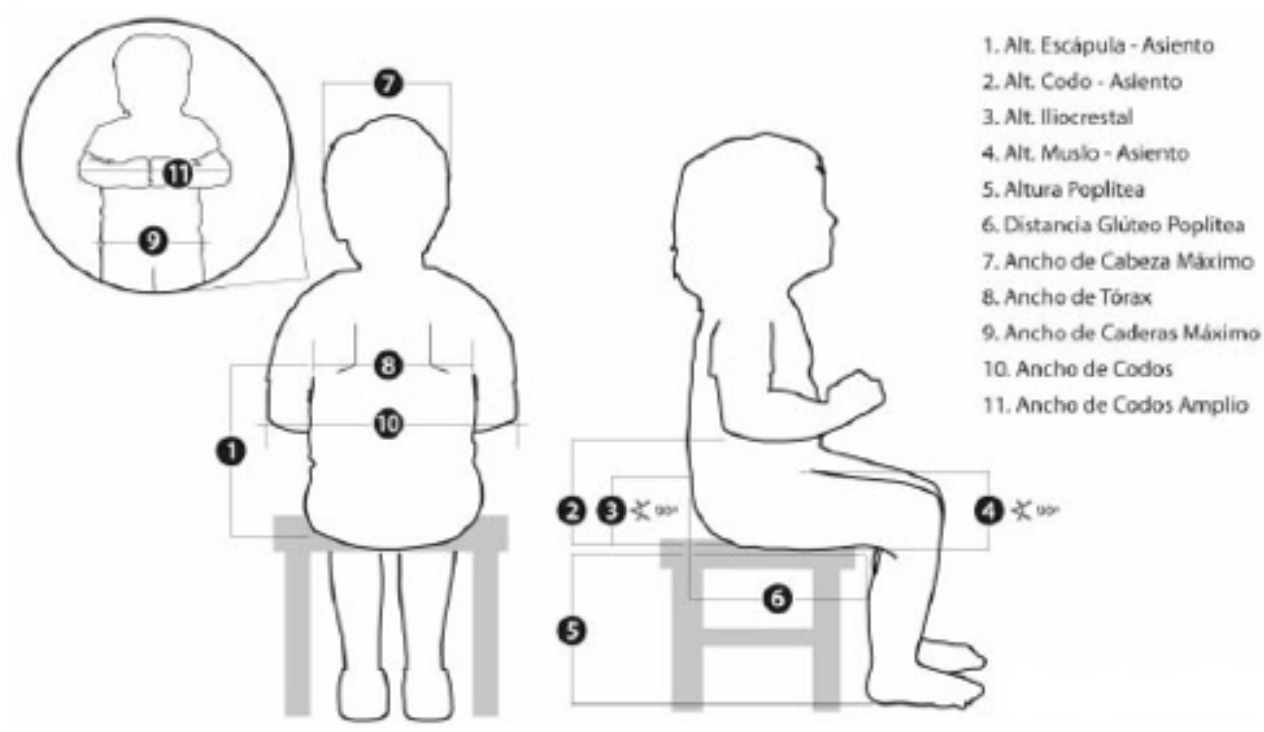

IMAGEN 36 - ATROPOMETRÍA NIÑOS-SCIELO (2010)

\begin{tabular}{|c|c|c|c|c|c|c|c|c|c|c|}
\hline \multirow{2}{*}{$\begin{array}{l}\text { ESTATCRA } \\
\text { Grupo etires }\end{array}$} & \multicolumn{4}{|c|}{ Sexe Mbseulise } & \multirow[b]{2}{*}{ 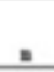 } & \multicolumn{5}{|c|}{ Sesse Fomenaise } \\
\hline & Promedio & $\mathrm{DE}$ & Sper & 98 per & & Promedio & $\mathrm{DE}$ & Eper & 95 per & - \\
\hline Haso9 & 7099 & 5,64 & 64,45 & 8098 & 23 & 6404 & 3,6 & 59.38 & 69,2 & 12 \\
\hline 10215 mees & 7593 & 5,4 & 70,45 & 827 & 63 & 72.68 & 3,28 & 67,04 & 79,06 & 48 \\
\hline 16224 mees & 8257 & 4.16 & 75,53 & 90.18 & 146 & 81.17 & 3,99 & 7472 & 87,39 & 123 \\
\hline 25,36 mees & 91,3 & 4,2 & 84.5 & 99 & 260 & 90,05 & 3,98 & 835 & 96,17 & 227 \\
\hline 37 a 48 mees & $98,6 !$ & 4.18 & 92,45 & 10695 & 351 & 97,39 & 4,23 & 90,71 & 104.10 & 348 \\
\hline 49 meses $y$ mix & 10531 & $4 * 0$ & 9831 & 1127 & 362 & 10445 & 510 & 96 & 11317 & 369 \\
\hline
\end{tabular}

\section{DATOS DE SEGURIDAD EN TANTO A LA ANTROPOMETRÍA DE LOS NIÑOS}

1. Zona de seguridad infantil: Es aquel espacio comprendido entre el suelo y 1,20 m de altura de toda la instalación y los accesos (incluyendo la zona de tránsito y la de uso habitual), donde no deben existir elementos peligrosos accesibles a los niños o que puedan causar daño físico o psíquico.

2. Accesos: la delimitación del centro y el control de accesos debe preservar la seguridad de los menores, protegiéndolos de extraños y de elementos que puedan causarle un accidente. (Por ejemplo, las vallas delimitadoras de los centros en pocos casos se encuentran reguladas por decretos, podemos encontrar desde vallas escalables, o con una distancia entre barrotes superior a los $10 \mathrm{~cm}$, lo que pude causar que el menor introduzca la cabeza entre ellos). 
3. Instalaciones generales. Bajo esta denominación podemos englobar los siguientes apartados:

a. Suelos: ligeramente blandos, en función de las necesidades que requieran las actividades que se realizan en cada espacio se aumentará el nivel de amortiguación de los mismos. (por ejemplo: no es lo mismo la actividad de los rincones en el aula, que la psicomotricidad o el suelo existente bajo un tobogán).

b. Paredes: teniendo en cuenta el desarrollo de las habilidades motrices hasta la consecución de las mismas, las caídas y los golpes son constantes, por lo que se deben proteger de forma que se minimicen las consecuencias de dichas caídas.

c. Puertas: en función del espacio al que derivan, éstas deben evitar la accesibilidad a la manipulación infantil, lesiones por atrapamiento de extremidades o por golpes contra vidrios, heridas y cortes a consecuencia de la rotura de vidrios y facilitar el acceso del adulto en caso de emergencia (por ejemplo, he encontrado en escuelas infantiles que las puertas de acceso al aula eras inaccesible a los menores, ya que la maneta se había situado de forma correcta a 1,40 m de altura y las que daban acceso a los espacios como cocina o limpieza y situadas en la zona de tránsito infantil eras totalmente accesibles)

d. Ventanas: inaccesibles a la manipulación infantil, no solo a su apertura, también a su hoja si esta permanece abierta y evitar siempre la disposición de los equipamientos de forma que no facilite la escalada. (por ejemplo en la zona de sueño, la disposición de las cunas nunca deben situarse debajo de una ventana, ya que la altura del niño cuando se pone de pie en ésta la hace accesible, estos problemas son de base de proyección y construcción del centro)

e. Escaleras y desniveles: todos los desniveles deben ser salvables para los niños que acoge la escuela infantil, el resto debe estar delimitado e inaccesible a la manipulación infantil.

f. Enchufes: los que no se sitúen por encima de la zona de seguridad, deben disponer de protecciones infantiles, en ningún caso pueden ser accesibles a los menores, pero no debemos olvidar que todos los dispositivos electrónicos y los cables derivados también deben situarse por encima de esa zona.

4. Instalaciones especificas: totalmente accesibles, espacios conectados (asistenciales y de actividades) con las características de: 
a. Visuales: atender una necesidad básica en particular no debe implicar la pérdida de contacto visual con el grupo en general.

b. Específicos: deben existir espacios diferenciados y adaptados para cada asistencia concreta y para actividad programada.

c. Polivalentes: espacios preparados a acoger a niños de diferente nivel y con distintas necesidades.

5. Equipamientos: los elementos que componen una escuela infantil, sea cual sea su utilidad (asistencial, lúdica y/o educativa) deben ser específicos para el desarrollo de su función, adaptados a las destrezas y habilidades de los niños, a sus medidas antropométricas y cumplir con las normativas vigentes. No se puede incluir equipamiento que no esté estrictamente pensado para los menores a los que va destinado y por supuesto jamás permitir la entrada de objetos desde el exterior que, con muy buena fe por parte de las familias, puede suponer un riesgo para uno o el resto de menores. (por ejemplo juguetes que no tengan el marcado $\mathrm{CE}$, peluches, piscinas, etc.)

6.Evaluación/auditoria de riesgos infantiles: ni con el estricto cumplimiento de todas las normativas y decretos vigentes se asegura una instalación adaptada y segura. Las herramientas que a nivel organizativo y de gestión, la planificación del mantenimiento, la prevención eficaz y concreta, solo lo ofrecen las evaluaciones de riesgo infantiles realizadas por profesionales y el derivado informe con las soluciones precisas en función de la prioridad del riesgo.

7. Gestión del mantenimiento: la mayoría de lesiones que ocurren en un centro infantil son derivadas de un ineficaz o nulo plan de mantenimiento. Lo que ocurre en ocasiones es que se destina la partida presupuestaria a un lavado de imagen obviando las prioridades en función del riesgo que determina el informe derivado de las evaluaciones.

8. Formación: el personal del centro infantil debe recibir formación de prevención de riesgos, y esta cultura preventiva es inusual, ya que se le da más importancia a los primeros auxilios (que también deben formarse), antes que a evitar llegar a estos últimos.

9. Emergencias: un Plan de Autoprotección debe contar con la implicación de todo el personal del centro, éste se debe diseñar bajo los preceptos de probables emergencias y siempre en función de las características de los niños. Aún de obligado cumplimiento, 
son muchas las escuelas infantiles de gestión pública que carecen del Plan de Autoprotección.

10. Vía pública: no puede quedar exenta de una auditoria vial. Los entornos escolares deben tener en cuenta las necesidades de los menores y de sus familias, como por ejemplo que todos los niños deben ir en un SRI homologado a su peso y talla y para ello necesitan espacios exteriores donde poder realizar esta acción de forma segura y adecuada. Asímismo, las espacios públicos deben contar con señalización que informen a los conductores que se encuentran en un espacio frecuentado por menores y actuar en consecuencia. 


\subsection{ANÁLISIS CUANTITATIVO Y CUALITATIVO DE LOS ESPACIOS FUNCIONALES}

\begin{tabular}{|c|c|}
\hline \multicolumn{2}{|c|}{ NOMBRE DEL ESPACIO : GUARDERÍA } \\
\hline DESCRIPCIÓN & $\begin{array}{l}\text { Este ambiente pertenece al paquete funcional de Zona Deportiva, } \\
\text { en el cual dejarían a los niños en una zona segura dentro del } \\
\text { establecimiento para que los padres o familiares puedan realizar } \\
\text { deporte. }\end{array}$ \\
\hline PAQUETE FUNCIONAL & ZONA DEPORTIVA \\
\hline FUNCIÓN & CUIDADO DE NIÑOS \\
\hline USUARIO PRINCIPAL & USUARIO DE 0-5 años \\
\hline NRO DE USUARIOS & 30 \\
\hline \multicolumn{2}{|c|}{ CONDICIONANTES AMBIENTALES } \\
\hline ILUMINACIÓN & PREFERENTEMENTE TAMIZADA Y ARTIFICIAL \\
\hline VENTILACIÓN & CRUZADA O ARTIFICIAL \\
\hline TÉRMICA & $\begin{array}{l}\text { CONTROLADA A TRAVÉS DE UN BALANCE EN EL INGRESO } \\
\text { DE LUZ Y VIENTO. }\end{array}$ \\
\hline ACÚSTICA & DE BAJOS DECIBELES PORQUE ES UN ESPACIO DE REPOSO \\
\hline PERCEPCIÓN & COLOR CLARO Y CALMADO RELACION CON NATURALEZA \\
\hline INSTALACIONES & $\begin{array}{l}\text { UNA ALTURA DEL ESPACIO DE UN MINIMO } 2.4 \text { SOBRE ESTO } \\
\text { PASAN LAS VIGAS Y LAS INSTALACIONES. }\end{array}$ \\
\hline MATERIALES & CONCRETO - ALBAÑILERIA ARMADA \\
\hline
\end{tabular}

\begin{tabular}{|l|l|}
\hline ILUMINACIÓN & PREFERENTEMENTE TAMIZADA Y ARTIFICIAL \\
\hline VENTILACIÓN & CRUZADA O ARTIFICIAL \\
\hline TÉRMICA & $\begin{array}{l}\text { CONTROLADA A TRAVÉS DE UN BALANCE EN EL } \\
\text { INGRESO DE LUZ Y VIENTO. }\end{array}$ \\
\hline
\end{tabular}




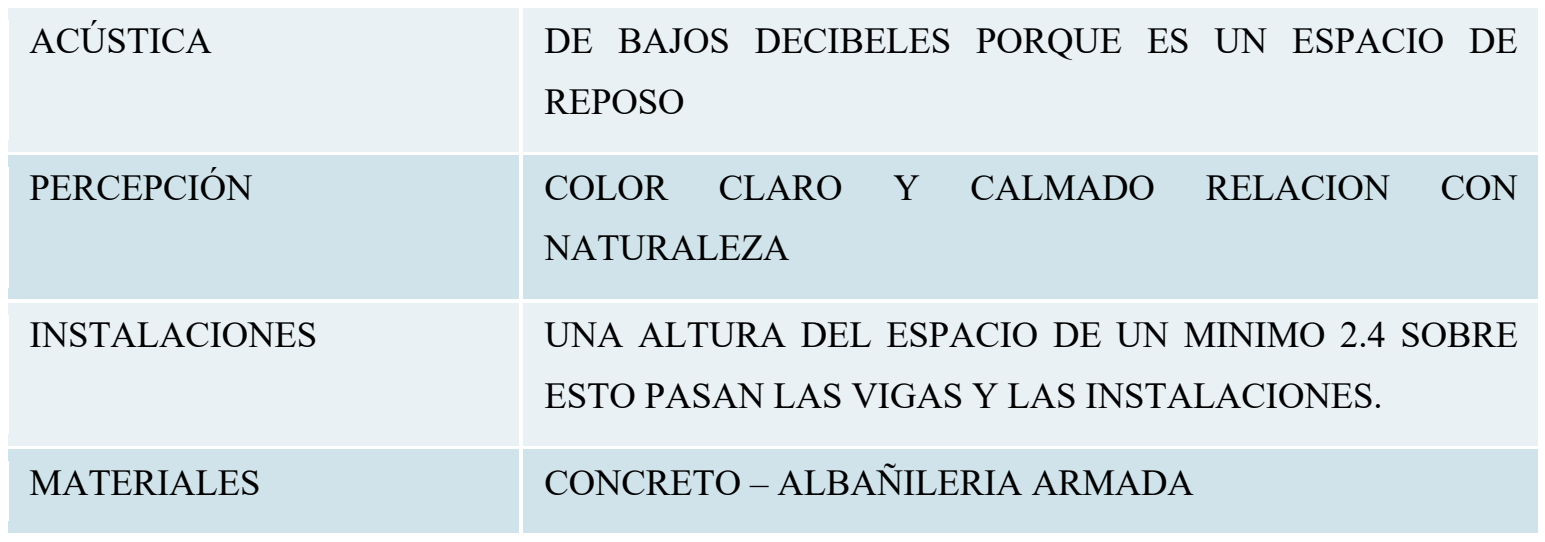
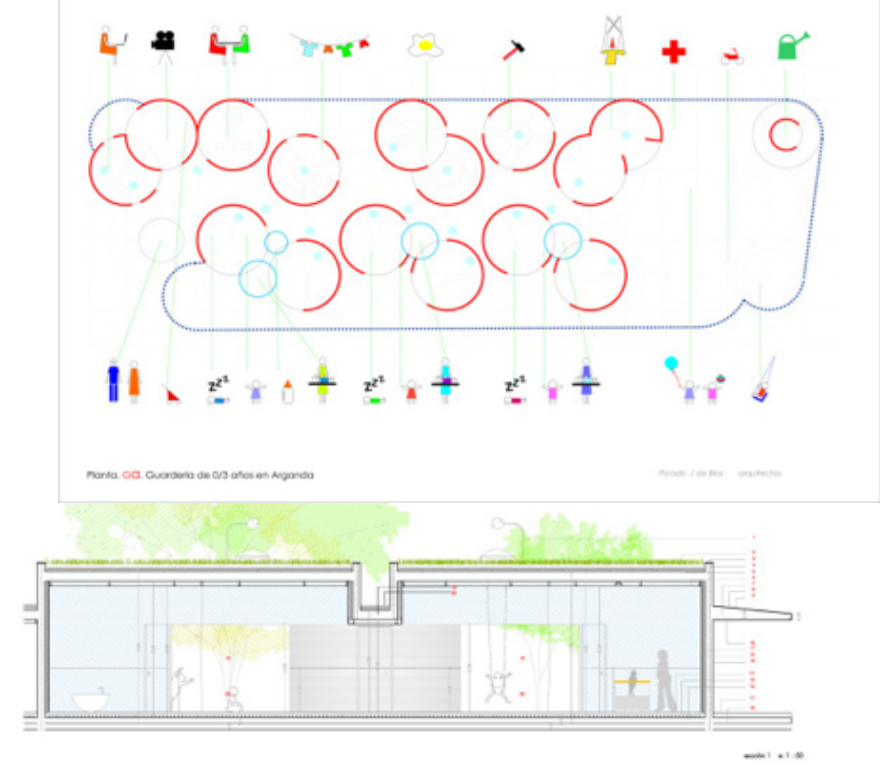

\section{CONDICIONANTES ESPECIALES}

He tomado como referente la guardería de Luca Peralta, porque logra que sea un espacio integrado por la luz exterior sin que los niños corran riegos mayores de perderse.

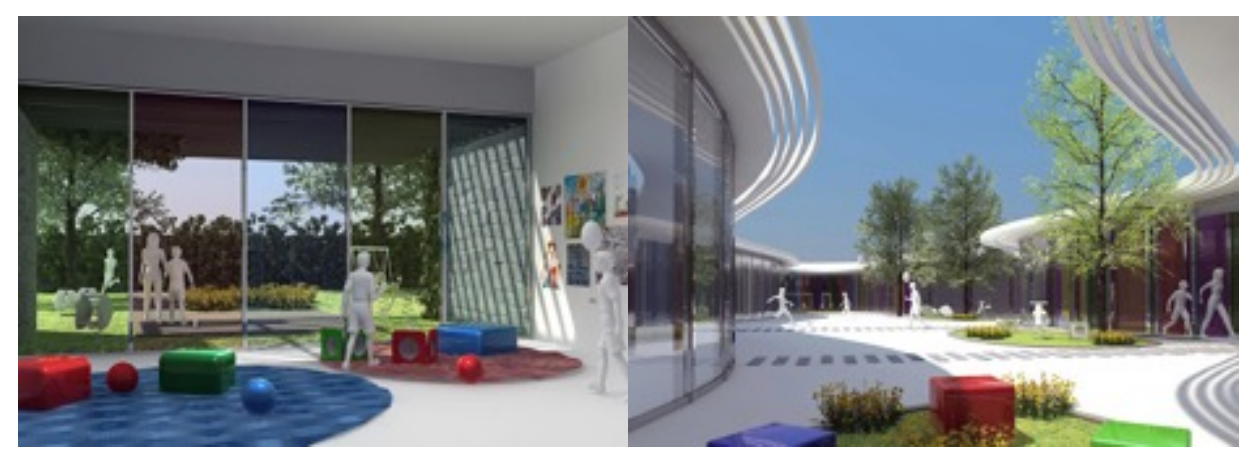

IMAGEN 44 - GUARDERÍA LUCA PERALTA STUDIO (2015) 


\begin{tabular}{|c|c|}
\hline \multicolumn{2}{|c|}{ NOMBRE DEL ESPACIO : OFICINAS } \\
\hline DESCRIPCIÓN & $\begin{array}{l}\text { Este ambiente pertenece al paquete } \\
\text { funcional de Zona Administrativa, en el cual } \\
\text { las oficinas, of de secretaria y directores } \\
\text { partirán de este modelo base de oficina. }\end{array}$ \\
\hline PAQUETE FUNCIONAL & ZONA ADMINISTRATIVA \\
\hline FUNCIÓN & ADMINISTRATIVA \\
\hline USUARIO PRINCIPAL & USUARIO ADMINISTRATIVO \\
\hline NRO DE USUARIOS & 22 \\
\hline \multicolumn{2}{|c|}{ CONDICIONANTES AMBIENTALES } \\
\hline ILUMINACIÓN & PREFERENTEMENTE TAMIZADA Y ARTIFICIAL \\
\hline VENTILACIÓN & CRUZADA O ARTIFICIAL \\
\hline TÉRMICA & $\begin{array}{l}\text { CONTROLADA A TRAVÉS DE UN BALANCE EN EL } \\
\text { INGRESO DE LUZ Y VIENTO. }\end{array}$ \\
\hline ACÚSTICA & $\begin{array}{l}\text { DE BAJOS DECIBELES PORQUE ES UN ESPACIO DE } \\
\text { TRABAJO }\end{array}$ \\
\hline PERCEPCIÓN & $\begin{array}{l}\text { COLOR CLARO Y CALMADO RELACIÓN CON } \\
\text { NATURALEZA }\end{array}$ \\
\hline INSTALACIONES & $\begin{array}{l}\text { UNA ALTURA DEL ESPACIO DE UN MÍNIMO } 2.4 \\
\text { SOBRE ESTO PASAN LAS VIGAS Y LAS } \\
\text { INSTALACIONES, TAMBIÉN ES IMPORTANTE EL } \\
\text { USO DE UN PISO TÉCNICO. }\end{array}$ \\
\hline MATERIALES & CONCRETO - ALBAÑILERIA ARMADA \\
\hline ÁREA DEL ESPACIO & $120 \mathrm{mts} 2$ \\
\hline ÁREA POR USUARIO & 3MTS2 \\
\hline
\end{tabular}
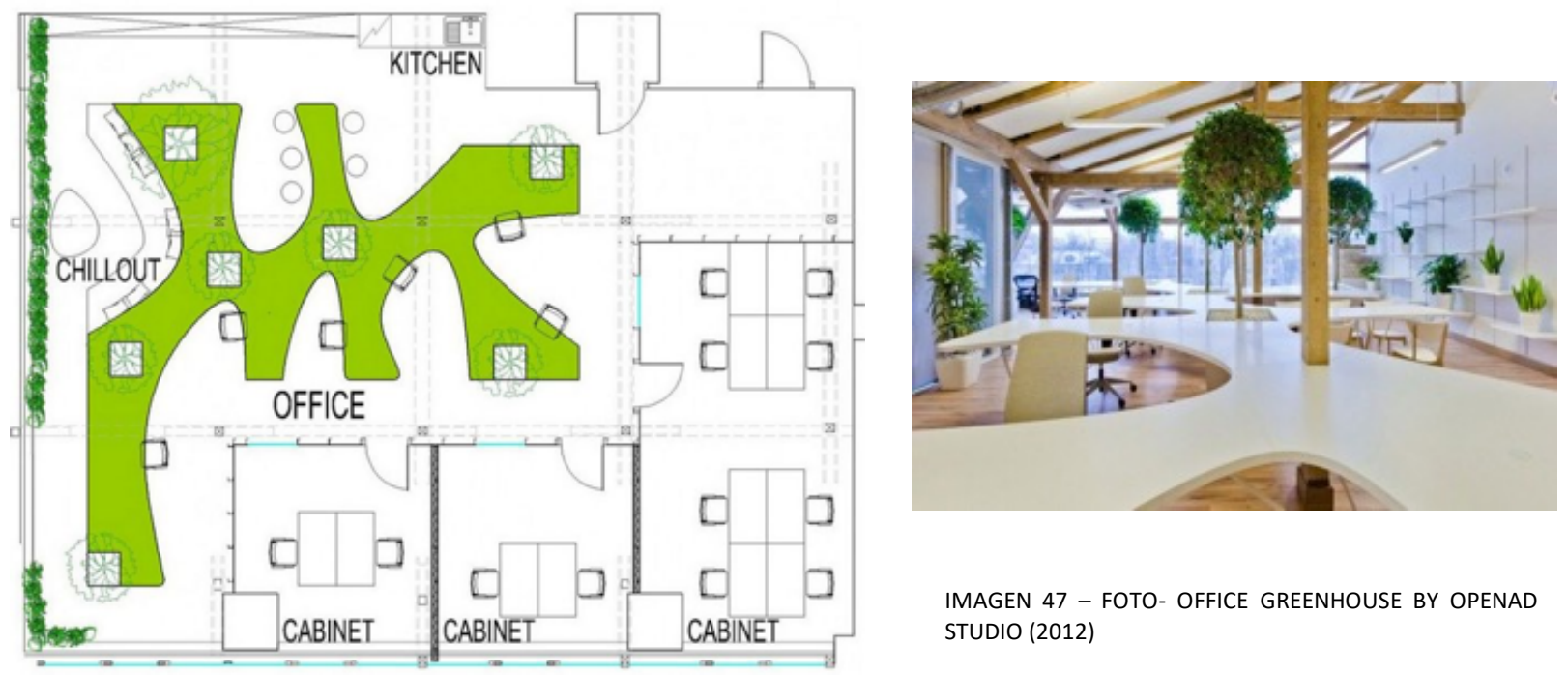

IMAGEN 47 - FOTO- OFFICE GREENHOUSE BY OPENAD STUDIO (2012)

IMAGEN 46 - PLANTA - OFFICE GREENHOUSE BY OPENAD STUDIO (2012) 
CONDICIONANTES ESPECIALES
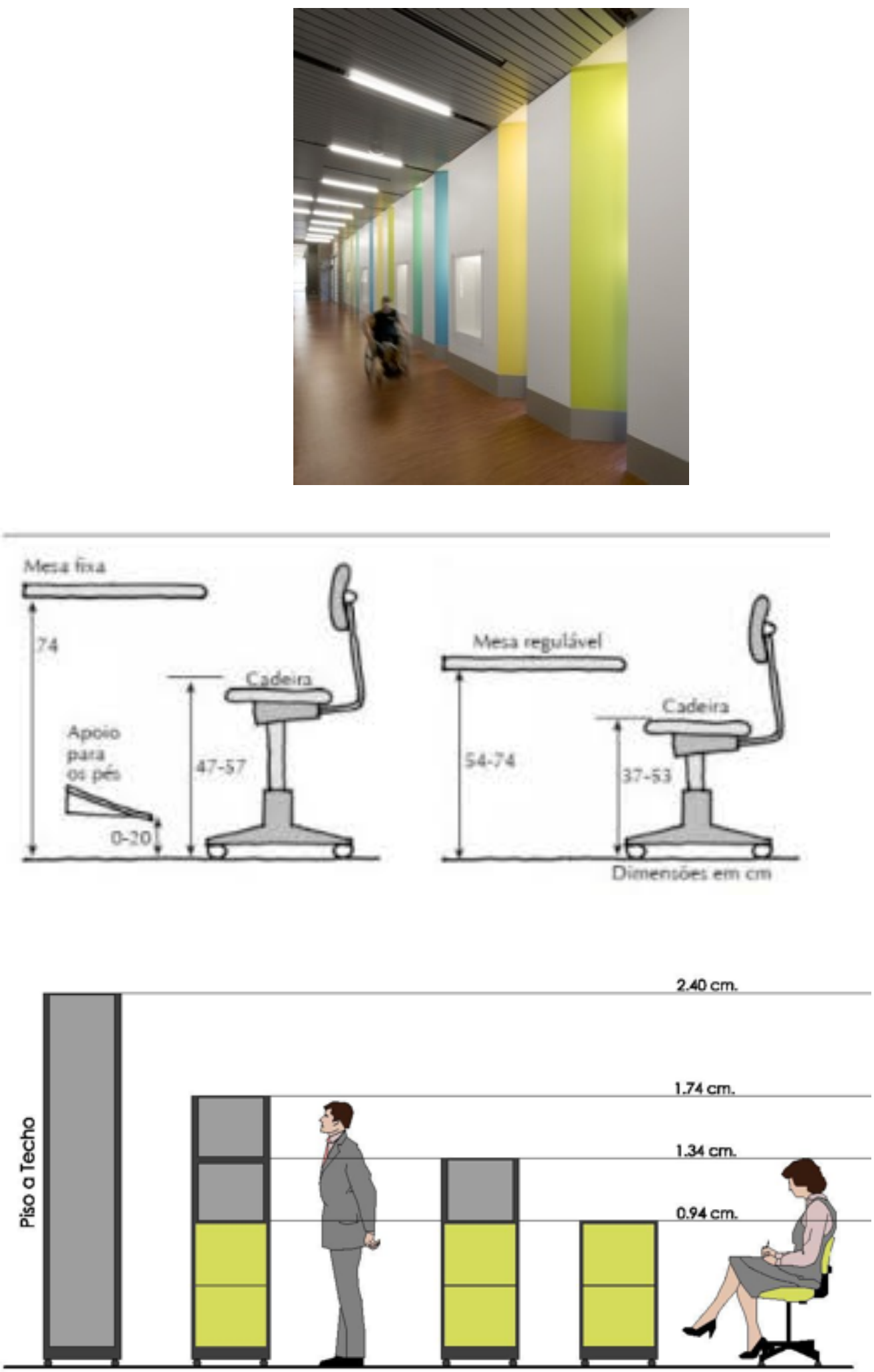


\begin{tabular}{|l|l|}
\hline DESCRIPCIÓN & $\begin{array}{l}\text { Este ambiente es el principal del } \\
\text { polideportivo, en el cual se realizan los } \\
\text { deportes, tiene que ser un espacio flexible en } \\
\text { el que puedan bajar unos paneles que } \\
\text { subdividan el espacio para que se realicen } \\
\text { deportes paralelamente. }\end{array}$ \\
\hline PAQUETE FUNCIONAL & ZONA DEPORTIVA \\
\hline FUNCIÓN & Práctica de Deportes \\
\hline USUARIO PRINCIPAL & Deportistas, Profesores y Rehabilitadores \\
\hline NRO DE USUARIOS & 400 \\
\hline
\end{tabular}

\section{CONDICIONANTES AMBIENTALES}

\begin{tabular}{|l|l|}
\hline ILUMINACIÓN & PREFERENTEMENTE TAMIZADA Y ARTIFICIAL \\
\hline VENTILACIÓN & CRUZADA O ARTIFICIAL \\
\hline TÉRMICA & $\begin{array}{l}\text { CONTROLADA A TRAVÉS DE UN BALANCE EN } \\
\text { EL INGRESO DE LUZ Y VIENTO. }\end{array}$ \\
\hline ACÚSTICA & NEUTRO \\
\hline PERCEPCIÓN & $\begin{array}{l}\text { COLOR CLARO Y CALMADO RELACIÓN CON } \\
\text { NATURALEZA, SENSACIÓN DE AMPLITUD }\end{array}$ \\
\hline INSTALACIONES & $\begin{array}{l}\text { UNA ALTURA DEL ESPACIO DE UN MINNIMO } \\
\text { 2.4 SOBRE ESTO PASAN LAS VIGAS Y LAS } \\
\text { INSTALACIONES. }\end{array}$ \\
\hline MATERIALES & \begin{tabular}{l} 
CONCRETO - ALBAÑILERIA ARMADA - \\
\hline
\end{tabular} \\
\hline
\end{tabular}




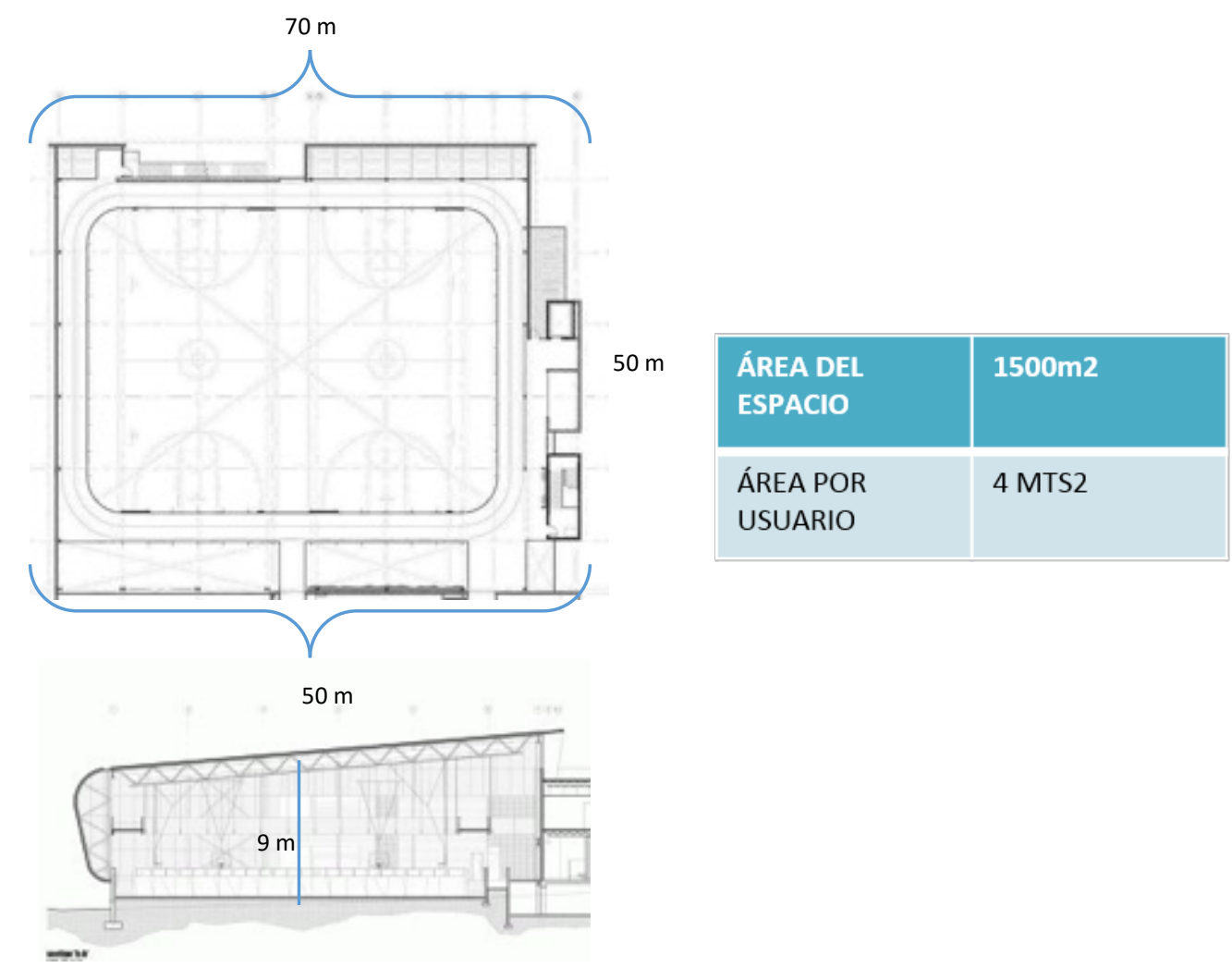

\section{CONDICIONANTES ESPECIALES}

Tiene una conexión directa con los vestuarios y baños (ZONA HUMEDA Y SECA) y circulaciones, ya sea rampas o escaleras y ascensores. Tiene una conexión visual con las tribunas.

El tipo de suelo debe ser antideslizante y evitar que sea demasiado reflejante, de tener pista de atletismo circundándolo, esta debe tener un piso de bajo impacto, para reducir impacto en la zona lumbar de los atletas.

\section{ESTUDIO DE LA ANTROPOMETRÍA Y EL MOBILIARIO}

Ya que el espacio es flexible y debe albergar varios deportes, a continuación, analizaré los deportes que se realizarían en este espacio.

\section{FUTBOL}

Este ambiente pertenece al Area Deportiva, contiene el deporte de box.

Tiene una conexión indirecta con los vestuarios y baños (los cuales deben tener una zona humeda y seca) y circulaciones, ya sea rampas o escaleras y ascensores. Tiene una conexión visual con las tribunas. 
El numero de usuarios para este espacio es de un máximo de 34 personas $(3 \mathrm{~m} 2$ por persona).

Contiene depósitos, equipos de sonido, mobiliario deportivo.

En tanto a la iluminación puede ser artificial o natural, la circulación de aire debe ser preferentemente cruzada y puede ser por aire acondicionado.

El tipo de suelo debe ser antideslizante y evitar que sea demasiado reflejante. El espacio cuenta con $36 \mathrm{~m} 2$

Tiene una altura de $9 \mathrm{mts}$ como mínimo y debe preverse el paso de cañerías y tubos con un falso cielo.

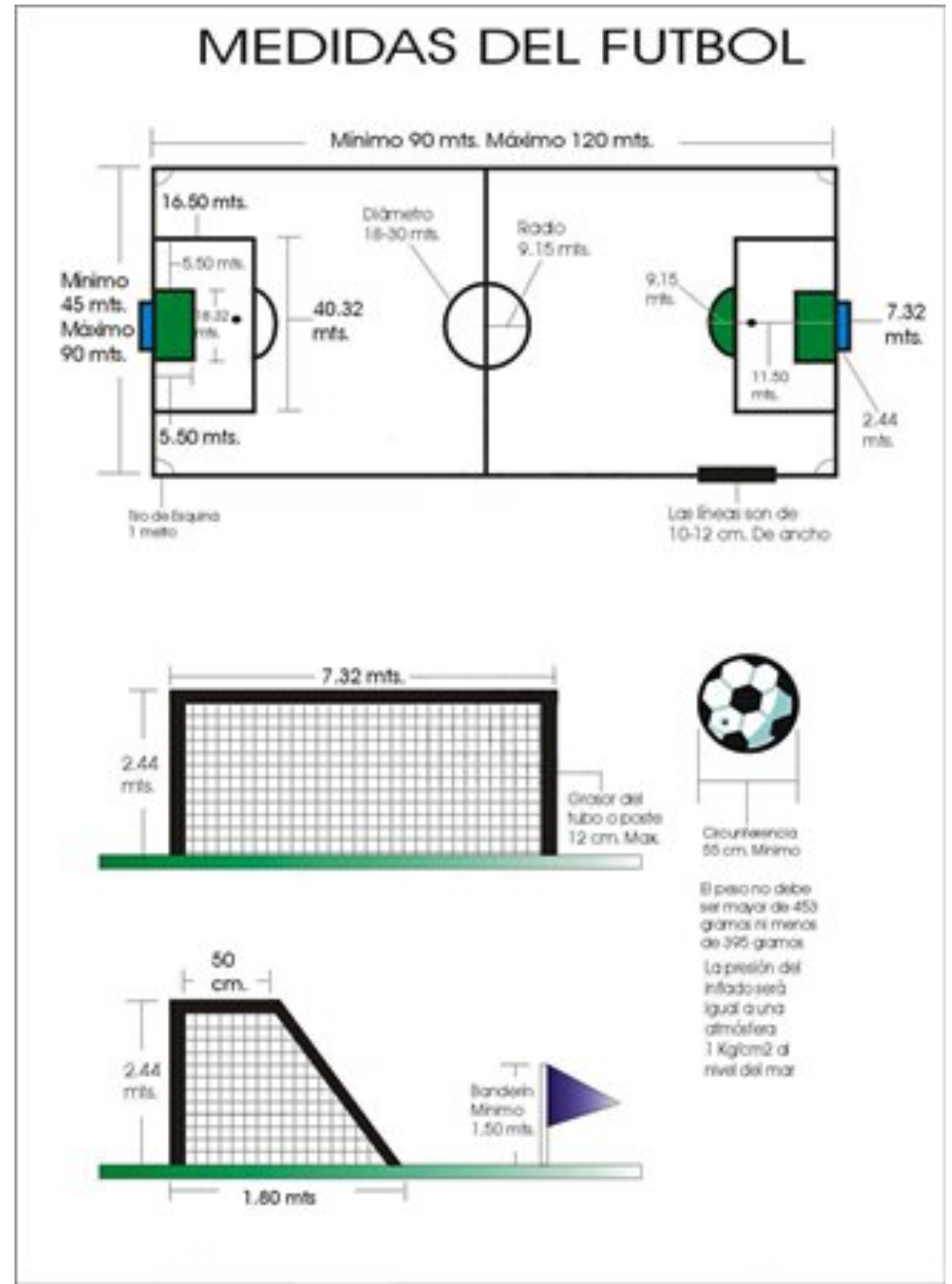




\section{ATLETISMO}

Este ambiente pertenece al Area Deportiva, contiene el deporte de atletismo.

Tiene una conexión indirecta con los vestuarios y baños (los cuales deben tener una zona húmeda y seca) y circulaciones, ya sea rampas o escaleras y ascensores. Tiene una conexión visual con las tribunas.

El número de usuarios para este espacio es de un máximo de 25 personas $(3 \mathrm{~m} 2$ por persona).

Contiene depósitos, equipos de sonido, mobiliario deportivo.

En tanto a la iluminación puede ser artificial o natural, la circulación de aire debe ser preferentemente cruzada y puede ser por aire acondicionado.

El tipo de suelo debe ser antideslizante y evitar que sea demasiado reflejante. El espacio cuenta con $36 \mathrm{~m} 2$

Tiene una altura de $9 \mathrm{mts}$ como mínimo y debe preverse el paso de cañerías y tubos con un falso cielo.

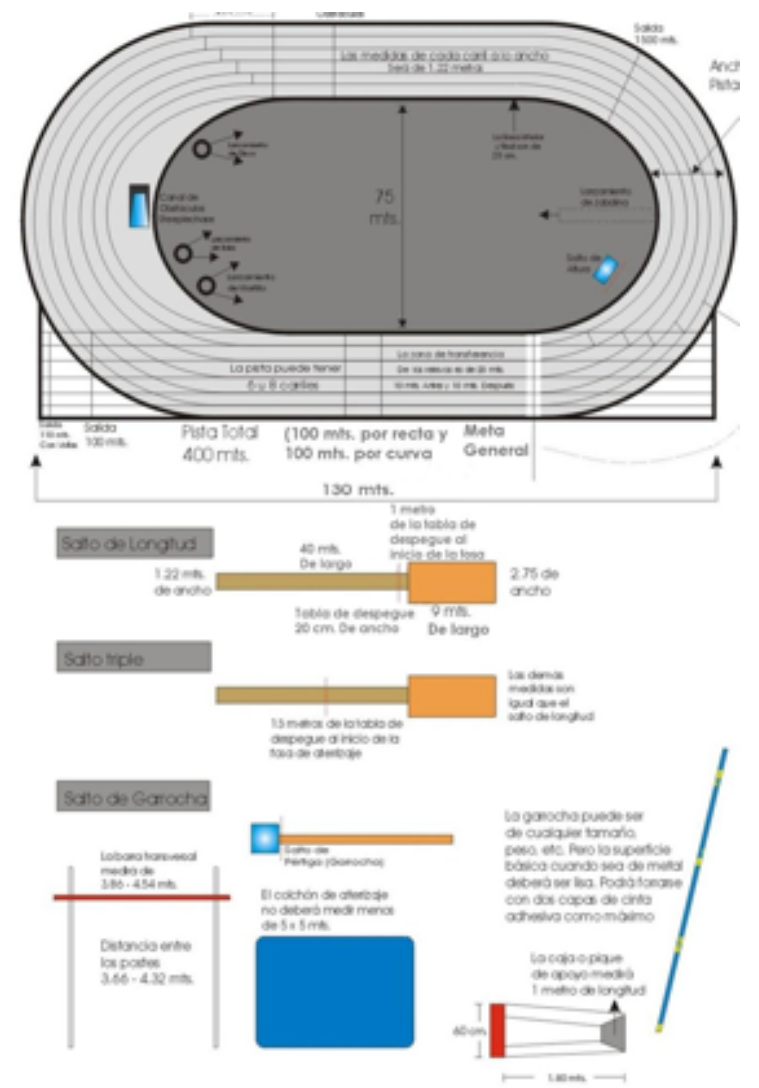




\section{BÁSQUET}

Este ambiente es parte del paquete funcional deportivo.

La cantidad de usuarios es de 18 entre deportistas, coach y rehabilitadores.

El ancho mínimo es de $14 \mathrm{~m}$ y el máximo $15 \mathrm{~m}$, el largo mínimo es de $26 \mathrm{~m}$ el máximo de $28 \mathrm{~m}$.

En las instalaciones bajo techo se puede utilizar una superficie de duela o madera especial, perfectamente nivelada y con características antideslizantes y de absorción de impacto, que debe cumplir con las especificaciones oficiales ya que, por lo general, estas superficies se instalan en centros deportivos de alta competencia o profesionales.

Otra opción de superficie de juego en un piso plano de concreto o asfalto, con un recubrimiento especial para canchas deportivas, con propiedades de absorción de impacto ya que es un juego que involucra muchos saltos por parte delos jugadores, para darle una mayor flexibilidad a la misma y así proteger a los deportistas de posibles daños en las rodillas y otras articulaciones.

Altura de $7 \mathrm{~m}$ como mínimo. Si se utiliza luz artificial, la cancha debe quedar uniformemente iluminada y la colocación debe ser hecha de manera que las luces no entorpezcan la visión del jugador al encestar.
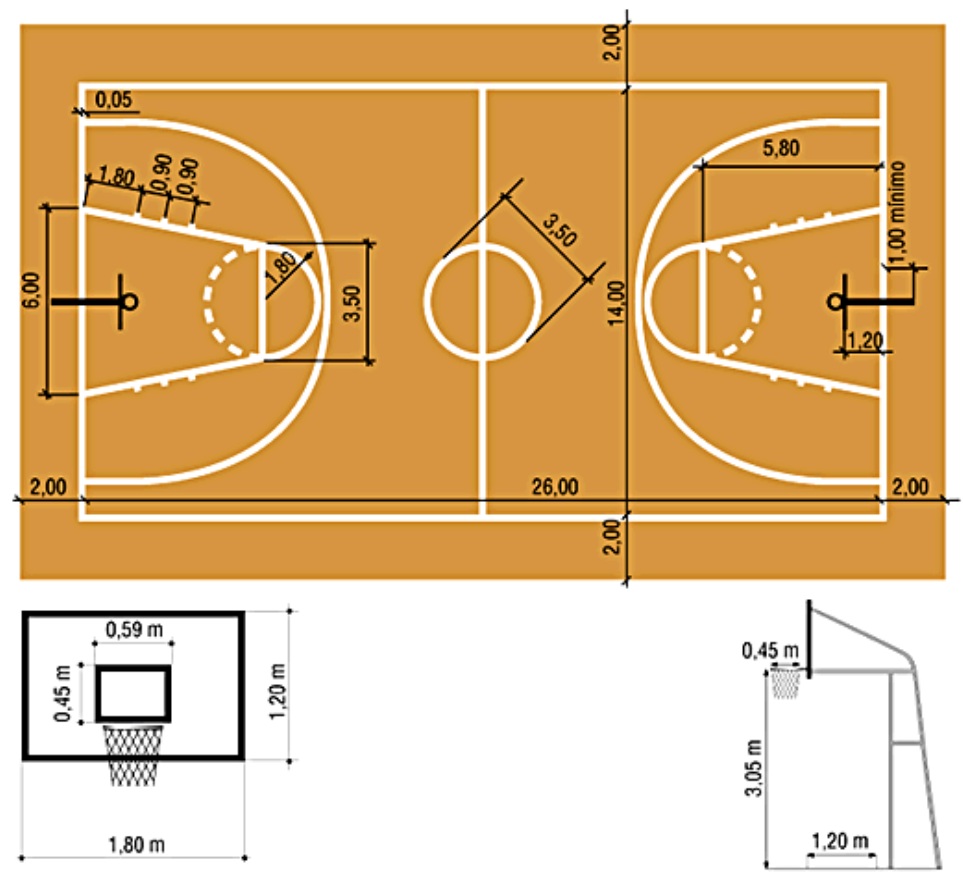


\section{VOLLEY}

La altura del techo o del obstáculo más bajo debe ser, como mínimo, de $7.00 \mathrm{~m}$. desde el suelo y en competiciones internacionales de $12,5 \mathrm{~m}$.

La superficie debe de ser plana, uniforme y horizontal.

Para realizar competiciones internacionales la superficie debe de ser sintética o de madera y además debe haber sido homologada por la F.I.V.B.

En las canchas que se encuentren en el interior de recintos deportivos la superficie de juego debe ser de color uniforme, claro y brillante.

En competiciones internacionales los colores de las líneas, la cancha y la zona libre tienen que ser diferentes.

Esta prohibido marca la líneas con materiales sólidos o duros.

En cancha en aire libre se permite una pendiente para el drenaje de $5 \mathrm{~mm}$. por metro.

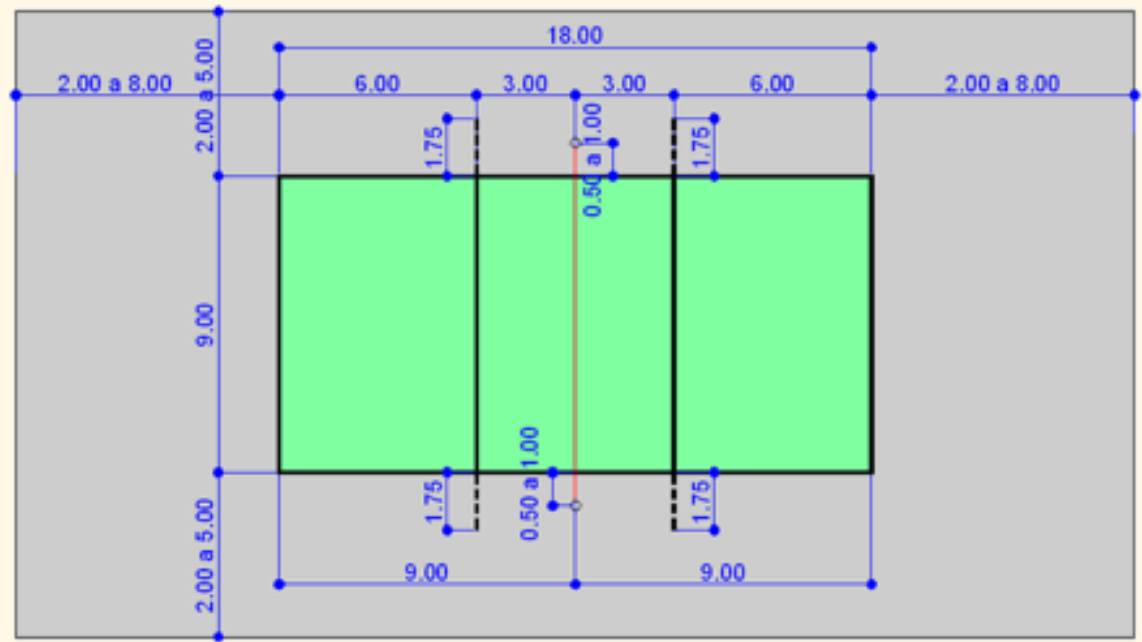

IMAGEN 58 - ANTROPOMETRÍA DEPORTIVA - ENCICLOPEDIA DEL DEPORTE (2004) 


\section{VOL VOLEIBOL}

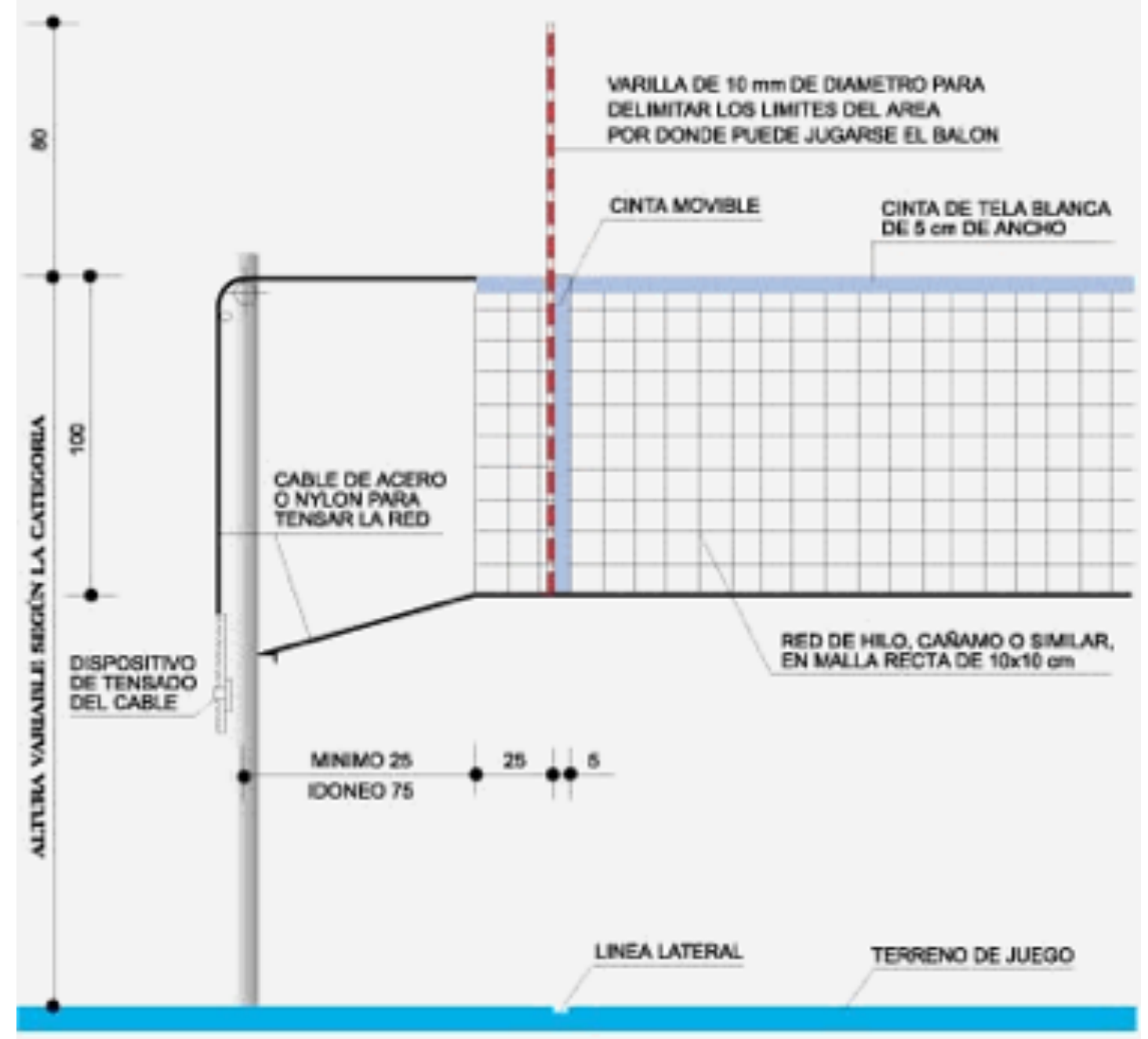

\section{ALTURA DEL. BORDE SUPERIOR DE LA RED DE VOLEIBOL}

\begin{tabular}{|c|c|c|}
\hline CATEGOELA & Mascuinos & FEMENTNOS \\
\hline Seniors & 2,43 mis. & Absolutas 2,24 mis. \\
\hline Juvenlles & 2,40 mts. (16 y 17 ahos) & Juvenlies 2,24 mts. (16 y 17 ahos) \\
\hline Cadetes & 2.30 mts. (14 y 15 anhos) & Cadetes 2,18 mts. (14 y 15 anos) \\
\hline Infantlies & $2.20 \mathrm{mts}$. (12 y 13 ahos) & Infantiles 2,10 mts. (12 y 13 an̂os) \\
\hline Alevines & 2,10 mis. (10 y 11 ahes) & \\
\hline Benjamines & 2,00 mis. (8 y 9 ańos) & \\
\hline
\end{tabular}

LOS POSTES Y LA RED. VOL-2 


\begin{tabular}{|c|c|}
\hline DESCRIPCIÓN & $\begin{array}{l}\text { Este ambiente pertenece al Area } \\
\text { Deportiva, contiene el deporte de box. }\end{array}$ \\
\hline PAQUETE FUNCIONAL & ZONA DEPORTIVA \\
\hline FUNCIÓN & Práctica de $\mathrm{BOX}$ \\
\hline USUARIO PRINCIPAL & $\begin{array}{l}\text { Deportistas, Profesores y } \\
\text { Rehabilitadores }\end{array}$ \\
\hline NRO DE USUARIOS & 150 ESPECTADORES 4 DEPORTISTAS \\
\hline \multicolumn{2}{|c|}{ CONDICIONANTES AMBIENTALES } \\
\hline ILUMINACIÓN & $\begin{array}{l}\text { PREFERENTEMENTE TAMIZADA Y } \\
\text { ARTIFICIAL. }\end{array}$ \\
\hline VENTILACIÓN & CRUZADA O ARTIFICIAL \\
\hline TÉRMICA & $\begin{array}{l}\text { CONTROLADA A TRAVÉS DE UN } \\
\text { BALANCE EN EL INGRESO DE LUZY } \\
\text { VIENTO. }\end{array}$ \\
\hline ACÚSTICA & NEUTRO \\
\hline PERCEPCIÓN & $\begin{array}{l}\text { COLOR INTENSO EN EL RING DE PELEA, } \\
\text { EL RESTO DEL AMBIENTE PUEDE SER DE } \\
\text { UN TONO NEUTRO }\end{array}$ \\
\hline INSTALACIONES & $\begin{array}{l}\text { UNA ALTURA DEL ESPACIO DE UN } \\
\text { MÍNIMO } 2.4 \text { SOBRE ESTO PASAN LAS } \\
\text { VIGAS Y LAS INSTALACIONES. }\end{array}$ \\
\hline MATERIALLES & $\begin{array}{l}\text { CONCRETO - ALBAÑILERÍA ARMADA - } \\
\text { TUERALES }\end{array}$ \\
\hline
\end{tabular}
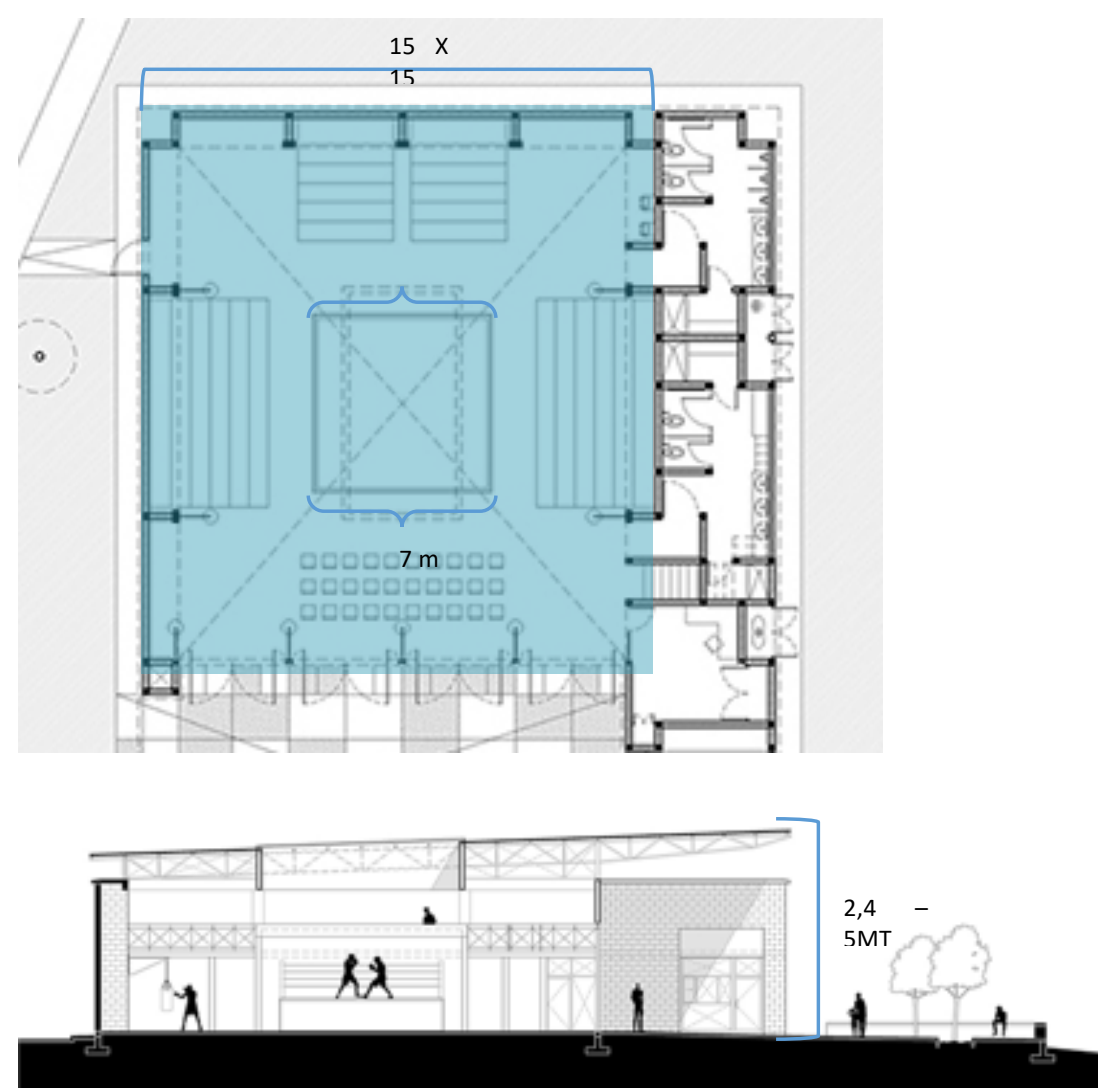

IMAGEN 59 - GIMNASIO DE BOX CATÁLOGO DE DISEÑO - (2013)

\begin{tabular}{|l|l|}
\hline ÁREA DEL ESPACIO & $225 \mathrm{~m} 2$ \\
\hline ÁREA POR USUARIO & $4 \mathrm{MTS} 2$ \\
\hline
\end{tabular}




\section{CONDICIONANTES ESPECIALES}

El tipo de suelo debe ser antideslizante y evitar que sea demasiado reflejante, de tener pista de atletismo circundándolo, esta debe tener un piso de bajo impacto, para reducir impacto en la zona lumbar de los atletas.

\section{ESTUDIO DE LA ANTROPOMETRÍA Y EL MOBILIARIO}

Debe contar con tribunas cómo mínimo en 1 de sus lados y una conexión indirecta con los baños y vestuarios para los deportistas y dirigentes.

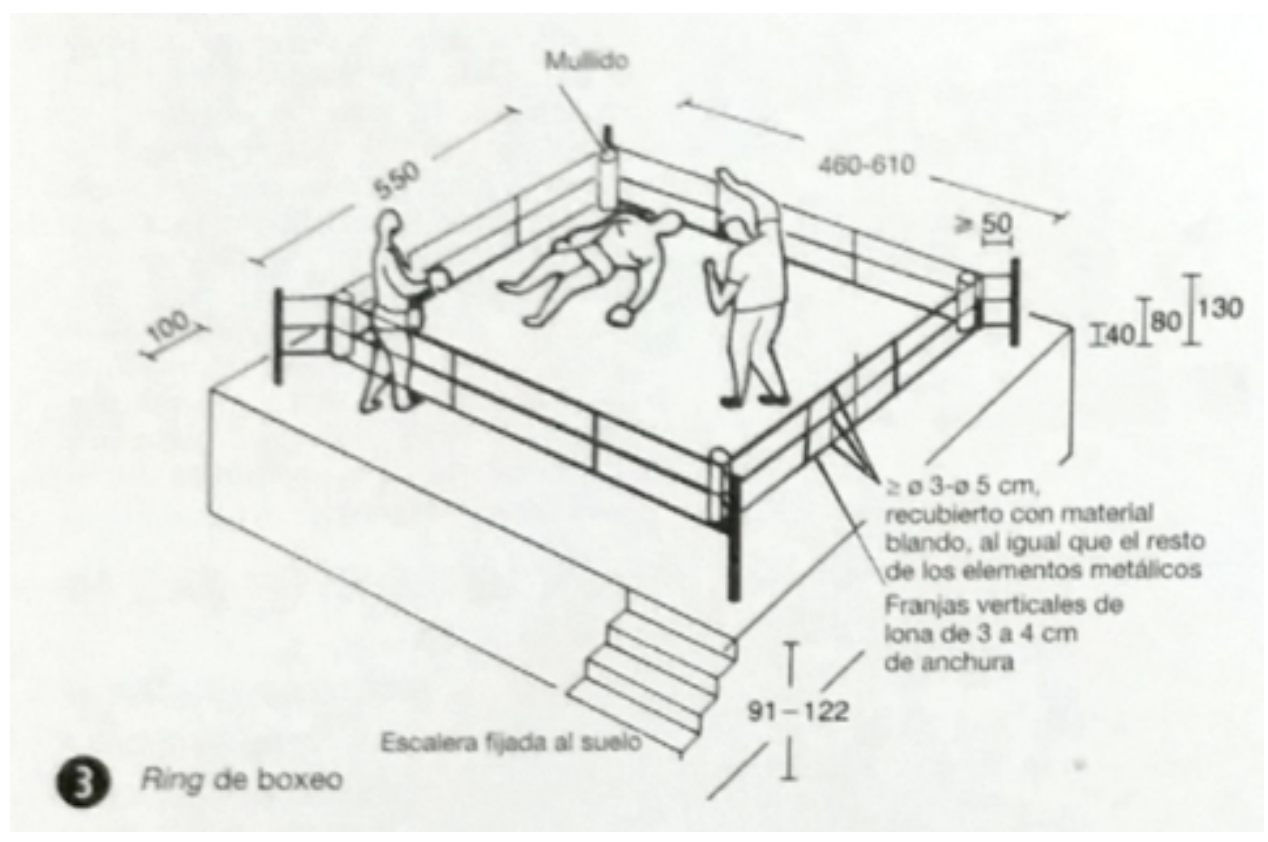

IMAGEN 62 - ANTROPOMETRÍA DEPORTIVA - ENCICLOPEDIA DEL DEPORTE (2004) 


\begin{tabular}{|c|c|}
\hline \multicolumn{2}{|c|}{ NOMBRE DEL ESPACIO : BOWLING } \\
\hline DESCRIPCIÓN & $\begin{array}{l}\text { Este ambiente pertenece al Area } \\
\text { Deportiva, contiene el deporte de } \\
\text { bowling. }\end{array}$ \\
\hline PAQUETE FUNCIONAL & ZONA DEPORTIVA \\
\hline FUNCIÓN & Práctica de BOWLING \\
\hline USUARIO PRINCIPAL & $\begin{array}{l}\text { Deportistas, Profesores y } \\
\text { Rehabilitadores }\end{array}$ \\
\hline NRO DE USUARIOS & 24 \\
\hline \multicolumn{2}{|c|}{ CONDICIONANTES AMBIENTALES } \\
\hline ILUMINACIÓN & $\begin{array}{l}\text { PREFERENTEMENTE TAMIZADA Y } \\
\text { ARTIFICIAL. }\end{array}$ \\
\hline VENTILACIÓN & CRUZADA O ARTIFICIAL \\
\hline TÉRMICA & $\begin{array}{l}\text { CONTROLADA A TRAVÉS DE UN } \\
\text { BALANCE EN EL INGRESO DE LUZY } \\
\text { VIENTO. }\end{array}$ \\
\hline ACÚSTICA & NEUTRA \\
\hline PERCEPCIÓN & $\begin{array}{l}\text { COLOR INTENSO, TEXTURAS QUE } \\
\text { TRANSMITAN CALIDEZ }\end{array}$ \\
\hline INSTALACIONES & $\begin{array}{l}\text { UNA ALTURA DEL ESPACIO DE UN } \\
\text { MÍNIMO } 2.4 \text { SOBRE ESTO PASAN LAS } \\
\text { VIGAS Y LAS INSTALACIONES. }\end{array}$ \\
\hline MATERIALES & $\begin{array}{l}\text { CONCRETO - ALBAÑILERÍA ARMADA - } \\
\text { TUERALES }\end{array}$ \\
\hline
\end{tabular}

IMAGEN 64 - ANTROPOMETRÍA DEPORTIVA - ENCICLOPEDIA DEL DEPORTE (2004)
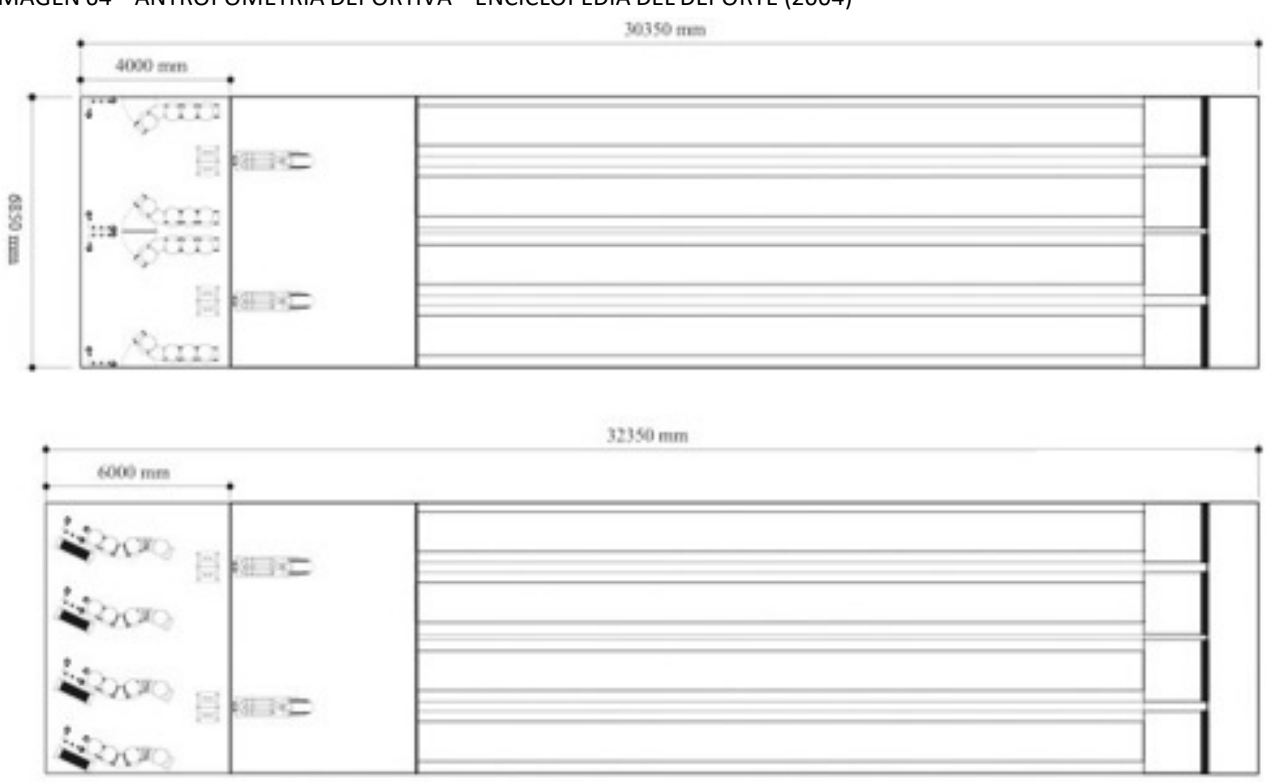

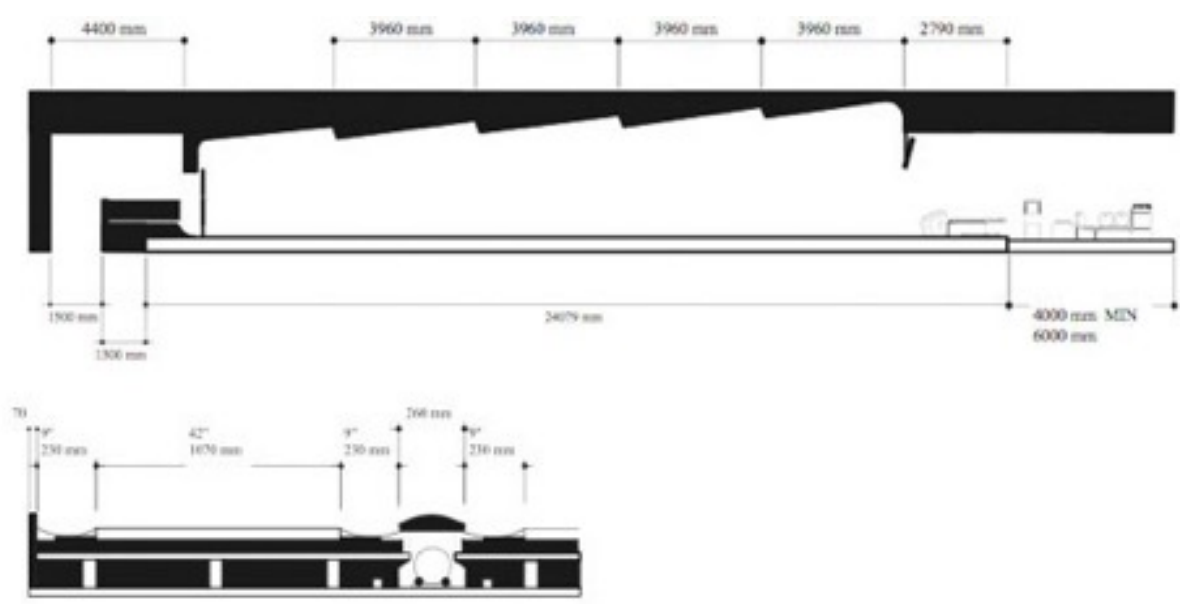

\section{CONDICIONANTES ESPECIALES}

width

\begin{tabular}{cll} 
Number of lanes & $\mathrm{mt}$ & feet \\
\hline 2 & 3.46 & $11^{\prime} 6^{\prime \prime}$ \\
\hline 4 & 6.85 & $22^{\prime} 71 / 4^{\prime \prime}$ \\
\hline 6 & 10.24 & $33^{\prime} 81 / 2^{\prime \prime}$ \\
\hline 8 & 13.63 & $44^{\prime} 93 / 4^{\prime \prime}$ \\
\hline 10 & 17.02 & $55^{\prime} 11^{\prime \prime}$ \\
\hline 12 & 20.41 & $67^{\prime} 1 / 4^{\prime \prime}$ \\
\hline 14 & 23.80 & $78^{\prime} 11 / 2^{\prime \prime}$ \\
\hline 16 & 27.19 & $89^{\prime} 23 / 4^{\prime \prime}$ \\
\hline 18 & 30.58 & $100^{\prime} 4^{\prime \prime}$ \\
\hline 20 & 33.97 & $111^{\prime} 51 / 4^{\prime \prime}$
\end{tabular}

width

\begin{tabular}{lrl} 
Number of lanes & \multicolumn{1}{c}{$\mathbf{m t}$} & feet \\
\hline 22 & 37.36 & $122^{\prime} 61 / 2^{\prime \prime}$ \\
\hline 24 & 40.75 & $133^{\prime} 73 / 4^{\prime \prime}$ \\
\hline 26 & 44.14 & $144^{\prime} 9^{\prime \prime}$ \\
\hline 28 & 47.53 & $155^{\prime} 101 / 4^{\prime \prime}$ \\
\hline 30 & 50.92 & $167^{\prime} 111 / 2^{\prime \prime}$ \\
\hline 32 & 54.31 & $178^{\prime} 3 / 4^{\prime \prime}$ \\
\hline 34 & 57.70 & $189^{\prime} 2^{\prime \prime}$ \\
\hline 36 & 61.09 & $200^{\prime} 31 / 4^{\prime \prime}$ \\
\hline 38 & 64.48 & $211^{\prime} 41 / 2^{\prime \prime}$ \\
\hline 40 & 67.87 & $222^{\prime} 53 / 4^{\prime \prime}$
\end{tabular}

IMAGEN 66 - ANTROPOMETRÍA DEPORTIVA - ENCICLOPEDIA DEL DEPORTE (2004)

\section{ESTUDIO DE LA ANTROPOMETRÍA Y EL MOBILIARIO}

Debe tomar en cuenta a los niños y a los discapacitados para evitar accidentes y eventualidades.

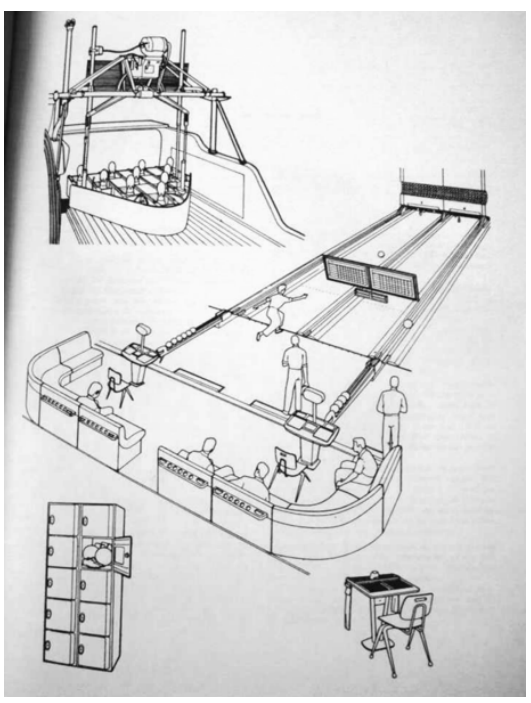




\begin{tabular}{|l|l|}
\hline NOMBRE DEL ESPACIO : SALAS DE BAILES & \\
\hline DESCRIPCIÓN & $\begin{array}{l}\text { Este ambiente pertenece al Area } \\
\text { Deportiva, contiene el deporte de } \\
\text { salones de baile. }\end{array}$ \\
\hline PAQUETE FUNCIONAL & ZONA DEPORTIVA \\
\hline FUNCIÓN & Bailes \\
\hline USUARIO PRINCIPAL & $\begin{array}{l}\text { Deportistas, Profesores y } \\
\text { Rehabilitadores }\end{array}$ \\
\hline NRO DE USUARIOS & 20 \\
\hline
\end{tabular}

\begin{tabular}{|l|l|}
\hline CONDICIONANTES AMBIENTALES & PREFERENTEMENTE TAMIZADA Y \\
\hline ILUMINACIÓN & ARTIFICIAL \\
\hline VENTILACIÓN & CRUZADA O ARTIFICIAL \\
\hline TÉRMICA & $\begin{array}{l}\text { CONTROLADA A TRAVÉS DE UN } \\
\text { BALANCE EN EL INGRESO DE LUZY } \\
\text { VIENTO. }\end{array}$ \\
\hline ACÚSTICA & $\begin{array}{l}\text { DE BAJOS DECIBELES PORQUE ES UN } \\
\text { ESPACIO DE TRABAJO }\end{array}$ \\
\hline PERCEPCIÓN & COLOR CLARO Y CALMADO \\
\hline INSTALACIONES & UNA ALTURA DEL ESPACIO DE UN \\
& MÍNIMO 5 M SOBRE ESTO PASAN LAS \\
& VIGAS Y LAS INSTALACIONES. \\
\hline MATERIALES & CONCRETO - ALBAÑILERIA ARMADA - \\
\hline
\end{tabular}

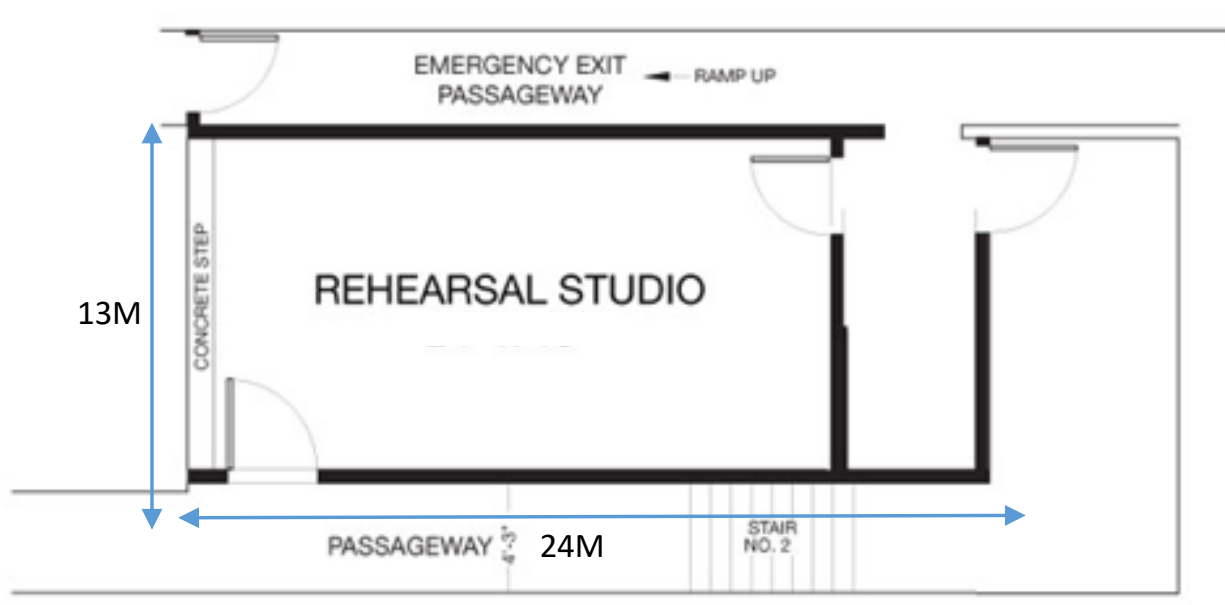

IMAGEN 69 - ANTROPOMETRÍA DEPORTIVA ENCICLOPEDIA DEL DEPORTE (2004) 


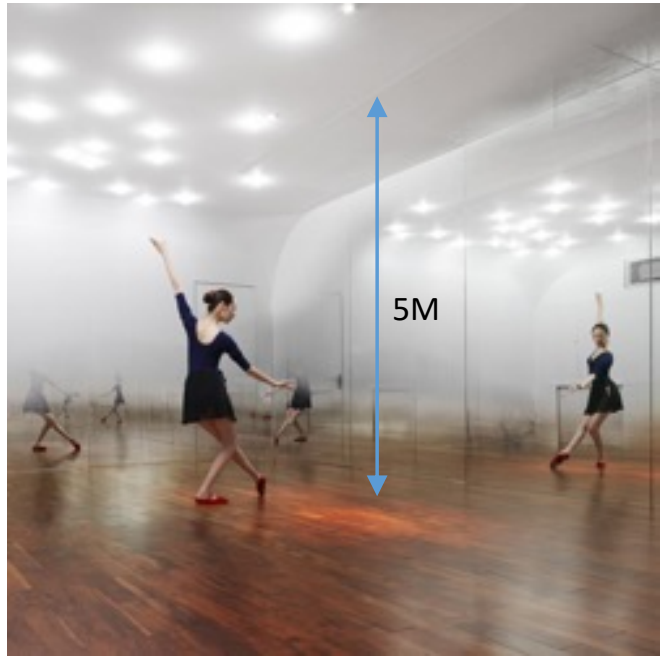

\begin{tabular}{|l|l|}
\hline $\begin{array}{l}\text { ÁREA DEL } \\
\text { ESPACIO }\end{array}$ & $314 \mathrm{~m} 2$ \\
\hline $\begin{array}{l}\text { ÁREA POR } \\
\text { USUARIO }\end{array}$ & 4 MTS2 \\
\hline
\end{tabular}

CONDICIONANTES ESPECIALES
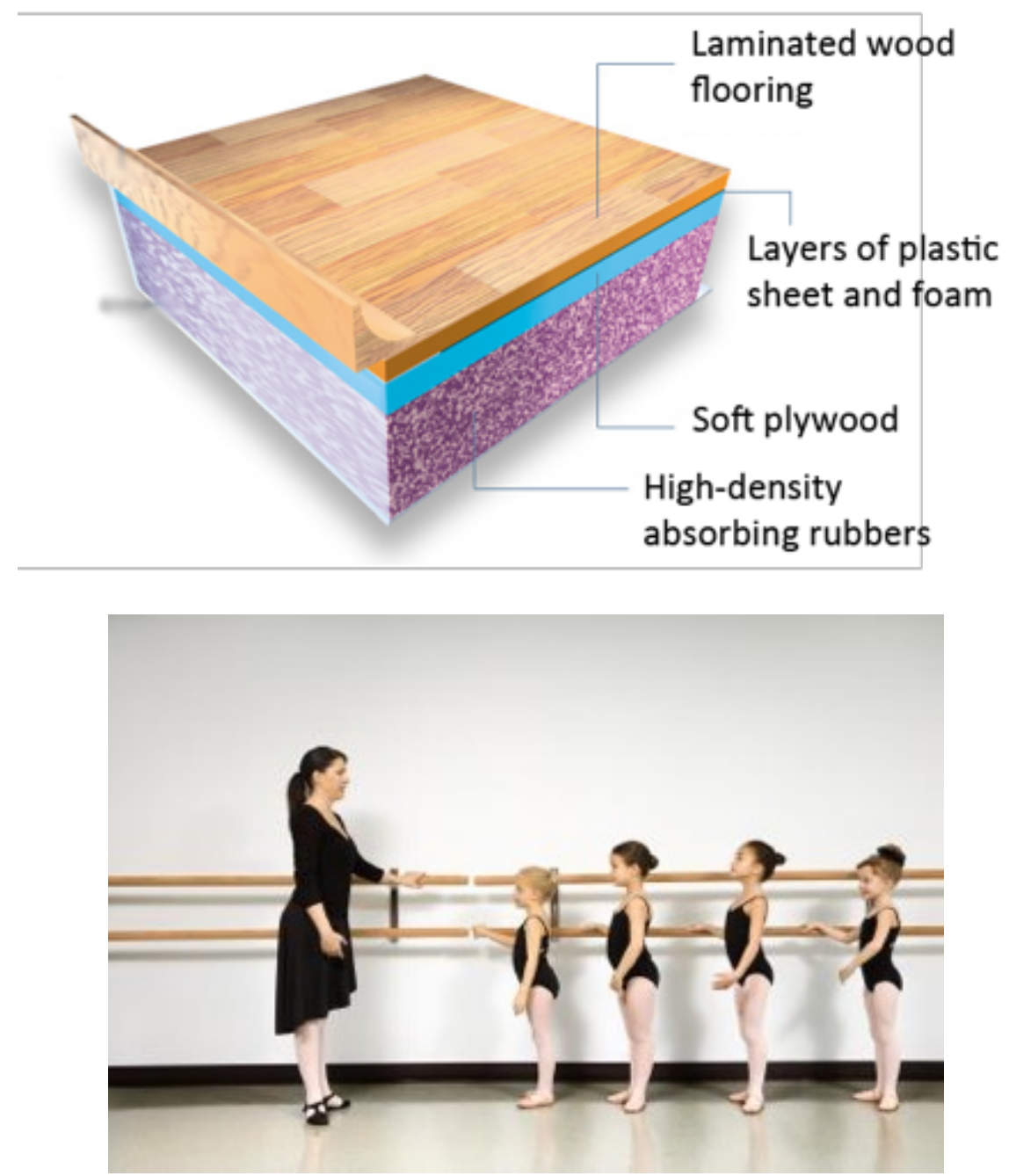
NOMBRE DEL ESPACIO : PISCINA OLÍMPICA

DESCRIPCIÓN

Este ambiente pertenece al Area Deportiva, contiene el deporte de natación y funcionaría debajo del espacio anteriormente mencionado, el principal de deportes flexible.

\section{PAQUETE FUNCIONAL}

FUNCIÓN

USUARIO PRINCIPAL

NRO DE USUARIOS

CONDICIONANTES AMBIENTALES

\section{ZONA DEPORTIVA}

Práctica de Natación

Deportistas, Profesores y Rehabilitadores

25 deportistas, 10 profesores $=35$

PREFERENTEMENTE TAMIZADA Y ARTIFICIAL

\section{CRUZADA O ARTIFICIAL}

TÉRMICA

CONTROLADA A TRAVÉS DE UN BALANCE EN EL INGRESO DE LUZ Y VIENTO.

La temperatura del agua debe ser controlada a 25-28 grados centígrados.

ACÚSTICA

DE BAJOS DECIBELES PORQUE ES UN ESPACIO DE TRABAJO

PERCEPCIÓN

COLOR CLARO Y CALMADO RELACION CON NATURALEZA, SENSACIÓN DE AMPLITUD

INSTALACIONES

UNA ALTURA DEL ESPACIO DE UN MINIMO 5 METROS SOBRE ESTO PASAN LAS VIGAS Y LAS INSTALACIONES.

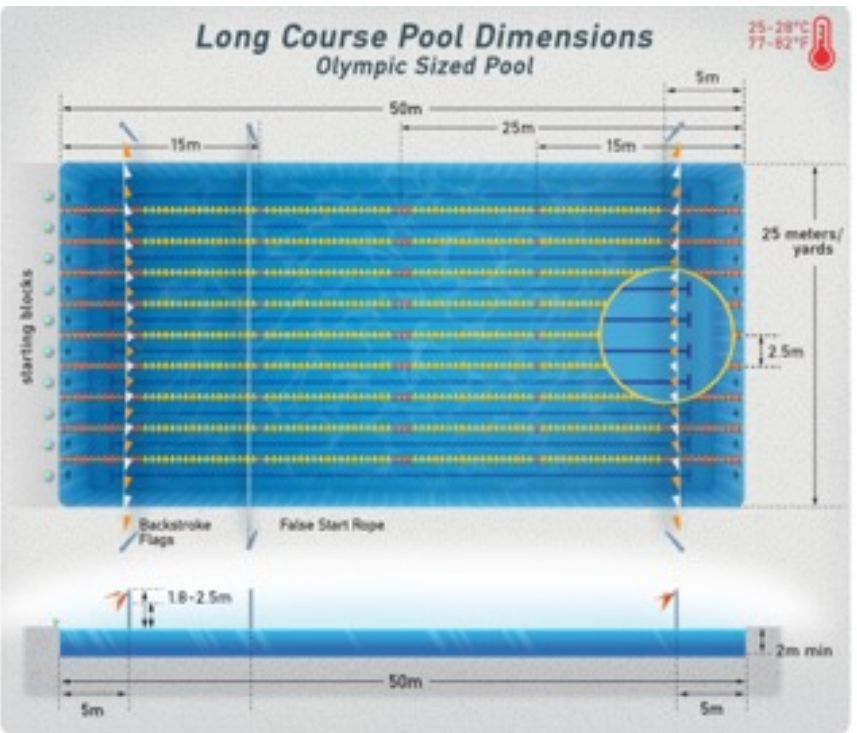

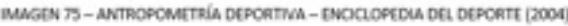

\begin{tabular}{l|l}
\hline $\begin{array}{l}\text { ÁREA DEL } \\
\text { ESPACIO }\end{array}$ & $1500 \mathrm{~m} 2$ \\
\hline $\begin{array}{l}\text { ÁREA POR } \\
\text { ar...man }\end{array}$ & $4 \mathrm{MTS2}$ \\
\hline
\end{tabular}




\section{CONDICIONANTES ESPECIALES}

Requiere de una cisterna grande dependiendo del tamaño de esta, la temperatura del agua debe estar estable entre $23-28$ grados centígrados.

\section{ESTUDIO DE LA ANTROPOMETRÍA Y EL MOBILIARIO}

Tiene una conexión directa con los vestuarios y baños (los cuales deben tener una zona húmeda y seca) y circulaciones, ya sea rampas o escaleras y ascensores. Tiene una conexión visual con las tribunas.

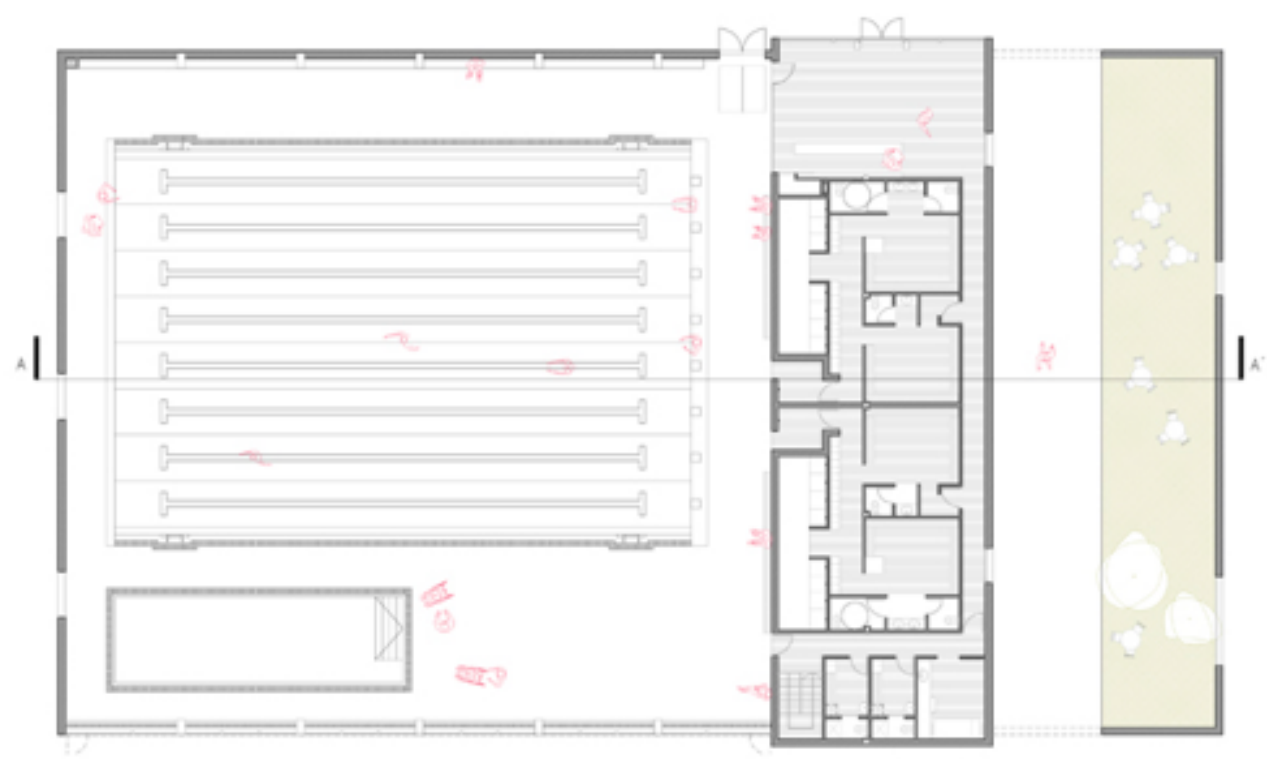

IMAGEN 77 - RELACION PISCINA VESTIDORES- ARCHDAILY (2015) 


\begin{tabular}{|l|l|}
\hline DESCRIPCIÓN & $\begin{array}{l}\text { Este ambiente pertenece al Area Deportiva, } \\
\text { contiene los vestuarios y baños }\end{array}$ \\
\hline PAQUETE FUNCIONAL & ZONA DEPORTIVA \\
\hline FUNCIÓN & USO DE SERVICIOS E HIGIENE \\
\hline USUARIO PRINCIPAL & Deportistas, Profesores y Rehabilitadores \\
\hline NRO DE USUARIOS & 25 USUARIOS \\
\hline
\end{tabular}

\begin{tabular}{|l|l|}
\hline CONDICIONANTES AMBIENTALES & \\
\hline ILUMINACIÓN & PREFERENTEMENTE TAMIZADA Y ARTIFICIAL \\
\hline VENTILACIÓN & CRUZADA O ARTIFICIAL \\
\hline TÉRMICA & CONTROLADA A TRAVÉS DE UN BALANCE EN \\
\hline EL INGRESO DE LUZ Y VIENTO. \\
\hline ACÚSTICA & $\begin{array}{l}\text { CONTROLADA PARA EVITAR EL ECO } \\
\text { PRODUCIDO POR LA AMPLITUD }\end{array}$ \\
\hline PERCEPCIÓN & $\begin{array}{l}\text { COLOR CLARO Y CALMADO RELACION CON } \\
\text { NATURALEZA, SENSACIÓN DE AMPLITUD }\end{array}$ \\
\hline INSTALACIONES & \begin{tabular}{l} 
UNA ALTURA DEL ESPACIO DE UN MINIMO \\
\hline
\end{tabular} \\
\hline MASTERIALES & LAS INSTALACIONES. \\
\hline CONCRETO - ALBAÑILERIA ARMADA
\end{tabular}
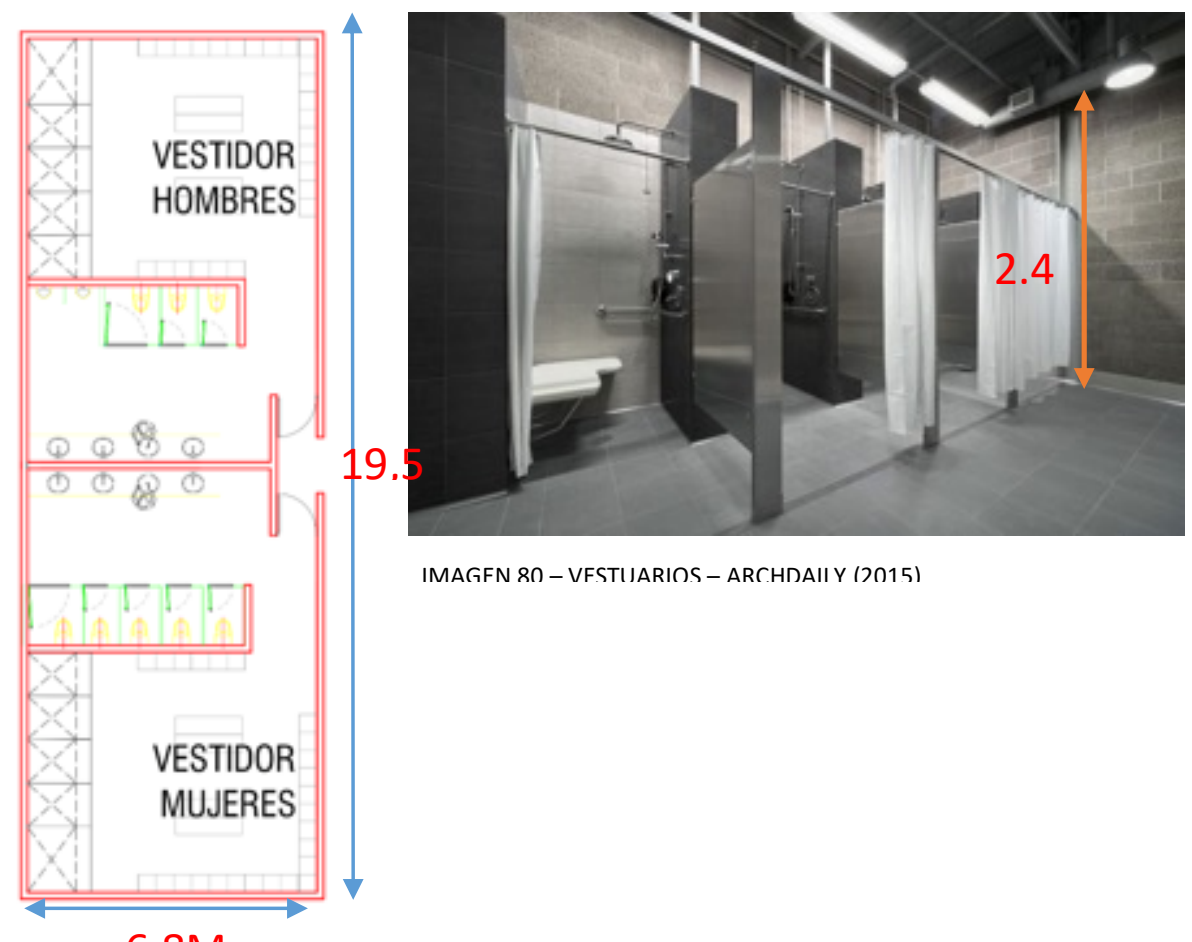

\section{$6,8 \mathrm{M}$}




\section{CONDICIONANTES ESPECIALES}

Debe haber una diferenciación entre la zona seca y húmeda de los vestidores, así como una ducha anterior a la salida hacia la piscina para poder mantener la limpieza del agua de la piscina.

\section{ESTUDIO DE LA ANTROPOMETRÍA Y EL MOBILIARIO}

Tiene una conexión indirecta con la Piscina o el espacio deportivo al que este asistiendo.

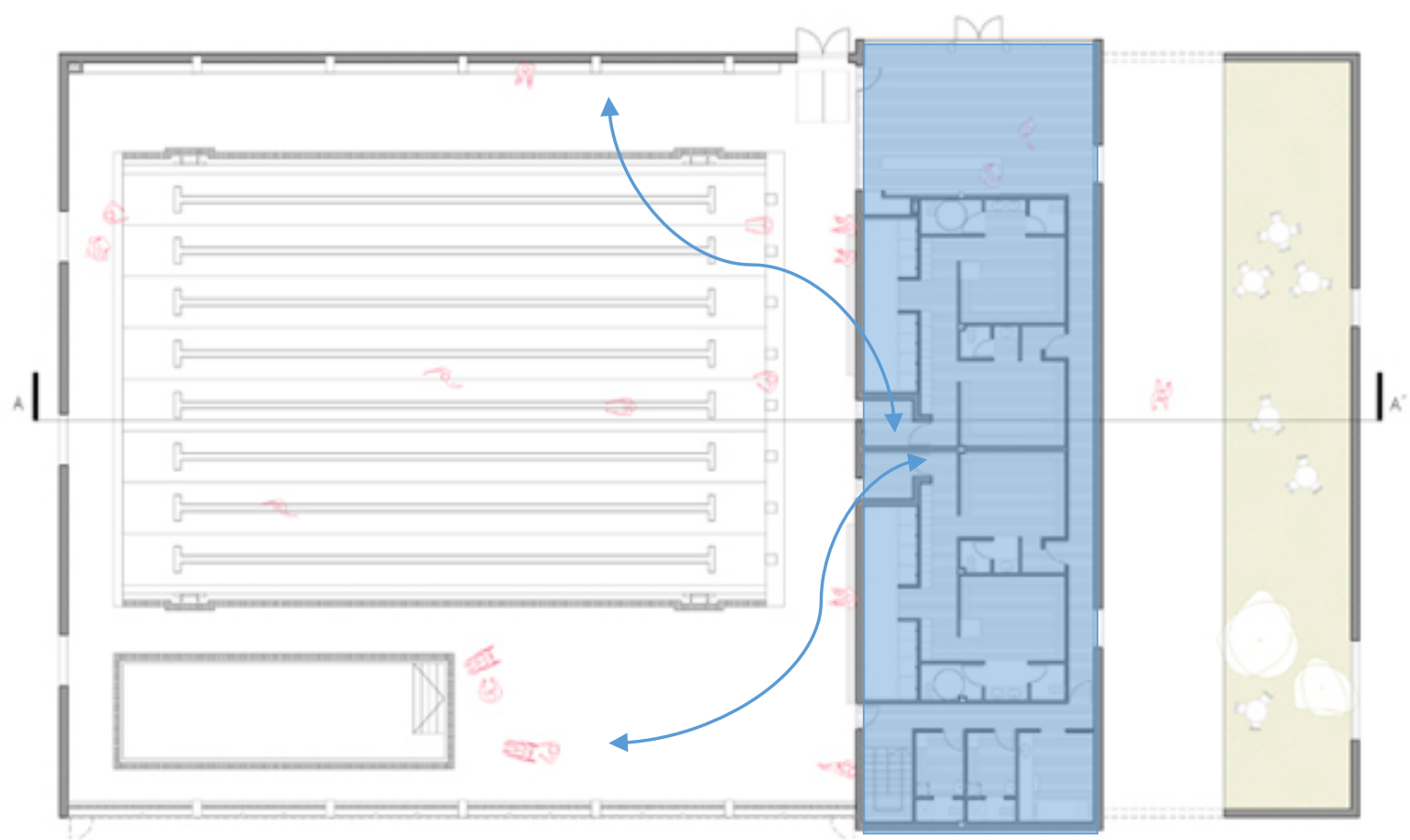




\subsection{CUADRO DE ÁREAS}

\begin{tabular}{|c|c|c|c|c|c|c|c|}
\hline \multirow{2}{*}{ PMQUER Funconal } & \multirow{2}{*}{ Амевовт } & \multirow{2}{*}{ nao of usuwasos } & \multirow{2}{*}{$\begin{array}{l}\text { Unibas } \\
\text { Lata }\end{array}$} & \multicolumn{2}{|c|}{ ConumTo of Umonoss } & \multirow{2}{*}{ suktoraus } & \multirow{2}{*}{ 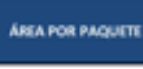 } \\
\hline & & & & nao & Nona & & \\
\hline \multirow{16}{*}{ zonaponuca } & necrotón & 4 & 60 & 2 & 120 & \multirow{16}{*}{ suo } & \multirow{16}{*}{390} \\
\hline & InFOPONT & s & is & 3 & is & & \\
\hline & corts & 30 & 100 & , & 100 & & \\
\hline & nevoas & 26 & 20 & 4 & so & & \\
\hline & SALA DE REPOSO & 150 & so & 1 & so & & \\
\hline & ImGreso TheunAs & 800 & 200 & 2 & 400 & & \\
\hline & Aubnomo & ж0 & 200 & 1 & 260 & & \\
\hline & roven & 20 & 160 & 1 & 160 & & \\
\hline & $\operatorname{sen}$ & 20 & ro & s & 350 & & \\
\hline & sulamertusos & $\omega$ & 15 & 3 & $2 s s$ & & \\
\hline & Cunoters & is & so & 1 & so & & \\
\hline & abvacs & is & $2 s$ & 6 & 150 & & \\
\hline & zonas of Frivo ON & 10 & 190 & 1 & 190 & & \\
\hline & senoctutess & 10 & no & 2 & 100 & & \\
\hline & treounas & 800 & 150 & 2 & 200 & & \\
\hline & roncos & s & 90 & 4 & 1200 & & \\
\hline
\end{tabular}

\begin{tabular}{|c|c|c|c|c|c|c|c|c|}
\hline \multirow{2}{*}{ mourt insoomal } & \multirow{2}{*}{ nenertit } & \multirow{2}{*}{ 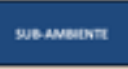 } & \multirow{2}{*}{ 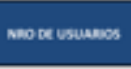 } & \multirow{2}{*}{ 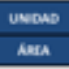 } & \multicolumn{2}{|c|}{ cenuvito ot unawes } & \multirow{2}{*}{ surrocus } & \multirow{2}{*}{ 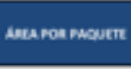 } \\
\hline & & & & & neo & nean & & \\
\hline \multirow{10}{*}{ menuceroatron } & \multirow{10}{*}{ cenotiserswes } & rowerce cuts & - & 110 & 1 & 10 & \multirow{10}{*}{3000} & \multirow{10}{*}{$n 050$} \\
\hline & & wat & 40 & 20 & 2 & 400 & & \\
\hline & & secuses & 6 & 300 & 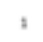 & 200 & & \\
\hline & & anuseoso & 26 & no & , & 300 & & \\
\hline & & $\begin{array}{l}\text { Derosessat } \\
\text { conestit }\end{array}$ & 20 & as & 1 & 225 & & \\
\hline & & STESrShNwewG & 20 & 30 & 1 & 300 & & \\
\hline & & onserer & 26 & no & 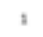 & 300 & & \\
\hline & & seven & 26 & 300 & $:$ & $\infty \infty$ & & \\
\hline & & 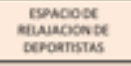 & as & 200 & 4 & $\$ \infty$ & & \\
\hline & & swer & 4 & 144 & 1 & sas & & \\
\hline
\end{tabular}




\begin{tabular}{|c|c|c|c|c|c|c|c|c|}
\hline \multirow{2}{*}{ magsera Pusconse: } & \multirow{2}{*}{ neavert } & \multirow{2}{*}{ sescomesn } & \multirow{2}{*}{ Neoset unaveors } & \multirow{2}{*}{$\begin{array}{c}\text { uneno } \\
\text { sash }\end{array}$} & \multicolumn{2}{|c|}{ 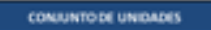 } & \multirow{2}{*}{ senothers } & \multirow{2}{*}{ 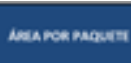 } \\
\hline & & & & & $n=0$ & $\sin x$ & & \\
\hline \multirow{14}{*}{ 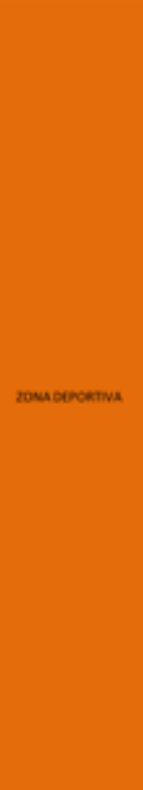 } & \multirow{9}{*}{ 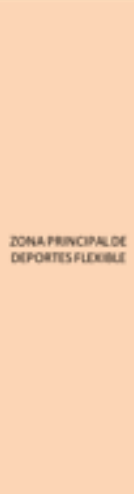 } & asover & is & $*$ & 2 & $n$ & \multirow{9}{*}{ 2no } & \multirow{14}{*}{ teas } \\
\hline & & vour & us & 16 & 2 & $n$ & & \\
\hline & & newes & 10 & $\omega$ & 2 & $n$ & & \\
\hline & & Funor & ss & ios & 1 & 10s & & \\
\hline & & anveses & s & 150 & 1 & 130 & & \\
\hline & & 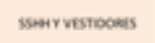 & $m$ & $\infty \infty$ & 1 & no & & \\
\hline & & м⿻上丨еrvinswe & 2 & $\omega$ & 2 & 120 & & \\
\hline & & colourosernver & is & $n$ & 1 & $n$ & & \\
\hline & & 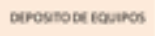 & , & $\infty 0$ & 1 & $4 \infty$ & & \\
\hline & \multirow{5}{*}{ sersoden } & 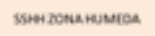 & so & $2 \infty$ & 1 & 200 & \multirow{5}{*}{2000} & \\
\hline & & ssorromusea & $\infty$ & 200 & 1 & 300 & & \\
\hline & & matron & 13 & 400 & 1 & 400 & & \\
\hline & & mocas sevocimea & 100 & aso & 1 & 1260 & & \\
\hline & & 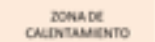 & so & 150 & 1 & 150 & & \\
\hline
\end{tabular}

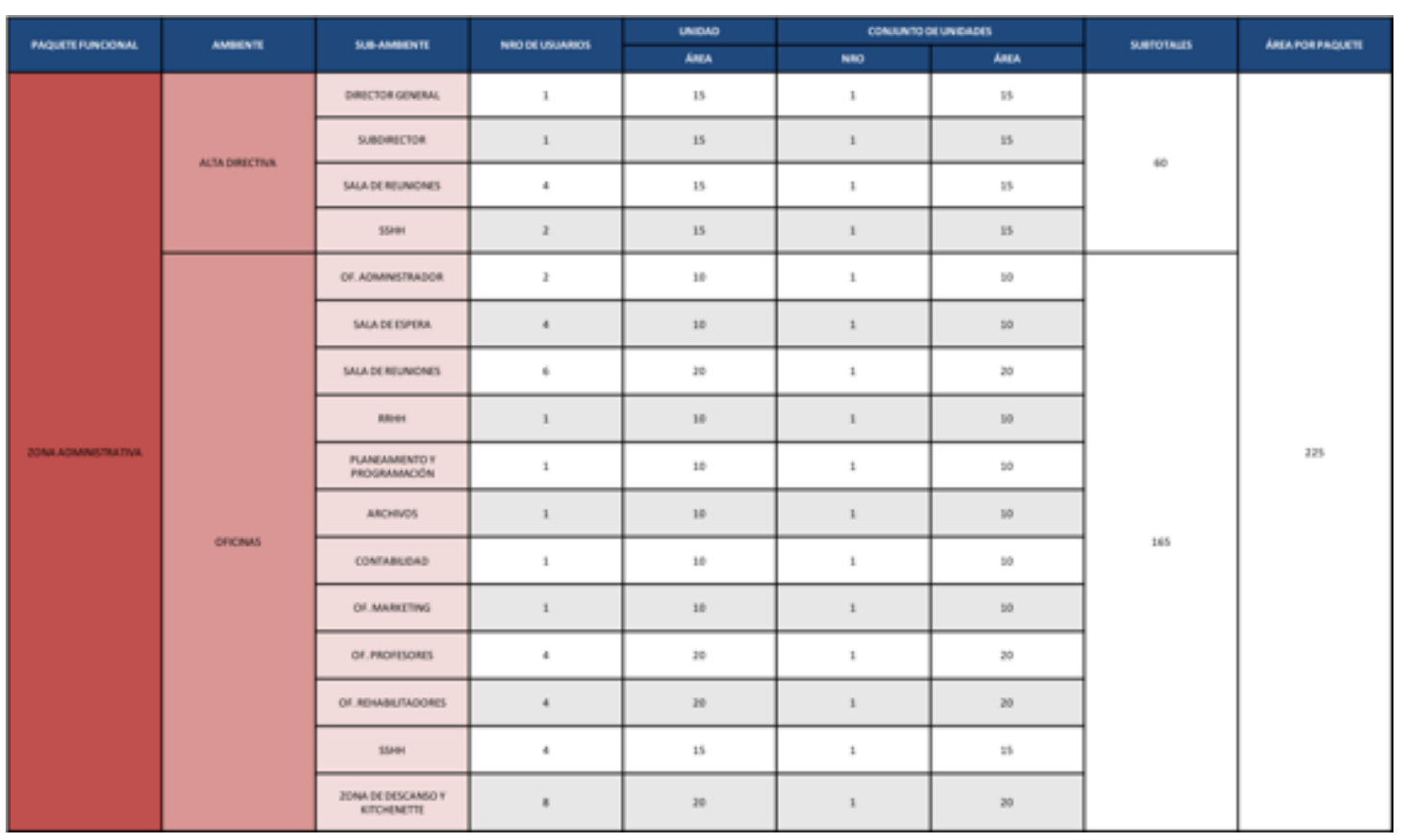




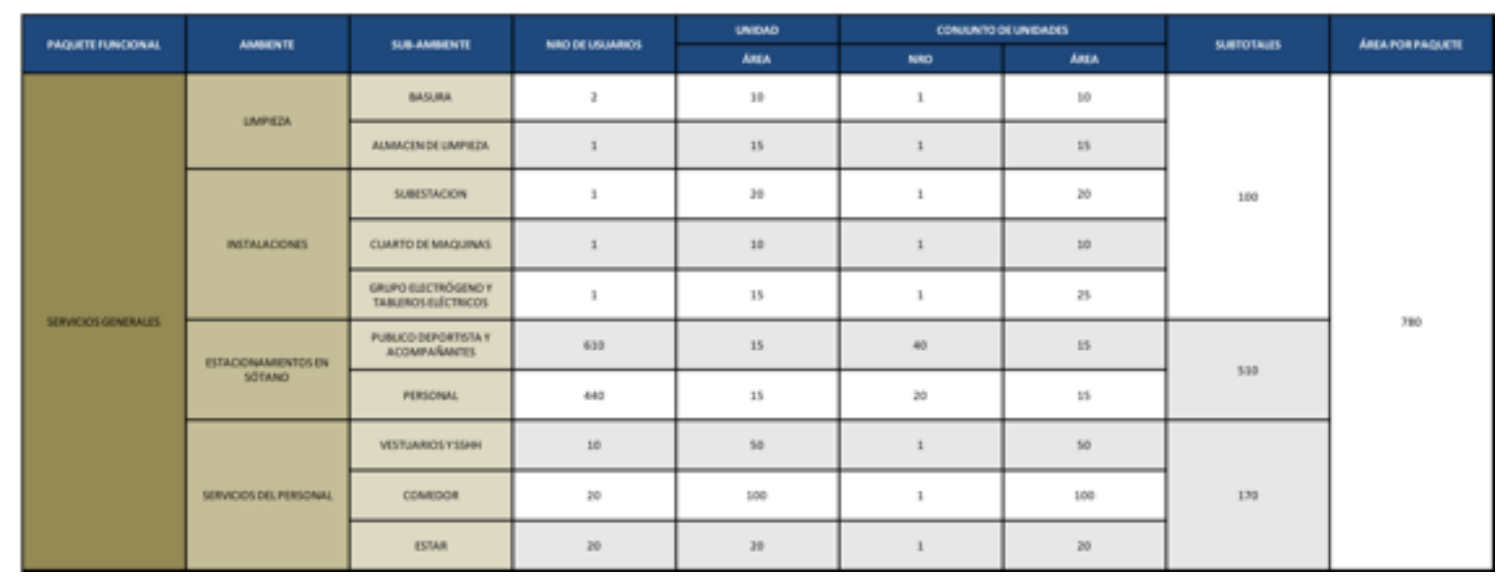

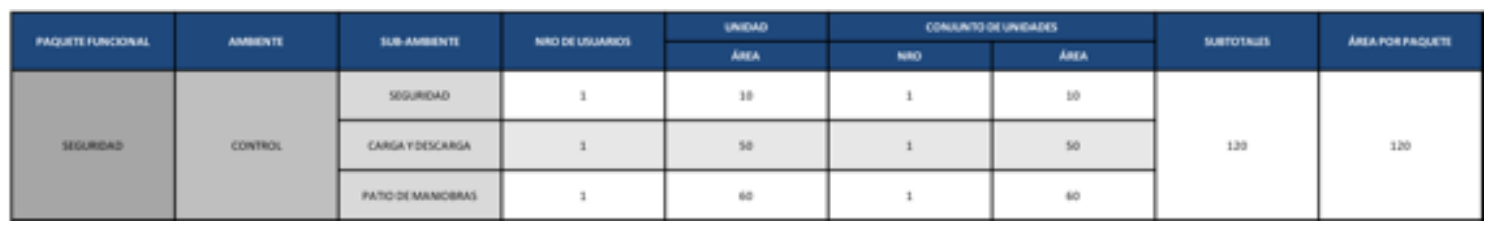

\begin{tabular}{|c|c|c|c|c|c|c|c|c|}
\hline \multirow{2}{*}{ 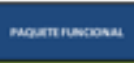 } & \multirow{2}{*}{ пемах } & \multirow{2}{*}{ 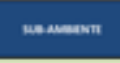 } & \multirow{2}{*}{ 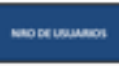 } & nowo & \multicolumn{2}{|c|}{ cencomocuneases } & \multirow{2}{*}{ nemoteas } & \multirow{2}{*}{ manonseum } \\
\hline & & & & $\operatorname{sen} x$ & $=0$ & $\operatorname{sen}$ & & \\
\hline \multirow{2}{*}{ mases. } & \multirow{2}{*}{ monowo } & weonestruear & $n$ & noso & 1 & nowe & \multirow{2}{*}{ sasena } & \multirow{2}{*}{ nasean } \\
\hline & & moses & $m$ & Noo & 1 & $n=0$ & & \\
\hline
\end{tabular}

\subsection{CUADRO DE RESUMEN DE ÁREAS POR PAQUETES FUNCIONALES Y ÁREA TOTAL CONSTRUIDA}

\begin{tabular}{|c|c|c|c|c|c|c|}
\hline \multicolumn{4}{|c|}{ CUADRO NORMATIVO } & \multicolumn{3}{|c|}{ CUADRO DE ÁREAS (m2) } \\
\hline & RÁMETROS & RNE & PROYECTO & & PARCIAL & TOTAL \\
\hline \multirow{2}{*}{\multicolumn{2}{|c|}{ 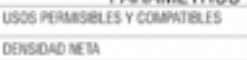 }} & DCD Y YeEChItes & pouceroentivo & Sotwo & $4500 \pi 2$ & \multirow{4}{*}{$2020072 \mathrm{mo}$} \\
\hline & & 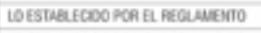 & SOO HE, Mh & $\operatorname{man} i-1$ & $605024 m 2$ & \\
\hline \multicolumn{2}{|c|}{ 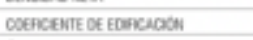 } & 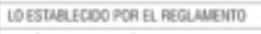 & & 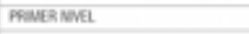 & $\operatorname{sectat} 24=0$ & \\
\hline \multicolumn{2}{|l|}{ Lashutuses } & 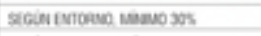 & $52 \pi$ & SEGMOO IVEl & $400024=2$ & \\
\hline \multirow[t]{3}{*}{ 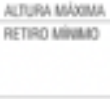 } & & 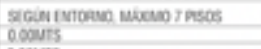 & 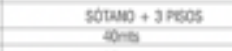 & 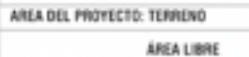 & & 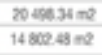 \\
\hline & monter & 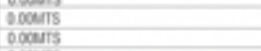 & $\operatorname{limb}_{2 k \rightarrow 0}$ & \multirow[t]{2}{*}{ 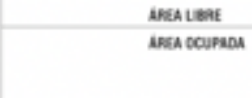 } & 1235 & \multirow{2}{*}{$1315846=2$} \\
\hline & Hastral & 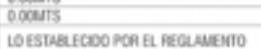 & 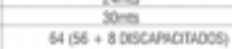 & & & \\
\hline
\end{tabular}


CAPITULO 8 EL PROYECTO CRITERIOS TECNOLOGICOS Y DE DISEÑO 


\title{
8. EL PROYECTO
}

\subsection{SINTESIS DE NECESIDADES Y PROBLEMASA RESOLVER}

\begin{abstract}
A) ENFOQUE DEL PROYECTO
El proyecto está enfocado en la cohesión social entre las personas discapacitadas y las que no lo son. El proyecto está situado donde tiene mayor demanda dentro del plan del IPD de tener un polideportivo inclusivo en el cono sur de Lima. El proyecto se ubica al lado de un vacío urbano de carácter deportivo en el distrito de Villa María del Triunfo. Se plantea diseñar un Polideportivo verdaderamente inclusivo, que sea accesible y seguro, de la mejor manera posible, basado en las necesidades analizadas y concluidas a través de esta investigación, así como la cultura, geografía, usuario, problemas sociales, topografía en Villa María del Triunfo. Para poder lograr tener un espacio que se sienta propio de las personas que lo usen.
\end{abstract}

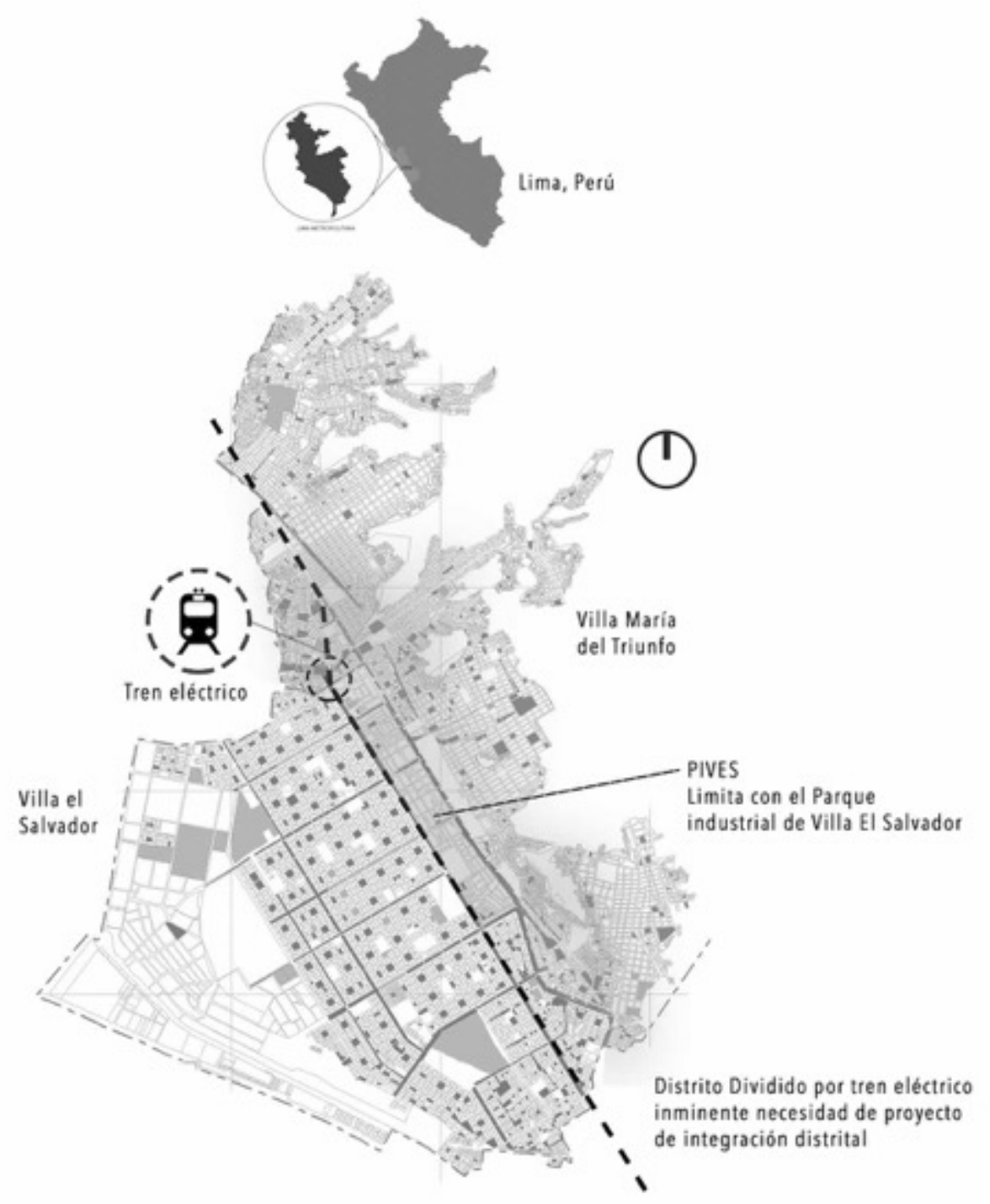




\section{B) DEFINICION DE CONCEPTOS}

Partiendo del análisis al usuario discapacitado y no discapacitado deportista y tomado en cuenta sus necesidades de movilidad y accesibilidad, se estudió el entorno, la ciudad y las variables del contexto. Se definieron los conceptos, el diseño universal y el ensamble con el entorno. El diseño universal el cual se basa en que si es completamente accesible para una persona discapacitada lo es para todos, y el ensamble con el entorno se logra tras haber analizado la ciudad, flujos y usuario. Los que sugieren una volumetría que se acomode respetando los flujos, costumbres, usos $\mathrm{y}$ visuales del terreno actualmente.
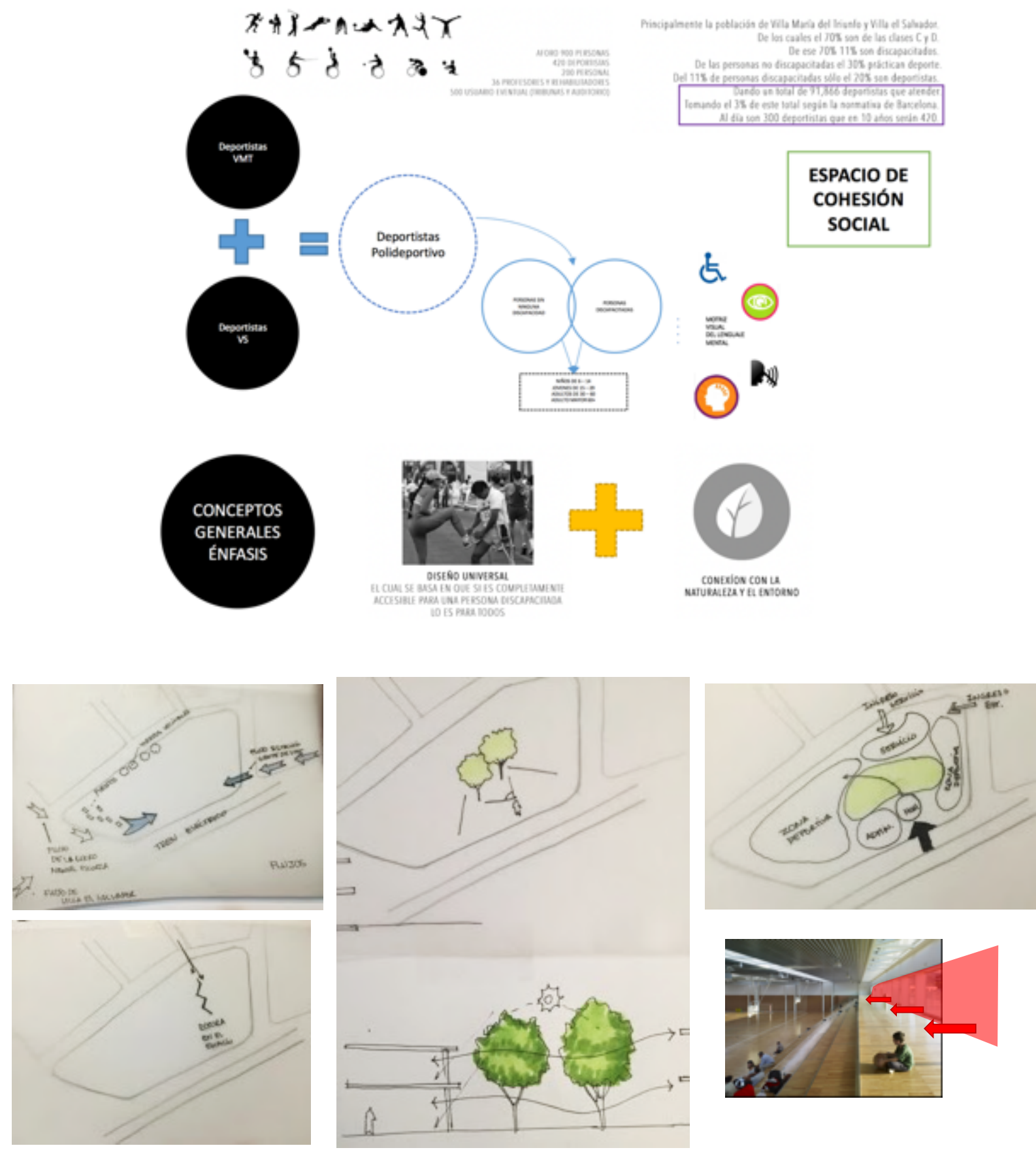


\section{C) DEFINICIÓN DE CRITERIOS ARQUITECTÓNICOS URBANOS}

Organización entorno a un centro vacío funcional central. La rampa como elemento jerarquizador, el uso de la naturaleza para crear calidad espacial y confort dentro del edificio, la conexión visual con el exterior, la agrupación del programa de una manera fluida para reducir circulaciones y la flexibilidad del espacio para maximizar la funcionalidad del polideportivo.
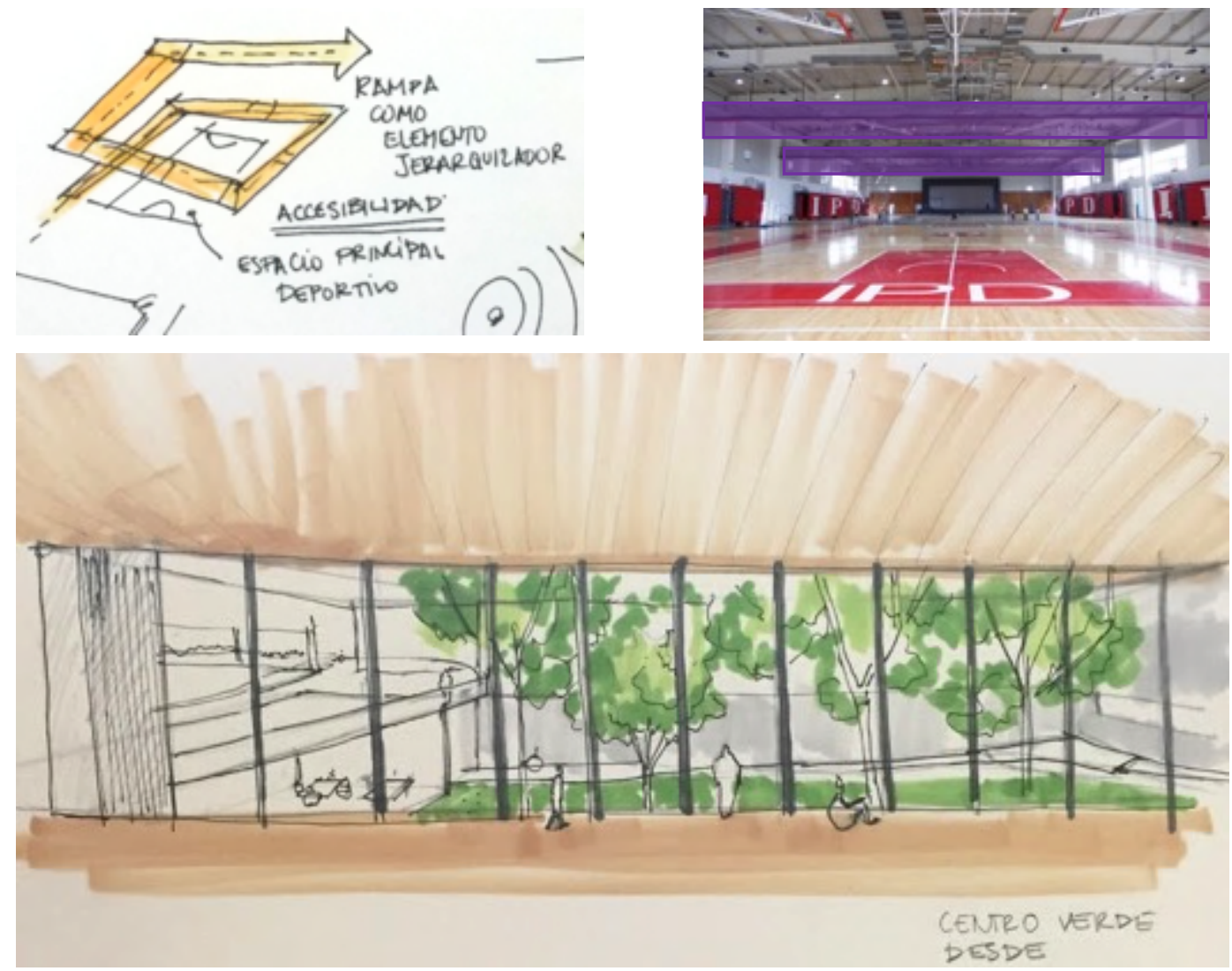

BOCETOS DEL PROCESO DE DISEÑO

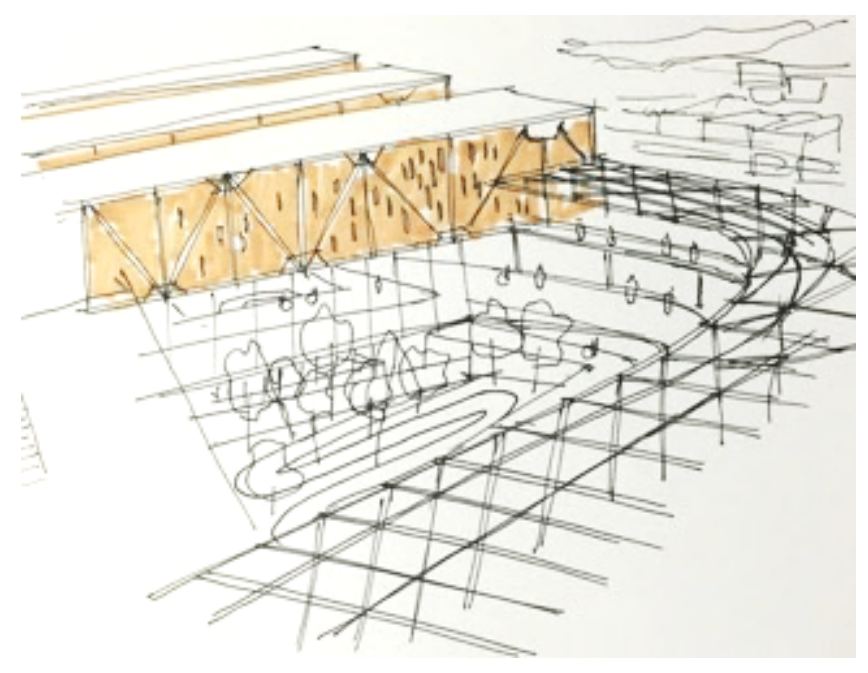




\section{D) DETERMINACIÓN DEL PROGRAMA ARQUITECTÓNICO}

Tomando en cuenta los resultados de la investigación previamente realizada, el proyecto está dividido en una zona principal, zona auxiliar, zona administrativa, zona de mantenimiento y zonas públicas e intermedias.

\section{E) PAQUETES FUNCIONALES}

Los paquetes funcionales que se organizaron entorno a este planteamiento son la zona deportiva, zona publica, servicios generales, zona administrativa y área libre. Se acceden a los diferentes niveles del proyecto a traves de rampas, ascensores y escaleras.

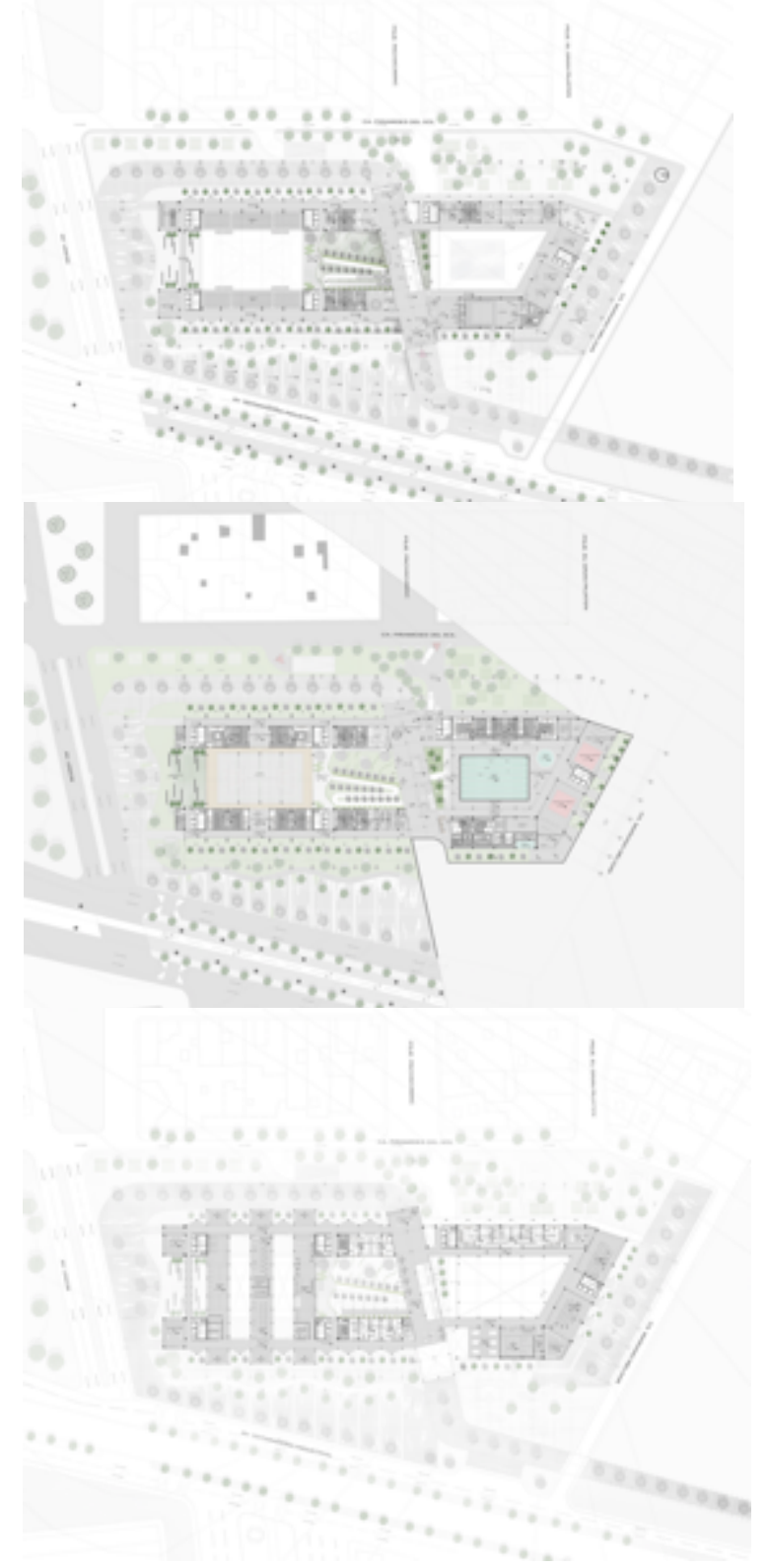




\section{F) UBICACIÓN}

El proyecto ha sido ubicado en una zona de fácil acceso para las personas discapacitadas contando con la estación Pumacahua de la Línea 1 del tren eléctrico a 100 metros del ingreso principal del edificio. El proyecto se retira en el ingreso principal para crear el espacio de encuentro necesario para la llegada a un proyecto de esta envergadura.

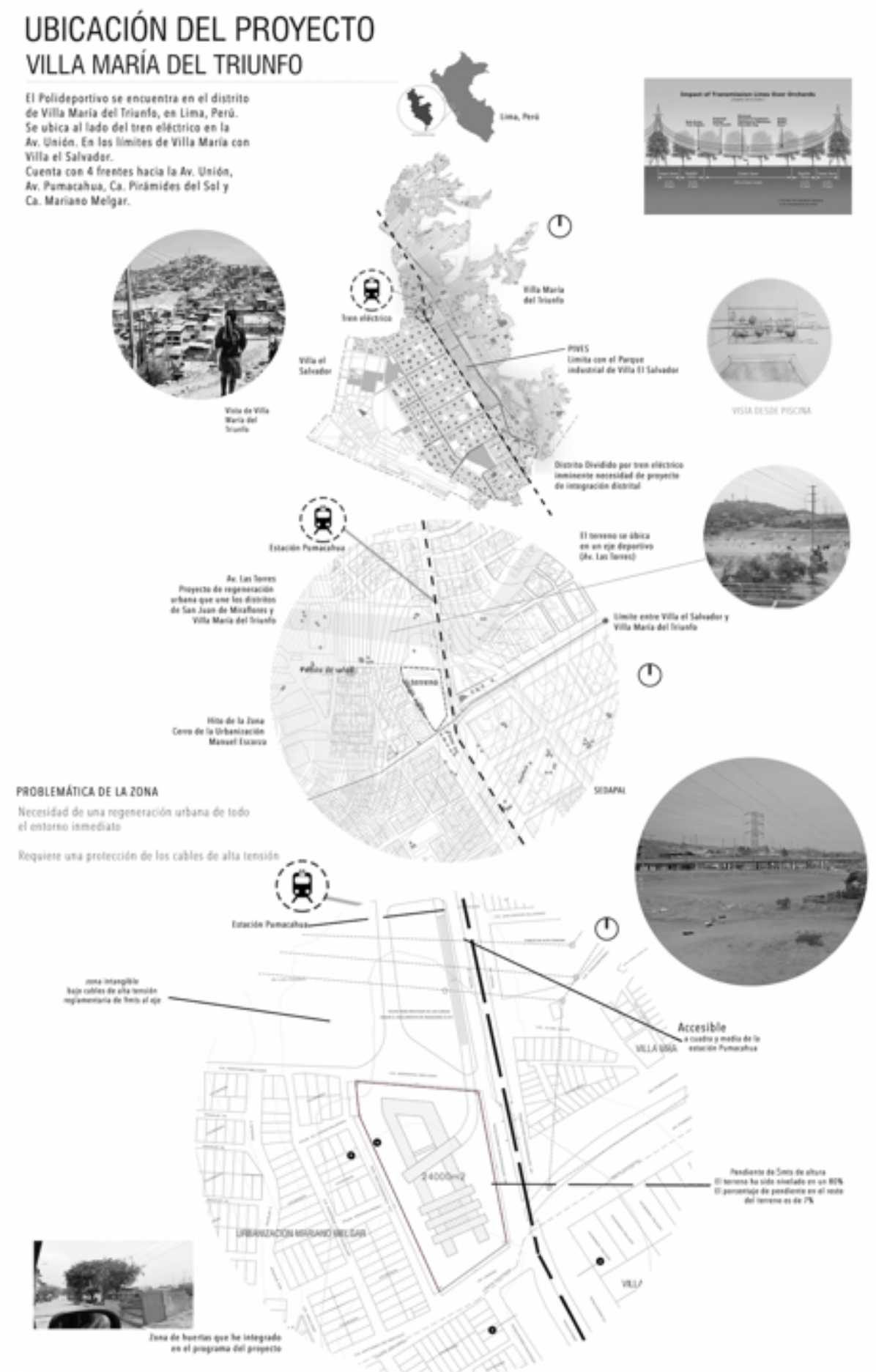




\section{G) RELACIÓN CON EL CONTEXTO}

El entorno, la llegada al proyecto y las costumbres del lugar, éstas son las 3 principales variables de la solución del proyecto. El entorno se analizó para poder lograr una volumetría que se adapte bien con el contexto y que ponga en valor las visuales y flujos de la ciudad. La llegada al proyecto desde la estación requiere un tratamiento urbano según la normativa de seguridad de instalaciones eléctricas para poder proteger a las personas de los cables de alta tensión, además el proyecto se retira los $9 \mathrm{mts}$ a eje de las torres creando la plaza principal de llegada al proyecto. También fue importante respetar la identidad de la zona, por lo que los puestos comerciales se conservan y se estandarizan y se potencia las huertas frente a las viviendas. Se mantiene el flujo peatonal actual, y los puestos comerciales se estandarizan y se potencian.

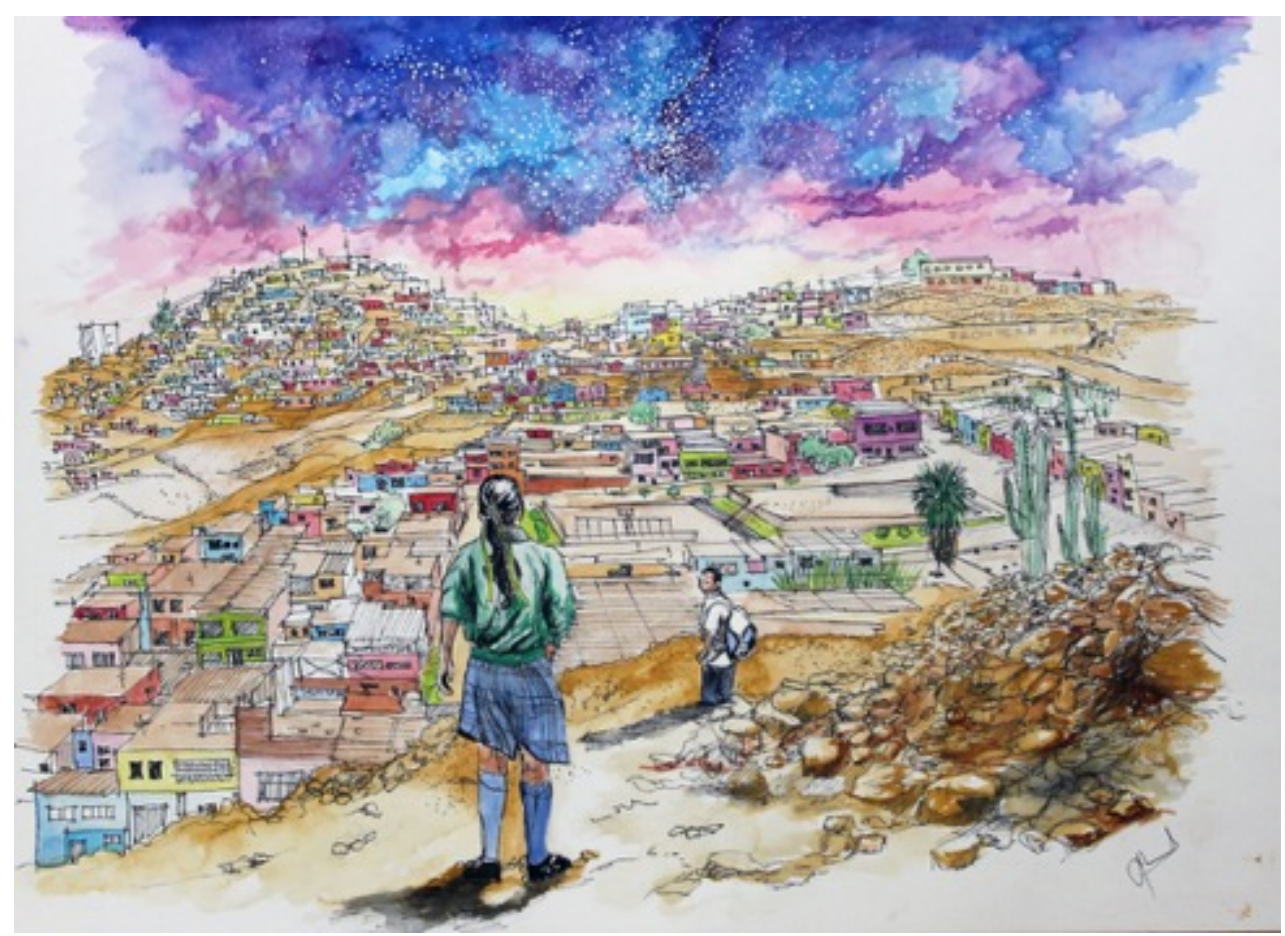

BOCETO HACIA CERRO DEL PROYECTO Y TERRENO LEVANTADO AL INVESTIGAR LA ZONA 


\section{H) SISTEMA CONSTRUCTIVO}

Está resuelto con una estructura aporticada de concreto con losa colaborante y placas. El último nivel tiene una solución de vigas edificio o edificio puente.

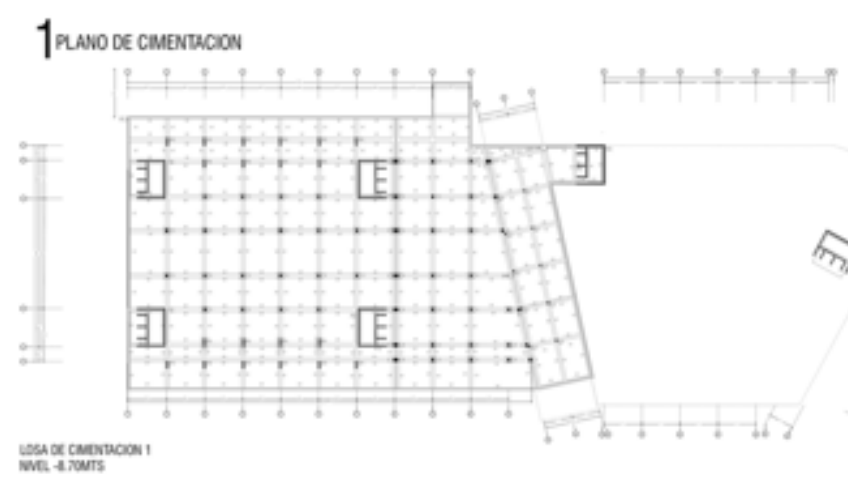

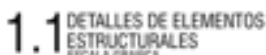
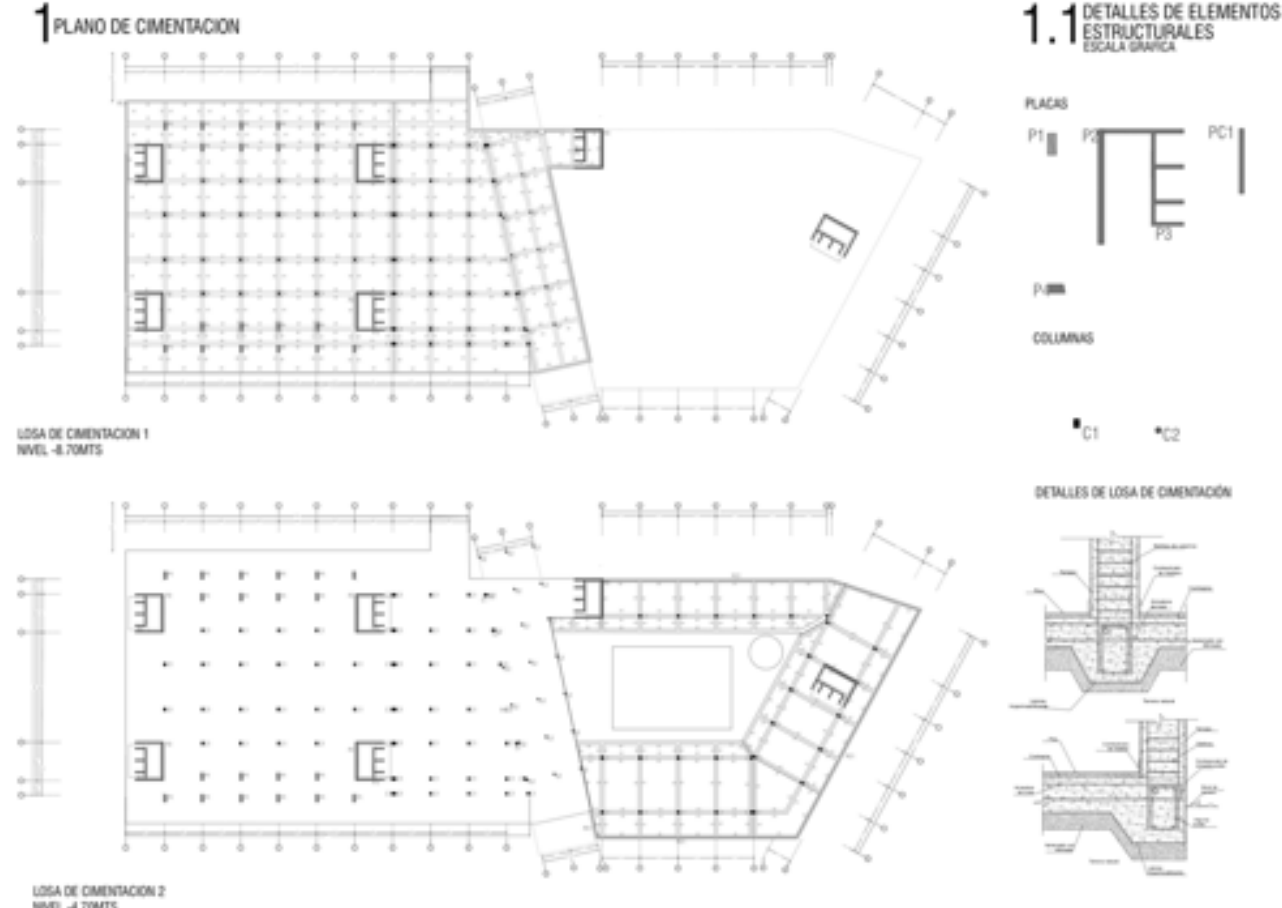

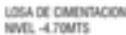

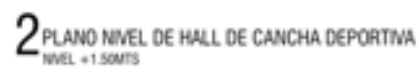

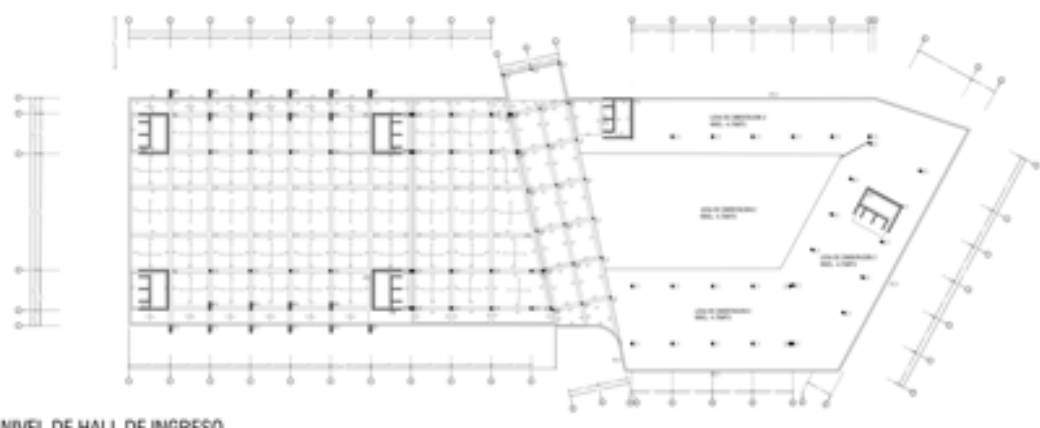

3 PLANO NNEL DE HaLL DE INGRESO

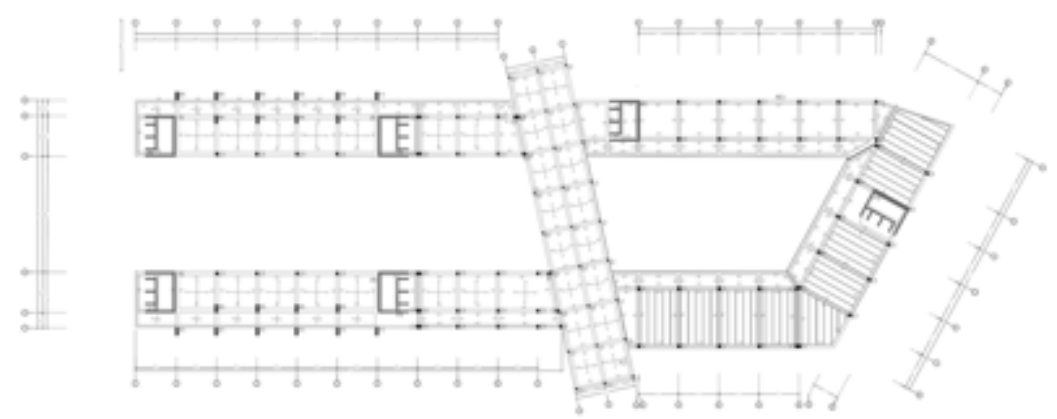

PLANOS DE ESTRUCTURAS 


\section{I) COMPOSICIÓN Y ESPACIOS ARQUITECTÓNICOS}

La calidad espacial se ve enriquecida por el centro vacío del proyecto donde se encuentra la rampa como elemento arquitectónico que es la que da acceso a todos los niveles y funciones del edificio, en donde también se encuentran funciones como la piscina, la circulacion central principal, el atrio verde y el escenario deportivo. El criterio espacial se da a través de dobles y triples alturas, conexión entre niveles y se crea fluidez espacial para una circulación simple que facilite la independencia del usuario discapacitado.
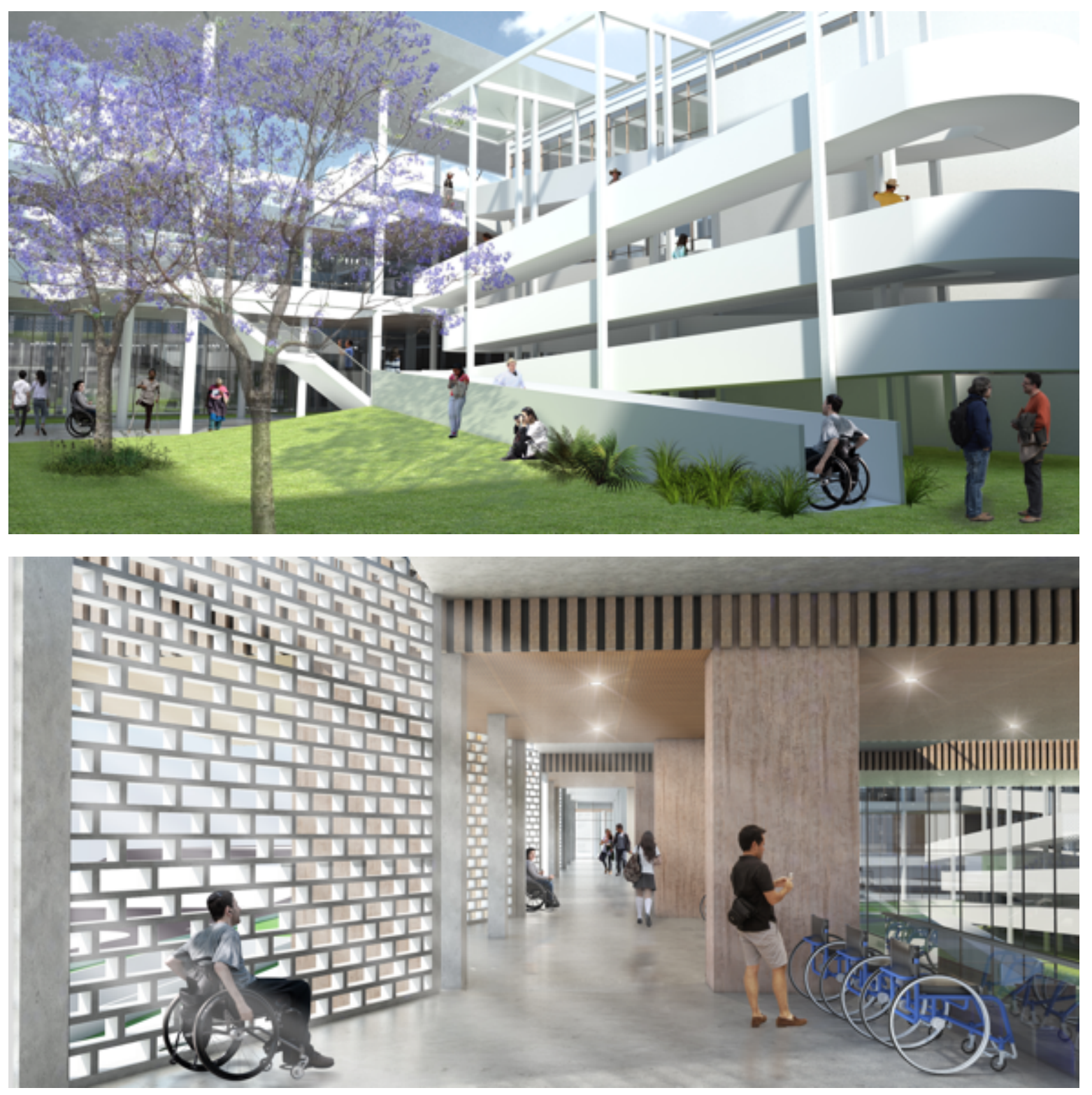

VISTAS INTERIORES, VISTA DE RAMPA CENTRAL Y VISTA DE EFECTO DE LUZ AL INTERIOR DEL ESCENARIO DEPORTIVO. 


\section{J) CONCLUSIONES}

En Lima existe un déficit de espacios públicos recreativos deportivos. Peor aún si se habla de espacios deportivos accesibles. El problema principal es la falta de instalaciones donde toda persona, en el estado físico en el que se encuentre, pueda practicar todo tipo de deporte de acuerdo a sus necesidades. Las instalaciones deportivas actuales son inaccesibles en todo sentido. La mayoría no se encuentran en vías principales y la manera de llegar a ellos no es posible para todos por la falta de redes inclusivas de transporte público. No son accesibles tampoco funcionalmente, están diseñados solo para un grupo de la población porque el 11\% (personas con algún tipo de discapacidad) se encuentra actualmente ignorado. Elijo Lima Sur porque tiene los distritos con mayor índice de discapacitados y porque vi que existe una directa relación entre discapacidad y pobreza. Por lo tanto, planteo que el proyecto tenga un eje de activación a nivel interdistrital que ayudaría con los problemas de inseguridad del distrito. Se plantea diseñar un Polideportivo verdaderamente inclusivo ecosostenible que sea accesible y seguro, basado en las necesidades analizadas y concluidas a través de esta investigación; así como la cultura, geografía, usuarios, problemas sociales y topografía en Villa María del Triunfo para lograr tener un espacio que se sienta propio de la comunidad.

La importancia del escenario polideportivo es clave para la jerarquización del edificio, por lo que una gran altura, que además es funcional, ayuda con el ingreso de luz y al confort del ambiente. En el aspecto tecnológico se planteó solucionarlo con puentes edificio y losas colaborantes.

Los atrios ayudan al mejor flujo del viento y mejoran el confort en el edificio naturalmente. Al representar un aspecto clave de la calidad espacial, es importante diseñar tomando en cuenta un centro verde para el Polideportivo. 


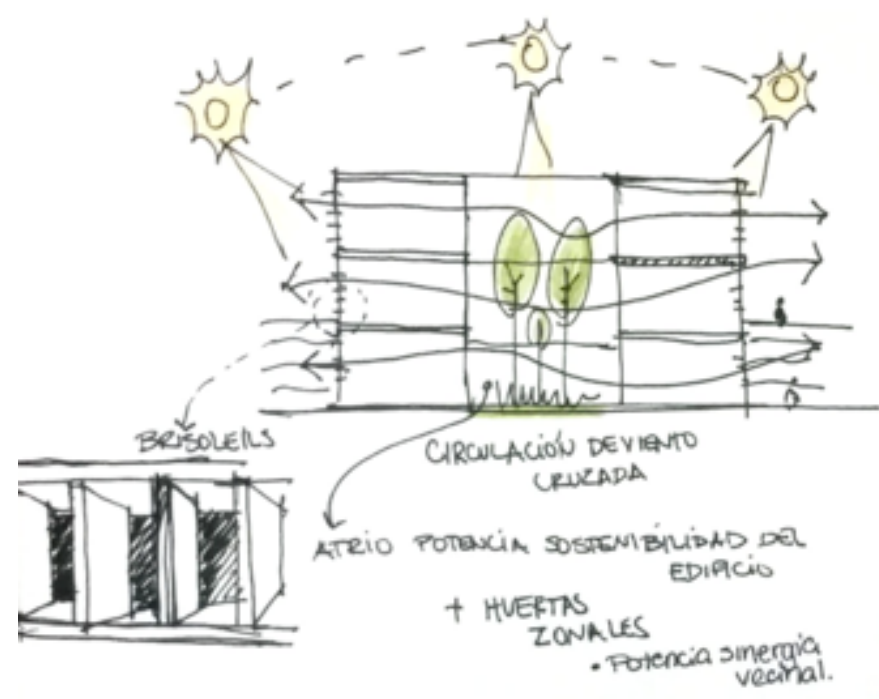

\section{BOCETO DE ANALISIS DE CONCEPTOS}

El deporte para todos es básico y si tienes una discapacidad más aún, porque no solo se trata de salud física, se trata de una superación mental, algo que te hace sentir fuerte y vivo. Por eso decidí hacer mi tesis sobre este tema, porque considero que necesitamos ser más humanos al diseñar, ponernos en el lugar de los demás. He buscado honrar el propósito en cada centímetro de este edificio.

El diseño universal se basa en el concepto de que, si funciona para una persona discapacitada, funciona para todos. Si se diseña tomando esto en cuenta desde el comienzo, ayudamos bastante a las personas. Se les discrimina con un escalón, con un pasadizo de $70 \mathrm{~cm}$, con un giro insuficiente, con una rampa con una pendiente imposible de subir, etc.

¿Porqué si se puede diseñar conscientemente, no hacerlo? La independencia es crucial para todos, en especial para una persona discapacitada, creemos espacios donde las variables de diseño no solo se basen en función, contexto y forma. Debe ser siempre verdaderamente inclusivo. 
VISTAS DEL PROYECTO:
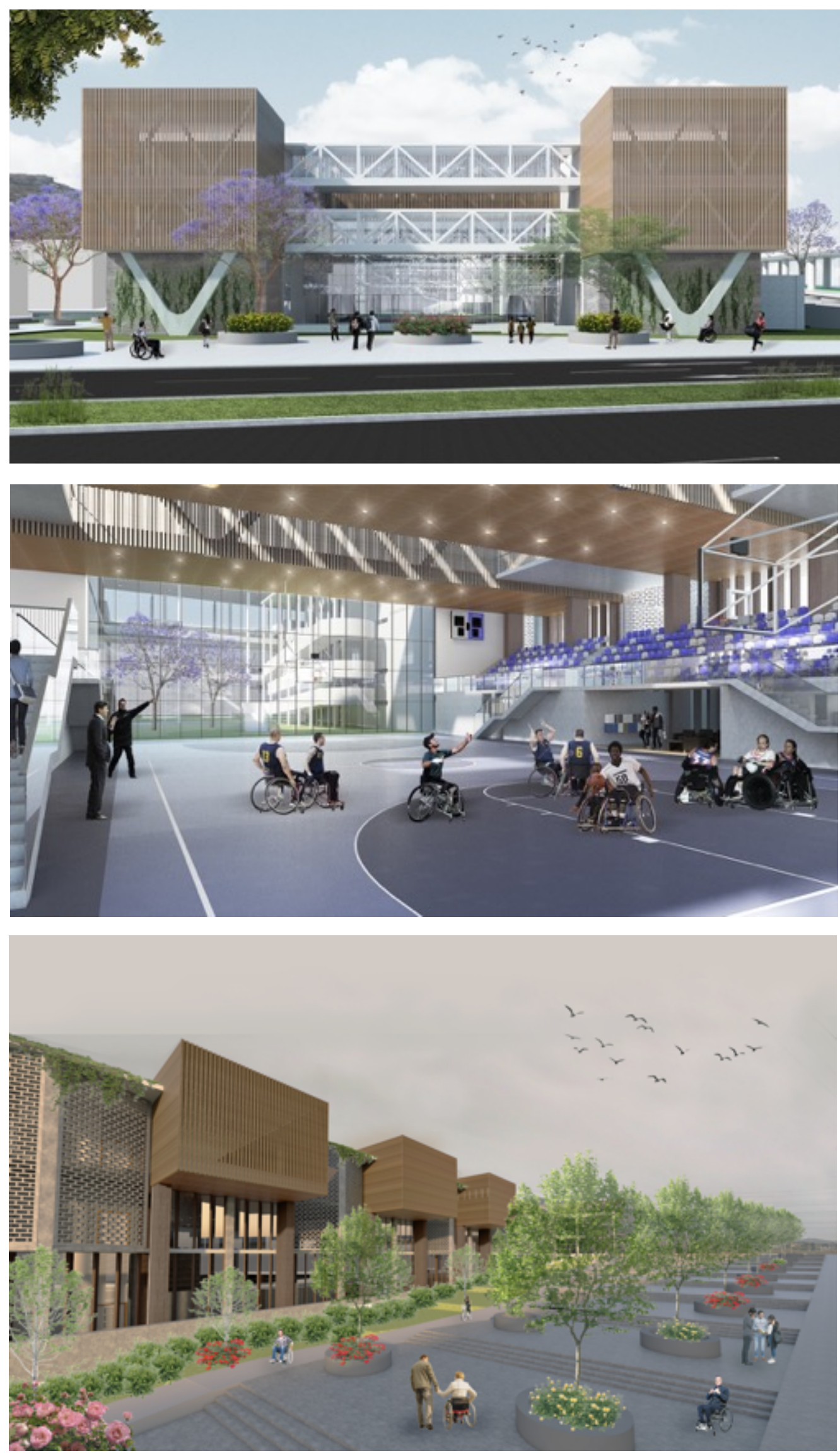
9. CONCLUSIONES 


\section{Conclusiones}

\section{CAPITULO 1:}

En Lima existe un déficit de espacios públicos recreativos deportivos. Peor aún si se habla de espacios deportivos accesibles. El problema principal es la falta de instalaciones donde toda persona, en el estado físico en el que se encuentre, pueda practicar todo tipo de deporte de acuerdo a sus necesidades. Las instalaciones deportivas actuales son inaccesibles en todo sentido. La mayoría no se encuentran en vías principales y la manera de llegar a ellos no es posible para todos por la falta de redes inclusivas de transporte público. No son accesibles tampoco funcionalmente, están diseñados solo para un grupo de la población porque el 11\% (personas con algún tipo de discapacidad) se encuentra actualmente ignorado. Elijo Lima Sur porque tiene los distritos con mayor índice de discapacitados y porque vi que existe una directa relación entre discapacidad y pobreza. Por lo tanto, planteo que el proyecto tenga un eje de activación a nivel interdistrital que ayudaría con los problemas de inseguridad del distrito. Se plantea diseñar un Polideportivo verdaderamente inclusivo eco-sostenible que sea accesible y seguro, basado en las necesidades analizadas y concluidas a través de esta investigación; así como la cultura, geografía, usuarios, flora y fauna, problemas sociales y topografía en Villa María del Triunfo para poder lograr tener un espacio que se sienta propio de las personas que lo usen, y que a su vez logre reducir la inseguridad actual del distrito.

\section{CAPITULO 2:}

La arquitectura deportiva está directamente ligada al desarrollo del deporte. Cuando este logra ser importante a nivel general de la población evoluciona y genera la necesidad de un desarrollo arquitectónico como respuesta a estas necesidades. El diseño de instalaciones deportivas cubre una inmensa cantidad de variaciones. Distintos programas, presupuestos, usuarios, culturas y más aspectos que producen diferentes respuestas de la misma tipología. Sin embargo, y tras haber explicado la evolución social histórica de la misma, algunas tipologías actuales pueden proveer algo de información acerca de estrategias de diseño. Las 4 estrategias prominentes son: Infraestructura, Contenedores decorados, Experiencia directa, Movimiento e Inmersión en el paisaje. Mientras fue 
evolucionando el concepto de arquitectura deportiva se fue incluyendo a usuarios discapacitados, ya que en un primer momento no fueron tomados en cuenta.

En el mundo las instalaciones deportivas ya son cada vez más accesibles, lo mismo no sucede en el Perú. Se puede evidenciar que el usuario discapacitado no es tomado en cuenta; es completamente ignorado en el diseño. A veces hay una intención de integrarlos al programa, pero es algo posterior al diseño. No es una premisa más que haría que el funcionamiento del edificio sea accesible y, por lo tanto, eficiente.

En tanto a la historia de Villa el Salvador y Villa María del Triunfo, puedo concluir que tienen una población luchadora y que quieren a su distrito con alta capacidad de organización que de ser potenciada podrían ser los mejores distritos de Lima.

\section{CAPITULO 3:}

Los proyectos analizados fueron Baldinger Architectural Studio Sport Center, La Videna de José Bentín, Arteixo Sport Center y Los Escenarios Deportivos de Medellín.

De estos, resalto conceptos que me parecen interesantes. De Baldinger destaco el concepto de usar la rampa como elemento arquitectónico plástico que resalta el espacio principal del Polideportivo. En cuanto a La Videna, es interesante el concepto de flexibilidad de ambientes lo que sería conveniente utilizar en el Polideportivo porque hace más eficiente el uso de los ambientes. En Arteixo Sport Center aprovechan la pendiente del terreno para integrar en 2 niveles al proyecto con la calle, creando espacios intermedios entre el proyecto y la vía pública. En el caso de mi terreno, sucede lo mismo porque tiene una pendiente que sugiere 2 entradas al polideportivo uno a nivel $0 \mathrm{y}$ otro a menos 3, por lo que podría tratarse con esta estrategia de integración calle-proyecto. En los Escenarios Deportivos de Medellín es importante rescatar el concepto de topografía entre cerros. Comparándolo con mi terreno también me ubico entre 2 cerros por lo que podría servir este concepto de topografía intermedia. Además, tiene un sistema de agrupaciones que organiza el programa. Así también, el movimiento de estos techos hace que sea controlado el ingreso de luz solar.

\section{CAPITULO 4:}

En este capítulo se analizó las características del lugar a nivel distrital y así poder elegir, a partir de estas condicionantes, el mejor terreno disponible. Se elige este terreno porque tiene zonificación OU, la orientación del sol es favorable, la topografía y los hitos de la 
zona. Principalmente por su accesibilidad, la cercanía a la estación Pumacahua del tren eléctrico favorece al usuario discapacitado. Así también, se elige este terreno porque tiene $26000 \mathrm{~m} 2$, tamaño apropiado para este proyecto. Además, porque es posible arborizar el eje al que está conectado en 2 direcciones, siendo el vértice en esta " $T$ " de vacío urbano, la que contribuirá a mejorar la calidad del aire de los distritos de Villa María y Villa el Salvador al igual que el clima.

\section{CAPITULO 5:}

En este capítulo analizamos los condicionantes importantes que deben ser tomados en cuenta para el diseño del polideportivo inclusivo y definimos una idea de cómo se va a lidiar con ellos. El más fuerte es la existencia de torres de alta tensión cerca del terreno. Estos cables cruzan el terreno en un tramo. Se retirarían los $9 \mathrm{mts}$ reglamentarios al eje de ellos y no se construiría en esa zona para evitar problemas. Además, se buscaría colocar cerca de esa zona el programa menos público del edificio. En cuanto al asoleamiento del edificio se orientaría inclinado de manera que el ingreso del sol sea indirecto, además del uso de brisoleils. Con respecto a la topografía del terreno, este cuenta con 3 metros de pendiente por lo que se plantean 2 ingresos: uno a $-3 \mathrm{mts}$ y uno a nivel $0 \mathrm{mts}$. El suelo es árido, lo que condiciona el diseño de las áreas verdes por lo que se utilizarían plantas que crezcan naturalmente en suelos áridos, como palmeras. Existe un cruce vehicular bajo el tren que tiene que ser controlado y ser parte del diseño de las zonas adyacentes al proyecto, así como las barandas que limitan el terreno de forma abrupta e inapropiada. En el aspecto de la basura, se haría una limpieza de la zona. Las vías no consolidadas, serían diseñadas. El comercio ambulatorio existente en la zona sur del terreno será integrado al proyecto. Le daría un espacio en el programa para consolidar sus negocios, y una plaza con puestos estandarizados para mantener las costumbres, pero controlando el aspecto del proyecto. La contaminación sonora es leve a pesar de que la zona se ubica en una avenida y cercana al tren, el flujo es leve, el tráfico es zonal y fluido. Ordenaría el programa de manera que los espacios que requieran más silencio se ubicaran en la zona opuesta al tren. Es importante también respetar las vistas hacia el cerro que tiene el lado oeste del terreno. 


\section{CAPITULO 6:}

El usuario de este polideportivo inclusivo son las personas de Villa el Salvador y Villa María del Triunfo. El total de personas discapacitadas en Villa el Salvador es de 40417 y el total de personas discapacitadas en Villa María del Triunfo es de 39133. De estas, el $18,9 \%$ son niños, el $20 \%$ jóvenes, el $36,1 \%$ adultos y el $25 \%$ adultos mayores. Haciendo un total de TOTAL DE 723,123 usuarios entre ambos distritos. Las personas discapacitadas son el $11 \%$ del total (79,550 personas). Las personas que practican deporte actualmente representan el $35 \%$ de la población sin ninguna discapacidad. El 20\% de los discapacitados practica deporte. El usuario total por lo tanto es de 225,277 personas sin ninguna discapacidad y 15,910 personas discapacitadas haciendo un total de 241,187 usuarios potenciales del polideportivo. (Basado en datos de Lima como vamos del 2014)

CONSIDERANDO QUE EL USUARIO FRECUENTE SEA SOLO EL 5\% DE LAS PERSONAS QUE PRACTICAN DEPORTE, EL USUARIO DEL POLIDEPORTIVO INCLUSIVO SOSTENIBLE DE LIMA SUR SERÍA 11260 PERSONAS AL AÑO, EN 10 AÑOS SERÍAN 14060 PERSONAS.

Clasifico a los usuarios por edades, discapacitados o no porque, si funciona para personas discapacitadas, funciona para todos. De esta manera no existe discriminación en el diseño y trato a ambos grupos de personas como un todo desde la definición del usuario.

Al mismo tiempo podría atender a 1056 personas (AFORO), las personas se quedan un promedio de 3 horas entrenando lo que permite 4 rotaciones de 1050 personas, lo que dejaría que atienda a 4200 personas diario, 29,400 semanalmente, 882,000 al mes.

\section{CAPITULO 7:}

El área total del terreno es de $26000 \mathrm{~m} 2$.

Si se le resta el $72.3 \%$ de área libre quedan $13156 \mathrm{~m} 2$. El edificio tiene un sótano de $4500 \mathrm{~m} 2$, primer nivel de $6800 \mathrm{~m} 2$, segundo nivel de $4500 \mathrm{~m} 2$ y tercer nivel de $4400 \mathrm{~m} 2$. Resultando en un área total de $20240 \mathrm{~m} 2$. Restando el porcentaje de muros y circulación el proyecto tiene $13,157 \mathrm{~m} 2$ de área ocupada. Sabiendo que mi usuario es de 1056 personas diarias base a este, me quedaría espacio para albergar al usuario eventual que acompaña al deportista o el usuario que asiste a los espectáculos deportivos. 


\section{CAPITULO 8}

En Lima existe un déficit de espacios públicos recreativos deportivos. Peor aún si se habla de espacios deportivos accesibles. El problema principal es la falta de instalaciones donde toda persona, en el estado físico en el que se encuentre, pueda practicar todo tipo de deporte de acuerdo a sus necesidades. Las instalaciones deportivas actuales son inaccesibles en todo sentido. La mayoría no se encuentran en vías principales y la manera de llegar a ellos no es posible para todos por la falta de redes inclusivas de transporte público. No son accesibles tampoco funcionalmente, están diseñados solo para un grupo de la población porque el 11\% (personas con algún tipo de discapacidad) se encuentra actualmente ignorado. Elijo Lima Sur porque tiene los distritos con mayor índice de discapacitados y porque vi que existe una directa relación entre discapacidad y pobreza. Por lo tanto, planteo que el proyecto tenga un eje de activación a nivel interdistrital que ayudaría con los problemas de inseguridad del distrito. Se plantea diseñar un Polideportivo verdaderamente inclusivo eco-sostenible que sea accesible y seguro, basado en las necesidades analizadas y concluidas a través de esta investigación; así como la cultura, geografía, usuarios, problemas sociales y topografía en Villa María del Triunfo para lograr tener un espacio que se sienta propio de la comunidad.

La importancia del escenario polideportivo es clave para la jerarquización del edificio, por lo que una gran altura, que además es funcional, ayuda con el ingreso de luz y al confort del ambiente. En el aspecto tecnológico se planteó solucionarlo con puentes edificio y losas colaborantes.

Los atrios ayudan al mejor flujo del viento y mejoran el confort en el edificio naturalmente. Al representar un aspecto clave de la calidad espacial, es importante diseñar tomando en cuenta un centro verde para el Polideportivo. 


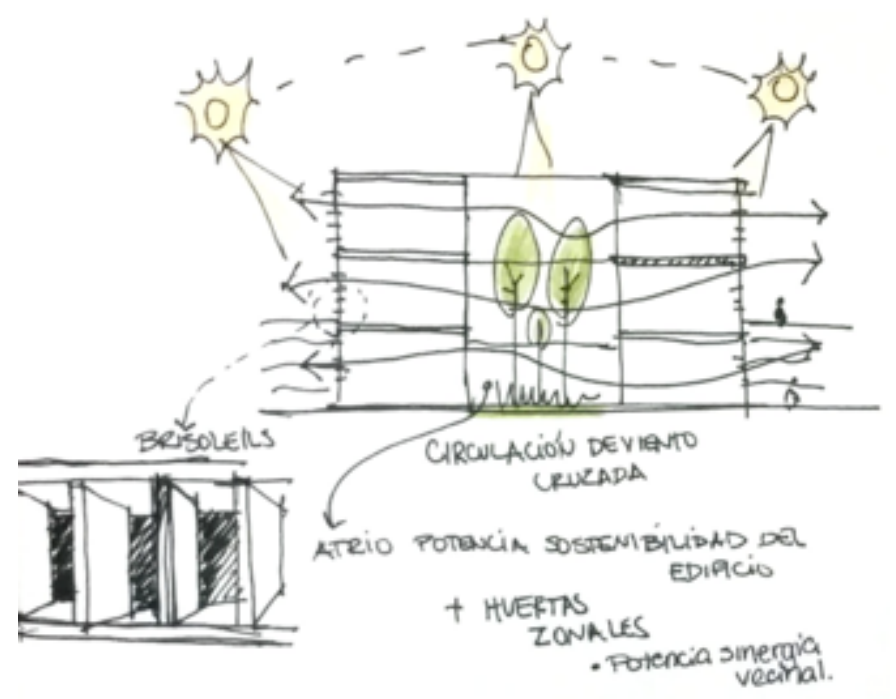

\section{BOCETO DE ANALISIS DE CONCEPTOS}

El deporte para todos es básico y si tienes una discapacidad más aún, porque no solo se trata de salud física, se trata de una superación mental, algo que te hace sentir fuerte y vivo. Por eso decidí hacer mi tesis sobre este tema, porque considero que necesitamos ser más humanos al diseñar, ponernos en el lugar de los demás. He buscado honrar el propósito en cada centímetro de este edificio.

El diseño universal se basa en el concepto de que, si funciona para una persona discapacitada, funciona para todos. Si se diseña tomando esto en cuenta desde el comienzo, ayudamos bastante a las personas. Se les discrimina con un escalón, con un pasadizo de $70 \mathrm{~cm}$, con un giro insuficiente, con una rampa con una pendiente imposible de subir, etc.

¿Porqué si se puede diseñar conscientemente, no hacerlo? La independencia es crucial para todos, en especial para una persona discapacitada, creemos espacios donde las variables de diseño no solo se basen en función, contexto y forma. Debe ser siempre verdaderamente inclusivo. 
10. BIBLIOGRAFIA 


\section{Bibliografía}

1. (2011) SEGUNDO INFORME EVALUANDO LIMA, Lima, Perú

2. (2015) STEREO VILLA - Aprueban convenio con IPD para la construcción de un polideportivo Lima, Perú. http://stereovilla.pe/aprueban-convenio-con-ipdpara-construcción-de-polideportivo/

3. (2006) BROTO, Carlos, Arquitectura Deportiva, Santiago, Chile.

4. (2012) Sports Structures and Facilities (http://encyclopedia2.thefreedictionary.com/Sports+Structures+and+Facilities)

5. (2015) LERTORA, Giancarlo - Entrevista en necesidades de la persona discapacitada

6. (2004) MCLENNAN, Jason F. "The Philosophy of sustainable design"

7. (2001) Speech at the EnvironDesign Conference

8. (2009) YEANG, Ken, SPECTOR, Arthur, GREEN DESIGN From theory to practice, Black Dog, London UK

9. (2011) HOLZ, Heather, Sensory Architecture : Redefining How One Interprets Space, Chicago

10. (2015) ARCHITECTS OF AIR, Luminarium, Hong Kong (http://www.architectsof-air.com/the-experience.html)

11. (2011).OLIVA, Jairon, Arquitectura inclusiva hacia personas con discapacidad. UNI

12. (2015) ARCHDAILY-Baldinger Architectural Studio, "Sport and Fitness for the disabled"

13. (2005) VARCARCE GARCIA, Amparo - "Manual para un entorno accesible" MTAS España 
14. Mapa del Perú

15. Plano del distrito de Villa el Salvador

16. Plano de Lima

17. (2012) - INEI “¿Cómo vamos en Seguridad Ciudadana?” - Lima, PE

18. (2015) - GOOGLE MAPS, Vista de Villa el Salvador

19. (2011) -JIMENEZ, Carlos- Nuevas Instalaciones del Tren Eléctrico - RPP- Lima, Perú

20. (2005) BROTO, Carles “Arquitectura para el deporte” - Cartoné, Santiago, Chile

21. (2006) LEONARD, John "Architecture and Sport" - Architectural Research Melbourne, Australia

22. (2008) DESARROLLO PERUANO BLOG - “Lima postulara para ser sede de Panamericanos del 2015” - Lima, Perú

23. (2012) GHINO "Deportes que practicaban los incas" - Historia y Cultura Peruana - Lima, Perú

24. (2008) DESARROLLO PERUANO BLOG - “ Lima postulara para ser sede de Panamericanos del 2015” - Lima, Perú

25. (2011) Lima la Única - El Hipódromo de Santa Beatriz - Lima, Perú

26. (2013) ECURED - Hipódromo de San Felipe - Lima, Perú

27. (2005) HIPODROMO DE MONTERRICO, Historia, Lima, Perú

28. (2005) HIPODROMO DE MONTERRICO, IPD, Lima, Perú

29. (2014) ESPACIMIENTO, Campos deportivos Villa Deportiva Nacional http://www.deperu.com/esparcimiento/campos-deportivos/villa-deportivanacional-videna-5323

30. (2011) MUSS, Cosas cotidianas, La Videna San Luis https://cositascotidianas.wordpress.com/2011/05/08/la-videna-de-san-luis 


\section{COLISEO DIBOS}

32. (2015) FRANK, Tim, NESPAGEDESIGNER, Infografía del Estadio Nacional

33. (2015) ALTO EFECTO, Infografía, Cosapi

34. (2014) GRUPO 1 - TALLER 7 - MOSER AMICO (ESPEJO, FELIPA, CABEJO, TELLO, LERTORA, OSORES, RAMOS, SANCHEZ, LOPEZ, HORNA, BERROCAL) - "Diagnóstico de Villa el Salvador" - Facultad de Arquitectura UPC, Lima, Perú.

35. (2008) MURILLO, Rosario - La inclusión de las personas con discapacidad, PROPOLI, Lima, Perú

36. (2005) SANTOS, Juan José, Varios Autores, Manual para un Entorno Accesible, Novena Edición, Gráficas Caro, España

37. (2015) MORSEY, Universal Design: The Next Step in the Equal-Access City Jackson College of Urban Planning and Public Affairs, University of Illinois at Chicago

38. (1997) State Center for Universal Design

39. (2014) GUTIERREZ. Eduardo - ARQUITECTURA SUSTENTABLE

40. (2002) PLAZOLA, Alfredo - Enciclopedia de Arquitectura - Editorial Limusa S.A.

41. LAND ECONOMICS SOCIETY, PHOENIX CHAPTER (2015) - Disability Empowerment Center - (16 de setiembre del 2015) - http://www.laiphx.org/events/event_details.asp?id=599165

42. ARCHDAILY (2015) - Sport and Fitness center for disabled People - (16 de setiembre del 2015) - http://www.archdaily.com/587732/sport-and-fitness-centerfor-disabled-people-baldinger-architectural-studio

43. BALDINGER ARCHITECTURAL STUDIO (2015) - Raúl García Photography - (16 de setiembre del 2015) - https://www.facebook.com/BaldingerArchitectural-Studio-323193866225/timeline/ 
44. SABMAGAZINE (2011) - Sustainable Design of Recreation Facilities- (16 de setiembre del 2015) - http://www.sabmagazine.com/blog/2011/04/12/sustainabledesign-of-recreation-facilities/

45. LLOYD MEDIA GROUP (2010) - Disability Empowerment Center - (16 de setiembre del 2015) - https://www.youtube.com/watch?v=DA6wQRsAtwE

46. BALDINGER STUDIO (2012) - Just Published Articles - (16 de setiembre del 2015) - http://www.baldinger-studio.com/just-published/

47. BALDINGER STUDIO (2015) - Portfolio, DEC - (16 de setiembre del 2015) http://www.baldinger-studio.com/portfolio/disability-empowerment-center/

48. THE WEATHER CHANNEL (2015) - Phoenix, AZ - (16 de setiembre del 2015) - http://www.weather.com/weather/monthly/1/USAZ0166:1:US

49. GAISMA (2012) - PHOENIX ARIZONA - (16 de setiembre del 2015) http://www.gaisma.com/en/location/phoenix-arizona.html

50. ARCHELLO (2012) - ATHLETIC RIPPLES - (16 de setiembre del 2015) http://84.38.224.208/en/project/athletic-ripples

51. INHABITAT (2011) - Solar-Powered Piezoelectric Sports Stadium - (16 de setiembre del 2015) - http://inhabitat.com/solar-powered-piezoelectric-sportsstadium-breaks-ground-in-india/studio-symbiosis_ripple-sketch-color/

52. EVOLO (2013) - BEIJAO SPORTS CENTER BY DECODE URBANISM OFFICE - (16 de setiembre del 2015) http://www.evolo.us/architecture/beijiaosports-center-by-decode-urbanism-office/

53. STYLE OF DESIGN (2012) - ARTEIXO SPORT CENTER - (16 de setiembre del 2015) - http://www.styleofdesign.com/architecture/arteixo-sport-center-joseramon-garitaonaindia-de-vera-2/

54. ARCHDAILY (2012) - ARTEIXO SPORT CENTER - (16 de setiembre del 2015) - http://www.archdaily.com/218481/arteixo-sport-center-jose-ramongaritaonaindia-de-vera 
55. A AS ARCHITECTURE (2014) - EDUCATIONAL AND SPORT CENTRE FOR YOUTH BY LUSINE BAGHDASARYAN \& ARAM SHAHOYAN http://aasarchitecture.com/2014/10/educational-sport-centre-youth-lusinebaghdasaryan-aram-shahoyan.html

56. ARCHIII (2012) - Universiade Sports Center Design by GMP Architects - (16 de setiembre del 2015) - http://www.archiii.com/2012/03/universiade-sports-centerdesign-by-gmp-architects/

57. ARCHITECTISM (2013) - THE MANTES-LA-JOLIE WATER SPORTS CENTER IN PARIS - (16 de setiembre del 2015) - http://architectism.com/themantes-la-jolie-water-sports-center-in-paris/

58. ARCHELLO (2015) - SPORTS HALL OF PHYSICAL EDUCATION - (16 de setiembre del 2015) - http://84.38.224.208/en/project/sports-hall-academyphysical-education-poznan

59. ARCHELLO (2015) - WEST AUSTRALIAN INSTITUTE OF SPORT - (16 de setiembre del 2015) - http://84.38.224.208/en/project/west-australian-institutesport-0

60. EVOLO (2011) - MEDELLIN SPORTS COLISEUM - (16 de setiembre del 2015) - http://www.evolo.us/architecture/medellin-sports-coliseum-mazzantiarquitectos-planb-arquitectos/\#more-9726

61. INHABITAT (2012) - FLOWING MEDELLIN SPORTS COLISEUM - (16 de setiembre del 2015) - http://inhabitat.com/flowing-medellin-sports-coliseumkeeps-its-cool-with-a-laser-cut-facade/medellin-sports-coliseum-3/

62. THE COOL HUNTER (2012) - SCHOOLS IN COLOR - (16 de setiembre del 2015) - http://www.thecoolhunter.net/cloud/view/Schools

63. MUSLIMRAHMAN (2010) - Modern Sports center design - (16 de setiembre del 2015) - http://www.muslimrahman.com/modern-sports-center-design-by-kozarchitects/

64. PLATAFORMA ARQUITECTURA (2012) - Ganador concurso público parque zonal sinchi roca en Lima - (16 de setiembre del 2015) - 
http://www.plataformaurbana.cl/archive/2012/08/01/ganador-concurso-publicoparque-zonal-sinchi-roca-en-lima/

65. FINDEARQ (2012) - Parque Zonal Flor de Amancaes - (16 de setiembre del 2015) - https://findearq.wordpress.com/parque-zonal-flor-de-amancaes-villamaria-del-triunfo/

66. BENTIN, JOSE (2015) - CAR LA VIDENA INFRAESTRUCTURA DEPORTIVA - Lima, PERU

67. ARQUITECTURA MODERNA PERU (2012) - Concurso Publico Parque Zonal - (16 de setiembre del 2015) - http://arquitectura-modernaperu.blogspot.pe/2012/06/concurso-publico-parque-zonal-sinchi.html

68. OBSERVATORIO URBANO http://www.urbano.org.pe/downloads/observatorio_urbano/

69. COMPOSICION URBANA

http://composicionurbana.blogspot.pe/2015_01_01_archive.html

70. VITRUVIUS (2009) - $\quad$ PROYECTOS

http://www.vitruvius.es/revistas/read/projetos/12.134/4264

71. ZOKAZOLA (2015) - CENTER FOR THE DISABLED http://www.zokazola.com/center_for_disabled.html

72. ARCHDAILY (2012) - ESCENARIOS DEPORTIVOS DE MEDELLIN http://www.archdaily.pe/pe/02-92222/escenarios-deportivos-giancarlo-mazzantifelipe-mesa-planb\#

73. SABMAGAZINE (2011) SUSTAINABLE DESIGN OF RECREATION FACILITIES - http://www.sabmagazine.com/blog/2011/04/12/sustainabledesign-of-recreation-facilities/

74. ECO FRIEND (2015) - RIPPLE EFFECT - http://www.ecofriend.com/designform-of-a-piezoelectric-powered-sports-complex-influenced-by-the-rippleeffect-of-water.html 
75. PLAN PHILLY (2009) - INITIAL DESIGN CONCEPTS http://planphilly.com/articles/2009/11/18/initial-design-concepts-race-street-pier

76. ARCHITNECT

ISTANBUL

http://archinect.com/features/article/77781/istanbul-istanbul

77. DEZEEN (2013) - STEVEN HOLL ON CAMPBELL SPORTS CENTRE http://www.dezeen.com/2013/07/17/quote-steven-holl-on-campbell-sportscentre/

78. ARQA (2010) - TIPOLOGIAS EDIFICIOS Y ESTADIOS DEPORTIVOS http://arqa.com/tipologias/edificios-y-estadios-deportivos

79. BDC NETWORK (2010) - BUILDING TYPES SPORTS AND RECREATIONAL FACILITIES - http://www.bdcnetwork.com/buildingtypes/sports-and-recreational-facilities

80. AMIGOS DE VILLA (2014) - PASEANDO POR VILLA EL SALVADOR http://www.amigosdevilla.it/paseando/14.htm

81. ARQUITECTURA SENSORIAL (2003) - ARQUITECTURA SENSORIAL CONCEPTOS - http://arquitectura-sensorial.blogspot.com/

82. LIBRARY NDSU (2009) - DEFINICION DE ARQUITECTURA SENSORIAL - http://library.ndsu.edu/repository/handle/10365/16910

83. FOROS PERU (2014) PLAN METROPOLITANO DE DESARROLLO URBANO DE LIMA Y CALLAO AL PLAM 2035 http://www.forosperu.net/temas/plan-metropolitano-de-desarrollo-urbano-delima-y-callao-al-2035-plam-2035.581972/

84. ARQHYS (2011) - CONSTRUCCION DE EDIFICIOS DEPORTIVOS http://www.arqhys.com/construccion/deporte-arquitectura.html

85. CONVENCION SOBRE LOS DERECHOS DE LAS PERSONAS CON DISCAPACIDAD - "Lima según sus ciudadanos

86. LOPEZ , Daniel (2010) - "Lima según sus ciudadanos, Informe de percepción sobre Calidad de Vida 2010" Lima, PERU 
87. TORRES, Andres (2009) - Revista sobre Derechos de Personas con Discapacidad; Sociedad y Discapacidad. Lima, PERU

88. DUSSAN, Carla (2012) - Derechos humanos y discapacidad - Lima, PERU

89. CENTER FOR INTERNATIONAL REHABILITATION RESEARCH INFORMATION AND EXCHANGE (2010) - INTERNATIONAL ENCYCLOPEDIA OF REHABILITATION - Buffalo, NY (http://cirrie.buffalo.edu/encyclopedia/en/article/355/)

90. GREAT CITIES (2015) - Universal Design the next step in the equal access city - (https://greatcities.uic.edu/2015/03/16/universal-design-the-next-step-in-theequal-access-city/)

91. MACPHEE, Riley (2010) - JOHN STON ARCHITECTS - pág. 33 - LONDON, UK

92. PLANNING AND ZONING (2015) WEB MAP VIEWER http://phoenix.maps.arcgis.com/apps/webappviewer/index.html?id=37027b930d 8340f1976824cbb605d92c

93. SKYCRAPERCITY (2006) MEDELLIN http://www.skyscrapercity.com/showthread.php?p=115248433

94. BIENALES DE ARQUITECTURA (2010) - ESCENARIOS DEPORTIVOS MEDELLIN

http://www.bienalesdearquitectura.es/index.php/es/proyecto?obra=08BI-06

95. BARAHONA, Luis Diego (2012) ABRAN CANCHA A LOS EJERCICIOS URBANOS - LA NACION http://www.nacion.com/archivo/Abran-canchaejercicios-urbanos_0_1244475667.html

96. GUERRA, Gustavo (2014) - ESCENARIO DEPORTIVO PARA LOS JUEGOS SURAMERICANOS 2010 DE MEDELLIN - Medellin, Colombia http://gustavoguerra.blogspot.es/1408393697/escenario-deportivo-para-losjuegos-suramericanos-2010-medellin-giancarlo-mazzanti-/ 
97. DESIGNBOOM (2012) - LONDON OLYMPICS ARCHITECTURE OF THE GAMES - http://www.designboom.com:8080/architecture/london-2012olympics-architecture-of-the-games/

98. ARQUITECTURA DE LOS JUEGOS OLIMPICOS (2012) http://arquitecturadejuegosolimpicos.blogspot.pe/

99. BUSINESS INSIDER (2012) - HOW THE OLYMPICS GAMES CHANGED BARCELONA FOREVER - http://www.businessinsider.com/how-the-olympicgames-changed-barcelona-forever-2012-7

100. BUILTRAGO, Juan Pablo (2008) TESIS DEPORTIVA http://www.coroflot.com/juanpablobuitrago/practica-profesional-2008

101. PLAN B ARQUITECTURA (2010) - PROYECTOS http://planbarquitectura.com/index.php?/proyectos/4-escenarios-deportivos/\# 102. ARQA (2011) - CUATRO ESCENARIOS DEPORTIVOS $\mathrm{http}$ ://arqa.com/arquitectura/cuatro-escenarios-deportivos.html

103. GAISMA (2008) - $\quad$ MEDELLIN

http://www.gaisma.com/en/location/medellin.html

104. THE WEATHER CHANNEL (2015) - Lima Perú- (16 de setiembre del 2015) - http://www.weather.com/weather/monthly/l/USAZ0166:1:US

105. THE WEATHER CHANNEL (2015) - Lima Perú- (16 de setiembre del 2015) - http://www.weather.com/weather/monthly/l/USAZ0166:1:US

106. MUNICIPALIDAD DE VILLA MARÍA DEL TRIUNFO (2015) NORMATIVA ZONIFICACIÓN - Lima Perú

107. MUNICIPALIDAD DE VILLA MARÍA DEL TRIUNFO (2015) NORMATIVA PARA EDIFICACIONES DEPORTIVAS PÚBLICAS - Lima Perú

108. MUNICIPALIDAD DE VILLA MARÍA DEL TRIUNFO (2015) NORMATIVA PARA EDIFICACIONES DEPORTIVAS PÚBLICAS - Lima Perú 
109. AMIGOS DE VILLA (2013) - Historia de Lima Sur, Lima, Perú

110. $\quad$ AMIGOS DE VILLA (2013) - Historia de Lima Sur, Lima, Perú

111. PROPOLI (2012) - INEI “¿Cómo vamos en Seguridad Ciudadana?” Lima, PE

112. LIMA COMO VAMOS (2014) - INEI “¿Cómo vamos en Deporte?” Lima, PE

113. RNE (2013) Normativa, Lima, PE

114. GUIA DE ACCESIBILIDAD BARCELONA (2005) Accesibilidad en Edificios Públicos, Barcelona, ES

\section{Gráficos}

\section{CAPITULO 1:}

1.1. VISTA DE VILLA EL SALVADOR - FOTOGRAFIA PROPIA

1.2. Luminarium "A sanctuary of the senses" - (2015) ARCHITECTS OF AIR, Luminarium, Hong Kong (http://www.architects-of-air.com/the-experience.html)

1.3. Sport and Fitness Center for the disabled - Foto de Raúl García ARCHDAILY (2015)

- Baldinger Architectural Studio , "Sport and Fitness for the disabled"

1.4. MAPA DEL PERU- Municipalidad de VES (2012) - Lima, Perú

1.5. MAPA DE LIMA SUR - Municipalidad de VES (2012) - Lima, Perú

1.6. MAPA DE LIMA - Municipalidad de VES (2012) - Lima, Perú

1.7. MAPA - ACCESIBILIDAD DEL DISTRITO Y PUNTOS DE CONCENTRACION - Municipalidad de VES (2012) - Lima, Perú

1.8. PLANO DE UBICACIÓN DE EJE DEPORTIVO INFORMAL EN VILLA EL SALVADOR Y VILLA MARIA DEL TRIUNFO - TALLER 7 (2014) - TRABAJO GRUPO A 
1.9. GRAFICO HECHO CON DATOS DEL PROPOLI DEL 2005 DE VILLA EL SALVADOR Y VILLA MARIA DEL TRIUNFO- LERTORA (2005) , LIMA PERU

1.10. DATOS PORCENTUALES DE INSEGURIDAD EN LOS DISTRITOS DE LIMA (2012) - SEGUNDA ENCUESTA METROPOLITANA DE VICTIMIZACIÓN 2012, LIMA, PERU

1.11. MAPA DE ESPACIOS PUBLICOS DE VS Y VMT - Municipalidad de VES (2012) - Lima, Perú

1.12. FOTOGRAFIAS DE PUENTE EN VILLA EL SALVADOR - Fotografías propias (2014)

1.13. Mapa de Lima - Posible red de polideportivos eco sostenibles - LERTORA, Ghianella (2015)

1.14. INSTALACIONES DEL TREN ELECTRICO DE LIMA - (2011) -JIMENEZ, Carlos- Nuevas Instalaciones del Tren Eléctrico - RPP- Lima, Perú

1.15. ESQUEMA METODOLOGICO POLIDEPORTIVO - LERTORA, Ghianella (2015)

1.16. ESQUEMA DE ACCIONES A REALIZAR - LERTORA, Ghianella (2015)

\section{CAPITULO 2:}

2.1. VISTAS DE OLYMPIA -(2006) LEONARD, John "Architecture and Sport" Architectural Research - Melbourne, Australia

2.2. LAS CARACTERISITCAS DEL DEPORTE SEGÚN LA EPOCA - (2006) LEONARD, John "Architecture and Sport" - Architectural Research - Melbourne, Australia

2.3. Coliseo Romano, Roma, IT - fotografía propia - LERTORA, Ghianella

2.4. BOCETOS DE ESPACIO DEPORTIVO EN INTERIORES -(2006) LEONARD, John "Architecture and Sport" - Architectural Research - Melbourne, Australia

2.5. VISTA DE POLIDEPORTIVO LONDINENSE-(2006) LEONARD, John "Architecture and Sport" - Architectural Research - Melbourne, Australia

2.6. FOTOS DE INSTALACIONES DEPORTIVAS-(2006) LEONARD, John "Architecture and Sport" - Architectural Research - Melbourne, Australia 
2.7. FOTOS DE ESPACIOS ACONDICIONADOS PARA DEPORTE EN ESPACIOS CERRADOS - (2006) LEONARD, John "Architecture and Sport" - Architectural Research - Melbourne, Australia

2.8. DIFERENCIAS DEL ESPACIO DEPORTIVO MODERNO Y POSTMODERNO(2006) LEONARD, John "Architecture and Sport" - Architectural Research Melbourne, Australia

2.9. CARACTERISTICAS DE EL DEPORTE EN EL TIEMPO- (2006) LEONARD, John "Architecture and Sport" - Architectural Research - Melbourne, Australia

2.10. ILUSTRACION DE CHASQUI - (2012) GHINO "Deportes que practicaban los incas" - Historia y Cultura Peruana - Lima, Perú

2.11. VISTAS DE EL ANTIGUO ESTADIO NACIONAL EN LOS 50'S (2008) DESARROLLO PERUANO BLOG - “Lima postulara para ser sede de Panamericanos del 2015" - Lima, Perú

2.12. VISTAS DE EL ANTIGUO ESTADIO NACIONAL EN LOS 90S (2008) DESARROLLO PERUANO BLOG - “ Lima postulara para ser sede de Panamericanos del 2015" - Lima, Perú

2.13. Fotografía de Santa Beatriz - (2011) Lima la Única - El Hipódromo de Santa Beatriz - Lima, Perú

2.14. Fotografía de Hipódromo de San Felipe - (2013) ECURED - Hipódromo de San Felipe - Lima, Perú

2.15. Fotografía de Hipódromo de San Felipe - (2013) ECURED - Hipódromo de San Felipe - Lima, Perú

2.16. Fotografía de Hipódromo de Monterrico - (2005) HIPODROMO DE MONTERRICO, Historia, Lima, Perú

2.17. Fotografías de Hipódromo de Monterrico - (2005) HIPODROMO DE MONTERRICO, Historia, Lima, Perú

2.18. FOTOGRAFIA VIDENA DE SAN LUIS (2011) MUSS

2.19. FOTOGRAFIA COLISEO DIBOS - LOPEZ (2010)

2.20. FOTOGRAFIA COLISEO DIBOS - LOPEZ (2010) 
2.21. INFOGRAFIA ESTADIO NACIONAL - (2015) FRANK, Tim, NESPAGEDESIGNER, Infografía del Estadio Nacional

2.22. INFOGRAFIA VIDENA, (2015) ALTO EFECTO, Infografía, Cosapi, LIMA, PERU

2.23-35. (2014) GRUPO 1 - TALLER 7 - MOSER AMICO (ESPEJO, FELIPA, CABEJO, TELLO, LERTORA, OSORES, RAMOS, SANCHEZ, LOPEZ, HORNA, BERROCAL) - "Diagnóstico de Villa el Salvador" - Facultad de Arquitectura UPC, Lima, Perú.

2.36. 2012 Sport and Fitness Center for the disabled - Baldinger Architectural Studio Foto de Raúl García - ARCHDAILY (2015) - Baldinger Architectural Studio , "Sport and Fitness for the disabled"

2.37. (2015) MORSEY, Universal Design: The Next Step in the Equal-Access City Jackson College of Urban Planning and Public Affairs, University of Illinois at Chicago

2.38. (2008) MURILLO, Rosario - La inclusión de las personas con discapacidad, PROPOLI, Lima, Perú

2.39. BIENESTAR HUMANO - SUSTEINABILIDAD SOCIAL, ECONOMICA Y AMBIENTAL

2.40. ESTRATEGIAS DE DISEÑO - MATERIALES, DESECHOS, AGUA Y ENERGIA

2.41. BRAMPTON SOCCER CENTER - IMAGEN 1 - SABMAGAZINE (2011) SUSTAINABLE DESIGN OF RECREATION FACILITIES http://www.sabmagazine.com/blog/2011/04/12/sustainable-design-of-recreationfacilities

2.42. BRAMPTON SOCCER CENTER - IMAGEN 2 - SABMAGAZINE (2011) SUSTAINABLE DESIGN OF RECREATION FACILITIES http://www.sabmagazine.com/blog/2011/04/12/sustainable-design-of-recreationfacilities

2.43. INNISFIL RECREATION COMPLEX - SABMAGAZINE (2011) SUSTAINABLE DESIGN OF RECREATION FACILITIES - 
http://www.sabmagazine.com/blog/2011/04/12/sustainable-design-of-recreationfacilities

2.44. VISTA PLAZA BEIJAO SPORTS CENTRE EVOLO (2013) - BEIJAO SPORTS CENTER BY DECODE URBANISM OFFICE - (16 de setiembre del 2015) http://www.evolo.us/architecture/beijiao-sports-center-by-decode-urbanism-office/

2.45. ESQUEMA BEIJAO - EVOLO (2013) - BEIJAO SPORTS CENTER BY DECODE URBANISM OFFICE - $(16$ de setiembre del 2015) http://www.evolo.us/architecture/beijiao-sports-center-by-decode-urbanism-office/

2.46. ESQUEMA BEIJAO - EVOLO (2013) - BEIJAO SPORTS CENTER BY DECODE URBANISM OFFICE - $(16$ de setiembre del 2015) http://www.evolo.us/architecture/beijiao-sports-center-by-decode-urbanism-office/

2.47. PLANTA 1 Y 2BEIJAO - EVOLO (2013) - BEIJAO SPORTS CENTER BY DECODE URBANISM OFFICE - $(16$ de setiembre del 2015) http://www.evolo.us/architecture/beijiao-sports-center-by-decode-urbanism-office/

\section{CAPITULO 3}

\section{BALDINGER PROJECT}

3.1.1. BALDINGER PROJECT - SPORTS CENTER - VISTA GOOGLE EARTH (2015)

3.1.2. VISTAS SPOFIT - ARCHDAILY - 2015 -Sport and Fitness center (22 de setiembre del 2015)

3.1..2 MAPA DE PHOENIX - GOOGLE MAPS (2015)

3.1..4-21. FOTOGRAFIAS ARCHDAILY- 2015 -Sport and Fitness center (22 de setiembre del 2015)

3.1.22. GRAFICO DE USOS - LERTORA, Ghianella

3.1.23. Grafico de accesibilidad - LERTORA, Ghianella

3.1.24. Fachada Baldinger - LERTORA, Ghianella

3.1.25. GRAFICO DE AREAS BALDINGER - LERTORA, Ghianella 


\section{ESCENARIOS DEPORTIVOS MEDELLIN}

3.2.1. IMAGEN DE CONJUNTO DEPORTIVO INSERTADO EN EL CONTEXTO ARCHDAILY - 2011 -Escenarios Deportivos / Giancarlo Mazzanti + PlanB (29 de setiembre del 2015)

3.2.2. MAPA DE MEDELLIN COLOMBIA, ADAMNELSONMRA (2015) MEDELLIN COLOMBIA

3.2.3. IMAGEN DE CELOSIA, ARCHDAILY - 2011 -Escenarios Deportivos / Giancarlo Mazzanti + PlanB (29 de setiembre del 2015)

3.2.4. PLOT PLAN ESCENARIOS DEPORTIVOS - ARCHDAILY - 2011 -Escenarios Deportivos / Giancarlo Mazzanti + PlanB (29 de setiembre del 2015)

3.2.5. MAPA VIAL DE LA CIUDAD DE MEDELLIN EN 17,000 - GOBIERNO DE MEDELLIN (2006)

3.2.6. MAPA VIAL DE LA CIUDAD DE MEDELLIN EN 17,000 - GOBIERNO DE MEDELLIN (2006)

3.2.7. PLANO DE ZONA DE ESTUDIO (2015) GOOGLE MAPS

3.2.8. PLANTA DE LOCALIZACION - ARCHDAILY - 2011 -Escenarios Deportivos / Giancarlo Mazzanti + PlanB (29 de setiembre del 2015)

3.2.9. IMAGEN DE CONJUNTO DEPORTIVO INSERTADO EN EL CONTEXTO ARCHDAILY - 2011 -Escenarios Deportivos / Giancarlo Mazzanti + PlanB (29 de setiembre del 2015)

3.2.10. RELACION CON EL CONTEXTO (ESCALA DEL PEATON) - GOOGLE EARTH STREET VIEW (2015)

3.2.11. RELACION CON EL CONTEXTO (ESCALA DEL PEATON) - GOOGLE EARTH STREET VIEW (2015)

3.2.12. IMAGEN DE CONJUNTO DEPORTIVO INSERTADO EN EL CONTEXTO ARCHDAILY - 2011 -Escenarios Deportivos / Giancarlo Mazzanti + PlanB (29 de setiembre del 2015) 


\subsubsection{CONCEPTO ESCENARIOS DEPORTIVOS MAQUETA - NHABITAT (2012)}

- FLOWING MEDELLIN SPORTS COLISEUM - (16 de setiembre del 2015) http://inhabitat.com/flowing-medellin-sports-coliseum-keeps-its-cool-with-a-laser-cutfacade/medellin-sports-coliseum-3/

\subsubsection{BOCETO DE CONCEPTO - INHABITAT (2012) - FLOWING MEDELLIN} SPORTS COLISEUM - (16 de setiembre del 2015) - http://inhabitat.com/flowingmedellin-sports-coliseum-keeps-its-cool-with-a-laser-cut-facade/medellin-sportscoliseum-3/

\subsubsection{BOCETO DE CONCEPTO - INHABITAT (2012) - FLOWING MEDELLIN} SPORTS COLISEUM - (16 de setiembre del 2015) - http://inhabitat.com/flowingmedellin-sports-coliseum-keeps-its-cool-with-a-laser-cut-facade/medellin-sportscoliseum-3/

\subsubsection{ASOLAMIENTO PROYECTO - EVOLO (2011) - MEDELLIN SPORTS} COLISEUM - (16 de setiembre del 2015) - http://www.evolo.us/architecture/medellinsports-coliseum-mazzanti-arquitectos-planb-arquitectos/\#more-9726

\subsubsection{PLANTA 1,2 Y CORTES PROYECTO ESCENARIOS DEPORTIVOS -} EVOLO (2011) - MEDELLIN SPORTS COLISEUM - (16 de setiembre del 2015) http://www.evolo.us/architecture/medellin-sports-coliseum-mazzanti-arquitectos-planbarquitectos/\#more-9726

3.2.18. TABLAS DE PROGRAMA CON AREAS - ELABORACION PROPIA LERTORA, Ghianella

3.2.19. PAQUETES FUNCIONALES - ELABORACION PROPIA - LERTORA, Ghianella

\subsubsection{BOCETO ESTRUCTURAL - EVOLO (2011) - MEDELLIN SPORTS} COLISEUM - (16 de setiembre del 2015) - http://www.evolo.us/architecture/medellinsports-coliseum-mazzanti-arquitectos-planb-arquitectos/\#more-9726

\subsubsection{FOTOGRAFIA INTERIOR ESTRUCTURA - ARCHDAILY (2012) -} ESCENARIOS DEPORTIVOS DE MEDELLIN - http://www.archdaily.pe/pe/0292222/escenarios-deportivos-giancarlo-mazzanti-felipe-mesa-planb 
3.2.22. FOTOGRAFIA INTERIOR ESTRUCTURA - ARCHDAILY (2012) ESCENARIOS DEPORTIVOS DE MEDELLIN - http://www.archdaily.pe/pe/0292222/escenarios-deportivos-giancarlo-mazzanti-felipe-mesa-planb

3.2.23. FOTOGRAFIA INTERIOR ESTRUCTURA - ARCHDAILY (2012) ESCENARIOS DEPORTIVOS DE MEDELLIN - http://www.archdaily.pe/pe/0292222/escenarios-deportivos-giancarlo-mazzanti-felipe-mesa-planb

\section{ARTEIXO SPORT CENTER}

3.3.1. FOTOGRAFIA FACHADA INGRESO ARTEIXO - ARCHDAILY (2012) ARTEIXO SPORT CENTER - $(16$ de setiembre del 2015) http://www.archdaily.com/218481/arteixo-sport-center-jose-ramon-garitaonaindia-devera

3.3.2. FOTOGRAFIA FACHADA INGRESO ARTEIXO - ARCHDAILY (2012) ARTEIXO SPORT CENTER - $(16$ de setiembre del 2015) http://www.archdaily.com/218481/arteixo-sport-center-jose-ramon-garitaonaindia-devera

3.3.3. FOTOGRAFIA FACHADA - ARCHDAILY (2012) - ARTEIXO SPORT CENTER - (16 de setiembre del 2015) - http://www.archdaily.com/218481/arteixo-sportcenter-jose-ramon-garitaonaindia-de-vera

3.3.4. FOTOGRAFIA FACHADA - ARCHDAILY (2012) - ARTEIXO SPORT CENTER - (16 de setiembre del 2015) - http://www.archdaily.com/218481/arteixo-sportcenter-jose-ramon-garitaonaindia-de-vera

3.3.5. MAPA DE A CORUÑA - GAISMA (2015)

3.3.6. PLOT PLAN PROYECTO - ARCHDAILY (2012) - ARTEIXO SPORT CENTER - (16 de setiembre del 2015) - http://www.archdaily.com/218481/arteixo-sport-centerjose-ramon-garitaonaindia-de-vera

3.3.7. VISTA DE GOOGLE MAPS - ESPAÑA - 2015

3.3.8. VISTA DE GOOGLE EARTH - ZONA DE ANALISIS (2015) 


\subsubsection{FOTOGRAFIA APERSIANADO - ARCHDAILY (2012) - ARTEIXO SPORT}

CENTER - (16 de setiembre del 2015) - http://www.archdaily.com/218481/arteixo-sportcenter-jose-ramon-garitaonaindia-de-vera

\subsubsection{FOTOGRAFIA APERSIANADO - ARCHDAILY (2012) - ARTEIXO SPORT} CENTER - (16 de setiembre del 2015) - http://www.archdaily.com/218481/arteixo-sportcenter-jose-ramon-garitaonaindia-de-vera

3.3.11. FOTOGRAFIA INTERIOR RELACION ESPACIAL -ARCHDAILY (2012) ARTEIXO SPORT CENTER - $(16$ de setiembre del 2015) http://www.archdaily.com/218481/arteixo-sport-center-jose-ramon-garitaonaindia-devera

3.3.12. FOTOGRAFIA INTERIOR RELACION ESPACIAL -ARCHDAILY (2012) ARTEIXO SPORT CENTER - (16 de setiembre del 2015) http://www.archdaily.com/218481/arteixo-sport-center-jose-ramon-garitaonaindia-devera

\subsubsection{VISTA DE GOOGLE EARTH 2015 - ARTEIXO}

3.3.14. IMAGEN GOOGLE EARTH 2015 - UBICACIÓN DE RIO Y PROYECTO EN EL CONTEXTO

3.3.15. VISTA DE GOOGLE EARTH (2015) RELACION PEATONAL CON CONTEXTO

3.3.16. FOTOGRAFIA FACHADA INGRESO ARTEIXO - ARCHDAILY (2012) ARTEIXO SPORT CENTER - $(16$ de setiembre del 2015) http://www.archdaily.com/218481/arteixo-sport-center-jose-ramon-garitaonaindia-devera

3.3.17. VISTA PANORAMICA DE A CORUÑA ESPAÑA - ARCHDAILY (2012) ARTEIXO SPORT CENTER - $(16$ de setiembre del 2015) http://www.archdaily.com/218481/arteixo-sport-center-jose-ramon-garitaonaindia-devera

3.3.18. ELEVACION 1,2,3,4 Y CORTE 1 Y 2 - ARCHDAILY (2012) - ARTEIXO SPORT CENTER - $\quad(16$ de setiembre del 2015) - 
http://www.archdaily.com/218481/arteixo-sport-center-jose-ramon-garitaonaindia-devera

3.3.19. PLANOS 1,2,3 - ARCHDAILY (2012) - ARTEIXO SPORT CENTER - (16 de setiembre del 2015) - http://www.archdaily.com/218481/arteixo-sport-center-joseramon-garitaonaindia-de-vera

3.3.20. ESQUEMA POR ESPACIOS - ARTEIXO - (2015) LERTORA, Ghianella

3.3.21. TABLA DE AREAS (2015) LERTORA, Ghianella

3.3.22-25. IMÁGENES ASPECTOS TECNOLOGICOS - ARCHDAILY (2012) ARTEIXO SPORT CENTER - $(16$ de setiembre del 2015) http://www.archdaily.com/218481/arteixo-sport-center-jose-ramon-garitaonaindia-devera

\section{VIDENA}

3.4.1. MAPA DEL PERU - GOOGLE MAPS (2015)

3.4.2. MAPA DE UBICACIÓN DE LA VIDENA EN SAN LUIS - COINSA (2014)

3.4.3. MAPA DE UBICACIÓN DE PROYECTO DENTRO DE COMPLEJO DEPORTIVO LA VIDENA - COINSA (2014)

3.4.4. VISTA DE GOOGLE MAPS (2015)

3.4.5. MAPA DE SISTEMA VIAL CON RELACION CON LA CIUDAD - MAPA DE GOOGLE MAPS (2015)

3.4.6. VISTA DE POLIDEPORTIVO 1 - BENTIN, JOSE (2015) - CAR LA VIDENA INFRAESTRUCTURA DEPORTIVA - Lima, PERU

3.4.7. VISTA DE POLIDEPORTIVO 2 - BENTIN, JOSE (2015) - CAR LA VIDENA INFRAESTRUCTURA DEPORTIVA - Lima, PERU

3.4.8. VISTA DE PLAZA DE INGRESO - BENTIN, JOSE (2015) - CAR LA VIDENA INFRAESTRUCTURA DEPORTIVA - Lima, PERU

3.4.9. FOTOGRAFIA RESIDENCIA PARA DEPORTISTAS - BENTIN, JOSE (2015)

- CAR LA VIDENA INFRAESTRUCTURA DEPORTIVA - Lima, PERU 
3.4.10. FOTOGRAFIA INTERIOR POLIDEPORTIVO 1 - BENTIN, JOSE (2015) CAR LA VIDENA INFRAESTRUCTURA DEPORTIVA - Lima, PERU

3.4.11. VISTAS DE PERFIL URBANO - VISTAS GOOGLE EARTH (2015)

3.4.12. MAPA ACCESIBILIDAD - GOOGLE MAPS (2015)

3.4.13. PLANO DE UBICACIÓN DE EDIFICIOS VIDENA - TESIS DEPORTIVA (2008)

3.4.14. IMAGEN ASOLAMIENTO - GAISMA (2015)

3.4.15. IMAGEN DE WASHINGTONIA - SOUTH FLORIDA PLANT GUIDE (2014)

3.4.16. IMAGEN PALMERA PHOENIX - SOUTH FLORIDA PLANT GUIDE (2014)

3.4.17. PLANO DE REMODELACION - BENTIN, JOSE (2015) - CAR LA VIDENA INFRAESTRUCTURA DEPORTIVA - Lima, PERU

3.4.18. ESQUEMA DE PAQUETES FUNCIONALES - ESQUEMA PROPIO (2015) LERTORA, Ghianella

3.4.19 - 26. IMÁGENES INTERIORES DEL PROYECTO - BENTIN, JOSE (2015) CAR LA VIDENA INFRAESTRUCTURA DEPORTIVA - Lima, PERU

3.4.27. TABLAS DE PROGRAMA AREAS - LERTORA (2015)

3.4.28. INFOGRAFIA DE REMODELACION DE LA VIDENA - COSAPI (2014)

3.4.29. PARTE 1 - TABLA COMPARATIVA DE PROYECTOS REFERENCIALES TABLA PROPIA - LERTORA, Ghianella (2015)

3.4.30. PARTE 2 - TABLA COMPARATIVA DE PROYECTOS REFERENCIALES TABLA PROPIA - LERTORA, Ghianella (2015)

\section{CAPITULO 4:}

1. MAPA DE LIMA SUR (2011) OBSERVATORIO URBANO (12 NOVIEMBRE 2015) 
2. MAPA DE LIMA SUR (2011) OBSERVATORIO URBANO (12 NOVIEMBRE 2015)

3. VISTA DE CERRO Y TERRENO DE LA ZONA (2015) LERTORA, GHIANELLA

4. PLANO TOPOGRÁFICO DE VILLA MARÍA DEL TRIUNFO Y VILLA EL SALVADOR (2015) LERTORA, GHIANELLA

5. PLANO DE VILLA EL SALVADOR T VILLA MARÍA DEL TRIUNFO (2015) LERTORA, Ghianella

6. PLANO DE VILLA EL SALVADOR T VILLA MARÍA DEL TRIUNFO (2015) LERTORA, Ghianella

7. PLANO DE VILLA EL SALVADOR T VILLA MARÍA DEL TRIUNFO (2015) MODIFICADO POR LERTORA, Ghianella

8. PLANO DE VILLA EL SALVADOR T VILLA MARÍA DEL TRIUNFO (2015) MODIFICADO POR LERTORA, Ghianella

9. PLANO DE VILLA EL SALVADOR T VILLA MARÍA DEL TRIUNFO (2015) MODIFICADO POR LERTORA, Ghianella

10. PLANO DE VILLA EL SALVADOR T VILLA MARÍA DEL TRIUNFO (2015) MODIFICADO POR LERTORA, Ghianella

11. TABLA DEL CLIMA DE LIMA PERÚ (2012) WEATHERBASE (15 NOVIEMBRE 2015)

12. PLANO DE VILLA EL SALVADOR T VILLA MARÍA DEL TRIUNFO (2015) LERTORA, Ghianella

13. IMAGEN CRUCE PEATONAL DE RÍO EN BARCELONA (2008) ARCHDAILY OSHBELT (12 de noviembre del 2015)

14. IMAGEN TERRENO 1 (2015) GOOGLE EARTH (17 noviembre 2015)

15. IMAGEN TERRENO 2 (2015) GOOGLE EARTH (17 noviembre 2015)

16. IMAGEN TERRENO 3 (2015) GOOGLE EARTH (17 noviembre 2015) 
17. PLANO DE ZONIFICACIÓN (2014) MUNICIPALIDAD DE VILLA MARÍA DEL TRIUNFO (15 noviembre 2015)

18. PLANO DE ZONIFICACIÓN (2014) MUNICIPALIDAD DE VILLA MARÍA DEL TRIUNFO (15 noviembre 2015)

19. PLANO DE ZONIFICACIÓN (2014) MUNICIPALIDAD DE VILLA EL SALVADOR (15 noviembre 2015)

20. IMAGEN TERRENO 1 (2015) GOOGLE EARTH (17 noviembre 2015)

21. IMAGEN TERRENO 1 (2015) GOOGLE EARTH (17 noviembre 2015)

22. IMAGEN TERRENO 1 (2015) GOOGLE EARTH (17 noviembre 2015)

23. IMAGEN TERRENO 1 (2015) GOOGLE EARTH (17 noviembre 2015)

24. IMAGEN TERRENO 1 (2015) GOOGLE EARTH (17 noviembre 2015)

25. IMAGEN TERRENO 1 (2015) GOOGLE EARTH (17 noviembre 2015)

26. IMAGEN TERRENO 2 (2015) GOOGLE EARTH (17 noviembre 2015)

27. IMAGEN TERRENO 2 (2015) GOOGLE EARTH (17 noviembre 2015)

28. IMAGEN TERRENO 2 (2015) GOOGLE EARTH (17 noviembre 2015)

29. IMAGEN TERRENO 2 (2015) GOOGLE EARTH (17 noviembre 2015)

30. IMAGEN TERRENO 2 (2015) GOOGLE EARTH (17 noviembre 2015)

31. IMAGEN TERRENO 2 (2015) GOOGLE EARTH (17 noviembre 2015)

32. IMAGEN TERRENO 2 (2015) GOOGLE EARTH (17 noviembre 2015)

33. IMAGEN TERRENO 2 (2015) GOOGLE EARTH (17 noviembre 2015)

34. IMAGEN TERRENO 2 (2015) GOOGLE EARTH (17 noviembre 2015)

35. IMAGEN TERRENO 2 (2015) GOOGLE EARTH (17 noviembre 2015)

36. IMAGEN TERRENO 2 (2015) GOOGLE EARTH (17 noviembre 2015) 
37. IMAGEN TERRENO 3(2015) GOOGLE EARTH (17 noviembre 2015)

38. IMAGEN TERRENO 3(2015) GOOGLE EARTH (17 noviembre 2015)

39. IMAGEN TERRENO 3(2015) GOOGLE EARTH (17 noviembre 2015)

40. IMAGEN TERRENO 3(2015) GOOGLE EARTH (17 noviembre 2015)

41. IMAGEN TERRENO 3(2015) GOOGLE EARTH (17 noviembre 2015)

42. IMAGEN TERRENO 3(2015) GOOGLE EARTH (17 noviembre 2015)

43. IMAGEN TERRENO 3(2015) GOOGLE EARTH (17 noviembre 2015)

44. CUADRO DE VALORACIÓN DE LOS TERRENOS SEGÚN CRITERIOS (2015) LERTORA, Ghianella

45. CUADRO DE VALORACIÓN DE LOS TERRENOS SEGÚN CRITERIOS VENTAJAS Y DESVENTAJAS (2015) LERTORA, Ghianella

\section{CAPITULO 5:}

1. ZONA DE ESTUDIO (2015) LERTORA

2. ZONA DE ESTUDIO (2015) LERTORA

3. ZONA DE ESTUDIO (2015) LERTORA

4. ZONA DE ESTUDIO (2015) LERTORA

5. ZONA DE ESTUDIO (2015) LERTORA

6. ZONA DE ESTUDIO (2015) LERTORA

7. ZONA DE ESTUDIO (2015) LERTORA

8. ZONA DE ESTUDIO (2015) LERTORA

9. ZONA DE ESTUDIO (2015) LERTORA

10. ZONA DE ESTUDIO (2015) LERTORA

11. ZONA DE ESTUDIO (2015) LERTORA 
12. ZONA DE ESTUDIO (2015) LERTORA

13. ZONA DE ESTUDIO (2015) LERTORA

14. ZONA DE ESTUDIO (2015) LERTORA

15. ZONA DE ESTUDIO (2015) LERTORA

16. ZONA DE ESTUDIO (2015) LERTORA

17. ZONA DE ESTUDIO (2015) LERTORA

18. ZONA DE ESTUDIO (2015) LERTORA

19. ZONA DE ESTUDIO (2015) LERTORA

20. ZONA DE ESTUDIO (2015) LERTORA

21. ESQUEMA HISTORIA (2015) LERTORA

22. PLANOS VILLA EL SALVADOR (2015) AMIGOS DE VILLA (Octubre, 2015)

23. PLANOS VILLA EL SALVADOR (2015) AMIGOS DE VILLA (Octubre, 2015)

24. PLANOS VILLA EL SALVADOR (2015) AMIGOS DE VILLA (Octubre, 2015)

25. ZONA DE ESTUDIO (2015) LERTORA

26. ZONA DE ESTUDIO FOTOGRAFIA (2015) LERTORA

27. ZONA DE ESTUDIO FOTOGRAFIA (2015) LERTORA

28. ZONA DE ESTUDIO (2015) LERTORA

29. ZONA DE ESTUDIO FOTOGRAFIA (2015) LERTORA

30. ZONA DE ESTUDIO FOTOGRAFIA (2015) LERTORA

31. ZONA DE ESTUDIO (2015) LERTORA

32. ZONA DE ESTUDIO FOTOGRAFIA (2015) LERTORA

33. ZONA DE ESTUDIO FOTOGRAFIA (2015) LERTORA 


\section{CAPITULO 6:}

1. PROPOLI (2005) INEI “¿Cómo vamos en Seguridad Ciudadana?” - Lima, PE

2. PROPOLI (2005) INEI “¿Cómo vamos en Seguridad Ciudadana?” - Lima, PE

3. GRAFICO SOBRE CARACTERÍSTICAS DEL USUARIO Y EL CONTEXTO EN EL QUE SE ENCUENTRA (2015) LERTORA

4. GRAFICO SOBRE CARACTERÍSTICAS DEL USUARIO (2015) LERTORA

5. DATOS CARACTERÍSTICAS DEL USUARIO DISCAPACITADO PROPOLI (2005) INEI “¿Cómo vamos en Seguridad Ciudadana?” - Lima, PE

6. GRAFICO CUANTITATIVO DEL USUARIO BASADO EN DATOS DE LIMA COMO VAMOS DEL 2014 (2015) LERTORA

7. GRAFICO CUALITATIVO DE LOS TIPOS DE USUARIOS (2015) LERTORA

8. GRAFICO CUALITATIVO DE LOS TIPOS DE USUARIOS (2015) LERTORA

9. GRAFICO CUALITATIVO DE LOS TIPOS DE USUARIOS (2015) LERTORA

10. GRAFICO CUALITATIVO DE LOS TIPOS DE USUARIOS (2015) LERTORA

11. GRAFICO CUALITATIVO DE LOS TIPOS DE USUARIOS (2015) LERTORA

12. GRAFICO CUALITATIVO DE LOS TIPOS DE USUARIOS (2015) LERTORA

13. GRAFICO CUALITATIVO DE LOS TIPOS DE USUARIOS Y SUS NECESIDADES (2015) LERTORA

14. GRAFICO CUALITATIVO DE LOS TIPOS DE USUARIOS Y SUS FLUJOS (2015) LERTORA

15. GRAFICO CUALITATIVO DE LOS TIPOS DE USUARIOS Y SUS FLUJOS (2015) LERTORA

16. CUADRO DE RESUMENDE LOS USUARIOS DEPORTISTAS (2015) LERTORA

17. CUADRO DE RESUMENDE LOS USUARIOS (2015) LERTORA 
18. CUADRO DE USUARIOS EVENTUALES (2015) LERTORA

19. CUADRO DE RESUMENDE LOS USUARIOS (2015) LERTORA

\section{CAPITULO 7:}

1. ORGANIGRAMA INSTITUCIONAL POIDEPORTIVO INCLUSIVO (2015) LERTORA, Ghianella

2. GRÁFICO DE INTERRELACIONES ESPACIALES (2015) LERTORA, Ghianella

3. ORGANIGRAMA RELACIONES ESPACIALES (2015) LERTORA, Ghianella

4. GRÁFICO EN QUE SE EL PROGRAMA QUE SE HA AGREGADO AL BÁSICO DE UN POLIDEPORTIVO BASADO EN PROYECTOS REFERENCIALES EXITOSOS Y EN NECESIDADES DEL USUARIO (2015) LERTORA, Ghianella

5. PLANO DE CONTEXTO ASOLEAMIENTO (2015) LERTORA, GHIANELLA

6. PLANO DE CONTEXTO ASOLEAMIENTO (2015) LERTORA, GHIANELLA

7. ACCESOS Y PASAJES (2013) RNE

8. TIPOS DE ESCALERAS (2013) RNE

9. TIPOS DE ESCALERAS (2013) RNE

10. TIPOS DE ESCALERAS (2013) RNE

11. ESPACIO BAJO ESCALERAS (2013) RNE

12. NUMERO Y ANCHO DE ESCALERAS (2013) RNE

13. ASCENSORES (2013) RNE

14. RAMPAS (2013) RNE 
15. ESTACIONAMIENTOS (2013) RNE

16. ACCESIBILIDAD (2013) RNE

17. ACCESIBILIDAD (2013) RNE

18. ACCESIBILIDAD (2013) RNE

19. ACCESIBILIDAD (2013) RNE

20. DIMENSIONES SILLA DE RUEDAS - GUIA DE ACCESIBILIDAD DE BARCELONA (2005)

21. TIPOS DE DISCAPACIDAD- GUIA DE ACCESIBILIDAD DE BARCELONA (2005)

22. ELEMENTOS DE ACCESIBILIDAD DEL ENTORNO URBANO - GUIA DE ACCESIBILIDAD DE BARCELONA (2005)

23. PERSONAS CON ALGUNA DISCAPACIDAD- GUIA DE ACCESIBILIDAD DE BARCELONA (2005)

24. MUEBLE DE ARENCIÓN INCLUSIVO - GUIA DE ACCESIBILIDAD DE BARCELONA (2005)

25. ANTROPOMETRÍA - VOLÚMENES (2012)

26. ANTROPOMETRÍA - VOLÚMENES (2012)

27. ANTROPOMETRÍA - VOLÚMENES (2012)

28. ANTROPOMETRÍA ACCESIBLE - CLIFFORD (2008)

29. ANTROPOMETRÍA ACCESIBLE - SALUD (2010)

30. ANTROPOMETRÍA ACCESIBLE - CLIFFORD (2008)

31. ANTROPOMETRÍA ACCESIBLE - CLIFFORD (2008)

32. OFFICE ANTROPOMORPHY - LEWIS (2008)

33. ANTROPOMETRÍA ACCESIBLE - CLIFFORD (2008) 
34. ANTROPOMETRÍA ACCESIBLE - CLIFFORD (2008)

35. ANTROPOMETRÍA NIÑOS - SCIELO (2010)

36. ANTROPOMETRÍA NIÑOS - SCIELO (2010)

37. ANTROPOMETRÍA NIÑOS - SCIELO (2010)

38. PLANTA GUARDERÍA ARGANDA - ARQ MÉXICO (2012)

39. CORTE GUARDERÍA ARGANDA - ARQ MÉXICO (2012)

40. GRÁFICO ANÁLISIS CUANTITATIVO - LERTORA (2015)

41. GRÁFICO ANÁLISIS CUANTITATIVO - LERTORA (2015)

42. GUARDERIA MOBILIARIO ANTROMOPRPHY ESSENTIALS (2008)

43. ANTROPOMETRIA NIÑOS SCIELO (2010)

44. GUARDERÍA LUCA PERALTA STUDIO (2015)

45. GRÁFICO ANÁLISIS CUANTITATIVO - LERTORA (2015)

46. PLANTA - OFFICE GREENHOUSE BY OPENAD STUDIO (2012)

47. FOTO- OFFICE GREENHOUSE BY OPENAD STUDIO (2012)

48. GRÁFICO ANÁLISIS CUANTITATIVO - LERTORA (2015)

49. ANTROPOMETRIA MOBILIARIO - RAIZEN (2009)

50. ANTROPOMETRIA MOBILIARIO - RAIZEN (2009)

51. BAS SPORT CENTER FOR THE DISABLED - IDEA DE AMPLITUD DEL ESPACIO

52. PLANTA, CORTE Y FOTOGRAFÍA DE SPORT CENTER BY BAL DINGER ARCHI TEC TURAL STUDIO - ARCHDAILY (2014)

53. GRÁFICO ANÁLISIS CUANTITATIVO - LERTORA (2015)

54. ANTROPOMETRÍA DEPORTIVA - PLAZOLA (2008) 
55. ANTROPOMETRÍA DEPORTIVA - ENCICLOPEDIA DEL DEPORTE (2004)

56. ANTROPOMETRÍA DEPORTIVA - ENCICLOPEDIA DEL DEPORTE (2004)

57. ANTROPOMETRÍA DEPORTIVA - ENCICLOPEDIA DEL DEPORTE (2004)

58. ANTROPOMETRÍA DEPORTIVA - ENCICLOPEDIA DEL DEPORTE (2004)

59. GIMNASIO DE BOX - CATÁlOGO DE DISEÑO (2013) CHIHUAHUA MEXICO

60. GRÁFICO ANÁLISIS CUANTITATIVO - LERTORA (2015)

61. GRÁFICO ANÁLISIS CUANTITATIVO - LERTORA (2015)

62. ANTROPOMETRÍA DEPORTIVA - ENCICLOPEDIA DEL DEPORTE (2004)

63. GRÁFICO ANÁLISIS CUANTITATIVO - LERTORA (2015)

64. ANTROPOMETRÍA DEPORTIVA - ENCICLOPEDIA DEL DEPORTE (2004)

65. GRÁFICO ANÁLISIS CUANTITATIVO - LERTORA (2015)

66. ANTROPOMETRÍA DEPORTIVA - ENCICLOPEDIA DEL DEPORTE (2004)

67. ANTROPOMETRÍA DEPORTIVA - ENCICLOPEDIA DEL DEPORTE (2004)

68. GRÁFICO ANÁLISIS CUANTITATIVO - LERTORA (2015)

69. ANTROPOMETRÍA DEPORTIVA - ENCICLOPEDIA DEL DEPORTE (2004)

70. ANTROPOMETRÍA DEPORTIVA - ENCICLOPEDIA DEL DEPORTE (2004)

71. GRÁFICO ANÁLISIS CUANTITATIVO - LERTORA (2015)

72. FLOOR FOR DANCING SCHOOLS LEWIS (2008)

73. BALLET ARTS DI SAINT LAUREN (2009)

74. GRÁFICO ANÁLISIS CUANTITATIVO - LERTORA (2015)

75. ANTROPOMETRÍA DEPORTIVA - ENCICLOPEDIA DEL DEPORTE (2004)

76. GRÁFICO ANÁLISIS CUANTITATIVO - LERTORA (2015)

77. RELACION PISCINA VESTIDORES - ARCHDAILY (2015)

78. GRÁFICO ANÁLISIS CUANTITATIVO - LERTORA (2015)

79. VESTUARIOS - (2015) LERTORA GHIANELLA 
80. VESTUARIOS - ARCHDAILY (2015) BALDINGER ARCHITECTURAL STUDIO

81. GRÁFICO ANÁLISIS CUANTITATIVO - LERTORA (2015)

82. VESTUARIOS - ARCHDAILY (2015) BALDINGER ARCHITECTURAL STUDIO

83. CUADRO DE ÁREAS - LERTORA, Ghianella (2015)

84. CUADRO DE ÁREAS - LERTORA, Ghianella (2015)

85. CUADRO DE ÁREAS - LERTORA, Ghianella (2015)

86. CUADRO DE ÁREAS - LERTORA, Ghianella (2015)

87. CUADRO DE ÁREAS - LERTORA, Ghianella (2015)

88. CUADRO DE ÁREAS - LERTORA, Ghianella (2015)

89. CUADRO DE ÁREAS - LERTORA, Ghianella (2015)

90. CUADRO DE RESÚMEN - LERTORA, Ghianella (2015)

91. CUADRO DE RESÚMEN ÁREAS POR PAQUETES - LERTORA, Ghianella (2015)

\section{CAPÍTULO 8:}

1. BOCETO TERRENO EJE VERDE 1 - LERTORA, Ghianella (2015)

2. BOCETO TERRENO EJE VERDE 2 - LERTORA, Ghianella (2015)

3. PARQUE LINEAL EN BARCELONA - MATHEWS, Oliver (2014)

4. PARQUE LINEAL - ARCHDAILY (2012)

5. BOCETO VISTA AL HITO - LERTORA, Ghianella (2015)

6. BOCETO RAMPA COMO ELEMENTO ARQUITECTÓNICO - LERTORA, Ghianella (2015) 
7. BALDINGER ARCHITECTURAL STUDIO SPOFIT FOR PEOPLE WITH DISABILITIES - ARCHDAILY (2015)

8. BOCETO FLUJOS QUE INDICAN FORMA DE LA VOLUMETRÍALERTORA, Ghianella (2015)

9. BEIJAO SPORT CENTER - BOP ARCHITECTS (2015)

10. BOCETO ASOLEAMIENTO VOLUMETRÍA ASPECTOS AMBIENTALES LERTORA, Ghianella (2015)

11. ATRIO, HSBC (2014) PIANO, RENZO

12. ATRIO, HSBC (2014) PIANO, RENZO

13. CELOSIAS ESCENARIOS DEPORTIVOS MEDELLÍN - PLATAFORMA DE ARQUITECTURA (2012)

14. ESPACIOS PÚBLICOS - PLATAFORMA ARQUITECTURA (2015)

15. BOCETO DE ZONAS DE SEGURIDAD, VOLUMETRÍA CON FLUJOS DE VIENTO Y INSCIDENCIA DEL VIENTO Y BAÑO DE LUZ EN ESPACIOS INTERMEDIOS PERIMETRALES DEL EDIFICIO (2015) LERTORA, Ghianella

16. BOCETO ESCENARIOS DEPORTIVOS MEDELLÍN - PLATAFORMA DE ARQUITECTURA (2012)

17. BOCETO CORTE DEL EDIFICIO IDEA DE RELACION DE LA PENDIENTE CON EL PROYECTO - (2015) LERTORA, Ghianella

18. ESCENARIOS DEPORTIVOS MEDELLÍN - PLATAFORMA DE ARQUITECTURA (2012)

19. ESCENARIOS DEPORTIVOS MEDELLÍN - PLATAFORMA DE ARQUITECTURA (2012) 